\author{
Afromees bo \\ Mamine Blology \\ POWONA 97
}


-

\section{.}




\section{Haring Liclogical Laboracop LIBRARY OCT 61980}

Woods Hole, Mass. 

- 


\section{Advances in MARINE BIOLOGY}

VOLUME 17 



\section{Advances in MARINE BIOLOGY}

VOLUME 17

Edited by

J. H. S. BLAXTER

Dunstaffnage Marine Research

Laboratory, Oban, Scotland

SIR FREDERICK S. RUSSELL

Plymouth, England

and

SIR MAURICE YONGE

Edinburgh, Scotland

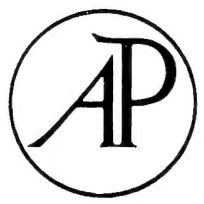

Academic Press

1980

A Subsidiary of Harcourt Brace Jovanovich, Publishers

London New York Toronto Sydney San Francisco 
ACADEMIC PRESS INC. (LONDON) LTD.

24-28 OVAL ROAD

LONDON NWI 7DX

\section{U.S. Edition published by}

ACADEMIC PRESS INC.

111 FIFTH AVENUE

NEW YORK, NEW YORK 10003

Copyright (c) 1980 by Academic Press Inc. (London) Ltd.

All rights reserved

NO PART OF THIS BOOK MAY BE REPRODUCED IN ANY FORM BY PHOTOSTAT, MICROFILM, OR ANY OTHER MEANS, WITHOUT WRITTEN PERMISSION FROM THE PUBLISHERS

British Library Cataloguing in Publication Data

Advances in marine biology.

Vol. 17

1. Marine biology

I. Blaxter, J. H. S. II. Russell, Sir Frederick

Stratten III. Yonge, Sir Maurice

$574.92 \quad$ QH91 $63-14040$

ISBN 0-12-026117-0

Printed in Great Britain by John Wright \& Sons Ltd,

The Stonebridge Press, Bristol 




\title{
ECOLOGY AND TAXONOMY OF HALIMEDA: PRIMARY PRODUCER OF CORAL REEFS
}

\author{
Llewellya Hillis-Colinvaux \\ Department of Zoology, The Ohio State University, \\ Columbus, Ohio, U.S.A.
}

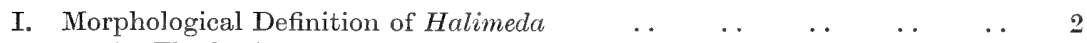
A. The basic plan ..

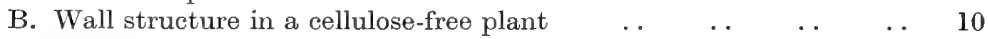

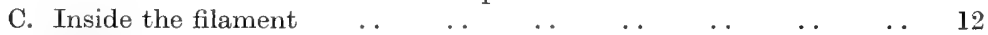

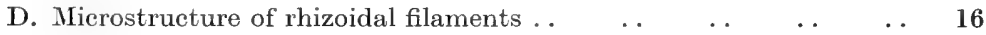
E. Summary: facets of the unusual structure and chemistry of Halimeda 16

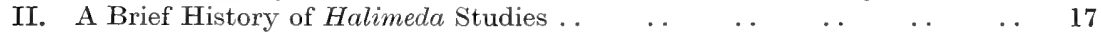

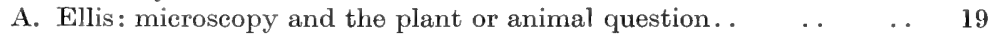

B. Halimeda discoveries: the beginnings of critical taxonomy $\quad$. 24

C. The discovery at Funafuti : the reef-building capabilities of Halimeda $\mathbf{2 5}$

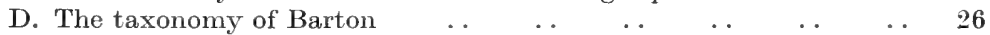

E. Howe, Børgesen, Taylor and Hillis: the modern taxonomy $\quad . .29$

F. Summary: the evolution of Halimeda studies $\quad \ldots \quad \ldots \quad \ldots 33$

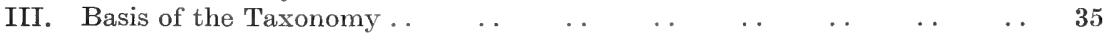

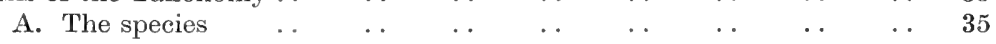

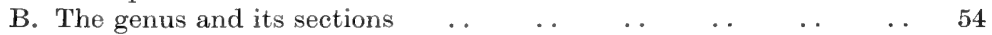

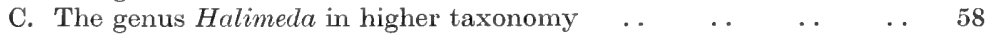

D. Summary: the identification and classification of Halimeda $\quad \ldots \quad 71$

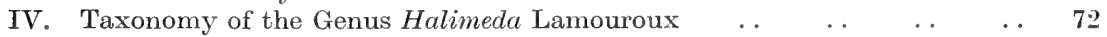

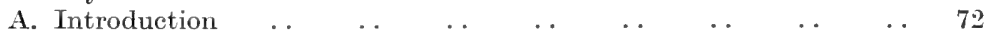

B. Species of the genus Halimeda Lamouroux, with index . . $\quad$. 84

C. Generic description of Halimeda Lamouroux, 1812 . $\quad \ldots \quad \ldots \quad$. 85

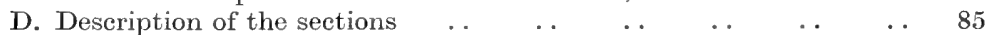

E. Taxonomic key to all species, and list of Indo-Pacific species $\quad \ldots \quad 86$

F. Key to Atlantic species, and list of Atlantic species $\quad \ldots \quad$. 991

G. Species descriptions $\quad \ldots \quad$.

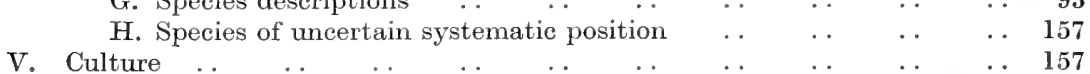

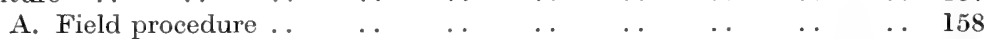

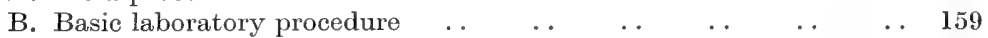

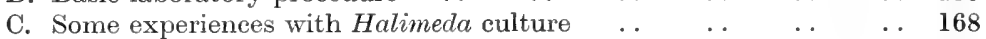

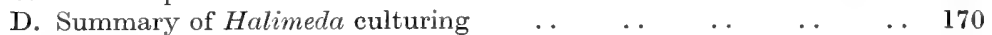

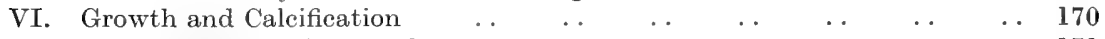

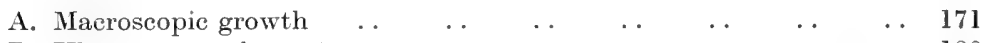

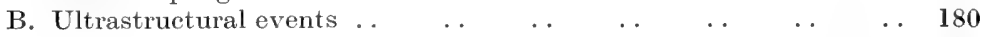

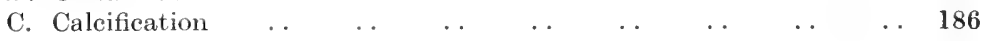




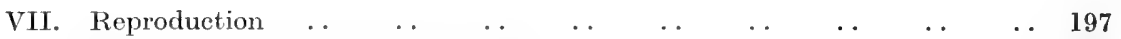

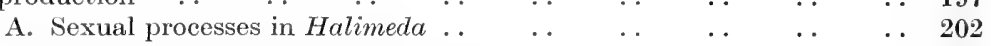

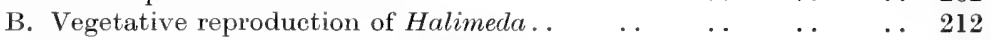

C. Reproduction in other Caulerpales $\ldots \begin{array}{llllll} & \ldots & \ldots & \ldots & \ldots & 215\end{array}$

D. Reproductive strategy and the strawberry-coral model . . $\quad . \quad 221$

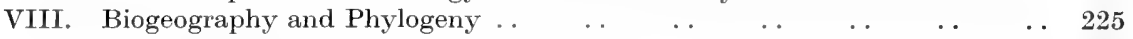

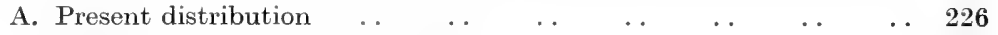

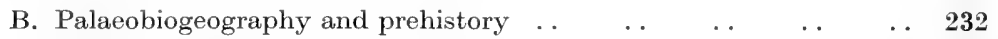

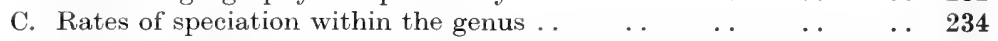

D. A biogeographical approach to the phylogeny of the Caulerpales .. 237

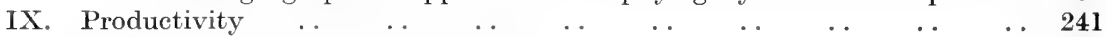

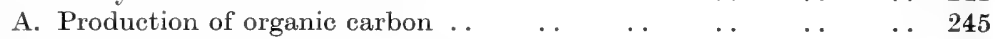

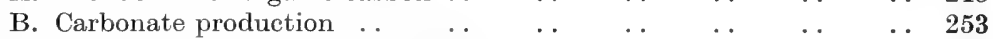

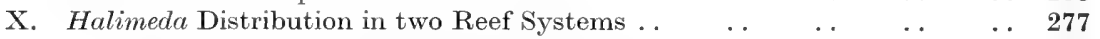

A. The Glory Be reef, Ocho Rios, Jamaica $\quad \ldots \quad \ldots \quad \ldots \quad \ldots \quad$. 278

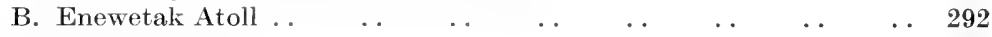

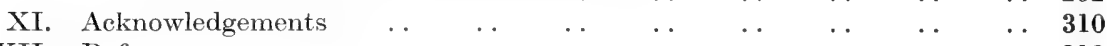

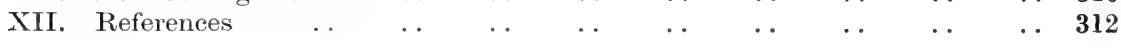

\section{Morphological Definition of Halimeda}

Opuntia marina. The Sea Garland.

This dainty plant groweth up from some Rockes or stones, in or neere the Sea, spreading sundry flat, thicke, short and round leaves, one set on the toppe of another, and some also growing from the sides, forming branches of leaves leaning downewards, each being as it were strung on a thred which yet is scarce to be discerned, like as a Country Garland of field and corne flowers, are used to be made to decke the Country houses, and their places of sport, so that the whole plant seemeth to be made of nothing but strung leaves, bearing a large yellow flower at the toppe saith Bauhinus, but I much doubt he taketh that supposition from the Ficus Indica Americana, the lower leaves are somewhat browne, the rest are whitish greene, and those that are new sprung are greene, and all of them smooth and shining, even kept betweene papers for a long time, and of a saltish taste, yet by long time growing rougher and full of wrinckles, but still tough and not brittle like Corall or Coralline, and growing soft againe steeped in water, yet still very salt.

\section{Parkinson (1640)}

Over 300 years ago Parkinson provided this first English description of a Halimeda, calling it Opuntia marina, the sea garland. With prose and drawing (Fig. 1), he so clearly captured the essence of the only species then known, H. tuna of the Mediterranean, that his words seem an appropriate introduction to this entire genus of green, calcareous marine algae. 


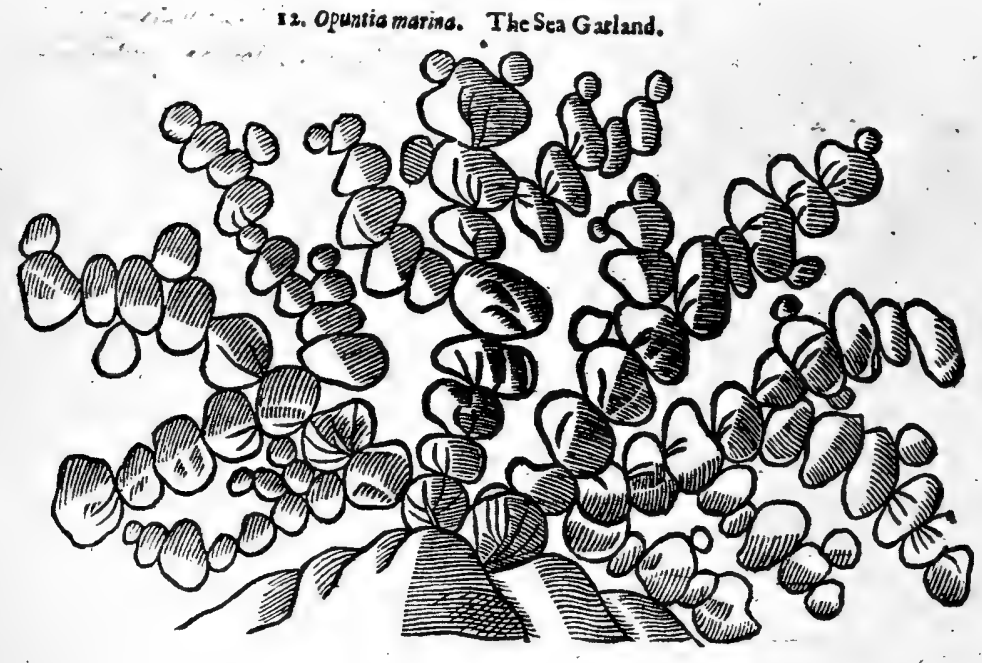

FIG. 1. Halimeda tuna, as Opuntia marina in Parkinson's "Theatrum Botanicum", 1640. (Photograph by the British Museum (Natural History).)

The discovery of other species, in the intervening years, has shown that the genus is not always dainty and the descriptive terminology has grown accordingly. Nevertheless, the overall appearance of the genus is characteristic, and whether one first encounters it while swimming in a coral reef, or examining an array of dried herbarium specimens, it can be identified almost at once, for it looks like some form of underwater cactus, with photosynthetic portions consisting of series of calcified segments or joints, the strung leaves of Parkinson, which may be arranged in some branching pattern. The plant body, or thallus, also possesses a holdfast which provides attachment to or in the substrate (Fig. 2).

All species of Halimeda deposit calcium carbonate in the form of aragonite. Hence, the green colour of the segments, which are the photosynthetic portions of the thallus, is muted. Calcification begins when the segment is about 36 hours old (Wilbur et al., 1969); therefore, even those small young thalli that appear flatulent and green are calcified. The only uncalcified portions are nodes (to be described below), apical segments younger than about 36 hours old, and rhizoidal filaments. 

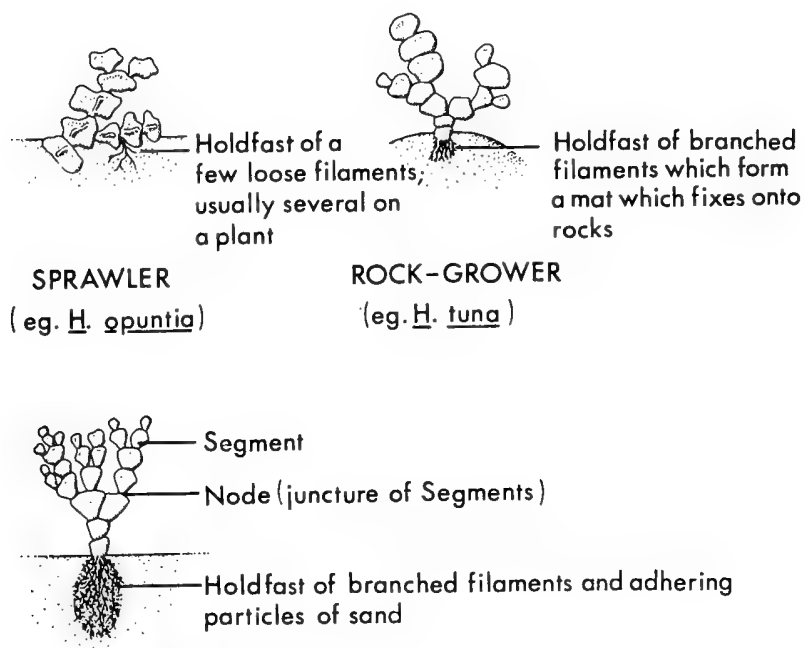

SAND-GROWER

(eg. $\underline{H}$. incrassata)

Frg. 2. Basic parts of a Halimeda, and the three main types of holdfast. Thalli which sprawl over rock or sand usually have a number of places of attachment, provided by a few loose filaments from between segments or sometimes from the ends of segments. In rock-growers generally the branched filaments form a mat which holds to rock, whereas in sand-growing species the branched holdfast filaments adhere to fine particles of substrate, and the whole forms a sizeable "root". (Drawings by D. Dennis, The Ohio State University.)

\section{A. The basic plan}

The constructional unit of the entire alga, both holdfast and segment, is the filament (Fig. 3), which has a diameter of approximately $0 \cdot 05-0.1 \mathrm{~mm}$. These filaments, with a resemblance to fungal hyphae, are matted and branched in such a way as to build plants which range in size from $5 \mathrm{~cm}$ or less in $H$. lacrimosa, to over $1 \mathrm{~m}$ in sprawling forms of $H$. opuntia.

The filament itself is unusual. Unlike those of most other plants it lacks cross walls which would divide it into a linear row of cells. The Halimeda organism, which is constructed out of a mass of these filaments, may therefore be considered one giant multinucleate cell. This filament without cross walls, or coenocytic filament, occurs also in a few other algae such as Penicillus, Tydemania, Udotea and Caulerpa, all of them green algae or members of the Chlorophyta, and in the Phycomycete fungi. These green algae, with their siphon-like filaments, 


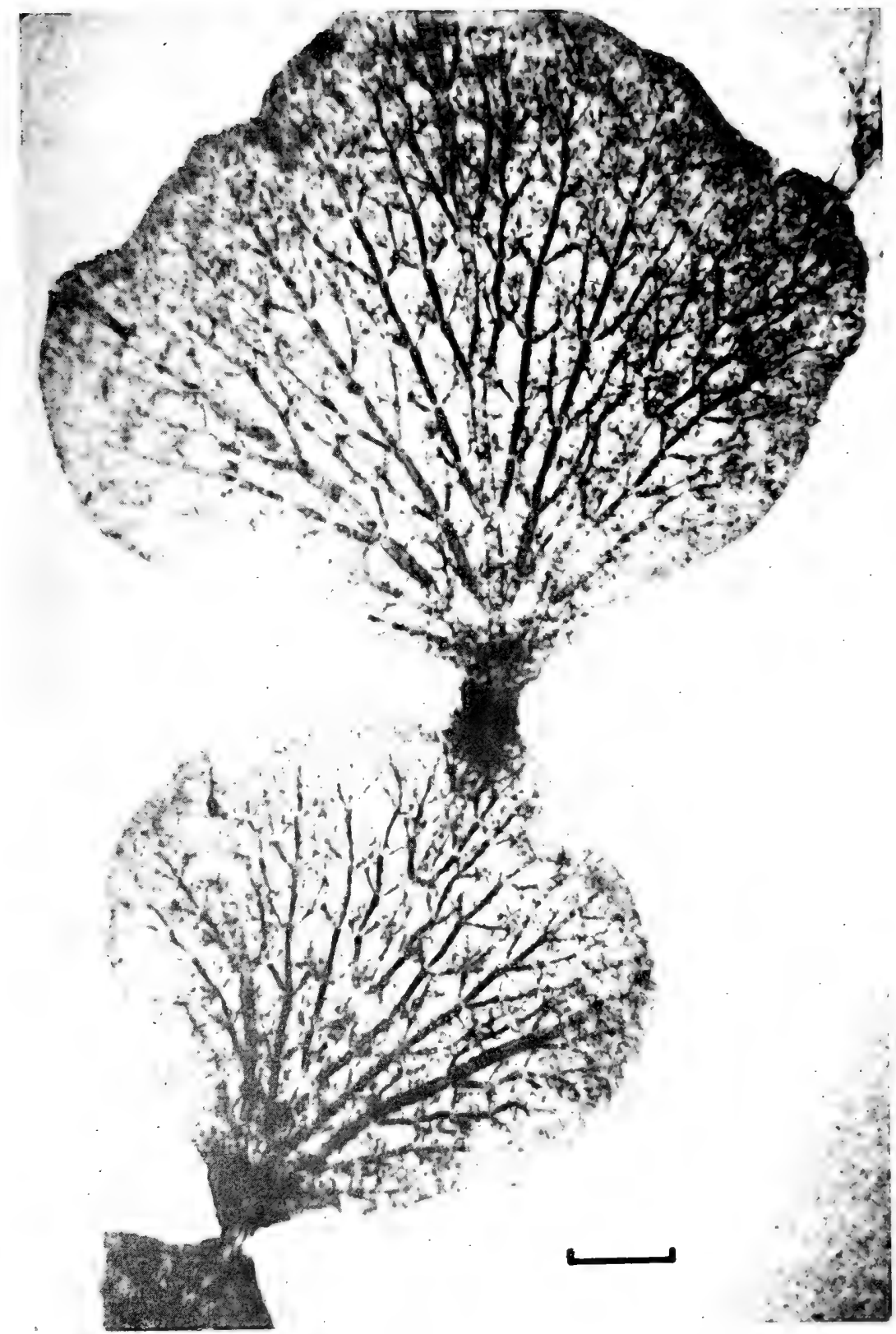

FIG. 3. The constructional unit of Halimeda is the coenocytic filament. In segments, in contrast to holdfasts, there is a definite pattern of organization which is least complex in $H$. cryptica, a species with a single main filament. This central medullary filament branches several times, producing lateral branches which also branch. In most species there are several to many medullary filaments. Scale bar is $1 \mathrm{~mm}$. Material is stained with dilute Lugol's solution, and mounted in glycerine. (From Colinvaux and Graham, 1964.) 
were formerly classified in the order Siphonales. Hence they often are described as siphonaceous.

Cross walls in the filaments have not been observed to form regularly at any stage in the life-history of Halimeda. In this way, and in its regular multinucleate condition, this genus differs from Acetabularia, another well-known calcareous green alga.

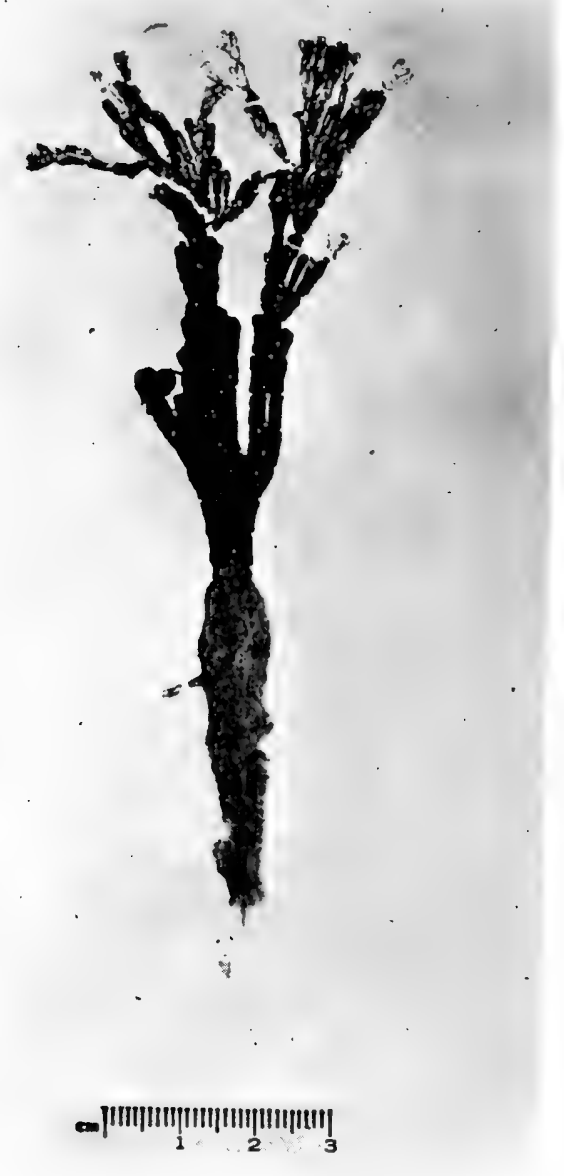

FIG. 4. H. cylindracea, from the lagoon of Enewetak Atoll. The specimen has been decalcified to show the extensiveness of the mass of holdfast filaments which are normally obscured by adhering particles of substrate. 


\section{Holdfast}

The filaments of the holdfast are not organized into a regular shape such as a segment. They generally branch irregularly to form a mass of threads, which may remain loose, as in much of the opuntia material, may become tangled into a mat as in $H$. tuna, or may adhere to fine particles of loose substrate and with these particles produce an impressive bulbous structure to $13 \mathrm{~cm}$ or more in length (Figs 2, 4, 5). These large holdfasts sometimes grow in a reducing environment.

In at least some species the main rhizoidal filaments have muchthickened walls, whereas the walls of the finer branches are not noticeably thickened.

\section{Segment}

In contrast to the holdfasts, the filaments within segments show a definite pattern of organization. In most species several central, socalled medullary or axial, filaments run the length of the segment (Figs 3,6) and the entire length of the branch, "stringing" the segments together. These filaments form the central axis, core or medulla. The exception, cryptica, has a core of but a single filament (Colinvaux and Graham, 1964), which is two or more times the diameter of such filaments in other species (personal observation).

The medullary filaments generally branch trichotomously, with the resultant branches becoming displaced laterally and rebranching one to three times. This lateral branch system is the cortex (Figs 3, 6). The branches themselves, called utricles, are relatively short, and become progressively shorter towards the periphery of the segment. They also may be swollen, except at their bases, where in most species they are usually constricted and the wall thickened. The outermost or peripheral branches are called primary utricles, the ones immediately to the inside are secondary utricles, and so on until cortex disappears into medulla (Figs 6, 7).

The primary utricles of most species touch at their peripheral edges and adhere in mature segments. In surface view, therefore, the peripheral utricles generally appear polygonal, like a section of honeycomb (Fig. 8). They give the impression of cells and in the older literature sometimes, erroneously, were called cells, although they are but the adhering tips of coenocytic filaments.

The cortex of the segment is not uniformly developed over the entire plant but varies with the relative age of the segment, and is 


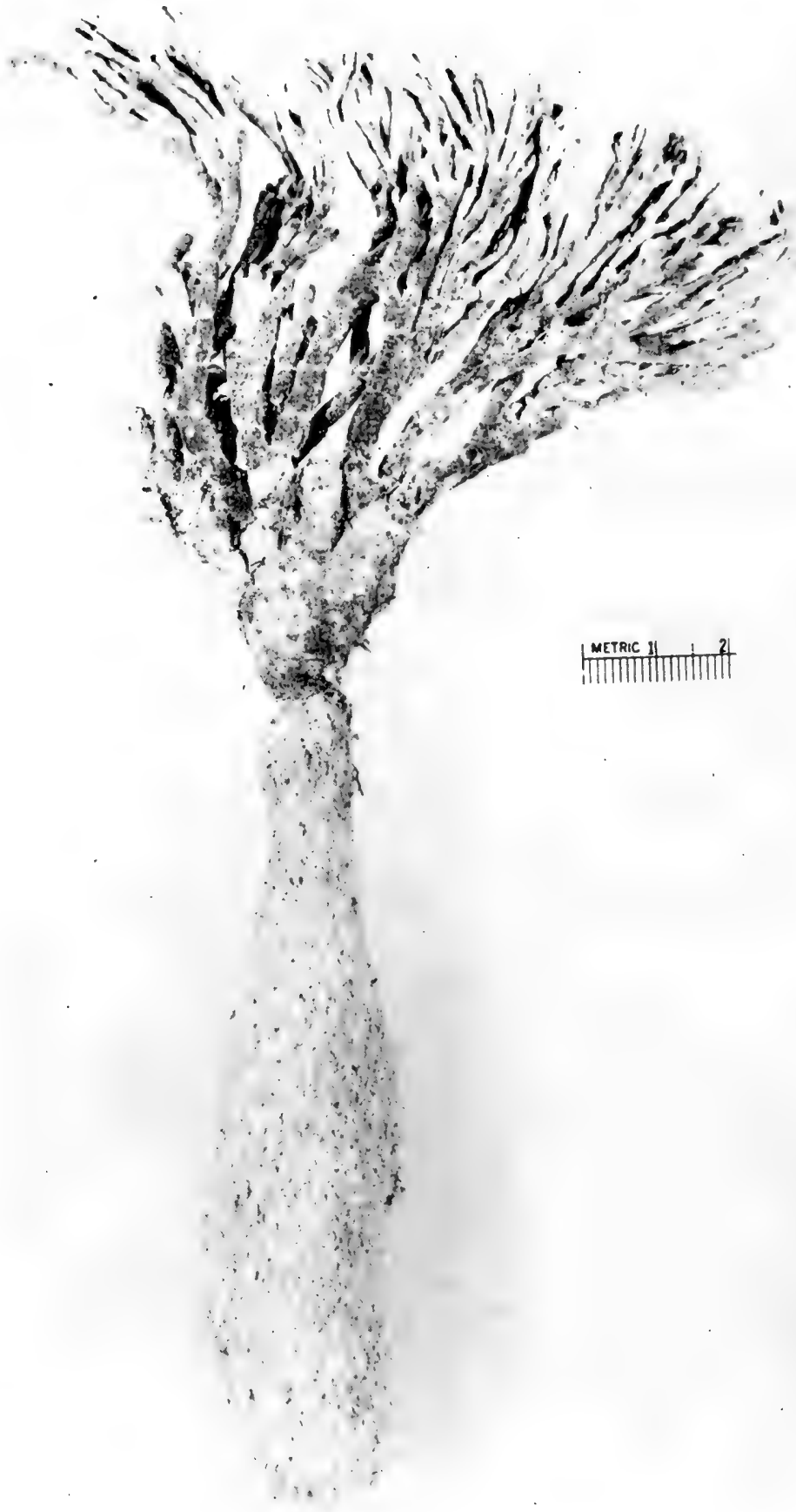




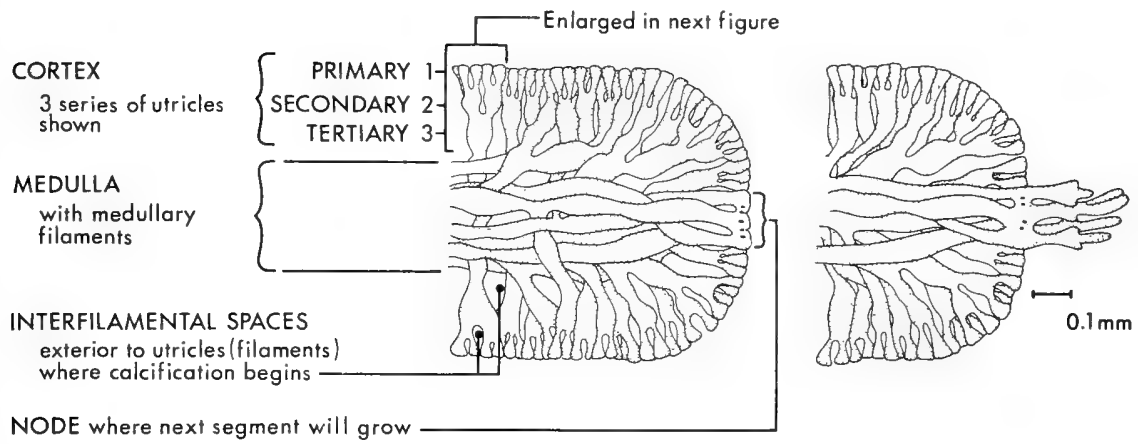

FIG. 6. Longitudinal sections through part of a segment (incrassata) showing its basic filamentous construction. Note absence of cross walls throughout, which makes this plant a coenocyte. In the right-hand diagram the medullary filaments at the apex of the segment (right) have started to grow and branch to form a new segment. Such filaments show a distinct gradient in kinds and quantities of organelles. (Redrawn by D. Dennis, The Ohio State University, from Hillis (1959).)

SEAWATER

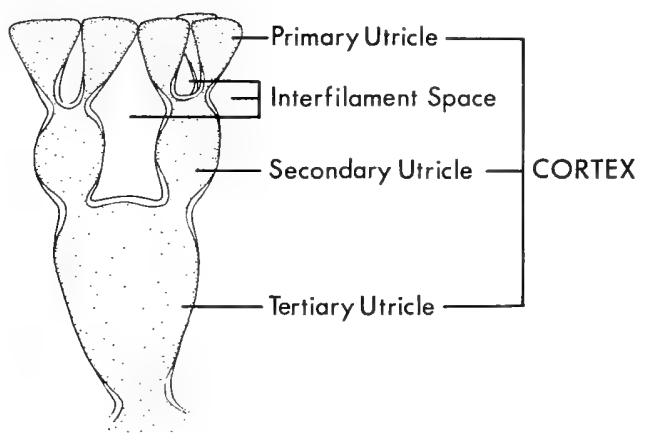

MEDULLA

FIG. 7. Schematic enlargement of a small portion of the cortex illustrated in Fig. 6 showing variable thickening of filament wall at bases of utricles, and the interfilamental spaces of the cortex. Those of the medulla are not included. It is in these interfilamental spaces that aragonite is deposited. (Drawing by D. Dennis, The Ohio State University.)

absent in the juncture between segments. Consequently, the intersegmental region or node, for a very short distance, is composed only of axial filaments. For most species this is where the filaments fuse in some characteristic pattern, a circumstance useful to taxonomy

FIG. 5. (Opposite.) H. cylindracea, a non-decalcified plant from Enewetak lagoon showing the usual appearance of the holdfast. The holdfast shown was one of the smaller ones of over 50 specimens examined from the lagoon. 
(Section III). Only in the species cuneala is the uncorticated region more extensive, and this is described in the discussion of this species.

In the spaces of the cortex and medulla (Figs 6,7 ), outside the filaments, the deposition of aragonite occurs (Askenasy, 1888; Wilbur et al., 1969; Borowitkza and Larkum, 1976a, b). Calcification, therefore, takes place entirely outside the filament.

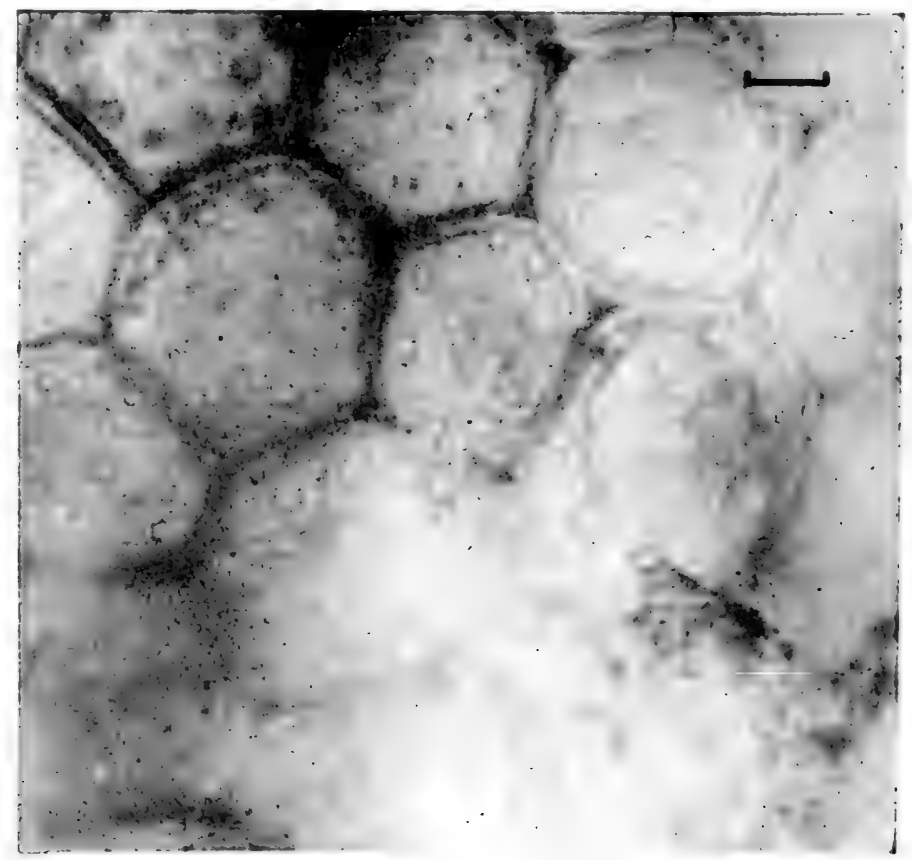

FIG. 8. H. monile, surface view of peripheral utricles of a segment about 48 hours old.

The ends of the filament, or peripheral utricles (large circles or polygons) adhere to form a continuous outer surface. The corners are less rounded in older segments. Scale bar is $10 \mu \mathrm{m}$.

\section{B. Wall structure in a cellulose-free plant}

The walls of the filaments, at least those comprising the segments, are microfibrillar (Preston, 1974; Borowitzka and Larkum, 1977), the microfibrils containing chains of $\beta-1,3$-xylan (Niwa et al., 1961). The chains within the crystalline xylan fibril are coiled in double helices (Preston, 1968). A $\beta$-1,3-linked glucan is also present, in the ratio of one glucan molecule to four of xylan, and may form the cortex of the microfibril surrounding a xylan crystallite (Preston, 1974). These investigations elucidate, as well as extend, early critical wall studies 
carried out by Mirande (1913) who, through differential staining techniques, deduced the walls to be composed mainly of what he called callose, which is a polymer of $\beta$-1,3-linked glucose residues (Aspinall and Kessler, 1957). Cellulose, until recently thought to be present in the walls of all plants except fungi, has not been found in Halimeda, although it has been demonstrated in some of its siphonaceous relatives (Feldman, 1946; Huitzing and Rietema, 1975).

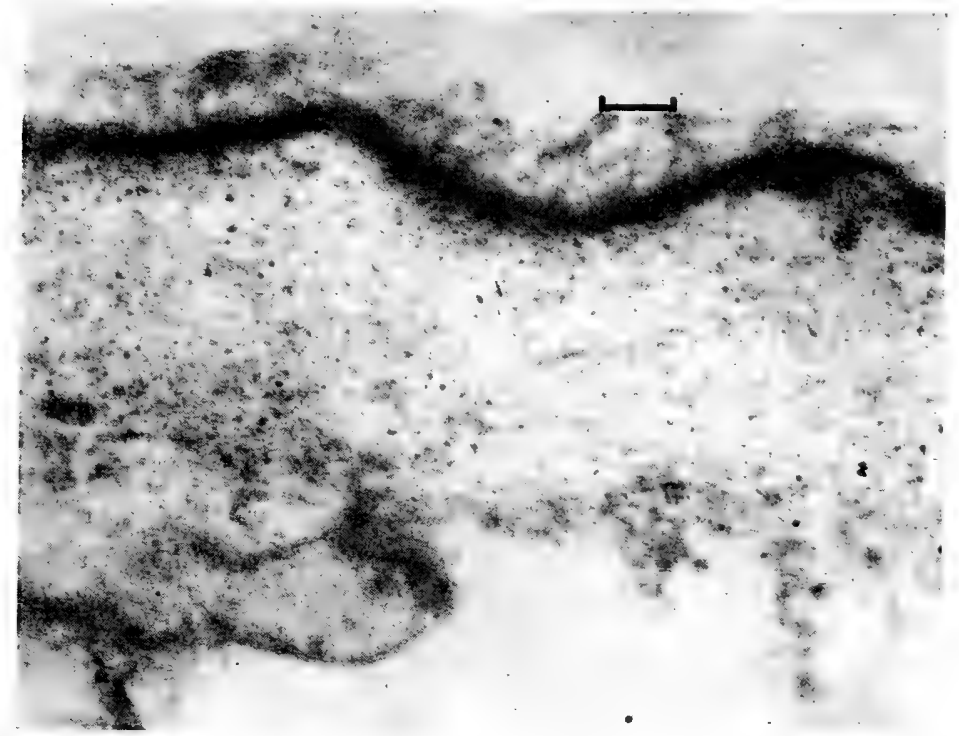

Fig. 9. The wall of a young filament from $H$. monile, showing the outer layer of fine fibrils (top), the osmiophilic covering lamella (appears dark) and main part of wall. Calcification has not yet started in this segment, but the first aragonite crystals form in the vicinity of the fine fibrils, and therefore outside the filament. The plasma membrane has separated from part of the wall. Scale bar is $0.1 \mu \mathrm{m}$.

The outermost region of the filament wall contains one or more osmiophilic layers (Fig. 9) which sometimes separate from the rest of the wall. Their precise chemical nature as yet is unknown. Although this region may be equivalent to the "cuticle" of Hanic and Craigie (1969), a word they employed with reservation, it seems more appropriate to use the earlier terminology of Brand (1901) and call it a "covering lamella" (Decklamella). This lacks the chemical connotation of cuticle, and clearly indicates the region of the filament wall involved. Numerous fine fibrils, approximately $5-10 \mathrm{~nm}$ in diameter and $200 \mathrm{~nm}$ long (Wilbur et al., 1969; Borowitzka and Larkum, 1977), often with knob-like ends, project from this covering lamella into the lumen of the segment. This fibrillar or pilose layer, which contains polysaccharide 
(Borowitzka and Larkum, 1977), is most readily observed in young segments and often is obscured by calcium carbonate crystals.

\section{Inside the filament}

The filament wall bounds the cytoplasm. The organelles are not uniformly distributed throughout the cytoplasm although the construction

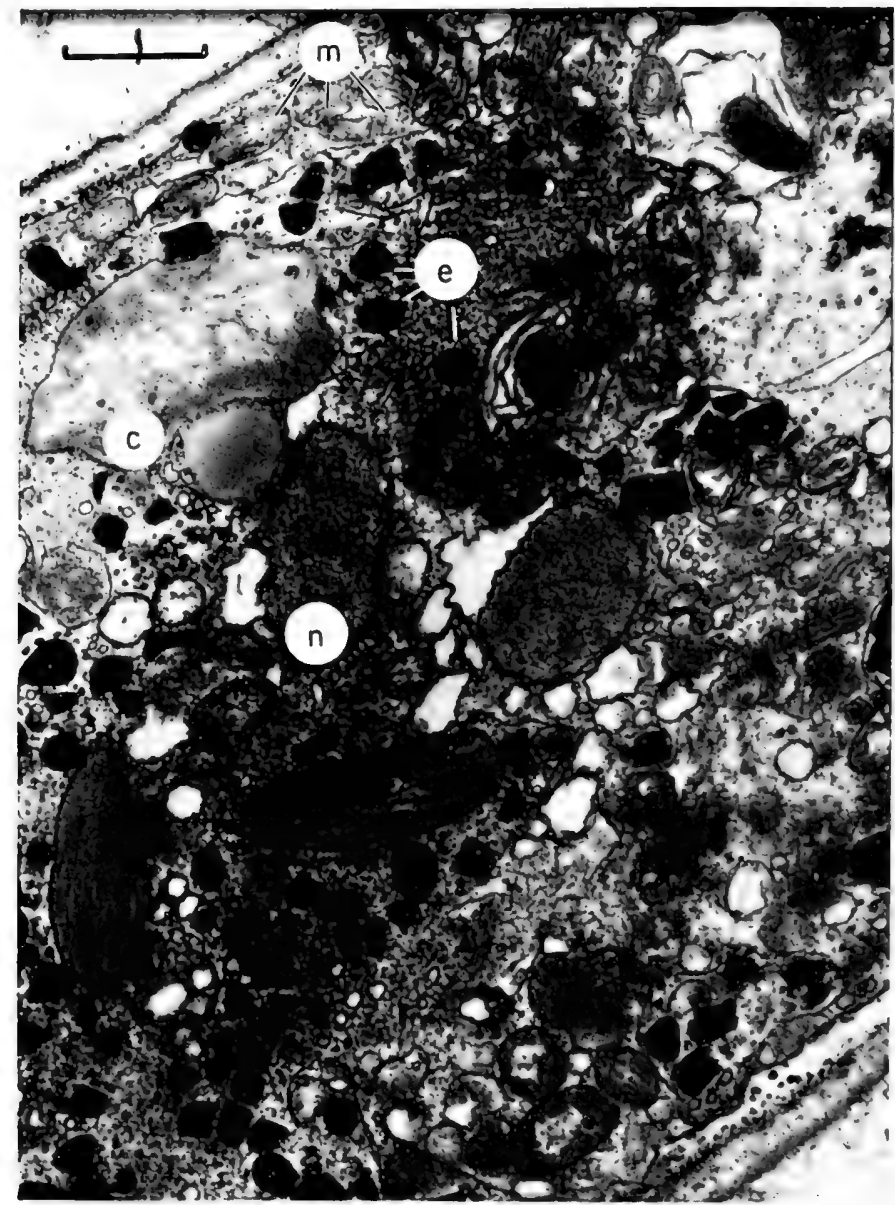

Fig. 10. H. monile. Section of a filament from a segment less than 48 hours old showing wall with fine fibrils on outer surface, two nuclei (n), chloroplasts (c), plastid with concentric lamellae and starch grain (upper right-hand corner), chloroplast with small starch grain (below the nuclei), mitochondria $(\mathrm{m})$ and electron-dense bodies (e). Calcification has begun in the spaces outside the filaments. The white spaces near the filament wall represent the location of crystals that were lost in the sectioning process. Stained with lead tartrate. Scale bar is $1 \mu \mathrm{m}$. 
is coenocytic (Fig. 10). In mature, metabolically active segments the cytoplasm of inner filaments is a thin peripheral layer with relatively few chloroplasts, whereas in outer filaments, that is, in the utricles, it occupies much of the volume, the vacuole thereby being less extensive. The small, disc-shaped chloroplasts may be very numerous in the peripheral portions of the organism, but are reported to move internally at night (Stark et al., 1969). A gradient in the kinds and quantities of organelles occurs in young growing filaments such as those forming a new segment (Fig. 6), and across a segment from periphery to medulla (Wilbur et al., 1969; Borowitzka and Larkum, 1977). The arrangement at times suggests cytoplasmic streaming.

\section{Plastids}

Feldmann (1946), building on the earlier microscopic observations of Askenasy (1888), Czurda (1928) and Chadefaud (1941), delimited two basic types of plastids in a number of siphonaceous algae including Halimeda. They were plastids with very large starch grains which he called amyloplasts (Figs 55, 59), and those with no starch grains, the chloroplasts (Figs 10,59). He called this two-plastid system heteroplasty. The plastic condition, however, is not so clear cut since starch is also present in chloroplasts (Section III; Figs 10, 59; Wilbur et al., 1969; Colombo and Orsenigo, 1977).

Amyloplasts are the only plastids in the rhizoidal filaments (personal observation), whereas chloroplasts predominate within photosynthesizing mature, but not aged, segments, at least in the daytime (Wilbur et al., 1969; Borowitzka and Larkum, 1974b; Colombo and Orsenigo, 1977). In the non-peripheral utricles of the segment both kinds of plastids may occur (personal observation). The pigments contained by the chloroplasts are chlorophylls $a$ and $b$, in a ratio usually of about $2: 1$ (Jeffrey, 1968), together with the principal carotenoids known for other green algae, as well as two additional carotenoids siphonoxanthin and siphonein (Kleinig, 1969).

The chloroplasts of Halimeda are bounded by a double membrane, although the outer one is not always intact. They are disc-shaped, and when mature are approximately $2-5 \mu \mathrm{m}$ long, $1-3 \mu \mathrm{m}$ broad (Wilbur et al., 1969; Palandri, 1972b; Borowitzka and Larkum, 1974b). Large amyloplasts have ruptured and lost much of their outer membranes and are about twice the size or larger (Wilbur et al., 1969). The membranes, before they break with age, may be as resistant to breaking as are those of the related, but non-calcified Caulerpa, which Giles and Sarafis (1974) were unable to rupture by blending, grinding, freezing, 
thawing, sonication or a variety of chemical treatments. Such rigescent membranes may explain the resistance of siphonaceous chloroplasts to digestion by opisthobranchiate molluse grazers, and the survival of the chloroplasts within the animals for a month or more.

Thylakoids, or photosynthetic lamellae, are present in chloroplasts, and in amyloplasts in which the starch grain does not completely fill the boundary membrane (Borowitzka and Larkum, 1974b; personal observation). They traverse the length of the plastid, and in so doing may encircle a central starch grain if present. The lamellae appear to be constructed of linearly arranged vesicles (Borowitzka and Larkum, 1974b) and are appressed into groups (Fig. 10). In chloroplasts, their number, within limits, increases with age, whereas in amyloplasts the starch grain may become so large that the development of thylakoids is restricted, and the lamellae are displaced outwards until the plastid membrane eventually ruptures.

Synthesis and organization of the thylakoids involve a system of concentric lamellae at one end of the plastid (Fig. 10), variously called "concentric lamellae" (Descomps, 1965), "concentric lamellar system", (Hori and Ueda, 1967; Hori, 1974), "thylakoid organizing body" or "TOB" (Borowitzka and Larkum, 1974a, b), and "dome-shaped body" (Turner and Friedmann, 1974). These concentric lamellae persist throughout much or all of the life of the plastid, and are also present in other siphonaceous heteroplastic algae such as Avrainvillea, Caulerpa, Chlorodesmis and Penicillus (Hori and Ueda, 1967; Turner and Friedmann, 1974). They also occur in amyloplasts in which starch does not fill the entire space (Palandri, 1972b).

Osmiophilic globules may be prominent in chloroplasts (Wilbur et al., 1969) and DNA fibrils are present (Palandri, 1972b; Borowitzka and Larkum, 1974b). Pyrenoids or starch-storing bodies have not been observed, but have been reported for some species of Caulerpa (Hori and Ueda, 1967 ; Calvert et al., 1976), a genus which is also heteroplastic.

\section{Nuclei and other components}

Our knowledge of most other microcomponents of the filament system of Halimeda is more restricted. The many small nuclei, each containing several small electron-dense masses but usually only a single nucleolus, are bounded by a double membrane possessing pores (Palandri, 1972b). This author has also reported an association between nuclear envelope and smooth endoplasmic reticulum. Data on nuclear division are scant, and studies of the chromosomes of Hatimeda do not appear to have been published (Puiseux-Dao, 1966; Lewin, 1976). 
Other components of the cytoplasm include both smooth and rough endoplasmic reticulum, free ribosomes, Golgi bodies, microtubules, lipid globules and mitochondria (Fabbri and Palandri, 1969; Wilbur et al., 1969; Palandri, 1972b; Borowitzka and Larkum, 1977). Palandri (1972a) describes some unusual forms of mitochondria, and Borowitza and Larkum (1977) report DNA-like fibrils in the matrix of giant mitochondria occurring in the tips of young growing filaments. Palandri $(1972 b)$ reported DNA in older mitochondria.

\section{Central vacuole}

The central vacuole in filaments of mature segments generally occupies much of the filament system of the medulla and inner cortex and contains a granular to somewhat fibrillar ground substance with a variety of inclusions. Prominent among these are two distinctive types of unidentified bodies (Wilbur et al., 1969). One is rounded or angu ar, usually of high electron density (Figs 10, 55, 65, 66); the other is spherical (Figs 56, 59, 66). Subsequently the spherical body has been reported by other workers (Palandri, 1972b; Borowitzka and Larkum, 1977; Colombo and Orsenigo, 1977). Both unidentified structures may also be associated with the cytoplasm.

The spherical unidentified bodies are the larger, measuring $0 \cdot 5-3 \mu \mathrm{m}$ in diameter (Wilbur et al., 1969). They may consist mostly or entirely of polysaccharide (Borowitzka and Larkum, 1977), and some may have a hollow core. Texture is of non-oriented fibrillar substance throughout, or of one or more zones of radially oriented material which at times shows some resemblance to the ground substance of the central vacuole. Sometimes the outer margin is barely distinguishable from surrounding material, and in places fibrils extend from the spherical body to the surrounding region. At other times tiny vesicles of varying sizes, together with the electron-dense unidentified bodies, are closely associated with the outer boundary (personal observation).

Similar spherical bodies and the considerably smaller electrondense unknowns have both been found in Penicillus (Turner and Friedmann, 1974). Borowitzka and Larkum (1977) also report spherical bodies for Udotea and the non-calcareous, siphonaceous genus Avrainvillea. These workers (1977) did not find them in Caulerpa, nor were they observed in another siphonalean non-calcareous genus Bryopsis, for which Burr and West (1970, 1971a, b) report a "schizogenous body". This unknown also seems to have some association with the fibrillarreticulum systems of the alga, but superficially is different from the spherical body, and schizogenous bodies are proteinaceous. 
The calcium oxalate monohydrate crystals observed in Penicillus (see Friedmann et al., 1972; Turner and Friedmann, 1974) have not been reported for Halimeda.

\section{Microstructure of rhizoidal filaments}

The rhizoidal filaments of the holdfasts have been little studied. Hillis (1959) provided a very basic account of gross microscopic structure. A preliminary examination of the fine structure of incrassata (personal observation) indicates that chloroplasts, as expected, are absent, but amyloplasts, together with starch grains without apparent plastid boundary membranes are common, at least in certain regions. Vesicles of various sizes are present, particularly along the peripheral edge of the cytoplasm, and both kinds of unidentified structures mentioned above were prominent in much of the material examined.

The walls of at least some of the rhizoidal filaments are layered, and up to several times thicker than the filament walls of the mature segments described above. No aragonite crystals were found associated. with them, but fine fibrils somewhat similar in appearance to those associated with the walls of the filaments in segments (as described above) were observed along the peripheral edge of the electron-dense outer wall layer of young filaments.

E. Summary: facets of the unusual structure and chemistry of Halimeda

Halimeda is one of the largest and most complex of the green algae. It is a filamentous alga which has been elaborated from a simple plan of rows of tube-like filaments and is without cells.

The resultant plant, which may sometimes reach $0.25 \mathrm{~m}$ in height if erect, or sprawl to over $1 \mathrm{~m}$ in length, is composed of a photosynthetic portion of many segments, the "strung leaves" of Parkinson, and a holdfast system which ranges from a few short loose filaments to a truly massive production which may extend to $13 \mathrm{~cm}$ or more. The holdfast may exist in an anoxic environment.

Such a plant is derived by the extensive growth, with limited and controlled branching, of one or a few closely associated filaments. Aided by their wall chemistry, the branch tips of the filaments, with growth completed, stick together forming a closed or nearly closed internal environment in which the precipitation of aragonitic calcium carbonate occurs.

The algal walls are made without cellulose and the component filaments lack cross walls. The resultant "siphon", which contains the 
nuclei equivalent to many cells but not the compartments, is a coenocytic filament.

Much of the filamentous system contains a large central vacuole pushing against a thin cytoplasmic layer which is pressed to the filament wall. Many of the usual microcomponents are present within the filament: nuclei, plastids, smooth and rough endoplasmic reticulum, free ribosomes, Golgi bodies, mitochondria, microtubules and lipid globules. Some plastids, the amyloplasts, contain mostly starch. Chloroplasts, with their well-developed system of photosynthetic lamellae, may contain some starch as well or this may be absent. No pyrenoids have been observed. The pigments present in the chloroplasts are chlorophylls $a$ and $b$, in a ratio usually of about $2: 1$, and the principal carotenoids known for the other green algae. Two other carotenoids, siphonoxanthin and siphonein, are also present.

The chloroplasts, which are discoidal, are relatively small compared to those of many green algae, and the nuclei are also small. Little is known about the chromosomes, DNA or RNA of this alga, although DNA has been reported to be present in chloroplasts and mitochondria.

Other microcomponents of the filament include two characteristic unknown bodies, one that is electron dense, the other which is spherical and reticular.

\section{A Brief History of Halimeda Studies}

The first taxonomic description of a Halimeda appeared in 1599, in a book of Mediterranean natural history by the naturalist Imperato (Fig. 11). Using the name Sertolara he both drew and wrote about a Mediterranean sea plant, which in subsequent binomial nomenclature eventually was called Halimeda tuna. This Halimeda species remained the only member of this taxon for more than a century, even though there was considerable botanical activity at the time. Its loneness, however, is not surprising, for it is the only recognized Halimeda species of this essentially tropical genus that grows in the Mediterranean. Authentic additions to the Halimeda species list had to await the work of naturalists and collectors in areas remote from European centres of learning.

All references to Halimedae in the seventeenth century, therefore, are to this one species, $H$. tuna, but it is heard of with many different names. Clusius (1601) called it Lichen marinus. Parkinson (1640) named it Opuntia marina. And in their catalogue of 1651 Bauhin and Cherler listed both these names, as well as introducing two more, Fucus folio rotunda and Scutellaria sive Opuntia marina. But all are the same plant. 
serestara fa marini, nell'effigie fimile alquanto ad Alpleno, de fogli lémicircoappuranza di li, de quali l'vno con picciolilimo piccino attaccando alla fommifoght infilati. tà dell altro, fanno contunuata filza de frondi fenza tronchi, e fenza coltole, ilche communemente nelli fogli marini fi edetro. lifteffa maniera feque nel ramificare, attaccandufi ad vno iftefo foglio due fogli c:pi di filze diuerfe:allunganfi circa due terzi di fpanna. lı fo. gli fono da ambe le bande di confiftenza fimile à vello ammaffato. il fuo colore è verdaccio.

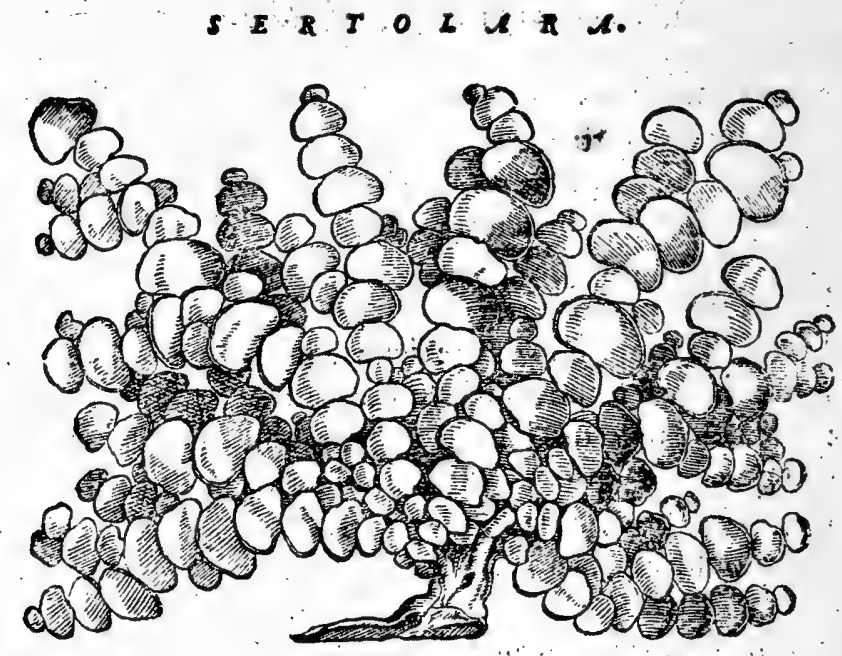

FIG. 11. The earliest description and scientific illustration of a Halimeda was by Imperato (1599). The species is $H$. tuna from the Mediterranean. (From Imperato (1599); photograph by the British Museum (Natural History).)

Further details of these epithets are listed in the species description for tuna by Barton (1901).

The first and possibly only published recipe for Halimeda as food is another seventeenth-century contribution. Bauhin and Cherler (1651) report that it makes a good dish when treated with vinegar, salt and oil.

The earliest non-Mediterranean collections of Halimeda came from the West Indies, notably those obtained in about 1687 by the physician Hans Sloane, later Sir Hans Sloane, who stopped at Jamaica in the suite of the Duke of Albemarle. Sloane's visit was curtailed by the 
death of the Duke, but nonetheless he collected some 800 new plant and animal species during the 15 months of his stay (Sloane, 1707). Among these was the second species of Halimeda to be discovered. In his volume dealing with the natural history of Jamaica, Sloane (1707) called this species Corallina opuntia. It is what is now known as Halimeda opuntia, the straggly cushion-shaped clusters of which are a prominent feature of shallow parts of Caribbean reefs. Sloane's specimen is contained in the Sloane Herbarium of the British Museum (Natural History).

\section{A. Ellis: microscopy and the plant or animal question}

The most significant contributor to early Halimeda history, however, was John Ellis, one of the outstanding naturalists of Great Britain of the last half of the eighteenth century. Indulging his interest in plants and animals of land and sea, he developed a network of correspondents in various parts of the world, especially America and the West Indies, receiving from them numerous materials for study. His eventual appointments as King's Agent for the province of West Florida (1764) and the Island of Dominica (1770) provided him with sufficient income to follow his inclinations more freely (Smith, 1819; Savage, 1948).

Of especial interest to Ellis were the "Corallines", a group of calcareous and horny sea organisms which he successfully established as an animal group in his classic "Essay Towards a Natural History of the Corallines" of 1755 , although Peyssonnel had somewhat earlier recognized an animal nature in at least some of them (Savage, 1948). This coralline group was diverse, and although the principal representatives were various cnidarians, the complex also included calcareous sea organisms such as the green alga Halimeda and the red alga Corallina. Because of this, two Halimeda species, subsequently known as incrassata and opuntia, were included in the 1755 publication as "Articulated Corallines of Jamaica".

Eventually Ellis separated five species of Halimeda: incrassata, tridens, monile, opuntia and tuna, but the genus had not been established as yet, and they were assigned to Corallina. As such they appear in his treatise with Solander (Ellis and Solander, 1786), published after the death of both Ellis and Solander under the direction of Ellis' daughter, Martha Watts. The use of binomial nomenclature in this work and in an earlier publication (Ellis, 1767) probably grew out of his extensive correspondence with Linnaeus and work with Solander, a favourite student of Linnaeus. Four of the species with their epithets are still accepted; the remaining one, tridens, has been placed in synonymy 
under incrassata (Section IV). The species incrassata (tridens) and monile were new with Ellis, whereas opuntia had been described by Linnaeus in his "Systema Naturae" (1758), using the binomial Corallina opuntia. Others before this had assigned other names to it, generally polynomials.

Ellis' examination of Halimeda material included microscopical study of both surface and internal features (Fig. 12) in what seems to

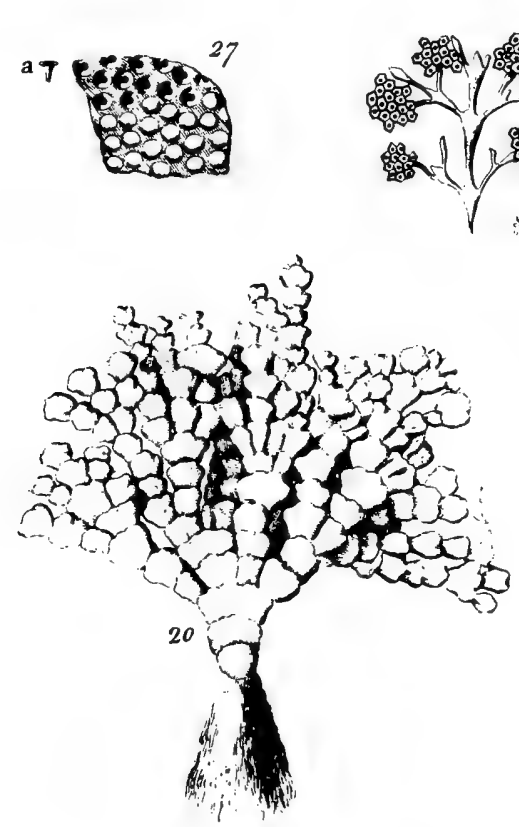

20. The Corallina incraffata, from the WertIndies.

21. One of the joints of its natural fize.

22. The fame magnified a little, to thew its pores in its calcareous furface.

23. Part of the infide tubes of the joint, of their natural fize.

24. The fame magnified, to thew the openings of the cells on the furface, connected together.

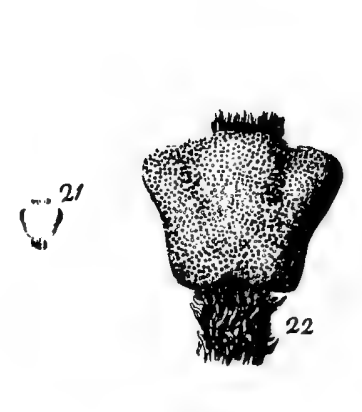

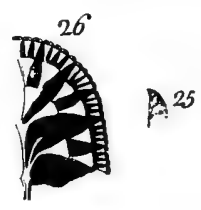

23

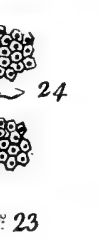
25. A perpendicular fection of half of one of thefe joints.

26. The fame magnified, to thew the figure of the veffels leading to the fuckers in the calcareous furface.

27. A piece of the calcareous furface highly magnified, to thew fome of the pores open, and others covered with their convex opercula; letter $a$ fhews the figure of one of the trumpet-Phaped fuckers highly magnified.

FIG. 12. Halimeda (Corallina) incrassata. These illustrations with analysis, by Ellis (1767), provide the type description of the species incrassata. Ellis' work also represents the earliest known microscopical study of the genus. The habit (No. 20) illustrates the caulescent effect obtained when basal segments remain unbranched. In older plants a number of basal segments may become consolidated into a relatively massive structure. (From Ellis (1767); photograph composition by The Ohio State University Department of Photography.) 
be the earliest comparatively detailed examination of internal structure in Halimeda. More intensive microscopic examination was not undertaken until over a century later, first by Askenasy (1888) and then by Barton (1901). Ellis particularly noticed the pits and facets given to the surface of Halimeda segments by the peripheral utricles, and compared them with the surface patterns of cnidarian corals:

We see in the greatest number of Corallines their surface full of holes; we saw the same in Escharas and Milleporas thirty years ago; since that time magnifying glasses have been improved, so as to shew us, that they are all orifices, for polype-like suckers; why should not we now admit that glasses may be still more improved, so as even to make us able to see what may be the intention and use of these minute orifices, which according to all rules of reasoning, we must suppose to approach in nature to them they are most alike.

This provided part of the basis for considering Halimeda as an animal.

Ellis' conclusions had force because of his skill and reputation as a microscopist. Linnaeus wrote to him, "I beg of you to lend me your lynx-like eyes" (Library of the Linnean Society of London; Savage, 1948). Furthermore, Ellis worked with some of the best laboratory hardware of the day including an "aquatic microscope" (Fig. 13) made by a London optician and "improved" by Ellis specifically for examining living corallines. I used Ellis' aquatic microscope at the Science Museum (London) and found the resolution to be surprisingly good. Figure 14 shows a photomicrograph of the surface of Halimeda incrassata made with it. The more obvious surface features of the plant can be conceived almost as certainly as with a modern microscope. The smallness of the field, and its curvature, are the main problems of these simple instruments. Chromatic aberration led to some vexing difficulties, but not as much as in the compound microscopes of the time.

Ellis provided additional contemporary insights on microscopes and viewing in a letter to Dr David Skene in 1770 (Library of the Linnean Society of London; Savage, 1948).

I find Wilsons or the Single microscope much the best; there need not be any plano convex glass screwd in at bottom if you have a good illuminating concave speculum to throw up the light, and at the same time to take instead of the plano convex on the bottom to screw on the bottom a brass circular plate with a hole in the centre in proportion to the size of your magnifier; the largest magnifier as No. 1 requires the smallest hole, by this means in a clear day youll easily see the minutest animal distinctly. Mr. Dollond has at my request fitted up a pocket microscope that pleases most people; it consists of my aquatic \& Wilsons combind together so as to be very little larger than the aquatic alone 


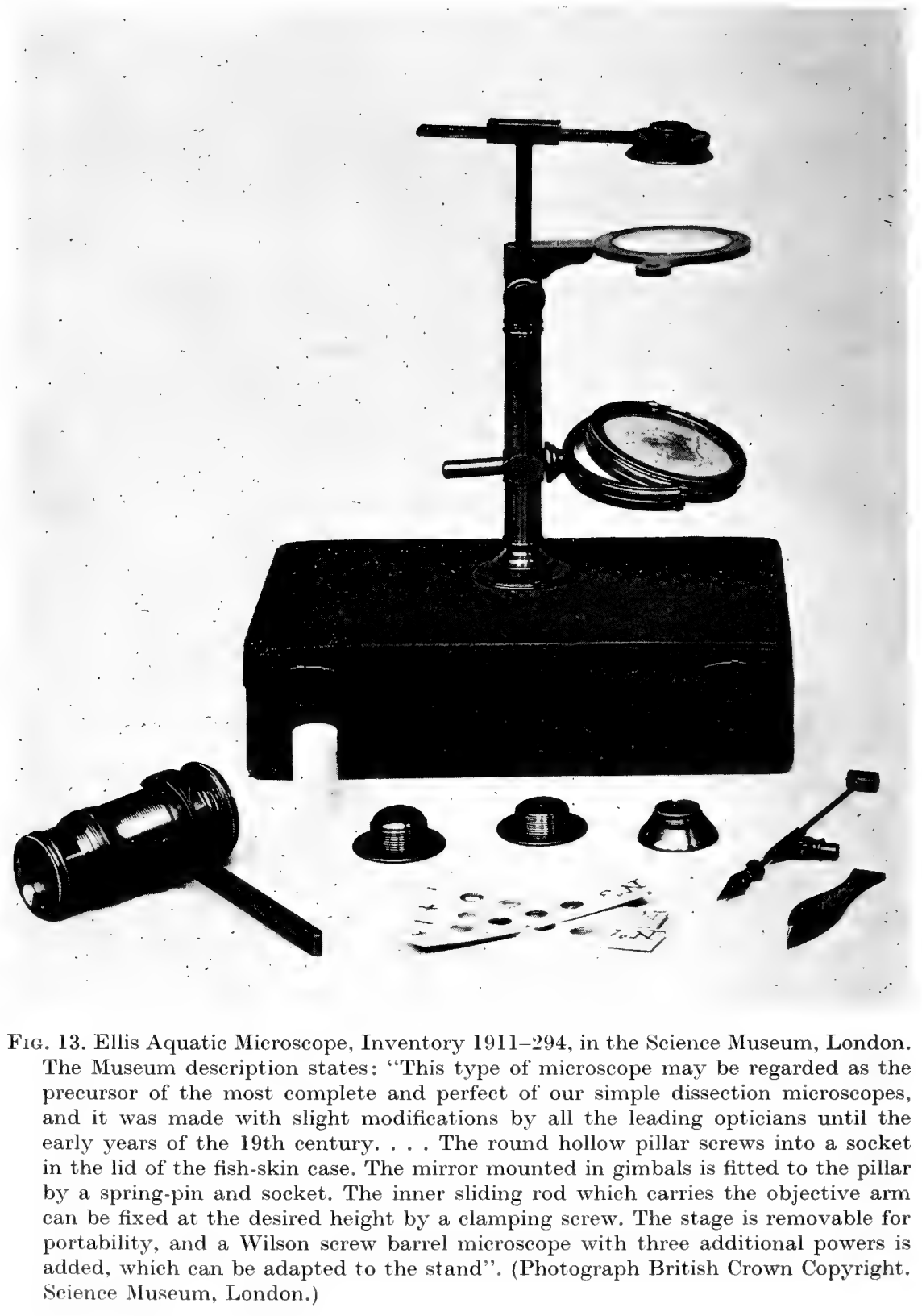




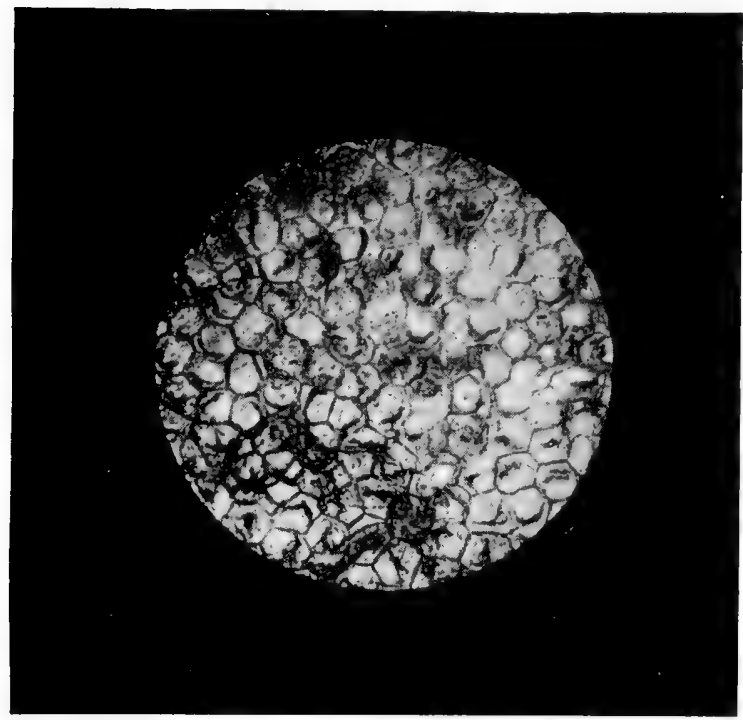

FIG. 14. Surface utricles of $H$. incrassata, as observed with an Ellis Aquatic Microscope (Fig. 13) from the collection of the Science Museum, London, using the No. 1 objective. Most of the numerous faint dots or small circles in the utricles are chloroplasts; the darker spots and curves are associated with subsurface structure. Both may have encouraged Fllis to think of polyps (cf. Fig. 12). The average diameter of the surface utricles is $45-85 \mu \mathrm{m}$. (Photograph British Crown Copyright. Science Museum, London.)

which he sells at 3 Guineas \& half; the Wilsons at the same time is fitted for the Solar apparatus so that by having a small box with the Solar apparatus which cost[s] $2 \& \frac{1}{2}$ Guineas more you have a compleat Microscope for any object. I never could see the smallest animalcules in the Double or Compound microscope. This does very well for the larger objects and is pleasing to many on acct of the largness of the Field.

Ellis' consideration of corallines as animals was further strengthened by his deductions about their chemistry such as he demonstrated to the Society of Arts, Commerce and others. He showed that corallines, when burned, produced not the "smell of burnt vegetables", but "an offensive smell like that of burnt bones, or hair". Indeed, the door of the room where the Society was meeting "was obliged to be opened, to dissipate the disagreeable scent, and let in fresh air" (Ellis, 1767).

Such arguments for the animal nature of Halimeda were part of the fascinating and well-reasoned letter Ellis wrote to Linnaeus in 1767. This letter, a portion of which is also a paper in the Philosophical Transactions, was one of two of Ellis' works chosen for citation in the 
presentation speech for the Royal Society's Copley Medal award to Ellis the following year (Smith, 1819).

Linnaeus accepted much of Ellis' position on the animal nature of corallines, and in his own last edition of "Systema Naturae" (1766-1767) wrote of calcareousness indicating animal origin: "Corallinas ad regnum animale pertinere ex substantia earum calcarea constat, cum omnem calcem animalium esse productum verissimum sit." That Linnaeus had reservations, however, is shown by his keeping the corallines in his rather ambiguous group "Zoophyta", which he defined as compound animals bearing flowers, their vegetating stem passing by metamorphoses into a flowering animal. Included under Zoophyta in the tenth edition (1758), as well as in the last (1767), was Halimeda opuntia (as Corallina opuntia), the only Halimeda species Linnaeus apparently knew.

Other contemporary workers such as Baxter (1761) and Pallas (1766) objected to this animal classification of the genus Corallina since the actual polyps had not been observed, but Ellis' arguments were sufficiently convincing that for the remainder of the century the genus generally was placed among the animals. The practice was continued into the nineteenth century with the work of naturalists such as Lamarck (1813) and Lamouroux $(1812,1816)$, but the term "zoophyte" was replaced with the preferred "polypier". More significantly, Lamouroux subdivided the coralline group into a number of genera. One of these was Halimedea (1812) or Halimeda (1816), to which he transferred the five species delimited by Ellis. The generic name we now use had been born. Another name, Sertolaria, with Imperato's Sertolara as type specimen, actually had been proposed earlier by Boehmer (see Ludwig, 1760), but the epithet Halimeda is the one that became established and in 1956 this familiar name was conserved (Lanjouw et al., 1956). That these organisms really were plants, however, still had to be worked out.

The first person in the nineteenth century recorded as definitely placing Halimeda in the plant kingdom, but under the name Hormisus, appears to have been Targioni-Tozzetti, whose unpublished manuscript was cited by Bertolini (1819). Link (1834), Chauvin (1842) and Decaisne (1842) also placed this genus in the plant kingdom, and by 1842 it was generally accepted that Halimeda was a plant.

\section{B. Halimeda discoveries: the beginnings of critical taxonomy}

Voyages of exploration as well as travels of individuals interested in living organisms in the eighteenth century yielded additional new species which were described by Decaisne (1841, 1842), Krauss (1846), 
Zanardini (1851, 1858), Kützing (1857-1858), Piccone (1879), Hauck (1886), Agardh (1887) and Askenasy (1888), changing the species total from 5 to 27 in about 50 years. Not all of these species proved satisfactory, however. Until 1888, the taxonomy was based almost entirely on external characteristics, with emphasis on what is now recognized as an exceedingly variable character, "segment shape". The microscope was not used critically for identification and Kützing's statement (1857), that internal organization was uniform among the species of Halimeda, provides some insight into the "state of the science" at that time. With such heavy reliance on segment shape, it is not surprising that certain taxa such as opuntia, and to a lesser extent incrassata, both of which commonly show a large variety of segment types, were at one time each described as more than one species. Segment shape, along with habit, also formed the basis of Agardh's (1887) sections within the genus which subsequently have been ignored (Hillis, 1959), at least partly because of their unsatisfactory definition.

The cornerstone of critical modern taxonomy and microscopy for the genus was laid by Askenasy (1888) who used microscopic characters to distinguish the few Halimeda species collected during an expedition of the S.M.S. Gazelle, as well as to delimit the new species macrophysa. Of special significance was the fusion he described of medullary filaments at the node in the species incrassata (Table III, Type 1). A brief reference to altered medullary filaments at the node, made by Agardh (1887) and by Ellis as early as 1755, provided some microscopic observations, but Askenasy's work represents the first detailed account of a major microscopic characteristic.

Askenasy not only emphasized nodal patterns of medullary filaments but also discovered that the sizes and shapes of peripheral utricles ("Rindenschläuche") differed significantly among taxa. He also provided a very clear description of the calcium carbonate deposits within Halimeda, pointing out that the crystals develop in the spaces outside the filaments, but within the confines of the segment, that is, that calcification is not external to the segment. The perceptive account shows his skills as an able contemporary microscopist and investigator. Little was added to this description until the $1960 \mathrm{~s}$ (Lewin, 1962), when the tools of electron microscopy and radioisotopes became available.

\section{The discovery at Funafuti: the reef-building capabilities of Halimeda}

At the close of the nineteenth century the Royal Society and the Government of New South Wales sponsored an expedition to Funafuti 
Atoll in the Ellice Islands of the south Pacific for the purpose of boring a deep hole to test Darwin's hypothesis on the origin of atolls. The first hole had to be abandoned after about $25 \mathrm{~m}$ of drilling, but two long cores were successfully taken, the deepest penetrating to $339 \mathrm{~m}$.

For the history of Halimeda this expedition and its results were especially significant for three reasons. An analysis of the cores showed not only that Halimeda segments were prominent, and hence that this alga participated in reef building, but also that in these particular cores this calcareous green alga, by the volume of sediment contributed, appeared to be more important than corals (Finckh, 1904). This activity will be discussed in Section IX.

A collection of intact specimens of Halimeda from various sites in the atoll was also made during the expedition, and was given to Miss Ethel Sarel Barton, later Mrs Gepp, of the British Museum (Natural History) to identify. This led to a paper on the Halimeda of Funafuti (Barton, 1900), but of much greater significance was her realization of the vast inconsistencies in the existing taxonomy of the genus and the need for its serious revision. Askenasy's skilful work pointed the way, and the opportunity soon arose. In 1900, Madame Weber-van Bosse asked Barton to work on the large collection of Halimeda made during the Siboga expedition led by her husband to the Dutch Indies in 1899 and 1900. Barton began an intensive study of the genus as then available to her, which led to the important monograph of 1901.

\section{The taxonomy of Barton}

Barton's investigation was a careful one. She dissected specimens and measured various characters. But, most importantly, she saw and examined as much of the type material of the species then recognized as she could obtain. Consequently, she was able to compare specimens with authority. She examined a number of characteristics in the many plants available, mostly East Indian, and concluded that the pattern of medullary filament fusion at the node was the most consistent character and the only one of significant taxonomic value.

Barton established three patterns of nodal medullary filaments (Table III, Types 1, 2, 3, respectively) as follows:

all medullary filaments come together into a single unit, often with conspicuous pits or pores between adjacent filaments, and then separate;

the filaments fuse, in pairs, for a short distance and then separate; 
filaments fuse completely in groups of twos or threes and do not separate thereafter, although the filaments eventually branch in the segment above that particular node.

The first type was originally described by Askenasy (1888) and is represented by the species incrassata. The second type, represented by opuntia, and the third by tuna and gracilis were first delimited by Barton.

The usefulness of Barton's monograph at that particular time was strengthened further by her rigid application of this nodal character. Her taxonomy was supplemented with one other microscopical character, the extent of adhesion of the peripheral utricles and by judicial use of segment shape. As a result, specimens with similar nodal anatomy, such as incrassata and tridens, were assigned the same epithet instead of different ones which had happened when the taxonomy was based on segment morphology. Ellis and Solander (1786), and subsequently others, including Agardh (1887), had considered them distinct species on the basis of the predominant segment shape being plano-convex in incrassata and tridentate in tridens.

A prime result of Barton's treatment was the retention of but 7 species of Halimeda (Table I) out of the more than 25 that had been recognized hitherto. A second result was that order within the genus was established.

A few specimens, however, were obviously troublesome to Barton, for they did not fit her scheme. Of these, a few are best interpreted as being poorly developed individuals. A very few were aberrant in that the medullary filaments did not fuse at the node in any of the designated ways, but remained entirely separate. Barton did not interpret this pattern as representing a separate category of nodal filament structure, however, because she felt she had plants with "all gradations of the character from filaments with well-developed pits to those which were entirely free and shewed even no trace of thin places on their unusually thick walls". Consequently those that she did not consider to be stunted or small specimens of the typical incrassata, she designated as a distinct form of incrassata, f. ovata. The form epithet was chosen because these plants resembled, at least externally, Agardh's incrassata v. ovata, the type of which she was unable to examine microscopically.

Although Barton was apparently satisfied with this decision, and her conservatism was reasonable considering the small number of such specimens available to her, the true nature of the material is more interesting. I have examined all Barton's material at the British Museum (Natural History) as well as the Siboga collection in the 


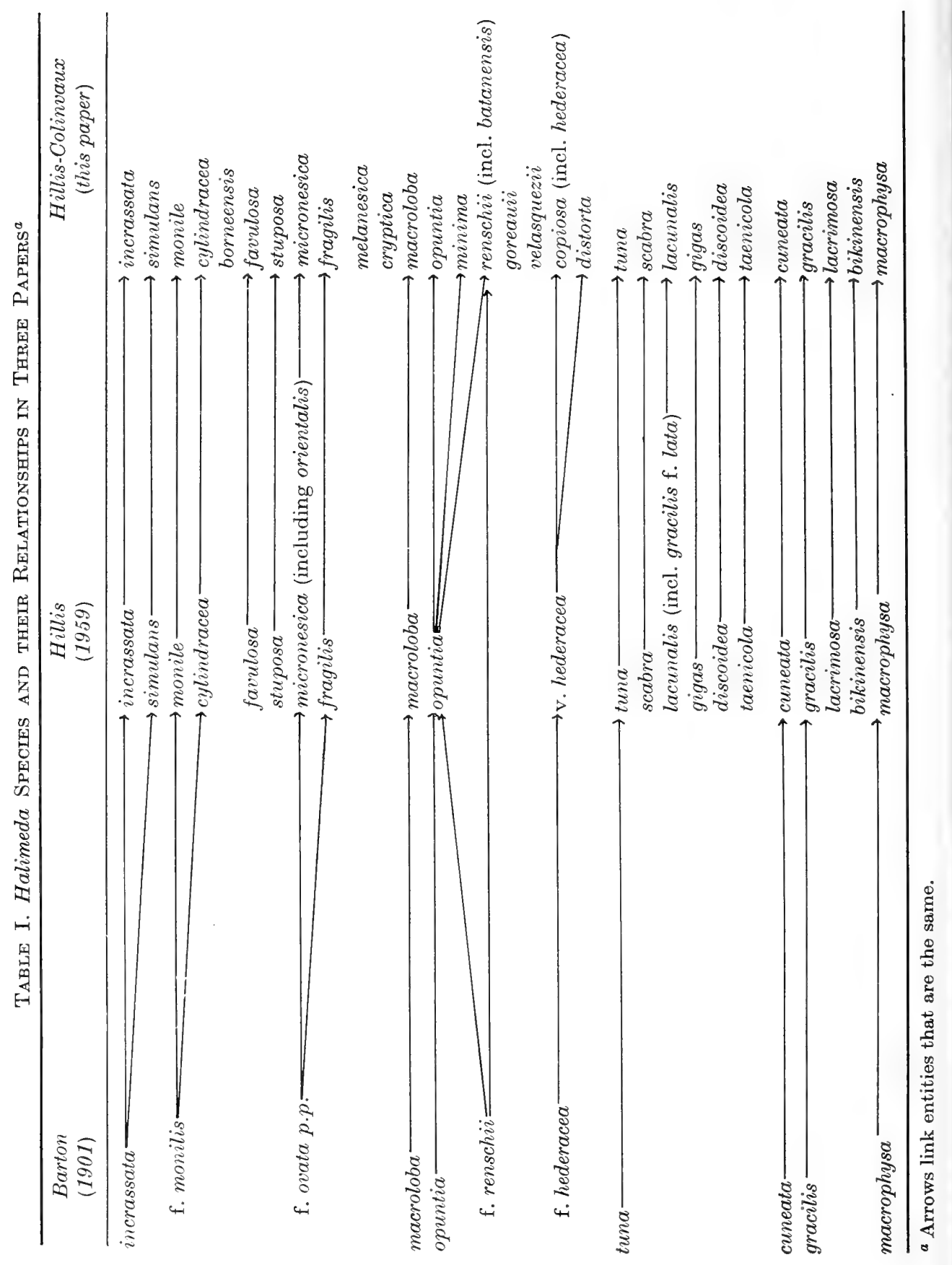


Rijksherbarium of Leiden, the herbaria where most, if not all, of the f. ovata material is deposited.

The f. ovata specimens are relatively few, occasionally poorly developed, and sometimes too scant to be adequately examined. However, most of those on which it has been feasible to work are micronesica, a species described in 1941 which will be discussed later on p. 32, and which is of especial interest because of the pattern of its nodal medullary filaments. A few are opuntia or simulans, the latter a taxon in which the pores of the fused nodal filaments are sometimes small and not readily noticeable (Hillis, 1959). It, therefore, presents some of the gradations Barton indicated for this character in the above quotation. These identifications of the anomalous f. ovata material have clarified and to a certain extent strengthened the major portions of Barton's work.

In retrospect, Barton's taxonomy was conservative, which was an approach much needed at the time. Its strengths lay in the discovery of essentially one microscopic characteristic of major taxonomic significance, in the fairly rigid application of it in identification, in the emphasis on examination of type specimens, and in the inclusion of material from other than the Siboga collection, which, although severely limited, did extend the work to all the tropical oceans. After the monograph was published, Barton continued identifying algae, published one paper on reproductive structures in Halimeda (Gepp, 1904), and more on Siboga algae in the important joint publication, with her husband, about the Codiaceae (Gepp and Gepp, 1911). The work after 1911 was not extensive, however; there appeared to be little further study of Halimeda, and one suspects that marriage in 1904 to Anthony Gepp, Curator of Botany at the British Museum (Natural History), and the contemporary attitude towards women and careers had their impact. For a brief time, however, the genus Halimeda was tidy.

\section{E. Howe, Børgesen, Taylor and Hillis: the modern taxonomy}

No taxonomic scheme of living organisms is fixed, however, and in a very short time after the publication of Barton's monograph many new collections became available to test the workability and validity of her system. Initially specimens came mostly from the Caribbean, a tropical region scantily represented in Barton's work, and for the first time the material was studied by workers who had some responsibility for collecting it. They were Marshall A. Howe of the New York Botanical Garden and Frederick Børgesen of the Botanical Museum, Copenhagen, 
Denmark, who worked in the Danish West Indies and published extensively on the algae of the Canary Islands and Mauritius. Both adopted Barton's fused filament characteristic for separating species, and Howe added other characters which subsequently proved as useful. While examining a certain abundant and distinctive West Indian plant, he noticed, for example, that its secondary utricles were more than twice as broad as those of most other specimens (Fig. 20, No. 11). Furthermore, the character was consistent. It could be used, therefore, to distinguish species, and Howe reasoned that specimens with this character should have separate status and not be considered synonymous with $H$. tuna as Barton had done. Howe (1907), therefore, reestablished the species discoidea, which brought the total of accepted Halimeda species to eight.

Table II. Use of the Microscopic Character of Average Diameter of Peripheral Utricles (surface view) by Howe (1907) to Separate Halimeda Species with the Same Type of Nodal Filament Pattern

\begin{tabular}{|c|c|c|}
\hline \multicolumn{2}{|c|}{$\begin{array}{l}\text { Peripheral utricles, average diameter } \\
<80 \mu \mathrm{m}\end{array}$} & $\begin{array}{c}\text { Peripheral utricles, average } \\
\text { diameter }>80 \mu \mathrm{m}\end{array}$ \\
\hline $\begin{array}{l}\text { Peripheral utricles, } \\
\text { average diameter } \\
49-77 \mu \mathrm{m}\end{array}$ & $\begin{array}{l}\text { Peripheral utricles, } \\
\text { average diameter } \\
30-44 \mu \mathrm{m}\end{array}$ & \\
\hline & $\begin{array}{c}\text { Predominant } \\
\text { segment shape }\end{array}$ & \\
\hline $\begin{array}{l}\text { tridens } \\
\qquad(=\text { incrassata })\end{array}$ & $\begin{array}{cc}\text { Subterete } & \text { Discoid } \\
\text { monile } & \text { simulans }\end{array}$ & favulosa \\
\hline
\end{tabular}

Among the microscopic characteristics investigated by Barton were those of appearance and size of the peripheral utricles in surface view. She did not find them particularly helpful, however, which in retrospect is reasonable because her species concept was exceedingly broad. Howe observed, though, that average diameters of the peripheral utricles in surface view could be used to separate entities with the same basic type of filament fusion at the nodes. Using the characters of average diameter of peripheral utricles (surface view) and predominant shape of segments (Table II), he re-established the species monile, which had been placed in synonymy under incrassata by Barton, and recognized a new species, simulans, which possessed the same type of nodal character as the other two species (Howe, 1907). 
This use of additional microscopic characters represents an important refinement of taxonomic criteria for the genus and an early application of field experience with this taxon, which Barton and most of the preceding workers on Halimeda did not have. Howe appears to have been provoked into looking for reliable differences in microscopic structure because he had observed incrassata (his tridens), and monile growing in close proximity in Bermuda, Puerto Rico and the Bahamas, yet remaining distinct. Where simulans was observed growing near incrassata he also reported no intergrading forms (Howe, 1907). This character remains one of the most useful microscopic criteria for separating species of Halimeda.

Howe (1907) also suggested changes in nomenclature to take account of apparent priority of species authorship. He renamed incrassata with the epithet tridens, which he believed had priority. Barton had chosen the epithet incrassata when merging older species, but Collins (1901), whose "Algae of Jamaica" preceded Barton's monograph by a few months, had chosen tridens for a similar merger. Howe's decision depended on Collins having correctly identified the type description of incrassata and tridens as being that referred to in a single publication by Ellis and Solander (1786). The first author to merge species erected in a single earlier paper has priority of choice for the name to be used (International Rules of Nomenclature). Collins chose tridens; Barton chose incrassata; Collins chose first.

Børgesen (1911, 1913) put the merged species back to incrassata where Barton put it. This argument over naming the species has had the heritage that American and European workers gave the same species different names for much of this century. Americans followed Howe in using tridens and Europeans followed Børgesen and Barton in using incrassata. This confusion was only resolved with the monograph of Hillis (1959). In this it was demonstrated that incrassata is the appropriate name because Ellis, in his 1767 publication, included excellent illustrations, with analyses, of a "coralline" to which he applied the specific epithet "incrassata" (Fig. 12). This meets the requirements for valid publication as stated in the Paris Code (Lanjouw et al., 1956, Article 43). The original merger proposed by both Collins and Barton is still accepted, and the name of the species is Halimeda incrassata and not $H$. tridens.

Børgesen's (1911, 1913) interpretation of Caribbean material tended to parallel Howe's, yet reflected his own thinking. He considered that monile and simulans differed sufficiently from incrassata to be treated as separate taxa, but that they were only varieties of incrassata. These subspecies were considered of specific rank by Hillis (1959), as originally 
suggested by Howe. In this way Hillis' monograph resolved both differences of usage between America and Europe: the correct name for Barton's $H$. incrassata, and the specific status of $H$. monile and H. simulans.

The preceding brief account of the history of Halimeda shows that the major collections which had been examined critically by the 1930 s had come, first from the Mediterranean, then the Dutch East Indies, followed by the West Indies. Not until the 1940s were concentrated studies made of Halimeda in Pacific atolls. The Japanese phycologist Yamada (1941) described a new species micronesica from the Caroline Islands. This taxon is particularly noteworthy because it possesses a fourth pattern of nodal medullary filaments (see discussion of $f$. ovata earlier on p. 29). The medullary filaments of this species do not fuse at the node, but pass unchanged, except for branching, from one segment to the next (Table III, Type 4).

In 1946, William Randolph Taylor of the University of Michigan participated in "Operation Crossroads", the detailed scientific study of the Marshall Islands before and after atom bomb trials. Prominent in his collection of the vegetation of four of the atolls was a large and exciting series of Halimeda plants which were included in his book "Plants of Bikini" (Taylor, 1950). Some were new species, and one of them, fragilis, was a second species with unfused medullary filaments.

By 1950, then, the species total of Halimeda, counting monile and simulans as species rather than varieties, was about three times that accepted by Barton. A quiet outburst of Halimeda data had occurred, and, as a result, Barton's monograph could no longer be used exclusively to study the Halimedae of any one region. It remained a useful introduction to the critical taxonomy of Halimeda, but was not the definitive work on the genus.

In the mid-1950s Hillis, later publishing as Colinvaux and HillisColinvaux, began working on Halimeda. Studying at the University of Michigan she had available the university's herbarium containing extensive collections from several Caribbean Islands as well as from the Marshall Islands. Curators of the New York Botanical Garden and the British Museum (Natural History) lent considerable portions of their large Halimeda holdings, the former collection containing much of Howe's and some of Børgesen's material, the latter including important specimens examined by Barton, although the bulk of Siboga expedition material, housed in the Rijksherbarium, was examined several years later in Leiden. A loan from the University of California provided additional plants from Pacific reefs. The collections, supplemented with other important although smaller loans and some live material, 
provided about as extensive a world coverage as then existed, and formed a good basis for the investigation which led to a revision of Halimeda taxonomy (Hillis, 1959), with the recognition of 21 species (Table I).

A weakness of the Hillis monograph is that important regions of the world, particularly the Indian Ocean, are poorly represented. This is because little collecting had been done in these regions up to the 1950s. Where phycologists had collected, their specimens provided little ecological information, so that the treatment of the data had to be without detail. In addition some type specimens and important collections could not be examined.

In the years since 1957 it has been possible to extend the work considerably in both traditional and new ways. The International Indian Ocean Expedition yielded good collections obtained by phycologists from new as well as familiar sites, and the new tool of scuba provided the opportunity of exploring and collecting in sites that grapple and dredge could not probe or penetrate. This led to the discovery of new species, including the first species of Halimeda with but a single medullary filament passing through the node (Fig. 15; Colinvaux and Graham, 1964), which represents a fifth nodal medullary filament pattern (Table III).

Scuba diving, supplemented with skin diving and submersibles, actually enable us, at last, to see these organisms in their communities down to the limits of their depth range of approximately $100 \mathrm{~m}$, and also to investigate and eventually to understand their role in the complex reef system. There have now been studies on the productivity of Halimeda in culture and on the reef, on the processes of calcification, on reef building, on ultrastructure and on ecology. This modern work is reviewed here and is added to with many unpublished data.

\section{F. Summary: the evolution of Halimeda studies}

Halimeda was first known from the single species $H$. tuna that lives in the Mediterranean Sea, and this species continued to be the only one known for more than a century. The second, the familiar $H$. opuntia, was found by Sloane (1707) in Jamaica. Only 8 of the species now accepted were known by the turn of this century, and most of the 30 species now accepted are discoveries of the last three decades. Halimeda, like so many other genera, was too easily split into many species on the basis of superficial surface features during the nineteenth century. The taxonomist who brought order to the genus was Barton (1901), and 


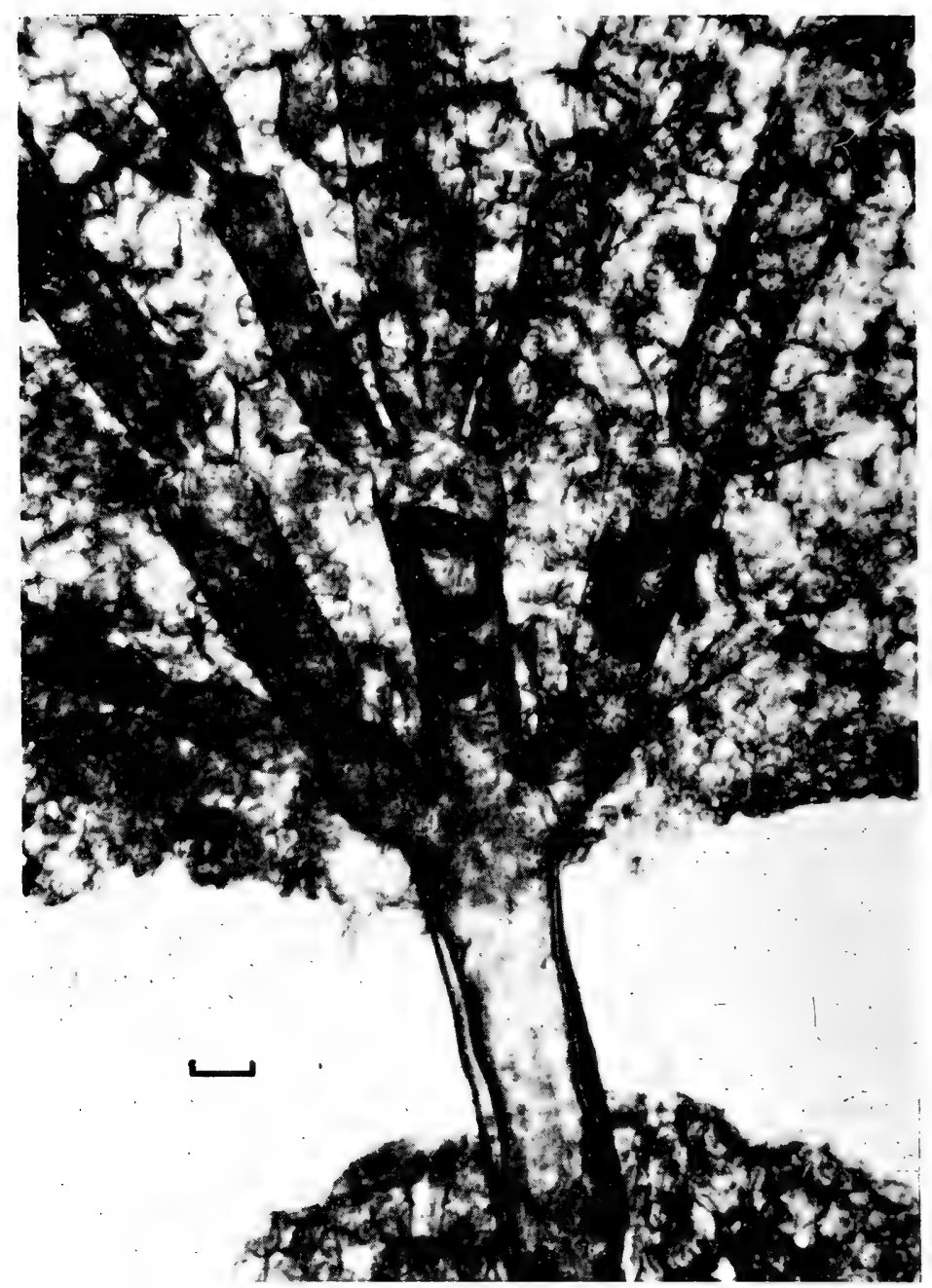

FIG. 15. A single medullary filament occurs in the node of $H$. cryptica, and the wall is much thicker in this region than elsewhere. The collar of smallish utricles from the upper segment which would surround much of the exposed filament has been dissected away. Scale bar is $100 \mu \mathrm{m}$. (From Colinvaux and Graham, 1964.)

the genus received its second monographic treatment by Hillis (1959). A number of new species has been found since then.

Studies on the structural and functional biology of the genus were begun by the early microscopist Ellis, and for long had the result of producing arguments over whether Halimedae were plants or animals. 
By 1842 this doubt was resolved, but little more structural work was undertaken until Barton's studies at the turn of this century. Functional and ecological studies had to await the demonstration that Halimeda would grow in culture (Colinvaux et al., 1965) and the availability of modern diving techniques. This article is the first review of these functional and ecological studies.

\section{Basis of the Taxonomy}

The principal theme of this section is the Halimeda species. In it I am concerned with the more obvious ways in which the species vary and how they may be distinguished, rather than with precise details of how one species differs from another. Details of species description, species synonymies and keys to species are therefore reserved for Section IV. Both types of data, however, are brought together in Table $\mathrm{X}$, which summarizes important characters for each of the currently recognized 30 species. The taxonomic information available up to the early 1960s also has been quantified and incorporated into a system of numerical taxonomy developed by Rogers and Fleming (1964) who were then working at the New York Botanical Garden.

So that the genus may be considered in the framework of the green algae (Chlorophyta) and the plant kingdom, I include a discussion of taxonomic categories above the genus level.

\section{A. The species}

Barton, as a pioneer in the microscopic taxonomy of this genus, relied principally on one anatomical characteristic, the organization of filaments in a mature node, to distinguish the seven species of Halimeda she recognized (1901). However, with the splitting of some of these species, and the discovery and description of others, such heavy reliance on a single microscopic character is not possible. And if the many new species have validity - there are now over four times the number Barton recognized (Table I) - it follows that reliable characters exist to separate them. For Halimeda many of these are known and tested, and as with most algae they are principally microscopic. However, I have found a few macroscopic characteristics to be reasonably dependable, and when they are combined with distributional data reliable field identification of some species is possible. These nonmicroscopic characters can, of course, also be used for laboratory determinations. 
I describe macroscopic and microscopic characters in the subsections that follow, but reserve distributional and ecological data for Sections VIII and X respectively. All may be useful in delimiting groups of species, or individual ones. Specialized reproductive structures or gametangia are described in Section VII. They are not present on most of the material collected and so far have not contributed significantly to taxonomy.

\section{Macroscopic characters}

Three characters are commonly used:

appearance of segment;

appearance of holdfast;

appearance of thallus.

The first of these, segment appearance, is the original character used to separate and establish the early species of Halimeda (Section II). The other two were developed as key characters by Hillis (1959), so that some specimens could be identified in the field. All three, together with data on geographic and ecological distribution, are essentially the only characters available for the field determinations essential to any critical ecological study involving the genus.

(a) Segment pattern. The usefulness of the appearance of segments to species identification may rightly be questioned when one recalls the early taxonomic confusion created by relying on this characteristic. From direct observation of extensive collections of dried material one is well aware that the segments, even of a single thallus, may be highly variable in shape and size, and species such as incrassata and opuntia are good examples.

Such doubts are further strengthened by evidence that some variability is environmentally induced. Techet (1908), for example, attributed the changed shape of the segments of Mediterranean tuna, when kept in laboratory tanks, to reduced salinity. In some of their culture studies, Colinvaux et al. (1965) observed a marked change in the segments of discoidea which may be a response to reduced light intensity. I have also noted a considerable reduction in the size, as well as change in shape of the segments of gigas growing in aquaria (Fig. 16). My field observations have also indicated changes of shape in response to environmental factors. The dwarf opuntia growing shallowly in a fastflowing inter-island channel of Enewetak Atoll in the Marshall Islands is a good example. 


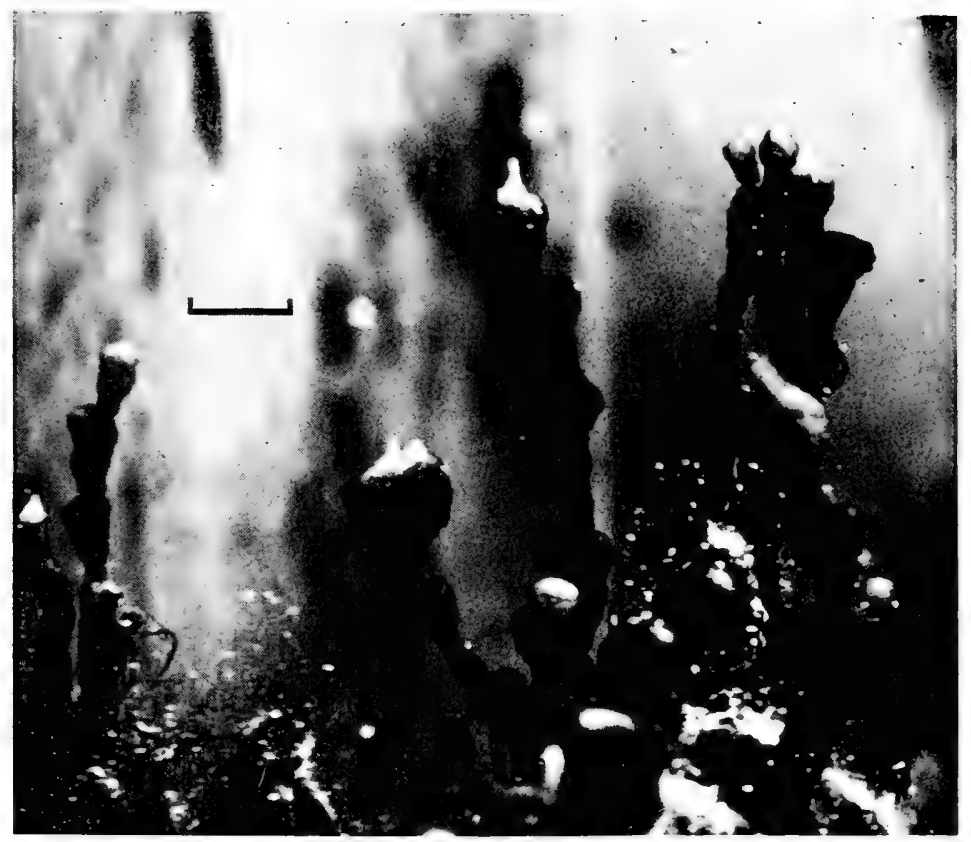

Fig. 16. Some of the variability which may occur in segment size and shape shown for $H$. gigas. Portions of the typical segments, which are reniform to discoidal and very large (Fig. 39), appear in the bottom of the picture, particularly the right-hand corner. The remainder of the segments, which are predominantly cuneate, were produced in culture at light intensities of approximately $125 \mathrm{ft}-\mathrm{c}$. The tips of several of the segments have the whitish cone-like extensions of medullary filaments, indicating that new segments are forming. Scale bar is $10 \mathrm{~mm}$.

Variations, therefore, do occur. The important point is that the variations do fall fairly well within the range recognizable for each species. I have found that size, shape, texture (and occasionally colour) of segments may, with care, be used in species identification. One can easily see, for example, that the segments of macroloba and lacrimosa are very different from those of incrassata or opuntia (Figs 28, 45, 22, 19, respectively), and other examples can be found in a study of the species illustrations of Section IV. By contrast, the segments of incrassata and simulans or even of monile and cylindracea may be so similar that identification by segment appearance alone is not reliable.

The shape of segments may be spherical, to cylindrical, to flattened, with the upper margin of broad flattened segments entire, undulating or lobed, and the lower margin cuneate to auriculate. In size, the range extenss from the small $(2-5 \mathrm{~mm})$, tear-shaped segments of lacrimosa to 

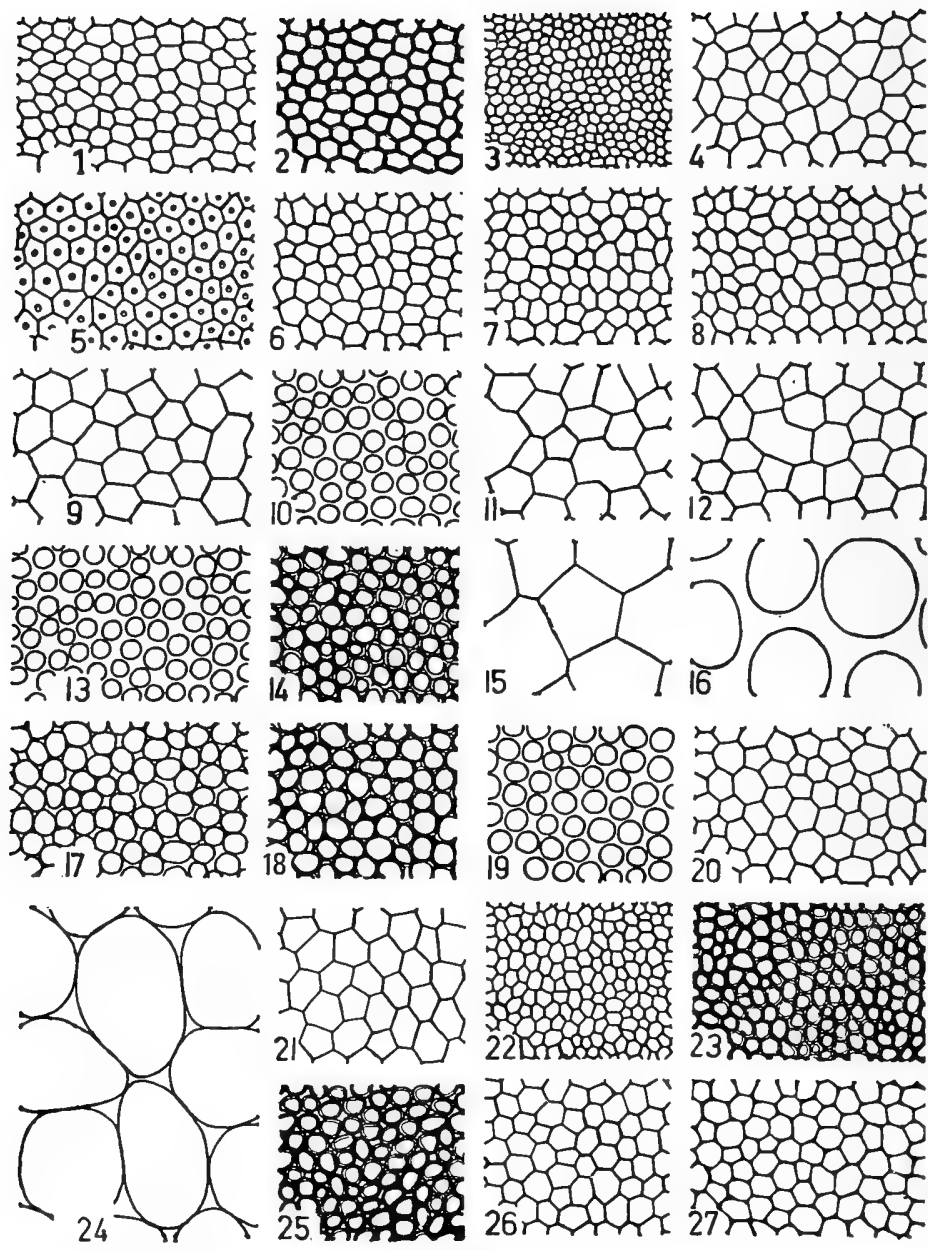

$\longmapsto 0.1 \mathrm{~mm}$

Fig. 17. Appearance of the'surface of a portion of a Halimeda segment, showing some of the range in size and pattern among the different species. Each polygon or circle represents the surface of a peripheral (primary) utricle, and is the tip of the cortical branch system. Some of the variations which occur with age are shown in Nos. 14, 18, 20 and 23. Taxonomic characters shown include size; whether the utricles adhere laterally, or separate as in Nos. $10,13,16$ and 19, or remain somewhat attached but separate easily as in Nos. 14, 17, 24 and 25; the presence of spines, No. 5; and the presence of thickening as in Nos. 2, 23 and 25. (1) H.cuneata, regular segment; (2) $H$. cuneata, from a cushion segment showing the thickened walls which are fairly common in these small segments; (3) H. opuntia; (4) H. copiosa; (5) H. scabra showing the spines as small circles in the polygons; (6) H. lacunalis; (7) H. gracilis; (8) H. lacrimosa; (9) H.tuna; (10) H. fragilis; (11) H. discoidea; (12) H. taenicola; (13) $H$. micronesica from a mature segment; (14) $H$. micronesica from a very young segment, showing slight adhesion of peripheral utricles; exact age unknown, but 


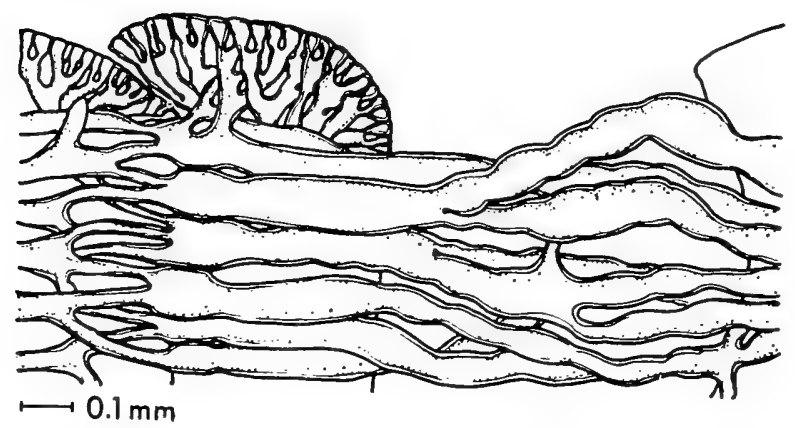

FIG. 18. H. cuneata, longitudinal section, showing parts of two regular segments, a "cushion" segment and a "stalk" region. At the left is the upper portion of a regular segment with part of the cortex included. To the right of it are parts of the small "cushion" segment which is corticated, and the uncorticated stalk region. One or both may be present, and commonly neither occurs. The pattern of medullary filaments at the node, shown at the juncture of regular and cushion segments, is that of fusion in twos and threes, with the participating filaments remaining fused. The entangled condition of the filaments just below the region of fusion adds to the difficulty of nodal dissection. The base of a regular segment, without cortical detail, is shown at the right. (From Hillis, 1959.)

the broad flat ones of gigas, which may measure to about $31 \mathrm{~mm}$ in length and $42 \mathrm{~mm}$ in breadth.

Thickness of segments varies with the number and height of the inner cortical layers, and often decreases from base to apex within a plant. This gradient reflects the relative ages of segments, with older segments towards the base, youngest at the branch tips. Some segments are ribbed, others plane, and the surface of macrophysa and favulosa often appears pitted or stippled because of the large diameters and separateness of their peripheral utricles (Fig. 17, Nos. 16, 24). The species cuneata is unusual in that a small "cushion" segment or an uncorticated "stalk" region, or both, may be interposed between a node and the next regular segment above (Figs 18,61).

Colour is influenced by the amount of calcification, proceeding from green to white or yellowish-brown as calcium carbonate increases with age. Young apical segments, therefore, may be a more prominent green than well-developed basal segments (Hillis, 1959). Colour, as a diagnostic

after the onset of calcification; (15) H. gigas; (16) H. macrophysa; (17) H. bikinensis, a mature segment; (18) $H$. bikinensis, a very young segment (green) showing adhesion of utricles at this stage of growth; (19) H. macroloba, mature segment; (20) $\mathrm{H}$. macroloba, young segment; (21) $H$. incrassata; (22) H. cylindracea, mature segment; (23) $H$. cylindracea, showing somewhat thickened walls of a basal (old) segment; (24) H. favulosa; (25) H. stuposa; (26) H. monile; (27) H. simulans. (From Hillis, 1959.) 
character, is rarely useful except in living specimens of scabra and micronesica, which may both have a pronounced bluish cast.

In some species the degree of calcification appears noticeably different between deep and shallow forms (Hillis, 1959; Goreau, 1963; Böhm, 1973a; Section IX), and species such as fragilis, gracilis, lacrimosa and bikinensis usually seem considerably more calcified than cuneata or lacunalis. Finally, the shape of basal segments may be noticeably different from the shape predominating in upper portions of the thallus. This is most marked in micronesica where the lowermost segment is usually several times larger than the other segments and very irregular in outline (Fig. 46). In members of the incrassata group several of the lowermost segments may remain unbranched, producing a caulescent effect, or adjacent basal segments may consolidate laterally forming a rather massive fan-shaped structure (Fig. 12).

(b) Holdfast style. Appearance of the holdfast is a character which is more useful in delimiting groups of species than in identifying individual ones, and is correlated, to some extent at least, with type of substrate.

Holdfasts of one group of species (Fig. 2) are conspicuous and bulbous. They consist of a mass of loose filaments to which particles of substrate freely adhere, so that the structure looks like cemented conglomerate of sand. These holdfasts range in length from about $1 \mathrm{~cm}$ to over $13 \mathrm{~cm}$. Halimedae with these holdfasts belong to the Rhipsalis section of the genus (Section IV), a group which contains all the species growing on unconsolidated substrates. Thalli with such holdfasts represent less than one-quarter of the described species, but as a group are the most readily separated. It is possible to find Rhipsalian. Halimedae attached to rocks or cobbles, usually where there is a thin layer of sand over the stone. The holdfast is then likely to be at the small end of the size range, but is still definite and is usually clearly separable from Halimedae with holdfasts of the remaining types.

Most Halimedae are attached to a firm, generally stable substrate such as coral rock. The holdfast is usually less than $1 \mathrm{~cm}$ long, is frequently inconspicuous, and may be missing from the specimen unless the thallus has been carefully collected. Holdfasts are commonly lacking in dredged material, for example. These smaller holdfasts often appear as orangey-brown, rather tightly compressed mats (e.g. tuna). The mats can be peeled off the rock substrate, though the operation is delicate. In some of these holdfasts the filaments remain loose so that the plant appears to be attached to the rock by a randon web of fine string.

(i) Multi-holdfast species. In a few species there is a complex system of attachments in place of a single holdfast. There are two 
multi-holdfast systems: the "rope-like extensions" of micronesica, and a system of adventitious attachment found in spreading and cushion life-forms.

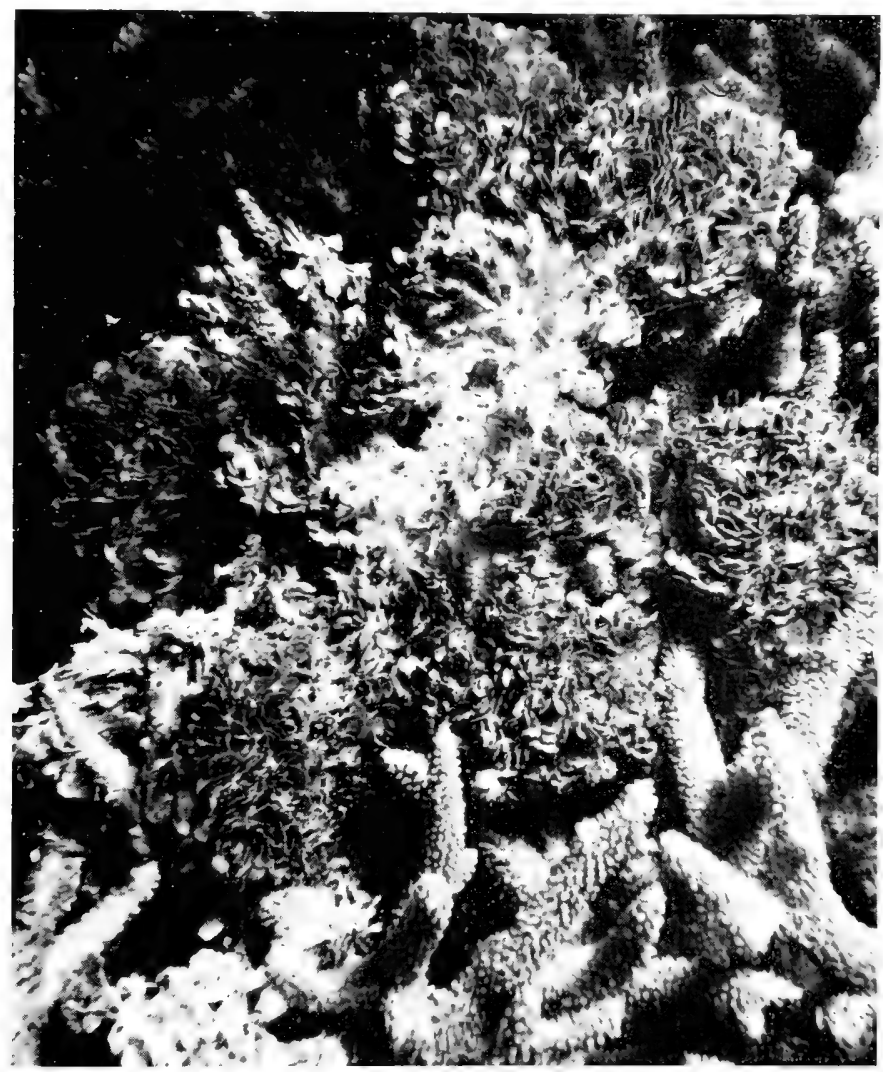

Fig. 19. H. opuntia, festooning Acropora sp. on the reefs of the Similan Islands, eastern Indian Ocean. The spreading thallus is anchored at several places, and the older parts of the thallus (shown near the centre) die away and become separated from the younger portions, producing a clone of several younger thalli. The multi-holdfast system is a useful growth strategy for a clone that may be grazed. Long dimension of the clump in right-centre is approximately $7 \mathrm{~cm}$.

"Rope-like extensions" were described by Hillis (1959) for micronesica. Fine rhizoidal-type filaments extend from several apical segments and become intertwined into ropes which attach to the substrate. Halimeda micronesica plants may be held down by an orange-brown mat of these ropes which may be up to $6 \mathrm{~cm}$ or more in length. 
In several species the basal point of attachment is poorly developed and may be difficult to locate, particularly in dried material. Instead, where some of the branches touch the substrate fine rhizoidal filaments may develop, giving attachment. This pattern may occur together with a spreading type of growth where thallus branches along crevices, or over and around coral heads. Adventitious holdfasts occur in some plants of opuntia (Fig. 19), distorta, gracilis and copiosa.

(c) Habit and growth form. The habit of the various species may be erect, pendant, prostrate or spreading, and may be distinctive for certain species such as the flaccid straggling thalli of the typical gracilis, the pendant form of a number of species of the Halimeda section (Section IV), or the generally erect pattern of members of the Rhipsalis. The axis of new growth is predominantly vertical for thalli with erect or pendant habits, horizontal for those that are prostrate or spreading. Some members of the section Opuntia, with their sprawling habit, may exhibit both horizontal and vertical axes of strong growth.

\section{Microscopic characters}

Three main sets of microscopic characters are useful in the taxonomy of Halimeda. They are:

pattern of medullary filaments at the node (Table III; Figs 3, 15); size and appearance of primary, secondary and tertiary utricles (Figs 17, 20);

pattern of cortex, and extent of its development (Fig. 20).

The use of these characters almost always requires the magnification of low and high powers $(\times 10$ and $\times 40)$ of a compound microscope, preceded by selection and preparation of the material.

(a) Choice of segments for examination. In using these characters to identify Halimedae, it is important to select only mature segments from the plant. In so doing much of the variation which is the product of growth rather than of the individual species is avoided. The ideal segment for examination is free of epiphytes and usually is about the middle of the thallus. Material from such a location is nearly always old enough to be reasonably calcified, but has not developed various features of aged or senescent segments which could mislead. The variations I describe herein and the range of measurements given in this section and in Section IV are from such "mature" segments. Some 
of the changes associated with yet older segments are also included in the account if they can be used in species identification.

\section{(b) Preparation of material}

(i) For nodal structure. Generally all the required information can be obtained by removing from the nodal region a thin rectangular strip approximately $6 \mathrm{~mm}$ long, $1.5 \mathrm{~mm}$ broad and the thickness of the segments included. The long axis of the rectangular strip should be along an imaginary line connecting nodes of sequential segments. The sample should include a small portion of the segments adjoining the node. If material is scarce, as it generally is with herbarium specimens, one can generally manage with only part of a node. By such parsimonious tactics, adjoining segments remain attached and the continuity of the thallus is maintained. If material is ample, as generous a strip can be cut as is desired. This rectangular strip may be sectioned or dissected.

For routine taxonomic examination the information on nodal structure often can be obtained from sections, and I prefer this approach because one frequently can obtain data on other microscopic characteristics from the same preparation.

A satisfactory technique is to section the strip lengthwise on a smooth card with a razor blade, using the short edge of a microscope slide as a guiding edge.

With a slightly moistened needle transfer the sections to a drop of water on a slide, decalcify with about $20 \%$ hydrochloric acid, remove excess acid with a tissue, and resuspend the sections in water. This sometimes is sufficient preparation, particularly if the material is living, and all that is needed before examining with a compound microscope is to add a coverslip. The slides subsequently may be made semi-permanent by infiltrating with glycerine or another medium if desired.

With some types of nodal structure, and with dried thin specimens, some teasing or dissecting apart of deflated filaments in the sections, with fine needles or fine pins such as insect mounting pins, is required before examining.

Entire nodes also may be decalcified and dissected for the required information. This technique is the obvious one for a species such as cryptica with only one nodal filament. For some species, however, the resultant numbers of filaments make elucidating the structure more difficult than working from sections.

(ii) For surface of peripheral utricles. The diameters of the peripheral (primary) utricles and surface detail are obtained from a 
thin slice of a bit of surface from about the centre of a segment. Place it in a drop of water on a slide making certain the outer surface is outermost, decalcify with $20 \%$ hydrochloric acid, drain excess acid with a tissue and refloat in water. The preparation is ready for examining with a compound microscope.

(iii) For inner utricles and development of cortex. Much of this information can be obtained from the same sections prepared for nodal examination if the rectangular strip removed extends sufficiently deeply in the segment below the node sampled. However, if a nodal sample was not made, cut a similarly shaped piece, oriented along the same axis, from slightly above the centre of the selected segment. Section and prepare according to the instructions for nodal preparation.

(c) Pattern of medullary filaments at the node. The character of medullary filament pattern at the node was referred to at some length in Section II because it is essentially the only character used by Barton (1901) in her taxonomy. The discussion herein involves their interpretation and use in modern Halimeda taxonomy.

The three patterns Barton recognized are:

the filaments all fuse together in a single unit for a short distance (about 1-1.5 times the diameter of the filament) and then separate; openings, pits or pores develop in the walls between adjacent filaments;

filaments fuse for a short distance in pairs and then separate;

filaments fuse completely in twos or threes and do not separate therafter (although the filaments continue their branching pattern).

With Yamada's (1941) new species a fourth category was needed:

filaments remain separate throughout the node.

A fifth type (Colinvaux and Graham, 1964) has been added:

node composed of a single filament.

Until the discovery of cryptica all known species of Halimeda were multiaxial, that is they possessed a core of medullary filaments. Species with this fifth pattern of nodal filaments are uniaxial.

The study of nodal anatomy can be as tedious and difficult as Taylor (1950) understandingly writes, and it should not be surprising that the structure one is seeking to unravel is not always clear cut. Since Barton's publication in 1901, many hundreds of Halimedae have been examined, and many new species recognized. The effect has been not only to add new categories of nodal pattern, but also to extend or modify the definition of patterns already recognized. 
The most difficult categories are the second and third which involve fusion of filaments in small groups, and they have sometimes been considered subunits of but one category (Taylor, 1950; Hillis, 1959). However, with the many additional species now placed in these categories this treatment no longer seems appropriate. In spite of apparent overlap, the two categories are distinct and should be considered of equal importance to the others. It has been necessary, however, to modify their definition. These new, or extended definitions have been used in Table III which is an illustrated listing of the five patterns, together with the species in which they are found. Modifications and variations are discussed below.

(i) Further definition of second and third patterns of nodal filaments, and their variations. In both categories fusion may be for a very short distance (approximately 1.5 times the filament diameter) or may be complete, with the participating filaments continuing as one filament which subsequently branches. These sometimes are referred to as "short" and "complete" fusion respectively.

In both categories the fusion may involve units of up to six filaments, and possibly more (Colinvaux, 1968a, and unpublished).

In both categories the occasional filament may remain separate. Such anomalous behaviour is perhaps most likely in filaments with a peripheral position (Colinvaux, 1968a, and unpublished).

Also, in certain species of both categories the fused units may adhere laterally, giving the impression of fusion into large bundles. Such adhesion may be demonstrated by teasing apart the units. This can be done with care, and the filament walls remain intact (Hillis, 1959; Colinvaux, 1968a).

However, in species of the second category, which is delimited (Table III) as "filaments mostly fuse in pairs for a short distance", this is the predominant type of nodal filament pattern. In addition, the participating filaments generally are not intricately intertwined before fusion. Therefore, the pattern "definite short fusion in pairs by most or all of the filaments, with participating filaments very little entangled" is diagnostic, whenever observed, for the species listed, that is, for the entire section Opuntia (Section IV).

Category three now is delimited as "filaments fusing in small groups, commonly twos or threes, for a short distance (approximately 1.5 times the filament diameter) or completely; filaments are frequently much intermeshed before fusing" (Table III). This category contains the greatest number of species, is the most variable, and its species are often the most tedious to dissect. The nodes may contain a more or less equal mixture of "short" and "complete" fusion units, or completely 


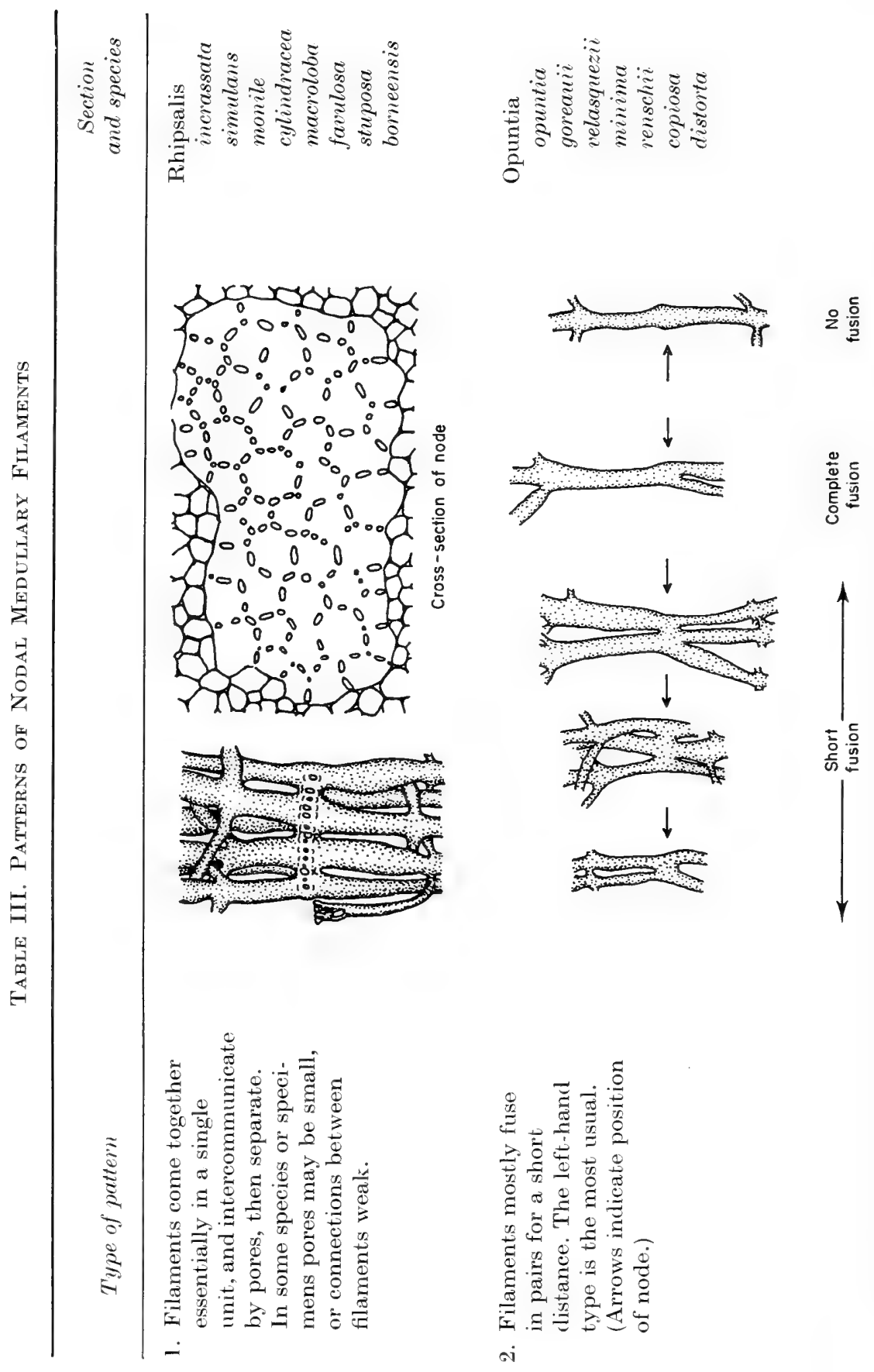



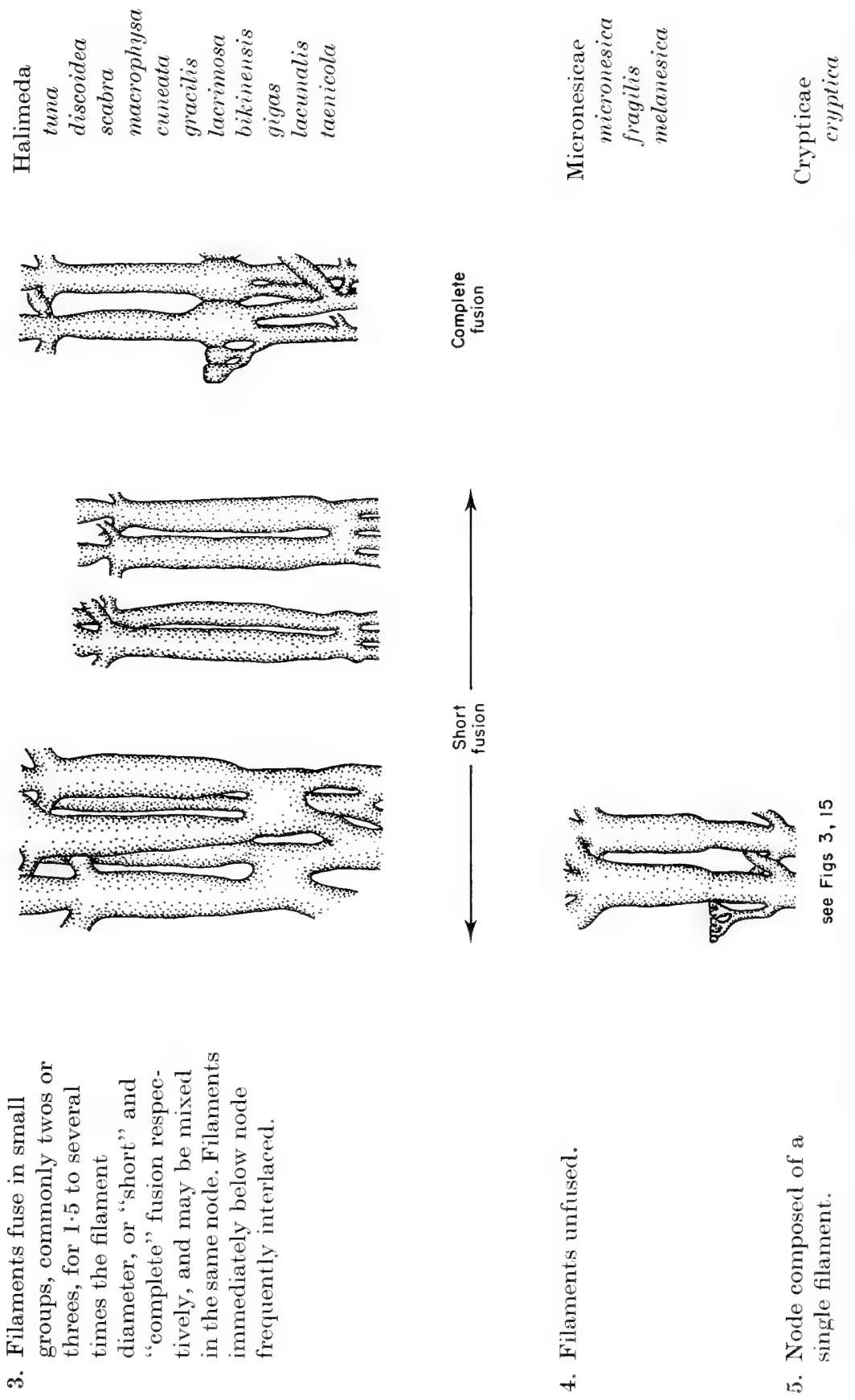
fused units may definitely predominate. The participating filaments may be so interlaced that the structure is very difficult to sort out, and the whole may be further complicated by the fused units firmly adhering for a length approximately equal to the diameter of a filament (Hillis, 1959), so that initially one feels that all the filaments are fused together as in pattern one.

(ii) Variations in the other three categories of nodal filaments. For most species of the first group (filaments fusing into a single unit) nodal structure is unequivocable. The pores associated with this pattern of filaments generally show up well if good longitudinal sections are made. The pores are lined up in adjacent filaments, and all the filaments appear to be involved in the fusion. Diagnosis for such material is straightforward. Occasionally, however, particularly in material of simulans, the pores may be small and relatively inconspicuous (Hillis, 1959). And in some specimens the connections between some of the filaments may be delicate and easily broken, giving the impression that the nodal structure is that of two or three large groups. Hillis (1959) reported this for monile. Occasionally, in monile two or three separate bundles of fused filaments occur.

The fourth group (separate filaments) is essentially uncomplicated, except that the filaments may adhere, usually only slightly, and then have to be gently teased apart without tearing, to establish the absence of fusion. In melanesica a very few filaments may join briefly in pairs.

The fifth category (a single filament) is straightforward.

(d) Pattern of peripheral or primary utricles. Useful characters are:

diameter in surface view;

surface appearance;

presence of spines (in scabra);

type and extent of lateral adhesion of adjacent utricles;

number borne by a single secondary utricle.

Length of these utricles, although usually given in species descriptions, has not proved useful taxonomically.

For the first two of the characters surface sections are required; tor the remainder, longitudinal sections are used. In three species surface characteristics are so outstanding that these microscopic characters may be checked in the field without magnification, or with a $\times 10$ handlens, and the identification subsequently verified in the laboratory. These species are scabra, macrophysa and favulosa. 
(i) Identification without a microscope. In scabra the surface of each peripheral utricle is prolonged into a spine (Fig. 20, No. 4), a feature which occurs in no other Halimeda. Consequently, thalli of this species without a surface growth of epiphytes feel slightly rough. This character may be used, with extreme caution, to distinguish scabra from tuna in the field. Halimeda scabra may be often bypassed in Caribbean reefs where it grows because it is considered to be tuna. Field identification should be checked with a handlens or (preferably) a microscope to verify the presence of spines. A lateral view (as in a longitudinal section) is preferred.

Halimeda macrophysa can be tentatively identified in the field by the very finely stippled appearance of the segment surface (Fig. 40). This pattern results from exceedingly large surface utricles which are round rather than hexagonal in appearance (Fig. 17, No. 16) and are separated by calcium carbonate partitions. However, if a first-time field identification for a given site is made this way, it should be verified microscopically.

Halimeda favulosa may give somewhat the same impression as macrophysa. The diameters of its surface utricles are larger, but the calcium carbonate partitions are not as complete. The two species cannot be confused because they look different macroscopically, and there is no overlap of distribution.

An awareness of this characteristic for favulosa may ease its being mistaken, and therefore bypassed in the reef, for incrassata which is considerably commoner.

(ii) Surface diameter of peripheral utricles. The surface diameters of the peripheral (primary) utricles together with their surface appearance are, perhaps, the most useful characters for separating Halimeda species at the microscopic level, and surface preparations are the most easily made. With $\times 100$ magnification these utricles generally appear as a "sheet of polygons" or like a honeycomb. Sometimes the units are roundish, and then may be disconnected rather than united into a "sheet". High-power magnification $(\times 400)$ is usually required for accurate measurement.

The range in diameters is shown in Fig. 17. The smallest occur in species of section Opuntia; the largest are in the species favulosa.

(iii) Surface appearance of peripheral utricles. The predominant surface pattern of the peripheral utricles is hexagonal (Fig. 17), a result of the pressing together of the many branch tips of the cortical filament system. In some species such as macrophysa, the separateness of the utricles is maintained by relatively thick deposits of calcium carbonate between utricles, and the utricles retain their roundness. Intermediate 

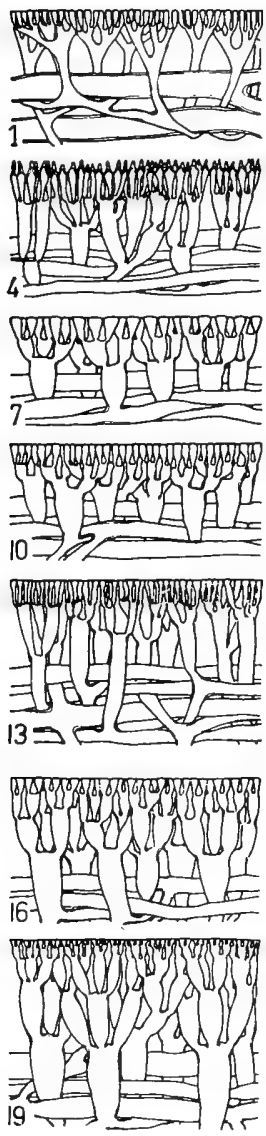
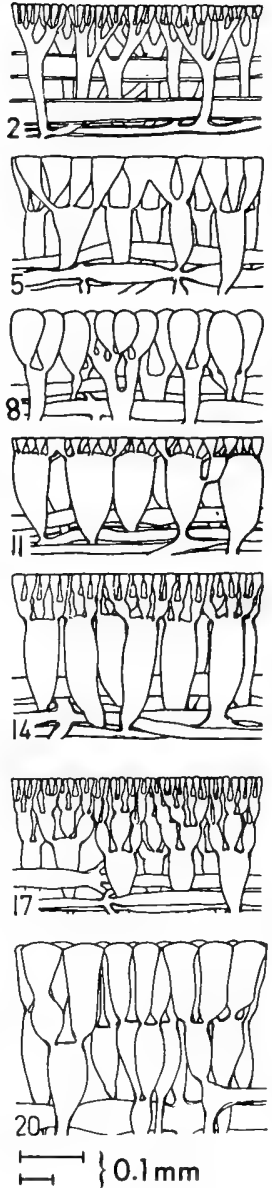
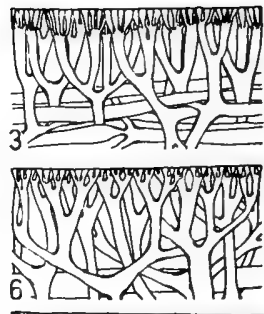

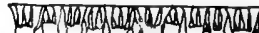
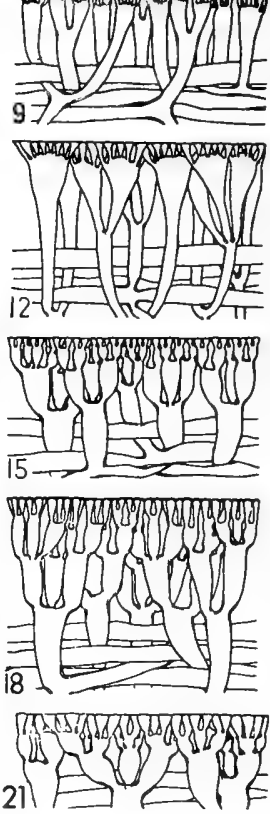

FIG. 20. Sagittal sections through an outer portion of about the middle of a Halimeda segment to show different characteristics of the cortical utricles, and of the extent of development of the cortex. A portion of the medulla is included in each. Important characters for the primary utricles are the extent of their lateral attachment, which ranges from about half their length in Nos. 10 and 11 to a thin platform-like edge in Nos. 9 and 12, to none at all in Nos. 1,8 and sometimes 20 ; and the number of peripheral utricles supported by each secondary utricle, which ranges from 1,2 or 4 in No. 20 to 14 in No. 11 and 18 in No. 12, but the usual number for most species is 2 or 4 . (All the utricles supported cannot be shown in a two-dimensional drawing, but the range is apparent.)

Useful taxonomic characters of the secondary and tertiary (inner) utricles include shape, diameter and length. In diameter, the largest secondary utricles are the bullate ones of discoidea (No. 11). Numbers 12, 9 and 3 are swollen at their peripheral ends. The tertiary utricles of No. 14 are diagnostic, except for some regional specimens of discoidea which have a swollen tertiary layer (see text).

There are two general patterns of development of the cortex. Most species have 
conditions occur in other species where the calcium carbonate deposits do not extend as completely to the surface and some of the utricles are slightly attached to each other.

An illusion of roundness seems to be produced by preparations from a few species, especially gracilis and lacrimosa. However, by focusing up and down with the microscope, very faint hexagonal lines can generally be observed (Hillis, 1959). The appearance seems to result both from the slightly convex outer surface of the peripheral utricles and by adjacent utricles touching only very slightly.

There are other variations. The walls appear somewhat thicker in stuposa and cylindracea for example (Hillis, 1959), and in velasquezii and cylindracea the "covering lamella" (Section I) of the outer surface of the peripheral utricles (Taylor, 1962, for velasquezii; Borowitzka and Larkum, 1977, for cylindracea ; both using the term "cuticle") appears to be more prominent than in some other species. This may also vary with condition of the material.

Yet another variation occurs in cuneata, discoidea, gigas, taenicola, tuna and sometimes other species, in the occasional lateral fusion of adjacent utricles in twos, threes and rarely fours (Fig. 17, Nos. 11, 12; Fig. 20, Nos. 5, 11). This fusion is distinct from adhesion, the usual pattern, where the utricles retain their individual walls.

(iv) Lateral adhesion of adjacent peripheral utricles. Longitudinal sections (Subsection 2.b.iii) are required to observe this character.

Adjacent peripheral utricles usually adhere where they touch. In cylindracea, and very possibly all of the species, this appears to be brought about by the fusion of the covering lamellae of the participating utricles (Borowitzka and Larkum, 1977). The remainder of the filament walls in the region of contact generally retain their distinctiveness, although there are exceptions as noted in Subsection (iii).

The extent, or length, of the adhesion ranges from none (macrophysa, fragilis and often favulosa) to about half their length (cuneata and discoidea; Fig. 20). In lacrimosa and gracilis it is restricted to a thin

distinct utricles (are utriculiform); but in species of section Opuntia and a few other species the utricles, formed by dichotomous branching, are not swollen or specialized, and hence appear like regular branches. This type of cortical development is shown in Nos. 1,2 and 6.

(1) H. fragilis; (2) H. micronesica; (3) H. bikinensis; (4) H. scabra; (5) H. gigas; (6) H. opuntia; (7) H. tuna; (8) H. macrophysa; (9) H. gracilis; (10) H. cuneata; (11) H. discoidea; (12) H. lacrimosa; (13) H. lacunalis; (14) H. taenicola; (15) H. simulans; (16) H. monile; (17) H. macroloba; (18) H. stuposa; (19) H. cylindracea; (20) H. favulosa; (21) H. incrassata. The long scale applies to No. 6; the short scale to the others. (Adapted from Hillis, 1959.) 
platform-like edge of the utricle (Hillis, 1959), so that these utricles may separate readily after decalcification if the coverslip over the preparation is pressed gently.

The degree of adhesion also varies somewhat with the age of the segment. In some species at least, the utricles, while adhering in young and mature segments, may separate readily in old yellowish or whitish basal segments (Hillis, 1959), and sometimes in mature segments as well (Fig. 17).

(v) Number of peripheral utricles supported by a secondary utricle. Longitudinal sections (Subsection 2.b.iii) are required to observe this character, and some of the range is illustrated in Fig. 20.

Usually 2 or 4 peripheral utricles are supported by each secondary utricle. In favulosa, however, sometimes only one is borne on a secondary utricle, in bikinensis and gracilis up to 8 frequently may be so supported, with as many as 14 in discoidea and 18 in lacrimosa. Numbers between 2 and 8 occasionally occur in species in which 2 or 4 are usual (Hillis, 1959).

(e) Shape, diameter and length of inner utricles. Inner utricles show up in longitudinal sections like those described in Subsection 2.b.iii. They are best seen at $\times 100$ magnification when they appear rather like expanded sacs, or sometimes as continuations of filaments, between the outermost (primary) utricles and the longitudinally oriented medullary filaments. Striking differences in shape and diameter are apparent in different species, and length may also be a useful parameter. Highpower magnification $(\times 400)$ should be used in measuring the diameters of the inner utricles at the small end of the size range. Utricle diameter is measured at what is usually the broadest part, just below the insertion of the primary utricles.

The most dramatic secondary utricles are the greatly swollen "bullate" utricles of the Atlantic discoidea (Fig. 20, No. 11), and in these plants usually only two layers of utricles, the peripheral and secondary, are present. In Pacific-Mexican and Hawaiian discoidea, a third or tertiary layer of utricles is commonly present and then the secondary utricles are less conspicuous and at the lower end of the size range (Howe, 1911; Hillis, 1959).

Other distinctive secondary utricles are those of lacrimosa, and to a lesser extent gracilis (Fig. 20, Nos. 12 and 9, respectively). Those of lacrimosa are frequently very long and are much swollen at their peripheral end. Those of gracilis are of a similar style, long and swollen, but the amount of distension at the peripheral end is considerably less and sometimes almost imperceptible (Hillis, 1959, and Section IV). 
It is the tertiary utricles of taenicola that are swollen and distinctive (Fig. 20, No. 14), rather like the secondary utricles of discoidea (Taylor, 1950; Hillis, 1959).

Length of the inner utricles in some species varies considerably with the age of the material or the number of layers of utricles. It is therefore generally not a helpful character.

(f) Pattern and extent of inner cortex. For many species the distinctiveness of the inner cortex lies as much in the pattern formed by the inner utricles (inner cortex) as a whole, as in the initial distinctiveness of secondary or tertiary utricles. The pattern may be observed in sagittal sections (Fig. 20).

There are two general patterns of development of the cortex (Hillis, 1959, and Fig. 20).

The branching and rebranching of the lateral filaments may be accompanied by generally pronounced constrictions and wall thickening at the sites of branching, and swelling of the intervening regions. These swollen regions form the distinctive utricles. Branching to form the inner utricles is generally tri- or tetrachotomous.

The branching and rebranching of the lateral filaments is dichotomous, and is not accompanied by pronounced constrictions at sites of branching, or by swelling of the intervening regions. The utricles appear like continuations of the branches.

The second of these patterns occurs in the Opuntia group of species (nodal filaments mostly fusing in pairs for a short distance) (Hillis, 1959; Colinvaux, 1968a), as well as in the sections Micronesicae (except for melanesica) and Crypticae (see Table III for species included and later (overleaf) for a discussion of sections). Somewhat modified, it also appears in gracilis, lacrimosa and bikinensis.

The first pattern occurs in members of section Rhipsalis and many members of section Halimeda. In members of the Rhipsalis except for favulosa, the diameters of the utricles become progressively larger proceeding towards the medulla.

(i) Extent of inner cortex. The number of layers of utricles in the cortex may be a helpful taxonomic character for some determinations, although this character is more variable than many of the others.

The number of layers ranges from two to five, rarely six, with two usual in discoidea, gigas and macrophysa, and five in opuntia and some of the species belonging to section Rhipsalis. Exceptions include the presence of a third layer in some material of discoidea (Subsection (e) above), and sometimes only two layers in lacunalis, where usually there are three. 
Extent of the cortex also varies with other factors including age and location in the segment. The number of layers is generally fewer in young segments, and greater in old basal segments which are often greatly thickened. Their number frequently is reduced or they may be absent in the vicinity of the node (Fig. 6), with peripheral utricles then being supported directly by short, unmodified branches of the medullary filaments. And, in cryptica, a Caribbean species found often in heavily shaded crevices at depths of about $25 \mathrm{~m}$ or greater (Colinvaux and Graham, 1964), and which grows more openly in the reef to $100 \mathrm{~m}$ (Moore et al., 1976), the cortex of the under (umbral) surface is frequently somewhat atrophied. Asymmetry in cortical development between the two surfaces of a segment is not conspicuous in typical thalli of the other known Halimeda species.

\section{B. The genus and its sections}

Although the pattern of nodal filaments can no longer be relied on almost exclusively for separating the species of Halimeda as Barton chose to do, it is helpful and reliable for recognizing groups of species. I became increasingly aware of the significance of this feature, as a kind of "master character", while working on my 1959 revision (Hillis, 1959), and in it referred to tuna and incrassata complexes. From continued herbarium studies, combined with more extensive field work, I have found that separation along these lines not only seems valid on the basis of phylogenetic implications, but also that each of these patterns of nodal filaments is frequently accompanied by other similarities. This seems especially true of a number of habit characters, and is well illustrated by species with the incrassata type of fusion (Table III, filaments fuse into a single unit), all of which possess a large bulbous holdfast and grow erect, or essentially so, in an unconsolidated substrate. These groups appear to represent natural units within Halimeda which should be recognized formally.

A meagre framework for sections within the genus exists in the extensive publication on algal systematics by Agardh (1887), in which four subcategories, Tunae, Pseudo-Opuntia, Opuntiae and Rhipsales, are indicated (Table IV). De Toni (1889) called them sections and applied Agardh's descriptions to them. Since appearance of the segments is the major character used, it perhaps is not surprising that the categories, as delimited, do not seem meaningful or useful. They were not even mentioned a few years later by Barton (1901). Indeed, they disappeared from use with De Toni (1889). Agardh's framework can be developed, however, into a modern system of categories delimiting various species groups. 
Table IV. The Categories of Halimeda Species Delimited by J. Agardh (1887), Recognized as Sections by De Toni (1889)

"Species, aegre characteribus circumscribendas, sequenti mode disponere conatus sum:

I. Tunae virescentes, parum incrustatae, adscendentes aut erectiusculae, articulis planis enervibus, simplicibus discoideis, ramos generantibus saepe subreniformibus, margine plerumque integerrimis."

H. tuna, H. papyracea, H. macroloba, (H. macrophysa $\left.{ }^{a}\right)$

II. "Pseudo-opuntiae albescentes et evidentius incrustatae, diffusae aut stipitatae articulis superioribus orbiculatis aut subreniformibus planis, saepius enervibus et margine integerrimis, plerumque in longos ramos simpliciusculos concatenatis."

$H$. gracilis, $H$. nervata, $H$. brevicaulis

III. "Opuntiae albescentes et evidentius incrustatae, conglobatae aut diffusae, nunc stipitatae, decomposito-ramoisissimae, articulis superioribus planis reniformibus, diametro transversali longitudinalem superante, enervibus aut plus minus conspicue nervosis, nervis ad lobos marginis superioris, saepe ramos plures generantes, excurrentibus."

H. cordata, H. opuntia (f. opuntia, f. tribola), H. incrassata (f. ovata, f. Lamourouxii, f. tridentata)

IV. "Rhipsales ex veridi aut cinereo albescentes et evidentius incrustatae, erectiusculae et saepius stipitatae, articulis aut teretiusculis, aut com. planatis et a basi cuneata dilatatis, diametre longitudinali transversalem aequante aut superante."

$H$. obovata, $H$. versatalis, $H$. tridens, $H$. cylindracea, $H$. monile, $H$. polydactylis, $\left(H\right.$. renschii $\left.{ }^{a}\right)$

"Species mihi ignota

H. discoidea."

${ }^{a}$ Species added by De Toni.

The obvious character around which sections of the genus Halimeda should evolve is that of medullary filament pattern at the nodes. This character is the most important one in the taxonomy of the genus, and so may be expected to reflect fundamental phyletic divergence. The five groupings given in Table III, based on pattern of medullary filaments, provide a logical framework for sections of the genus. Consequently, I propose they be designated as sections, and called Rhipsalis, Opuntia, Halimeda, Micronesicae and Crypticae. The nodal structure on which they are based, and the species each contains, are shown in Table V. Formal descriptions are given in Section IV. 


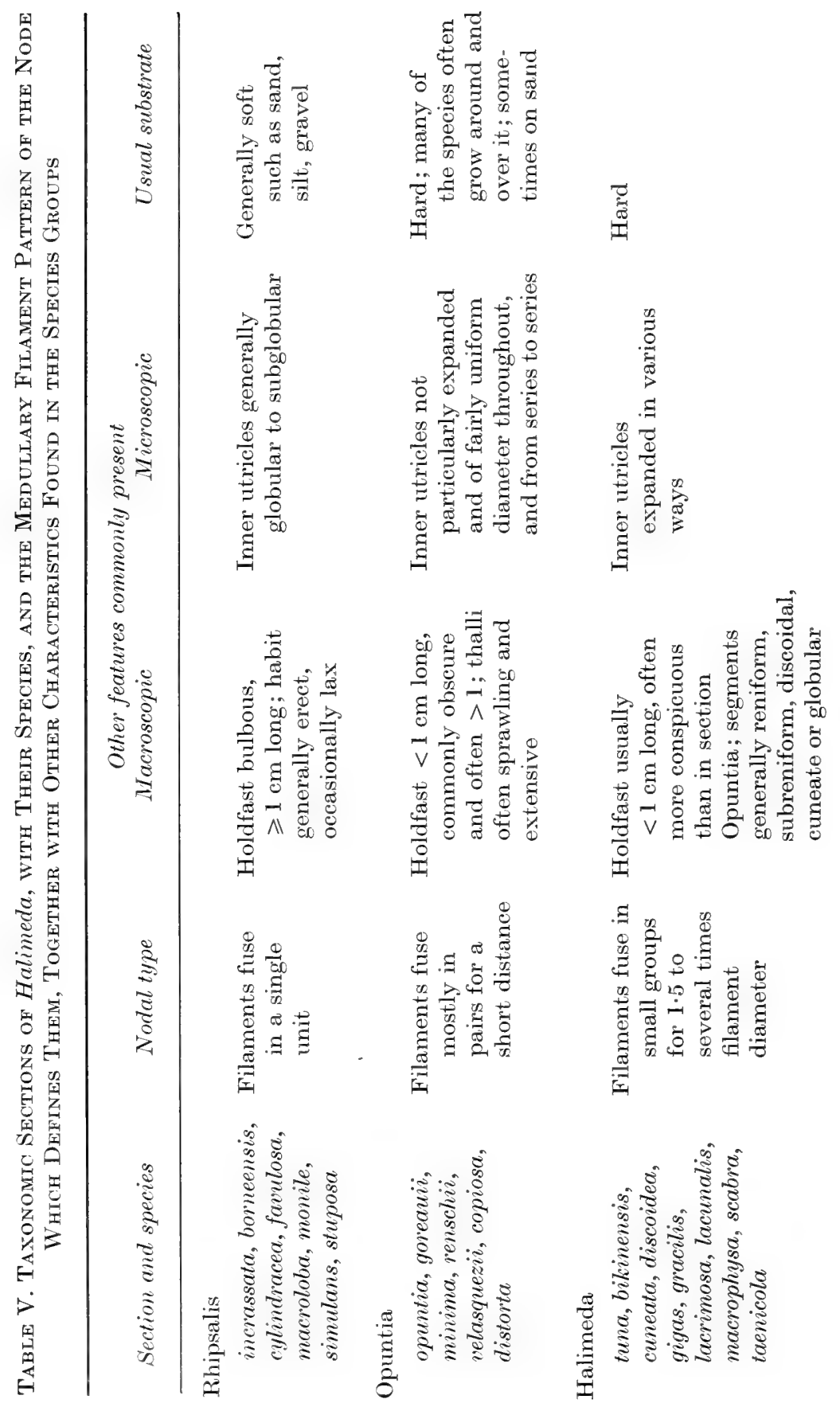




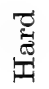

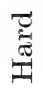

鸪

of

苛

密

$\ldots$

원

을 흘

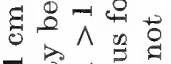

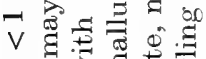

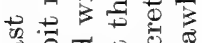

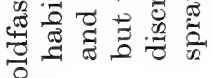

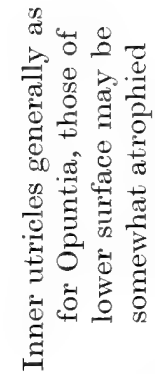

도

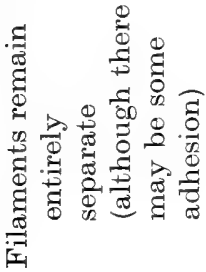

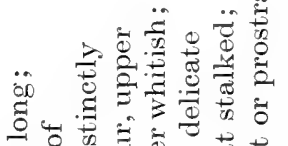
สำ

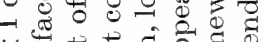

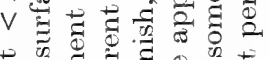

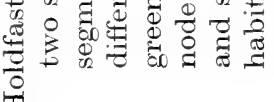

I

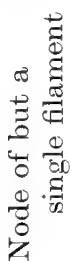
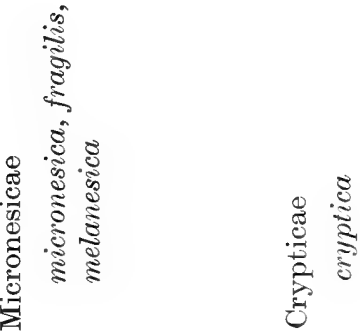
The first two section names are taken from Agardh with spelling altered to the proper endings. The change from Tunae to Halimeda is required by the International Rules of Botanical Nomenclature, since this section includes the type genus tuna. Agardh's fourth section, Pseudo-Opuntiae, to which he assigned gracilis and two species of uncertain identity, is redundant in this nodal filament system since gracilis has been included in section Halimeda. This name, therefore, is not used. Each of these three sections retains some of the species originally placed in it by Agardh.

The two new categories, Micronesicae and Crypticae, have each been given the epithet (with appropriate ending) of the first species described with the pattern of nodal filaments characteristic of that particular section.

Section Crypticae (at present with only one species) could, with its single medullary filament, be considered an extreme form of section Micronesicae. Such treatment, however, with its phylogenetic implications, does not seem justified by our present knowledge of the species involved, which includes a distribution of Caribbean for section Crypticae and Indo-Pacific for Micronesicae. I consider them two separate groups.

For all five sections the only character truly diagnostic is the pattern of the filaments at the nodes. However, a few other characters, some of them macroscopic, seem to be associated, fairly reliably, with the nodal groups. These also are given in Table $\mathrm{V}$.

Finally, the original circumscription of the genus by Lamouroux (1812) described its construction as multiaxial ("axe fibreux"). This excludes the uniaxial species cryptica. Therefore, in Section IV, the genus description is extended to include uniaxial as well as multiaxial species.

\section{The genus Halimeda in higher taxonomy}

For the first few decades of the twentieth century Halimeda seemed securely placed in the order Siphonales. But just as taxonomy within the genus is changing to reflect new knowledge and concepts, so too is that above the genus level. New tools such as the electron microscope enable us to probe the structure of these algae more precisely, while improved culture and chemical techniques provide additional data on life-histories and chemical organization, and lead to new insights and evaluations of the position of Halimeda and its close relatives within the plant kingdom. A survey of some of the taxonomic changes is provided 
in Table VI. Other aspects of a history which impinge on Halimeda are presented by Chapman (1964), Ducker (1967), Egerod (1952), Parker (1970) and Round (1963, 1971).

\section{Classification of Halimeda in the early twentieth century}

When Barton wrote her monograph on Halimeda she considered the genus belonged to the "order Siphoneae in the group Chlorophyceae". The descriptive term for this designated order was first introduced into the algal literature by Greville (1830), to delimit those green algae with "frond either composed of membranous, filiformis, single or branched tubes, or formed of a combination of similar tubes". It included the genera Codium, Bryopsis, Botrydium and Vaucheria. Blackman and Tansley (1902) formally established the order Siphonales for this group of plants which by then included Halimeda. They subdivided their new order Siphonales into two suborders, the Siphonocladeae for septate thalli, and the Siphoneae for those that were non-septate, that is, coenocytic. Soon afterwards Oltmanns (1905) elevated the first group to order status (Table VI), leaving only true coenocytes in the Siphonales.

\section{Subdivision of the Siphonales: Setchell and Feldmann}

Setchell (1929), in a discussion of the taxonomic position of Microdictyon, referred to the incorrectness of Siphonales as an ordinal name (since it was not based on the name of a genus), and mentioned, without discussion, that this order would be better separated into Codiales and Caulerpales.

Feldmann (1946) treated the subject considerably more substantially. Building on the microscopical observations of Ernst (1904), Czurda (1928) and Chadefaud (1941), he pointed out that in some members of the Siphonales only one kind of plastid occurred, the chloroplast. Such genera he called homoplastic. In other genera of the Siphonales two kinds of plastid were present, the chloroplast and the starch-storing leucoplast or amyloplast. These genera were heteroplastic. The heteroplastic genera included Udotea, Pseudochlorodesmis and Halimeda, for which "les chloroplastes sont entièrement depourvus d'amidon, l'amylogenèse étant assurée uniquement par les leucoplastes".

Feldmann also noted a complete correlation between wall chemistry as worked out by Mirande (1913) and the nature of the plastids in the siphonaceous taxa that he had studied. 
Table Vi. a History of the Classification of Halimeda ${ }^{a}$

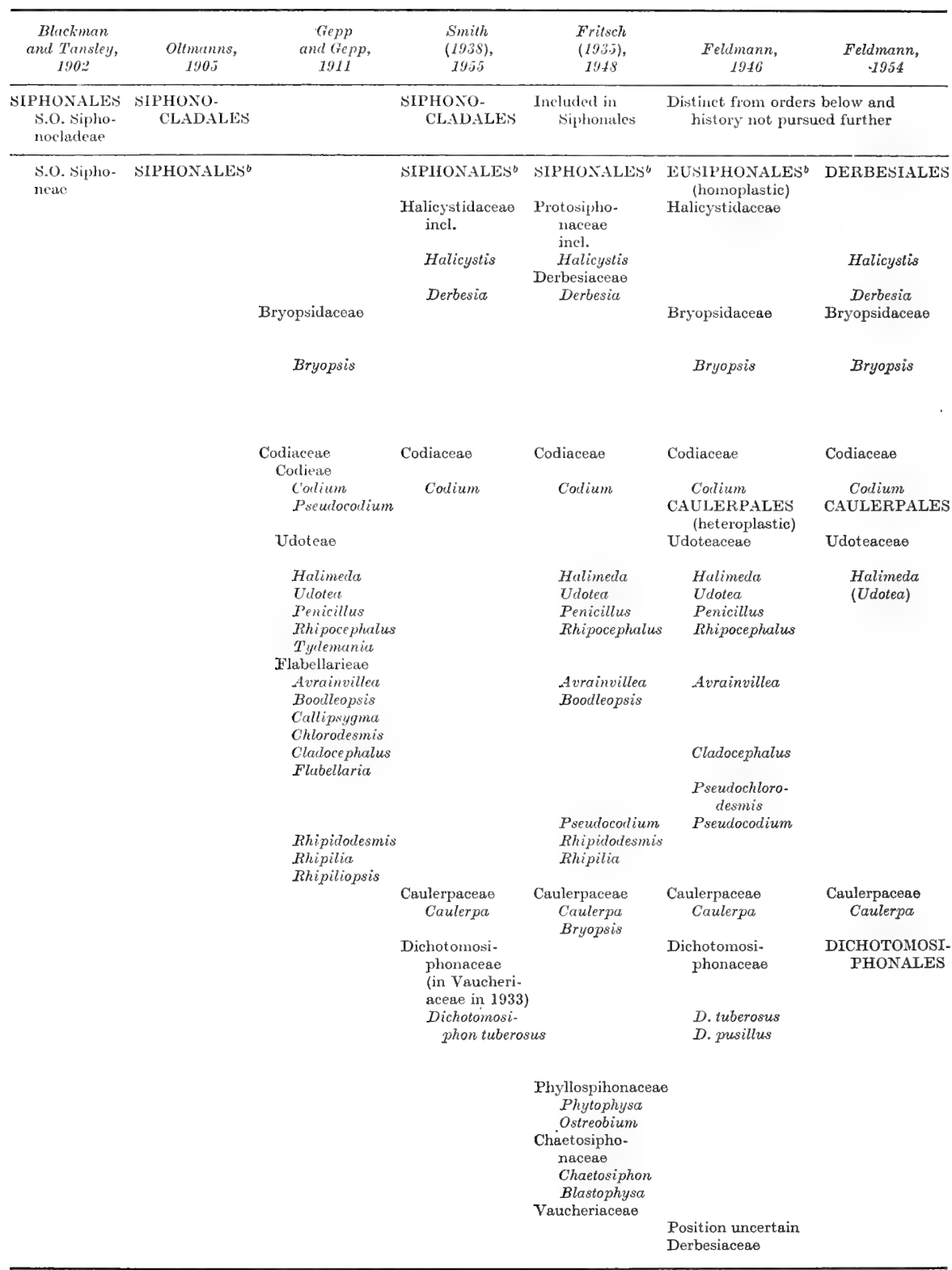

a Some lists may not include all the genera recognized by the authors since some of the papers deal with specific groups.

- Not tenable under the rules of botanical nomenclature. 


\begin{tabular}{|c|c|c|c|c|c|c|c|}
\hline $\begin{array}{l}\text { Egerod, } \\
1952\end{array}$ & $\begin{array}{c}\text { Chadefaud, } \\
1960\end{array}$ & $\begin{array}{l}\text { Miva } \\
\text { et al., } \\
1961\end{array}$ & $\begin{array}{c}\text { Round } \\
(1963,1971) \\
1973\end{array}$ & $\begin{array}{c}\text { Christensen, } \\
\text { I9t6 }\end{array}$ & $\begin{array}{c}\text { Neumann, } \\
197 \pm\end{array}$ & $\begin{array}{c}\text { Rietema, } \\
197 ;\end{array}$ & $\begin{array}{c}\text { Bold and Wynne, } \\
\qquad 1978\end{array}$ \\
\hline
\end{tabular}

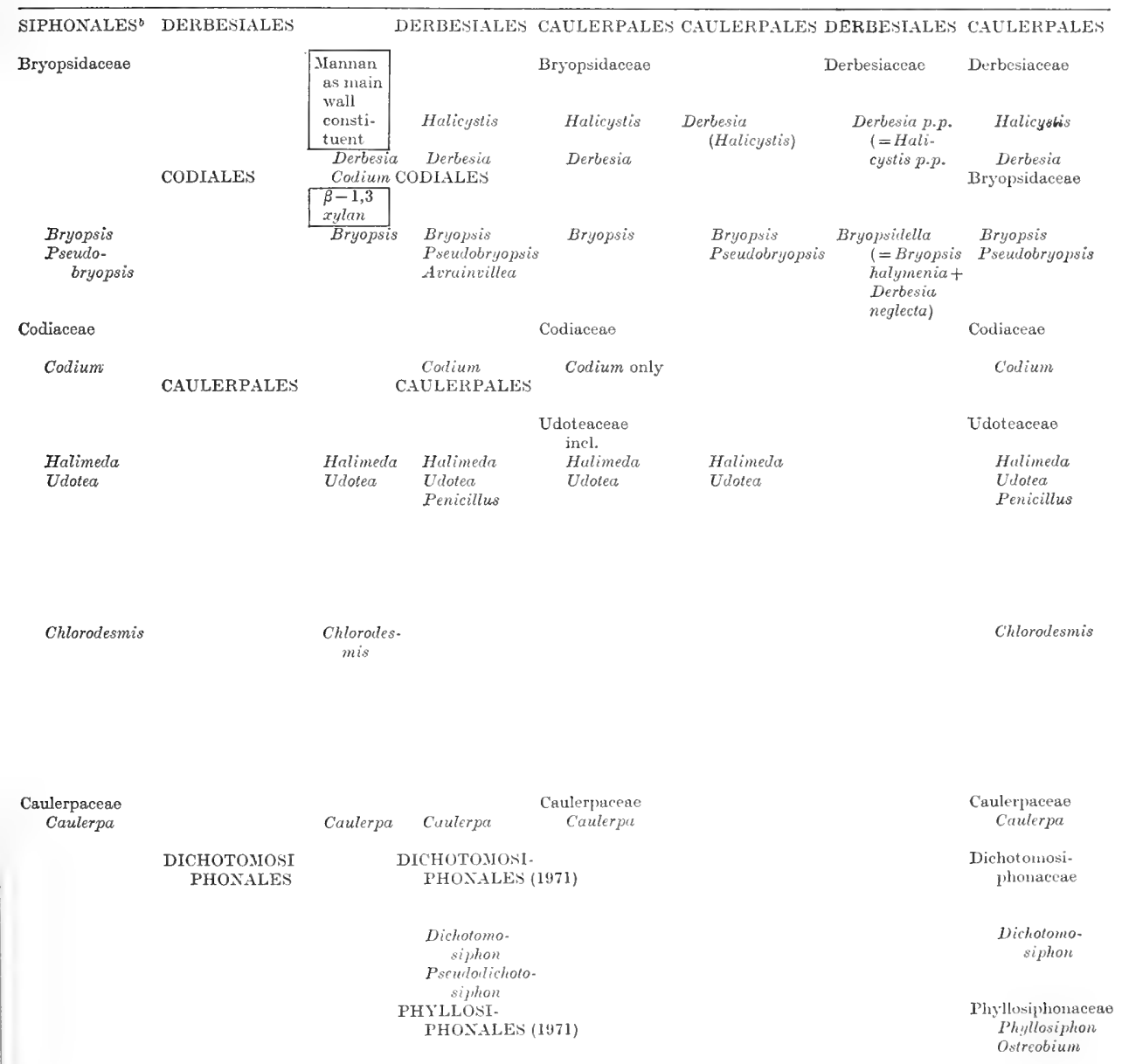


Table VII. Feldmann's (1946) Subdrvision of the Siphonales

SIPHONALES

Homoplastic (chloroplast only)

Filament wall with cellulose
Heteroplastic (chloroplast and amyloplast) Filament wall without cellulose
ORDER Eusiphonales

Halicystidaceae

Bryopsidaceae

Bryopsis

Codiaceae

Codium
ORDER Caulerpales

Udoteaceae

Halimeda, Udotea, Avrainvillea,

Penicillus, Cladocephalus,

Rhipocephalus, Pseudochlorodesmis,

Pseudocodium

Caulerpaceae

Dichotomosiphonaceae

D. tuberosus, D. pusillus

Table VIII. Feldmann's (1954) Extended Subdivision of the Siphonales

SIPHONALES, sensu lato

\begin{tabular}{|c|c|c|c|}
\hline \multicolumn{2}{|c|}{ Homoplastic } & \multicolumn{2}{|c|}{ Heteroplastic } \\
\hline$C O D I A L E S$ & $D E R B E S I A L E S$ & $C A U L E R P A L E S$ & $\begin{array}{l}\text { DICHOTOMO } \\
\text { SIPHONALES }\end{array}$ \\
\hline $\begin{array}{l}\text { Life cycle mono- } \\
\text { phasic and } \\
\text { diplontic }\end{array}$ & $\begin{array}{c}\text { Cycle hetero- } \\
\text { morphic }\end{array}$ & $\begin{array}{c}\text { Gametes slightly } \\
\text { anisogamous }\end{array}$ & Oogamous \\
\hline (Not holocarpic) & $\begin{array}{c}\text { Zoospores with } \\
\text { crown of } \\
\text { flagellae }\end{array}$ & $\begin{array}{l}\text { Entire thallus } \\
\text { involved in } \\
\text { sexual repro- } \\
\text { duction, and } \\
\text { dies thereafter } \\
\text { (holocarpy) }\end{array}$ & \\
\hline $\begin{array}{c}\text { Gametes strongly } \\
\text { anisogamous }\end{array}$ & $\begin{array}{c}\text { Anisogamous } \\
\text { gametes }\end{array}$ & & \\
\hline $\begin{array}{l}\text { Individual } \\
\text { gametangia } \\
\text { present }\end{array}$ & $\begin{array}{l}\text { Individual } \\
\text { gametangia } \\
\text { absent }\end{array}$ & $\begin{array}{l}\text { Individual } \\
\text { gametangia } \\
\text { absent }\end{array}$ & \\
\hline $\begin{array}{l}\text { Codium } \\
\text { Bryopsis }\end{array}$ & $\begin{array}{l}\text { Derbesia } \\
\text { Halicystis }\end{array}$ & $\begin{array}{l}\text { Halimeda } \\
\text { Caulerpa }\end{array}$ & Dichotomosiphon \\
\hline
\end{tabular}


To reflect these differences he proposed a division of the Siphonales into two new orders, the Eusiphonales (a name which was also untenable) and the Caulerpales. Taxa of the Eusiphonales were homoplastic and had a wall containing cellulose; those of the Caulerpales were heteroplastic, and lacked cellulose in their walls. The division into families, and the genera assigned to them are included in Table VII which shows this subdivision of Siphonales.

Feldmann (1954) developed this yet further when, on the basis of available life-history data, he divided his two orders of 1946 (Eusiphonales and Caulerpales) each into two more orders (Table VIII). In doing so he abandoned the epithet Eusiphonales, thereby removing one nomenclatural problem.

From the Eusiphonales he separated the orders Derbesiales and Codiales. The Derbesiales were established as possessing a heteromorphic life-cycle, or a life-cycle in which the alternating gametophytic and sporophytic phases looked very different, and as a consequence may have been given different names. The culture studies of Kornmann (1938) provided some of the basic data, for Kornmann had observed the zoospores of Derbesia marina (Lyngbye) Sol., a small, branched filamentous alga, develop into plants identifiable as the sac-like Halicystis ovalis (Lyngbye) Aresch. And Feldmann (1950), in the years subsequent to his 1946 paper on siphonalean taxonomy, had linked Derbesia tenuissima (De Not.) Crn. with Halicystis parvula Schmitz.

In contrast, members of the Codiales were known for a life-cycle in which there was only one free-living phase (haplobiontic) which was diploid in these algae. As another difference between the two new orders special gametangia developed on the filaments of members of the Codiales, whereas specialized structures did not occur in the Derbesiales, the entire thallus of the gamete-bearing phase, Derbesia, functioning as a gametangium.

The other two orders of Feldmann's (1954) paper were derived by separating the oogamous Dichotomosiphon tuberosus (A. Br.) Ernst, a freshwater filamentous alga, from the Caulerpales, and placing it in its own order because of this distinctive reproductive feature which is unknown in the rest of the Siphonales. In contrast, the Caulerpales, from the data then available on the life-histories of Caulerpa and Halimeda, produced gametes that were only slightly different (anisogamous). In addition, the entire contents of the thalli of these two genera were transformed into gametes when gametogenesis occurred, so that death of the plant followed sexual reproduction (holocarpy).

In both of the Feldmann $(1946,1954)$ schemes the classification of Halimeda is in the family Udoteaceae of the order Caulerpales. 
3. Caulerpales: its classification among the Chlorophyta, or Chlorophycophyta (Papenfuss, 1946)

(a) Round's scheme of classification. Relatively recently Round $(1963,1971)$ considered the classification of the Chlorophycophyta as a group, and his $197 \mathrm{I}$ scheme is shown in Fig. 21. Only that part which impinges on Halimeda will be discussed.

The old order Siphonales is replaced by five orders, four of which are those of Feldmann (1954). In the fifth, Phyllosiphonales, Round places the single genus Phyllosiphon, which, as he suggests, may belong to the Xanthophyceae. Ostreobium, which is commonly allied with Phyllosiphon and which would seem reasonable to include here, is mentioned with the Chlorochytriales. Families within these orders are not discussed in these papers.

Round $(1963,1971)$ places the siphonaceous orders in the separate class Bryopsidophyceae, and within the class recognizes the three groups or "cohorts" as he calls them, and which appropriately could be considered subclasses, of Hemisiphoniidae, Cystosiphoniidae and Eusiphoniidae, which were set up by Chadefaud (1960) as Hémisiphonées, Eusiphonées cystosiphonées and Eusiphonées typiques. The orders within each are shown in Fig. 21. The Hemisiphoniidae, with walls dividing the thallus into multinucleate units, is the simplest of the three groups. Members of the Cystosiphoniidae produce cysts and may or may not have segregative division. Taxa belonging to Eusiphoniidae possess the additional carotenoid pigments siphonein and siphonoxanthin, have polysaccharides other than cellulose in their cell walls, and do not have the special characteristics of the other two groups.

(i) Advantages of Round's scheme. For siphonaceous algae the system of cohorts (subclasses) brings together three series of green algae with the multinucleate condition. The designation of a separate class (Bryopsidophyceae) for this group of three recognizes some of their distinctive differences from the other green algae, and seems particularly reasonable in a system which recognizes a number of classes of green algae (Zygemaphyceae, Oedogoniophyceae and Chlorophyceae). There are, as Round (1971) summarizes, a number of important features in the Bryopsidophyceae such as pigments, wall chemistry and plastid structure which separate them from the class Chlorophyceae, but none of these embraces the class as a whole.

(b) Classification scheme of Bold and Wynne (1978). In their massive and splendidly comprehensive introductory text on the algae these two authors recognize 15 orders within the division Chlorophycophyta (Table VI). One of these, the Caulerpales, replaces the former 


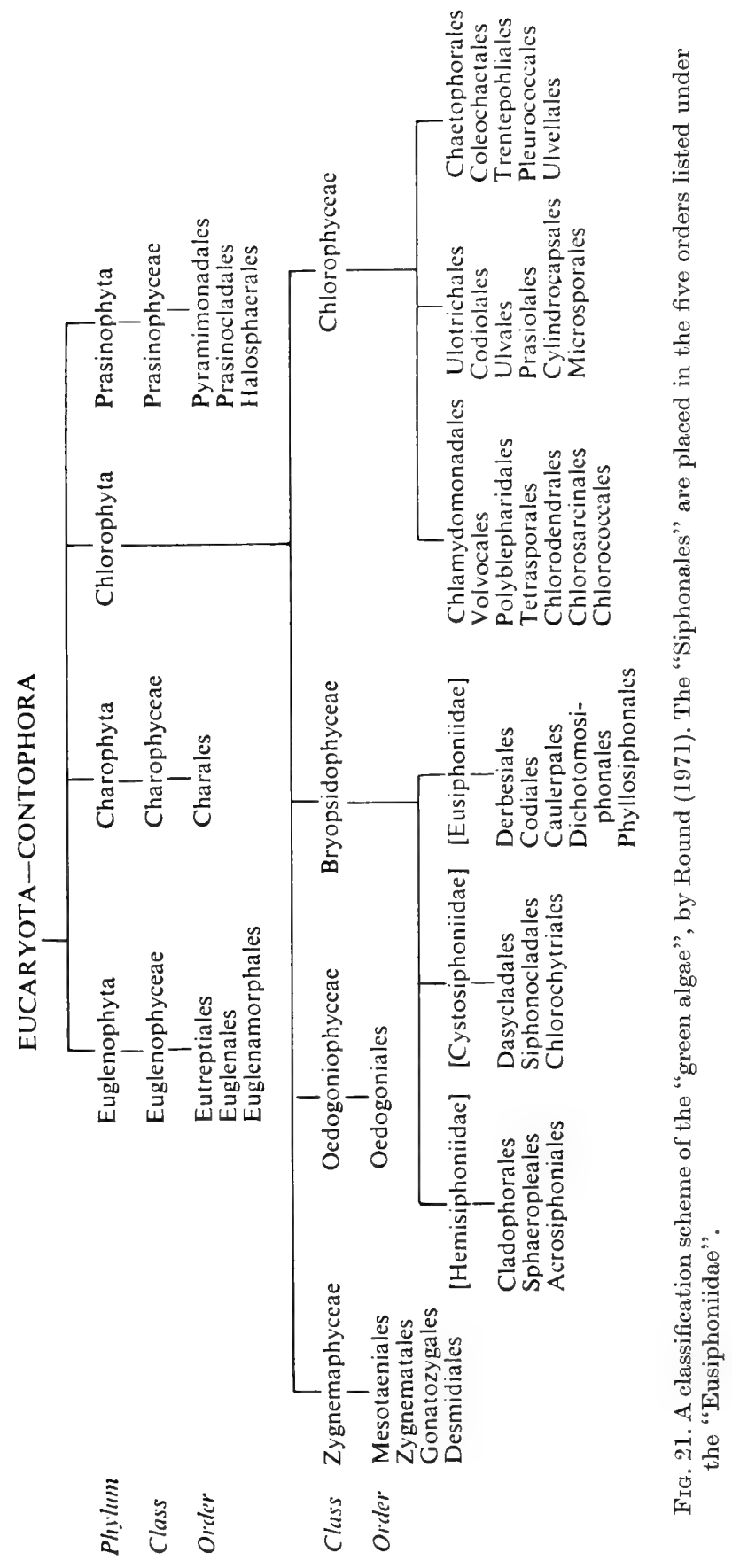


"Siphonales" in such a scheme. Within it 7 families are recognized: Derbesiaceae, Codiaceae, Bryopsidaceae, Udoteaceae, Caulerpaceae, Dichotomosiphonaceae and Phyllosiphonaceae.

(i) Advantages of the Bold-Wynne scheme. The recent discoveries such as chloroplast organization and wall chemistry are clearly and well described in the text dealing with the Caulerpales, and the authors have avoided premature taxonomic changes by treating the order as a broad assemblage of a number of families.

(c) Validity of life-history, plastid and filament-wall data. There is the urge, as well as the goal in classification schemes, to present the interrelationships of the various categories and the evolutionary trends. The three criteria used by Feldmann (1946, 1954), plastid structure, wall-chemistry and life-history data, appeared to provide such an approach for the truly siphonaceous algae.

In the intervening years, however, difficulties have developed with the use of each of these criteria. There also has been some support.

(i) Life-history data. Culture studies by Hustede (1964), subsequently confirmed by Rietema (1975), have indicated that Bryopsis halymediae Berth. and Derbesia neglecta Berth., taxa placed in different orders by Feldmann (1954), are alternate phases in the life-cycle of a single taxon. And Rietema (1969, 1970, 1975), working with several populations of Bryopsis plumosa (Hudson) C. Ag. in culture, has obtained a second life-cycle phase, a microthallus which, depending on the population, produces the familiar Bryopsis thalli directly, or produces zoospores which give rise to the Bryopsis thallus.

The linking of Bryopsis sp. and Derbesia sp. in a single life-cycle, the presence of heteromorphic life-cycles in some members of the Codiales, and other life-history data do not support the recognition of two separate orders Codiales and Derbesiales using the life-history criteria of Feldmann (1954). This conclusion was also reached by Rietema (1975), and Bold and Wynne (1978) suggest that the separation into two orders was premature. Hoek et al. (1972) earlier indicated problems with the division.

In contrast, the life-history character Feldmann (1954) applied to the Caulerpales, holocarpy or the complete involvement of the thallus in the production of gametes and its death thereafter, has received some additional support. Feldmann could cite only two examples, Halimeda and Caulerpa, where such a pattern had been observed. Holocarpy has now been reported for Chlorodesmis (Ducker, 1965), Penicillus (HillisColinvaux, 1973; Meinesz, 1975) and Udotea (Nizamuddin, 1963). The one apparent modification is that holocarpy may involve only a portion 
of the thallus. In my laboratory aquaria I have occasionally observed Halimeda to produce the conspicuous grape-like clusters of gametangia on only one to two branches of the thallus, or a relatively small portion of the entire plant. Subsequently, it was only this part of the plant that died.

Although the entire thallus (or branch) is involved in this production of gametes, specialized gametangia are formed in the process. Feldmann (1951) had described them on a Mediterranean Halimeda. Hence his key character "holocarpie sans gamétocystes individualisés" is surprising, and is misleading for Halimeda, although appropriate for Caulerpa as currently known. For the Codiales he indicates "gamètes ... . se formant dans des gamétocystes individualisés". The difference between the Codiales and Caulerpales, based on the available sexual thalli, is more appropriately described as the presence of a cross wall at the base of the gametangium in the Codiales, its absence in the Caulerpales.

(ii) Wall chemistry. Parker (1970) provided a very useful review of wall chemistry which included this group of algae and presented the problems of using this character for taxonomy. Data available on Caulerpalean algae have shown $\beta$-1,3-xylan to be a component of Caulerpa, Chlorodesmis, Halimeda and Udotea (Miwa et al., 1961; Parker, 1970). It also occurs in Penicillus, and in Dichotomosiphon, the only member of the Dichotomosiphonales of Feldmann's classification (Frei and Preston, 1964), as well as in algae that would not be assigned to either the Caulerpales or Dichotomosiphonales, such as Bryopsis sp. (Miwa et al., 1961; Frei and Preston, 1964; Maeda et al., 1966). The complexity of wall chemistry and the difficulties of applying it broadly in the siphonaceous algae have recently been illustrated by the identification of different wall polysaccharides as predominating in alternating stages of the life-cycle of some taxa (Huizing and Rietema, 1975). Their evidence showed a mannan (probably $\beta$-1,4-mannan) as the principal filament-wall polysaccharide of the sporophytic stages of Bryopsis plumosa (Huds.) C. Ag. and Derbesia tenuissima (De Not. in Mor. et De Not.) Crouan frat. (Banyuls material), and a xylan (probably $\beta-1,3-x y l a n$ ) and cellulose as predominant wall polysaccharides of the gametophytic stages of both genera.

The work of Huizing and Rietema (1975), as they point out, does not support the division of the siphonaceous green algae into a "xylan group" (including Bryopsis) and a "mannan group" (including Derbesia and Codium) as proposed by Miwa et al. (1961) and adopted by Maeda and Nisizawa (1972). However, the evidence so far available on wall chemistry in Caulerpalean genera (sensu Feldmann, 1954) indicates that 
the $\beta$-1,3-xylan of their walls may be a consistent characteristic. Round (1971) has accepted it as such. There is a need, however, to examine the walls of many more of the genera within the group, as well as of different species, particularly of Caulerpa where there is a range of chloroplast structure. The walls of holdfast filaments of different species of Halimeda should also be examined, as well as those of the filament developing from zygotes (Section VII).

(iii) Plastid structure. The presence of only one kind of plastid (the chloroplast) or of two kinds (chloroplast and amyloplast) with distinct photosynthetic and storage roles was the basis of Feldmann's separation (1946) of Caulerpalean and non-Caulerpalean orders of siphonaceous algae.

Amyloplasts or starch-storing plastids have been demonstrated in. species of Avrainvillea, Caulerpa, Chlorodesmis, Halimeda and Udotea (Hori and Ueda, 1967, 1975), and in Penicillus (Turner and Friedman, 1974). Hori and Ueda $(1967,1975)$ report their absence in species of Codium, Derbesia, Bryopsis and Pseudodichotomosiphon. Concentric lamellar systems (Section I) have also been demonstrated in the amyloplasts of the above genera and in the chloroplasts of all but Avrainvillea (Hori and Ueda, 1967, 1975), and may be a Caulerpalean characteristic. Workers who have made similar observations on one or more of the above taxa include Descomps (1965) on Caulerpa, Halimeda and Udotea; Dawes and Rhamstine (1967) on Caulerpa; Sabnis (1969) on Caulerpa; Wilbur et al. (1969 and unpublished) on Halimeda; Borowitzka and Larkum (1974a, b) on Halimeda; Hori (1974) on Caulerpa; and Calvert et al. (1976) on Caulerpa.

In general, the presence of the so-called "heteroplastid" system seems reasonably substantiated for the Caulerpa-Halimeda-Udotea series of algae, as does its absence in the Codium-Derbesia algae. However, as mentioned in Section I, there is some modification of Feldmann's original account.

Feldmann (1946) indicated that some heteroplastic algae, Avrainvillea and Cladocephalus, have a starch-depositing pyrenoid in their chloroplasts, and that in Penicillus and Rhipocephalus the chloroplasts secrete several small grains of starch. However, in Udotea, Pseudochlorodesmis and Halimeda the chloroplasts "sont entièrement dépourvus d'amidon, l'amylogenèse étant assurée uniquement par les leucoplastes".

At least for Halimeda this is not so, as has been indicated by Wilbur et al. (1969), Borowitza and Larkum (1974b) and Colombo and Orsenigo (1977). Starch, with and without pyrenoids, also is present in the chloroplasts of Caulerpa sp. (Feldmann, 1955; Hori and Ueda, 1967; 
Hori, 1974; Calvert et al., 1976), a genus not discussed by Feldmann (1946). It seems likely that at least small grains of starch in chloroplasts may be fairly commonplace throughout the heteroplastic green algae, that their number or size may vary with the time of day, although not invariably (see Calvert et al. (1976) for behaviour in Caulerpa sp.), and that the real point of emphasis, as well as of interest, should be in the presence or absence of a separate starch-storing body (the amyloplast). The Caulerpa-Halimeda-Udotea algal series, then, has evolved a separate starch-storing plastid, whereas the Codium-Derbesia series does not use this starch storage plan, at least to any great extent.

(d) Proposed scheme for classification of Halimeda. Although filamentwall chemistry and life-history data do not satisfactorily delimit orders among the Codium-Derbesia group of algae at this time, there is more support for a separation of the Caulerpa-Halimeda-Udotea group from the Codium-Derbesia group. The data are limited to examination of the commoner genera and species, but the members of the CaulerpaHalimeda-Udotea group examined have:

a separate starch-storing body (amyloplast);

xylan in their filament walls, at least those of the photosynthetic portions of the plant (although not detected in walls of cultured Caulerpa ambigua Okamura ( $=C$. vickersiae Børgesen) which was also morphologically unusual in lacking pinnae (Huizing et al., 1979));

a life-history that involves the death of the alga (or the part of it involved) after sexual reproduction.

A fourth characteristic is valid for many of the taxa:

the presence of chloroplast lamellar systems.

To reflect these differences I suggest the recognition, or retention, of a system of either four or two orders (depending on the classification used):

Derbesiales (containing Codium, Bryopsis and Derbesia as well as related genera), and

Caulerpales (the Caulerpa-Halimeda-Udotea series), with the continued use or acceptance, for the other genera as required, of the orders

Dichotomosiphonales

Phyllosiphonales (or Ostreobiales if Phyllosiphon is transferred to Xanthophyta). 
This scheme could fit into either the Bold-Wynne or Round systems, but is shown in Table IX as part of the Round scheme of classification. The effect of my proposal is to unite the Codiales-Derbesiales group of Feldmann (1954), which was also done by Rietema (1975), with the name Derbesiales. The proposed scheme also recognizes the distinctiveness of the Caulerpa-Halimeda-Udotea series.

Table IX. Modified Scheme of Orders for the Eusiphonitdae

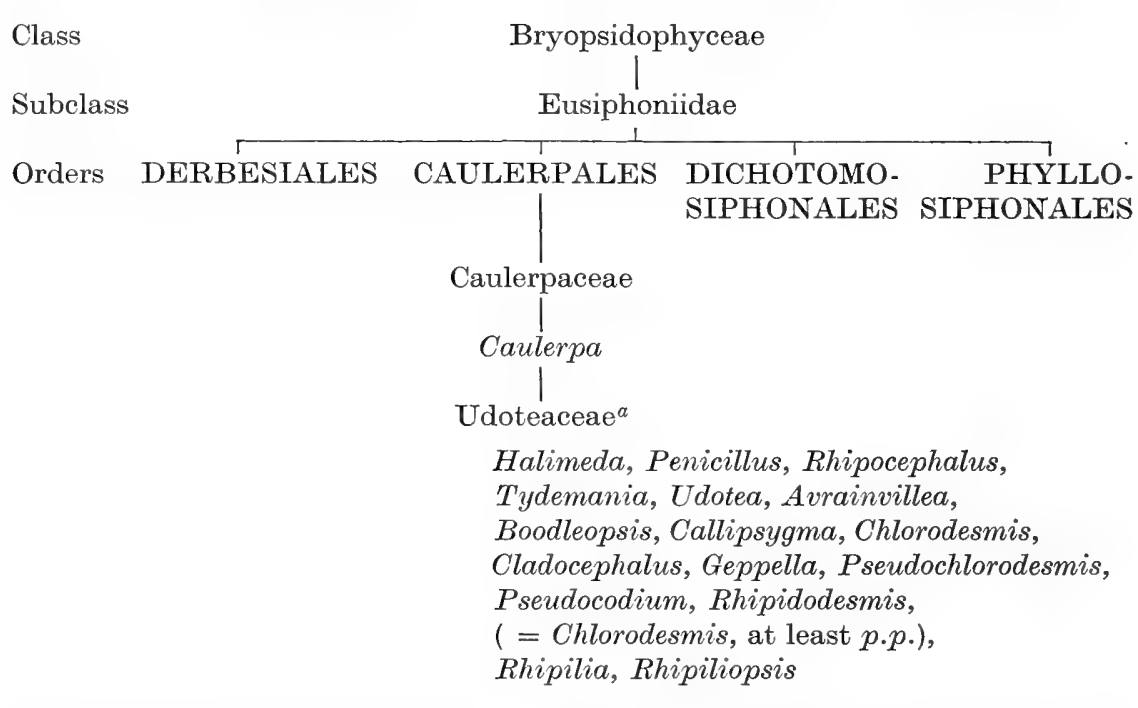

${ }^{a}$ Many of the genera are tentatively placed herein and require cytological and lifehistory studies.

Within the Caulerpales, I have followed, for the present, the traditional separation into two families, Caulerpaceae (which is monogeneric) and Udoteaceae, since we know very little about a number of genera in the Udoteaceae. One of the characters used to separate these two groups (Bold and Wynne, 1978), the presence of trabeculae or wall ingrowths in the filaments of Caulerpa, has been observed in the walls of the filaments of the segments of Halimeda tuna (Borowitzka and Larkum, 1977).

I have not accepted within the Caulerpales, either as delimited above or in the sense of Bold and Wynne (1978), the separation, by Gepp and Gepp (1911), of Udotean genera into calcareous (Udoteae) and non-calcareous (Flabellarieae and Codieae) categories, with Codium and Pseudocodium belonging to the Codieae, Halimeda, Penicillus, 
Rhipocephalus, Tydemania and Udotea to the Udoteae, and Avrainvillea, Boodleopsis, Callipsygma, Chlorodesmis, Cladocephalus, Flabellaria, Rhipidodesmis, Rhipilia and Rhipiliopsis to the Flabellarieae.

The Gepps considered the calcified and uncalcified groups to have developed from calcified and uncalcified ancestors, and that they were "fundamentally and physiologically distinct", with their separation occurring far back in their developmental history.

This interpretation of evolution within the group has, as one of its weaknesses, the re-establishment of the two species of the type genus Flabellaria in the genus Udotea from whence the Gepps had removed them. In addition, MacRaild and Womersley (1974) have demonstrated the alternation of a calcified (aragonitic) with an uncalcified phase in the life-cycle of a single alga, the former Derbesia clavaeformis (J. Ag.) De Toni, which they transferred to the new genus Pedobesia MacRaild and Womersley of the order Derbesiales. Such an alternation of calcified and uncalcified phases, which may prove to be more widespread, indicates that the Gepps' scheme is neither as useful nor as basic as the proposed separation along cytological and reproductive lines of the two orders Caulerpales and Derbesiales.

\section{Summary: the identification and classification of Halimeda}

Many of the characters which separate the different species of Halimeda require the use of a compound microscope (magnification usually $\times 100$ and $\times 400$ ), and some prior sectioning, followed by decalcification of the material. Nonetheless, a few macroscopic characters are separated which, within limits, are helpful in field determinations of groups or taxonomic sections of species, and occasionally of species themselves. These are : the appearance of the plant as a whole, of the holdfast system, and the of majority of the segments. Finer determination of species, or of species groups, in the field is helped by a knowledge of their geographic range.

Microscopic taxonomic characters which are most used are: pattern of medullary filaments at the node (Table III), size and appearance of the different series of utricles (Figs 17, 20), and pattern and extent of cortex (Fig. 20). All these characters vary somewhat with age and the position of the segment on the thallus. The specialized reproductive structures, the grape-like clusters of gametangia, do not occur on most material, and have not proved particularly useful in taxonomic work.

The different patterns of nodal filaments found in different groups of Halimeda species are useful in delimiting groups of species and are considered to reflect fundamental phyletic divergence. Five taxonomic 
sections of the genus are established using this character. They are Rhipsalis, Opuntia, Halimeda, Micronesicae and Crypticae.

The presence of a special starch-storing body (amyloplast), xylan in the filament walls and a life-history that involves the death of the alga after sexual reproduction in the Caulerpa-Halimeda-Udotea group of algae, or at least in the genera examined, is the basis of a recommendation that this group of algae be placed (or retained, depending on the system of classification) in an order Caulerpales which would be separate from an order Derbesiales containing Codium, Bryopsis, Derbesia and related genera.

\section{Taxonomy of the Genus Halimeda Lamouroux}

\section{A. Introduction}

In this section descriptions are provided for 30 species of Halimeda, as well as for the genus. Two keys are given, one to all the species, the other to the Atlantic taxa together with a list of Atlantic species. A list of Indo-Pacific species is provided but not a separate key because over two-thirds of the species are present in that region.

In choosing key characters I have avoided as much as possible those which involve extensive preparation of material. Microscopic characters can be checked when the identification has been made. This approach precludes the necessity of detailed microscopy for a single species identification. Within the limits of reliability macroscopic characters are the first pair of choices, and at times it has seemed sufficient that such characters provide the sole choice. At other times they are supplemented with microscopic characters.

The characters used in the species descriptions and in the keys were described in Section III. Some of the figures and tables presented therein will be useful here as well, particularly Fig. 17, showing peripheral utricles in surface view; Fig. 20, longitudinal sections of cortex; and Table III, nodal filament patterns. Table $\mathrm{X}$, in this section, presents a synopsis of important taxonomic characters for the species, together with geographic ranges.

Section III, A.2.b on preparation of Halimeda for microscopic study should also be useful.

\section{Materials studied}

The specimens examined for the Halimeda revision (Hillis, 1959) provided the nucleus consisting of the 451 "representative specimens" 
cited and many not cited because of limited space. All the uncited material represented overlaps in geographic range. Institutes providing these specimens were the herbaria of the University of Michigan, Ann Arbor, and the University of California, Berkeley; the New York Botanical Garden; and the British Museum (Natural History), London. Dr W. E. Isaac, then of the University of Cape Town, South Africa, provided liquid-preserved material of $H$. cuneata.

Subsequently, Halimeda specimens and collections have been examined from the British Museum (Natural History); Royal Botanic Gardens, Kew (algal collections now housed in the former); the herbarium of the Linnean Society, London; Rijksherbarium, Leiden; Botanical Museum, Lund; Botanical Museum, Copenhagen; National Museum of Natural History, Paris; Botanic Garden, Brussels; Museum of Western Australia; Institute of Jamaica, Kingston, Jamaica ; United States National Museum; New York Botanical Garden; Duke University; Farlow Herbarium, Harvard; University of California, Berkeley; University of Hawaii; University of Michigan; Yale University; and the personal herbaria of Drs R. Tsuda and G. Valet. Professor Y. Yamada kindly loaned the type collections he had made of gracilis $\mathrm{f}$. elegans, incrassata f. distorta and opuntia f. intermedia, the second of which is now the holotype specimen for the species distorta. Professor W. R. Taylor and Dr G. Valet provided authentic material of goreauii and melanesica respectively.

In addition, many workers have sent specimens from special sites and expeditions. To these I have added my own field collections, principally from the eastern Indian Ocean, Jamaica and Enewetak Atoll in the Marshall Islands, and the especially valuable experience of having made them myself, which has provided understanding of populations of the various species in the reef, including their variation.

\section{Measurement of characters}

The various dimensions recorded, both macroscopic and microscopic, have been obtained mostly from dried specimens, some from preserved material, a few from living plants. The measurements on the dried and on some preserved material are smaller than would be obtained using living plants, but for microscopic characters the effect of shrinkage on the measurements for taxonomic purposes is probably generally relatively little.

For the macroscopic character of segment dimensions, however, the change on drying may be considerable for large segments. In the species 
gigas, which has the largest segments in the genus, length and width data on two segments from living plants, measured a few hours after they were collected from the lagoon of Enewetak Atoll, were $31 \times 36 \mathrm{~mm}$ and $20 \times 36 \mathrm{~mm}$. After drying, these segments measured $21 \times 32 \mathrm{~mm}$ and $17 \times 30 \mathrm{~mm}$, respectively. Thickness may also be affected, and some segments, particularly those of many discoidea, macroloba and taenicola thalli, become conspicuously concave with drying. The change in all three dimensions is less dramatic with smaller, thinner segments.

Drying may occasionally collapse the filaments, particularly if segments are lightly calcified. For such specimens, it is very difficult to obtain good measurements from sagittal sections.

In the species descriptions of this section the principal measurements given are for the diameters of the peripheral utricles in surface view (from surface sections), the lengths of the peripheral utricles, the diameters of the secondary utricles and the diameters of the tertiary utricles (from longitudinal sections). For each specimen examined a minimum of ten measurements for each of these characters has been made, and very often more than twice that number, and at times two to several sets of preparations were made for each specimen. The precise number of measurements depends on the species, the reasons for examining it and the quality of the preparations. A good preparation of the surface of the peripheral utricles is usually relatively easy to make, and may have 100 or more utricles, depending on their size and how lavish one is with the specimen. With such a large sample the diameters of utricles were measured randomly, then the field specifically searched for the smallest and largest ones (fusions excepted).

In sagittal sections, the sample size per section is much more limited because there are many fewer utricles from which to choose initially, and of these some may not be fully expanded or may be damaged. As much as possible, the approach in measuring was the same as for the peripheral utricles.

For all but a few species the minimum number of measurements obtained for each of the microscopic characters is 100. The average for all species is well over 400 , and for some species it is in the thousands.

The minimum number of nodes dissected for most species is 10 , and for many species it is many times this.

These data provide a spread of measurements which are given in the species descriptions and synopsis (Table $\mathrm{X}$ ) as the range of measurements for the various characters. Figures in parentheses usually represent a few extreme measurements which are included to provide a concept of the range that may be encountered. The narrower range is the one considered representative of the species. 


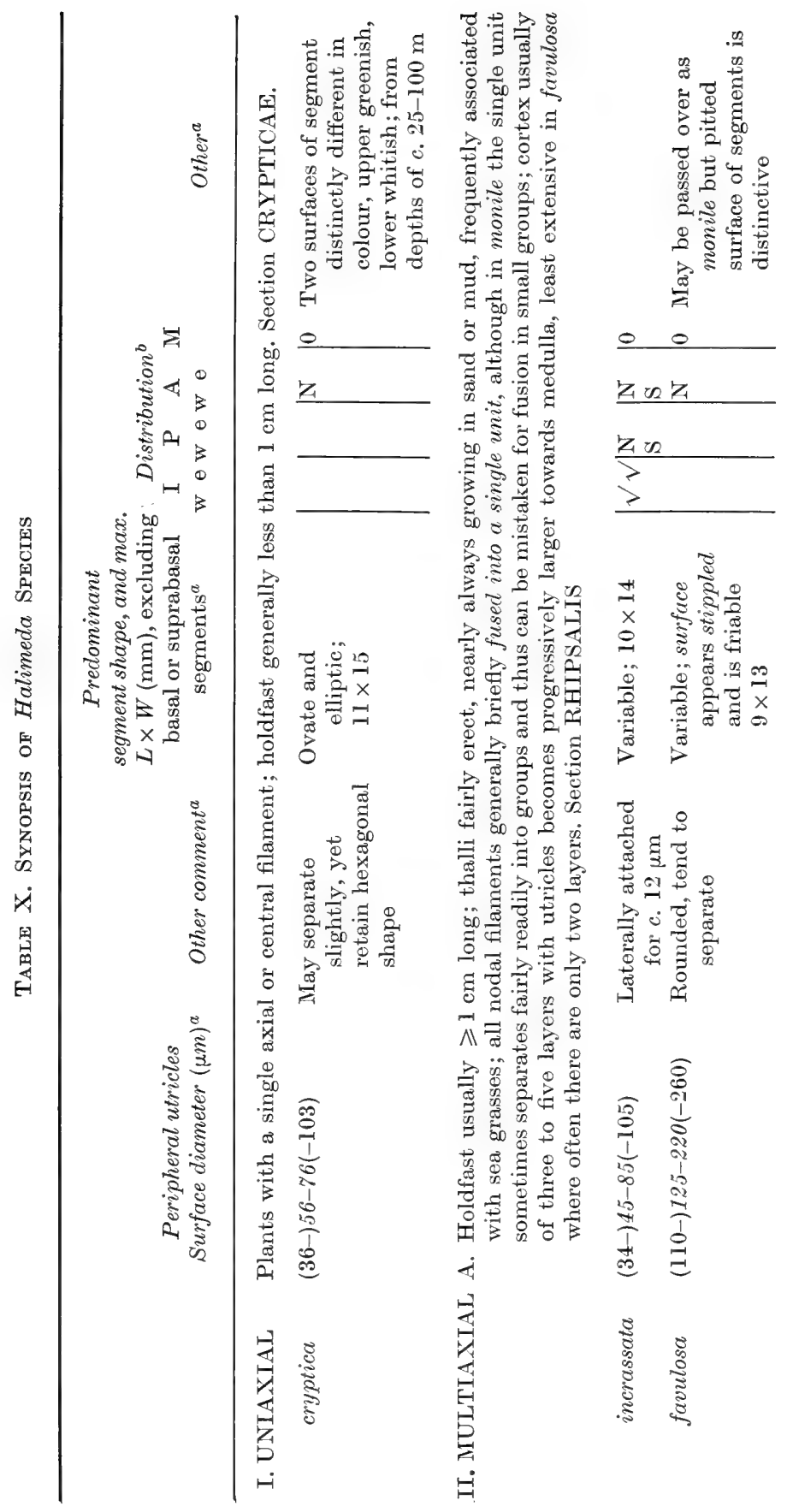




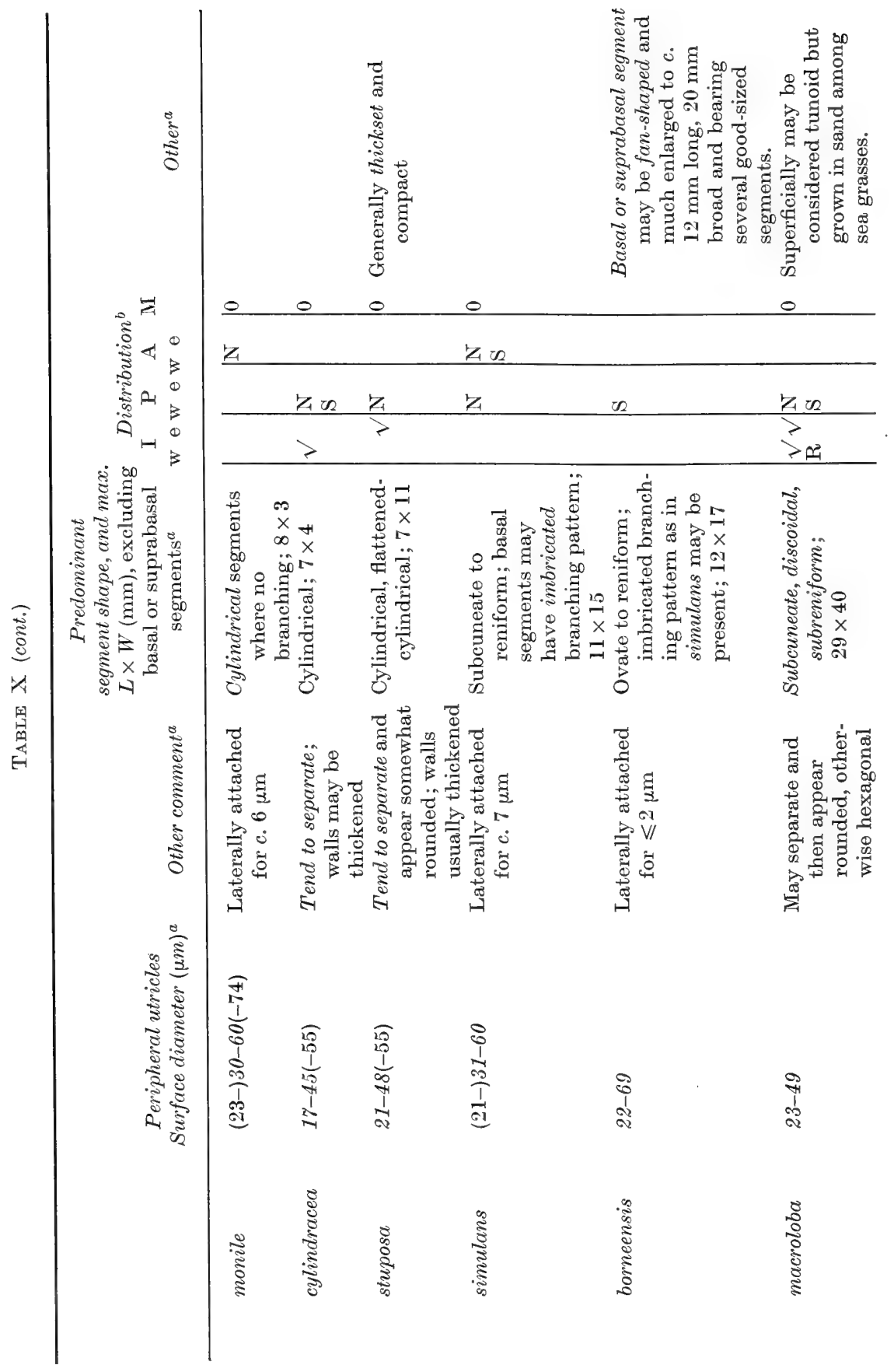




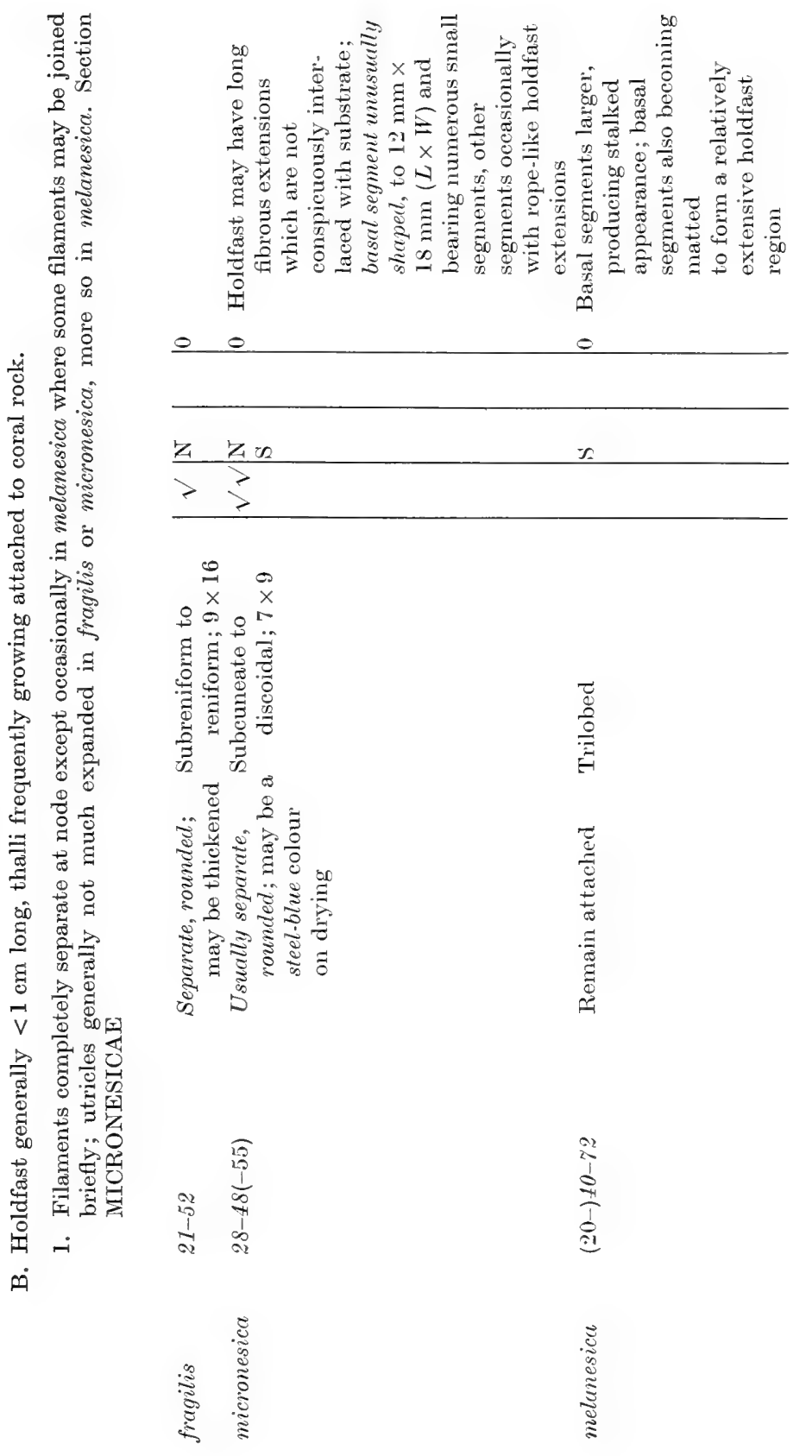




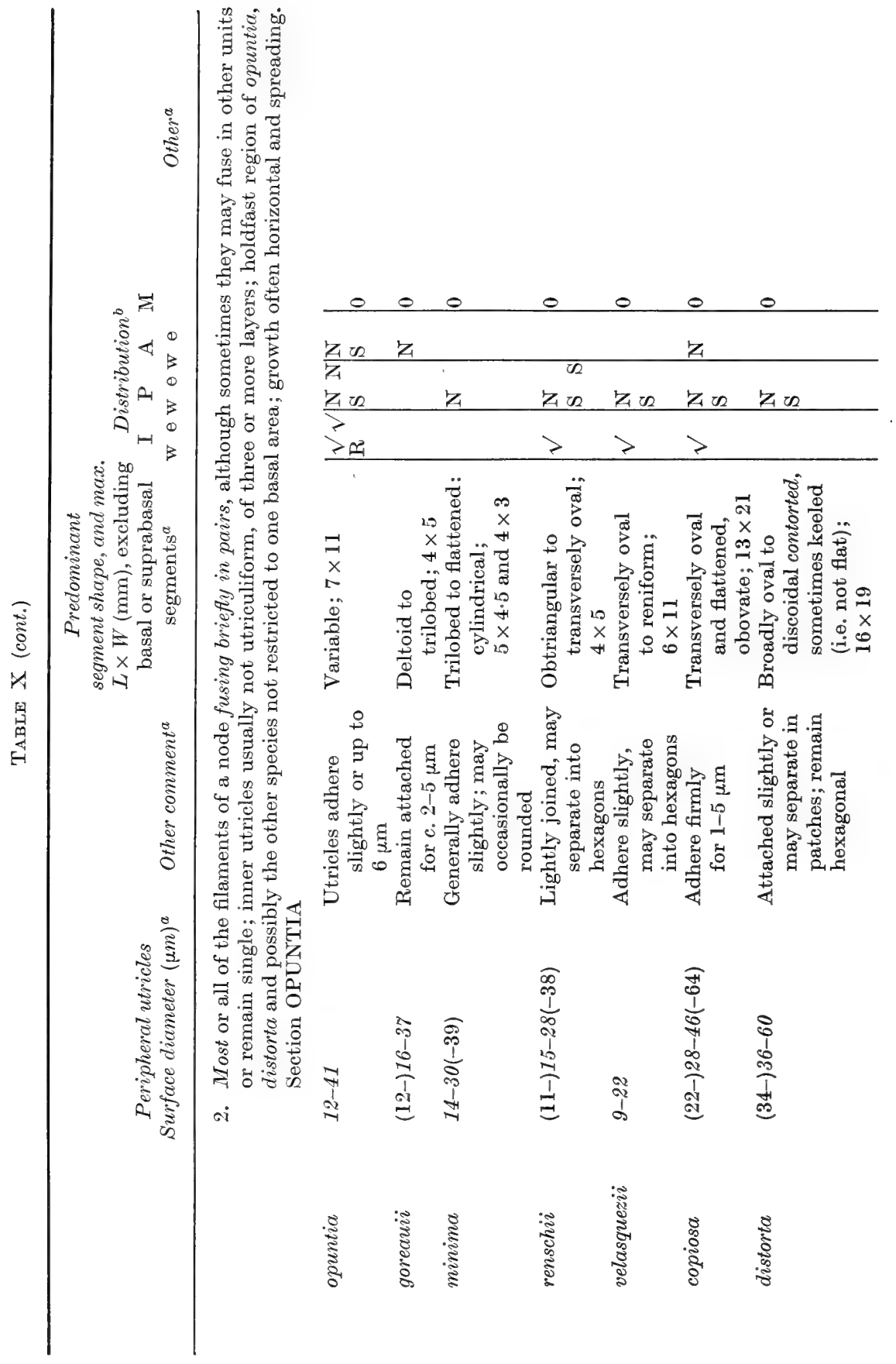




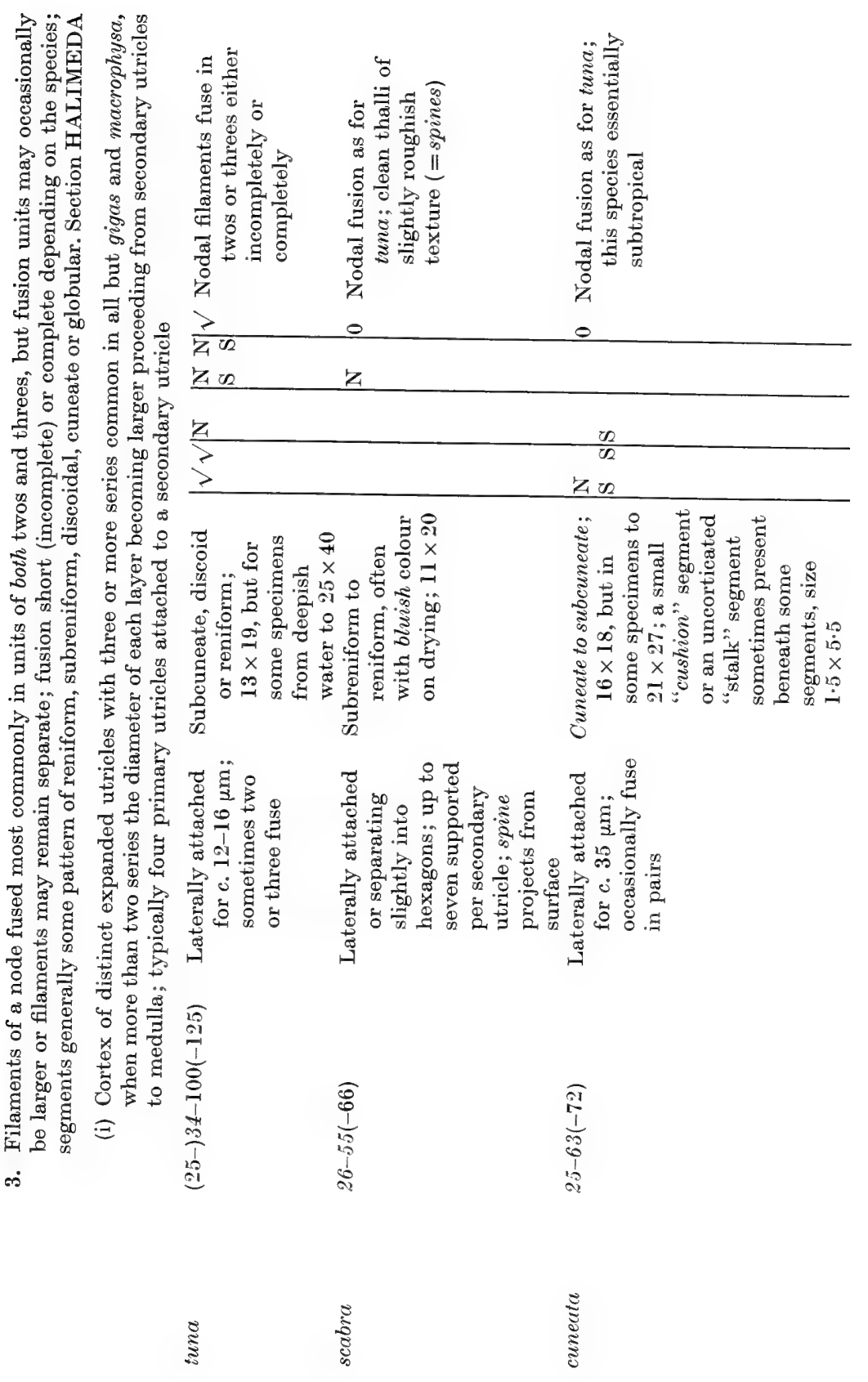




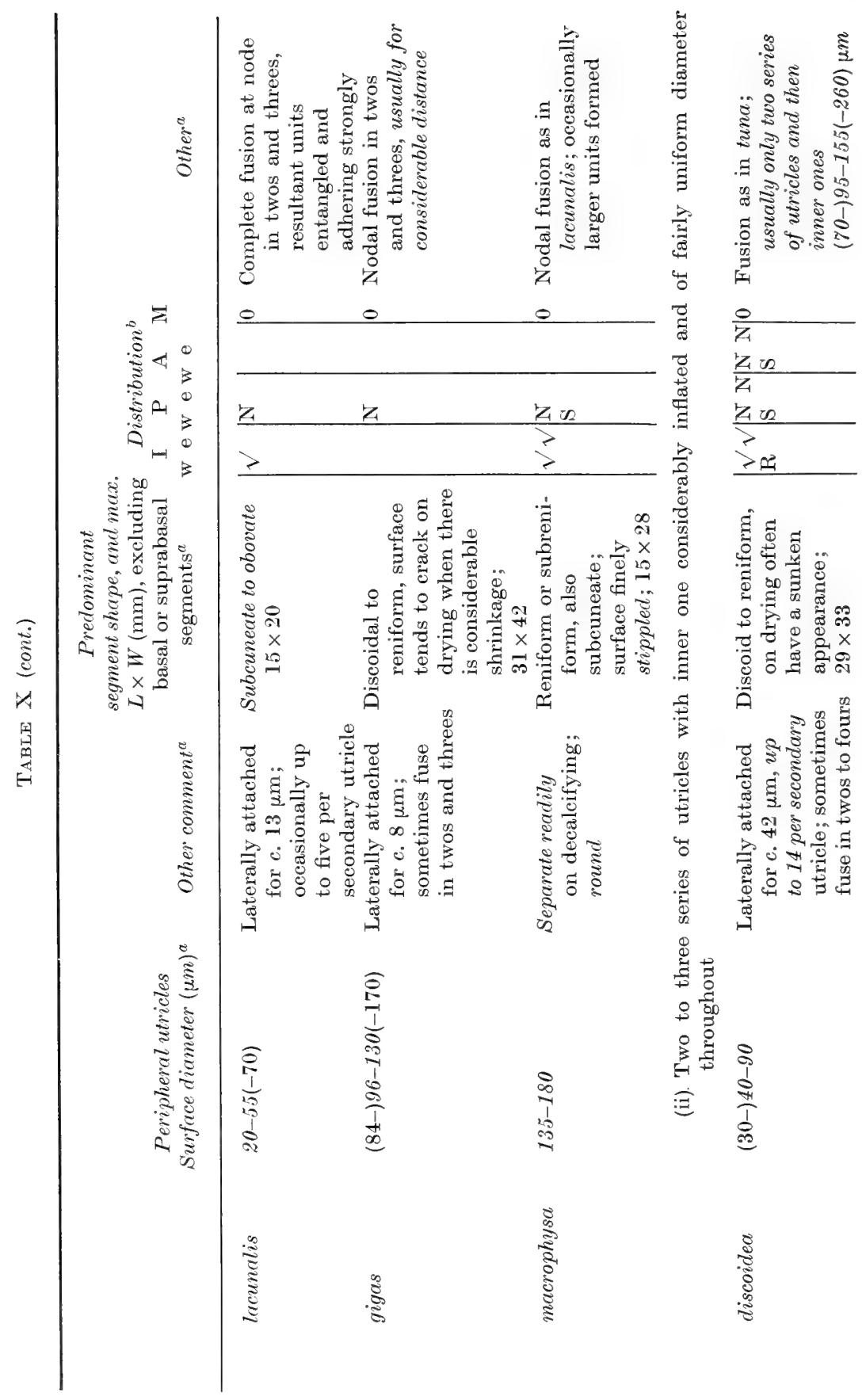




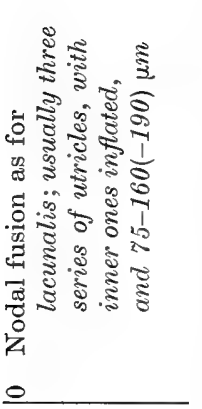

ซ్ణ

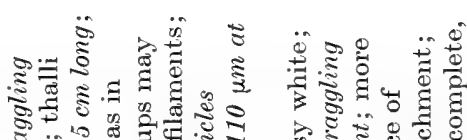

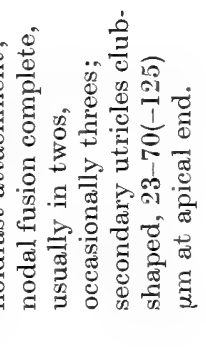

के

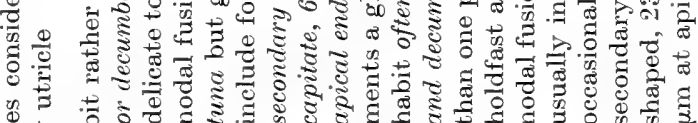

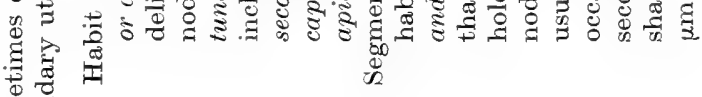

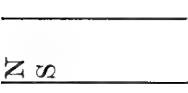

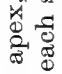

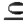

每

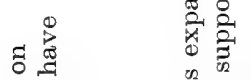

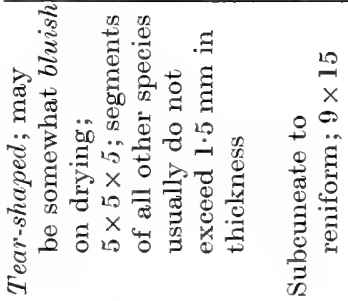

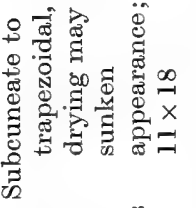

¿

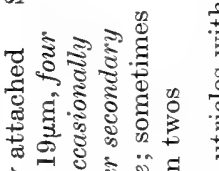

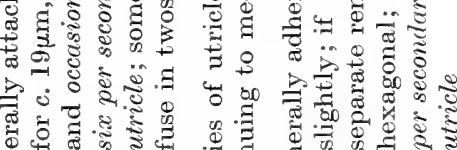

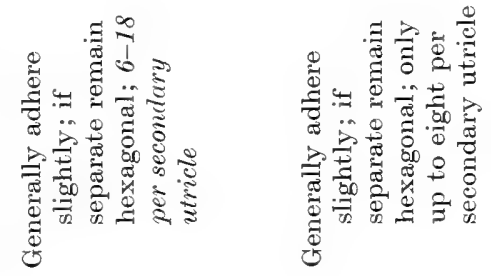

0
0
1
$\frac{1}{20}$
$\frac{1}{1}$
$\frac{9}{71}$
$\frac{1}{1}$
0
0

$\circ 8$

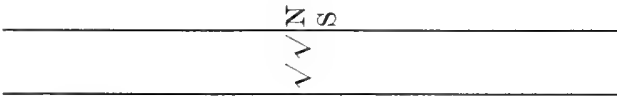

范

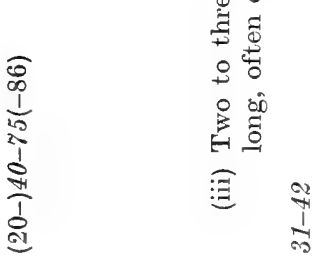

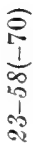

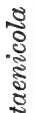

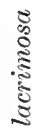

$\stackrel{\infty}{0}$ 


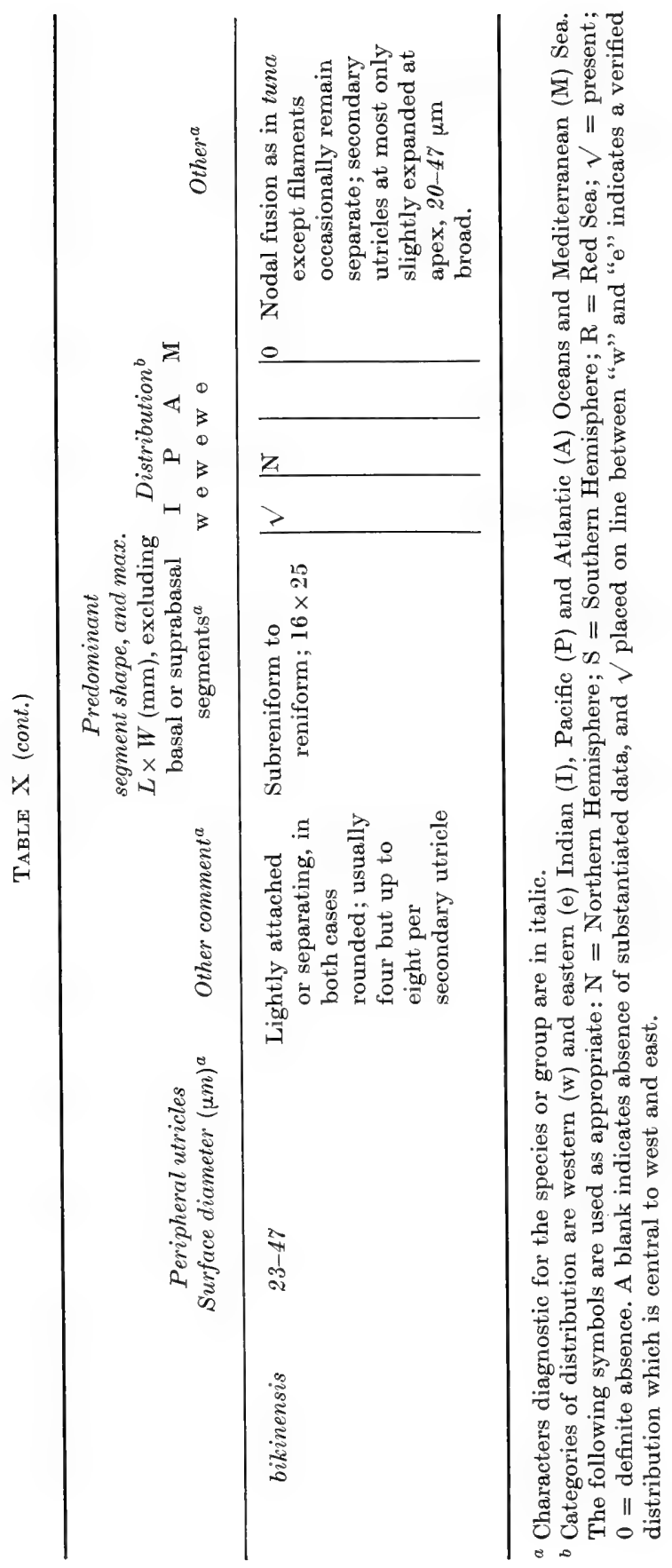


For the three species borneensis, distorta and melanesica, the material available is relatively scant and hence the data given are based on fewer than 100 measurements and 10 node dissections.

\section{Treatment of forms and varieties}

In the 1959 revision I placed a number of forms in synonymy, and discussed them in the text of the pertinent species. These details, therefore, are available in Hillis (1959). Since then I have encountered a number of variants in the reef which could be described as forms of species. This is not unexpected since a wide range of variation has occurred in the appearance of the species grown in the laboratory, including that shown in Fig. 16. To provide many of these variants with separate names, however, seems of questionable value to the taxonomist as well as to the ecologist who is probably working with Halimedae living under a different set of reef conditions, showing variations that are similar, yet not the same. In time we may know enough about the habitat of the different species and the variations encountered within a region to separate forms or varieties meaningfully by habitat, but we do not yet have his information.

\section{Synonymies}

For the earliest known Halimeda species such as tuna and incrassata the lists of synonymies are relatively extensive. The complete list to the time of Barton's monograph (1901) is given in that publication. I have provided in this section references to the type descriptions and species information since 1901 .

\section{Geographic distribution}

This information is provided by general region in each ocean, and is discussed further in Section VIII. Detailed distributions are given in Hillis (1959).

\section{Type specimen depositories}

The abbreviations of Lanjouw and Stafleu (1964) are used to indicate the location of type material. 
B. Species of the genus Halimeda Lamouroux, with index

Section Rhipsalis J. Ag. ex De Toni 1889

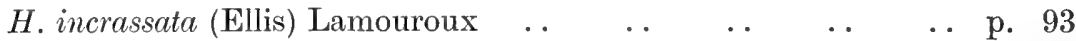

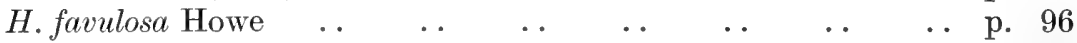

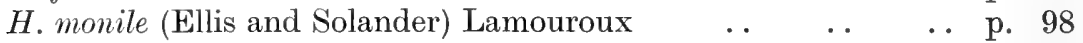

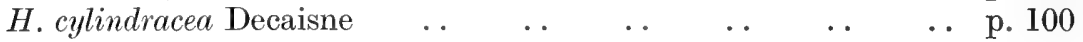

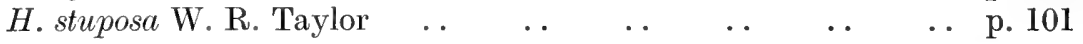

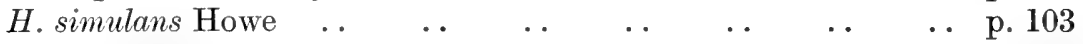

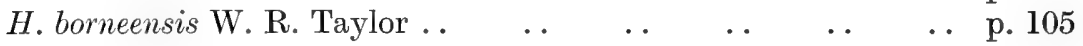

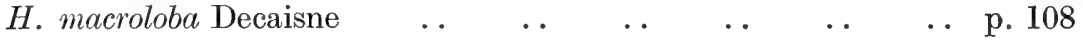

Section Opuntia J. Ag. ex De Toni 1889

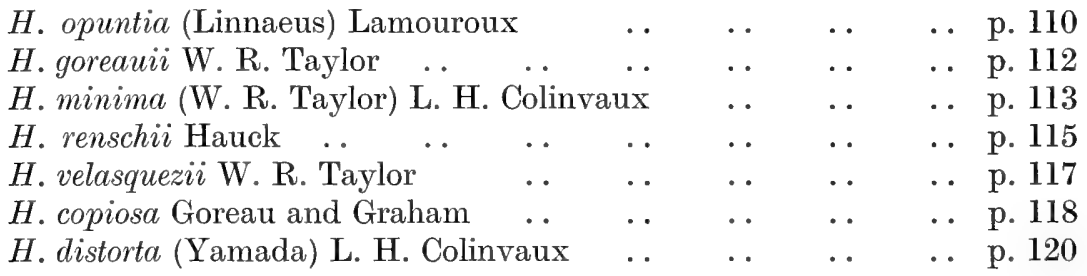

Section Halimeda J. Ag. ex De Toni 1889

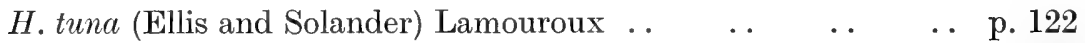

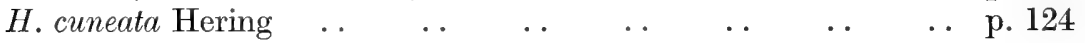

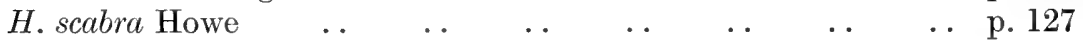

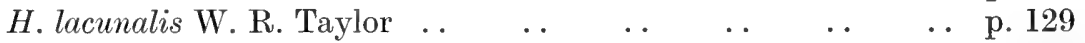

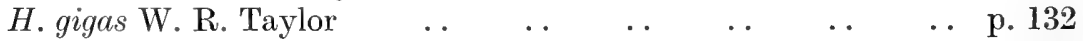

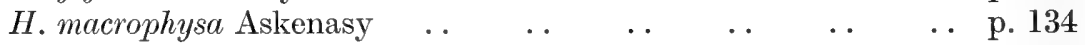

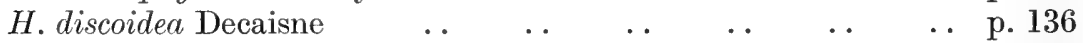

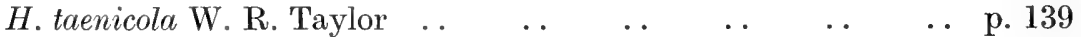

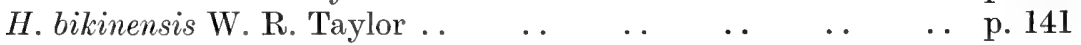

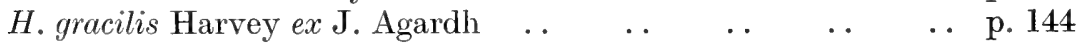

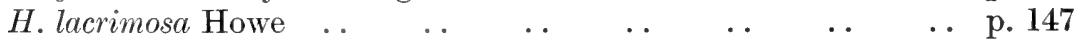

Section Micronesicae $n$. sect.

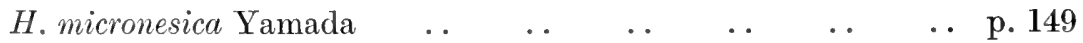

$\begin{array}{lllllllll}H \text {. fragilis W. R. Taylor } & \ldots & \ldots & \ldots & \ldots & \ldots & \text {.. } & \text { p. } 151\end{array}$

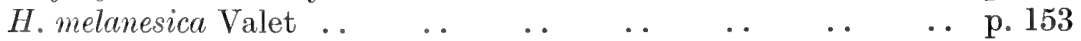

Section Crypticae n. sect.

H. cryptica L. H. Colinvaux and Graham .. $\quad \ldots \quad \ldots \quad \ldots \quad$ p. 154 


\section{Generic description of Halimeda Lamouroux,1812: the circumscription is emended to include uniaxial species}

Halimedea Lamouroux (1812), p. 186.

Halimeda Lamouroux (1816), p. 302, nomen conservandum.

Ormus Hill (1751), p. 12, Plate 3.

Sertularia Boehmer ex Ludwig (1760), p. 504.

Corallina p.p. Linnaeus (1758), p. 805; Pallas (1766), p. 420; Petiver (1767),

Plate 20, Fig. 19; Ellis and Solander (1786), p. 108; Esper (1798-1806),

Plate 11.

Flabellaria p.p Lamarck (1813), p. 302; Delle Chiaie (1829), p. 9, Plate 10.

Fucus p.p. Bertolini (1819), pp. 224, 316.

Ulva p.p. Pollinius (1824), p. 507.

Codium p.p. Springel (1827), p. 366.

Opuntia p.p. Naccari (1828), p. 104.

Sertolara Nardo (1834), p. 673.

Plants flaccid, prostrate or erect, and generally bushy, arising from a filamentous holdfast system, usually not exceeding $25 \mathrm{~cm}$ in height although to $1 \mathrm{~m}$ or more in sprawling specimens; branches composed of linear series of calcified segments, the nodes being uncalcified and flexible; segments plane or ribbed, spherical, tear-shaped, compressed-cylindrical, or cuneate to reniform in shape, with upper margins entire or lobed; organization consisting of coenocytic filaments which produce a multiaxial or occasionally a uniaxial core of medullary filaments surrounded by a cortex composed of layers of utricles, the outer walls of the peripheral utricles forming a continuous or slightly discontinuous surface; the medullary filaments, when more than one, remaining separate, or anastomosing in small groups, or into a single large unit at the nodes, their walls generally thickened in these regions; sexual reproduction by biciliate gametes produced in large globular to pyriform gametangia on stalks which are simple or branched, and arise from the node, segment margin or surface.

Lectotype species. Halimeda tuna (Ellis and Solander) Lamouroux.

\section{Description of the sections}

Five sections of the genus were delimited in Section III (including Table V) on the basis of pattern of the medullary filaments at the node. Their formal descriptions are given below.

Section Rhipsalis J. Ag. ex De Toni 1889 as Rhipsales. Filaments of a node fusing briefly into a single unit.

Section Opuntia J. Ag. ex De Toni 1889 as Opuntiae.

Most or all of the filaments of a node fusing briefly in pairs; occasionally fusing in other units, or remaining single. 
Section Halimeda J. Ag. ex De Toni 1889 as Tunae.

Filaments of a node most commonly fusing in both twos and threes; units occasionally may be larger, or filaments may remain single; fusion short or complete depending on the species.

Section Micronesicae $n$. sect.

Filaments of a node remaining completely separate, or a few may be joined briefly in $H$. melanesica.

Section Crypticae $n$. sect.

Single medullary filament unchanged at the node.

Latin diagnoses for new sections

Section Micronesicae

Filamenta nodi omnino discreta manentia, vel, in $H$. melanesica, aliquot interdum curte conjuncta.

Section Crypticae

Unicum filamentum medullosum ad nodos immutabile.

E. Taxonomic key to all species, and list of Indo-Pacific species

\section{Composite key to all species}

1. Plants growing in sand or other loose substrates; holdfast usually well developed, rarely less than $1 \mathrm{~cm}$ long and frequently massive; nodal medullary filaments uniting into a single group, the adjacent filaments usually communicating by pores ... . section Rhipsalis..

1. Plants generally attached to rock, or if associated with sand lacking a well-developed bulbous holdfast; holdfast rarely exceeding $1 \mathrm{~cm}$ in length, although sometimes it may spread laterally to this size or somewhat larger; more than one holdfast region may be present; nodal medullary filaments remaining separate or uniting in twos, threes and occasionally fours. . . .

2. Segments large, broad, flat, to $29 \mathrm{~mm}$ long and $40 \mathrm{~mm}$ broad ..

2. Segments smaller, flat or cylindrical, to $12 \mathrm{~mm}$ long and $16 \mathrm{~mm}$ broad (excluding basal or fusion segments)

3. Segments predominantly large, subcuneate to reniform and little lobed, to $29 \mathrm{~mm}$ long, $40 \mathrm{~mm}$ broad; fan-shaped basal or suprabasal segment absent (Fig. 27); peripheral utricles sometimes separate and round .. .. ..

H. macroloba, p. 108

3 Segments rarely exceeding $12 \mathrm{~mm}$ long and $17 \mathrm{~mm}$ broad, margins often crenulated or lobed; if peripheral utricles separate on decalcification they remain hexagonal $\quad \begin{array}{llllll} & \ldots & \ldots & \end{array}$

.


4. Fan-shaped basal or suprabasal segment present; plant heavy-set and somewhat squat with predominantly broad, reniform or ovate segments with crenulated margins, to $12 \mathrm{~mm}$ long, $17 \mathrm{~mm}$ broad

H. borneensis, p. 105

4. Fan-shaped basal or suprabasal segment absent; basal portion of plant of two to three cylindrical to subcuneate or at times reniform segments, the upper one supporting several subcuneate segments which are often arranged in an imbricated fashion, or sometimes a stalk region present which has developed from the fusion of small adjacent segments; segments to $11 \mathrm{~mm}$ long, $15 \mathrm{~mm}$ broad, margins sometimes shallowly trilobed or undulating but

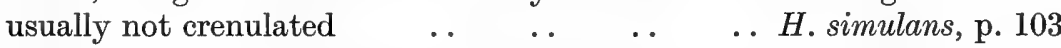

5. Segment surface appearing pitted when viewed macroscopically; peripheral utricles generally exceeding $110 \mu \mathrm{m}$ in surface

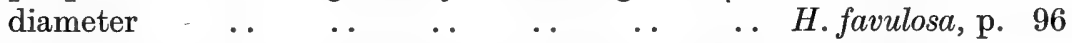

5. Segment surface not appearing pitted when viewed macroscopically; peripheral utricles generally less than $100 \mu \mathrm{m}$ in surface diameter

6. Segments of the upper half of the plant, except those supporting branches, predominantly cylindrical, their length usually at least three to four times their diameter $\ldots$.

6. Segments of the upper half of the plant flat, or if cylindrical the length usually not more than twice their diameter. . . . . .

7. Diameter of the cylindrical segments remaining fairly constant from base to apex of the plant and averaging $1.0-1.5 \mathrm{~mm}$; stalk of thallus short, of one to two segments; plant of Atlantic

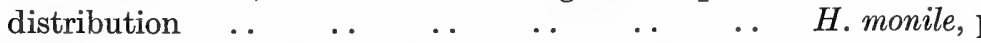

7. Diameter of the cylindrical segments decreasing from base to apex of the plant, averaging 3-4 $\mathrm{mm}$ near the base, and $1.0-1.5 \mathrm{~mm}$ towards the apex; caulescent, or in older plants a number of these cauline structures may be consolidated laterally into a basal fanshaped structure; of Indo-Pacific distribution H. cylindracea, p. 100

8. Plants thick-set in appearance, the segments averaging $2 \mathrm{~mm}$ in thickness; segments subcuneate to cylindrical, often becoming subspherical towards the plant apex .. H. stuposa, p. 101

8. Plants not appearing thick-set, segments (excluding the basal ones) averaging $0.75-1.00 \mathrm{~mm}$ in thickness; segments generally $\begin{array}{lllllll}\text { subcuneate to reniform } & \ldots & \ldots & \ldots & \ldots & \ldots & \ldots\end{array}$

9. Peripheral utricles generally $50 \mu \mathrm{m}$ or less in surface diameter; segments predominantly subcuneate to reniform with outer margin entire to shallowly lobed; basal portion of plant commonly of two to three cylindrical to subcuneate or at times reniform segments, the upper one supporting several subcuneate segments often in an imbricated arrangement; plants to $10 \mathrm{~cm}$ tall .. . .

H. simulans, p. 103 
9. Peripheral utricles generally exceeding $50 \mu \mathrm{m}$ in surface diameter; segments cylindrical to cuneate to discoidal and reniform with the outer margin often deeply lobed; plants to $24 \mathrm{~cm}$ tall $H$. incrassata, p. 93

10. Basal holdfast region appearing to involve several of the lowermost segments which consequently may be obscured by particles of sand adhering to the rhizoidal filaments of the region; entire holdfast area may spread laterally for $1 \mathrm{~cm}$ or more

10. Basal holdfast region restricted to a single segment, holdfast ranging from relatively conspicuous and about $1 \mathrm{~cm}$ in greatest dimension to almost negligible, any adhering particles of loose substrate usually can be scraped away readily to show a localized holdfast

11. Area of basal segments of thallus generally two or more times larger than those of rest of thallus so that a pronounced stalked

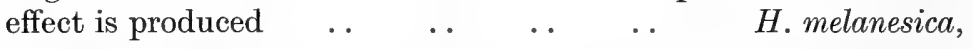

11. Segments of fairly uniform size (area) throughout, with maximum size approximately $4 \mathrm{~mm}$ long, $5 \mathrm{~mm}$ broad $\quad . \quad H$. renschii, p. 115

12. Growth pattern often forming laterally spreading thalli to $25 \mathrm{~m}$ or more which may be accompanied by some erect growth, or growth pattern mostly erect producing densely branched clumps; branching often multidirectional so that thallus does not lie flat; holdfast attachment generally in several places rather than by a single basal holdfast attachment although these small attachments may be lost during collecting $\quad \begin{array}{llllll} & \ldots & \ldots & \ldots & \text {. . }\end{array}$

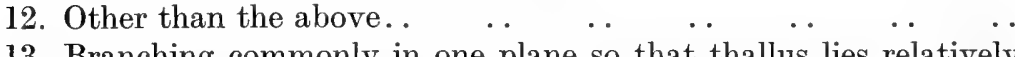

13. Branching commonly in one plane so that thallus lies relatively flat; segments generally flat but sometimes arched, commonly white, glossy, broadly subcuneate, sometimes trilobed; cortex generally of two layers of utricles with secondary utricles slightly to distinctly clavate at apical end; secondary utricles supporting

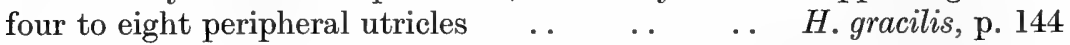

13. Branching commonly multidirectional so that thallus does not lie flat; segments flat or contorted, their surfaces dull; cortex generally of three or more series of utricles which are not expanded at the apical end and which bear only four peripheral utricles at $\begin{array}{llllllllll}\text { most } & \text {. } & \text {. } & \ldots & \ldots & \ldots & \ldots & \ldots & \ldots & \ldots\end{array}$

14. Segments relatively large, to $16 \mathrm{~mm}$ long, $19 \mathrm{~mm}$ broad; often contorted; peripheral utricles measuring $36-60 \mu \mathrm{m}$ in surface

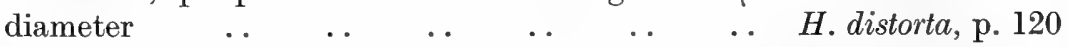

14. Segments smaller, plane or somewhat contorted, to approximately $7 \mathrm{~mm}$ long, $11 \mathrm{~mm}$ broad; peripheral utricles measuring $12-41 \mu \mathrm{m}$ $\begin{array}{lllllll}\text { in surface diameter } & \ldots & \ldots & \ldots & \ldots & \ldots & \text { H. opuntia, p. } 110\end{array}$

15. Basal segment flabellate (Fig. 46), to approximately $12 \mathrm{~mm}$ long, $18 \mathrm{~mm}$ broad, supporting numerous branches H. micronesica, p. 149

15. Basal segment not flabellate

. . . . 
16. A small "cushion" segment to $1.5 \mathrm{~mm}$ long, $5.5 \mathrm{~mm}$ broad interposed between some or all of the segments (Figs 18,61) H. cuneata, p. 124

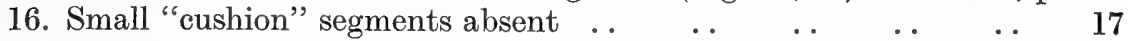

17. Mature plants small, not exceeding $5 \mathrm{~cm}$ in length; the segments of at least the upper half of the plant spherical or tear-shaped, to $5 \mathrm{~mm}$ long, $5 \mathrm{~mm}$ broad and $5 \mathrm{~mm}$ thickness; secondary utricles capitate (Fig. 20, No. 12), supporting 6-18 peripheral utricles . .

H. lacrimosa, p. 147

17. Mature plants larger; segments flat or somewhat contorted but not spherical

18. Average surface diameter of the peripheral utricles exceeding $120 \mu \mathrm{m}$

18. Average surface diameter of the peripheral utricles less than $120 \mu \mathrm{m}$

19. Segments large, to $31 \mathrm{~mm}$ long, $42 \mathrm{~mm}$ broad, not friable; colour on drying brownish-green; calcification rather light H. gigas, p. 132

19. Segments smaller, to $15 \mathrm{~mm}$ long, $24 \mathrm{~mm}$ broad, friable; colour on drying white or pale greenish-white; calcification moderate

H. macrophysa, p. 134

20. Peripheral utricles each projecting into a central spine $H$. scabra, p. 127

20. Peripheral utricles with smooth outer surface

21. Node consisting of a single medullary filament .. H. cryptica, p. 154

21. Node consisting of several to many medullary filaments _ . 22

22. Secondary utricles noticeably inflated, generally exceeding $90 \mu \mathrm{m}$ in diameter (Fig. 20, No. 11) $\quad$. $\quad \ldots \quad$ H. discoidea, p. 136

22. Secondary utricles less than $90 \mu \mathrm{m}$ in diameter $\ldots \ldots \ldots 23$

23. Tertiary utricles averaging $110 \mu \mathrm{m}$ or more in diameter, with length two to three or more times the diameter . . H. taenicola, p. 139

23. Tertiary utricles averaging less than $110 \mu \mathrm{m}$ in diameter and length not more than twice the diameter of the utricles . . . .

24. Diameters of secondary and tertiary utricles swollen in comparison to diameters of medullary filaments, utricles noticeably contracted

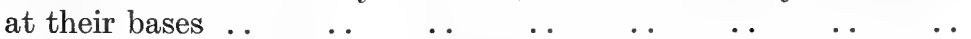

24. Diameters of secondary and tertiary utricles not appreciably greater than diameters of medullary filaments, secondary and tertiary utricles not conspicuously contracted at their bases ..

25. Segments, at least those of the upper half of the plant, predominantly reniform to discoid; peripheral utricles generally exceeding $50 \mu \mathrm{m}$ in surface diameter; nodal fusion in small units, for a short

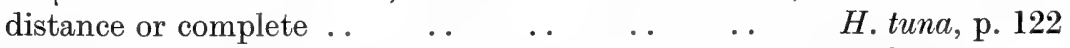

25. Segments predominantly subcuneate to obovate; peripheral utricles generally $50 \mu \mathrm{m}$ or less in surface diameter; nodal units . fusing completely in twos and threes; units entangled and adhering strongly for $80-150(-280) \mu \mathrm{m} \quad \ldots \quad \ldots \quad \ldots$. lacunalis, p. 129

26. Nodal filaments remaining separate although adjacent filaments

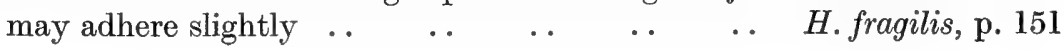


26. Nodal filaments fusing in small groups although the occasional filament may remain separate

27. Mature thalli relatively small, usually $13 \mathrm{~cm}$ or less in length; segments also relatively small, with length usually less than $6 \mathrm{~mm}$, width usually less than $11 \mathrm{~mm}$

27. Mature thalli larger, generally exceeding $13 \mathrm{~cm}$ in length; segments also larger with length to approximately $16 \mathrm{~mm}$, width to about $25 \mathrm{~mm} \quad$.

28. Plants to about $20 \mathrm{~cm}$ tall, generally growing erect, thallus somewhat heavy-set; nodal fusions mostly in twos or threes, the fusions within the units being for a short distance or complete .. ..

H. bikinensis, p. 141

28. Plants to $70 \mathrm{~cm}$ long although they may be considerably shorter, frequently pendant from rock, branches relatively long and somewhat sparse so that overall appearance of thallus is of delicacy; nodal filaments most commonly fusing in small groups for

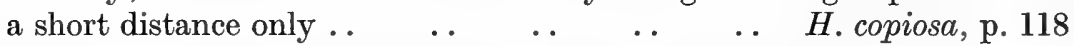

29. Segments predominantly slightly reniform or transversely oval; average diameter of peripheral utricles in surface view about

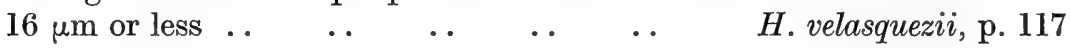

29. Segments predominantly other shapes, average diameter of peripheral utricles in surface view $22 \mu \mathrm{m}$ or greater . . .

30. Segments generally longer than broad, except for those bearing branches; segments in upper part of plant flattened-cylindrical to cylindrical; plants often bushy and in shallow water tending to grow erect; nodal fusion mostly in pairs but also in threes with filaments occasionally separate; of Indo-Pacific distribution

H. minima, p. 113

30. Segment length generally equalling width or somewhat broader in upper part of thallus; plant growth form somewhat pendant; fusion units of nodal filaments in pairs; of Atlantic distribution

H. goreauii, p. 112

2. List of Indo-Pacific species of Halimeda

Section Rhipsalis

$H$. incrassata

H. cylindracea

H. stuposa

$H$. borneensis

H. macroloba

Section Opuntia

H. opuntia

H. minima
H. renschii

H. velasquezii

$H$. copiosa

$H$. distorta

Section Halimeda
H. tuna
H. cuneata
$H$. lacunalis
H. gigas 
Section Halimeda (cont.)
H. macrophysa
H. discoidea
H. taenicola
H. bikinensis
H. gracilis

Section Micronesicae

H. micronesica

$H$. fragilis

H. melanesica

\section{F. Key to Atlantic species, and list of Atlantic species}

\section{Key to Atlantic species}

1. Plants growing in sand or other loose substrate; holdfast usually well developed, rarely less than $1 \mathrm{~cm}$ long and frequently massive; nodal medullary filaments uniting into a single group, the adjacent filaments usually communicating by pores ... section Rhipsalis. .

1. Plants generally attached to rock or if associated with sand lacking a well-developed bulbous holdfast; holdfast rarely exceeding $1 \mathrm{~cm}$ in length, although sometimes it may spread laterally to this size or somewhat larger; more than one holdfast region may be present; nodal medullary filaments remaining separate or uniting in twos, threes and occasionally fours ..

2. Segment surface appearing pitted when viewed macroscopically; peripheral utricles generally exceeding $110 \mu \mathrm{m}$ in surface $\begin{array}{lllllllll}\text { diameter } & \text {. } & \ldots & \ldots & \ldots & \text {.. } & \text {.. } & \text { H. favulosa, p. } 96\end{array}$

2. Segment surface not appearing pitted when viewed macroscopically; peripheral utricles generally less than $100 \mu \mathrm{m}$ in surface diameter

3. Segments of the upper half of the plant, except those supporting branches, predominantly cylindrical, their length usually at least three to four times their diameter . . $\quad \ldots \quad$. . $\quad$ H. monile, p. 98

3. Segments of the upper half of the plant flat, or if cylindrical the length usually not more than twice their diameter .. . .

4. Peripheral utricles generally $50 \mu \mathrm{m}$ or less in surface diameter; segments predominantly subcuneate to reniform with outer margin entire to shallowly lobed; basal portion of plant commonly of two to three cylindrical to subcuneate or at times reniform segments, the upper one supporting several subcuneate segments often in an imbricated arrangement; plants to $10 \mathrm{~cm}$ tall

H. simulans, p. 103

4. Peripheral utricles generally exceeding $50 \mu \mathrm{m}$ in surface diameter; segments cylindrical to cuneate to discoidal and reniform with the outer margin often deeply lobed; plants to $24 \mathrm{~cm}$ tall 
5. Node consisting of a single medullary filament; plant growing at approximately $-25 \mathrm{~m}$ and deeper .. $\quad . . \quad$.. $\quad$ H. cryptica, p. 154

5. Node consisting of several to many medullary filaments . . ..

6. Growth pattern often forming laterally spreading thalli to $0.25 \mathrm{~m}$ or more which may be accompanied by some erect growth, or growth pattern mostly erect producing densely branched clumps; branching often multidirectional so that thallus does not lie flat; holdfast attachment generally in several places rather than by a single basal holdfast attachment although these may be lost in

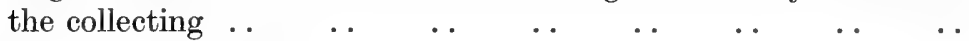

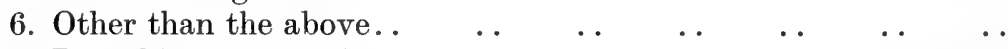

7. Branching commonly in one plane so that thallus lies relatively flat; segments generally flat but sometimes arched, commonly white, glossy, broadly subcuneate, sometimes trilobed; cortex generally of two layers of utricles with secondary utricles slightly to distinctly clavate at apical end; secondary utricles supporting

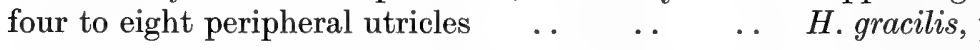

7. Branching commonly multidirectional so that thallus does not lie flat; segments flat or contorted, their surfaces dull; cortex generally of three or more series of utricles which are not expanded at the apical end and which bear only four peripheral utricles at most; the commonest species of many rocky areas in extremely shallow water $(-0.3 \mathrm{~m})$ where it grows as sprawling skeins, or as

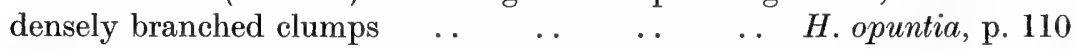

8. Mature plants small, not exceeding $5 \mathrm{~cm}$ in length; the segments of at least the upper half of the plant spherical or tear-shaped, to $5 \mathrm{~mm}$ long, $5 \mathrm{~mm}$ broad and $5 \mathrm{~mm}$ thickness; secondary utricles capitate (Fig. 20, No. 12), supporting 6-18 peripheral utricles ..

H. lacrimosa, p. 147

8. Mature plants larger; segments flat or somewhat contorted, but not spherical

9. Peripheral utricles each projecting into a central spine; surface of clean plants somewhat rough to the touch, colour on drying $\begin{array}{lllllll}\text { often bluish-green } & \text {. } & \text {. } & \text {. } & \text {. } & \text {. } & \text { H. scabra, p. } 127\end{array}$

9. Peripheral utricles with smooth surface, a central spine being $\begin{array}{llllllllll}\text { absent . . } & \text {. } & \text {. } & \ldots & \ldots & \ldots & \text {. } & \text {. } & \ldots & \ldots\end{array}$

10. Secondary utricles noticeable inflated, generally exceeding $90 \mu \mathrm{m}$

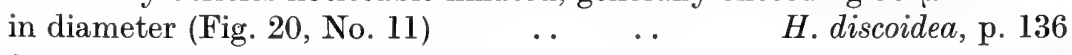

10. Secondary utricles less than $90 \mu \mathrm{m}$ in diameter $\ldots \quad \ldots \quad \ldots \quad \ldots \quad 11$

11. Diameters of secondary and tertiary utricles swollen in comparison to diameters of the medullary filaments, and utricles noticeably

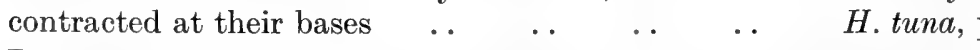

1. Diameters of secondary and tertiary utricles not appreciably greater than diameters of medullary filaments, secondary and tertiary utricles not conspicuously contracted at their bases .. 
12. Mature plants relatively small and delicate, to approximately $13 \mathrm{~cm}$ long; segments commonly subcuneate and sometimes strongly trilobed, to $4 \mathrm{~mm}$ long and $5 \mathrm{~mm}$ broad; peripheral utricles averaging about $27 \mu \mathrm{m}$ in diameter; commonly associated

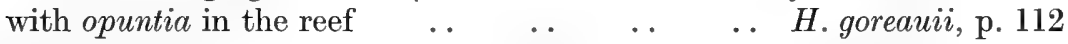

12. Mature plants to $70 \mathrm{~cm}$ long although they may be considerably shorter; segments commonly transversely oblong to depressed ovate, to $13 \mathrm{~mm}$ long and $21 \mathrm{~mm}$ broad; peripheral utricles averaging approximately $37 \mu \mathrm{m}$; commonly associated with cryptica in deeper parts of the reef $\quad$. $\quad \ldots \quad$ H. copiosa, p. 118

2. List of Atlantic species of Halimeda

Section Rhipsalis

$H$. incrassata

$H$. simulans

H. favulosa

H. monile

Section Opuntia

H. opuntia

H. goreauii

H. copiosa
Section Halimeda

H. tuna

H. scabra

H. discoidea

$H$. gracilis

H. lacrimosa

Section Crypticae

H. cryptica

\section{G. Species descriptions}

1. Section Rhipsalis J. Ag. ex De Toni

Halimeda incrassata (Ellis) Lamouroux

Figure 22.

Corallina incrassata Ellis (1767), Plate 17, Figs 20-27; Ellis and Solander (1786), p. 111, Plate 20, Figs $D_{1-6}, d, d_{1-3}$.

Corallina tridens Ellis and Solander (1786), p. 109, Plate 20, Fig. a.

Halimedea incrassata Lamouroux (1812), p. 186; Halimeda incrassata

Lamouroux (1816), p. 307; Barton (1901), p. 25, Plate 4, Figs 39, 41-51;

Hillis (1959), p. 365, Plates 4-6, 12.

Halimeda incrassata f. gracilis Børgesen (1913), p. 111, Fig. 89.

Halimeda incrassata f. rotunda Barton (1901), p. 28, Plate 4, Fig. 45.

? Halimeda incrassata f. tridentata Duchassaing ex J. Agardh (1887), p. 86.

Halimeda incrassata f. tripartita Barton (1901), p. 27, Plate 4, Fig. 43. 


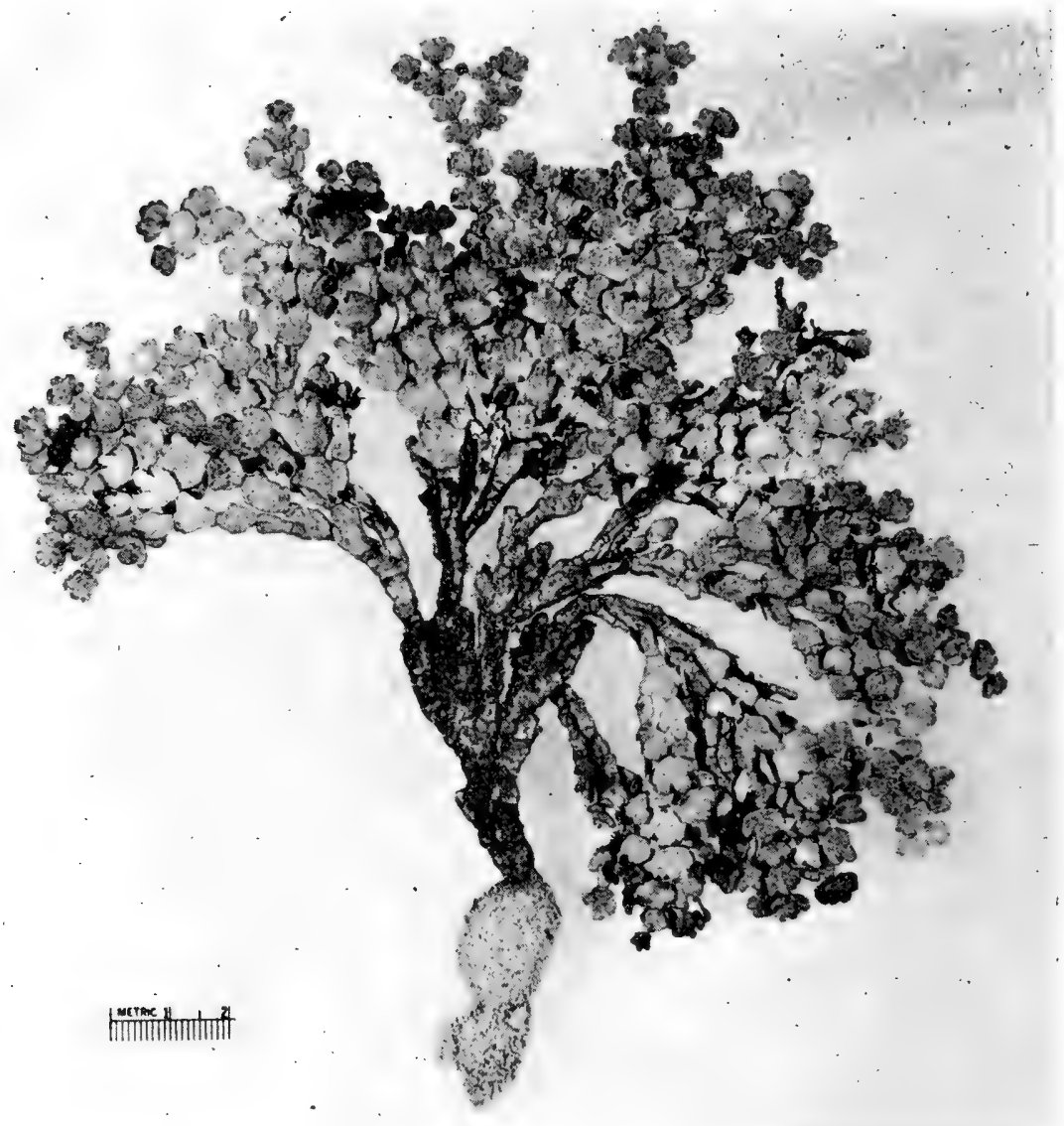

FIG. 22. H. incrassata. Basal portion of thallus shown is caulescent, and trilobed segments are common towards branch extremities. Basal third is also more heavily epiphytized, and appears to have functioned as perennating structure. Specimen from Curaçao, Spaanse Baai, south-east coast, 19 XI 62, Diaz-Piferrer. Scale bar is $2 \mathrm{~cm}$ long. (Photograph by The Ohio State University Department of Photography.)

Halimedea tridens Lamouroux (1812), p. 186; Halimeda tridens Lamouroux (1816), p. 308; Collins (1909-1918), p. 398; Taylor (1928), p. 84, Plate 10, Fig. 14; Taylor (1950), p. 92.

? Halimeda brevicaulis Kützing (1858), p. 11, Plate 25, Fig. 2.

Plants occasionally lax in habit, but more commonly erect and compact, to $24 \mathrm{~cm}$ tall excluding the holdfast region, which may extend to $9 \mathrm{~cm}$ in length; calcification rather heavy at the base, becoming moderate to light in the middle and upper portions; branching mainly di- to tetrachotomous, the lower part of the plant often remaining simple for some distance, or branching 
immediately above the first to second basal segments, the resultant segments at times becoming consolidated laterally into a rather massive fan-shaped structure; the basal first to second segments cylindrical to subcuneate, others plane, ribbed or keeled, shape variable, from cylindrical to reniform, the outer margin entire, undulating or deeply lobed, to about $10 \mathrm{~mm}$ long, $14 \mathrm{~mm}$ broad, and averaging $0.75-1.00 \mathrm{~mm}$ in thickness.

Cortex of three to five layers of utricles; the outermost utricles generally remaining attached after decalcification for an average distance of $12 \mu \mathrm{m}$, their lateral and peripheral walls occasionally thickened, (34-)45-85(-105) $\mu \mathrm{m}$ in surface diameter, (40-)50-95(-125) $\mu \mathrm{m}$ long in section, two or four supported on each secondary utricle; secondary utricles often globose or subglobose, 23-70(-95) $\mu \mathrm{m}$ broad, 30-90(-118) $\mu \mathrm{m}$ long; innermost utricles $(32-) 46-100(-150) \mu \mathrm{m}$ broad.

Nodal medullary filaments uniting as a single group for a distance of approximately $25-80 \mu \mathrm{m}$, the adjacent filaments communicating by pores or tubular processes; walls in this region thickened and often deeply pigmented.

Type specimen. Collected by Ellis in Jamaica; according to Barton (1901) this specimen has been lost.

Habitat. Grows in sand, mud or other unconsolidated substrate from just below low-tide line to about $-65 \mathrm{~m}$. In the Caribbean it may form very dense stands, often with $H$. monile, of more than 300 thalli of the two species per square metre just below low-tide line. In shallow environments that are somewhat exposed, as opposed to sheltered, the long axis of older plants is perpendicular to the direction of the wave motion.

Halimeda incrassata frequently is associated with sea grasses. In the Caribbean $H$. monile and $H$. simulans may occur with it. It is also associated with species of Penicillus, Udotea and Rhipocephalus.

At Enewetak Atoll it was found in moderately exposed to sheltered sites and in more exposed habitats than cylindracea. Extensive patches of it such as are common in the Caribbean were not observed.

Geographic distribution. Pantropical; includes western and eastern Indian Ocean; north and south in the western Pacific; north and south in the western Atlantic including Bermuda (western Atlantic).

This species is best known from the Caribbean where it appears to be the commonest of the Rhipsalian taxa, and often forms extensive populations in the shallow sandy regions of the reef.

Modifications other than those of segment shape occur in specimens of incrassata. These include an increase in the number or height of the cortical layers, either or both conditions producing thicker segments. 
The firmness of the connections between the nodal medullary filaments also varies, the constituent filaments at times communicating mainly by a restricted number of narrow tubular processes which may be relatively easily severed, rather than by numerous well-developed broad short tubes. In addition, the general appearance of the basal portion of the plant may differ. Specimens from the Caribbean often appear distinctly caulescent, and in older plants from this region the lower branches may consolidate laterally to form a fan-shaped, erect basal portion. The stipe region in many Pacific specimens generally is restricted to one or two subcylindrical to subcuneate segments, the upper one supporting several branches.

\section{Halimeda favulosa Howe}

Figure 23.

Halimeda favulosa Howe (1905b), p. 563, Plate 23, Fig. 2; Plate 24; Plate 26, Figs 1-6; Collins (1909-1918), p. 401; Hillis (1959), p. 370, Plates 4-6, $8,12$.

Plants attenuate, suberect or somewhat flaccid, to $22 \mathrm{~cm}$ tall excluding the holdfast, which is moderately well developed; calcification moderate; surface dull, rugose and appearing pitted; branching sparse, mainly ditrichotomous; basal segments commonly compressed-cylindrical to trapezoidal, often forming a short stipe and supporting several segments which remain separate or consolidate laterally, either entirely or in part, to form a fan-shaped unit; other segments friable, cylindrical to subcuneate, the upper margin two to five lobed, the resultant arms compressed or terete, to $9 \mathrm{~mm}$ long, $13 \mathrm{~mm}$ broad and averaging $1 \cdot 0-1.5 \mathrm{~mm}$ in thickness.

Cortex of two to three layers of utricles; outermost utricles (110-)125$220(-260) \mu \mathrm{m}$ in surface diameter, $170-280(-400) \mu \mathrm{m}$ long in section, separating or remaining slightly attached after decalcification, appearing rounded in surface view, in section sometimes constricted basally forming a conspicuous bulb; one, two or four supported by each secondary utricle; secondary utricles 100-150(-190) $\mu \mathrm{m}$ broad, 170-275(-424) $\mu \mathrm{m}$ long.

Nodal medullary filaments uniting as a single group for a distance of approximately $28-50 \mu \mathrm{m}$, adjacent filaments communicating by pores; walls in this region thickened and pigmented.

Type specimen. Bahamas, Cave Cays, Exuma Chain, Howe 3981, 19 February, 1905 (NY).

Habitat. Grows in sand, mud, or other unconsolidated substrate.

Geographic distribution. North-western Atlantic; uncommon to rare. 


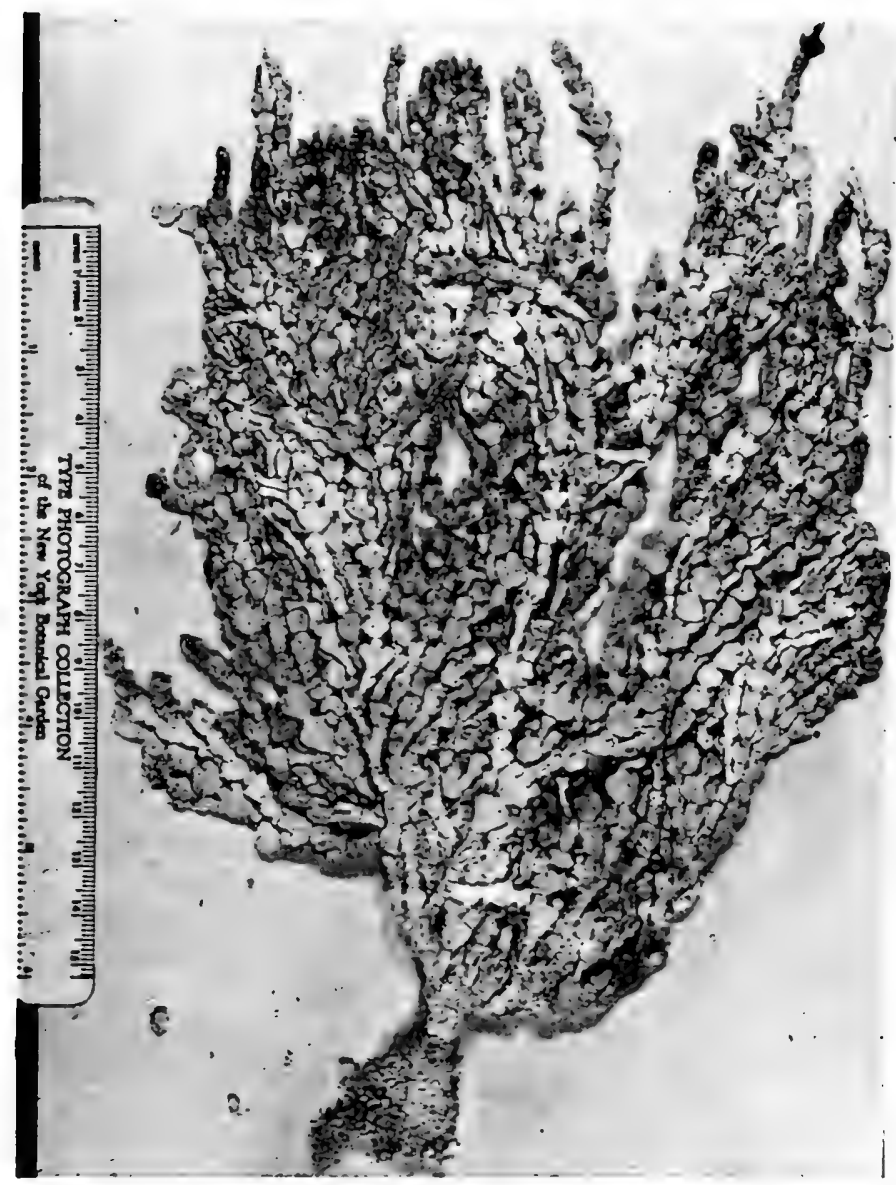

Fig. 23. H. favulosa. Holotype, Bahamas, Cave Cays, Exuma Chain, Howe 3981. (Photograph courtesy of the New York Botanical Garden.)

Since favulosa fairly (losely resembles the relatively common monile it may easily be passed over as such in the field. This perhaps partly explains its extremely restricted recorded distribution.

This species can be distinguished macroscopically from monile and other Rhipsalian species by the friable nature of its segments and their pitted surface. The pitted texture results from the large diameters of the peripheral utricles, and their partial or complete separation by calcium carbonate partitions. Histologically, farulosa is characterized by a relatively poorly developed inner cortex and by the large dimensions of the peripheral and secondary utricles. 


\section{Halimeda monile (Ellis and Solander) Lamouroux}

Figure 24.

Corallina monile Ellis and Solander (1786), p. 110, Plate 20, Fig. c.

Halimedea monile Lamouroux (1812), p. 186; Halimeda monile Lamouroux (1816), p. 306; Howe (1907), p. 501; Collins (1909-1918), p. 399; Taylor (1928), p. 82; Hillis (1959), p. 371, Plates 4-8, 12.

Halimeda incrassata v. monilis Harvey (1858), p. 24; Børgesen (1911), p. 138; Børgesen (1913), p. 112.

Halimeda incrassata v. monilis f. cylindrica Børgesen (1911), p. 143, Fig. 10; Børgesen (1913), p. 113, Fig. 91.

Halimeda incrassata v. monilis f. robusta Børgesen (1911), p. 143, Fig. 9; Børgesen (1913), p. 113, Fig. 90.

Halimeda incrassata f. monilis Barton (1901), p. 27, but not Plate 4, Fig. 40.

Plants sometimes elongate and sparsely branched, but more commonly compact and robust, to $16 \mathrm{~cm}$ tall excluding the holdfast which may extend to $4 \mathrm{~cm}$ in length; calcification moderate, becoming heavier towards the base, branching mainly ditrichotomous; basal first to second segments forming a short stipe, generally cylindrical to subcylindrical but becoming almost semicircular in densely branched plants, these supporting two to several segments which may consolidate laterally into a modified fan-shaped structure; other segments plane or ribbed, generally trilobed with terete arms, or cylindrical, the former usually predominating in regions of branching, the latter in the upper part of the plant, cylindrical ones to $8 \mathrm{~mm}$ long, $3 \mathrm{~mm}$ broad and averaging $1.5 \mathrm{~mm}$ in diameter, others excluding the modified basal ones to $8 \mathrm{~mm}$ long and $8 \mathrm{~mm}$ broad.

Cortex of three to five layers of utricles; outermost utricles remaining attached after decalcification for an average distance of $6 \mu \mathrm{m},(23-) 30$ $60(-74) \mu \mathrm{m}$ in surface diameter, 48-95(-116) $\mu \mathrm{m}$ long in section, two or four supported by each secondary utricle; secondary utricles $23-70 \mu \mathrm{m}$ broad, 23-100(-140) $\mu \mathrm{m}$ long; tertiary utricles 30-90 $\mu \mathrm{m}$ broad.

Nodal medullary filaments usually uniting in twos, threes or larger groups for a distance of approximately $49-80 \mu \mathrm{m}$, these units held together by short narrow tubular processes which are easily broken; filament walls thickened and pigmented.

Type specimen. Collected by Ellis in Jamajca; according to Barton (1901) this plant has been lost.

Habitat. Grows in sand, mud or other unconsolidated substrate, from near low-tide line to about $-13 \mathrm{~m}$ and possibly deeper. In water of about $0.3 \mathrm{~m}$ depth, low tides, it may form exceedingly dense stands, and one Jamaican quadrat I counted had 360 compressed monile thalli per square metre, together with 140 flattened incrassata thallj. Such dense growth may be restricted to very 


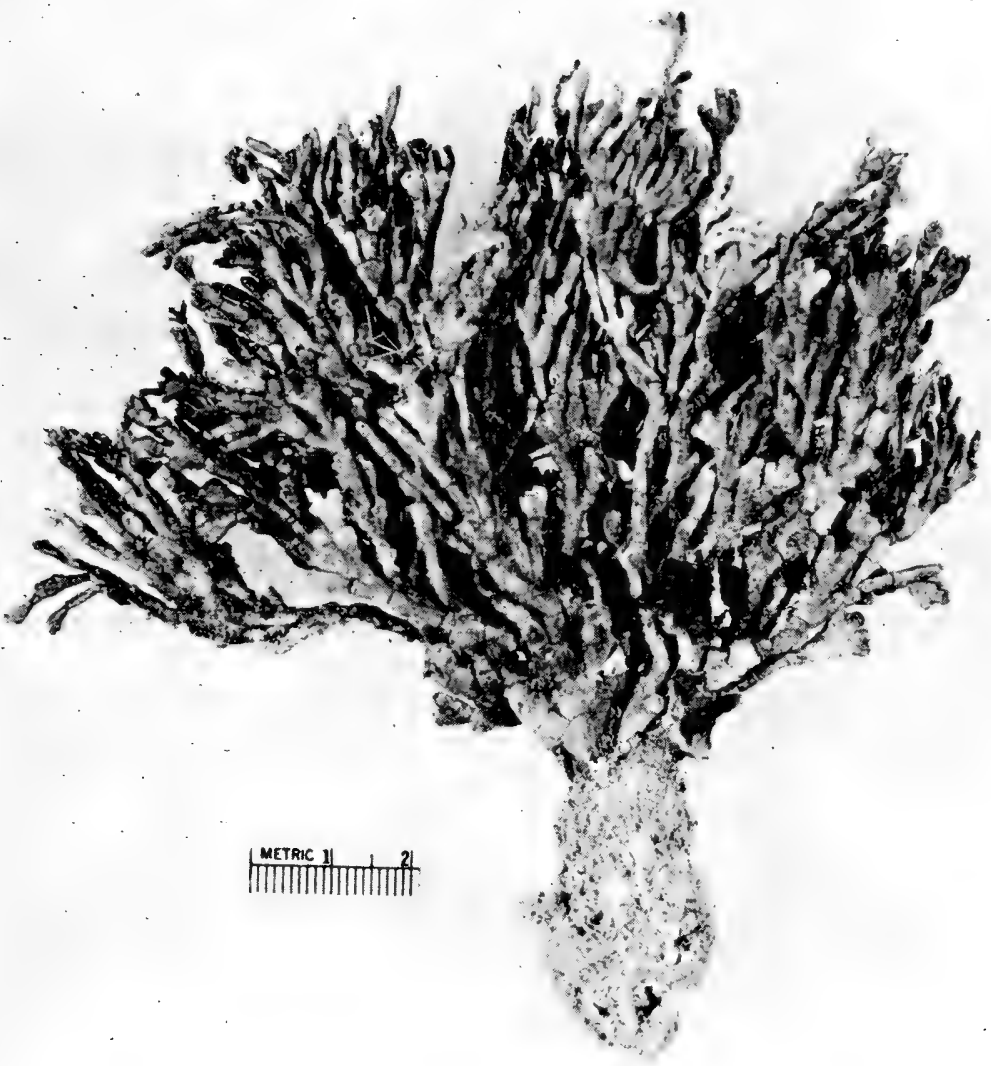

FIG. 24. H. monile. Specimen from Jamaica, Glory Be reef top, IX 1967, Hillis-Colinvaux and Colinvaux. Scale bar is $2 \mathrm{~cm}$ long. (Photograph by The Ohio State University Department of Photography.)

shallow water. The thalli sometimes are partially buried by shifting sand.

Halimeda monile is associated with sea grasses and Rhipsalian Halimedae.

Geographic distribution. North-western Atlantic, where it is relatively common. Pacific material identified as monile (including Taylor, 1950) has thus far proved to belong to the species cylindracea (Hillis, 1959).

As seen from the preceding list of synonymy this species has had a rather varied taxonomic history since it was first described by Ellis and 
Solander (1786). The earlier synonymy is given by Barton who, in addition to considering monile as a form of incrassata, equated with it cylindracea Decaisne and polydactylis J. Agardh.

Cylindrical segments, which are a characteristic of monile, also occur in other species. The predominance of them in monile, together with the general form of the plants, usually enables this taxon to be identified macroscopically. In doubtful cases, differences in nodal anatomy and in the diameters of the peripheral utricles, the latter averaging $46 \mu \mathrm{m}$ in monile and $73 \mu \mathrm{m}$ in incrassata, are diagnostic. The somewhat modified pattern of the nodal filaments in monile was discussed in Section III.

\section{Halimeda cylindracea Decaisne}

Figures 4, 5, 104.

Halimeda cylindracea Decaisne (1842), p. 103; Hillis (1959), p. 373, Plates 4-7, 12.

Halimeda polydactylis J. Agardh (1887), p. 89.

Halimeda incrassata Harvey (1860), p. 125 p.p. including Plate 125.

Halimeda incrassata f. monilis Barton (1901), p. 27 p.p. including Plate 4,

Fig. 40.

Plants erect, elongate, usually attenuated from base to apex, to $19 \mathrm{~cm}$ tall excluding the holdfast which may extend to over $12 \mathrm{~cm}$ in length; branching restricted, mainly ditrichotomous; basal segments cask-shaped, to $7 \mathrm{~mm}$ long, $12 \mathrm{~mm}$ broad and averaging $3-4 \mathrm{~mm}$ in thickness, forming a distinct terete or subterete stalk with the lower forkings often becoming consolidated laterally to form a fan-shaped structure in older plants; branch segments subcuneate with lobed upper margins, others generally plane and predominantly cylindrical, although at times becoming subspherical towards the plant apex, to $7 \mathrm{~mm}$ long, $4 \mathrm{~mm}$ broad and averaging $1.5 \mu \mathrm{m}$ in thickness.

Cortex of three to five layers of utricles; outermost utricles tending to separate on decalcification, their lateral and peripheral walls sometimes thickened, 17-45(-55) $\mu \mathrm{m}$ in surface diameter, 24-62 $\mu \mathrm{m}$ long in section, two or four supported by each secondary utricle; secondary utricles 17-62 $\mu \mathrm{m}$ broad, 23-80(-100) $\mu \mathrm{m}$ long; tertiary utricles 30-90 $\mu \mathrm{m}$ broad.

Nodal medullary filaments uniting as a single group for a distance of approximately 34-72 $\mu \mathrm{m}$, the adjacent filaments communicating by pores; walls in this region thickened and pigmented.

\section{Type specimen. Madagascar, Nossi-Bé, Pervillé (PC).}

Habitat. Grows in unconsolidated substrate, but its holdfast, which is sometimes massive, is frequently attached to one or more fragments of buried broken coral or rock; from about $-0.3 \mathrm{~m}$ to 
at least $-58 \mathrm{~m}$. At Enewetak Atoll it is sometimes associated with stuposa, and of three Rhipsalian Halimedae present (incrassata, stuposa and cylindracea), it was the commonest and grew in the least exposed habitats. At Enewetak it was commoner in sandy regions near coral patches than in open stretches of sand. This distributional pattern may partly result from bioturbation.

Geographic distribution. Western Indian Ocean, western Pacific, both north and south.

\section{Halimeda stuposa Taylor}

Figure 25.

Halimeda stuposa Taylor (1950), p. 90, Plate 43, Fig. 1; Plate 49; Plate 50, Fig. 2; Hillis (1959), p. 374, Plates 3, 5-7, 11.

Plants erect, rather small, thick-set, compact, to $10 \mathrm{~cm}$ tall excluding the holdfast which is often massive, this generally extending to $5 \mathrm{~cm}$ in length but on occasion to $13 \mathrm{~cm}$; calcification moderate; branching mainly ditrichotomous; basal segments subcuneate or compressed-cylindrical, often forming a stipe or else consolidating laterally with adjacent segments to form a short trunk-like structure; other segments plane or occasionally ribbed; subcylindrical or cylindrical, at times becoming subspherical towards the apex, the upper margins entire to slightly lobed, to $7 \mathrm{~mm}$ long, $11 \mathrm{~mm}$ broad and averaging $2 \mathrm{~mm}$ in thickness.

Cortex of three to five layers of utricles; outermost utricles separating slightly on decalcification or remaining attached for an average distance of $4 \mu \mathrm{m}$, their lateral and peripheral margins usually thickened, $21-48(-55) \mu \mathrm{m}$ in surface diameter, 50-80(-100) $\mu \mathrm{m}$ long in section, two or more commonly four supported by each secondary utricle; secondary utricles (17-)25-50 um broad, (23-)30-90(-125) $\mu \mathrm{m}$ long; tertiary utricles $38-65 \mu \mathrm{m}$ broad.

Nodal medullary filaments uniting as a single group for a distance of approximately $30-50 \mu \mathrm{m}$, the adjacent filaments communicating by pores; walls in this region thickened and pigmented.

Type specimen. Marshall Islands, Rongelap Atoll, Naen Island, Taylor 46-591, 17 July, 1946 (MICH).

Habitat. Grows in sand, mud or other unconsolidated substrate from about low-tide line to at least $-10 \mathrm{~m}$, and sometimes develops extensive stands. In places, it may be partially buried in shifting sand, producing a very long holdfast which requires use of a trowel or knife to extract it completely. Sometimes it is associated with cylindracea. 


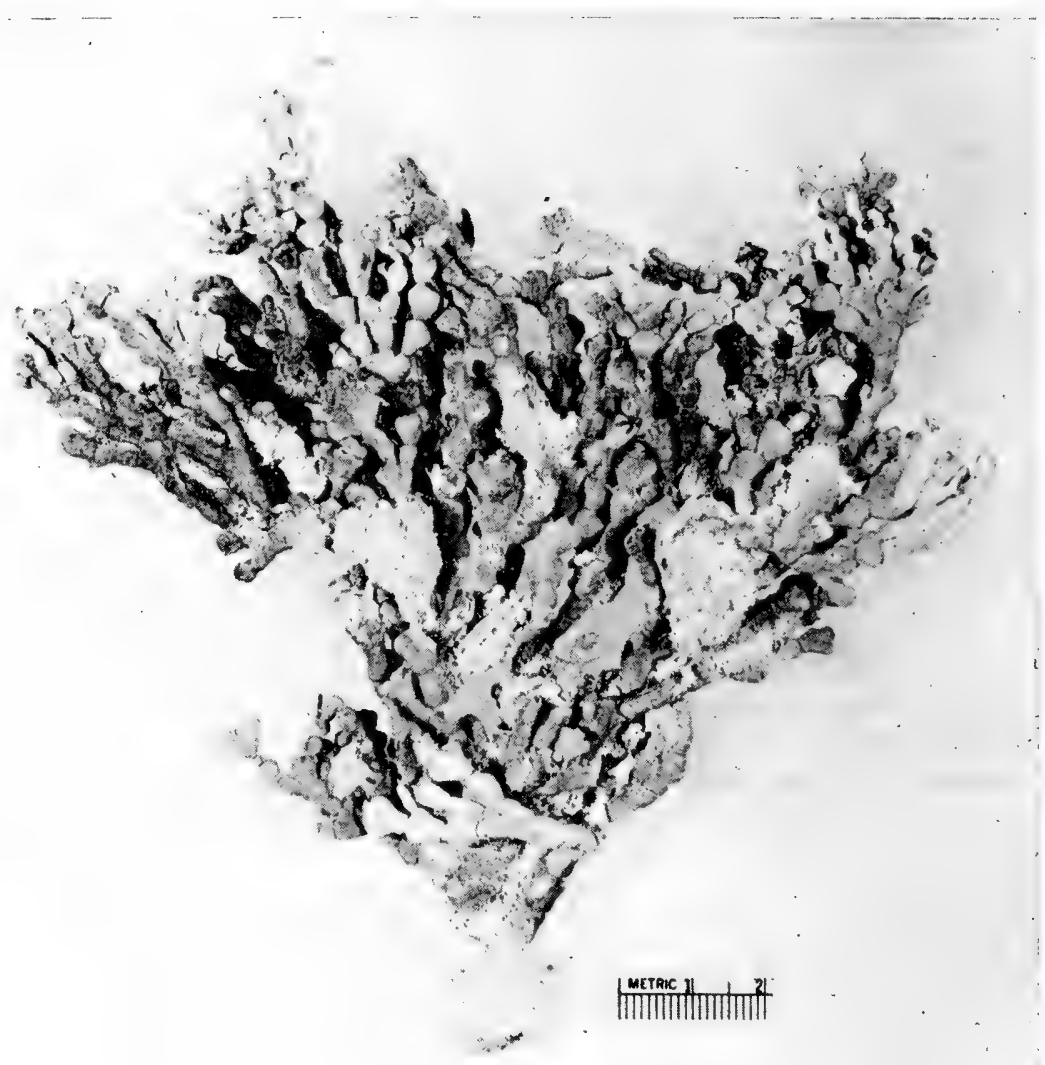

FIG. 25. H. stuposa. Most of the lower half of this specimen was buried by shifting sand in $1-2.5 \mathrm{~m}$ of water, and holdfast filaments are present in the sand masses adhering to the segments. The basal holdfast is not massive as it is in some specimens (e.g. Taylor, 1950), and the thallus branching is less compact. Specimen from Enewetak Atoll, Enjebi Islet, lagoon, 20 XII 75, Hillis-Colinvaux and Colinvaux. Scale bar is $2 \mathrm{~cm}$ long. (Photograph by The Ohio State University Department of Photography.)

Geographic distribution. Western Indian Ocean, western Pacific, north and south.

This Rhipsalian Halimeda at times may resemble monile and certain forms of incrassata, but can usually be identified macroscopically by its short, rather thick-set appearance, the thickness of the segments averaging $2 \mathrm{~mm}$. Also characteristic are the relative infrequence of deeply trilobed segments, and the presence of relatively short 
cylindrical ones, the lengths of which rarely exceed twice the diameter, unlike similar segments in monile and cylindracea which, in general, are at least four times as long as broad.

Histologically, the thickened walls of the peripheral utricles of stuposa are generally fairly conspicuous in mature segments, particularly as viewed from the surface. This thickening is extremely well developed in basal segments where the utricles usually separate on decalcification. Towards the plant apex the induration is less pronounced and the utricles remain more firmly attached after decalcification. Although such thickening may occur in other species, particularly in basal segments, it is generally not as constant a feature as in stuposa.

\section{Halimeda simulans Howe}

Figure 26.

Halimeda simulans Howe (1907), p. 503, Plate 29; Collins (1909-1918), p. 401; Taylor (1928), p. 84, Plate 10, Fig. 12; Plate 11, Figs 18-19; Hillis (1959), p. 368, Plates 3, 5, 6, 11.

Halimeda incrassata v. simulans Børgesen (1911), p. 144, Fig. 11; Børgesen (1913), p. 114, Fig. 92.

Plants erect, compact, forming cushion-like clumps, to $12 \mathrm{~cm}$ tall excluding the holdfast region which may extend to $4 \mathrm{~cm}$; calcification moderately heavy; branching complanate, frequent, mainly di- to tetrachotomous; stalk region sometimes moderately well developed, resulting from the fusion of small adjacent segments, more commonly short and rather inconspicuous, of two to three cylindrical to subcuneate or at times reniform segments, the upper one supporting several subcuneate segments which often have an imbricated arrangement; other segments frequently ribbed, occasionally cylindrical but more commonly subcuneate to reniform, the outer margin entire, undulating or shallowly lobed, to $11 \mathrm{~mm}$ long, $15 \mathrm{~mm}$ broad, and averaging $0.75-1.00 \mathrm{~mm}$ in thickness.

Cortex of two to four layers of utricles with a fifth zone occasionally present; outermost utricles generally remaining attached after decalcification for an average distance of $7 \mu \mathrm{m},(26-) 31-60 \mu \mathrm{m}$ in surface diameter, $30-60(-90) \mu \mathrm{m}$ long in section, two or four supported by each secondary utricle; secondary utricles 25-60(-78) $\mu \mathrm{m}$ broad, 28-70(-110) $\mu \mathrm{m}$ long; innermost utricles (34-)40-90 $\mu \mathrm{m}$ broad.

Nodal medullary filaments uniting as a single group for a distance of approximately $25-55 \mu \mathrm{m}$, the adjacent filaments communicating by pores; walls in this region thickened and pigmented.

Type specimen. Puerto Rico, Culebra Island, Howe 4332, 6 March, 1906 (NY). 


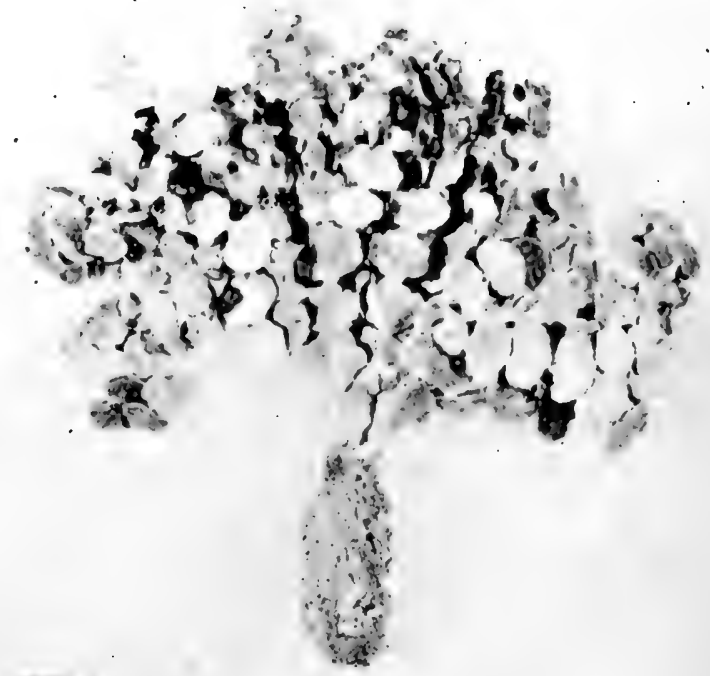

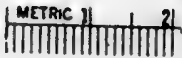

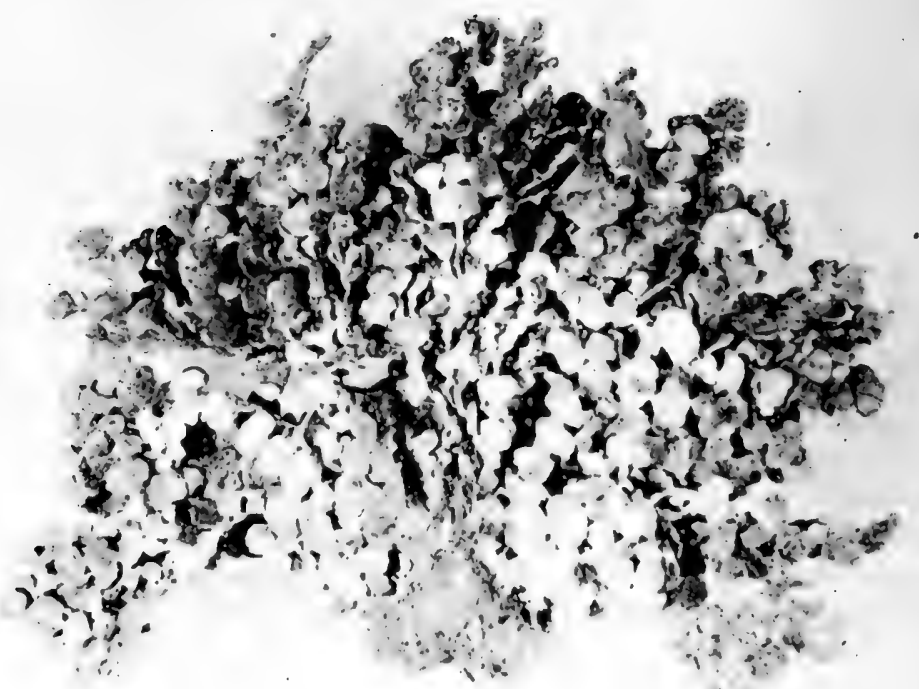

FtG. 26. H. simulans. Imbricated arrangement of suprabasal segments is most readily seen in top plant. Specimens from less than $3 \mathrm{~m}$ depth, Jamaica, Sombra (smaller plant), and Runaway Bay, Spanish Cove (larger plant), IX 1967, Hillis-Colinvaux and Colinvaux. Scale bar is $2 \mathrm{~cm}$ long. (Photograph by The Ohio State University Department of Photography.) 
Habitat. Grows in sand, mud or other unconsolidated substrate, from about -0.3 to $-75 \mathrm{~m}$, but is comparatively uncommon at the extreme depths. Halimeda simulans may be associated with monile in the Caribbean but is more commonly found in patches of incrassata. In the laboratory it sometimes can be initially mistaken for incrassata (see below), but in the reef it often seems fairly distinct, and sometimes can be readily spotted from above, by noting the rounder thalli in patches of Rhipsalian Halimedae. These individuals are generally simulans, since thalli of incrassata tend to have a more linear appearance. Relatively large populations of simulans may occur, or it may be present as a few thalli at the edge of a grove of incrassata.

Geographic distribution. Eastern Indian Ocean, north-western Pacific, north and south in the western Atlantic including Bermuda. It is best known from the Caribbean.

This species often may be distinguished from incrassata macroscopically by its substipitate or occasionally stipitate habit with basal segments of the lowermost branches commonly imbricated. Other distinguishing characteristics are the predominantly greenish-cream, reniform or slightly trilobed segments, and the smaller diameters of the peripheral utricles which average $45 \mu \mathrm{m}$ in simulans as compared to $73 \mu \mathrm{m}$ in incrassata. In incrassata the peripheral utricles adhere more firmly, whereas in simulans the corners often appear slightly rounded in surface view, the utricles nevertheless usually remaining attached. The pores between adjacent nodal medullary filaments in simulans at times may be relatively small and consequently not particularly conspicuous in longitudinal sections. Their presence then is more easily demonstrated by transverse section through the node.

The reniform segments of this species sometimes lead to confusion with tuna from which it is entirely distinct microscopically. Characteristics of habit, segment colour, the tendency for segments to be lobed in simulans rather than entire as in tuna, and particularly the presence of a more extensive holdfast with adhering particles of fine substrate distinguish these two species macroscopically.

\section{Halimeda borneensis W. R. Taylor}

Figure 27.

Halimeda borneensis Taylor (1975), p. 81, Figs 1, 2.

Plants erect, compact and rather small, to $12 \mathrm{~cm}$ broad and $7 \mathrm{~cm}$ tall excluding the holdfast region which may extend to $3 \mathrm{~cm}$ in length; bașal or 
suprabasal segment fan-shaped, at times small, but also to $12 \mathrm{~mm}$ long, $20 \mathrm{~mm}$ broad, bearing a few to eight or more branching series of segments which tend to lie flat; other segments to about $12 \mathrm{~cm}$ long, $16 \mathrm{~cm}$ broad, ovate to reniform, their bases often a little contracted, the distal margins entire to frequently slightly three to seven crenate, to $12 \mathrm{~mm}$ long, $17 \mathrm{~mm}$ broad.

Cortex of three or more series of utricles; outermost utricles remaining attached after decalcification often by a very thin extension of the utricle, or separating slightly, 22-69 $\mu \mathrm{m}$ in surface diameter, two or four supported by each secondary utricle; secondary utricles of approximately the same diameter as the peripheral utricles, and two to seven times as long.

Nodal medullary filaments uniting as a single group for a distance about equal to the filament width, adjacent filaments communicating by pores; walls in the region thickened and pigmented.

Type specimen. North Borneo, Pulau Gaya off the east coast, Cleland, Station 10, 5 February, 1965 (MICH).

Habitat. Grows on unconsolidated substrates, in shallow water. The extent of its vertical range is, at present, not known.

Geographic distribution. South-western Pacific.

The Rhipsalian Halimeda this species most closely resembles is simulans. Although few samples of borneensis are presently available for an extensive evaluation of characters, the following comparisons can be made. The basal or suprabasal segment in borneensis is generally conspicuously broad, and the other segments often both broader and more reniform than those of simulans. The general appearance of borneensis is of a somewhat squatter, more heavy-set plant.

Microscopic differences include the peripheral utricles being somewhat larger and less firmly joined laterally in borneensis as compared to simulans. In addition, the secondary utricles of borneensis are generally longer, sometimes considerably more so, than those of simulans.

Halimeda borneensis is not known from the Atlantic where simulans is common, but there may be some overlap of ranges in the IndoPacific.

At times the species borneensis and macroloba could be confused, at least initially, and more data are needed on geographic and reef distribution to know the extent of overlap in their ranges. Differences between these two species are discussed under macroloba.

Both the habitat and habit of borneensis are distinctly different from those of micronesica, a species to which Taylor (1975) compared it, although there is a similarity in the especially large basal or suprabasal fan-shaped segments of the two. 


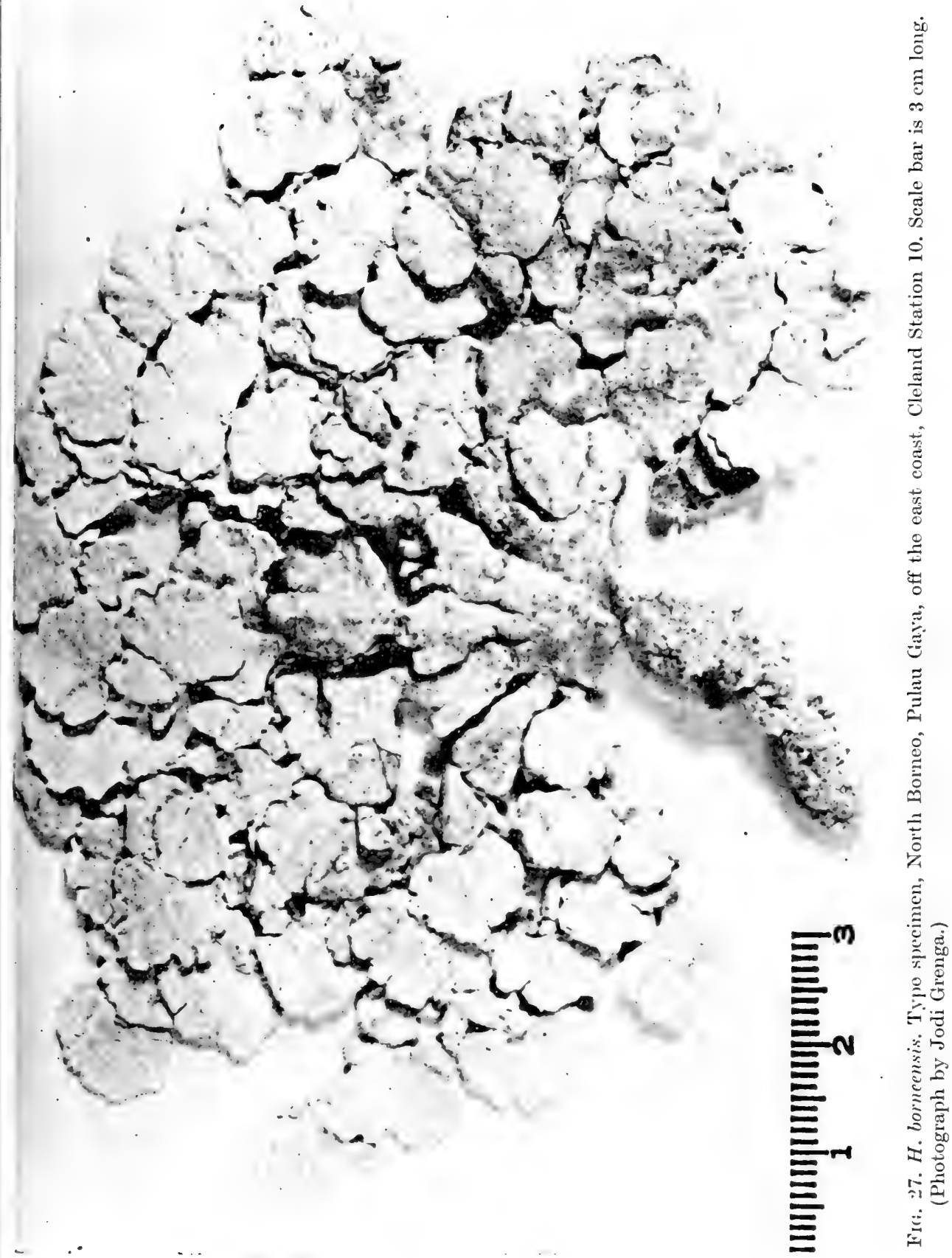


The limited nodal material of borneensis I have been able to examine showed firm fusion of all the medullary filaments into a single unit for a short distance with well-developed pores. I did not find the filaments to separate more readily than in other Rhipsalian species, although Taylor (1975) reported a very light fusion, with filaments separating easily.

\section{Halimeda macroloba Decaisne}

Figure 28.

Halimeda macroloba Decaisne (1841), p. 118; Decaisne (1842), p. 91; Barton (1901), p. 24, Plate 3, Figs 33-38; Hillis (1959), p. 375, Plates 3, 5, 6, 12. Halimeda macroloba v. ecalcarea Weber-van Bosse (1926), p. 88.

Plants erect, flat or somewhat bushy, to $23 \mathrm{~cm}$ tall excluding the holdfast which is usually well developed and may extend to $5 \mathrm{~cm}$ in length; calcification moderate to rather light; branching relatively sparse, mainly ditrichotomous but often becoming polychotomous in the basal region; basal segments commonly compressed-cylindrical to trapezoidal, of a somewhat stipitate nature and supporting several segments which may remain separate or consolidate laterally, either entirely or in part, to form a fan-shaped unit which may lie flat or become somewhat undulated or folded; other segments plane or slightly ribbed, at times compressed-cylindrical but more commonly subcuneate, discoidal or subreniform, the upper margin entire, undulating or occasionally somewhat lobed, to $29 \mathrm{~mm}$ long, $40 \mathrm{~mm}$ broad and averaging $1 \mathrm{~mm}$ in thickness.

Cortex occasionally of two, but more commonly of three to four layers of utricles; outermost utricles separating on decalcification or remaining slightly attached, their lateral and peripheral margins occasionally thickened, 23-49 $\mu \mathrm{m}$ in surface diameter, (46-)62-110(-144) $\mu \mathrm{m}$ long in section, usually four or occasionally two supported by each secondary utricle; secondary utricles $20-58(-68) \mu \mathrm{m}$ broad, (30-)40-80(-140) $\mu \mathrm{m}$ long; tertiary utricles $36-90(-110) \mu \mathrm{m}$ broad.

Nodal medullary filaments uniting as a single group for a distance of approximately $44-80(-115) \mu \mathrm{m}$, the adjacent filaments communicating by pores; walls in this region thickened and pigmented.

Type specimen. Red Sea, Schimper 871, 1837; isotype material in several herbaria including the British Museum (Natural History) and the New York Botanical Garden.

Habitat. Grows in mud or other unconsolidated substrate, from above low-tide line to $-12 \mathrm{~m}$, sometimes developing extensive stands in the shallows. Its holdfast may also be associated with bits of coral rock and is then smaller. It often grows in the quiet waters 

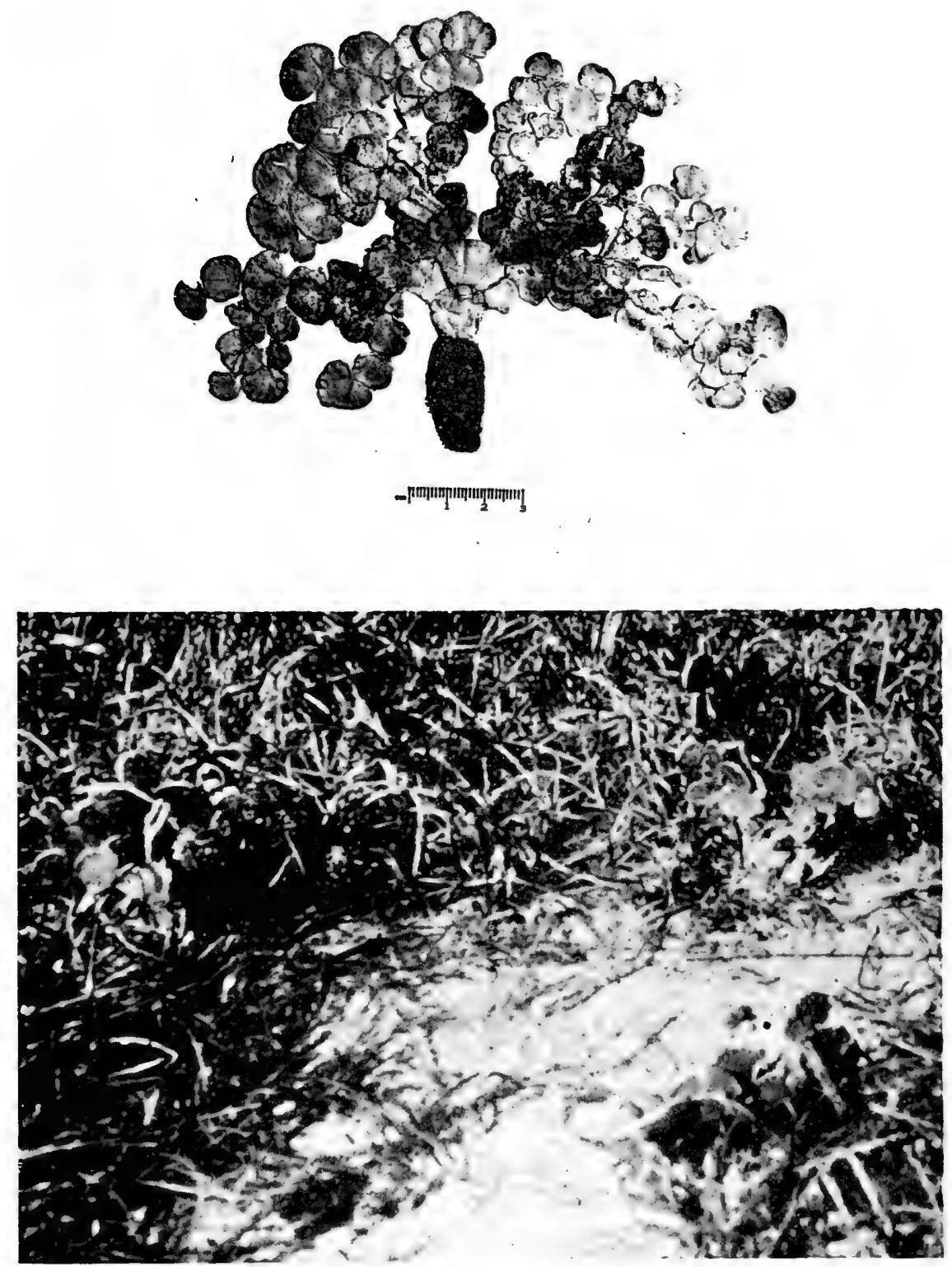

FIG. 28. H. macroloba. (Top) Specimen from Kenya, Malindi, on the reef flat, 4 IV 66, Isaac 2972. (Photograph by Jodi Grenga.) (Bottom) A grove of macroloba exposed at low tide, Nuku Alofa, Tonga, April. (Photograph by R. Lewin, reproduced with permission.) 
associated with mangroves, and is associated with sea grasses and species of Avrainvillea, Udotea and sometimes with $H$. opuntia.

This is a well-known species of which many collections have been made. Hence, although it may grow somewhat more deeply than $12 \mathrm{~m}$, it seems reasonable to consider this a species of very shallow to shallow waters, and one often achieving prominence in quiet mangrove waters.

Geographic distribution. Western and eastern Indian Ocean including the Red Sea; western Pacific, both north and south.

This species can usually be distinguished macroscopically from other Rhipsalian Halimedae by its broad, flat segments with distal margins usually very little lobed. These segments are relatively large, to $29 \mathrm{~mm}$ long and $40 \mathrm{~mm}$ broad, although in certain plants they do not exceed $11 \mathrm{~mm}$ in length and $20 \mathrm{~mm}$ in breadth. Histologically, the diameters of the utricles decrease towards the outer surface, those of the peripheral utricles being relatively small.

This species is at times confused with discoidea and taenicola, two members of section Halimeda. Although doubtful specimens can be readily identified on histological grounds, macroscopic criteria are usually adequate. These include the extent of development of the holdfast region, the general appearance of the basal part of the plant, and the size and appearance of the segments. In discoidea and taenicola, large segments, although often present, usually do not account for $50 \%$ or more of the segments as they often do in macroloba.

Of the Rhipsalian species, macroloba is most likely to be confused with borneensis because they both have relatively large, broad segments. In general, those of macroloba has a less-lobed distal margin and are larger. The mature thallus of macroloba is also larger than that of borneensis, and it lacks the distinctive fan-shaped basal or suprabasal segment which is characteristic of most thalli of borneensis.

Microscopically, the diameters of the peripheral utricles of borneensis tend to be somewhat larger than those of macroloba, and these utricles adhere, at least in some material, somewhat more firmly to each other. The secondary utricles of borneensis also tend to be longer than those of macroloba.

\section{Section Opuntia J. Ag. ex De Toni}

\section{Halimeda opuntia (Linnaeus) Lamouroux}

Figures 19, 51, 92.

Corallina opuntia Linnaeus (1758), p. 805 p.p. 
Halimedea opuntia Lamouroux (1812), p. 186; Halimeda opuntia Barton (1901), p. 18, Plate 2, Figs 19-27; Collins (1909-1918), p. 400, Plate 17, Fig. 156; Taylor (1928), p. 82; Taylor (1950), p. 80, Plate 39, Fig. 1; Egerod (1952), p. 397, Plate 37, Figs 19a, e, f; Hillis (1959), p. 359, Plates 2, 5-7, 10.

Halimeda multicaulis (Lamarck) Lamouroux (1816), p. 307. Flabellaria multicaulis Lamarck (1813), p. 302.

Halimeda opuntia f. typica Barton (1901), p. 20, Plate 2, Fig. 19; Taylor (1928), p. 83, Plate 10, Figs 5-7, Plate 11, Fig. 17.

Halimeda opuntia f. cordata (J. Agardh) Barton (1901), p. 20, Plate 2, Fig. 21. Halimeda cordata J. Agardh (1887), p. 83.

Halimeda opuntia f. triloba (Decaisne) Barton (1901), p. 20, Plate 2, Fig. 20;

Taylor (1928), p. 83, Plate 10, Fig. 2; Taylor (1950), p. 81, Plate 40,

Fig. 2. Halimeda triloba Decaisne (1842), p. 102.

Plants compact or sprawling, often with both lateral and erect systems of growth, holdfast region not restricted to the initial area but diffuse, with patches of rhizoids occurring at intervals where the plant comes in contact with the substratum, to $1 \mathrm{~m}$ or more in length; calcification moderate to heavy; branches sometimes few but often numerous, arising in more than one plane from successive segments; segments extremely variable, flat or somewhat contorted, and frequently ribbed, cylindrical or oblong to auriculate, the upper margin entire, undulate or lobed, to $7 \mathrm{~mm}$ long, $11 \mathrm{~mm}$ broad, averaging $0 \cdot 3-0.5 \mathrm{~mm}$ in thickness, with the occasional larger segment.

Cortex of up to five layers of utricles formed by dichotomies in the lateral branches of the medullary filaments (that is, not utriculiform); outermost utricles adhering slightly after decalcification or for as much as $6 \mu \mathrm{m}$, appearing somewhat rounded or hexagonal in surface view, 12-41 $\mu \mathrm{m}$ in surface diameter, $15-39(-50) \mu \mathrm{m}$ long in section; secondary utricles 11-35 $\mu \mathrm{m}$ broad.

Nodal medullary filaments uniting most commonly in pairs for a distance of approximately 1.5 times the filament diameter, occasionally fusing in threes but rarely in fours, seldom remaining separate; adjacent fused units free or laterally attached for up to $25 \mu \mathrm{m}$.

\section{Type locality. Jamaica.}

Habitat. This species sprawls over rock surfaces, fills crevices, and produces ropes of thallus which grow at the bases of rocks or sometimes traverse patches of sand, with attachment provided by a multi-holdfast system. In water of about $0.3-0.5 \mathrm{~m}$ this species sometimes provides about $90 \%$ cover of rock surfaces.

In deeper water it may be associated with $H$. goreauii. It also grows as clumps on Acropora.

It is known from close to the surface to $-90 \mathrm{~m}$. 
Geographic distribution. Pantropical; western and eastern Indian Ocean including Red Sea; western Pacific both north and south; north-eastern Pacific; western Atlantic, both north and south. Not in Bermuda.

Special features of the thallus of this species include segments with a wide range of shapes, the occasional termination of a branch with rhizoidal rope-like strands rather than segments, a feature also of a few other species particularly micronesica, and the development in certain specimens of two fairly dissimilar growth systems, an upright (cushion) pattern and a spreading (axial) pattern. Of these, the spreading system, which is somewhat loosely organized and composed of cylindrical and deeply trilobed segments or occasionally subcuneate ones, often produces discrete clumps of intense erect growth at intervals, in which flat, relatively broad segments with entire slightly lobed margins are often the most common.

\section{Halimeda goreauii W. R. Taylor}

Figure 29.

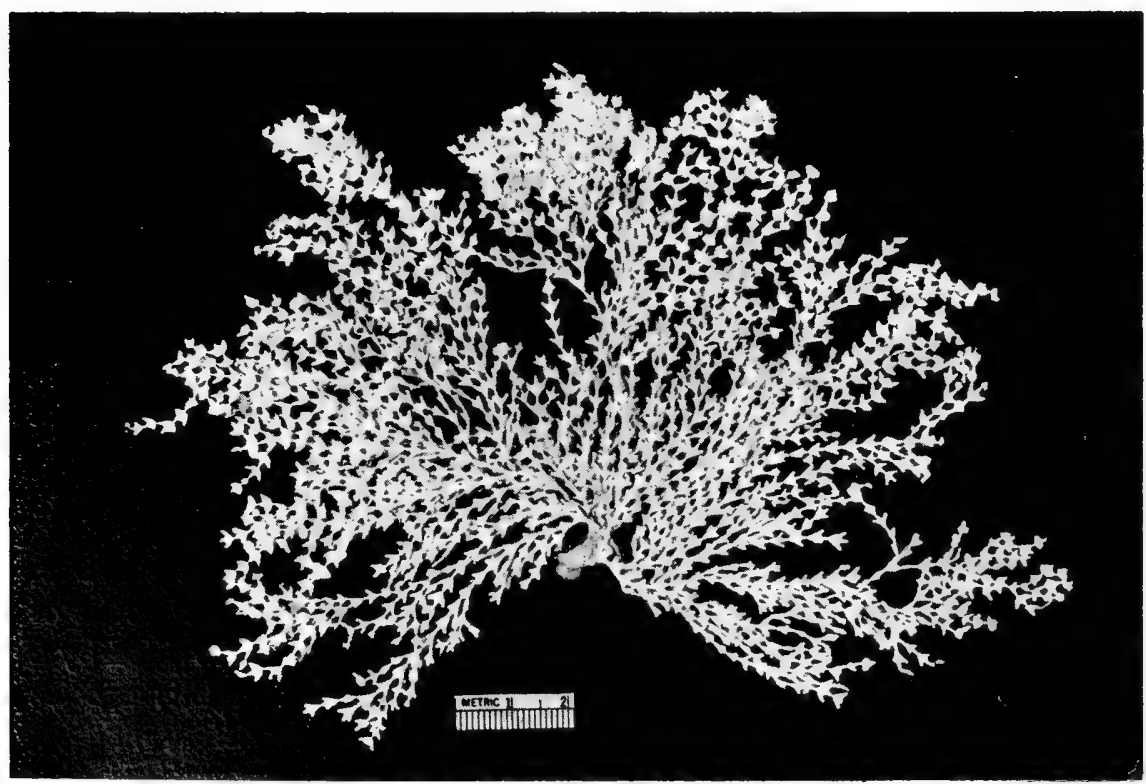

FIG. 29. H. goreauii. Isotype specimen, Jamaica, St Ann Parish, reef off Cardiff Hall beach at about $-30 \mathrm{~m}$, T. F. Goreau et al. 3337 . Scale bar is $2 \mathrm{~cm}$. (Photograph by The Ohio State University Department of Photography.) 
Halimeda goreauii Taylor (1962), p. 173, Figs 1-7.

Halimeda opuntia f. minor Vickers (1905), p. 57; Taylor (1928), p. 83, Plate 10.

Plants at least to $13 \mathrm{~cm}$ tall from a small stupose base, simple below, a few of the lower segments subterete, above abundantly loosely branched, with branches lying essentially in a plane; segments at the bases of the lower branches subterete to subcuneate, those above and in all the upper branching deltoid to most characteristically strongly trilobed, the lobes terete in the central parts of the plant, more flattened above, the segment faces shiny, often slightly ribbed, the margins minutely erose, in length $2 \cdot 5-4 \cdot 0 \mathrm{~mm}$, in width $2 \cdot 5-5 \cdot 0 \mathrm{~mm}$, the upper segments generally wider in proportion than the lower ones.

Cortex generally of three or more series of utricles, not utriculiform; peripheral utricles remaining attached for a distance of up to $5 \mu \mathrm{m}$, appearing somewhat rounded or hexagonal in surface view, (12-)16-37 $\mu \mathrm{m}$ in surface diameter, (12-)17-40 $\mu \mathrm{m}$ long in section; secondary utricles 10-30 $\mu \mathrm{m}$ broad.

Nodal medullary filaments uniting in pairs for a distance of approximately 1.5 times the filament diameter, at times adhering strongly with other pairs.

A separate form has been described.

\section{f. compacta W. R. Taylor}

Halimeda goreauii f. compacta Taylor (1962), p. 174.

Plants to $4 \mathrm{~cm}$ tall, short stalked and very densely branched, the upper segments a little smaller and less sharply trilobed than in typical plants.

Type specimens. For $H$. goreauii f. goreauii Jamaica, St Ann Parish, reef off Cardiff Hall beach at about $-30 \mathrm{~m}, \mathrm{~T}$. F. Goreau et al. 3337, 21 July, 1961; for f. compacta Jamaica, St Ann Parish, Llandovery, on the reef sill at $-33 \mathrm{~m}$ to $-57 \mathrm{~m}$, T. F. Goreau A3362, 31 December, 1960. Both in Museum of Science, Institute of Jamaica (isotypes MICH).

Habitat. Growing attached to rocks from near low-tide line to $-65 \mathrm{~m}$ or more, in places associated with $H$. opuntia.

Geographic distribution. Western Atlantic.

\section{Halimeda minima (W. R. Taylor) Colinvaux}

Figure 30.

Halimeda minima (W. R. Taylor) Colinvaux (1968a), p. 32, Figs 5, 6.

Halimeda opuntia f. minima Taylor (1950), p. 82, Plate 39, Fig. 2. 


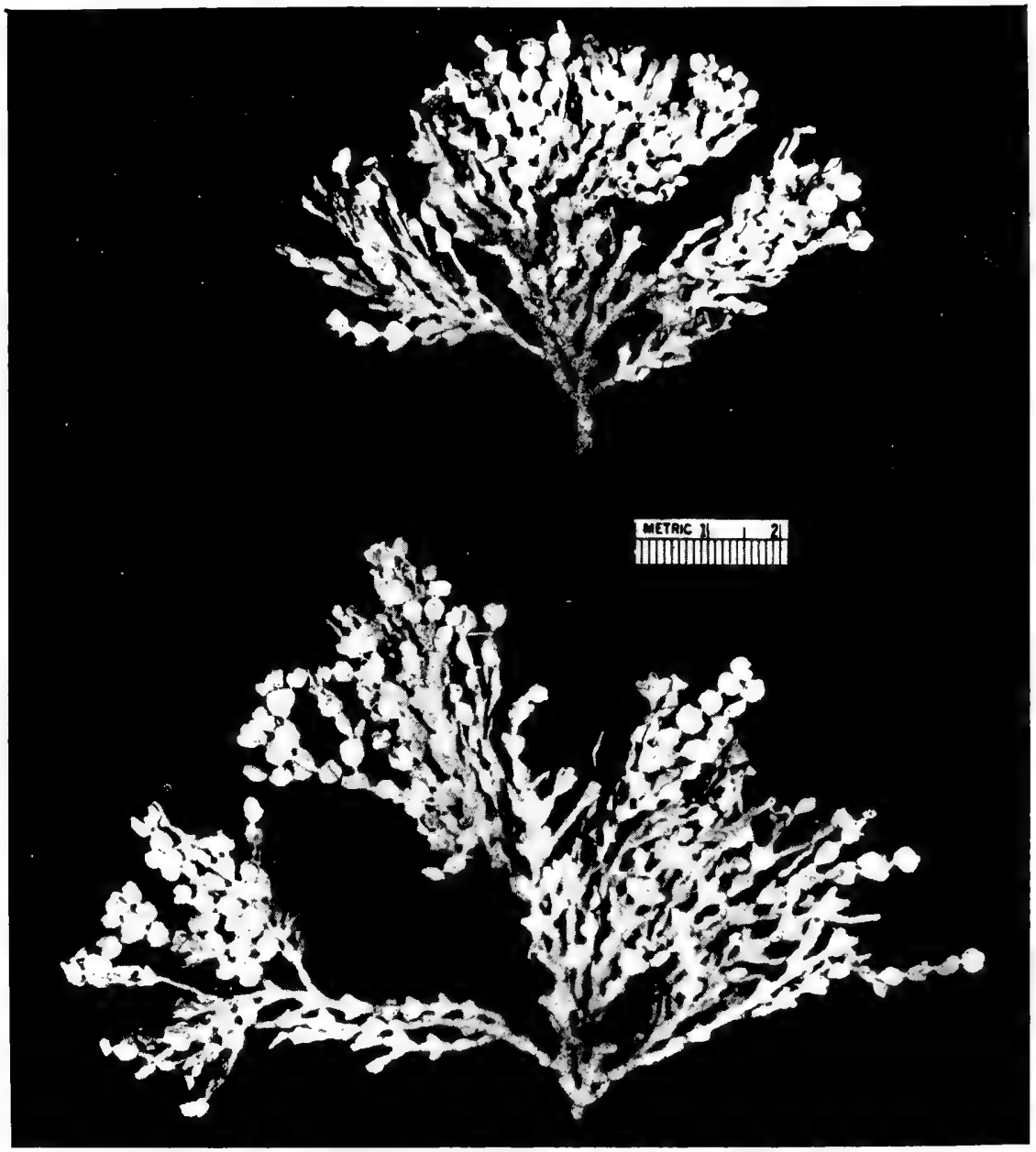

FIG. 30. H. minima. Small holdfast is present on upper specimen. Material from Enewetak Atoll, Enewetak Islet, Quarry, 4 XII 75, Hillis-Colinvaux. Scale bar is $2 \mathrm{~cm}$. (Photograph by The Ohio State University Department of Photography.)

Plants to at least $9 \mathrm{~cm}$ tall, usually bushy, from a single tiny holdfast although at least occasionally there may be additional points of attachment; calcification moderate to heavy; branching in a single plane except possibly near the base, most commonly trichotomous, less commonly dichotomous; segments may be brittle and glossy, hardly ribbed, frequently trilobed in the lower half of the plant, trilobed to flattened-cylindrical to cylindrical in the upper half, trilobed segments to $5 \mathrm{~mm}$ long and $4.5 \mathrm{~mm}$ wide, others to $4 \mathrm{~mm}$ long and $3 \mathrm{~mm}$ wide. 
Cortex of up to four series of utricles with inner ones usually not utriculiform; outermost utricles generally adhering slightly after decalcification, in surface view most commonly polygonal although occasionally somewhat rounded with a covering lamella (Section I) sometimes evident, diameter in surface view 14-30(-39) $\mu \mathrm{m}$, in section 14-32 $\mu \mathrm{m}$ long, more than four supported by each secondary utricle; secondary utricles 10-18(-25) $\mu \mathrm{m}$ broad.

Medullary filaments numerous in mature segments, most commonly united at the node in pairs or sometimes in threes for $(52-) 56-75(-87) \mu \mathrm{m}$, occasionally completely separate; nodal units sometimes adhering slightly.

Type specimen. Marshall Islands, Bikini Atoll, Bikini Lagoon, dredged at $-55 \mathrm{~m}, \mathrm{~W}$. R. Taylor 46-108, 29 March, 1946 (MICH; isotypes in $\mathrm{C}, \mathrm{L}, \mathrm{PC}$ ).

Habitat. Known from $-1 \mathrm{~m}$ low tide to $-55 \mathrm{~m}$. At the shallowest depths it grows erect on shallow ledges of coral rock, appearing like a miniature bush. Sometimes growing in the vicinity are $H$. distorta, $H$. gracilis and $H$. macrophysa.

Geographic distribution. Northern Pacific Ocean.

In a re-evaluation of some of the entities assigned to opuntia, this and two other species were separated out by Colinvaux (1968a). A discussion of characters is provided in that paper.

\section{Halimeda renschii Hauck}

Figure 31.

Halimeda renschii Hauck (1886), p. 167; Hillis-Colinvaux (1975), p. 93.

Halimeda batanensis W. R. Taylor (1973), p. 34.

Halimeda opuntia f. renschii (Hauck) Barton (1901), p. 21, Plate 2.

Plants compact, erect or somewhat repent, to $8 \mathrm{~cm}$ tall, from a nondiscrete base of matted filaments and sometimes loose particles of substrate which may exceed $1 \mathrm{~cm}$ in largest dimension, but is not bulbous as in typical Rhipsalian species; branching tending to produce a flat (plane) thallus; lower segments of thallus may be obscured by the matted base, segments commonly obtrianglar but sometimes transversely oval towards the apex particularly in Pacific specimens, flat or faintly ribbed, to $4 \mathrm{~mm}$ long, $5 \mathrm{~mm}$ broad.

Cortex of three or more series of utricles formed by dichotomies of the lateral branches of the medullary filaments and hence not particularly utriculiform; outermost utricles adhering only slightly and sometimes separating after decalcification, polygonal, but sometimes rounded with a covering lamella sometimes present, (11-)15-28(-38) $\mu \mathrm{m}$ in surface diameter, $20-33 \mu \mathrm{m}$ long in section; secondary utricles 14.8-22 $\mu \mathrm{m}$ broad. 


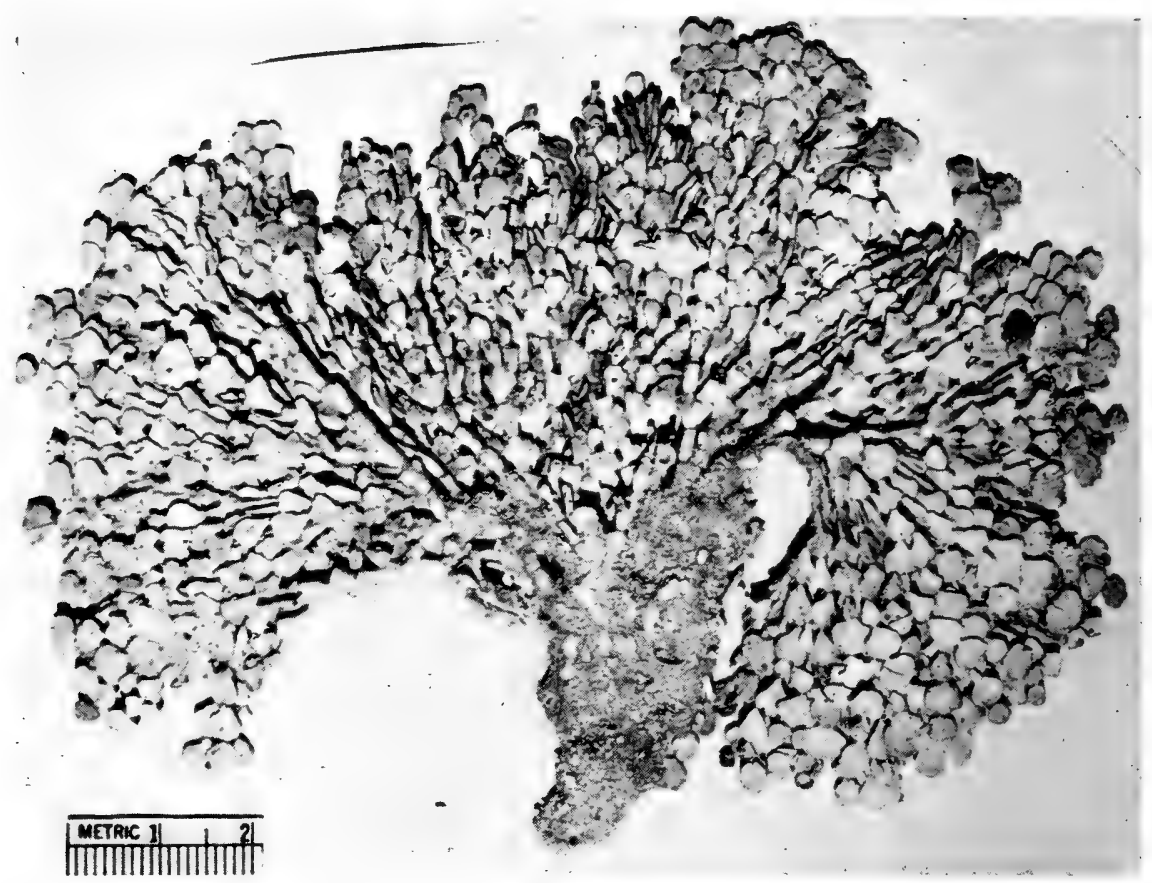

FIG. 31. H. renschii. Basal portion of specimen is extensively matted. Specimen from

Kenya, Diani, Isaac 3193. Scale bar is $2 \mathrm{~cm}$. (Photograph from Hillis-Colinvaux, 1975.)

Nodal medullary filaments uniting in pairs for a distance of $1-1.5$ times the filament diameter, sometimes fusing in groups of three, or filaments remaining single.

Lectotype specimen. Comoro Islands, Johannes Island, J. M. Hildebrandt No. 1889 (L), designated by Hillis-Colinvaux (1975); isotype material BM, C, PC, NY. The epithet brevicaulis appears on some of this material, and its use cannot be readily explained for macroscopically and microscopically the specimens so named are the same as renschii. The taxon $H$. renschii is distinct from $H$. brevicaulis from the Bahamas described by Kützing (1858). Some sheets are also labelled with the orthographic variant $H$. reinshcii.

Habitat. Growing in outer reef pools under moderate wave wash, where it forms dense masses (Womersley and Bailey, 1970; Isaac, 1971).

G'cographic distribution. Eastern Indian Ocean; western Pacific both north and south, south-eastern Pacific. 


\section{Halimeda velasquezii W. R. Taylor}

Figure 32.

Halimeda velasquezii W. R. Taylor (1962), p. 176, Figs 8-14.

Halimeda opuntia f. intermedia Yamada (1934), p. 81, Figs 50, 51.

Plants compact, to $7 \mathrm{~cm}$ tall, from a very small stupose base; branching producing a flat (plane) thallus; the lower one to four segments small,

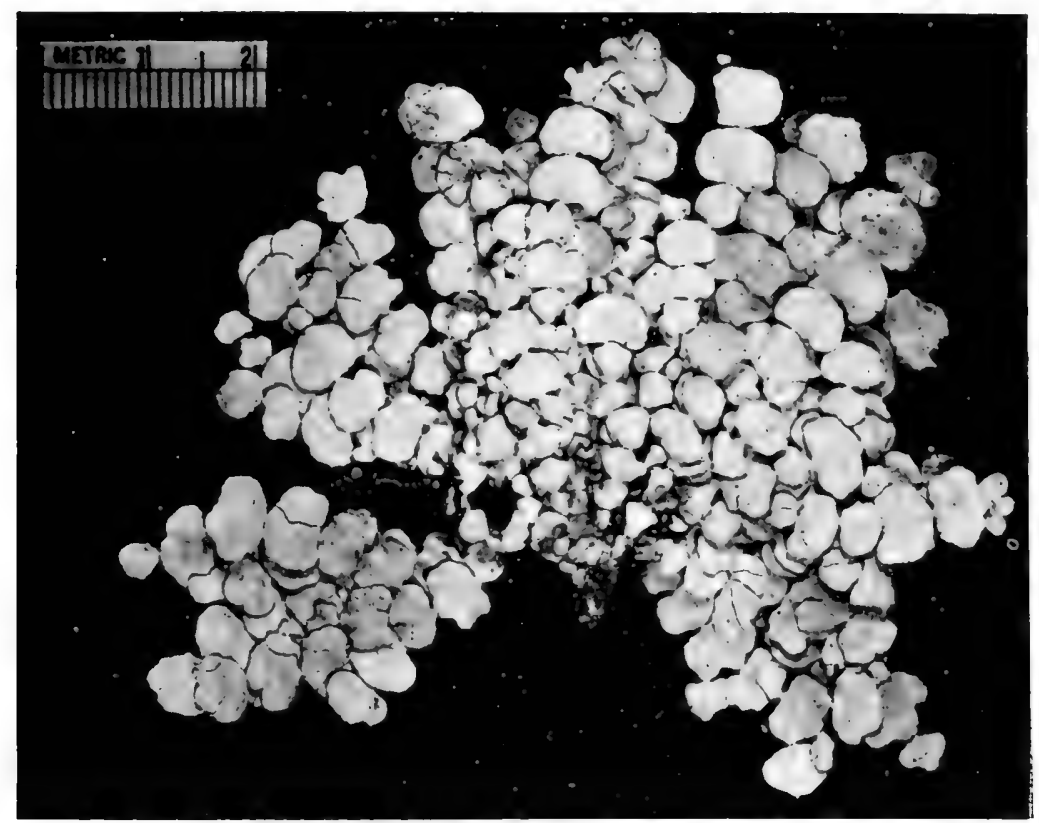

FIG. 32. H. velasquezii. Specimen from Ryuku Island, Waha, Yamada V-1933 = holotype of opuntia $\mathrm{f}$. intermedia. Scale bar is $2 \mathrm{~cm}$. (Photograph by The Ohio State University Department of Photography.)

subterete or compressed, other segments transversely oval to reniform, to $6 \mathrm{~mm}$ long, $11 \mathrm{~mm}$ broad, the margins entire, surface often glossy, sometimes with a faint trace of a midrib.

Cortex of three or more series of utricles formed by dichotomies of the lateral branches of the medullary filaments and hence not particularly utriculiform; outermost utricles adhering only slightly and sometimes separating after decalcification, in surface view round or somewhat compressed, a distinct covering lamella usually present which parts in a polygonal pattern when slight pressure is applied to the utricles; $9-22 \mu \mathrm{m}$ in surface diameter, 15-34 $\mu \mathrm{m}$ long in section; secondary utricles $8.5-15(-22) \mu \mathrm{m}$ broad. 
Nodal medullary filaments uniting in pairs for a distance of 1-1.5 times the filament diameter, also fusing for a short distance in threes, rarely fours, and sometimes remaining single; the fusion units commonly adhering firmly in one or a few groups.

Type specimen. Philippines, Sta. Ana, Prov. Cayagan, Luzon Island, Velasquez 2379, $17 \mathrm{July,} 1950(\mathrm{MICH})$; isotype material at the University of the Philippines.

Habitat. From about $-3 \mathrm{~m}$ to $-100 \mathrm{~m}$. The shallow records are from rock tidepools and surge channels in Guam, both with strong currents (R. Tsuda, personal communication); the deep records were obtained by dredging during the Sealark Expedition, 1905, with specimens housed in the British Museum (Natural History).

Geographic distribution. Western Indian Ocean; western Pacific, both north and south.

\section{Halimeda copiosa Goreau and Graham}

Figures 33, 101.

Halimeda copiosa Goreau and Graham (1967), p. 433, Figs 1-10.

Halimeda hederacea L. H. Colinvaux (1968a), p. 30, Figs 1-3, 6; (1969a), p. 88. Halimeda opuntia f. hederacea Barton (1901), p. 21, Plate 3.

Halimeda opuntia v. hederacea (Barton) Hillis p.p. (1959), p. 360.

Plants to $70 \mathrm{~cm}$ long, loose or compact of habit, from a single holdfast; calcification moderate; branching in a single plane, most commonly dichotomous but also trichotomous; segments commonly one to three ribbed although not strongly so, a "skin" of peripheral utricles sometimes separating from the rest of the cortex when the segment dries; the first two or three segments at the base of the thallus and often the first on a branch small, trilobed, terete or rhombic, other segments transversely oblong to depressed ovate with upper margin entire, three-lobed or crenate, and basal margin truncate to cordate, often forming a short stalk at the nodal junction, to $13 \mathrm{~mm}$ long, $21 \mathrm{~mm}$ broad, and $0 \cdot 3-1 \cdot 0 \mathrm{~mm}$ thick when dried.

Cortex of three to four series of utricles with subperipheral ones usually not utriculiform; outermost utricles adhering firmly for about $\mathbf{1 - 5} \mu \mathrm{m}$; in surface view polygonal with polygons measuring $(22-) 28-46(-64) \mu \mathrm{m}$ in diameter or if only the utricles with hexagonal surface appearance considered then $(27-) 32-46(-64) \mu \mathrm{m}$; in section outermost utricles $(22-) 30-50(-68) \mu \mathrm{m}$ long, not more than four supported by each secondary utricle; secondary utricles (16-)19-30(-45) $\mu \mathrm{m}$ broad.

Medullary filaments numerous in mature segments, most commonly united at the node in pairs, less commonly in threes to sixes, all for a short distance; occasionally fused in pairs for about two to three times this 


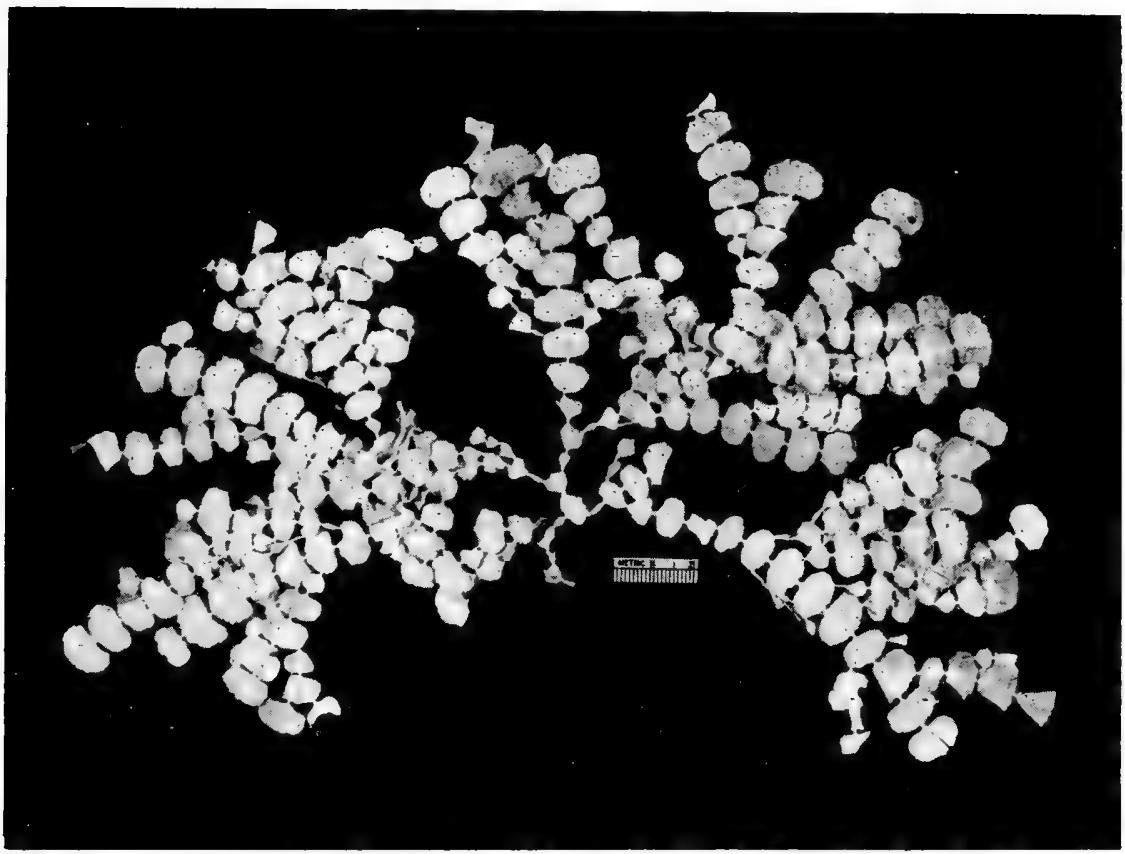

Fig. 33. H. copiosa, from approximately $-37 \mathrm{~m}$ to $-50 \mathrm{~m}$ on rock. Specimen from Jamaica, Maria Buena, 5 V 62, Goreau and Graham. Scale bar is $2 \mathrm{~cm}$. (Photograph by The Ohio State University Department of Photography.)

distance, or completely separate; nodal filaments sometimes adhering slightly to somewhat firmly but usually not much entangled.

Type specimen. Jamaica, Parish of St Ann, Runaway Bay, from $-30 \mathrm{~m}$, Graham and Goreau, 10 April, 1964 (IJ ; isotypes BM, NY, UWI, UM).

One special form has been described.

\section{f. elongata (Barton) L. H. Colinvaux}

Halimeda cuneata v. elongata Barton (1900), p. 480, Plate 18.

Halimeda copiosa f. elongata (Barton) L. H. Colinvaux (1969a), p. 88.

Halimeda opuntia f. elongata (Barton) Barton (1901), p. 21 , Plate 2.

Halimeda hederacea f. elongata (Barton) L. H. Colinvaux (1968a), p. 32, Fig. 2.

Segments predominantly longer than broad, although the two dimensions may be equal; in shape elliptical, rhombic and obtrullate, to $12 \mathrm{~mm}$ long, $10.5 \mathrm{~mm}$ broad. 
Type specimen. Ellice Islands, Funamanu, dredged $-72 \mathrm{~m}$, No. A 54, Funafuti Expedition, 1896-1898 (BM box coll. 196, as $H$. opuntia f. elongata).

Habitat. Attached to rock surfaces where it may grow from between the plates of corals, or as pendant fronds beneath coral overhangs. Its range is from about $-10 \mathrm{~m}$ to $-100 \mathrm{~m}$. In Jamaica it reaches its greatest development on the fore-reef slope (Goreau and Goreau, 1973), and is associated with H. cryptica at this and greater depths. In the lagoon of Enewetak Atoll, it is a common Halimeda of the pinnacles.

Geographic distribution. Western Indian Ocean; western Pacific, both north and south; north-western Atlantic.

\section{Halimeda distorta (Yamada) L. H. Colinvaux}

Figure 34 .

Halimeda distorta L. H. Colinvaux (1968a), p. 33, Figs 4, 6.

Halimeda incrassata f. distorta Yamada (1941), p. 119, Fig. p. 120; Yamada (1944), p. 28, Plate 4.

Halimeda opuntia v. hederacea (Barton) Hillis p.p. (1959), p. 360.

Plants to at least $26 \mathrm{~cm}$ long, sometimes bushy, with prostrate and erect portions and a diffuse holdfast region (i.e. not restricted to single basal region); calcification heavy; branching in more than one plane from successive segments, usually di- and trichotomous; segments often ribbed, sometimes keeled, very commonly contorted, brittle; segment shape commonly broadly ovate to discoidal, the lower margins truncate to auriculate and sometimes somewhat cuneate, upper margins smooth to moderately lobed; segments to $16 \mathrm{~mm}$ long, $19 \mathrm{~mm}$ wide.

Cortex of up to several series of utricles with inner ones usually not utriculiform; outermost utricles attached but slightly after decalcification, frequently tending to separate at least in patches, but retaining their polygonal shape in surface view, diameter in surface view $36-60 \mu \mathrm{m}$, in section outermost utricles 39-54(-62) $\mu \mathrm{m}$ long, not more than four supported by each secondary utricle; secondary utricles $17-37 . \mu \mathrm{m}$ broad.

Medullary filaments numerous in mature segments, commonly united at the node in pairs for a relatively short distance; complete fusion in pairs, short and complete fusion in threes and occasionally other groupings, or the filaments completely separate; short fusion for the distance of (66-)100$160(-193) \mu \mathrm{m}$; nodal units may be entangled and adhere firmly; medullary filaments above the node sometimes not developing a cortex but continuing as long, sometimes tangled, threads.

Type specimen. Caroline Islands, near Ponape, lagoon of Ants Atoll, Y. Yamada, S 15-1 (SAP). 


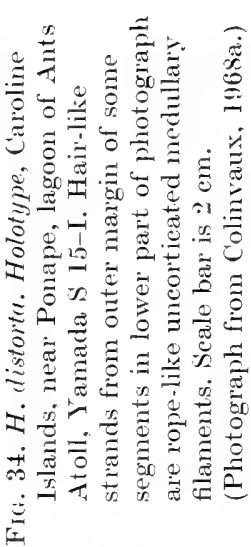
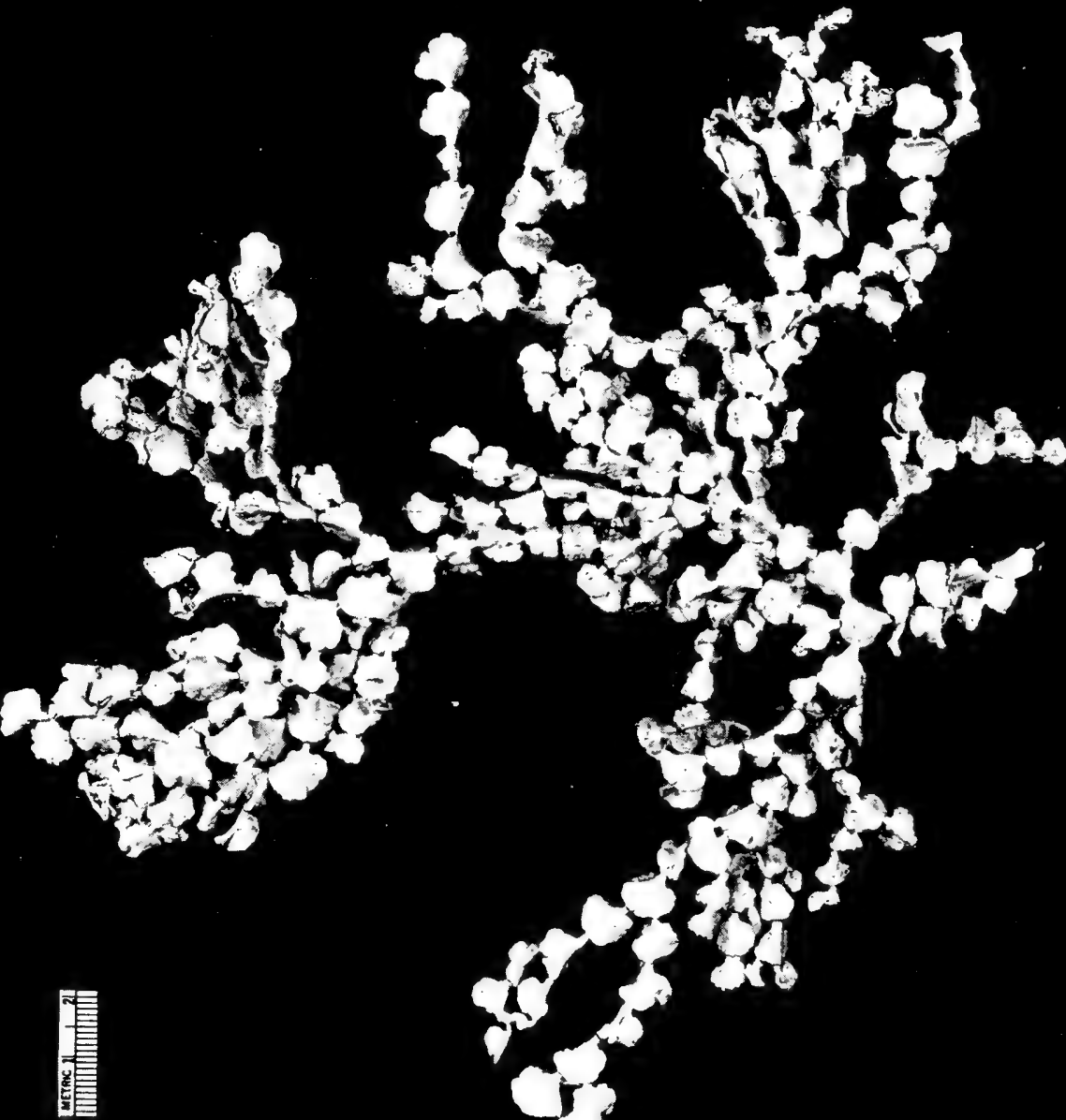

1)

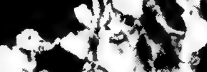

$48 \cos ^{2}$

$\sin$.

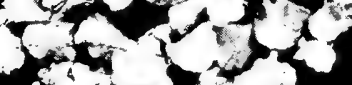

$(-1)+3$

$x^{4}+C^{2}$

其

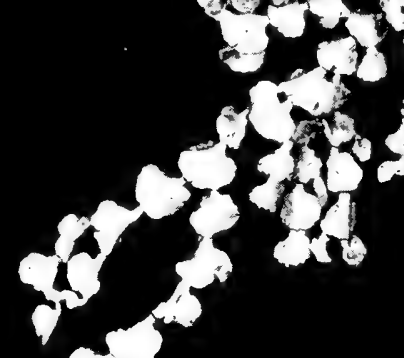


Habitat. A spreading alga, growing on rock, in and through its crevices, and around the bases where it may extend into sand. Attachment is provided by a multi-holdfast system. This species grows in regions of strong currents such as the inter-island passes and quarry at Enewetak. The limited depth records are all from water of $-0.6 \mathrm{~m}$ to $-3 \mathrm{~m}$. south.

Geographic distribution. Western Pacific Ocean, both north and 3. Section Halimeda J. Ag. ex De Toni

\section{Halimeda tuna (Ellis and Solander) Lamouroux}

Figure 35.

Corallina tuna Ellis and Solander (1786), p. 111, Plate 20, Fig. e. Halimedea tuna Lamouroux (1812), p. 186; Halimeda tuna Lamouroux (1816), p. 309, Plate 11, Fig. 8; Barton (1901), p. 11, Plate 1, Figs 1-6; Collins (1909-1918), p. 400; Taylor (1928), p. 85; Hillis (1959), p. 342, Plates 1, $5,6,9$.

? Halimeda tuna f. albertisii Piccone (1879), p. 23, Fig. 2; Barton (1901), p. 14, Plate 1, Fig. 3.

Halimeda tuna f. platydisca (Decaisne) Barton (1901), p. 14, Plate 1, Fig. 2; Halimeda platydisca Decaisne (1842), p. 102.

Halimeda tuna v. platydisca Børgesen (1911), p. 134; Børgesen (1913), p. 106, Collins (1909-1918), p. 102; Taylor (1928), p. 85, Plate 10, Fig. 13.

Plants spreading or compact, often forming cushion-like clumps, arising from an inconspicuous holdfast, to $15 \mathrm{~cm}$ tall; calcification moderate to light, sometimes becoming heavier towards the base; branching generally ditrichotomous; basal segments often subcuneate, the others plane or sometimes ribbed, mainly subcuneate, discoid or reniform, commonly relatively small, to $13 \mathrm{~mm}$ long, $19 \mathrm{~mm}$ broad, and averaging $0.50-0.75 \mathrm{~mm}$ in thickness, but in other specimens, often from deep water, to $25 \mathrm{~mm}$ long and $40 \mathrm{~mm}$ broad.

Cortex of two to four layers of utricles; outermost utricles remaining firmly attached after decalcification for a distance of approximately $12-16 \mu \mathrm{m}$, sometimes fusing laterally in twos or threes for this same distance; lateral and peripheral walls occasionally somewhat thickened; unfused peripheral utricles measuring (25-)34-100(-125) $\mu \mathrm{m}$ in surface diameter, $(46-) 60-130(-230) \mu \mathrm{m}$ long in section, two to four or occasionally up to seven supported by each secondary utricle; secondary utricles (20-)30$80(-110) \mu \mathrm{m}$ broad; tertiary utricles $40-130 \mu \mathrm{m}$ broad.

Nodal medullary filaments uniting in twos and threes, the length of fusion usually 1.5 times the filament diameter or else complete; resultant units 


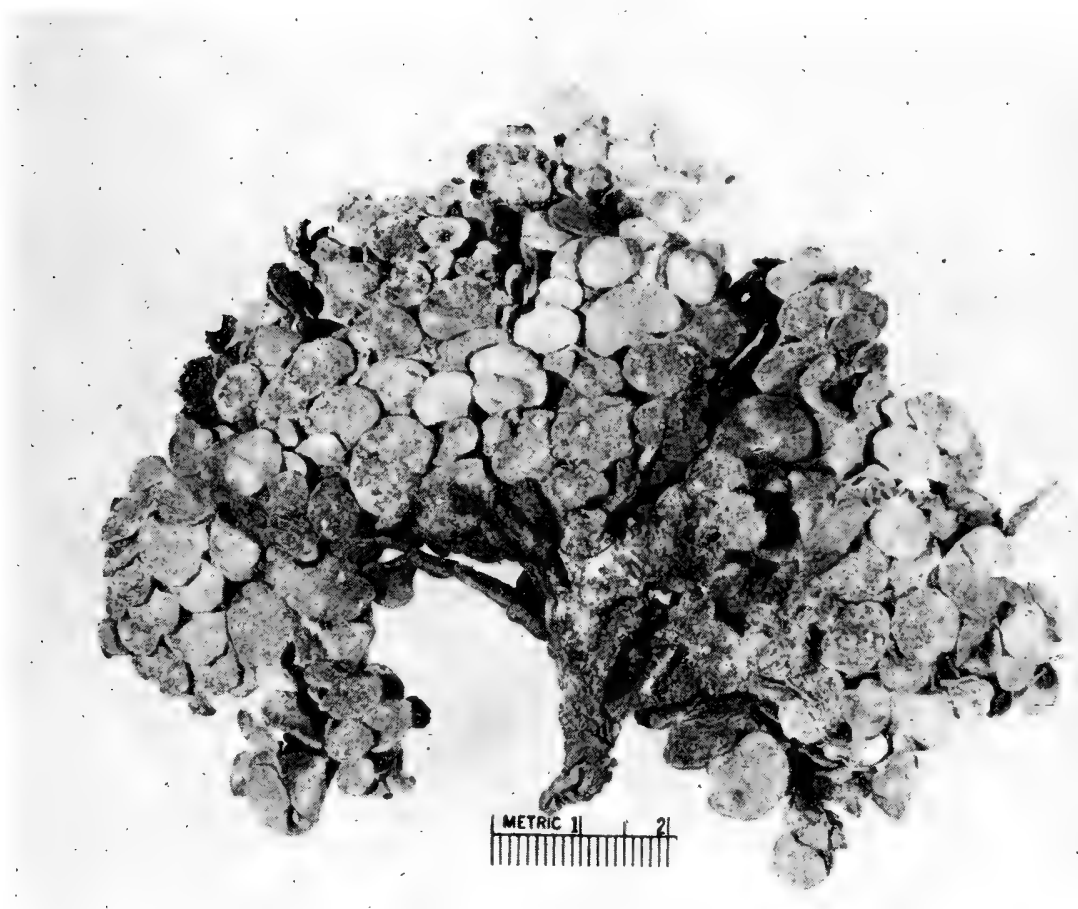

Fig. 35. H. tuna. Densely branched, slightly stipitate plant with holdfast slash-shaped and immediately above centimetre scale. Specimen from Jamaica, Boscobel, IX 62, Hillis-Colinvaux and Colinvaux. Scale bar is $2 \mathrm{~cm}$. (Photograph by The Ohio State University Department of Photography.)

usually densely entangled and remaining separate or laterally adhering for an average distance of $85 \mu \mathrm{m}$.

Type locality. Mediterranean Sea. This species is the type for the genus.

Habitat. Grows attached to coral rock or other hard surface, from just below low-tide to about $-80 \mathrm{~m}$. Apart from opuntia it is probably the commonest rock-growing Halimeda of the Caribbean.

Geographic distribution. Pantropical; western and eastern Indian Ocean; north-western Pacific; western Atlantic, both north and south including Bermuda; eastern Atlantic, both north and south; Mediterranean. 
This species, which was first described for the Mediterranean, has subsequently been attributed to most tropical areas. The specimens from these other regions, however, usually differ in one or more respects from the small-segmented Mediterranean plants which represent the type.

In habit, the typical small-segmented Mediterranean plants seem small and cushion-like, whereas specimens with small segments from the Atlantic and Indian Oceans are often larger and less compact. The lower segments of western Atlantic plants are commonly subcuneate in shape rather than reniform, and the surface diameters of peripheral utricles in western Atlantic and Indian Ocean material average approximately $50 \mu \mathrm{m}$ as opposed to $65 \mu \mathrm{m}$ for the Mediterranean plants. The tuna plants of Bermuda, a region at the extreme edge of the tropical range, resemble the Mediterranean tuna more closely than do Caribbean plants (Howe, 1905a), an observation well substantiated by herbarium specimens. Some of the observed differences may be a response to a stress environment as well as to geographical isolation. The range encountered in the various characters has been considered within the range of the species.

Large-segmented plants occur throughout the entire range of tuna and are sometimes assigned to f. platydisca. The surface diameters of their peripheral utricles are at the larger end of the range given.

\section{Halimeda cuneata Hering}

Figures 36,61 .

Halimeda cuneata Hering in Krauss (1846), p. 214; Barton (1901), p. 15,

Plate 1, Fig. 7, but not Plate 2, Fig. 9, or Plate 1, Fig. 10; Hillis (1959), p. 345 , Plates $1,5-7,9$.

Halimeda obovata Kützing (1858), p. 11, Plate 25, Fig. 1.

Halimeda versatilis J. Agardh (1887), p. 86.

Plants rather loosely organized or occasionally compact, arising from a small but distinct holdfast region, to $25 \mathrm{~cm}$ tall; calcification light; the surface smooth and usually somewhat glossy; branching mainly dichotomous but with up to six segments arising from a single one; the basal first to second segments cylindrical to subcylindrical, often giving the appearance of a short stipe; other segments plane, mostly cuneate, sometimes discoid, generally to $16 \mathrm{~mm}$ long, $18 \mathrm{~mm}$ broad and averaging $0.50-0.75 \mathrm{~mm}$ in thickness, but in some specimens reaching $21 \mathrm{~mm}$ in length and $27 \mathrm{~mm}$ in breadth; many of the segments supported by a cushion segment, to $1.5 \mathrm{~mm}$ long, $5.5 \mathrm{~mm}$ broad, or a stalk region of uncorticated medullary filaments, or both. 


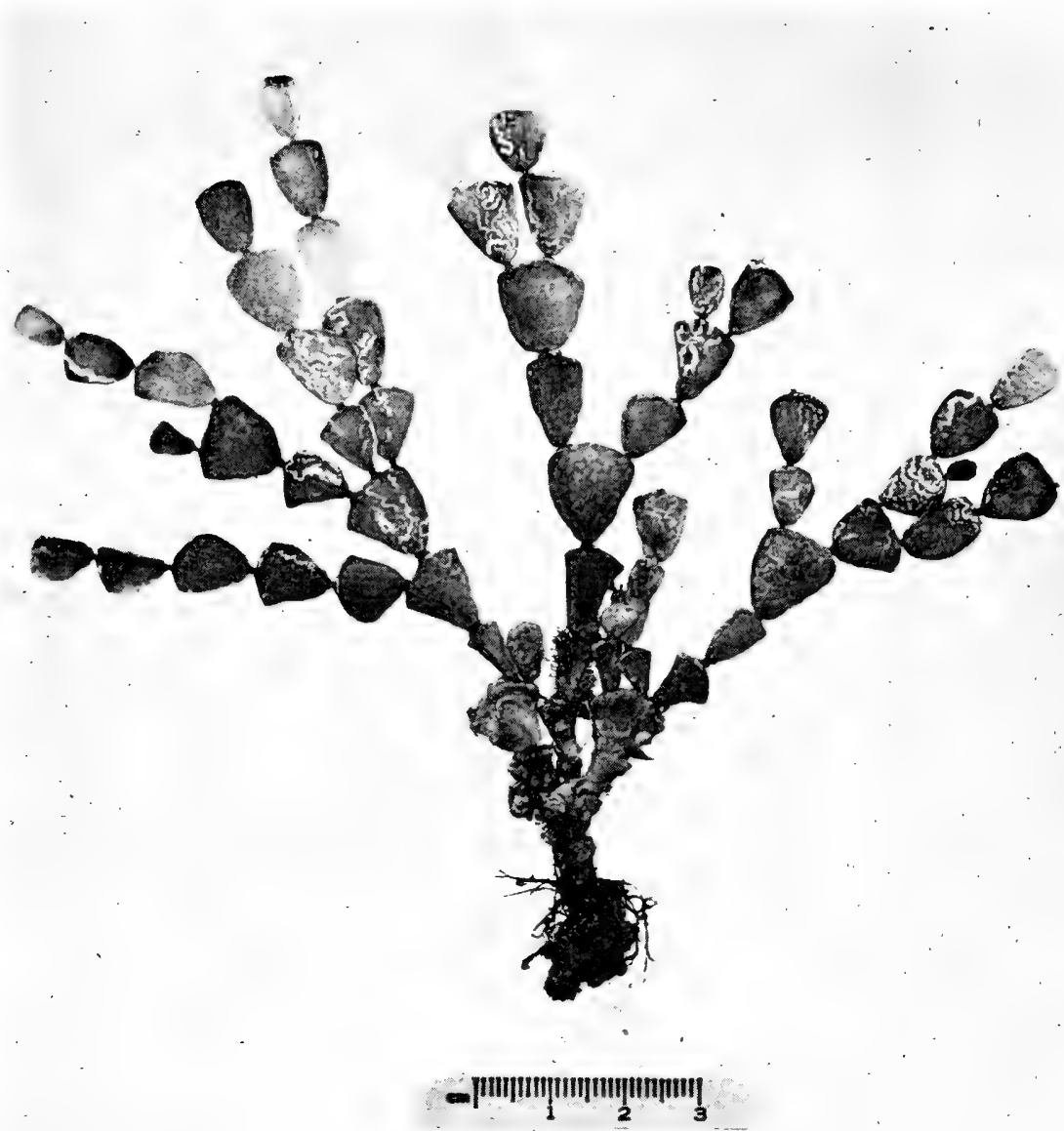

FIG. 36. $H$. cuneata. A stalk region of uncorticated medullary filaments occurs between some of the segments shown. Specimen from East Africa, Inhaca Island, 24 IV 56, Isaac 799. (Photograph by Jodi Grenga.)

Cortex of two to four layers of utricles; outermost utricles remaining firmly attached after decalcification for an average distance of $35 \mu \mathrm{m}$, occasionally fusing laterally in pairs for this same distance; unfused peripheral utricles 25-63(-72) $\mu \mathrm{m}$ in diameter, (43-)58-100(-135) $\mu \mathrm{m}$ long in section, usually four but occasionally two supported by each secondary utricle; secondary utricles 20-67(-79) $\mu \mathrm{m}$ broad, 20-67 $\mathrm{m}$ long; tertiary utricles (40-)50-80(-94) $\mu \mathrm{m}$ broad.

Nodal medullary filaments united in twos and threes, the length of fusion usually 1.5 or several times the filament diameter; fused units densely 
entangled but at most adhering only slightly; filament walls thickened and pigmented at the node, and in the cushion joint and stalk region.

Lectotype specimen. Collected by Krauss at Durban (Natal Bay), South Africa (BM).

Habitat. Growing on rocks near low-water mark and under ledges of reef pools, also dredged to $-40 \mathrm{~m}$.

Geographical distribution. Subtropical; western Indian Ocean, both north and south; south-eastern Indian Ocean; south-western Pacific.

This range includes the first authentic material I have seen from the northern hemisphere. It was collected by $\mathrm{R}$. Norris at Okah, Gujarat State, India, 9 March, 1963 (Smithsonian Oceanographic Sorting Center No. 28).

This species differs from all other species of the genus in the presence of what have been called "stalked" as opposed to "sessile" segments at the base of a few segments of the thallus. The "stalk" consists of either a small cushion segment or a stalk region or both.

The medullary filaments, subsequent to fusion in twos and threes in the node region of a typical segment, may extend into a "cushion" segment which consists of cortical layers as in a regular segment. However, the inner layers are usually not as regular in appearance or as extensively developed. In cushion segments near the base of the plant the cortex may be replaced by rhizoidal filaments. Such segments are readily recognized by their looser, rather disorganized appearance. The walls of the main filaments in cushion segments and often those of their branches are somewhat indurated. This is evident in section, and also in surface view of the peripheral utricles, although care must be taken in the latter to distinguish between actual thickening and the effects of shrinkage.

At the apex of these cushion segments, the medullary filaments commonly branch dichotomously, but may also remain unforked. Either way they usually become torulose and proceed uncorticated for some distance. This represents the stalk. These filaments ultimately branch, generally trichotomously, and their rami develop the cortical layers of the new segment.

The preceding account describes the complete expression of the "stalk" region between segments. The extent of its development varies with the individual specimen, and it may be influenced by age since it was rather uncommon in the few young plants observed. Rarely does a plant occur without either of these structures being interposed between some of its segments. 
A second prominent characteristic of $H$. cuneata is the extensive attachment of adjacent peripheral utricles which is for approximately $0 \cdot 3-0 \cdot 5$ of their length. Extensive attachment, however, is not unique for cuneata. The peripheral utricles also adhere for a considerable distance in $H$. discoidea, and for somewhat shorter distances in $H$. tuna, and $H$. incrassata. When working with dried material this region is generally compressed and, as a result, the utricles may present the illusion in surface view of being thick-walled.

The concept of this species as presented by Barton was broad, and included both "stalked" and "sessile" plants such as discoidea. Hence, the reported geographic range of cuneata has sometimes been considerably extended as has been noted by Gilbert (1947), Papenfuss and Egerod (1957) and Hillis (1959).

Two forms of this species, f. digitata and $f$. undulata, have been designated (Barton, 1901, p. 16, Plate 1, Fig. 9, Plate 2, Fig. 10), the type specimens of which have not been located. However, since these are based on "sessile" plants which are not included in the present concept of the genus, they no longer seem applicable to $H$. cuneata.

\section{Halimeda scabra Howe}

Figure 37.

Halimeda scabra Howe (1905a), p. 241, Plates 11, 12 ; Collins(1909-1918), p.401;

Taylor (1928), p. 84, Plates 10, 11; Hillis (1959), p. 348, Plates 1, 5, 6, 8, 9.

Plants generally compact forming cushion-like clumps, or somewhat spreading, occasionally lax and decumbent and then to $25 \mathrm{~cm}$ in length but more commonly not exceeding $9 \mathrm{~cm}$; calcification moderate; colour on drying bluish-green, olive or whitish, the surface dull and somewhat rough; branching frequent, usually dichotomous; basal segments often subcuneate, others plane or slightly ribbed, most commonly subreniform to reniform but also subcuneate and discoidal, to $11 \mathrm{~mm}$ long, $20 \mathrm{~mm}$ broad and averaging $0 \cdot 50-0.75 \mathrm{~mm}$ in thickness.

Cortex of two to three layers of utricles with a fourth zone occasionally present; outermost utricles remaining attached after decalcification, or separating slightly but retaining their hexagonal shape as viewed from the surface, each bearing a central indurated spine which may extend to twothirds the length of the rest of the utricle, 26-55(-66) $\mu \mathrm{m}$ in surface diameter, (50-)70-165(-240) $\mu \mathrm{m}$ long in section including the spine, up to seven supported by each secondary utricle; secondary utricles $30-60(-70) \mu \mathrm{m}$ broad, their length variable and often extending to the medulla; tertiary utricles when present approximately 39-65 $\mu \mathrm{m}$ broad.

Nodal medullary filaments united in twos and threes, the length of fusion approximately 1.5 times the filament diameter or complete; resultant units entangled and sometimes adhering for up to $60 \mu \mathrm{m}$. 


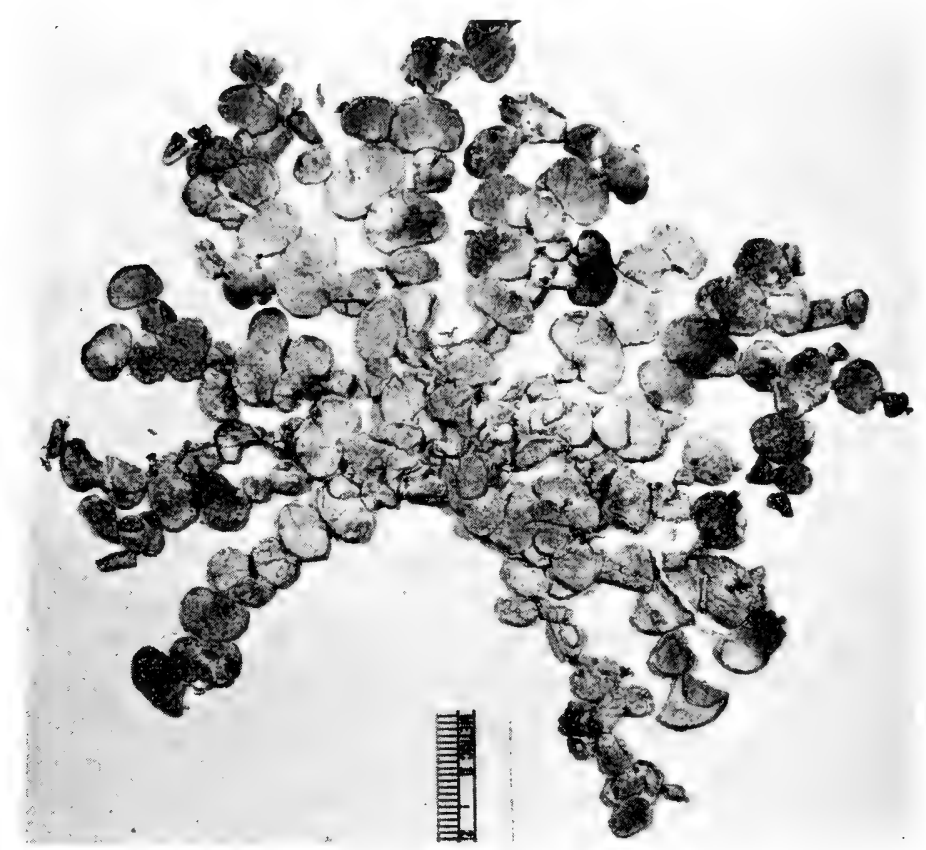

FIG. 37. H. scabra. Specimen from Florida, IX 1895, Curtiss. Scale bar is $2 \mathrm{~cm}$.

Type specimen. Florida, Sands Key, Howe 2905, 30 March, 1904 (NY).

Habitat. Growing on rocks from near low-tide line to at least $-20 \mathrm{~m}$.

Geographic distribution. North-western Atlantic.

In general form and anatomy $H$. scabra is closely allied to H. tuna, particularly to the somewhat modified plants of the Caribbean, and has frequently been identified as tuna in herbaria. From this species it can often be distinguished macroscopically by the rather bluish cast which commonly occurs towards the apices of the branches, and by the rough texture which results from the indurated spines which project from the peripheral utricles, their length varying to a limited extent with the age of the segment. When well developed, the spines are usually visible with a good handlens. The relative ease of separation of the peripheral utricles after decalcification and their small surface diameters are also characteristic of this species, the latter averaging $42 \mu \mathrm{m}$ in $H$. scabra as opposed to $70 \mu \mathrm{m}$ in $H$. tuna. Adjacent fused nodal units may remain 
separate or else adhere for an average distance of $30 \mu \mathrm{m}$, whereas in the Caribbean $H$. tuna the filaments are usually attached laterally for an average length of $85 \mu \mathrm{m}$.

\section{Halimeda lacunalis Taylor}

Figure 38.

Halimeda lacunatis Taylor (1950), p. 91, Plate 51; Hillis (1959), p. 349, Plates 1, 5-7, 9.

Plants erect or somewhat flaccid, arising from a small holdfast region, to $18 \mathrm{~cm}$ tall; calcification light to moderate; the surface often glossy; branching complanate, sometimes sparse, commonly dichotomous but with up to four segments arising from a single one; basal segments often relatively small and subcylindrical to subcuneate; suprabasal segments at times fusing laterally, others occasionally ribbed, most commonly subcuneate or obovate, but also discoidal or reniform, to $15 \mathrm{~mm}$ long, $20 \mathrm{~mm}$ broad, and averaging $0.50-0.75 \mathrm{~mm}$ in thickness.

Cortex of two to four layers of utricles; outermost utricles sometimes thickened towards the periphery, remaining attached after decalcification for an average distance of $13 \mu \mathrm{m}, 20-55(-70) \mu \mathrm{m}$ in surface diameter, 45100(-190 in subcylindrical segments) $\mu \mathrm{m}$ long in section; two, four or occasionally five borne on each secondary utricle; secondary utricles 15-50(-60) $\mu \mathrm{m}$ broad, (15-)23-80 $\mu \mathrm{m}$ long, these small utricles absent at times; innermost utricles $35-80 \mu \mathrm{m}$ broad.

Nodal medullary filaments fusing completely in twos and threes; resultant units entangled and adhering strongly for approximately $80-150(-280) \mu \mathrm{m}$.

Type specimen. Marshall Islands, Enewetak Atoll, Taylor 46-464, 6 June, 1946 (MICH).

One special form has been described.

\section{f. lacunalis f. lata (W. R. Taylor) Hillis}

Halimeda lacunalis f. lata (W. R. Taylor) Hillis (1959), p. 349. Halimeda gracilis f. lata Taylor (1950), p. 83, Plate 42.

Plants sometimes rather lax, but generally compact; segments usually broader than long, occasionally subcuneate but more generally discoid to reniform, to $15 \mathrm{~mm}$ long, $20 \mathrm{~mm}$ broad, and averaging $0.75-1.00 \mathrm{~mm}$ in thickness.

Type specimen. Marshall Islands, Bikini Atoll, Enyu Island, Taylor 46-21, 15 March, 1946 (MICH).

Habitat. The known depth range for the genus is $1-55 \mathrm{~m}$. At Enewetak, the form f. lata was relatively common in the fast-flowing 


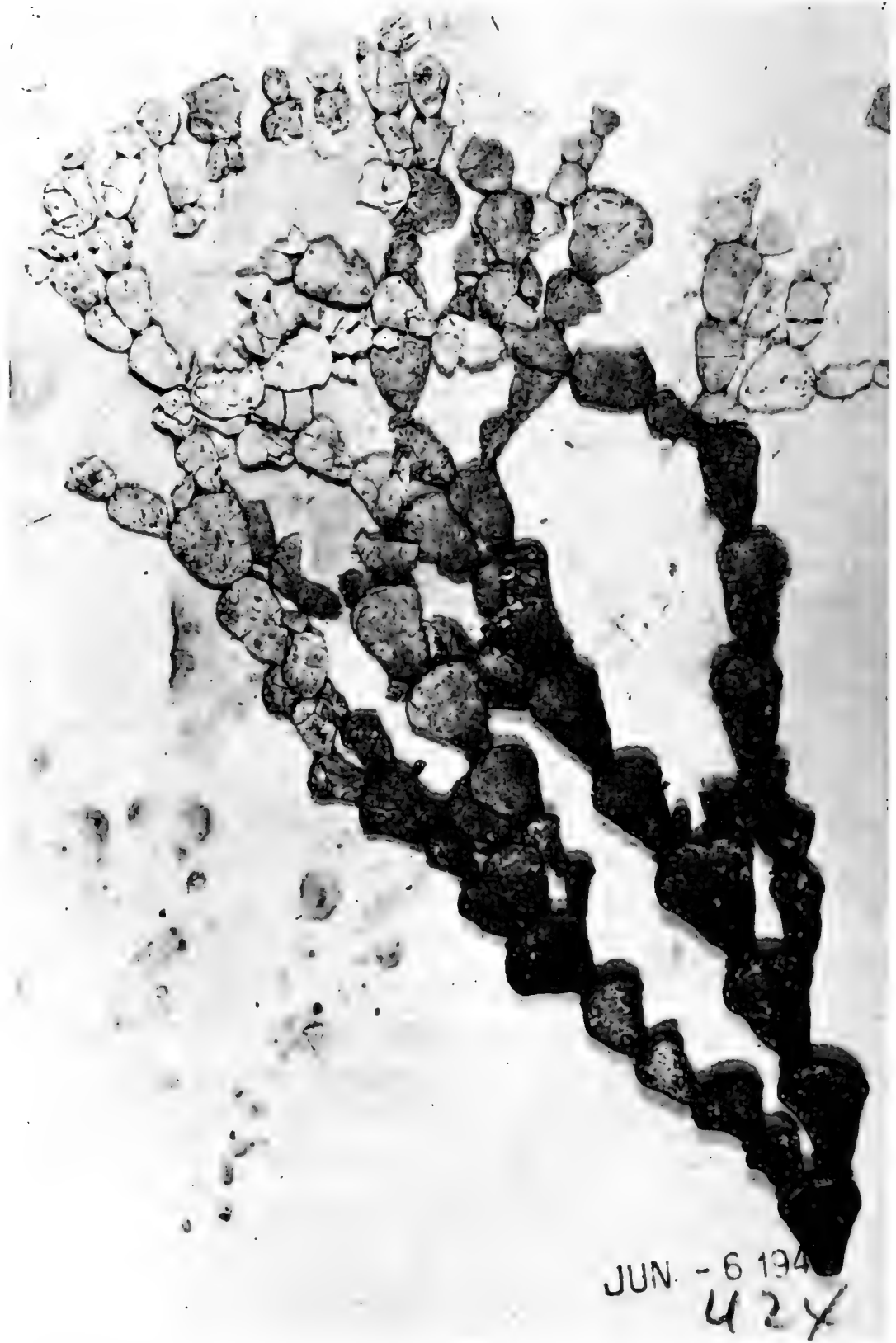

FIG. 38a. H. lacunalis f. lacunalis. Holotype, Marshall Islands, Enewetak Atoll, Taylor 46-424. Height of axis on right-hand side from bottom to top of broken segment is $13 \cdot 2 \mathrm{~cm}$. (Photograph courtesy of the Division of Biological Sciences, University of Michigan.) 


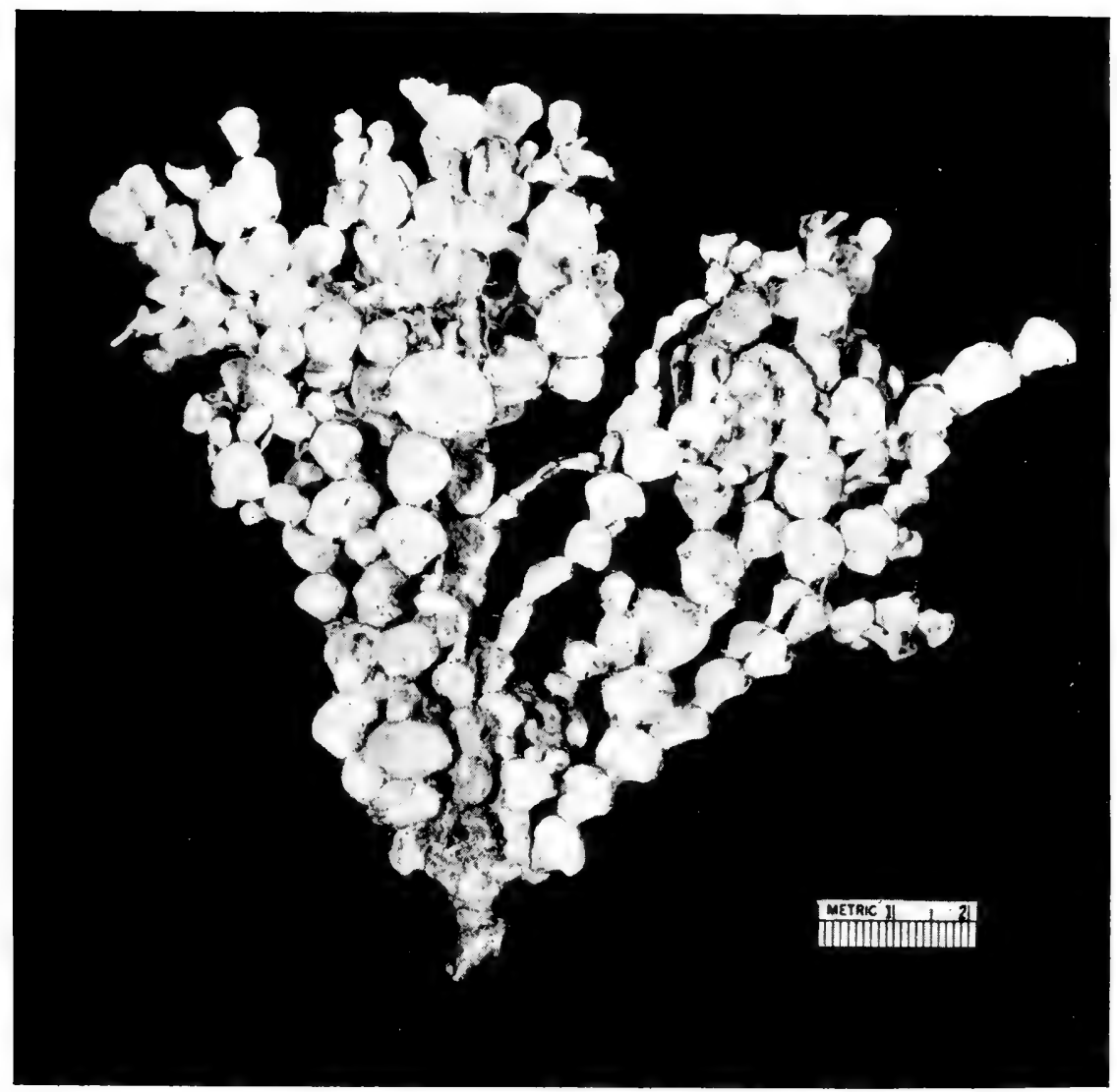

FIG. 38b. H. lacunalis f, lata, showing small holdfast, thickened basal segments and multi-branching near the base, all characteristic features. (Specimen from the Marshall Islands, Enewetak Atoll, pass between Alembel and Lojwa Islets, $-2 \mathrm{~m}$ to $-3 \mathrm{~m}, 18$ XII 75, Hillis-Colinvaux. Scale bar is $2 \mathrm{~cm}$. (Photograph by The Ohio State University Department of Photography.)

waters of an inter-island channel (Section $\mathrm{X}$ ) where it grew erect on the seaward and leeward faces of the rock substrate, or protruded slightly from rock crevices. The thalli were also attached near the eroded bases of rock, under miniature overhangs. Dwarf forms of $\mathrm{f}$. lata occurred at these sites also.

Halimeda lacunalis $\mathrm{f}$. lacunalis was not encountered at these sites, and seems to be the rarer of the two.

Geographic distribution. For lacunalis f. lacunalis north-western Pacific Ocean; for f. lata western Indian Ocean; north-western Pacific Ocean. 
This species can be fairly readily distinguished from other Halimedae, except possibly cuneata, by the frequent occurrence of subcuneate or obovate segments. The absence of stalk or cushion segments separates it from this one species. Any confusion with discoidea or taenicola can be resolved microscopically by the absence of swollen secondary or tertiary utricles in lacunalis.

Histologically, the commonness of small secondary utricles is fairly characteristic of mature segments of this species. These small utricles are absent, however, when the cortex is composed of only two layers.

In other anatomical aspects lacunalis resembles tuna, particularly the Atlantic and Indian Ocean specimens. Features the two species have in common are the lateral adhesion of the nodal fusion units, the regular surface appearance of the peripheral utricles and the apparent absence of lateral fusions among them.

Halimeda lacunalis differs from tuna in the significantly smaller diameters of its peripheral utricles, with those of $f$. lata generally towards the lower limit of the broad tuna range.

The adherence of the nodal groups is usually fairly considerable, the rigidity of the resulting nodal structure sometimes leading to confusion with the Rhipsalian pattern. From this type of nodal union it is, nevertheless, entirely distinct, the units in lacunalis separating on teasing. Halimeda lacunalis also lacks the well-developed bulbous holdfast of Rhipsalian species.

\section{Halimeda gigas W. R. Taylor}

Figure 39 .

Halimeda gigas Taylor (1950), p. 84, Plate 44; Hillis (1959), p. 350, Plates 1, $5,6,9$.

Plants loosely organized, to $15 \mathrm{~cm}$ tall; calcification rather light; colour brownish-green, the surface slightly glossy, rugose, tending to crack somewhat on drying; branching complanate and sparse, although up to six segments may arise from a single segment; basal segments subterete, the others plane, mainly discoidal to reniform, the outer margin entire or very slightly undulating, to $31 \mathrm{~mm}$ long, $42 \mathrm{~mm}$ broad and averaging $0.75-1.00 \mathrm{~mm}$ in thickness; shrinkage on drying fairly considerable, leaving a brown stain on paper.

Cortex of two, occasionally three layers of utricles; outermost utricles remaining attached after decalcification for an average distance of $8 \mu \mathrm{m}$, at times fusing laterally in twos and occasionally threes for this same distance; unfused peripheral utricles (84-)96-130(-170) $\mu \mathrm{m}$ in surface diameter, $130-240$ um long in section, borne two or four on each secondary utricle; secondary utricles $60-120(-160) \mu \mathrm{m}$. 


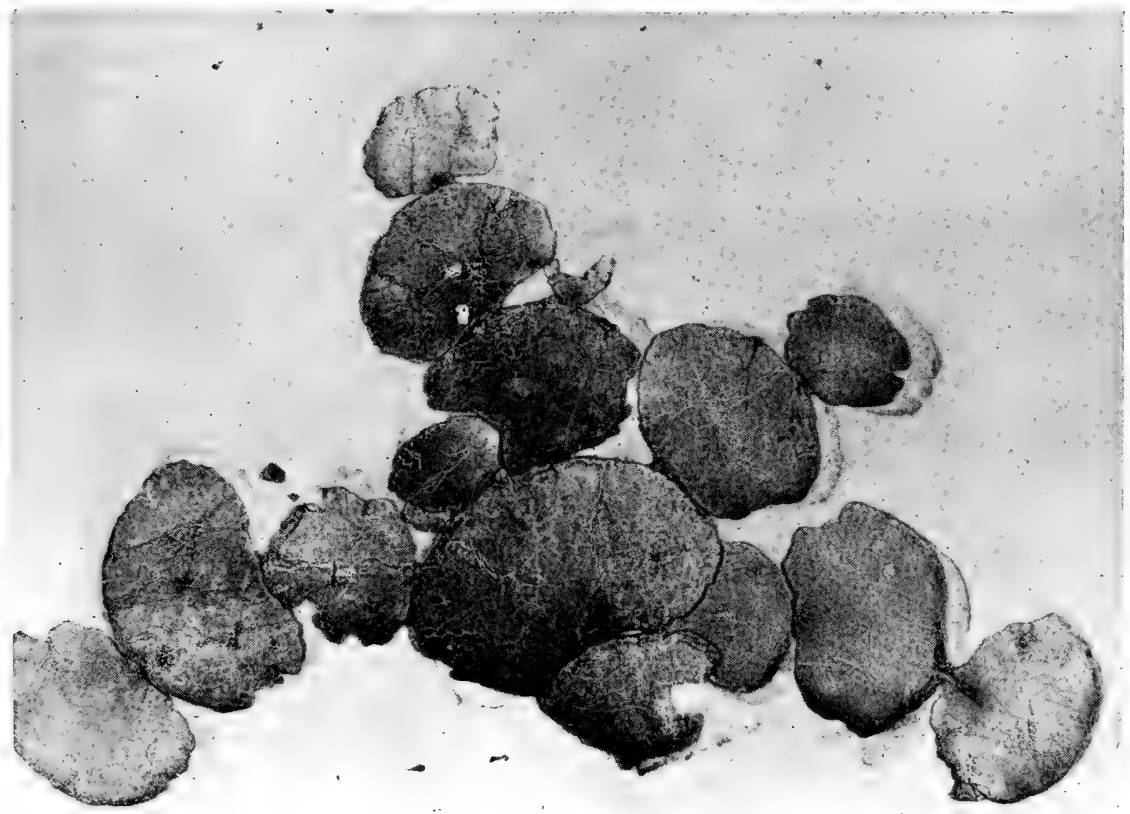

FIG. 39. H. gigas. Holotype, Marshall Islands, Enewetak Atoll, Taylor 46-419. Actual width of specimen is $\mathbf{1 4} \cdot 3 \mathrm{~cm}$. (Photograph courtesy of the Division of Biological Sciences, University of Michigan.)

Nodal medullary filaments fusing completely in twos and threes, although occasionally and most particularly towards the periphery of the node uniting for only a short distance (incomplete fusion); fused groups entangled but at most adhering only slightly.

Type specimen. Marshall Islands, Enewetak Atoll, Taylor 46-419, 6 June, 1946 (MICH).

Habitat. Pendant on rocks in relatively quiet water, and growing from approximately $-1.5 \mathrm{~m}$ to $-46 \mathrm{~m}$. In shallow water it is sometimes relatively common and at some sites it is associated with H. macrophysa.

\section{Geographic distribution. North-western Pacific Ocean.}

This species may initially be mistaken for a large segmented tuna or discoidea. Microscopic differences with tuna include the large surface diameters of the peripheral utricles, these averaging $115 \mu \mathrm{m}$ in gigas as compared to $70 \mu \mathrm{m}$ in tuna and a less extensive development of the cortex in gigas as opposed to tuna. 
In comparing it with discoidea, the surface utricles of discoidea are smaller (average diameter $65 \mu \mathrm{m}$ ), and the secondary utricles larger (average $125 \mu \mathrm{m}$ as compared to $90 \mu \mathrm{m}$ in gigas).

\section{Halimeda macrophysa Askenasy}

Figures 40, 99.

Halimeda macrophysa Askenasy (1888), p. 14, Plate 4, Figs 1-4; Barton (1901), p. 17, Plate 2, Figs 15-18; Hillis (1959), p. 351, Plates 2, 5, 6, 11.

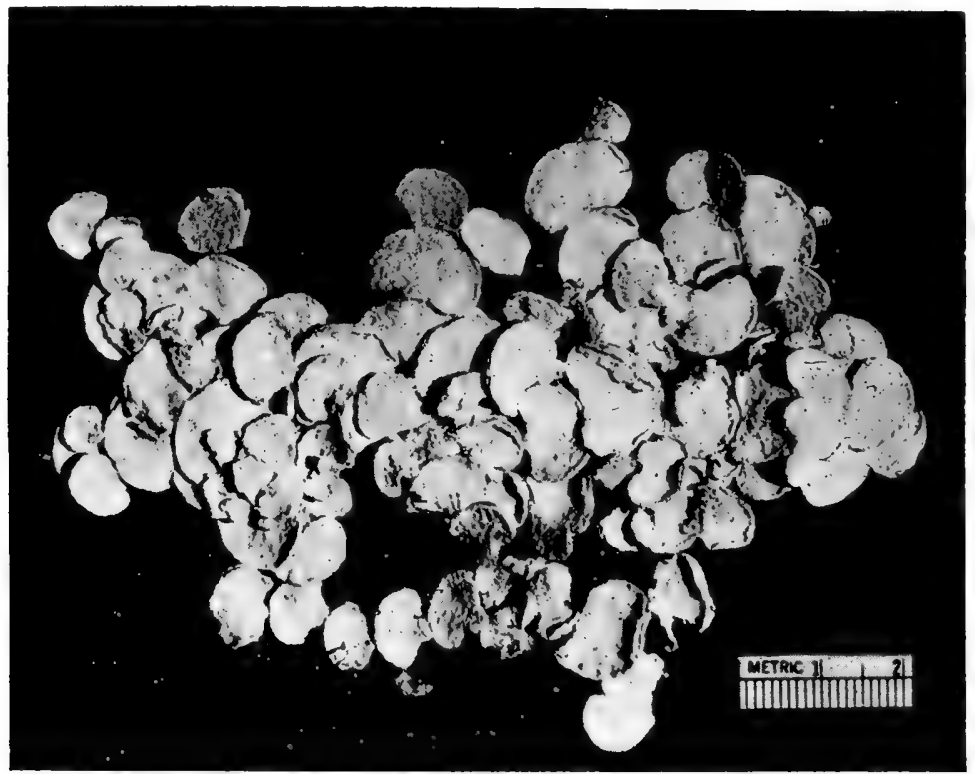

Frg. 40a. H. macrophysa. Habit. Scale bar is $2 \mathrm{~cm}$. (Photograph by The Ohio State

University Department of Photography.)

Plants fragile, compact and erect, arising from a single small holdfast region, to $10 \mathrm{~cm}$ tall; calcification moderate; the surface dull, rugose and appearing pitted; branching complanate, mainly ditrichotomous but with several segments arising from some of the larger ones; basal segments often subcuneate, the others friable, plane, commonly reniform or subreniform but also subcuneate, the upper margin entire, to $15 \mathrm{~mm}$ long, $24 \mathrm{~mm}$ broad and averaging $0.5 \mathrm{~mm}$ in thickness.

Cortex most commonly of two layers of utricles; outermost utricles separating readily on decalcification, appearing round in surface view, $135-180 \mu \mathrm{m}$ in surface diameter, 170-230(-290) $\mu \mathrm{m}$ long, most commonly two but also one or four supported by each secondary utricle; secondary utricles $40-100 \mu \mathrm{m}$ broad, 73-140(-230) $\mu \mathrm{m}$ long. 
Nodal medullary filaments fusing completely in twos, threes and occasionally larger units; resultant units densely entangled and often adhering slightly.

Type locality. Matuku, Fiji Islands, South Pacific.

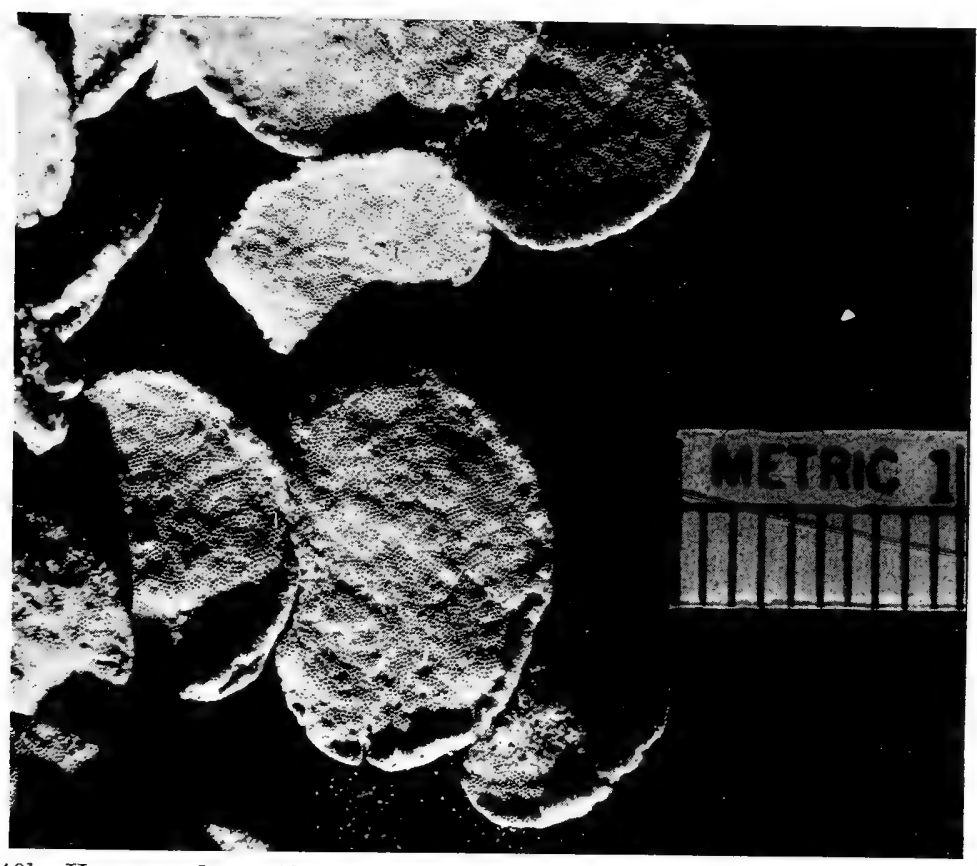

FIG. 40b. H. macrophysa. Close-up of segments showing pitted surface which, macroscopically, often gives a stippled appearance to the segment. Specimen from Mentawei Islands west of Sumatra, Pulau Stupai north of Sanding Island, 4 XII 63, Hillis-Colinvaux LH-29c. Scale bar is $1 \mathrm{~cm}$. (Photograph by The Ohio State University Department of Photography.)

Habitat. Hanging from rocks, filling crevices, or growing more openly as compact clumps; from approximately $-1.5 \mathrm{~m}$ to $-50 \mathrm{~m}$. At Enewetak it formed relatively dense populations on flat surfaces on the tops of pinnacles and on a buttress on the seaward site of Mut Island. It was a very common species in the lagoon, and was at times associated with $H$. gigas, $H$. distorta and $H$. gracilis (Section X).

Geographic distribution. Western and eastern Indian Ocean; western Pacific, both north and south.

This species is readily distinguished from all species of the genus other than favulosa by its friable nature, and the pitted condition of the 
segment surface, the latter resulting from the extremely large peripheral utricles and their separation by calcium carbonate partitions. From favulosa it can be separated macroscopically by its habit including the absence of the bulbous holdfast of the Rhipsalian species, and by the morphology of its segments. Reniform segments commonly occur in macrophysa, the plants themselves usually being compact and less than

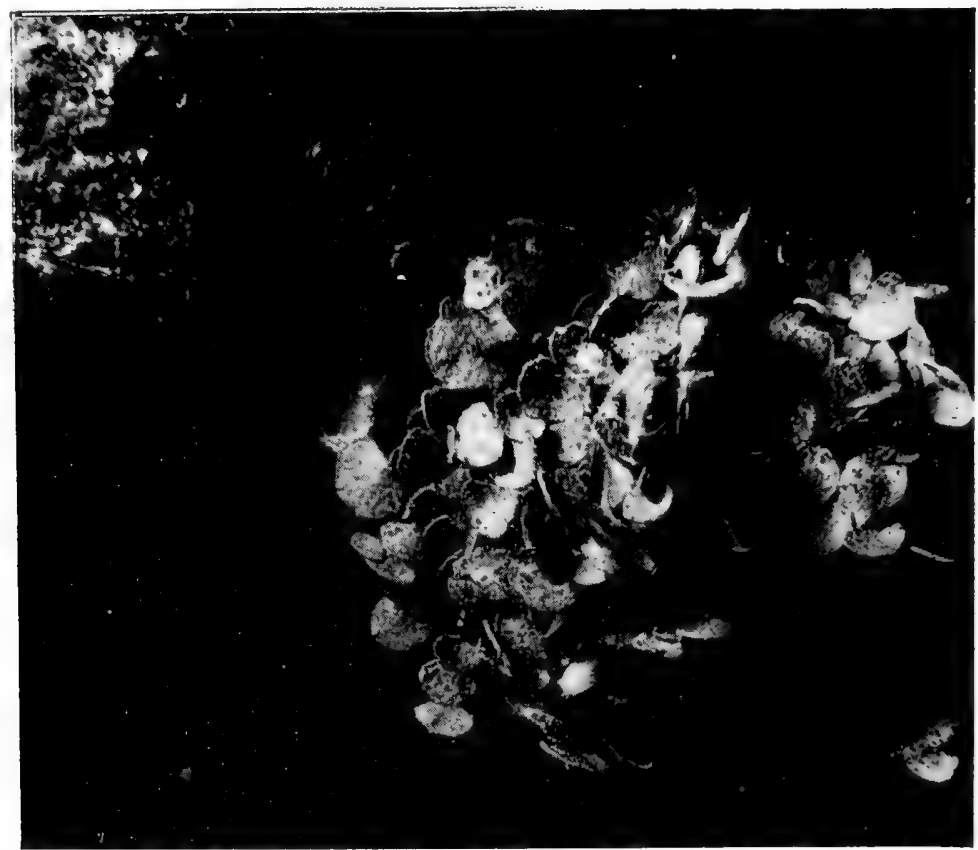

FIG. 40c. H. macrophysa. Fertile specimen, pendant from coral rock, Pulau Stupai. "Growths" on most of the segments are gametangia supported by gametophores (Fig. 64). Average width of segments is $13 \mathrm{~mm}$. (Photograph by K. Rützler, reproduced with permission.)

$10 \mathrm{~cm}$ tall, whereas in favulosa trilobed or cylindrical segments predominate, and the plants are attenuate and to $22 \mathrm{~cm}$ in height. In microscopic details the cortex in both species is rather poorly developed, but the node structure is different.

\section{Halimeda discoidea Decaisne}

Figure 41.

Halimeda discoidea Decaisne (1842), p. 91; De Toni (1889), p. 527; Collins (1909-1918), p. 400; Howe (1907), p. 495, Plate 25, Figs 11-20, Plate 26; Taylor (1928), p. 82, Plate 10, Fig. 17; Plate 11, Fig. 23; Taylor (1950), 
p. 85, Plate 45, Figs 1-2; Egerod (1952), p. 398, Plate 38, Figs 19b-d; Hillis (1959), p. 352, Plates 2, 5-8, 11.

Halimeda discoiden v. platyloba Borgesen (1911), p. 134, Fig. 3; Borgesen (1913), p. 107, Fig. 86.

Halimeda discoidea f. intermedia Gilbert (1947), p. 126.

Halimeda discoidea f. subdigitata Gilbert (1947), p. 125.

Halimeda tuna Barton (1901), p. 11 p.p.

? Halimeda cuneata f. digitata Barton (1901), p. 16, Plate 2, Fig. 9.

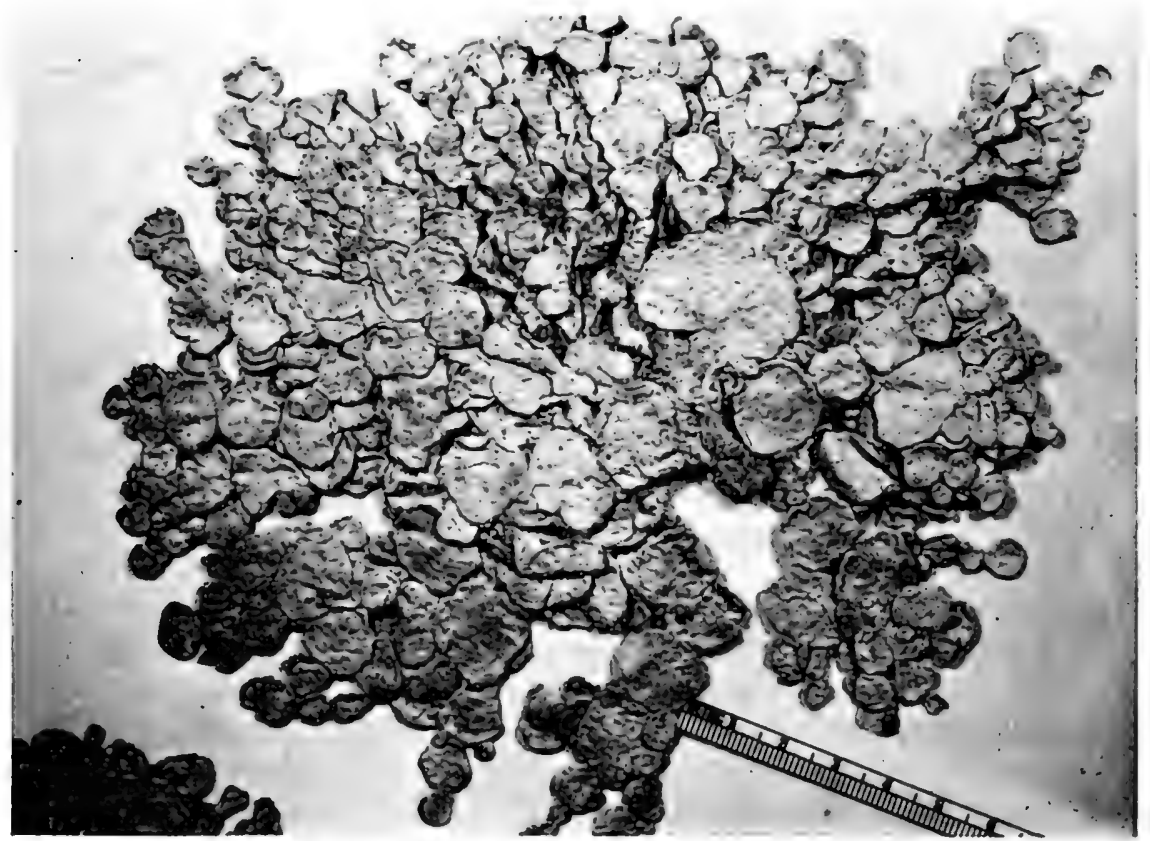

Fig. 41. $H$. discoidea. A densely branched plant with some of the relatively large segments which commonly occur in the lower portion of robust, mature thalli. Specimen from Florida, 31 III 04, Howe 2964.

Plants generally compact, forming cushion-like clumps but occasionally loose, arising from a small but distinct holdfast region, to $18 \mathrm{~cm}$ tall; calcification light; hranching mainly ditrichotomous hut polychotomous from large segments; the basal first or second segments subcylindrical or broadly cuneate and often of a substipitate nature; other segments usually plane, commonly discoidal to reniform but also compressed-cylindrical, cuncate or subcuneate. the outer margin entire, undulating or occasionally somewhat deeply cleft, to $29 \mathrm{~mm}$ long, $33 \mathrm{~mm}$ broad and averaging $0 \cdot 75-1 \cdot 25 \mathrm{~mm}$ in thickness.

Cortex of two, occasionally three layers of utricles; outermost utricles remaining firmly attached after decalcification for an average distance of 
$42 \mu \mathrm{m}$, often fusing laterally in twos, threes and occasionally fours for this same distance, unfused peripheral utricles (30-)40-90 $\mu \mathrm{m}$ in surface diameter, $45-120(-210) \mu \mathrm{m}$ long in section, up to 14 being supported by each secondary utricle; innermost utricles somewhat contiguous at their apical end, or when well developed for most of their length, (70-)95-155(-260) $\mu \mathrm{m}$ broad, 100-350(-435) $\mu \mathrm{m}$ long.

Nodal medullary filaments united in twos and threes, the fusion both complete and incomplete; fused units entangled but at most adhering only slightly.

Type specimen. In the Musée National d'Histoire Naturelle, Paris; label indicates the plant was collected at Kamtschatka during voyage of the Venus; at least locality incorrect.

Habitat. Growing erect; associated with rock surfaces which sometimes may be veneered or partly buried with sand; from slightly below low-tide line to $-50 \mathrm{~m}$.

Geographic distribution. Pantropical; western and eastern Indian Ocean including Red Sea; western Pacific both north and south; north-eastern Pacific, western Atlantic, both north and south; north-eastern Atlantic.

The epithet discoidea was first applied by Esper (1798-1806, Plate 11) to a drawing of Halimeda labelled Corallina discoidea. This plant, apparently Mediterranean, was later placed in synonymy under tuna by Hammer (1830) in his continuation of Esper's work. Even were this relationship not accepted, Esper does not qualify as author of discoidea, since a plate unaccompanied by analysis of parts does not constitute valid publication (Lanjouw et al., 1966). The species discoidea was later described by Decaisne (1842).

This species, although frequently mistaken for tuna and cuneata, is microscopically distinct, and is characterized in particular by the swollen utricles of the inner cortex, one layer being the most common. When an additional zone is present, it rarely occurs uniformly throughout the segment, the innermost utricles then tending towards the lower limit of the size range. Relatively small secondary utricles often occur in Pacific-Mexican plants, and in some of the Hawaiian discoidea. This irregularity was also noted by Howe (1911).

Subsequent to the removal, by Howe (1907), of this species from synonymy under tuna where it had been relegated by Barton (1901), three subspecific taxa have been described: v. platyloba (Børgesen, 1911) from deep water, f. subdigitata (Gilbert, 1947) including plants which resemble cuneata, and f. intermedia (Gilbert, 1947) containing 
specimens intermediate between $\mathrm{f}$. discoidea and f. subdigitata. Consistent with the treatment accorded entities based mainly on modifications of habit or segment morphology which seem unaccompanied by significant histological differences, these three have not been given separate taxonomic standing. The type of the subspecific taxon $H$. cuneata $\mathrm{f}$. digitata has not been located with certainty. It does not appear to belong to cuneata, as already mentioned, and is retained in synonymy with discoidea where it was tentatively placed by Hillis (1959).

\section{Halimeda taenicola W. R. Taylor}

Figure 42.

Halimeda taenicola Taylor (1950), p. 86, Plate 46. Fig. 1; Hillis (1959), p. 354, Plates 2, 5, 6, 11.

Plants erect and compact, arising from a small holdfast region, to $15 \mathrm{~cm}$ tall; calcification moderate; the surface generally glossy and smooth but sometimes rugose; branches numerous with up to five arising from a single segment; the lowermost one to two segments usually compressed-cylindrical to subcuneate and often of a substipitate nature, others plane, often becoming concave on drying, generally subcuneate to trapezoidal, less commonly subcylindrical or reniform, the upper margin entire, to $11 \mathrm{~mm}$ long, $18 \mathrm{~mm}$ broad, and averaging $1 \cdot 0-1.5 \mathrm{~mm}$ in thickness.

Cortex of two to three layers of utricles; outermost utricles remaining firmly attached after decalcification for an average distance of $19 \mu \mathrm{m}$, sometimes fusing laterally in twos and threes for this same distance, unfused peripheral utricles $(20-) 40-75(-86) \mu \mathrm{m}$ in surface diameter, (45-)56125(-140) $\mu \mathrm{m}$ long in section, their lateral and peripheral margins sometimes thickened, four or occasionally up to six supported by each secondary utricle; if three layers of utricles present the secondary ones relatively small, 26-60(-80) $\mu \mathrm{m}$ broad, (30-)40-90 $\mu \mathrm{m}$ long; innermost utricles usually relatively large, $75-160(-190) \mu \mathrm{m}$ broad.

Nodal medullary filaments generally uniting completely in twos and threes; fused units entangled and adhering laterally for $40-70 \mu \mathrm{m}$.

Type specimen. Marshall Islands, Rongerick, Enyvertik Island, Taylor 46-551, 29 June, 1946 (MICH).

Habitat. The known depth range is $-1 \mathrm{~m}$ to $-47 \mathrm{~m}$. At Enewetak this species occupied microsites in the fast-flowing inter-island channels similar to those filled by lacunalis $\mathrm{f}$. lata, but taenicola was less common. These sites were the seaward and leeward faces of the coral rock on which the thalli were growing, often tucked into microcaves or attached near the eroded bases of the rock, under miniature overhangs (Section $\mathrm{X}$ ). 


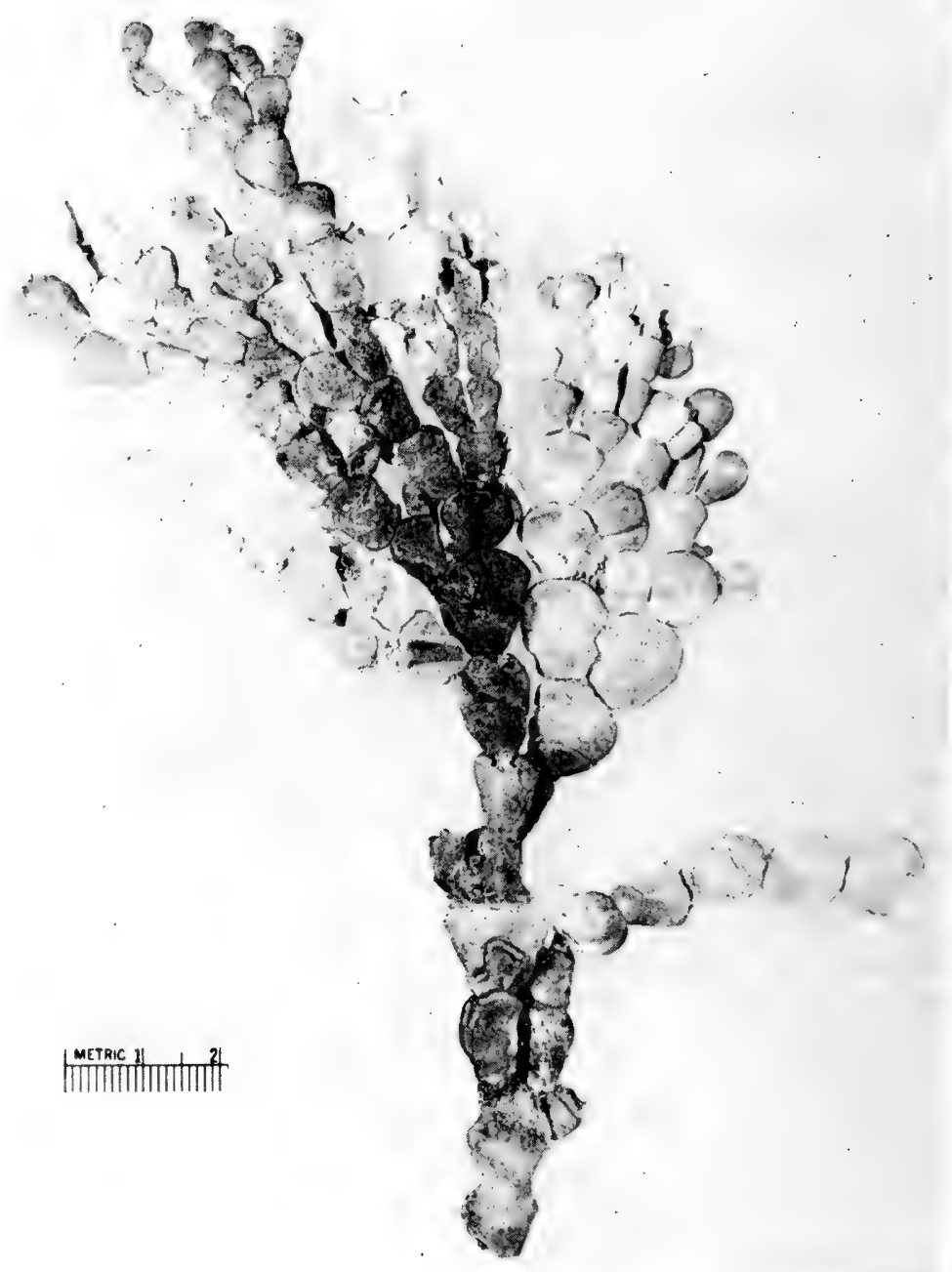

FIG. 42. H. taenicola, with single basal holdfast, from approximately $-4 \mathrm{~m}$ to $-6 \mathrm{~m}$. Specimen from Enewetak Atoll, lagoon side of pass between Alembel and Lojwa Islets, 18 XII 75, Hillis-Colinvaux and Colinvaux. Scale bar is $2 \mathrm{~cm}$. (Photograph by The Ohio State University Department of Photography.)

Geographic distribution. Western Pacific Ocean, both north and south.

In general form, taenicola frequently appears like a Caribbean discoidea with thick segments, from which it can sometimes be 
distinguished macroscopically by its trapezoidal-shaped segments which are often somewhat greenish on drying. Thalli of discoidea often possess relatively large discoidal segments which dry to a brownish colour. The segments of taenicola also appear to be somewhat more heavily calcified than those of discoidea.

Microscopically it also shows resemblances to discoidea, with the rather characteristically expanded utricles of the innermost, usually tertiary, layer of the cortex, although somewhat smaller in average diameter, suggesting the secondary utricles of discoidea. In taenicola these utricles often support five or six relatively small secondary utricles, as opposed to only four or two which are the more usual numbers for most species with a three-layered cortex. Occasionally the intermediate zone may be absent, but this rarely happens uniformly throughout the segment.

In more basal segments of taenicola an additional layer of utricles is frequently present, the length of the peripheral and secondary utricles is often greater, and the breadth of the innermost utricles is towards the lower limit of the range. These modifications, however, occur fairly commonly throughout the genus.

Microscopically, taenicola differs from discoidea in the somewhat smaller surface diameters of the peripheral utricles, these averaging $57 \mu \mathrm{m}$ in taenicola and $65 \mu \mathrm{m}$ in discoidea. Other differences include the relatively fewer lateral fusions of these utricles, and the degree of their lateral attachment, which in taenicola is approximately half that occurring in discoidea. Although the basic nodal structure is similar in these two species, incomplete fusion is considerably commoner in discoidea with the fusion groups at most adhering only slightly. In taenicola groups of fused filaments adhere for an appreciable distance.

The external appearance of this species sometimes leads to confusion with macroloba. These two species can be distinguished macroscopically on the basis of the bulbous holdfast and the somewhat fused condition of the basal or suprabasal segments in macroloba. These features are absent in taenicola. Histologically also, the two species are entirely distinct. The peripheral utricles in macroloba often separate after decalcification, and the pattern of its nodal filaments is that of the section Rhipsalis.

\section{Halimeda bikinensis Taylor}

Figure 43.

Halimeda bikinensis Taylor (1950), p. 87, Plate 48, Fig. 1; Hillis (1959), p. 358, Plates $2,5,6,10$. 
Plants erect, moderately compact or somewhat loose, arising from a small holdfast region, to $20 \mathrm{~cm}$ tall; calcification relatively heavy; branching somewhat sparse with up to four or five segments and occasionally more arising from a single one; basal segments subcylindrical, subcuneate to subreniform, the three to four lowermost ones often devoid of branches; the others brittle, sometimes discoid but more commonly subreniform to reniform with subcuneate segments frequently occurring at the bases of the branches, the outer margin entire or slightly undulating, frequently raised and infolded, measuring to $16 \mathrm{~mm}$ long, $25 \mathrm{~mm}$ broad, and averaging $0.7-1.0 \mathrm{~mm}$ in thickness.

Cortex of two to three layers of utricles produced by dichotomies in the lateral branches of the medullary filaments; the outermost utricles remaining slightly attached or separating on decalcification, appearing rounded in surface view, 23-47 $\mu \mathrm{m}$ in surface diameter, (48-)60-105(-125) $\mu \mathrm{m}$ long in section, most commonly four but up to eight borne on each secondary utricle; secondary utricles usually not constricted at their origin, $20-47 \mu \mathrm{m}$ broad.

Nodal medullary filaments occasionally remaining separate but more commonly uniting in twos and threes, the fusions within these units being complete or incomplete; fusion units not particularly entangled, and at most adhering only slightly.

Type specimen. Marshall Islands, Namu Islands, Bikini Atoll, Taylor 46-156, 3 April, 1946 (MICH).

Habitat. In deep holes of inner reef flats (Taylor, 1950); it is also known to $-90 \mathrm{~m}$ from material dredged during the Sealark Expedition, 1905 (Hillis, 1959).

Geographic distribution. Western Indian Ocean; north Pacific.

In external appearance this species is most commonly confused with specimens of tuna with large segments, with discoidea, and to a lesser extent with gigas. A number of well-defined distinctions exist for bikinensis, however, including the greater degree of calcification of its segments, the dichotomous nature of theinner cortex, the smaller surface diameters of the peripheral utricles, and the relative ease of separation of these utricles. This last characteristic varies somewhat with age.

Microscopically, this species appears to have most in common with gracilis and lacrimosa. Characteristic of these two species and most particularly lacrimosa are the somewhat swollen apical ends of the secondary utricles which in turn support several, usually 6-18, peripheral utricles. These are absent in bikinensis, although the appearance is somewhat simulated by some of the broader secondary utricles which may bear up to eight peripheral utricles rather than the more usual two or four. 


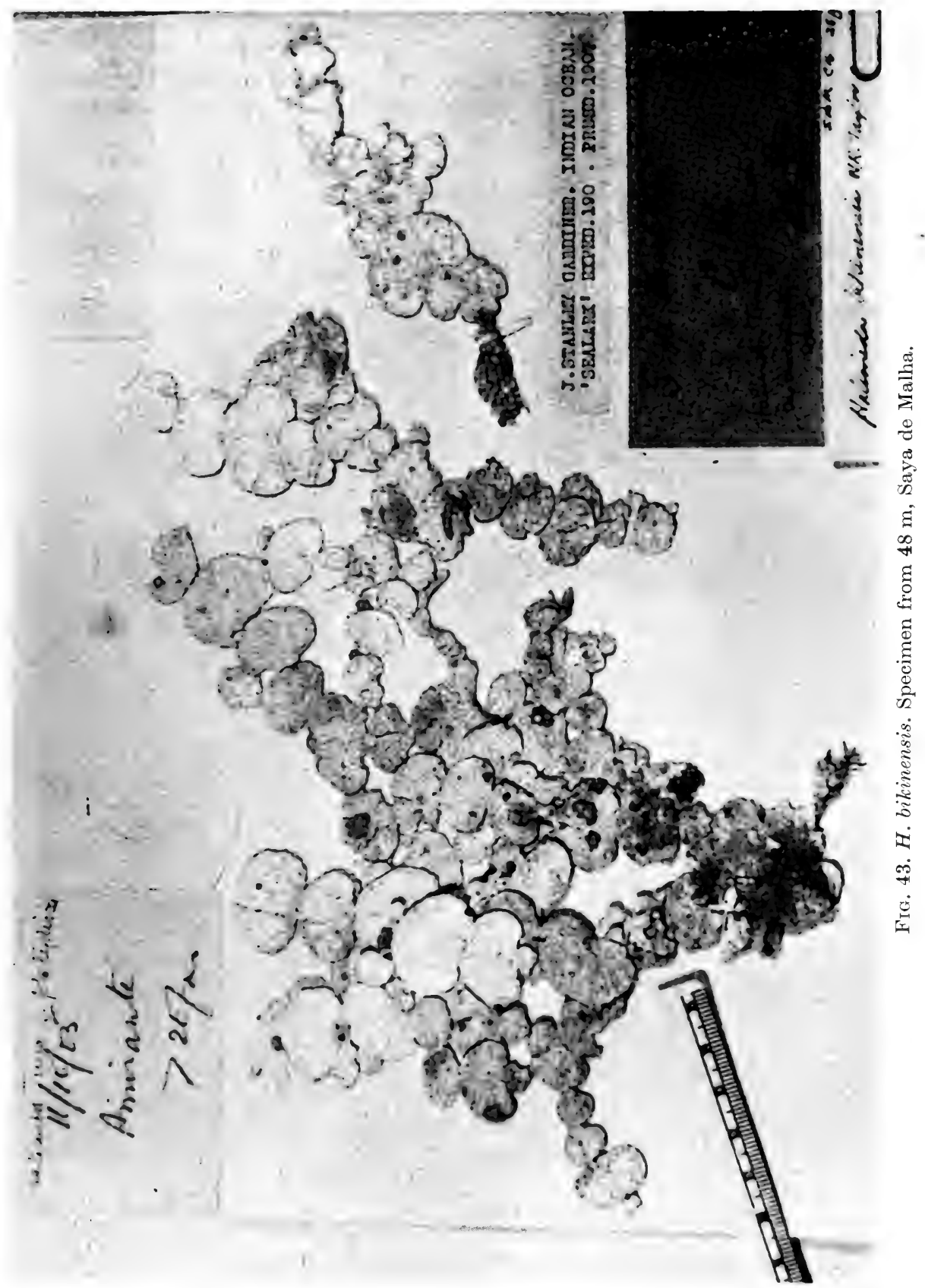




\section{Halimeda gracilis Harvey ex J. Agardh}

Figure 44 .

Halimedu gracilis Harvey or J. Agardh, 1857. p. S2; Harvey's ('eylon Algae No. 7:2: Barton (1901), p. 20. Plate 3. Figs 28-32: Vickers and Shaw (1!us). p. 24. Plate 34: Collins (1909-1915). p. 399: Hillis (1959), p. 356, Plates 2, 5, 6, 7, 10.

Ilulimedu !racilis v. opuntioides Borgesen (1911). p. 1.H, Fig. 11; Borgesen (1913), p. 108, Fig. 87.

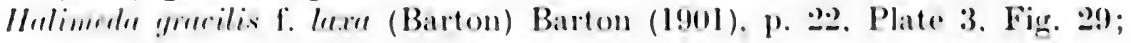
Halimeda laxa Barton (1900), p. 479, Plate 18, Figs 1-3.

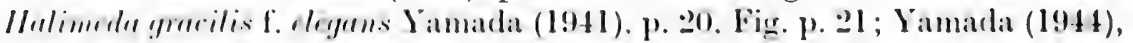
p. 28 , Plate 3.

Halimeda cuneata Kützing (1857), p. 8, Plate 21, Fig. 3.

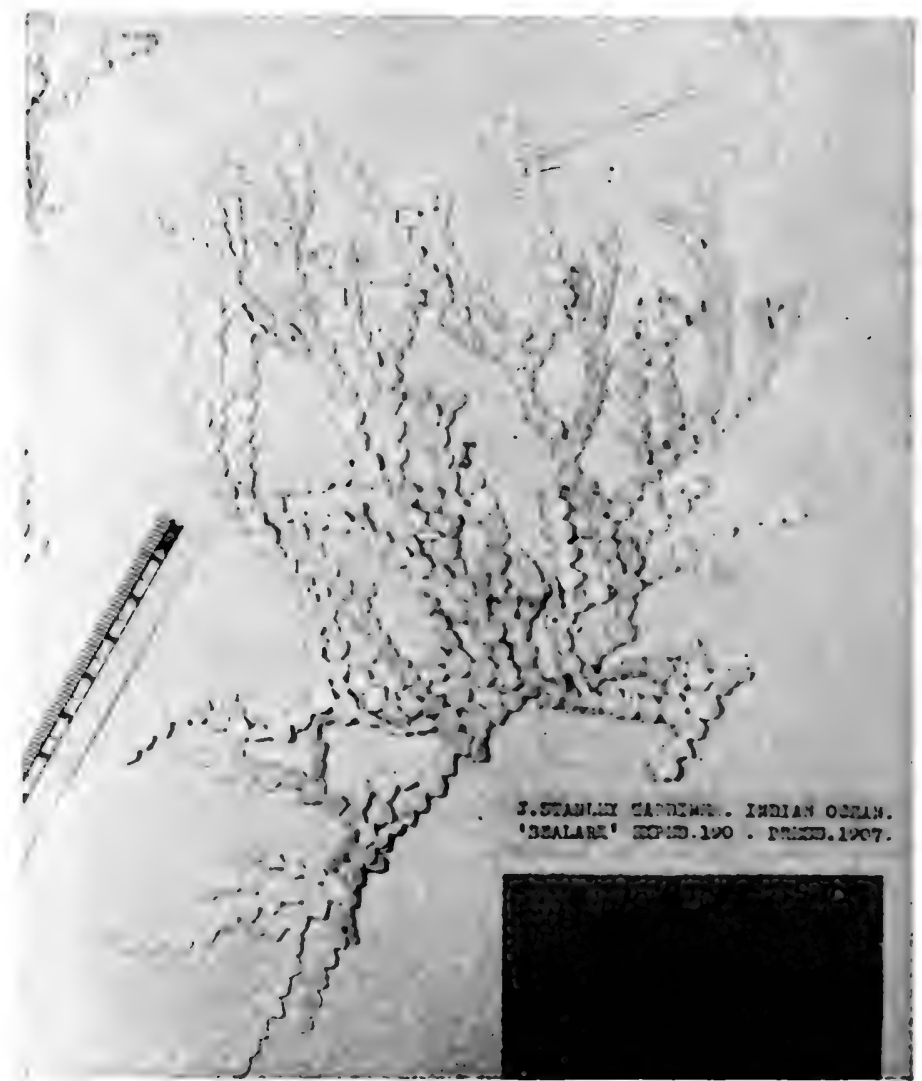

FIG. 44a. H. gracilis. Photograph shows spreading habit characteristic of many thalli. specimen from Saya de Malha. 
Plants flaccid, straggling and decumbent, sometimes to over $1 \mathrm{~m}$ long; holdfast attachment not restricted to a single basal region but at several places where the sprawling thallus contacts substrate; calcification moderate to heavy; the surface usually glossy; branching sometimes sparse but usually frequent with up to five branches arising from a single segment; segments ribbed, chalky to brittle, at times subcylindrical but more commonly subcuneate to reniform, the upper margin entire, undulate or lobed, to $9 \mathrm{~mm}$ long, $15 \mathrm{~mm}$ broad, and averaging $0.50-0.75 \mathrm{~mm}$ in thickness.

Cortex of two, sometimes three, layers of utricles, these generally produced by dichotomies in the lateral branches of the medullary filaments; outermost

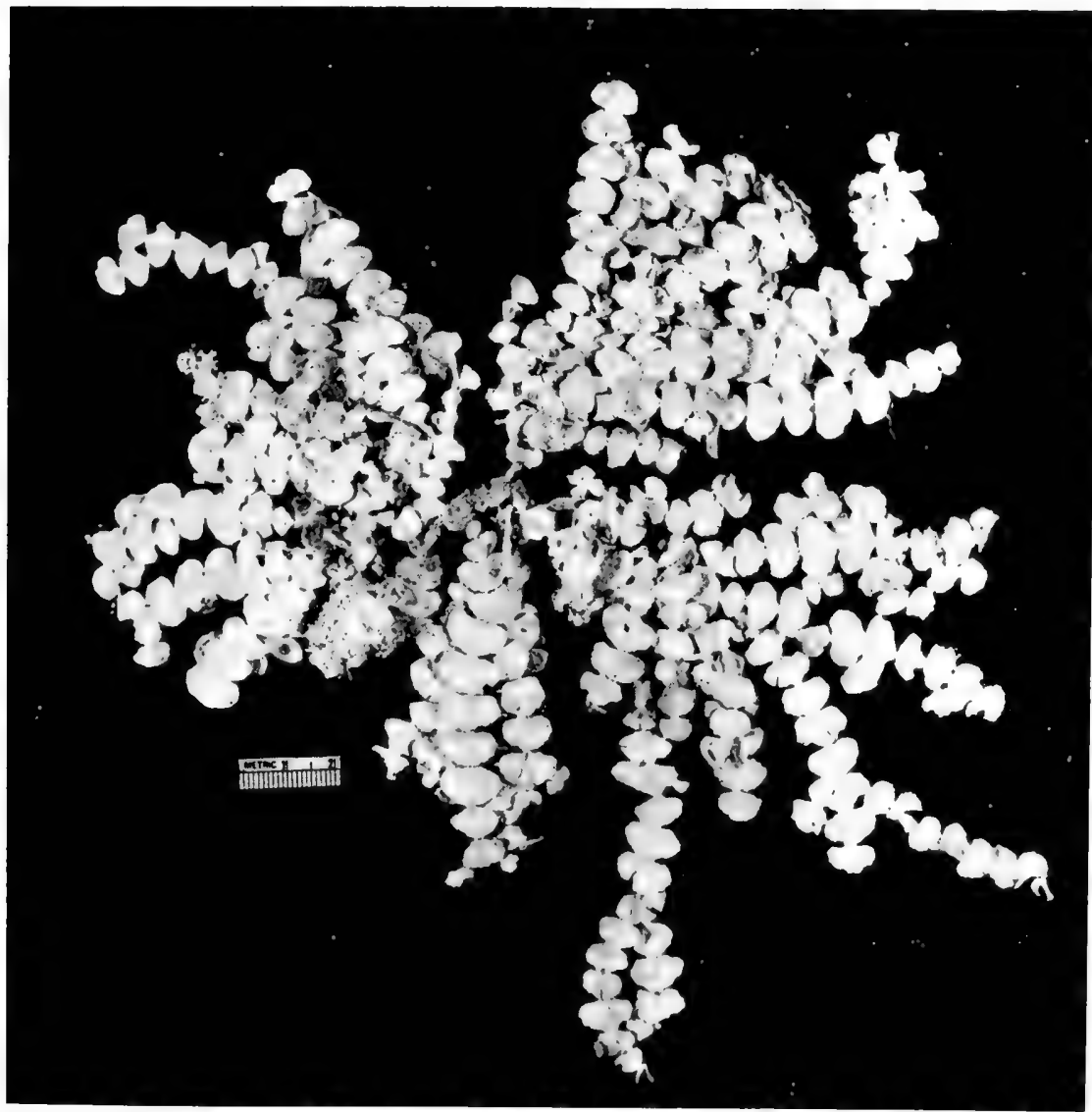

FIG. 44b. H. gracilis showing a more compact, broader segmented habit than that in Fig. 44a. Both are relatively common. Specimen from Mentawei Islands, west of Sumatra, Pulau Stupai, northern edge of Sanding Islands, in c. $-1.1 \mathrm{~m}$ to $-5 \mathrm{~m}$, 4 XII 63, Hillis-Colinvaux LH 29c. Scale bar is $2 \mathrm{~cm}$. (Photograph by The Ohio State University Department of Photography.) 
utricles usually remaining slightly attached on decalcification, occasionally separating but still appearing hexagonal rather than rounded in surface view, 23-58(-70) $\mu \mathrm{m}$ in surface diameter, 40-90(-110) $\mu \mathrm{m}$ long in section, up to eight supported by each secondary utricle; secondary utricles clavate, $23-70(-125) \mu \mathrm{m}$ broad, usually relatively long and frequently extending to the medulla.

Nodal medullary filaments fused most commonly in twos but occasionally in threes, fusion complete; fusion groups not entangled and at most adhering only slightly.

Type specimen. Harvey's Ceylon Algae No. 72 ; isotype material in several herbaria including BM, NY.

Habitat. This species, which is often straggling and sprawling frequently grows at the bases of coral rock and therefore may be associated with sand as well as rock. Attachment is provided by a multi-holdfast system. At Enewetak Atoll gracilis was most commonly associated with distorta and macrophysa, occasionally with minima. The known vertical range for the species is $-1 \mathrm{~m}$ to $-70 \mathrm{~m}$.

Geographical distribution. Pantropical; western and eastern Indian Ocean; western Pacific, both north and south; western Atlantic, both north and south.

This species seems closely related to lacrimosa and probably also to bikinensis. From bikinensis, a taxon of relatively compact specimens with large segments, to $16 \mathrm{~mm}$ long and $25 \mathrm{~mm}$ broad, gracilis is often readily distinguished by its loose straggling habit which reaches a length of $1 \mathrm{~m}$ or more, and by its smaller segments, to $9 \mathrm{~mm}$ long and $15 \mathrm{~mm}$ broad. In contrast, plants of lacrimosa reach about $5 \mathrm{~cm}$ in length and are composed of spherical or tear-shaped segments rather than flat ones.

Although gracilis is pantropical, its known distribution is extremely limited as compared to that of discoidea or opuntia. The paucity of records can be partly attributed to the relatively frequent misidentifications of material of this species as opuntia, and less commonly as incrassata or tuna. Identity problems can be resolved microscopically because nodal medullary filament pattern and appearance of the cortical layers are both distinctive for gracilis.

The peripheral utricles in plants of this species may initially appear rounded in surface view and give the impression of being separate. A more careful examination, however, usually reveals that they are at least slightly attached, though often by only the thin platform-like extensions of the outer surface. The different optical properties of these edges and the slightly convex outer face of the utricles combine to 
produce the illusion of roundness. These edges, in addition, may sometimes create the impression of a matrix, perhaps formed of the covering lamella, surrounding the utricles. This may represent the condition described by Barton for some of these plants.

Four infraspecific categories have been designated for this species: v. opuntioides (Børgesen, 1911), f. laxa (Barton, 1901), f. elegans (Yamada, 1941), and f. lata (Taylor, 1950). The latter has been transferred to lacunalis (Hillis, 1959). Since the variations in appearance on which the other three forms are based also occur in typical plants, these three forms were placed in synonymy under gracilis (Hillis, 1959).

\section{Halimeda lacrimosa Howe}

Figure 45 .

Halimeda lacrimosa Howe (1909), p. 93, Plate 4, Fig. 1; Plate 6, Figs 3-11; Collins (1909-1918), p. 399; Hillis (1959), p. 357, Plates 2, 5-7, 10.

Plants fragile, straggling and decumbent, to $5 \mathrm{~cm}$ long; calcification heavy; colour on drying white, often becoming bluish-green towards the apex, the surface smooth and usually glossy; branching restricted, generally di- or trichotomous; segments easily crushed on drying, the basal ones usually cylindrical, often moniloid; others and particularly the more apical ones commonly spherical or tear-shaped, to $5 \mathrm{~mm}$ in the three dimensions.

Cortex of two to three layers of utricles, these often produced by dichotomies or tetrachotomies in the lateral branches of the medullary filaments; outermost utricles usually remaining slightly attached on decalcification, occasionally separating but still appearing hexagonal rather than rounded in surface view, 31-42 $\mu \mathrm{m}$ in surface diameter, 40-110 $\mu \mathrm{m}$ long in section, generally 6-18 supported by each secondary utricle; secondary utricles capitate, $66-110 \mu \mathrm{m}$ broad at the apical end, 105-340(-400) $\mu \mathrm{m}$ long.

Nodal medullary filaments uniting in twos, threes and fours, incompletely or completely, short and complete fusions often mixed so that fewer filaments may emerge than participate in the fusion; resultant units not particularly entangled and at most adhering only slightly.

Type specimen. Bahamas, Mariguana, Howe 5524, 11 December, 1907 (NY).

Habitat. Howe (1909) reports this tiny species growing on stones, in sand, and on the stipes of Avrainvillea. It is also associated with Pocockiella (Diaz-Piferrer collection). Its known vertical range is $-1 \mathrm{~m}$ to $-20 \mathrm{~m}$.

Geographic distribution. North-western Atlantic. 


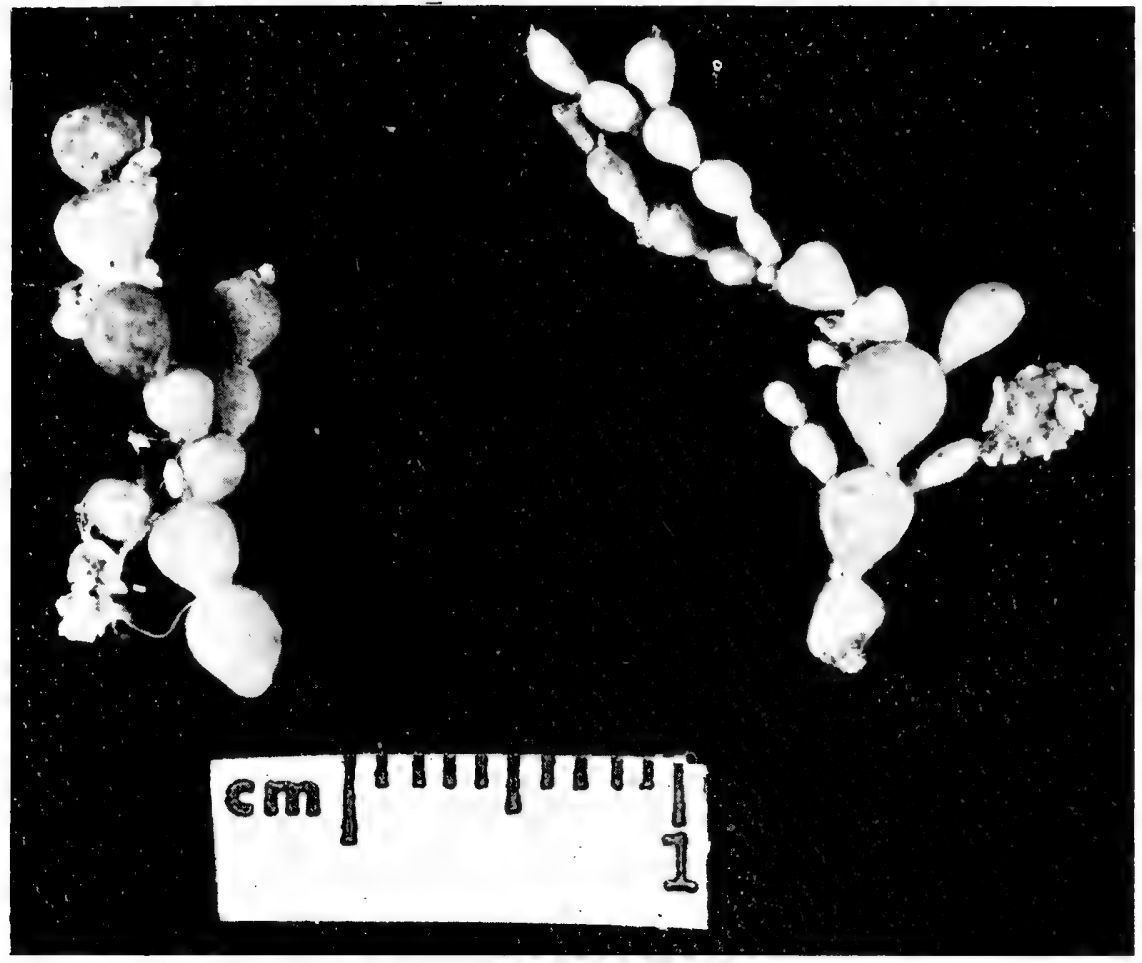

FIG. 45. H. lacrimosa. Specimen from Florida, Content Key, 23 IV 66, Croley 1061. (Photograph by The Ohio State University Department of Photography.)

This delicate species is readily distinguished from all other species of the genus by its small size and by the presence of spherical or pyriform (tear-shaped) segments. It shares with one of the commonest growth forms of gracilis, apparently the most closely related species, several features including a lax decumbent habit and an essentially dichotomous inner cortex. The general appearance and degree of attachment of the peripheral utricles are also common to the two species.

Microscopically, lacrimosa is characterized by capitate secondary utricles which appear circular in cross-section and support up to 18 peripheral utricles. The pattern of nodal medullary filaments is complex, and is perhaps best interpreted as a combination of short and complete fusion with, for example, two filaments sometimes resulting from a fusion of three or four. The usual type of complete fusion also occurs.

The restricted distribution of this species may be partly accounted for by the ease with which such small specimens are overlooked. 
4. Section Micronesicae n. sect.

\section{Halimeda micronesica Yamada}

Figure 46.

Halimeda micronesica Yamada (1941), p. 121, Fig. 15; Yamada (1944), p. 29, Plate 5; Taylor (1950), p. 89, Plate 46, Fig. 2; Plate 47; Hillis (1959), p. 364, Plates 3, 5, 6, 9.

Halimeda orientalis Gilbert (1947), p. 126, Fig. 1.

? Halimeda incrassata f. pusilla Barton (1901), p. 28, Plate 4, Fig. 44.

Plants compact, spreading, to $10 \mathrm{~cm}$ tall excluding the rhizoidal region which is often small but sometimes long and fibrous, the rhizoids not noticeably interlaced with sand particles; calcification moderate; colour on drying white or steel-grey, the surface usually dull; branching, except for the basal region, mainly trichotomous and complanate; basal segment larger than the others and more or less reniform, its outer margin frequently undulate, to $12 \mathrm{~mm}$ long, $18 \mathrm{~mm}$ broad, supporting numerous cylindrical to subcuneate segments; other segments occasionally slightly ribbed, sometimes cylindrical but more commonly subcuneate to discoidal, the upper margin entire to trilobed, to $7 \mathrm{~mm}$ long, $9 \mathrm{~mm}$ broad and averaging to $0.5 \mathrm{~mm}$ in thickness.

Cortex mainly of three or occasionally four layers of utricles produced by successive dichotomies in the lateral branches of the medullary filaments; outermost utricles usually separating on decalcification but in young segments often slightly attached, usually appearing rounded in surface view, 28-48(-55) $\mu \mathrm{m}$ in surface diameter, 40-82(-94) $\mu \mathrm{m}$ long in section, borne two or four on each secondary utricle; secondary utricles generally not constricted at their origin, $15-45 \mu \mathrm{m}$ broad.

Nodal medullary filaments remaining unfused although sometimes adhering slightly with adjacent ones; filament walls in nodal region thickened and usually somewhat pigmented.

Type locality. Ants Atoll, near Ponape Island in the east Caroline Islands.

Habitat. Growing attached to rock in relatively exposed sites such as inter-island channels of Enewetak Atoll. Rope-like noncorticated extensions from segments provide additional attachment and the resultant growth form is semi-prostrate. Known vertical range for this species is $-1 \mathrm{~m}$ to $-37 \mathrm{~m}$.

Geographic distribution. Western and eastern Indian Ocean; western Pacific, both north and south.

This was the first species described in which the medullary filaments continued unfused through the node. Barton (1901) mentioned such a 

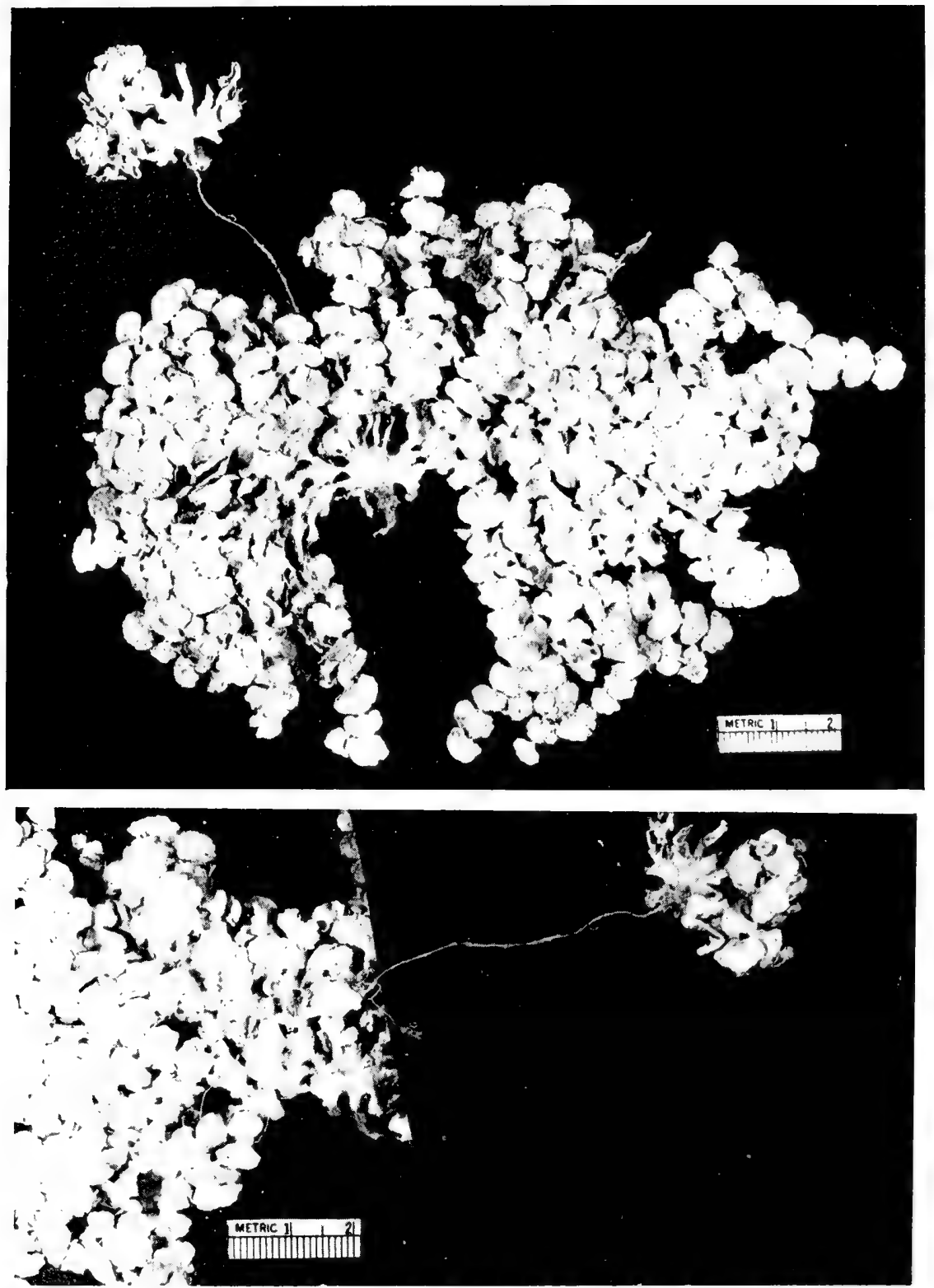

FIG. 46. H. micronesica, showing small holdfast, and much enlarged basal segment which is somewhat contorted and bears many branches. In the specimen shown the nodal medullary filaments of a segment near the base (bottom photograph) have remained uncorticated, forming a rope-like strand which terminates in a young plant. This is an example of asexual reproduction by runners which are ahove the substrate. Specimen from vicinity of South Pagi Island, west of Sumatra, 2 XII 6:3, Hillis-Colinvaux LH $27 \mathrm{a}, \mathrm{b}$, c. Scale bars are $2 \mathrm{~cm}$. (Photographs by The Ohio sitate University Department of Photography.) 
condition but felt that it occurred largely in stunted plants. She assigned some of them to incrassata f. ovata.

In addition to having this special nodal pattern, micronesica is characterized by peripheral utricles which usually separate readily, and by an extremely modified basal, rarely suprabasal, segment which may become very large in some specimens but is less distinctive in others. In well-developed plants the growth is prostrate, with branches projecting in all lateral directions from the greatly enlarged basal (suprabasal) segment. These branches occasionally terminate in ropelike extensions to approximately $6 \mathrm{~cm}$ in length, which consist of intertwined rhizoidal filaments.

\section{Halimeda fragilis W. R. Taylor}

Figure 47.

Halimeda fragilis Taylor (1950), p. 88, Plate 48, Fig. 2 ; Hillis (1959), p. 363, Plates 3, 5-9.

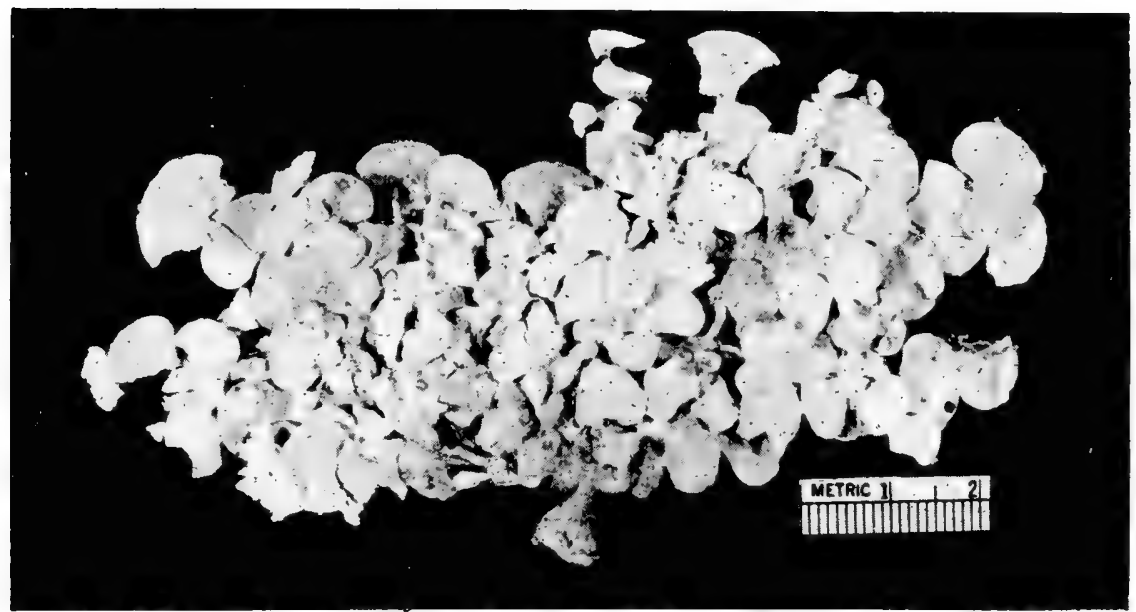

FIG. 47. H. fragilis, with holdfast. From Enewetak Atoll, pass between Alembel and Lojwa Islets, towards seaward side, 18 XII 75, Hillis-Colinvaux. Scale bar is $2 \mathrm{~cm}$. (Photograph by The Ohio State University Department of Photography.)

Plants compact, often cushion-like, to $8 \mathrm{~cm}$ tall including the rather small holdfast region, rhizoids not noticeably interlaced with sand particles; calcification heavy; colour on drying white, cream or greyish-green, the surface dull; branches occurring in more than one plane with up to four arising from a single segment; basal segment generally inconspicuous, cylindrical to reniform; others brittle, frequently ribbed and sometimes 
keeled, occasionally cylindrical, these usually occurring as the basal segments of branches, sometimes subcuneate but more commonly subreniform to reniform, the lower margin truncate to auriculate, the upper margin entire to trilobed, to $9 \mathrm{~mm}$ long, $16 \mathrm{~mm}$ broad, and averaging $0.50-0.75 \mathrm{~mm}$ in thickness.

Cortex of three to four layers of utricles produced by successive dichotomies in the lateral branches of the medullary filaments; outermost utricles separating on decalcification, appearing rounded in surface view and at times thickened along the peripheral margin, 21-52 $\mu \mathrm{m}$ in surface diameter, (32-)43-81 $\mu \mathrm{m}$ long in section, borne two or four on each secondary utricle; secondary utricles usually not constricted at their origin; 15-46 $\mu \mathrm{m}$ broad.

Nodal medullary filaments remaining unfused although adjacent filaments may adhere slightly; filament walls in this region usually extremely thickened and deeply pigmented.

Type specimen. Marshall Islands, Enewetak Atoll, Taylor 46-394, 2 June, 1946 (MICH).

Habitat. Growing on rock in the fast-moving waters of interisland passes at Enewetak where it seemed to be rare; reported commoner in the deeper waters of the lagoon attached to pinnacles (Gilmartin, 1960). The known vertical range of the species of $-1.5 \mathrm{~m}$ to $-57 \mathrm{~m}$.

Geographic distribution. Central Indian Ocean; north-western Pacific.

Macroscopically, fragilis is most frequently confused with opuntia, gracilis and to a lesser extent bikinensis. In all four species the cortex is formed essentially by dichotomous branching of the lateral medullary filaments and thus internally there are also similarities. Difficulties in macroscopic determination, however, can always be resolved by an examination of the nodal medullary filaments which remain separate in fragilis, but fuse in twos and threes in the other species. The separate peripheral utricles in fragilis are also distinctive. In bikinensis the peripheral utricles separate only with pressure, whereas they generally remain attached in opuntia and gracilis.

From micronesica, a second species in which the nodal filaments remain separate, fragilis can be distinguished macroscopically by its heavier calcification and by its often complanate branching. In addition, the segments are somewhat thicker, larger, more brittle and commonly reniform in shape rather than discoid or trilobed, and the lowermost segment is usually smaller than the others rather than being generally much larger and flabellate as is typical for micronesica. 
Halimeda melanesica Valet

Figure 48.

Halimeda melanesica Valet (1966), p. 680, Figs 1, 2, Plate 1.

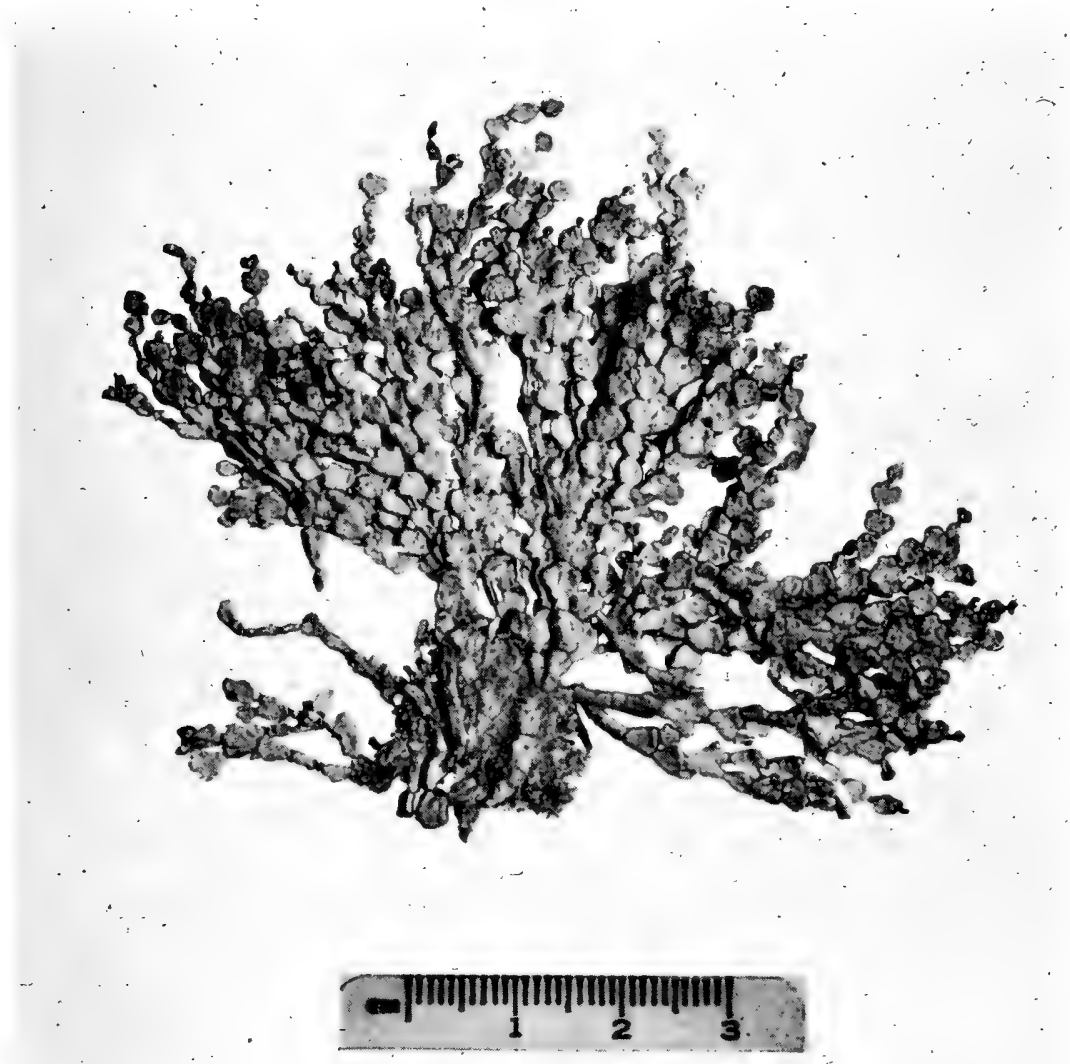

Fig. 43. H. melanesica. Isotype, New Caledonia, region of Luengöni, Loyalty Islands, Isle Lifou, 10 I 64, Valet 1853. Discrete holdfast absent although photograph shows rhizoidal filaments with sand associated with lower segments. (Photograph by Jodi Grenga.)

Plants forming flaccid clumps, to about $12 \mathrm{~cm}$ tall; holdfast function appears to be served by aggregates of basal segments and adhering particles of sand and shell which fix the thallus firmly to hard (rock) substrate, this holdfast mass to $1 \mathrm{~cm}$ and possibly more in width; calcification light; basal segment reniform, to $5 \mathrm{~mm}$ long, $9 \mathrm{~mm}$ broad, bearing two to four branches 
of which the first segments are cylindrical to cuneate and often conspicuously larger than those above although not as large as basal segment; other segments cuneate, with lobed or entire margins, to $4 \mathrm{~mm}$ long, $3 \mathrm{~mm}$ broad and $0.5 \mathrm{~mm}$ thick.

Cortex generally of three series of utricles which are often constricted at their bases; outermost utricles remaining attached after decalcification and appearing polygonal in surface view, $(20-) 56-72 \mu \mathrm{m}$ in surface diameter, 62-90 $\mu \mathrm{m}$ long; secondary utricles 47-72 $\mu \mathrm{m}$ in diameter.

Nodal medullary filaments remaining unfused, or at times fusing in pairs for a distance of $1-1.5$ times the diameter of the filaments.

Type specimen. Loyalty Islands, vicinity of Luengoni, Lifou, Valet, 1853, 1 October, 1964 (PC; an isotype in Hillis-Colinvaux herbarium).

Habitat. Growing on coral rock in agitated water at $-3 \mathrm{~m}$.

Geographic distribution. South-western Pacific.

5. Section Crypticae n. sect.

Halimeda cryptica L. H. Colinvaux and Graham

Figures 3, 15, 49 .

Halimeda cryptica L. H. Colinvaux and Graham (1964), p. 5, Plates 3-5.

Plants to about $9 \mathrm{~cm}$ tall, loosely to somewhat compactly organized, with a small distinct holdfast which is usually less than $\mathrm{I} \mathrm{cm} \mathrm{long;} \mathrm{calcification}$ heavy to moderate; colour of lighted and umbral surfaces of plant distinctly different, the lighted surface on drying usually green but sometimes greenishcream to off-white, the umbral surface white to cream, both surfaces generally dull though sometimes glossy in younger segments; branching usually di- or trichotomous; segments generally plane but occasionally slightly ribbed, brittle, the bases of all but the basal segment attenuated into a short narrow beak or stalk; basal segment usually turbinate, the others most commonly very broadly to depressed ovate or transversely broadly to transversely elliptic, sometimes with upper margins shallowly trilobed and lower margins auriculate to truncate, occasionally and particularly in the lower third of the plant the segments broadly to transversely rhombic or angular-obovate; segments often largest in the middle third of the plant measuring when dried to $11 \mathrm{~mm}$ long, $15 \mathrm{~mm}$ broad and about $0 \cdot 33-0 \cdot 66 \mathrm{~mm}$ thick.

Cortex of two to three, less commonly to four series of utricles, with the inner utricles often not particularly expanded at the apices or constricted at their bases; outermost utricles very broadly obovate to depressed obovate, remaining attached after decalcification or separating slightly, although still 

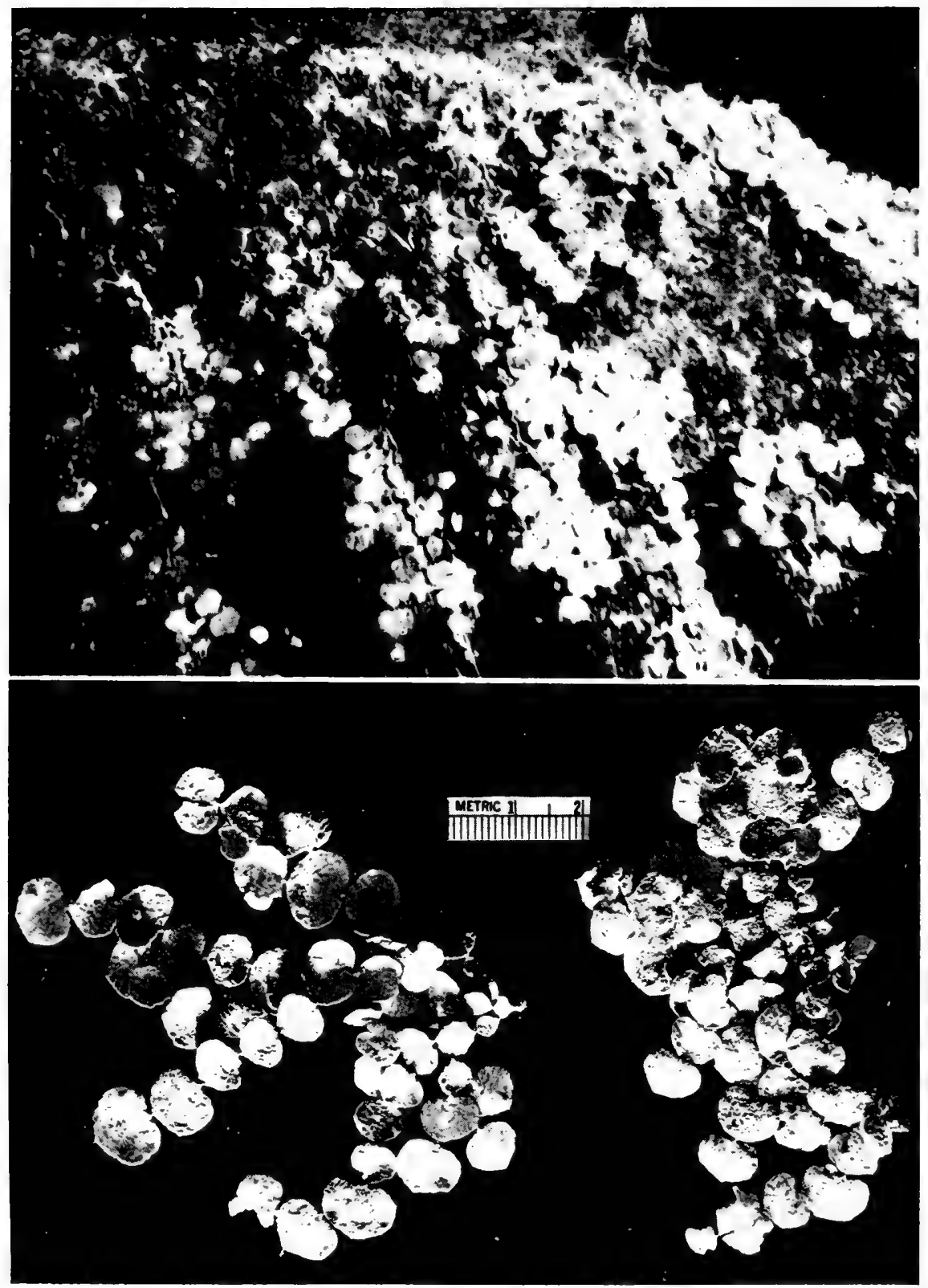

Fig. 49. H. cryptica. (Top) A vertical, heavily-shaded rock wall at about $-43 \mathrm{~m}$ with attached pendant clumps of $H$. cryptica. (Photograph by T. F. Goreau, Jamaica, Maria Buena Bay, Duncans; from Colinvaux and Graham (1964).) (Bottom) Habit to two plants, each with a basal segment. The plant on the left also has a typical small holdfast. Scale bar is $2 \mathrm{~cm}$. (Left-hand plant $=$ isotype, NY; from Colinvaux and Graham, 1964.) 
generally retaining their hexagonal appearance in surface view, (36-)56$76(-103) \mu \mathrm{m}$ in surface diameter, (42-)54-69(-83) $\mu \mathrm{m}$ long in section including the sometimes prolonged pedicels, usually four supported by each secondary utricle; secondary utricles (20-)27-40(-65) $\mu \mathrm{m}$ broad.

Plants uniaxial, the single medullary filament generally broadest in the node region where the wall is often yellowish and (11-)18-45(-58) $\mu \mathrm{m}$ in maximum thickness.

Type specimen. Jamaica, Parish of St Ann, Runaway Bay off Cardiff Hall beach, from a depth of $34-41 \mathrm{~m}, \mathrm{~T}$. F. Goreau and E. A. Graham, 26 August, 1962 (IJ ; isotypes in BM, NY, UC, UCWI, UM).

Habitat. Hanging from rock surfaces or flattened against them, on the fore-reef, fore-reef slope and deep fore-reef, this species develops its largest populations in the deep fore-reef (Goreau and Goreau, 1973; Moore et al., 1976). Down to $-100 \mathrm{~m}$ it is associated with copiosa, but cryptica is much the commoner. Its vertical range is $-25 \mathrm{~m}$ to $-100 \mathrm{~m}$.

\section{Geographic distribution. Western Atlantic Ocean.}

The external aspect of these plants suggests the Indo-Pacific species fragilis. Yet cryptica is readily separated from this and all other described species of Halimeda, with the possible exception of some specimens of copiosa, by the consistently different colour of its lighted and umbral surfaces, the light-exposed surfaces usually being green, the umbral ones white or off-white. Less striking but equally characteristic of cryptica is the especial delicacy of the nodes, an expression of this species' uniaxial construction (Figs 3, 15). All other described Halimedae are multiaxial (Hillis, 1959). Smallish utricles from the upper, and to a lesser extent from the lower, of two adjoining segments form a collar (Fig. 3) which almost covers the medullary filament at the node, and produces the beaked or stalked macroscopic appearance of the upper of the segments.

The lighted and umbral surfaces of mature segments can be readily distinguished microscopically also. The peripheral cortical utricles of the umbral surface generally seem delicate. They collapse easily, and seem to become detached readily from the secondary utricles. To observe them satisfactorily the mature segments must usually be very slowly decalcified. Preparations to show the surface of the peripheral utricles of the umbral surface are more easily made from immature segments. In contrast, the peripheral utricles of the lighted surface and of the edge of the segment continuing slightly into the umbral surface 
are well developed, and retain their shape on decalcification as do those of other Halimeda species. The plastids in the material studied were generally conspicuously denser in the utricles of the lighted surface.

\section{H. Species of uncertain systematic position}

Authentic specimens have not been located for four described species which can therefore not be placed in the system.

\section{Halimeda irregularis Lamouroux}

Halimeda irregularis Lamouroux (1816), p. 307, Fig. 7.

Type locality. Antilles, West Indies.

\section{Halimeda nervata Zanardini}

Hatimeda nervata Zanardini (1858), p. 289, Plate 12, Fig. 2.

Type specimen. Collected by Portier in the Red Sea.

\section{Halimeda papyracea Zanardini}

Halimeda papyracea Zanardini (1851), p. 37; Zanardini (1858), p. 288, Plate 13, Fig. 2.

Type specimen. Collected by Portier in the Red Sea.

\section{Halimeda rectangularis J. Agardh}

Halimeda rectangularis J. Agardh (1894), p. 100.

Type locality. Australia.

\section{Culture}

Serious attempts to culture Halimedae and their relatives apparently date from the 1960s. Techet (1908) showed that tuna could be kept in aquaria supplied with seawater at a marine station. In addition, very many coral reef organisms, including Halimedae, were kept for short times in aquaria at the Discovery Bay Laboratory in Jamaica by Dr T. F. Goreau in the early 1960s. This suggested that Halimedae could be grown in aquaria, if necessary, far from the sea. This has been done (Colinvaux et al., 1965), and Halimedae have been maintained at inland laboratories for over two years, in both natural and artificial seawater, 
with the production of more than one vegetative generation. Only the completion of the sexual cycle, with the development of the characteristic segmented thallus from the loose filaments obtained by the germination of zygotes (Meinesz, 1972b), still remains to be carried out in culture.

The basic approach, which can be modified in many ways to suit facilities and the particular problem being investigated, is given in the following subsections. Considerably more elaborate arrangements are possible and may at times be feasible, but much can be done simply. Halimedae and their calcareous relatives such as Penicillus, Udotea, Rhipocephalus, Acetabularia and Batophora all seem relatively hardy. They can be transported for several days in dim light and at temperatures of $20^{\circ} \mathrm{C}$ or less, and still grow satisfactorily in the laboratory.

It is not yet possible to begin Halimeda cultures with clean zygotes, not only because fertile plants of most species are hard to find, but also because it is not yet known how to germinate and grow the mature thallus from zygotes. It is only with tuna from the Mediterranean that development beyond the zygote has been obtained (Meinesz, 1972b), and this has not been the adult plant as we know it (Section VII). It is necessary, therefore, to begin cultures with direct transplants from the sea, a procedure that unavoidably introduces troublesome contaminants into the cultures. The basic procedure is to collect good field material, to clean it by hand, to plant it in simple aquaria, to bubble air into the water, to provide light and to combat epiphytes.

\section{A. Field procedure}

It is obviously important to select healthy vigorous specimens; the difficulty is to identify the signs of vigour and health. It seems natural to avoid thalli with segments which tend to fall off when touched, with white segments, or with large numbers of epiphytes. The thalli selected should be collected with minimal damage to the holdfast, and rock-growing species should have a portion of the rock to which the holdfast is attached included if possible.

After collecting, the thalli are carefully cleaned of as much associated plant or animal material as is possible without breaking the segment surface or pulling away the holdfast filaments. Then, until the algae can be transported to home base, they are maintained in three to four times their volume of clear seawater at about $24-25{ }^{\circ} \mathrm{C}$ with a bubbler, and exposed to diffuse light. For travel, the water is replaced with fresh clean seawater, the amount being decreased to that manageable for the journey, and the containers closed. If accessible, compressed air is 
bubbled in at this stage. Large heavy-gauge plastic bags are useful for separating different collections, those with and without attached pieces of rock, for example. The bags can then be tied off and arranged carefully in styrofoam chests to minimize damage. Buckets with fitted lids and collapsible carboys are also suitable containers, and can be carried in the pressurized cabins of aircraft. About 50 sand-dwelling Halimedae can be transported in a $4.5 \mathrm{l}$ carboy half-full of seawater. They survive up to 3 days of travel in this way.

The algae are replanted as soon as possible after arrival. If time and facilities permit, it is a good plan to check for smaller epiphytes with a dissecting microscope and remove them.

\section{B. Basic laboratory procedure}

The Halimedae are grown in closed aquaria without recirculating water, lighted for part of the day, provided with about $2.5 \mathrm{~cm}$ of calcareous gravel, and equipped with an air bubbler (Fig. 50). Sanddwelling forms with bulbous holdfasts are simply planted in aquaria containing about $2.5 \mathrm{~cm}$ of sand over the calcareous gravel. Rockattached forms are anchored to the bottom or suspended from an arrangement of rocks or pieces of clean dead coral in a manner that resembles their normal growth habit. Species with a sprawling growth pattern such as opuntia are merely placed in an aquarium without sand but which usually contains chunks of rock or coral (Fig. 51). The aquaria are covered with glass or a thin sheet of transparent plastic. The thalli are regularly cleaned by hand of epiphytes and animals as far as is possible without damaging them.

\section{Culture medium}

Natural seawater and the commercial artificial seawater "Instant Ocean" have been the main media used.

Natural seawater is collected from areas free of wastes and filtered through a Millipore filter with average pore size $0.45 \mu \mathrm{m}$.

Commercial artificial seawaters were not available when I first started culturing. They are now readily obtainable, however, and have proved as satisfactory for this work as natural seawater. The composition of "Instant Ocean" is given in Table XI. Some minor elements are missing from it, but results seem comparable to those with natural seawater.

No nutrients are added directly to either medium in routine culturing. Some nutrients are probably introduced by the sand substrates, 


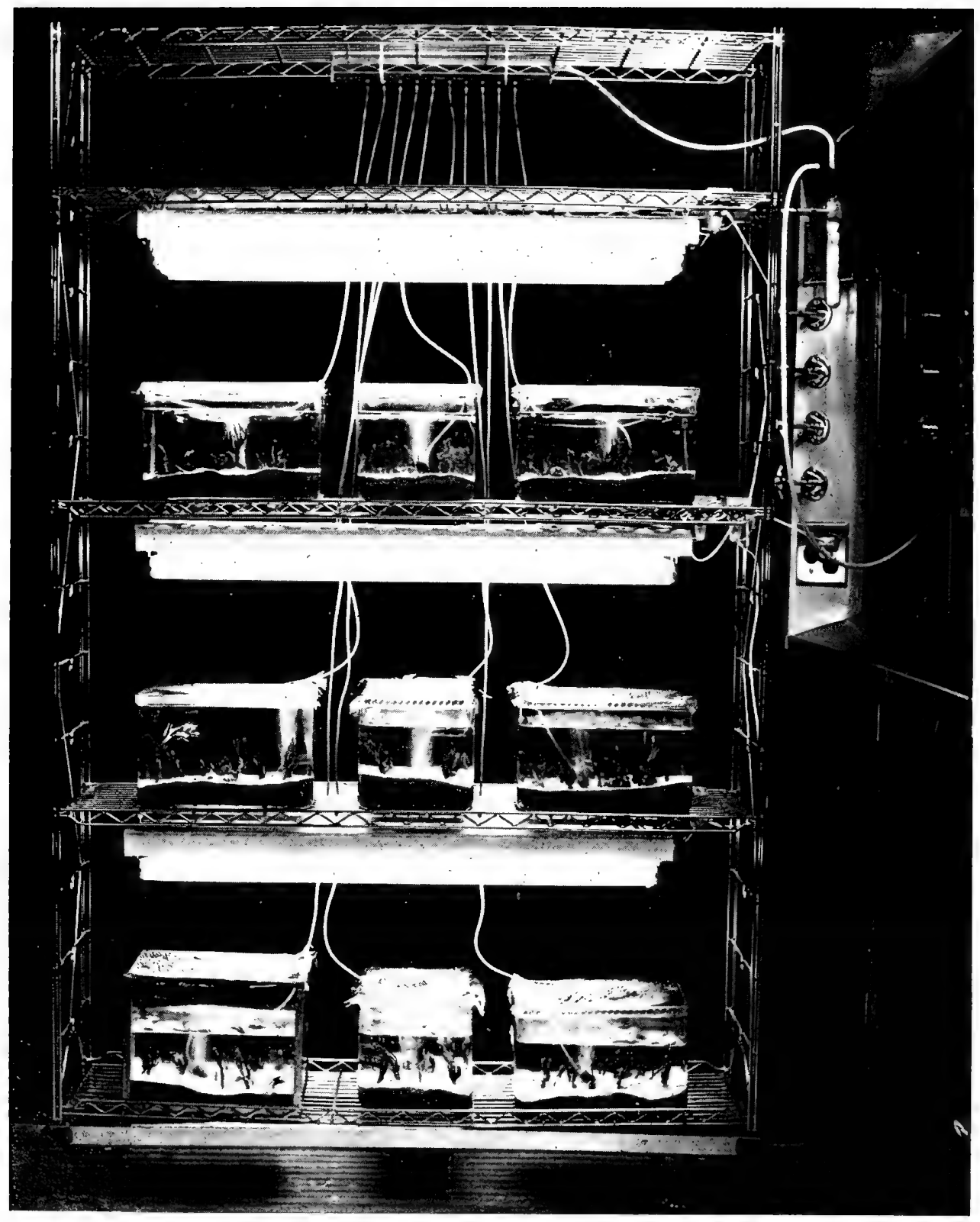

Fif. 50). Holimeda cultures in glass aquaria, showing arrangement of lights and aeration system. Compressed air is filtered through glass wool (in tube at far upper right) and enters a manifold (suspended from top shelf). From there is passes through 'Teflon tubing to a bubbler in each aquarium. The rate of flow to each aquarium is controlled by a tubing clamp. Arrangements similar to this can line the walls of a controlled enviromment chamber. A Udotec plant is in the left-hand corner of the micldle aquarium in the upper row. (From Colinvaux et al., 1964.) 


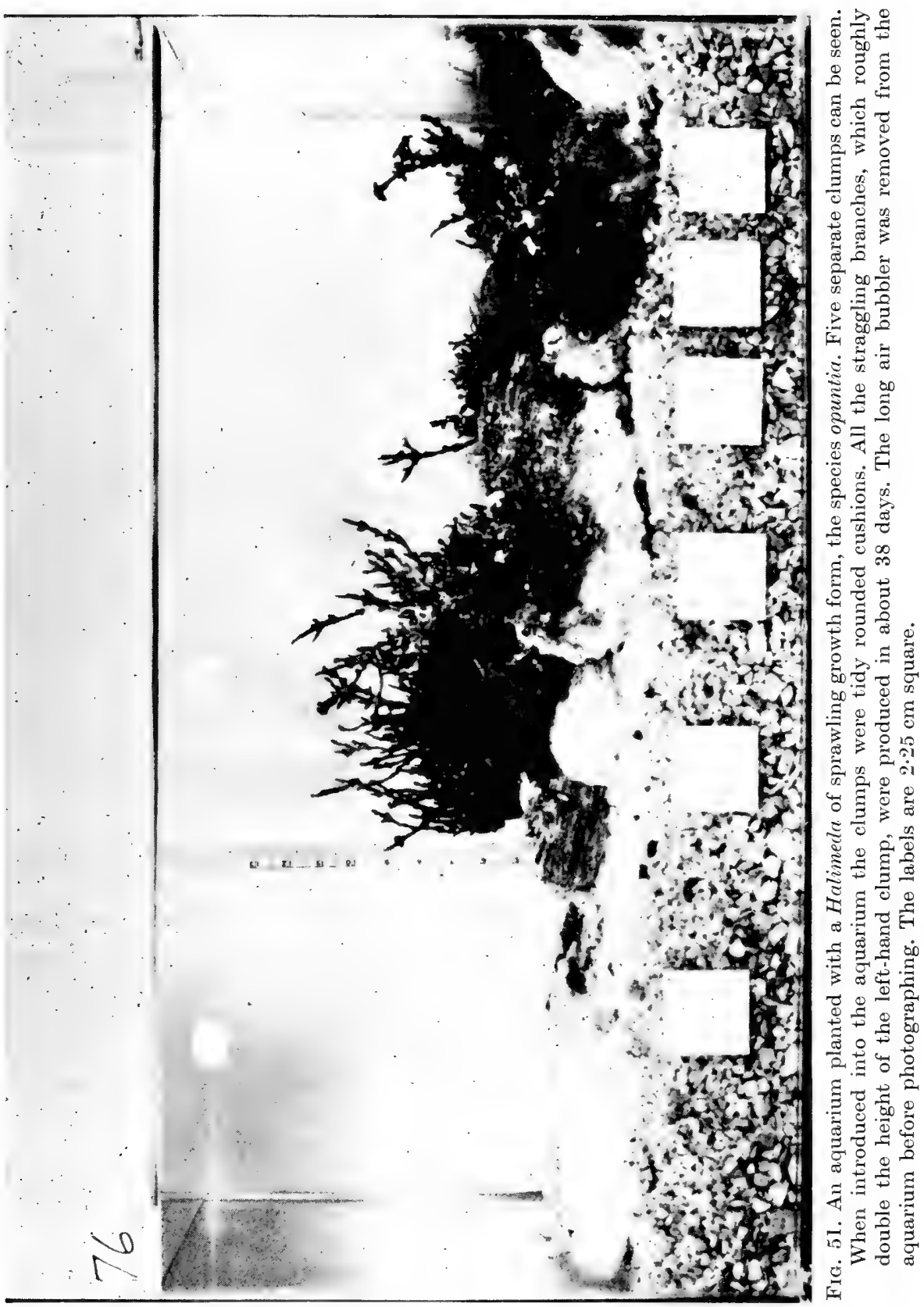


Table XI. Chemical Analysis of the Commerctal Artificlal Seawater "Instant Ocean" a

\begin{tabular}{|c|c|}
\hline Component & Percentage by weight \\
\hline $\mathrm{NaCl}$ & $65 \cdot 226$ \\
\hline $\mathrm{MgSO}_{4} \cdot 7 \mathrm{H}_{2} \mathrm{O}$ & $16 \cdot 307$ \\
\hline $\mathrm{MgCl}_{2} \cdot 6 \mathrm{H}_{2} \mathrm{O}$ & $12 \cdot 762$ \\
\hline $\mathrm{CaCl}_{2}$ & 3261 \\
\hline $\mathrm{KCl}$ & $1 \cdot 737$ \\
\hline $\mathrm{NaHCO}_{3}$ & 0.4963 \\
\hline $\mathrm{KBr}$ & 0.07206 \\
\hline $\mathrm{H}_{3} \mathrm{BO}_{3}$ & 0.06214 \\
\hline $\mathrm{SrCl}_{2} \cdot 6 \mathrm{H}_{2} \mathrm{O}$ & $0 \cdot 04689$ \\
\hline $\mathrm{MnSO}_{4} \cdot \mathrm{H}_{2} \mathrm{O}$ & 0.009379 \\
\hline $\mathrm{Na}_{2} \mathrm{HPO}_{4} \cdot 7 \mathrm{H}_{2} \mathrm{O}$ & 0.009379 \\
\hline $\mathrm{LiCl}$ & 0.002343 \\
\hline $\mathrm{Na}_{2} \mathrm{MoO}_{4} \cdot 2 \mathrm{H}_{2} \mathrm{O}$ & 0.002343 \\
\hline $\mathrm{Na}_{2} \mathrm{~S}_{2} \mathrm{O}_{3} .5 \mathrm{H}_{2} \mathrm{O}$ & 0.002343 \\
\hline $\mathrm{Ca}\left(\mathrm{C}_{6} \mathrm{H}_{11} \mathrm{O}_{7}\right)_{2} \cdot \mathrm{H}_{2} \mathrm{O}$ & 0.001669 \\
\hline $\mathrm{Al}_{2}\left(\mathrm{SO}_{4}\right)_{3} .18 \mathrm{H}_{2} \mathrm{O}$ & 0.001202 \\
\hline $\mathrm{RbCl}$ & 0.0004005 \\
\hline $\mathrm{ZnSO}_{4} \cdot 7 \mathrm{H}_{2} \mathrm{O}$ & 0.0002563 \\
\hline KI & 0.0002403 \\
\hline EDTA $\mathrm{NaFe}$ & 0.0001936 \\
\hline $\mathrm{CoSO}_{4} \cdot 7 \mathrm{H}_{2} \mathrm{O}$ & 0.0001335 \\
\hline $\mathrm{CuSO}_{4} \cdot 5 \mathrm{H}_{2} \mathrm{O}$ & 000002670 \\
\hline
\end{tabular}

a Data from Aquarium Systems, Inc., Wickliffe, Ohio.

while the bulbous holdfast system of sand-growers may supply their own.

When the aquaria are filled with seawater to the desired level and the plants added, the level of the medium is marked on each aquarium wall. Water evaporated from the system is replaced every few days by topping up to the level marked with distilled or glass-distilled water. This maintains a constant volume and accordingly a constant salinity. If the aquaria are maintained for six months or longer, the salinity is monitored. The seawater is siphoned out and replaced every six to nine months.

\section{Substrates}

(a) Unconsolidated. About $2.5 \mathrm{~cm}$ of a calcareous material and another $2.5 \mathrm{~cm}$ of a readily available sand are used, with, for convenience, the larger-grained material providing the bottom layer. 
Suitable calcareous materials are quartz gravel, calcareous filtrant material as used in many aquarium systems, Halimeda sand and pieces of cuttle bone. The first two can be obtained from aquarium suppliers, and the second one, the calcareous filtrant, is also available from the suppliers of "Instant Ocean". Halimeda sand is collected in the reef. Cuttle bone, which is only practicable on a small scale, can usually be obtained from pet shops.

It is not known if a calcareous substrate is necessary for Halimeda growth, but their possession of a calcareous structure suggests that it may be important. The natural populations commonly grow in sand which is largely composed of old Halimeda segments and which is usually highly calcareous.

Calcareous substrates are washed several times in distilled water before use.

Sand materials which have been used include reef sand, beach sand and playbox sand. The stand is autoclaved at $15 \mathrm{lb}$ pressure for 20 minutes before using.

(b) Rock substrates. Dead and cleaned coral rock or other soft rock is used partly for substrate, partly for the support and anchorage of rockgrowing Halimedae collected with holdfast intact on their own small piece of rock. The rock-growing Halimedae are arranged and supported in a rock framework in such a way that they simulate their natural position in the reef.

Before being used the rock is washed, and autoclaved for 20 minutes at $15 \mathrm{lb}$ pressure.

\section{Aquaria}

The most used sizes have been $9 \cdot 5,11.5$ and 191 aquaria which preferably are all-glass. These small sizes are manoeuvrable, and growth can be readily seen and photographed from all sides. Height is a critical dimension in selecting aquaria. One that is too shallow will seriously restrict the size of the thalli selected. A $30 \mathrm{~cm}$ height or slightly more would seem close to the ideal unless one is working only with small squat species. This height permits a reasonably thick sand-gravel layer as well as air space at the top which decreases the amount of water bubbling over from changes of pressure in compressed air lines of the circulation system.

Between uses, aquaria are scrubbed with $10 \%$ hydrochloric acid, then filled with tap water and allowed to stand for at least 24 hours. This operation is repeated at least twice more. If possible aquaria are not reused immediately. 


\section{Circulation system}

In the small 11.51 aquaria used most frequently, circulation is provided by aquarium air-bubblers, sometimes with the addition of an outside or inside water-filtering system.

Long air bubblers (approximately $14 \mathrm{~cm}$ ) are connected to a compressed air system by Teflon tubing. An air-filter system of glass-wool is interposed, and a manifold is used so that several aquaria may feed off the system. Rate of flow to individual aquaria is regulated by C-clamps on the Teflon leads to each aquarium. The particular bubblers used function well after autoclaving.

A closed-circuit water-filtering system is sometimes used by adding the standard inside or outside aquarium filter, fitted only with glasswool, which fits against the vertical walls of the aquaria. Bottom or under-gravel filters might be feasible for Halimedae which grow on rocks or sprawl but are not suitable for sand-growing species. The Rhipsalian Halimedae do not normally have water circulating past their holdfast systems, which, in some reef sites, even grow in an anoxic environment. The reducing environment may facilitate the exchange of certain ions between substrate and holdfast, with such reactions being important to the successful growth of these particular species.

\section{Temperature control}

Kinsman (1964) gives a range of $25-29{ }^{\circ} \mathrm{C}$ as the temperature at which reef corals best flourish, while indicating that these organisms can withstand limited exposure to $16-17^{\circ} \mathrm{C}$, and that some corals continue to grow at temperatures as high as $36^{\circ} \mathrm{C}$.

For Halimeda, temperatures of $27-29^{\circ} \mathrm{C}$ are probably about optimal, although these plants are exposed to higher and lower temperatures in the reef. A range of approximately $25-29{ }^{\circ} \mathrm{C}$ is acceptable.

Lighting will increase the water temperature of the small aquaria by $2{ }^{\circ} \mathrm{C}$ and more, depending on the intensity and duration.

\section{Light intensity and cycle}

Light intensities for much of the Halimeda culturing have ranged from 375 to 780 foot-candles, measured just above the sand-water interface. Intensities as low as $100 \mathrm{ft}$-c have been used, but growth is very slow or absent.

Lighting on a 12-hour light:12-hour dark cycle is provided by cool-white fluorescent light placed about $22 \mathrm{~cm}$ above the aquaria. The lighting cycle was chosen because it is that of the tropics. 
The lower intensities of this range were initially chosen because they were similar to those commonly used in algal culture including work with siphonaceous algae. Puiseux-Dao (1970) gives a range of approximately 100-300 ft-c for Acetabularia, and Chen and Jacobs (1966) used $100 \mathrm{ft}-\mathrm{c}$ in their culture of Caulerpa.

Better growth is obtained, at least initially, at intensities such as $700 \mathrm{ft}-\mathrm{c}$. This improvement is often paralleled by increased epiphyte growth, and the epiphytes can become very difficult to control. The water of small self-contained aquaria also becomes overheated at the higher intensities, necessitating a cooling system.

Light intensities of approximately $375-500 \mathrm{ft}$-c are somewhat of a compromise in the range given. Growth as well as vegetative and sexual reproduction occur at these intensities. It is realized, however, that they are considerably below the light intensities of the shallow reef, some of which are recorded in Table XII, using a Gossen Tri-Lux foot-candle meter in an underwater case at two of our north shore Jamaican work sites, Runaway Bay and Glory Be (Section X). They indicate that plants growing at $-1.5 \mathrm{~m}$ to $-2 \mathrm{~m}$ receive approximately $47-73 \%$ of the surface light which, on three sunny Jamaican days, about midday, averaged $7530 \mathrm{ft}$-c.

It is realized too that the unusual segment shapes often obtained in culture (Fig. 16; Colinvaux et al., 1965, Fig. 3) may be the result of growing these plants in intensities equivalent to those of the bluelighted regions in the reef at about $-40 \mathrm{~m}$ to $-50 \mathrm{~m}$.

\section{Epiphyte control}

A wide range of organisms, plant and animal, are introduced on the cleaned Halimedae thalli. A number of them grow very well in the system, and if uncontrolled will usually overgrow the Halimeda population eventually. Some of the introduced organisms also grow on the sand and rock substrates, as well as on the glass sides of the aquaria. Epiphyte control is important for aquaria which will be maintained longer than about six weeks, and for shorter-term aquaria when light intensities are $1000 \mathrm{ft}$-c or higher.

The contaminant plants include a number of soft red and green, as well as blue-green, algae. There have also been occasional dense dinoflagellate blooms.

Phytoplankton blooms, if troublesome, can be controlled by changing the water and using a filter system. Since some inoculum remains on the Halimedae and on the sand or rock substrate, the improvement may only be temporary. 
'CAble XII. Lighi' Intenstties at Glory Be Reef, North Shore of JAmaica ${ }^{a, b}$

\begin{tabular}{|c|c|c|c|c|c|}
\hline Date & Time & $\begin{array}{l}\text { Depth } \\
(m)\end{array}$ & $\begin{array}{l}\text { Light intensity } \\
\quad(f t-c) \\
\text { (meter in case) }\end{array}$ & $\begin{array}{c}\text { Ratio water } \\
\text { to air }(\%)\end{array}$ & Location \\
\hline \multirow[t]{11}{*}{16.6 .69} & 0728 & +2 & $440\}$ & \multirow{6}{*}{73} & Shaded beach steps \\
\hline & 0735 & -1.5 & $320\}$ & & Shaded quadrat site $\left(Q_{1}\right)$ \\
\hline & 0812 & $-1 \cdot 5$ & $200-300$ & & Shaded quadrat site $\left(Q_{1}\right)$ \\
\hline & 0735 & $-1 \cdot 5$ & 1000 & & Patch of light north of $Q_{1}$ \\
\hline & 0820 & $-1 \cdot 5$ & 700 & & Patch of light north of $Q_{1}$ \\
\hline & 9745 & $-3 \cdot 7$ & $600-1000$ & & $\begin{array}{l}\text { Range on sand patches } \\
\text { outside zooanthid reef }\end{array}$ \\
\hline & 0825 & $-3 \cdot 7$ & 1500 & \multirow{5}{*}{67} & $\begin{array}{l}\text { Dune sand pass in } \\
\text { zooanthid reef }\end{array}$ \\
\hline & 0747 & $-3 \cdot 1$ & $1000-1200$ & & Urchin barren \\
\hline & 0810 & $-1 \cdot 5$ & $<200$ & & Red algal patch under rock \\
\hline & 0830 & $-1 \cdot 8$ & 20007 & & $\begin{array}{l}\text { Halimeda sand without } \\
\text { plants }\end{array}$ \\
\hline & 0836 & 0 & 3000 & & $\begin{array}{l}\text { Halimeda sand without } \\
\text { plants }\end{array}$ \\
\hline \multirow[t]{3}{*}{16.9 .68} & 1115 & $+2 \cdot 5$ & $6400-72007$ & \multirow{3}{*}{$\begin{array}{r}47-69 \\
(-78)\end{array}$} & Sun in and out of clouds \\
\hline & 1230 & -2 & $3000-5000\}$ & & $\mathrm{Q}_{1}$, sun in and out of clouds \\
\hline & 1250 & $+2 \cdot 5$ & $6400 \quad$ & & \\
\hline \multirow[t]{2}{*}{ August } & & 0 & 15007 & \multirow[t]{2}{*}{53} & $\begin{array}{l}\text { Odum and Odum (1954), } \\
\text { with Weston light } \\
\text { meter, Enewetak Atoll }\end{array}$ \\
\hline & & -0.5 & 800 & & $\begin{array}{l}\text { Odum and Odum (1954), } \\
\text { with Weston light } \\
\text { meter, Enewetak Atoll }\end{array}$ \\
\hline
\end{tabular}

${ }^{a}$ For description of sites see Section $\mathrm{X}$.

${ }^{b}$ Intensities were measured with a Gossen Tri-Lux foot-candle meter in an underwater case.

The most successful method for controlling the other epiphytes, once established, has been by hand cleaning, an operation which is tedious and time-consuming. The soft red and green algae can usually be plucked off their hosts fairly easily, but many of the blue-greens, with their slimy coatings and mats, must be scraped off, using tools such as a fingernail for the thalli, or a long-handled aquarium cleaner with razor blade for the sides of the aquarium. Tissues also are helpful for cleaning aquarium sides and retaining some of the material. Mats and slime coatings on the sand can be lifted off.

External or internal water filters, which may be initially useful for avoiding phytoplankton blooms or eliminating or minimizing successful 
development of new organisms from released zoospores or gametes, are of minimum help in controlling attached organisms, a number of which reproduce by non-motile means.

Other methods tried include the use of the invertebrate poison Lindane, and the antibiotic Penicillin. Lindane had previously been found helpful in Ulva culture (Strand et al., 1966). Halimedae were immersed for 15 minutes in seawater containing Lindane at a concentration of 15 parts per million. The results for the limited number of thalli available for experimental treatment were inconclusive.

For the testing of Penicillin the antibiotic was added to two aquaria at a concentration of 1000 units ml $^{-1}$ for one and 3000 units $\mathrm{ml}^{-1}$ for the other. The higher concentration killed the vegetative stage of many epiphytes and they dropped off within the first two weeks. By the end of about two months, however, epiphytes, particularly blue-greens, were again abundant (Hillis-Colinvaux, 1972). When the treatment was repeated, it was not as effective. Penicillin may be helpful in short-term epiphyte control, particularly if added to the medium initially.

\section{New approaches to epiphyte control}

Two additional techniques could be helpful. Sand-growing species might initially be planted in trays which could then be transferred out of one aquarium to a cleaner one, or used for experimental purposes. The trays could also be suspended over bottom filters since the circulation pattern would not then interfere with any reducing environment established by the holdfasts in the trays.

Epiphyte-free stock also can provide cleaner cultures. One source of such plants is the young Halimedae developing in the aquaria by vegetative multiplication. They can be successfully transplanted into fresh aquaria. Another potential source of clean thalli are individuals produced by regeneration. The basic procedure is to remove branches of several segments from robust thalli by cutting at the node (where there are fewer filaments), briefly pressing the cut ends together to induce wall formation (Jacobs, 1958), thereby preventing excessive loss of cytoplasmic materials, and then anchoring or planting the cuttings in substrate. I have had limited success with such cuttings which have ranged from two to a dozen segments. The longer cuttings were the most successful, and although none grew into a large thallus (all tended to get overgrown with epiphytes), a few produced new plants from rhizoidal runners in the sand (Section VII), and others produced rhizoids and segments. 
9. Controlled environment room

A walk-in controlled environment room, if available, permits a finer control of both the temperature and lighting cycles, and some investigation of environmental effects which are not possible if aquaria are maintained in a multi-use room. Such a room, however, may restrict sizes of aquaria and intensity of lighting.

\section{Some experiences with Halimeda culture}

Table XIII lists the species of Halimeda cultured, together with other plants that have been introduced intentionally or inadvertently.

Table XiII. Partial List of Organisms Maintained in Aquaria for Two MoNThS TO OVER ONE YeAR

1. HALIMEDA SPECIES

incrassata

cylindracea

macroloba

monile

simulans tuna

discoidea

gigas opuntia

copiosa

goreauii

2. OTHER CAULERPALES

$\begin{array}{ll}\text { Boodleopsis } & \text { Rhipocephalus } \\ \text { Caulerpa } & \text { Udotea } \\ \text { Penicillus } & \text { Tydemania }\end{array}$

3. DASYCLADALES

Cladophoropsis

Cymopolia

4. PARTIAL LIST OF EPIPHYTES

\begin{tabular}{llll} 
CYANOPHYTA & \multicolumn{2}{c}{ CHLOROPHYTA } & DIATOMS \\
& Dasycladales & Cladophorales & \\
Aphanocapsa & Acetabularia & Rhizoclonium & Navicula \\
Calothrix & Batophora & Cladophora & \\
Lyngbya & Dictyosphaeria & & \\
Oscillatoria & Valonia & & \\
Spirulina & & &
\end{tabular}

Using the approach described, sand-growing Halimedae have settled in and grown well, with the first obvious growth of the transplants often appearing in about five days (Section VI). On the few occasions that some Rhipsalian Halimedae have been kept in seawater and not planted immediately, rhizoidal growth has been noted on about the third day, 
followed by new segments two or so days later. Non-rhipsalian species have not grown as well, at least initially, and tuna has been the most difficult to maintain under these conditions.

At the beginning of the culture work, when looking for evidence of success, some growth observations were especially troubling. Examples include the turning white of segments or branches which then fall off, and the overburdening of thalli with epiphytes, the latter being distinct from the problem of maintaining Halimeda in culture with a minimum number of epiphytes. Both developments, however, are part of the Halimeda growth cycle.

Segments and branches are shed, at least in some species, rather like leaves being dropped from a bush or tree in the autumn, and the growth of Halimeda is thereby different from that of Penicillus capitatus Lamarck and Udotea flabellum (Ellis and Solander) Lamouroux (Colinvaux et al., 1965) in which there are no dehisceable units. The shedding of segments or branches also relieves the Hatimeda thallus of a crop of epiphytes, and produces sites where vigorous new growth can occur.

In the reef, epiphytes are, at times, very evident on Halimeda. Blue-green algae may cover much of the Halimeda thallus and contribute a coating or matting to the surrounding sand. Matheison et al. (1971), in a transect study at $-17.3 \mathrm{~m}$ to $-21.5 \mathrm{~m}$ in the Virgin Islands, reported 17 species of epiphytes, mostly red algae, on $H$. incrassata. These workers did not seriously include blue-green algae in their study, so Cyanophyta may have occurred as well. It may be that massive imposition of epiphytes is a hazard to which Halimeda populations are adapted, and that their reproductive and persistence strategies will be influenced by this recurrent event. It is also possible that patterns of grazing on the Halimeda beds may be reflected in blooms of epiphytes. That the phenomenon occurs in nature suggests that it is an ecosystem event of some significance. It is also one such event that we can study in our cultures.

A number of animals, introduced inadvertently with the thalli, live successfully in the culture systems described, and some of the grazers, particularly the snails, may clean the plants and aquaria of some growths. Introduced animals include tube worms, anemones and polychaetes, with occasional snails, bivalves and brittle stars. From time to time there also have been blooms of small medusae of about $2 \mathrm{~mm}$ diameter. What are presumed to be different species of opisthobranch molluses, both identified as Elysia spp., have fed, one type on Tydemania, the other on Halimeda incrassata. The Tydemania lived only about three months, and too little is known of its growth pattern to have assessed the impact of Elysia grazing. However, the other 
Elysia, a lone specimen, appeared to feed mostly on one individual Halimeda although there were others of the same species in the aquarium. This it did for a year, when it was preserved and sent off for identification. During the year it was alive, new segments started to form many times on the host Halimeda plant, but they generally did. not complete their development.

These observations show that it is possible to maintain simple marine grazing systems in the laboratory.

\section{Summary of Halimeda culturing}

Eleven species of Halimeda have been grown in the laboratory, some through one or more vegetative generations, while individuals have been maintained for more than two years.

It is not yet possible to start cultures with clean zygotes since the segmented Halimeda has not been grown from them in the laboratory. Cultures, therefore, must be started with direct transplants from the sea, a technique that introduces troublesome contaminants.

The basic procedure is to collect good field material, to clean it by hand, to plant it in simple aquaria, to light it, to bubble air into the water and to combat epiphytes.

Other Caulerpacean and various Dasycladalean genera also grow satisfactorily in this system, as well as a number of inadvertently introduced animals, showing that it is possible to maintain simple marine grazing systems in the laboratory.

Although large numbers of epiphytes in laboratory culture usually lead to the swamping of Halimeda thalli, on the reef this may be a hazard to which Halimeda populations are adapted, and the reproductive and persistence strategies of Halimedae may be influenced by this recurrent population event.

\section{Growth and Calcification}

Patterns of growth in Halimedae must result in fronds which may be likened to strings of beads because each frond is a linear array of segments fastened at the nodes by a string-like structure of filaments. This string-of-beads structure is constructed from a non-cellular syncitium. The segmental "beads" of each species tend to have characteristic shape, suggesting a rather refined system for controlling the web of growing filaments; and this system operates as nuclei are spread along the filament, without obvious physical separation of individual 
nuclear domain. Furthermore, the shape imposed on a filament becomes fixed in a matrix of mineral calcium carbonate. Clearly, there are interesting questions to ask about the patterns of growth in Halimedae that concern control of growth, rates of growth, maintenance of structure and the process of calcification.

One of the reasons Acetabularia, a relative of Halimeda with a single nucleus instead of many, has yielded so many data about the nucleocytoplasmic control of growth is that it could be cultured. Halimeda can be easily grown too, if initial care is taken in obtaining clean starting plants. But nucleo-cytoplasmic and chemical aspects of its growth have not yet been approached. Our information on growth is at the thallus, filament and ultrastructural levels.

The classical accounts of growth are basically three. Askenasy (1888) provided the first short description when he noted that after a "rest period" the nodal filaments of an apical segment produced filamentous extensions which branched many times. The branches in turn branched and rebranched to the tips or peripheral utricles, which adhered, forming an outer surface and, as a result a new segment.

Barton's (1901) account of the development of a new segment varied from that of Askenasy only in the branching pattern of the medullary filaments. The initial branching was trichotomous, with the middle branch continuing as part of the medulla while the two side branches divided and redivided until they terminated in the peripheral utricles. A demonstration of this pattern can be seen in cryptica (Figs 3, 15) with its single medullary filament.

The first field datum on rate of growth was obtained about this time too, and appears to have been originally published by Barton (1901). This was the observation by Finckh (1904), at Funafuti, that a branch of Halimeda growing through a hole in a submerged board of wood on the reefs added three inches of height and thickness in six weeks, or $14.38 \mathrm{~g}$ of calcareous matter. Thereafter, until these algae were grown in the laboratory (Colinvaux et al., 1965) little more was known about growth of Halimeda or, indeed, of any of the calcareous Caulerpales.

\section{A. Macroscopic growth}

Much of the following account uses hitherto unpublished data and some reported by Colinvaux et al. (1965). It is based mostly on the species incrassata, simulans and monile from the Caribbean, and although many of the developments described have been observed in the field, all of the quantitative data, particularly those on rates, are of 
growth in laboratory culture at approximately $27^{\circ} \mathrm{C}$, with light intensities mostly of 310-560 ft-c for 12 hours, followed by 12 hours of darkness. The only field study of some duration is that of Merten (1971), working in Guam. She reported growth rates in macroloba over a period of 10 months, and included some laboratory study of it as well. Like incrassata, macroloba is a Phipsalian Halimeda, but the appearance and size of its segments are very different (Figs 22 and 28, respectively). The maximum length $\times$ width $\times$ thickness measurements for an incrassata segment are $10 \times 14 \times 0 \cdot 75-1 \cdot 0 \mathrm{~mm}$. For macroloba they are $29 \times 40 \times 1 \mathrm{~mm}$. The two species also have different habitats within the reef, with macroloba seemingly restricted to water of $-12 \mathrm{~m}$ or shallower and growing best in waters of $-2 \mathrm{~m}$ or less.

In incrassata transplanted to the laboratory, the first obvious growth is usually in the holdfast, as delicate new filaments extend out into the surrounding medium. It can be readily observed in unplanted thalli lying horizontally in seawater. In thalli so arranged most of the first new rhizoidal growth is oriented downwards.

Within the next few days there are also obvious signs of the development of new segments, as white, conical protrusions appear from the apical edges of terminal segments (Figs 16, 52, 53). These are the extensions of the medullary filaments which branch and ramify as they grow. The branches develop into the cortical series of utricles of which the outermost ones are contiguous. Within about 24 hours, the albino protrusions from an apical segment develop a fairly complete, somewhat greenish segment. The outer surface, however, is spongy and disconnected, for the peripheral utricles have not yet formed a continuous outer surface. This separateness of the peripheral utricles is unlike the pattern encountered in mature segments of most species (Sections III, IV). The very young filaments of a segment, therefore, may have a different environment before and after being enclosed within the segment since at the earliest stages of growth they are in direct contact with seawater. The resulting closed or almost enclosed spaces may be important in calcification (Colinvaux et al., 1965; Wilbur et al., 1969; Böhm and Goreau, 1973; Borowitzka and Larkum, 1976a, b, c, 1977; Borowitzka, 1977). Within the next 12-24 hours or somewhat longer, adhesion of peripheral utricles occurs in most species at least, and it is at about this stage that the first granules of calcium carbonate appear.

The pattern of a segment, its length and width are essentially set within the first couple of days. Subsequent development is mostly in the calcification of the segment, with some change in thickness, depending on the location of the segment within the thallus and the species. 

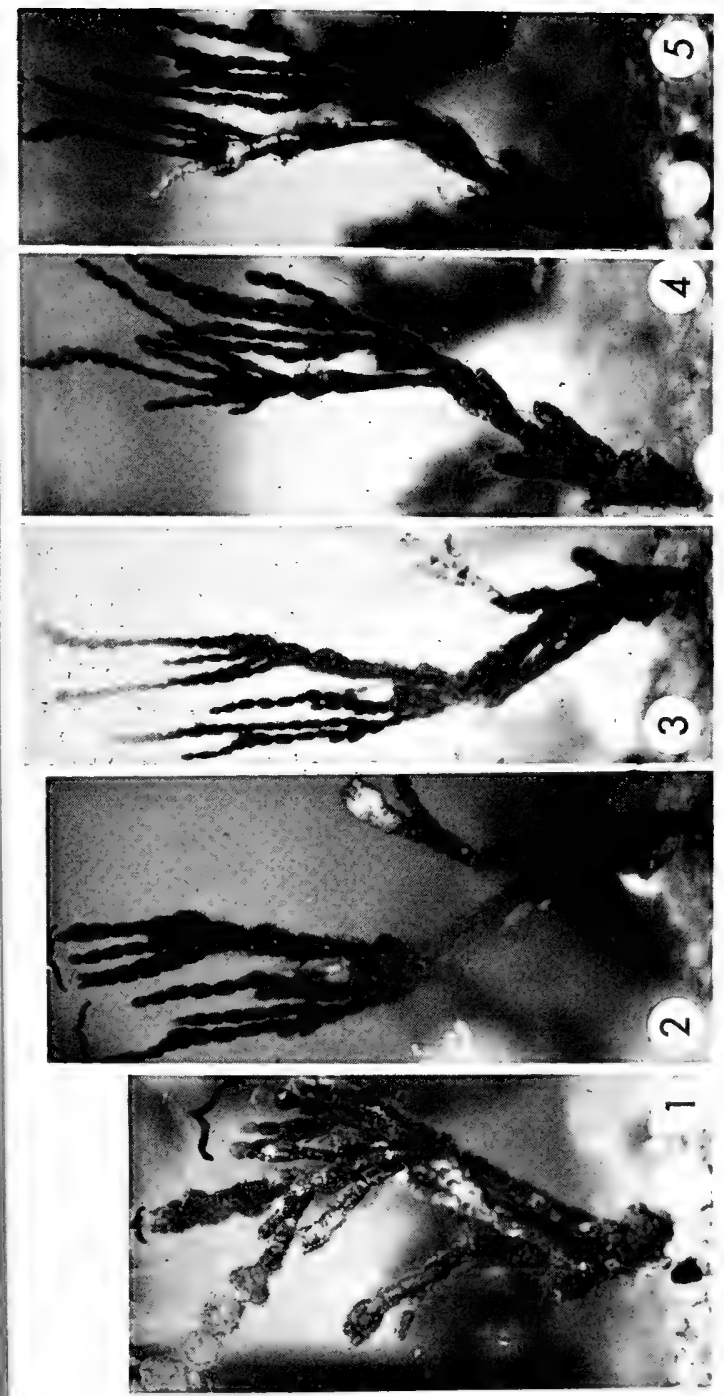

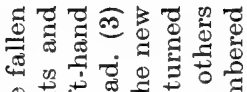

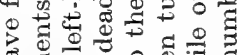

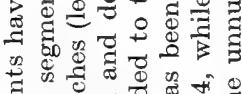

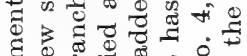

50

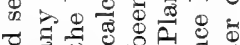

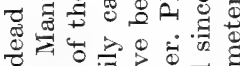

ก

$\stackrel{+}{+\infty}$

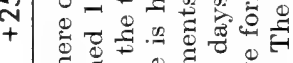

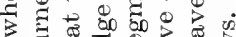

in

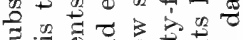

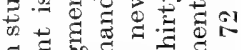

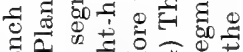

可

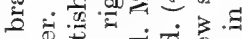

⿷匚⿱

o

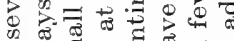

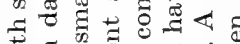

웡용

$+E$ E

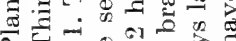

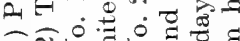

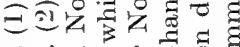

نं

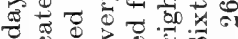

a $=$ * . Ts

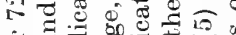

क्ष

을

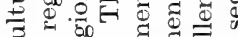

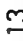

m ఫ

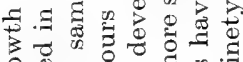

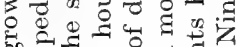

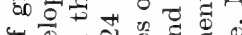

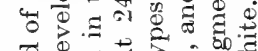

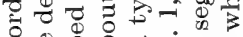

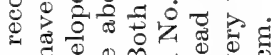

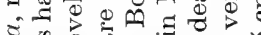

¿

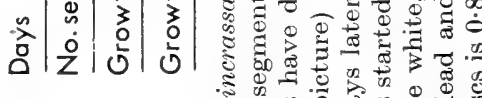

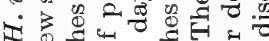

乙 000

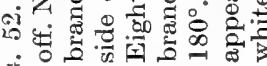
空 


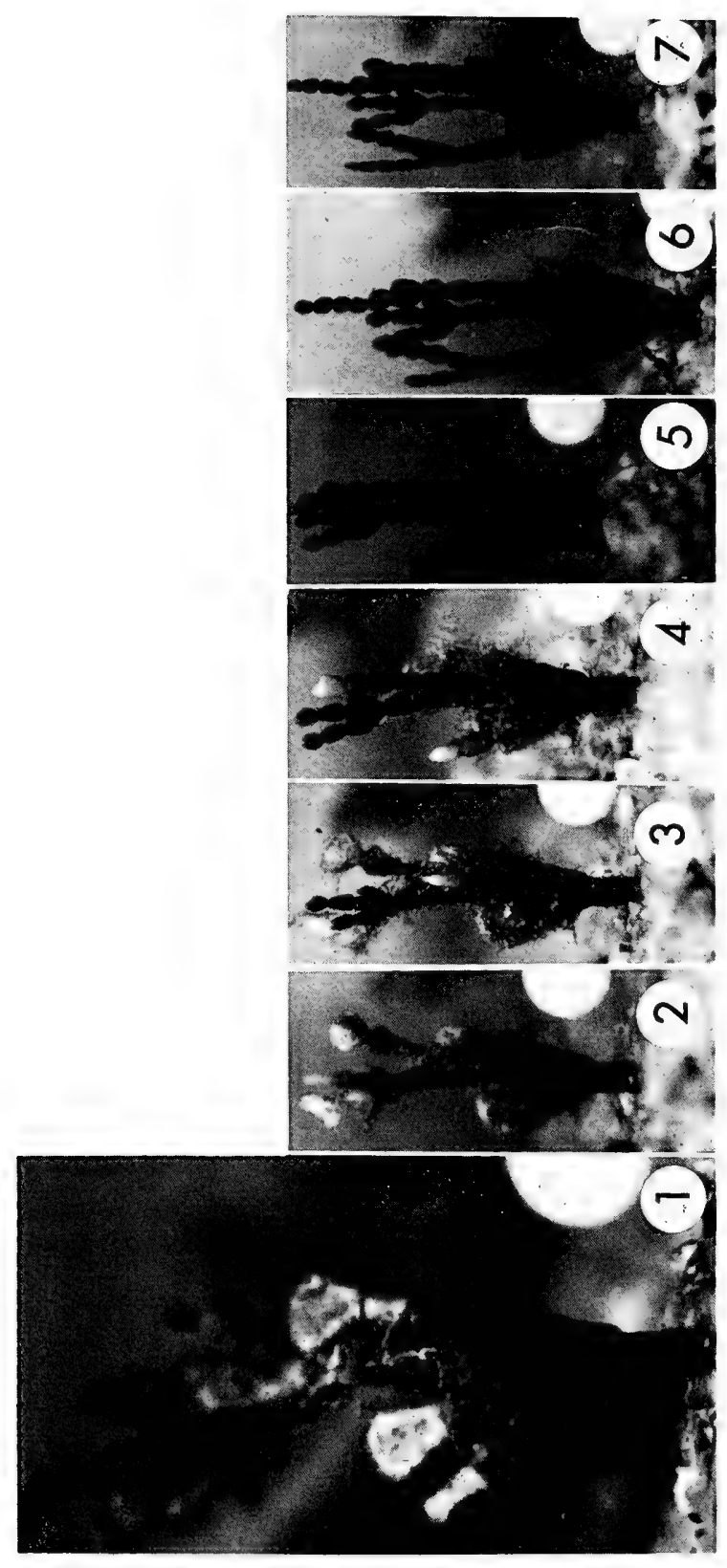

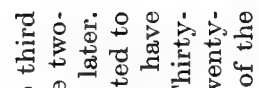

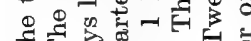
E के

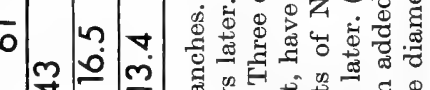

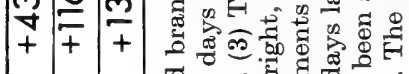
o 0 .

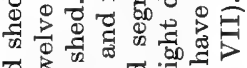

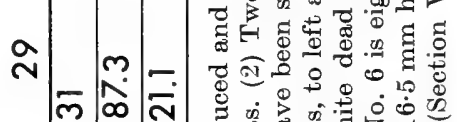

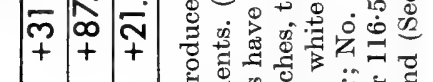

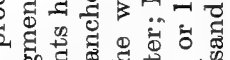
4.

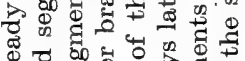

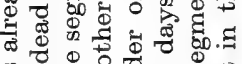
证

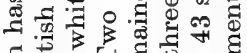

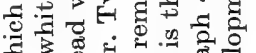

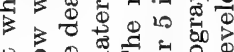

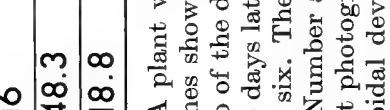

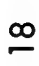

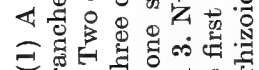
过

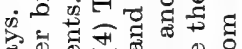

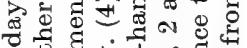

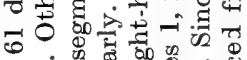

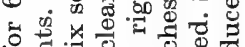

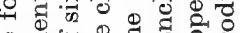
\& 5 的

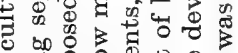
ฐ

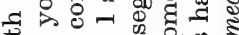
है 品

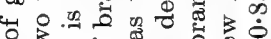

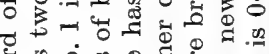

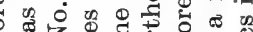

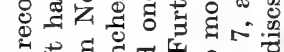

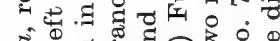

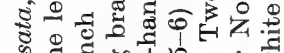

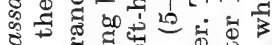

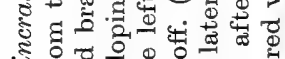
ह है

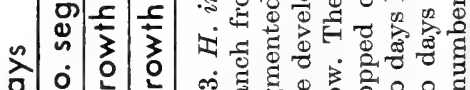

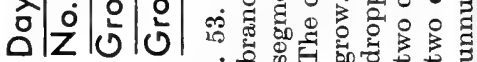
量 
In very old segments the peripheral utricles may separate more readily or may be somewhat thickened.

New segments may develop daily or every other day on each branch so that many new segments can be added in a relatively short time. This growth pattern has been observed also with cylindracea, opuntia and gigas, growing in running seawater aquaria maintained for three weeks in the roofed open-air wet laboratory of the Mid-Pacific Marine Laboratory at Enewetak.

The growth which occurred on two thalli of incrassata over a time span of 72 and 61 days is shown in Figs 52 and 53, respectively. Thirteen days after the photographic series was started for the plant of Fig. 52 it had added 35 segments or $114 \mathrm{~mm}$. Seventy-two days after the beginning of the series it has added 96 segments or $265 \mathrm{~mm}$. These figures represent a rate of growth of $6.1 \mathrm{~cm} \mathrm{wk}^{-1}$ for the first two weeks, and $2 \cdot 6 \mathrm{~cm} \mathrm{wk}^{-1}$ at the end of the tenth week. For the plant of Fig. 53, 16 segments or $48.3 \mathrm{~mm}$ were added in 18 days yielding a growth rate of $1.9 \mathrm{~cm} \mathrm{wk}^{-1}$, after 29 days 31 segments or $87.3 \mathrm{~mm}$ had been added representing a rate of $2 \cdot 1 \mathrm{~cm} \mathrm{wk}^{-1}$, and by 61 days 43 segments or $116.5 \mathrm{~mm}$ had been added making the growth rate $1.3 \mathrm{~cm} \mathrm{wk}^{-1}$. Twenty-two days later a new plant as well as new segments had been produced, and some segments had been shed. These rates and other similar ones from my cultures indicate some of the growth potential of incrassata at low light intensities, as does the growth analysis by Chen and Jacobs (1966) on Caulerpa prolifera (Forsskål) Lamouroux. They cultured Caulerpa on supplemented seawater at $24 \pm 1{ }^{\circ} \mathrm{C}$ at $100 \mathrm{ft}-\mathrm{c}$ on a 12-hour light: 12-hour dark cycle, and found that rhizomes, rhizoid clusters and "leaves" elongated at the rate of approximately $4.4 \mathrm{~mm} \mathrm{~d}-1$ or $3.1 \mathrm{~cm} \mathrm{wk} \mathrm{w}^{-1}$. It seems likely that the incrassatae of the reef, when actively growing, may have a growth rate which is at least comparable to the best of those reported, that is, to $6 \mathrm{~cm} \mathrm{wk}^{-1}$.

Merten (1971), in Guam, worked with 200 plants of macroloba in both field and laboratory environments. The average growth rates for her four populations followed the same pattern, and all four were of the same general order of magnitude. For the 200 plants she gives an average growth rate of $5 \cdot 8 \mathrm{~cm}$ for the first month, and $1 \cdot 5-3 \cdot 0 \mathrm{~cm}$ for the other months, with the laboratory populations performing as well or slightly better than the three field populations in overall height, although the plants were less branched and the segments irregular. The higher rate obtained is of the same order of magnitude as the opportunistic growth measure of Finckh (1904) on an unknown species of Halimeda.

Marten's rates are lower than those given for the incrassata plants although three-quarters of her measurements were of reef plants, under 
supposedly good to optimal conditions of growth. The comparison may not be meaningful, however. These are two widely distinct species of Halimeda and different growth rates can be expected. In addition, a linear measure is perhaps not the best for either comparing or measuring their growth, although for these two species it is considerably more meaningful than the number of segments produced.

This growth activity of relatively rapid segment formation has, in the laboratory, generally been followed by a quiescent period of a week or two to a month or more, in which no new segments form. Goreau (1963), observing a number of representative species of calcareous algae over a period of 15 months, also noted this pattern of growth in spurts in cultured Halimedae. A quiescent phase may be a laboratory phenomenon, although many of the thalli I have observed in the reef have not given the impression of active growth at that particular time. It also may be a species-related phenomenon. Merten (1971) calculated the life-span for the shallow-water macroloba populations she worked with to be four months. The pattern for them appeared to be one of growth, sexual reproduction and death.

Growth of many of the species has another component as well, that of "negative growth". Some of the mature segments turn white or yellowish, and eventually fall off, to be added to the calcareous sediments (Figs 52, 53). In culture their death and final dehiscence may take a month or so, depending upon the presence and extent of grazing activity, intensity of water flow around the thallus and weight of epiphytes. The first losses of segments are generally restricted to the apical portion of the thallus, and vigorous new branches generally develop to replace fallen ones (Figs 52,53). Occasionally there has been a massive whitening in a laboratory aquarium, with the segments of the upper third or half of the thalli of an aquarium population falling off a week or so after transplanting. New branches routinely develop at these sites.

In some taxa this decay of segments or "negative growth" may occur just as commonly, or even more so, in basal portions. The species opuntia, and probably others with sprawling or prostrate habit such as macrophysa, micronesica, distorta, gracilis and possibly copiosa, at times show signs of decay in the lower regions of their thalli. The younger and more vigorous segments and branches above them have initiated rhizoidal development and attachment and continue as separate plants when the older segments fall away. This pattern of growth thereby also functions as a method of vegetative reproduction. In some species or environments, thalli being buried in shifting sand behave similarly. The buried basal portions whiten and loosen, while a new holdfast system is 
established above them; then new segments are produced by the apical branches of unburied portions (Section VII).

Some species, or the thalli of some sites, may not lose segments as part of their growth pattern. Merten (1971) does not mention segment loss in the Guam macroloba populations, but one would expect few losses if the life-span is four months. And Feldmann (1968), writing briefly of the Mediterranean tuna, speaks of ageing the thallus by the length of the branches. "Les individus bien développés, qui présentent souvent 8 à 10 articles successifs, doivent donc être agés d'une dizaine d'années." This does notimply much loss of segments, if the growth rate is as implied.

Certainly dead whitish segments would be more apparent in the laboratory because they remain on the thallus rather than being removed by currents. It is possible, too, that they may be commoner in laboratory culture.

In a few incrassata I followed this pattern of gain and loss of segments several times for up to $2 \frac{1}{2}$ years. During that time branches and segments closer and closer to the base of the thallus were shed, until all but a few basal segments had been lost. A stump, or markedly reduced thallus, remained which was composed of whitish or yellowish, very heavily calcified, segments. Holdfast filaments stopped growing, and the thallus stump was loose in the substrate. Eventually the remaining segments fell off, or the remnants of the alga toppled over, and that individual had died.

This pattern of growth is characterized by what could be called a "perennating thallus", from which new segments and branches arise. This perennating thallus not only consists of a well-anchored holdfast, but also a few to several basal segments, together with a few vigorous segments possibly of a younger generation (Figs 52, 53, first photographs). Very reduced, old, basal portions do not appear to be able to develop new growth.

\section{Growth axis}

Depending upon the species, the addition of new segments may result mostly in either a horizontal or a vertical extension of the thallus. In Rhipsalian species the main growth axis is vertical, and a thallus that is generally erect results. In gracilis the predominant axis is commonly horizontal and a spreading or creeping habit is produced. In opuntia and distorta both types of growth are common, and the resulting habit is frequently a spreading cushion of many centimetres thickness.

The size of the resulting thalli is partly determined by this direction of growth, with mature erect thalli such as incrassata generally being 
shorter than mature pendant thalli such as copiosa, some plants of which are $1 \mathrm{~m}$ long (Goreau and Goreau, 1973). The confines of a spreading thallus such as opuntia are often exceedingly large. Hence, precise boundaries for this species may be difficult to determine, making field counts meaningless.

Halimeda, in its ability to continue adding to its thallus over a relatively long period of time, resembles Udotea which periodically resumes growth, adding onto the margins of its fan-shaped thallus (Colinvaux et al., 1965) and Tydemania, which adds new glomeruli (unpublished data). Both genera differ from Penicillus (Colinvaux et al., 1965) and Rhipocephalus (unpublished data) for which extensive new growth from the mature photosynthetic portion of the thallus is unusual. Although the filaments of the brush may elongate, another capitulum is not formed and the original thallus dies within a few months.

\section{Perennating structures and the systems of Raunkiaer and Feldmann}

Feldmann (1968) has modified for algae the Raunkiaer (1931) system of classifying life-forms of terrestrial plants on the basis of the position of the perennating bud, but did not develop the system to define communities by life-form spectra as Raunkiaer did. This system may have little interest to contemporary community analysts (Whittaker, 1975), and this doubtful utility becomes apparent when we attempt to apply Feldmann's version to Halimeda. We find that a single species can behave as two or more of the categories.

A Halimeda with a perennating thallus as described earlier would fit the hemiphanerophyte category in Feldmann's (1968) description of life-forms, that is, only a part of the erect frond persisting. Some Atlantic populations of tuna appear to fall into this category. The Mediterranean tuna Feldmann considered a phanerophyte, that is, an alga in which the entire thallus functions as the perennating structure, and very young Halimeda thalli of many species after their initial bout of growth would also fit this category.

It is possible too, although there is no evidence as yet, that some species, including tuna, may have rhizoidal structures functioning as perennating structures. As such they would be classified as hemicryptophytes. Feldmann placed the Mediterranean Caulerpa prolifera and Udotea petiolata $(=U$. minima) in this last category because they live through the winter without their leaf-like parts. Other populations or individuals of tuna may be annuals, thereby fitting another category. 
What any system of classifying life-forms is bound to do is to recognize common adaptations to common environmental constraints. But these systems can easily mislead. Raunkiaer (1934), for instance, remarks on an absence of phanerophytes (essentially trees) from the tundra. This absence of trees in the Arctic may be accounted for by arguments based on heat balance, desiccation or maintenance of biomass, yet Raunkiaer's classification must have convinced many students that the critical difficulty is exposing buds to cold air, a proposition for which there is no evidence. In the same way there seems to be no reason for suggesting that the environmental range of a species of Halimeda is directly responsible for imposing a particular system of perennation. The showing in at least two of Feldmann's perennating taxa of a single species of Halimeda is evidence that this approach is or limited use.

\section{Some conclusions about macroscopic growth}

Halimedae grow a segment at a time. A segment begins from the medullary (nodal) filaments of the preceding segment which grow out as whitish filaments. These filaments branch and rebranch forming first a whitish cone, then a segment-shaped mass of branching bundles of filaments. The tips of these outgrowing filaments become the peripheral utricles and the external surface of the plant. A new segment may be fairly completely formed in about a day. It turns noticeably green by the end of the second day, and by this time has started to calcify. The length and width of the segment are essentially fixed at this stage, but the segment becomes increasingly calcified with age within certain limits, and also may thicken somewhat. Several segments may be produced by a frond in a week, although this varies with the species. Rates of growth for some incrassata thalli of $61.4 \mathrm{~mm} \mathrm{wk}^{-1}$ were obtained.

The youngest segments are at the periphery of the plant, the oldest at the base. Therefore, a gradient of segment ages exists in the alga.

A Halimeda thallus may lose some fronds even as others are actively growing. The moribund segments first lose their colour, turn white, may attract epiphytes, then fall off, a process reminiscent of the shedding of leaves by terrestrial plants. The resulting Halimeda litter is responsible for much of the mass of carbonate in coral reefs.

Whole Halimeda plants may die, and the process is essentially the same as the death of a frond. In addition, the holdfast becomes loose in the sand, if the species is a Rhipsalian one, because rhizoidal filaments have stopped growing. For species like incrassata, simulans and monile there seems to be a definite pattern of youth, growth, old age and death. 
These thalli may persist, however, as offspring from asexual reproduction (Section VII). Spreading forms such as opuntia appear to persist as senile portions of the plant fall away only to be replaced in the spreading mass by younger fronds which make their own attachments to the substrate with rhizoids from between younger segments (Section V). Halimeda thalli may appear senile and dehisce many of their segments only to regenerate later from the remaining segments and possibly from buried rhizoidal filaments (Section VII). These patterns of growth, life and death obviously raise questions of the strategies of Halimeda species. One of the most striking of the aspects of growth in Halimeda is that individual thalli have life-spans; they die like so many other organisms, after a life-span typical to the species.

\section{B. Ultrastructural events}

The basic ultrastructure of Halimeda has been described in Section I. The approach in this subsection is to consider aspects of the ultrastructure of the filaments that are associated with the growth of a segment. Two of the studies, Wilbur et al. (1969) and Borowitzka and Larkum (1977), were undertaken initially to provide data on calcification. Borowitzka and Larkum (1974b) provide additional information on chloroplast development, and Colombo and Orsenigo (1977) give some information on distribution of organelles within the mature segment.

From the descriptions of the preceding section three stages of segments can be delimited. They are:

the young developing segment;

the mature segment;

the old basal segment.

Some of the ultrastructural features of these three ages of segment are given in Table XIV.

\section{Young developing segment}

Embodied in the young segment are all the stages in the development of a new segment, from the first filamentous extensions of the medullary filaments of the preceding segment to the establishment of lateral branch filaments (cortex), to the peripheral filaments (utricles) making contact and eventually adhering, at least in most species. This whole process takes about 24-48 hours, and seems to start early in the day or light cycle. In about the last 12 hours, which corresponds to the 


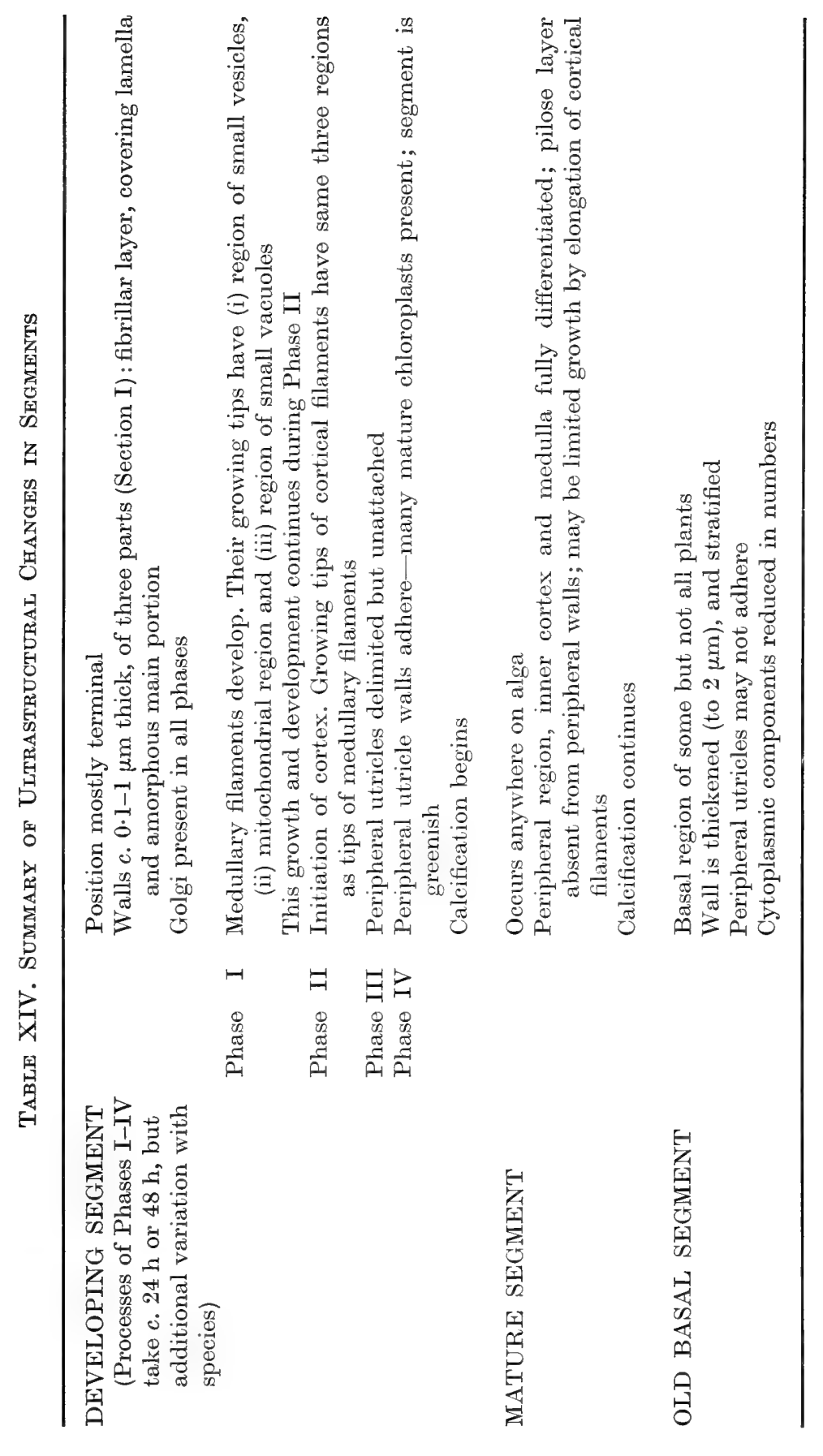


dark cycle but is not necessarily related, noticeable greening occurs. Adhesion of the peripheral utricles also takes place at about this time, and the first granules of calcium carbonate appear.

The growing medullary filaments are thin-walled $(0 \cdot 1-1 \mu \mathrm{m})$. Their tips show a gradient of organelles, and three regions have been delimited (Borowitzka and Larkum, 1977). At the very apex and extending sometimes for a length of about $4 \mu \mathrm{m}$ is a region of numerous small vesicles, some with granular material resembling wall components, others with osmiophilic material.

The region below the tip is characterized by much endoplasmic reticulum and many mitochondria with DNA-like fibrils in part of their matrix. Some of the mitochondria are several times the length of mitochondria elsewhere in the thallus. There is also much nuclear division.

The third growing-tip region contains many small vacuoles together with microtubules, mitochondria and young plastids with and without starch depending on the age of the filament.

Golgi bodies are present throughout the three regions although not uniformly so. Migration of organelles from the preceding segment and their participation in the development of the new segment have not been studied.

The tips of the filaments forming the cortex show a similar differentiation into three regions (Borowitzka and Larkum, 1977).

The remainder of the filaments of the developing segment may be somewhat more vacuolate, and other organelles may be present such as amyloplasts (Fig. 54). The spherical and electron-dense bodies (Section I) may occur in some material (Wilbur et al., 1969).

Young peripheral utricles, when their walls become laterally attached, possess many well-developed chloroplasts as well as young plastids, amyloplasts and a vacuole which may contain many spherical bodies (Borowitzka and Larkum, 1977). Calcification begins at about this stage.

(a) Adhesion of peripheral utricles. In cylindracea the osmiophilic covering lamella bulges outwards, away from the rest of the filament wall, and appears to fuse with the covering lamella of the neighbouring peripheral utricle (Borowitzka and Larkum, 1977). The resulting space between covering lamella and filament wall contains a granular material.

This is the only species for which lateral adhesion has been studied and reported at the ultrastructural level. The process is probably similar in most other species, but interesting variations may occur. In some species, particularly macrophysa (Sections III, IV), the peripheral 


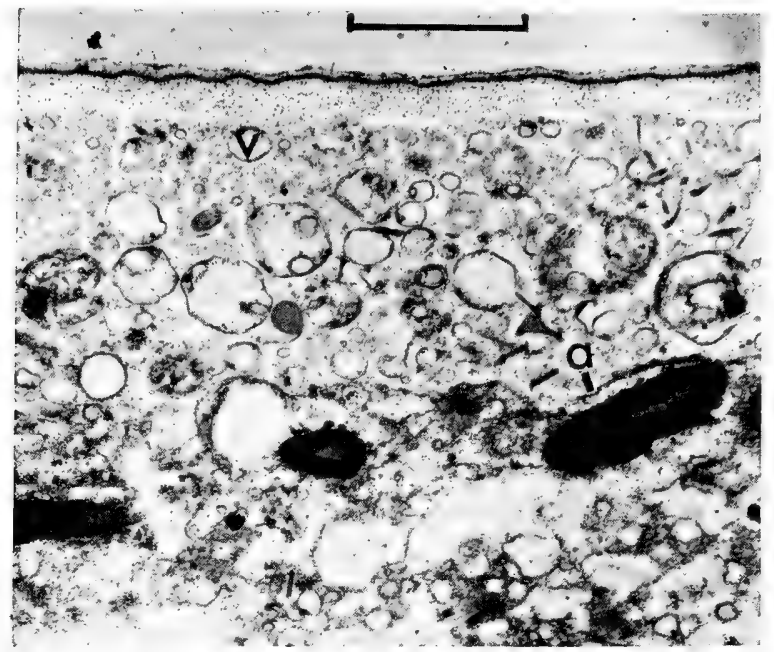

FIG. 54. H. monile. Filament from a segment less than 24 hours old, showing a variety of sizes of vesicles (v) near the wall, and amyloplasts (a) towards the centre. Approximately half the filament width is shown. Aragonite deposition has not begun, and the fibrous coating of the wall can be seen. Stained with lead tartrate. Scale bar is $1 \mu \mathrm{m}$.

utricles are free in mature segments. What happens in the developing segment has not been investigated. In other species where peripheral utricles barely touch each other (gracilis, Section IV) the covering lamella would provide the matrix to hold the utricles together and also provide the continuous outer covering of the segment.

\section{Mature segment}

In these segments, which may be all the segments on many thalli, the growth process is essentially complete, and the three regions of the segment (peripheral utricles representing the exterior, the inner cortex and the medulla) are fully delimited. Some subsequent elongation of these regions may occur, with possibly the addition of another layer of inner cortex in much older segments. There may be increased vacuolation of the filaments, and calcification continues, although the full extent of it varies with the species and with depth.

The outer surface of a mature segment shows some physical differences from the walls of the filaments within them. The outer pilose layer has been lost, and in cylindracea a second layer of covering lamella develops beneath the original one, which then becomes detached except in the corners where it appears to reinforce utricle adhesion (Borowitzka and Larkum, 1977). 


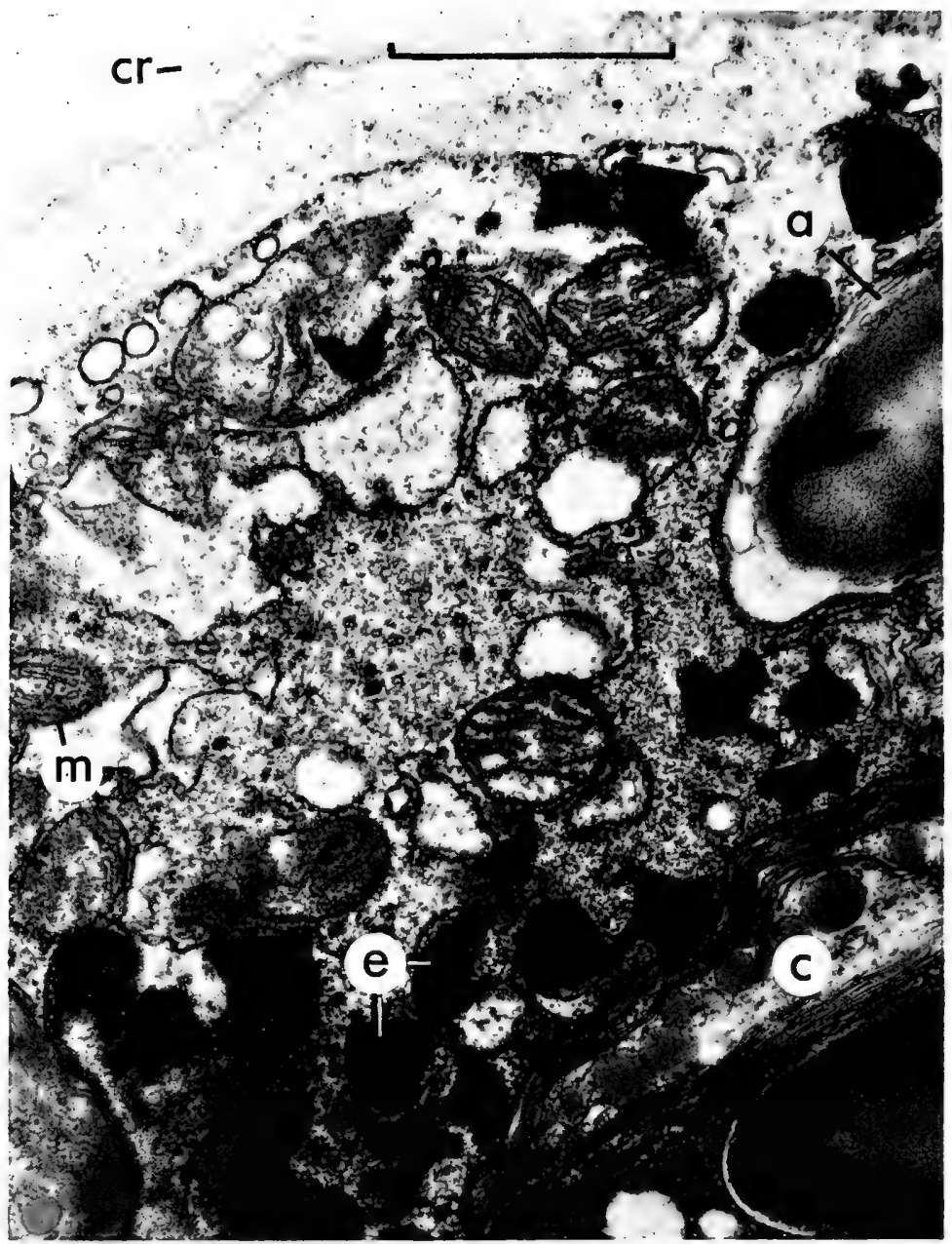

FiG. 55. H. monile. Filament from a mature segment but one which is less than 48 hours old. There appears to be much cytoplasmic activity in material of this age. Mature chloroplasts (c) are present as well as immature ones, although the latter are not present in the photomicrograph. Calcification has begun, but the crystals (cr) were lost in sectioning. $\mathrm{a}=$ Amyloplast, $\mathrm{e}=$ electron-dense body, $\mathrm{m}=$ mitochondrion. Stained with lead tartrate. Scale bar is $1 \mu \mathrm{m}$.

Although the full range of organelles may occur (Fig. 55), there is also a gradient in the kinds of organelles predominating from periphery to centre of the mature segment, the chloroplasts being commonest towards the periphery and amyloplasts commoner in inner regions, but since the chloroplasts migrate inward at night (Stark et al., 1969) and amyloplasts presumably migrate too, the picture is not so simple. 


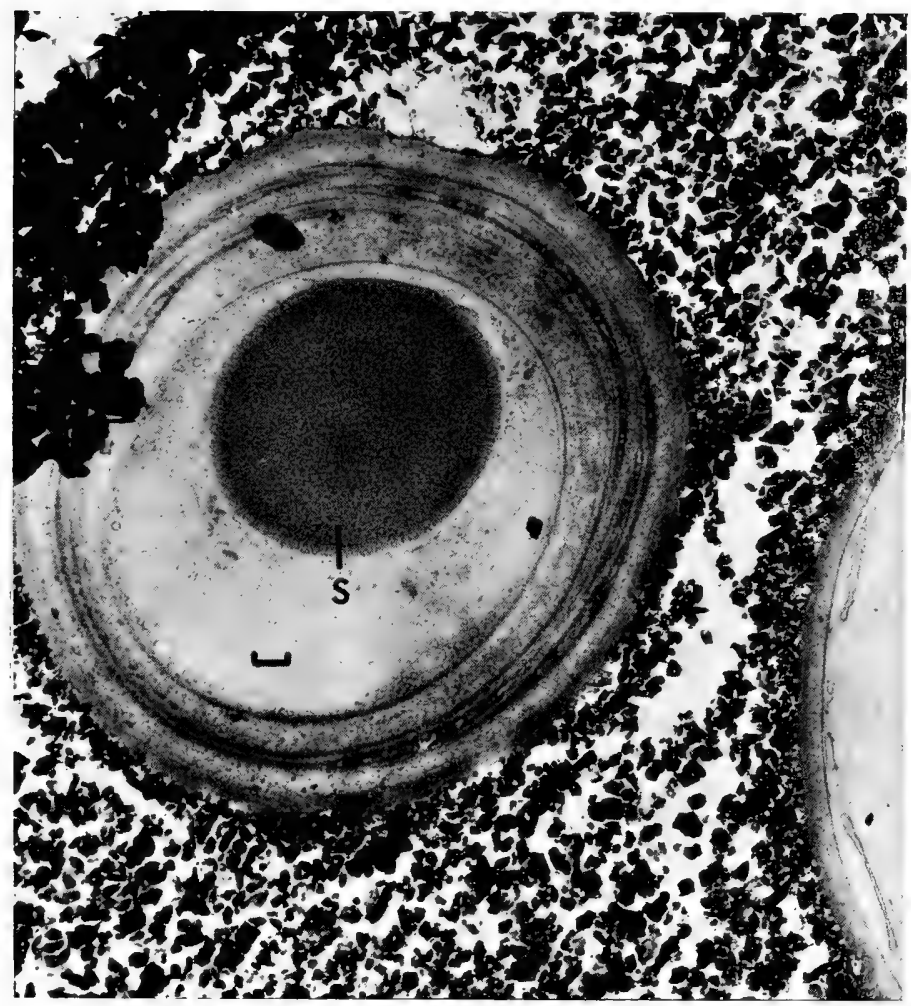

FIG. 56. H. monile. Cross-section of a filament from an old, white suprabasal segment, showing the much thickened wall of some of the filaments, spherical body (s), and aragonite crystals filling the segment space. The density of cytoplasmic organelles appears to be comparatively low in old, white, heavily calcified segments. A portion of a filament with wall of more usual thickness appears on right-hand side. Stained with lead tartrate. Scale bar is $0.1 \mu \mathrm{m}$.

\section{Old basal segments}

In these segments, which occur mostly on perennating thalli or old thalli, the filament wall may be considerably thickened, up to at least $2 \mu \mathrm{m}$, and stratified (Fig. 56), although there is also local thickening in younger material. Amyloplasts are relatively prominent in some of the material as are spherical bodies (Wilbur et al., 1969).

\section{Wounding response}

Siphonaceous algae, when wounded, quickly produce a yellowish material often referred to as a callose or mucilagenous substance 
(Mirande, 1913) which clots at the site of the injury. Burr and West (1971b) have studied this process in Bryopsis where proteinaceous schizogenous bodies are involved. Wounding has not been examined in Halimeda. The spherical bodies may be involved in this process.

\section{Summary of ultrastructural changes}

In the developing segment a gradient of organelles and activities occurs in the tips of the growing medullary filaments and their lateral branches. At the extreme tip is a region of small vesicles. This region may be up to about $4 \mu \mathrm{m}$ long. Behind it is a mitochondrial region, followed by a region of small vacuoles.

By the time utricle adhesion takes place, which in some species occurs by the fusion of the osmiophilic covering lamellae of adjacent walls, the utricles contain many mature chloroplasts, as well as some amyloplasts.

Migration of organelles from the preceding segment and their participation in the development of the new segment have not been studied.

When utricle adhesion occurs growth is essentially complete. Thereafter utricle surfaces on the outside of the plant slough off much of the pilose layer of their walls, utricle layers may elongate somewhat, and calcium carbonate deposits build up.

In very old segments the walls may be much thickened, up to at least $2 \mu \mathrm{m}$, and stratified. In some specimens or species the peripheral utricles do not adhere in these segments although they adhere elcewhere on the plant (Hillis, 1959). In the limited material examined cytoplasmic components of old basal segments are much reduced.

\section{Calcification}

Somewhat over 100 genera of algae calcify, and there are calcareous representatives in most algal divisions (Table XV). Two species of calcium carbonate are deposited, aragonite and calcite, and the type is constant for the species. Aragonite rather than calcite precipitation is avoured by high temperatures, high $\mathrm{pH}$ and the presence of sodium succinate, chondroitin sulphate and the cations of strontium, barium and lead (Milliman, 1974). The precipitation of calcite but not aragonite is inhibited by the presence of magnesium in solution, while sulphate ions may inhibit precipitation as aragonite (Milliman, 1974).

In Halimeda, as the new segment is completing its development calcification begins, and the process continues for much or all of the life of the segment. X-ray diffraction studies (McConnell and Colinvaux, 


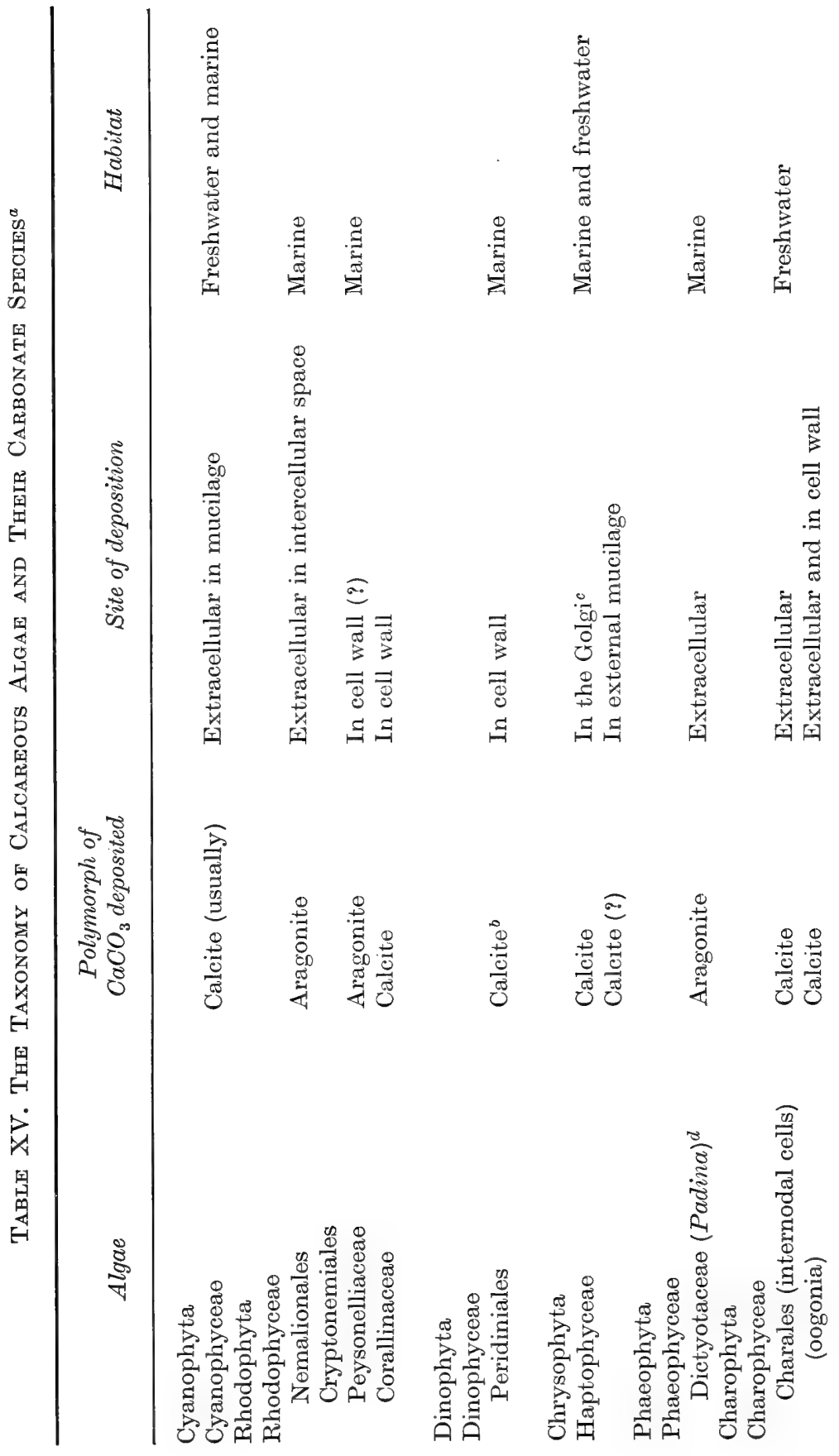




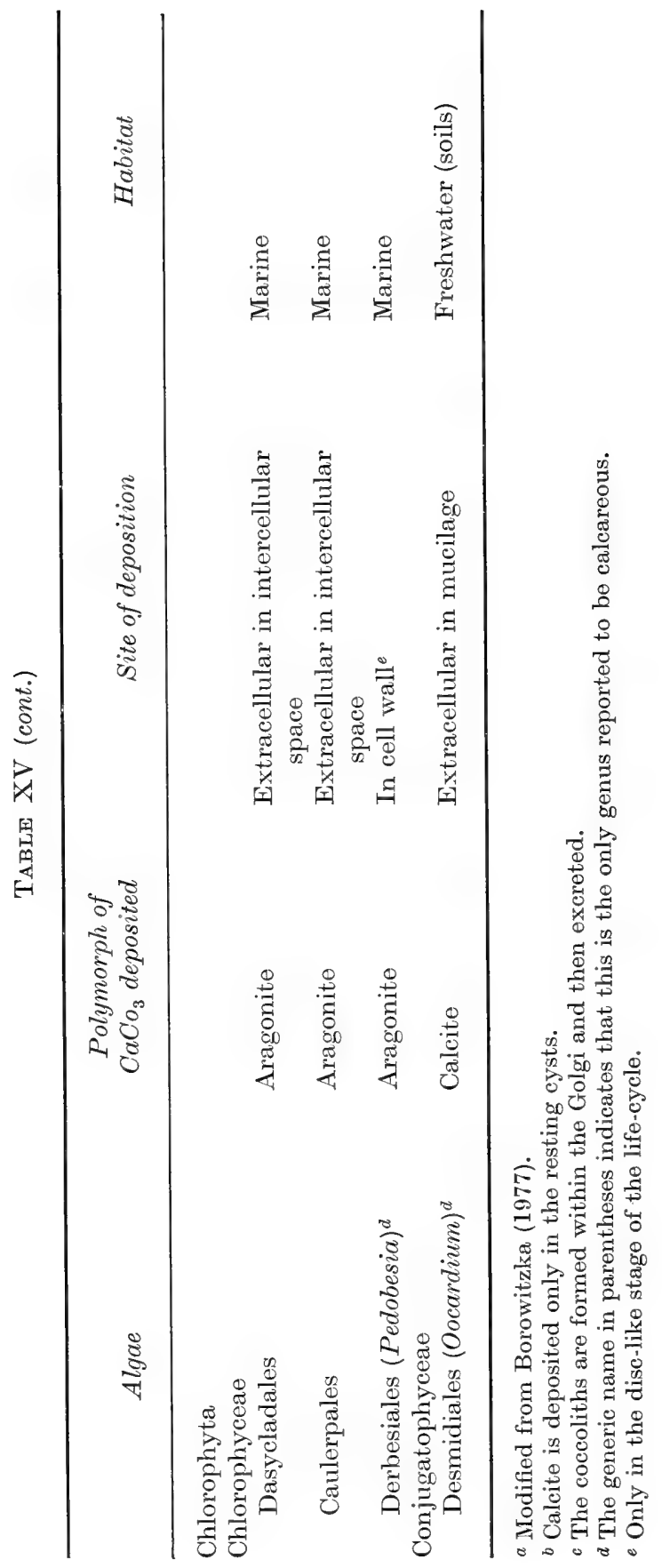


1967) have shown that only aragonite is deposited in the genus, all the then known species being tested.

The crystals are generally needle-shaped, reaching about $10 \mu \mathrm{m}$ in length, $0.08-0.60 \mu \mathrm{m}$ in width and $0.01 \mu \mathrm{m}$ and less in thickness (Wilbur et al., 1969; Marszalek, 1971; Borowitzka et al., 1974). Wilbur et al. (1969) observed granular and polygonal crystals, up to $0.6 \mu \mathrm{m}$ in diameter, in some material of incrassata. The size and numbers of crystals vary with the age of segment, with the species and to some extent from specimen to specimen of the same species, particularly specimens from different sites.

Carbonate deposition seems to be an important function in the metabolism of Halimeda, and needs to be understood both as a physiological process, and as an adaptation to life in a reef.

In its simplest form the reaction of calcification is the following:

$$
\mathrm{Ca}^{2+}+2 \mathrm{HCO}_{3}^{-} \rightleftharpoons \mathrm{CaCO}_{3} \downarrow+\mathrm{H}_{2} \mathrm{O}+\mathrm{CO}_{2}
$$

That more than a physical precipitation from a supersaturated solution is involved for many organisms is shown by the isotopic composition of the algal carbonate. That of Halimeda is enriched in ${ }^{13} \mathrm{C}$ and poor in ${ }^{18} \mathrm{O}$ as compared to natural limestone (Fig. 57 ), and the organic matter of this alga is enriched in ${ }^{12} \mathrm{C}$ (Milliman, 1974). These differences indicate metabolic involvement of the plant in calcification.

\section{Aragonite deposition: a process working outside filament walls}

Askenasy (1888) in an early microscopical study of the calcium carbonate deposits in Halimeda observed that deposits were present soon after the segment was completed, that they increased with age, and that deposition began on the outer surface of the lateral walls of the peripheral utricles and soon spread over the entire space between them.

Few further studies were made of the calcification of any alga until the 1960s (Lewin, 1962), by which time new techniques and equipment, particularly radiocarbon isotopes and the electron microscope, had become available.

These new tools, however, had already been applied, in the years before Lewin's review of the subject, to studies of animal calcification, and research by two workers into calcification included algae as well. Goreau, working on the reefs of Jamaica and calcification in corals, included the calcareous red and green algae, and Wilbur at Duke University, working with molluses, included coccolithophorids.

It was known from the work of Wilbur and others that calcium carbonate deposition in molluses was associated with an external 


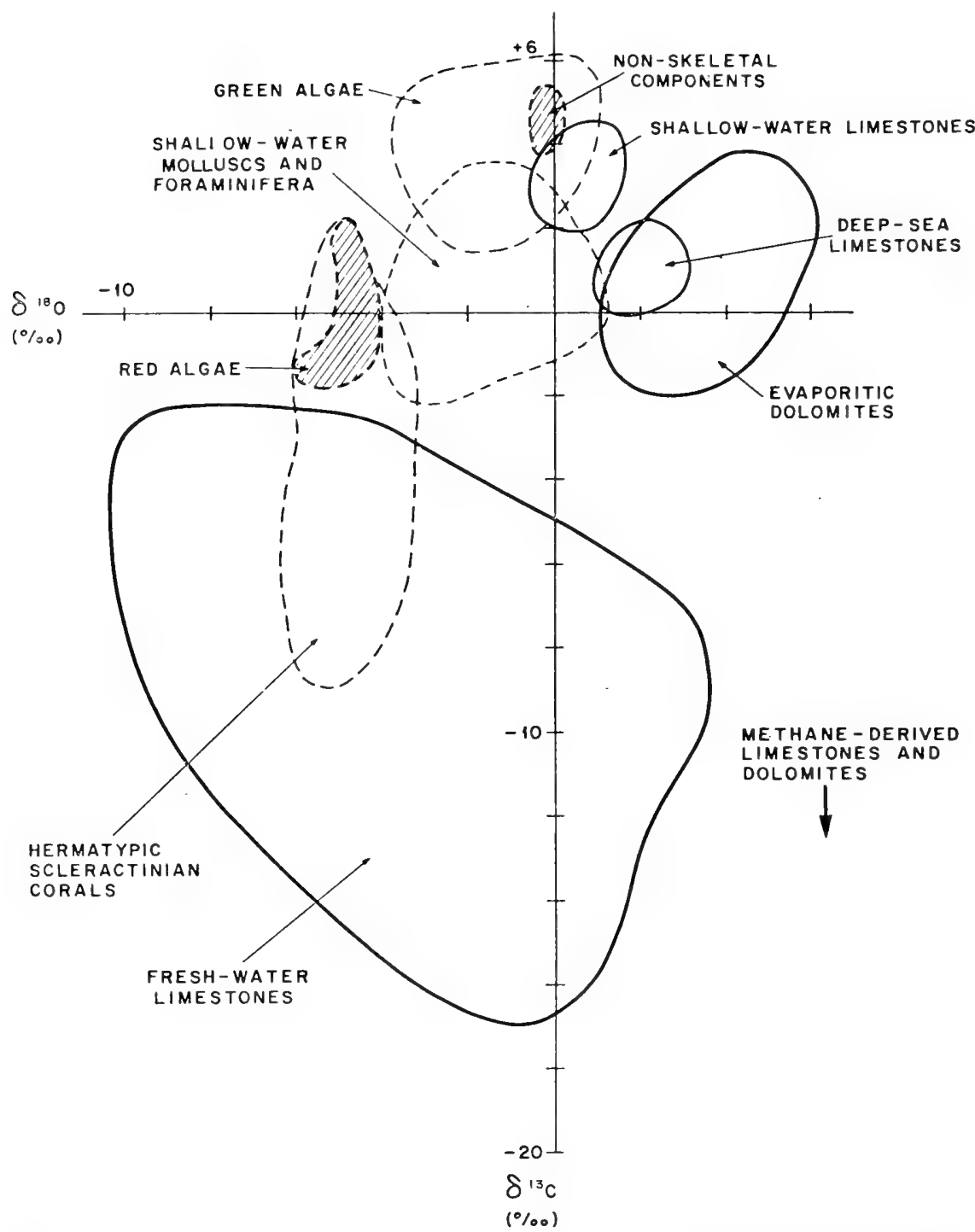

FIG. 57. Comparison of the deviations of ${ }^{18} \mathrm{O}$ and ${ }^{13} \mathrm{C}$ in Halimeda (green algae) with those of other calcareous organisms and natural carbonates. (From Milliman (1974), reproduced with permission.)

organic matrix, and that crystallization was internal in coccolithophorids, the crystals subsequently being extruded onto the cell surface. One might, therefore, anticipate a matrix or internal precipitation in 
Halimeda. An electron microscope study of calcification in Halimeda (Wilbur et al., 1969), however, showed that the pattern was different.

Working with cultured incrassata and monile, Wilbur et al. (1969) noted that aragonite crystals were first formed on the outer surface of the utricle walls when the segment was about 36 hours old (Fig. 55), although this varies somewhat with the material, and that the crystals formed in the immediate vicinity of the fine fibrils of the filament wall. No organic matrix was observed at the site of crystallization (Fig. 58)

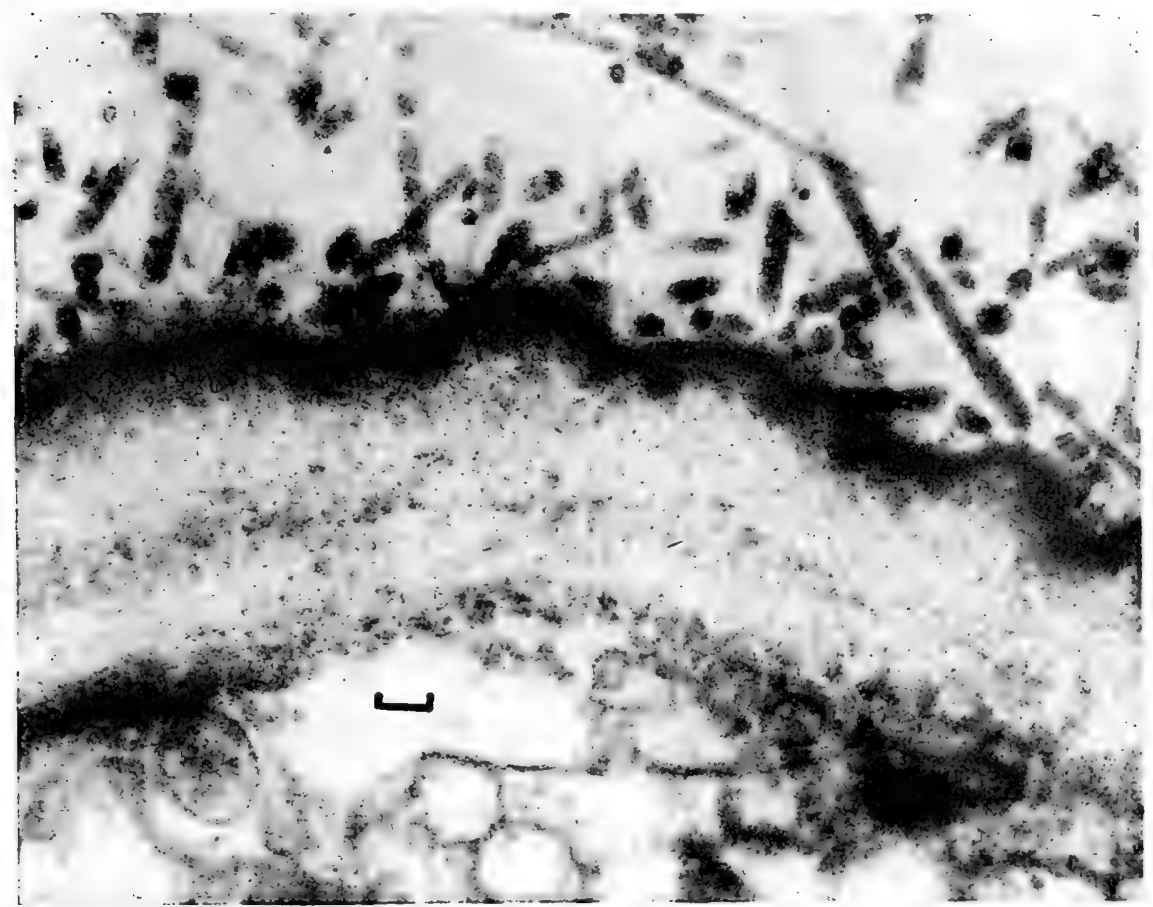

Fig. 58. H. monile. An early stage in the development of aragonite crystals. Both granular crystals and needles occur in the region of the fibres of the filament wall. The needles extend at various angles into the interutricular spaces. Scale bar is $0 \cdot 1 \mu \mathrm{m}$.

and in contrast to other calcification systems it also was not evident in sections decalcificated with uranyl acetate which retains an organic matrix in molluscan shell. Crystal orientation was random. These aspects have subsequently been confirmed with cylindracea (Borowitzka and Larkum, 1977).

Sections through older material showed that following the formation of crystals within the fibrous matting of the walls of the peripheral 
utricles, the crystals grow into the spaces (Fig. 58) until eventually the interutricular space is completely filled (Figs 56,59). The crystals also extend, depending somewhat on species, into the spaces between the central medullary filaments with, in old segments, some secondary

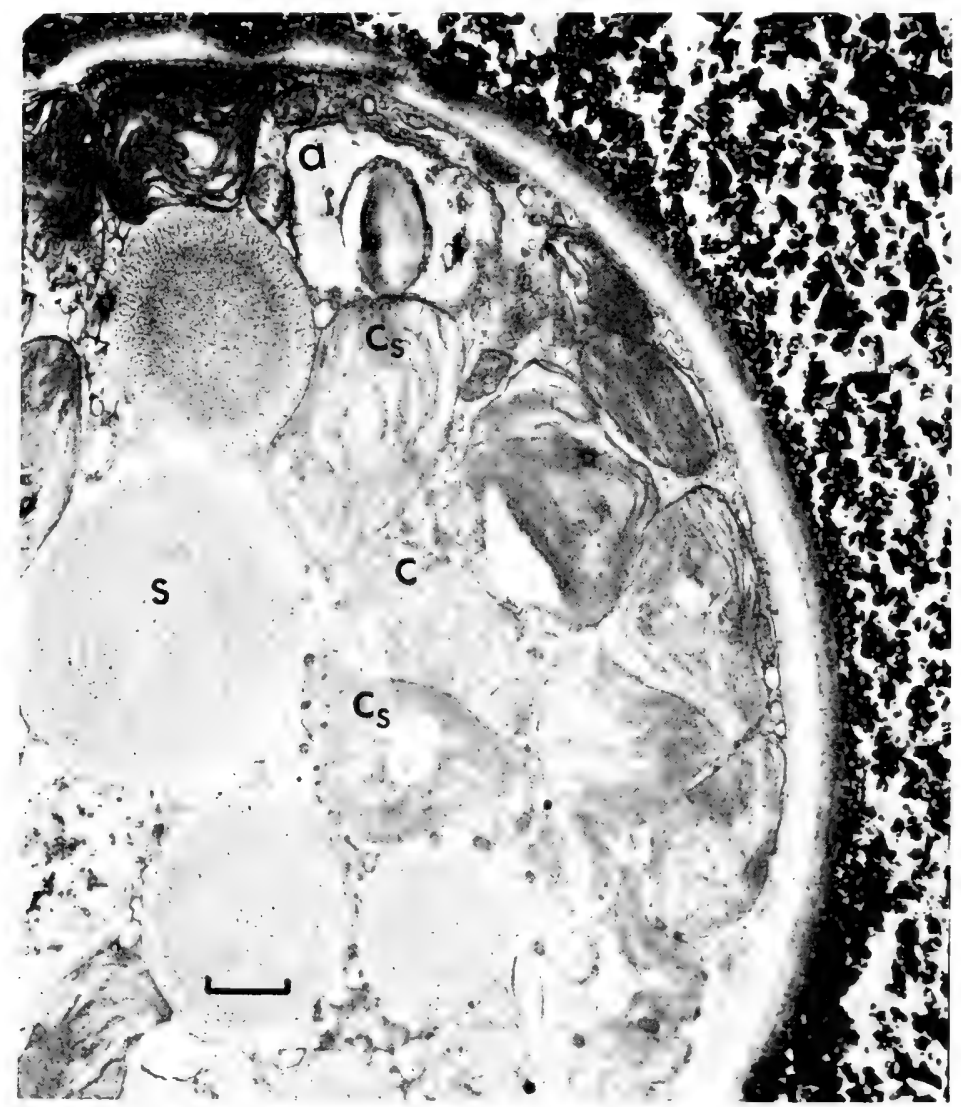

FIG. 59. $H$. incrassata. Cross-section of a filament from a mature green segment near the base of the thallus showing amyloplast (a), chloroplasts (c), chloroplasts with starch $\left(\mathrm{c}_{\mathrm{s}}\right)$, and spherical bodies (s). The segment is well calcified, with aragonite crystals filling the spaces of the segment. Stained with lead tartrate. Scale bar is $1 \mu \mathrm{m}$.

crystal formation around the aragonite needles (Borowitzka and Larkum, 1977).

This work by Wilbur and his coworkers (1969) demonstrated that the process of calcification in Halimeda occurs in the spaces of the segments, and they pointed out that since the peripheral utricles usually 
adhere laterally, the solution filling these spaces is not in free communication with the surrounding seawater except in the very youngest, segments. They considered that a completely enclosed volume within the segment would favour crystallization, but that crystallization might also occur without complete isolation from the seawater outside.

\section{Calcium-binding properties of the filament wall}

With the first aragonite crystals being formed in close proximity to the filament wall, it would seem natural to scrutinize the nature and activities of the wall more closely. Böhm (1972) reported the presence of a calcium-binding polysaccharide fraction in the wall of opuntia. In a more detailed study of the mucilages (water-soluble polysaccharides) the calcium-binding strength was described as low and of the same order of magnitude as succinate (Böhm, 1973b).

The fibrous matting layer, on the basis of tests with ruthenium red and proteolytic enzymes, appears to be polysaccharide (Borowitzka and Larkum, 1977).

\section{Calcification and metabolic activity}

The enhancement of calcification by light was initially demonstrated by Goreau (1963) working with eight species of Halimeda, and later by Stark et al. (1969), the latter group working with opuntia and discoidea in the reefs of Puerto Rico and the laboratory of the University of Maryland. Goreau's results were, however, somewhat clouded by greater rates being obtained for deposition of calcium carbonate in the dark with four of the eight species. The overall average for the eight species, however, gave a greater light : dark ratio. The difficulty appears to lie in the ${ }^{45} \mathrm{Ca}$ methodology which included a short labelling time followed by a long wash in unlabelled medium (Borowitzka and Larkum, 1976a).

Calcium pathways were first worked on by Stark et al. (1969) and Böhm and Goreau (1973). By comparing the differential washout rates for ${ }^{45} \mathrm{Ca}$ absorbed in the light with those obtained in the dark, Stark et al. (1969) suggested a two-step mechanism in the calcification process. The ions were first bound to the wall and their ionic concentration increased. Then there was precipitation.

Böhm and Goreau (1973), from an analysis of their ${ }^{45} \mathrm{Ca}$ activity data, proposed a two-compartment exchange system, the seawater-alga system. They considered that at least two pools existed within the alga, making the whole at least a three-compartment catenary system of the 
type seawater-polysaccharides-skeleton, with free space and organelles qualifying as additional compartments. The dynamics of the system include the uptake of calcium from the seawater and its release into the seawater. Some calcium is deposited and remobilized in the skeleton, with most if not all of the calcium that is returned to the seawater originating from the carbonate deposits. The water-soluble polysaccharides of the wall incorporate calcium 7-14 times more rapidly than the calcium carbonate deposits. Böhm and Goreau did not, however, obtain conclusive evidence for linking calcium binding of the wall and crystallization.

Many aspects of this work have been continued by Borowitzka and Larkum (1976a, b, c, 1977) working in Australia with the species cylindracea, discoidea, macroloba and tuna from the Great Barrier Reef. Lheir experiments with the living alga utilized branches of seven or more segments rather than entire thalli. Light intensities in photosynthesis experiments, measured at the water surface, were 2800 lux, while Halimedae which were planted but not yet used in experiments at the time received 1200 lux at the water surface over a 16-hour light period. Carbon-14 techniques were used for much of the photosynthetic work.

Their study included an investigation of the exchange of calcium between seawater and alga using ${ }^{45} \mathrm{Ca}$, of the sources of inorganic carbon for photosynthesis and calcification, and of the effects of metabolic inhibitors on these two processes. Part of the work included calculations of the effects on $\mathrm{pH}$ and on the concentration of carbonate ions in a closed seawater system such as the spaces of a Halimeda segment, when carbon dioxide and bicarbonate ions are removed by photosynthesis, and calcium carbonate precipitation occurs.

From their work and the results of others, they concluded that calcification in Halimeda is primarily a function of the anatomy of the alga and the uptake of carbon dioxide during photosynthesis, and that the calcium-binding polysaccharide of the wall plays little or no role in the process.

Since the spaces of the segment are enclosed, entry of ions into them must be by movement through the confluent walls of the peripheral utricles or through the filaments. Borowitzka and Larkum considered that the pathway of carbon and calcium to the spaces was mainly by diffusion through the shared peripheral utricle walls. In the light, carbon dioxide uptake for photosynthesis from the seawater of the spaces, which is supersaturated with calcium carbonate, results, according to their calculations, in an increase of $\mathrm{pH}$ and in the conrentration of carbonate ions within the spaces, thereby stimulating the cate of aragonite precipitation. When respiration only takes place, the 
released carbon dioxide lowers the $\mathrm{pH}$ and concentration of carbonate ions in the spaces, inhibiting calcification.

Before light stimulation of calcification can occur the photosynthetic rate must exceed a certain threshold value (Borowitzka and Larkum, 1976b), and the rate of carbon dioxide removal by photosynthesis from the spaces must exceed, by a certain factor, the supply entering the spaces. A model of this scheme is shown in Fig. 60.

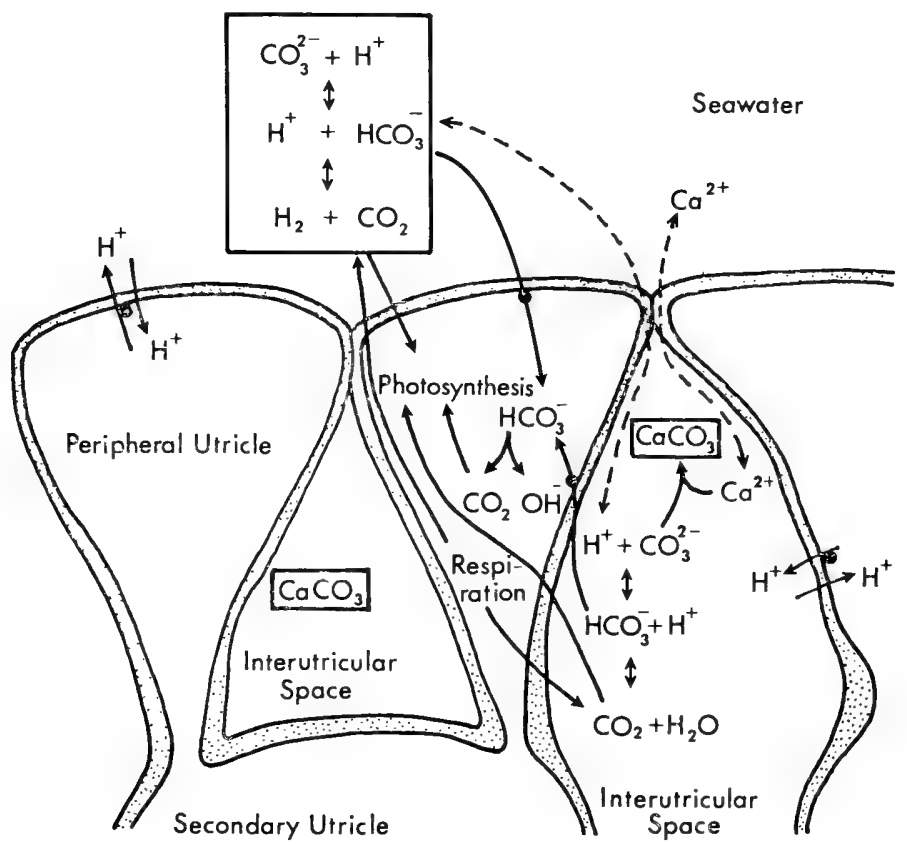

Frg. 60. A model of calcification in Halimeda, which takes place within the spaces of the segment. These spaces are separated, in most species, from the outer seawater environment by a fusing or adhering of the covering lamellae of adjacent peripheral utricles. The extent of the adhesion depends on the species and somewhat on the age of the material. The postulated movements and fluxes of ions during photosynthesis, which takes place within the peripheral utricles and to a lesser extent in the remainder of the filament system of the segment, are shown. These include a light-stimulated proton flux. The end result is the precipitation of calcium carbonate in the interutricular and interfilamental spaces of the segments. Black dots at the plasmalemma indicate fluxes postulated to be active. (Modified from Borowitzka, 1977.)

4. Progress in calcification studies: a review

Calcification, although not widespread among algae, occurs regularly in over 100 genera. The calcium carbonate crystals are deposited 
as calcite or aragonite, but the two species forms are not mixed within plants. In the genus Halimeda aragonite is deposited, and the crystals are predominantly needle-shaped. Carbonate deposition seems to be an important function in the metabolism of Halimeda.

The deposition of aragonite in Halimeda occurs within the segment but outside the filaments that comprise it, that is, it takes place within the closed or essentially closed spaces of the Halimeda plant.

The first crystals form in the spaces between the peripheral utricles, at the filament wall surface (interutricular and not intercellular space), when the segments are about one to two days old. A distinct organic matrix has not been observed, and crystal orientation is random. The deposits increase rapidly with age until most of the space within a segment is filled. Secondary crystal formation occurs, the aragonite needles acting as nuclei.

The spaces within the segments are essentially closed since the peripheral utricles of most species adhere laterally at their outer edges. The seawater environment of the segment is not in free communication with the surrounding seawater except in the very youngest segments, and possibly the very oldest segments of some thalli. Such an environment could favour crystallization.

The mucilages of the filament walls contain a calcium-binding polysaccharide fraction. Its calcium complexing strength, however, is low, and conclusive evidence linking it with calcium carbonate deposition has not been obtained. The fibrous matting layer of the filament walls appears to be polysaccharide.

Two- and three- or more compartment systems have been proposed as representing the pathway of calcium from seawater to aragonite deposit. Other workers have concluded that calcification in Halimeda is primarily a function of the uptake of carbon dioxide during photosynthesis from the enclosed spaces of the segment. Theoretical calculations indicate a resultant increase in $\mathrm{pH}$ and in the concentration of carbonate ions within the spaces, which in turn stimulate the rate of aragonite precipitation.

These combined studies on calcification in Halimeda have added much in a relatively short time to our appreciation of calcification in this alga. They have also left unanswered questions which have interested more than one group of workers, such as the precise $\mathrm{pH}$ within the spaces of the segment at different metabolic phases and the importance of crystal nuclei in initiating aragonite deposition. We need more information on calcium within the filaments, and also some comparison between results of physiological experiments using intact 
growing Halimedae, Halimedae recently collected from their reef habitats, and branches removed from these coenocytic plants.

The importance of calcification to the life of the plant is not understood. What is the energy cost? What are the benefits that pay for this cost? Is the process important to the cycle of senescence in Halimeda? Being conducted within the closed spaces of the plant, the process can scarcely be a passive consequence of manipulating carbonate ions. But we do not know why it is done.

Halimeda is an admirable plant to grow in culture and in which to study the control of chemistry outside a biological membrane. And in mastering the mechanism used by Halimeda to control the medium between its filaments we will learn something of how the whole organism maintains homeostasis without the benefit of cellular epithelium or, indeed, even an intact boundary layer.

\section{REPRODUCTION}

Much of the reproduction of Halimeda may be by vegetative cloning, the details of which have now been followed in laboratory culture and are understood in outline. The complete sexual cycle, however, is still not known, with no observations of the development of a zygote into the familiar Halimeda thallus. A sexual episode appears to be an outpouring of the energy reserves of an entire thallus into the gametes, and involves the death of the parent plant. This is a breeding strategy reminiscent of an annual weed, though here it is followed by a plant that we now know can maintain itself for an indefinite number of generations between sexual episodes by vegetative means. The breeding strategy has much in common with that described by Williams (1975) as the "strawberry-coral model", though, as we shall see, the Halimeda version presents some unusual twists.

There was little information about reproduction in Halimeda when Fritsch $(1935,1948)$ wrote his treatise on the algae, or Dawson (1966) his book on marine botany. It was known, however, that plants were occasionally collected bearing tiny globules clustered on stalks along the margins of the segments or over their surfaces (Figs 61, 62). The clusters looked like miniature bunches of greenish to blackish grapes, and were sometimes sparse and restricted to one or a few segments; at other times they were dense and covered much of the thallus. The general form of these structures in a number of species had been 


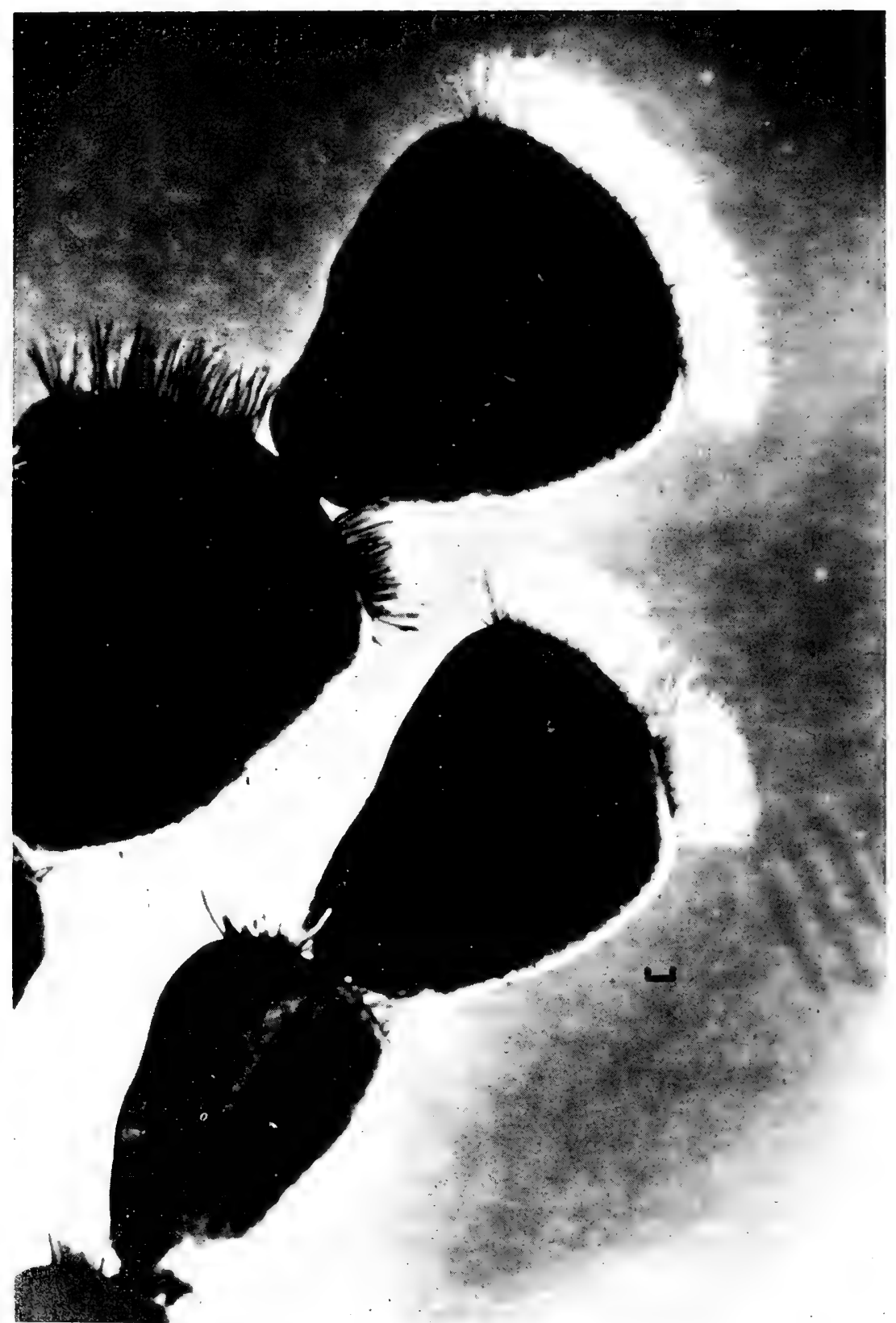

FIG. 6la. Figures $6 \mathrm{la}, \mathrm{b}$ and $62 \mathrm{a}$, b show stages of sexual reproduction in Halimeda. Above, early stage in production of gametangia in $H$. cuneata showing outgrowth of white filaments from segments. Scale bar is $1 \mathrm{~mm}$. (Photograph courtesy of L. Böhm.) 


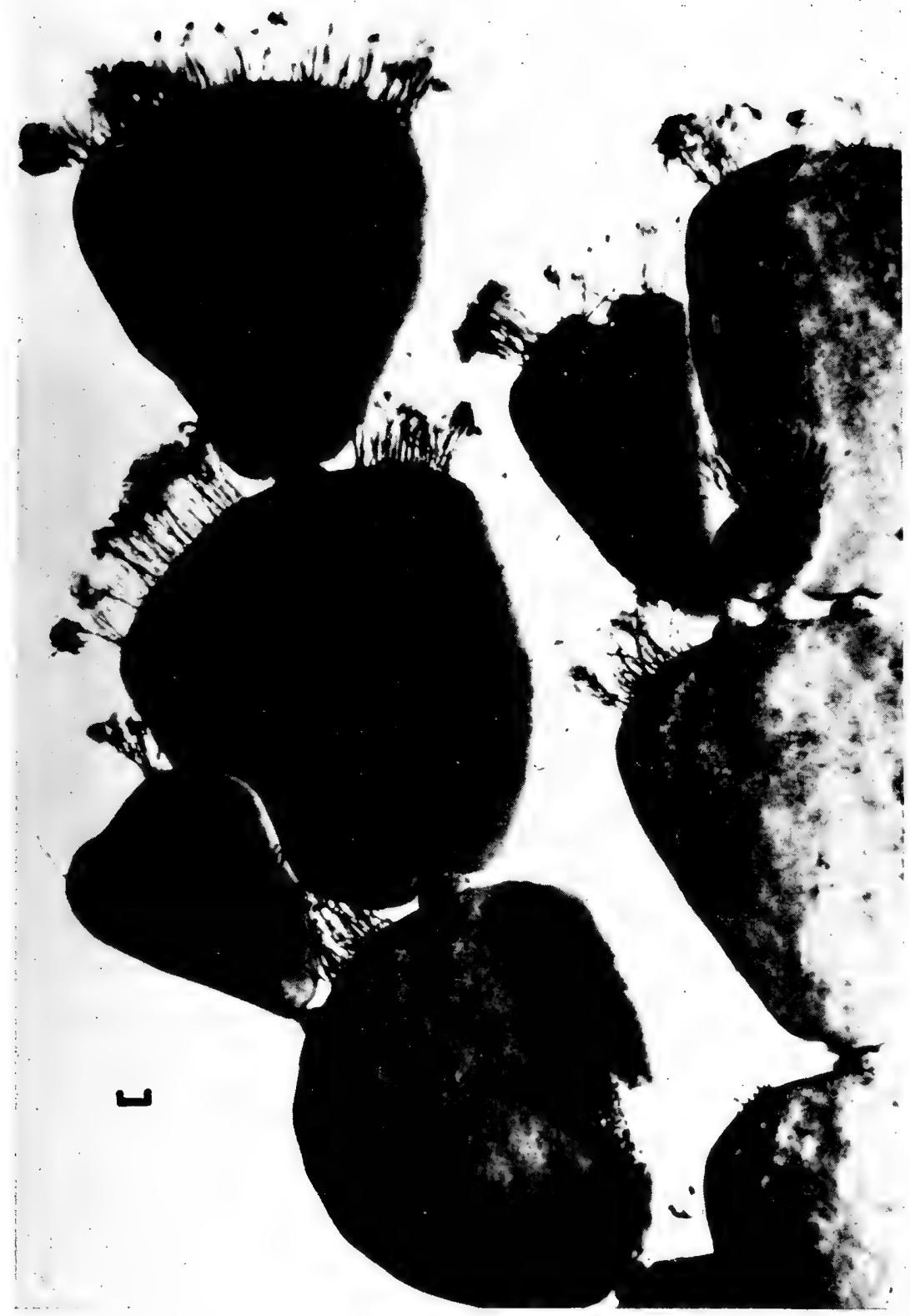

FIG. 61b. Gametangia, 26-36 $\mathrm{mm}$ in diameter, have developed at the tips of many of the stalks (gametophores) on $H$. cuneata. Small cushion segments are particularly apparent between consecutive large segments. Scale bar is $1 \mathrm{~mm}$. (Photograph courtesy of L. Böhm.) 


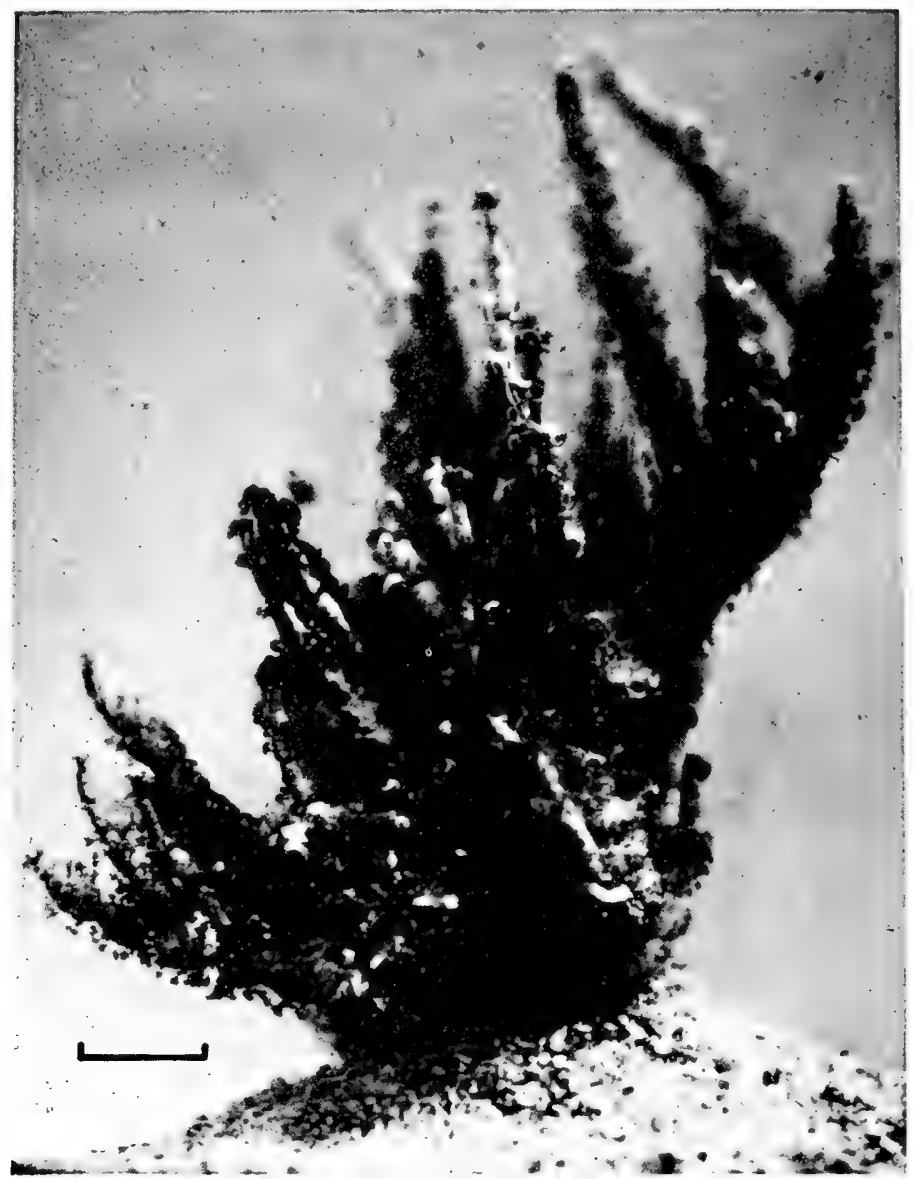

FIG. 62a. H. monile, covered with clusters of greenish gametangia. Scale bar is $1 \mathrm{~cm}$.

described by several workers, some of them having only preserved or dried material to work with, and the review of reproduction for the genus (Hillis, 1959) indicated that plants bearing these clusters were rarely collected and were known for only nine species.

The first workers to report these tiny globules, Derbès and Solier (1856) and later Schmitz (1880), worked with fresh tuna from the Mediterranean. They noted not only the structures but the release from them of biflagellated zooids. For some time thereafter, the contents of the globules were referred to, sometimes as zoospores, at other times as gametes, and there was little support for the choice of term other than 


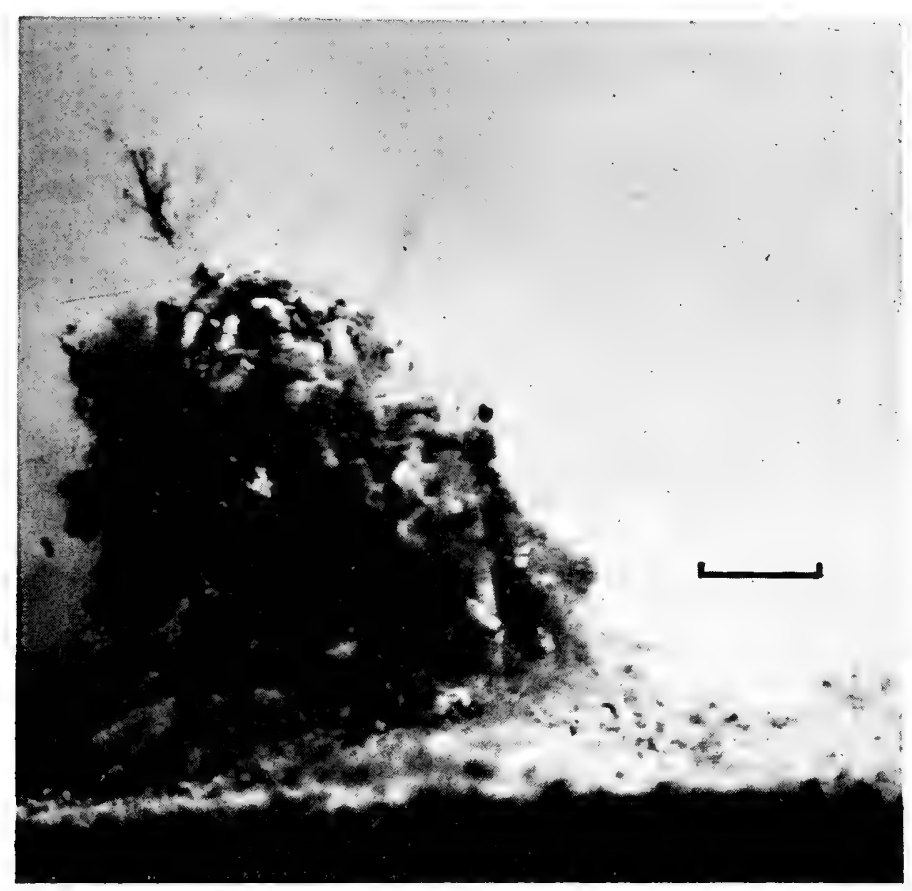

FIG. 62b. Same plant shown in Fig. 62a, in culture, five weeks later, showing complete disintegration of the thallus. In the reef the thallus would have collapsed sooner from currents and animal disturbances. Scale bar is $1 \mathrm{~cm}$.

inference. That the flagellated zooids were evidence of a sexual cycle was not finally demonstrated until fusion was observed in remarkably recent times (Nasr, 1947; Chihara, 1956; Kamura, 1966; Merten, 1971; Meinesz, 1972b).

The demonstration of vegetative reproductive cycles in Halimeda has been even more recent. Field workers have long noticed that some sort of reproduction by creeping growth through sand must occur, but only recent culture work has shown the details and varieties of this process (Colinvaux et al., 1965; Colinvaux, 1968b; Hillis-Colinvaux, 1973). This work shows that individual Halimeda thalli have a definite term to their existence, and that new thalli are cloned from creeping rhizoids of the parent thallus, or from broken portions partially buried by chance. There is no difficulty in recognizing generations in Halimeda (Fig. 63), whether these be sexual or asexual, and the life-cycle always seems to involve youth, a maturity measured in months, sometimes longer, senescence and death. 


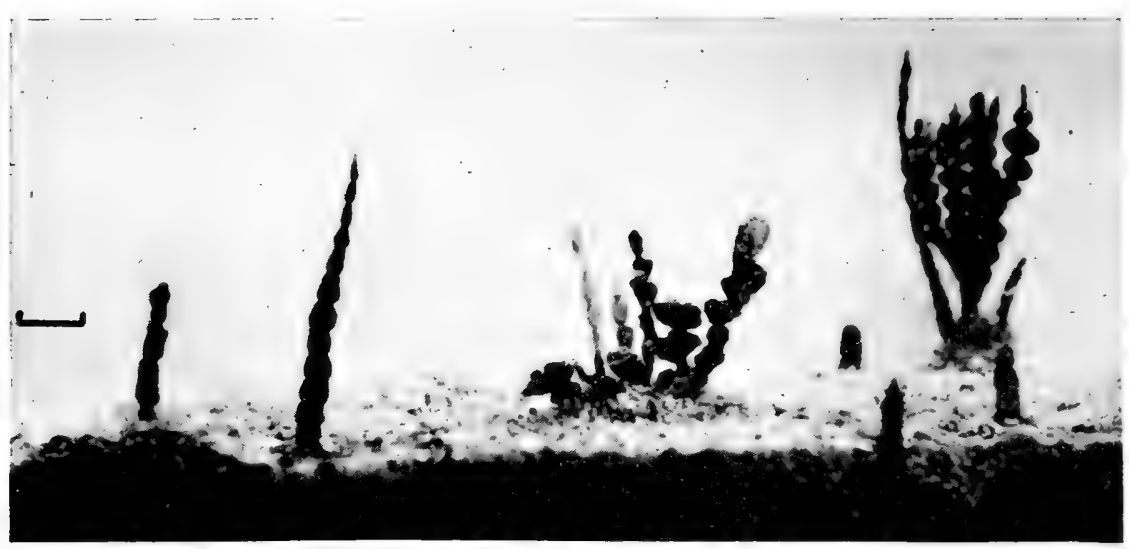

FIG. 63. Cloning of incrassata. The two large thalli have lived in the aquarium for approximately 14 weeks. The tallest of the five young thalli, produced by "runners" in the sand, is 23 days old. The others are less than 10 days old. Scale bar is $1 \mathrm{~cm}$.

\section{A. Sexual processes in Halimeda}

Feldmann (1951) provided the first modern description of the contents of the small globules or gametangia borne externally on a segment. His material was the large-segmented Mediterranean tuna, and he noted that mature gametangia were of two different colours, brown and green, which occurred on different thalli. The gametes released by the two were different also. Those from the brown gametangia were slightly larger (macrogametes), and usually contained three small chloroplasts and a posterior eyespot. Those from the green gametangia (microgametes) possessed the same number of chloroplasts but lacked an eyespot. He noted, too, that when the gametangia were first formed almost all the contents of the coenocytic filaments of the segment, especially the chloroplasts and amyloplasts, moved into the gametangia. The filaments of the segment, therefore, were essentially empty, and the thallus, as a result, appeared white.

These observations show that the sexual process involves:

(i) growth of gametangia on stalks or gametophores (Fig 64);

(ii) the transfer of the free organic matter of the thallus, including reserves, to the gametangia (holocarpy), a process that turns the parent thallus white;

(iii) release of gametes of different sizes;

(iv) fusion of gametes;

(v) death of parent thallus;

(vi) development of the zygote. 

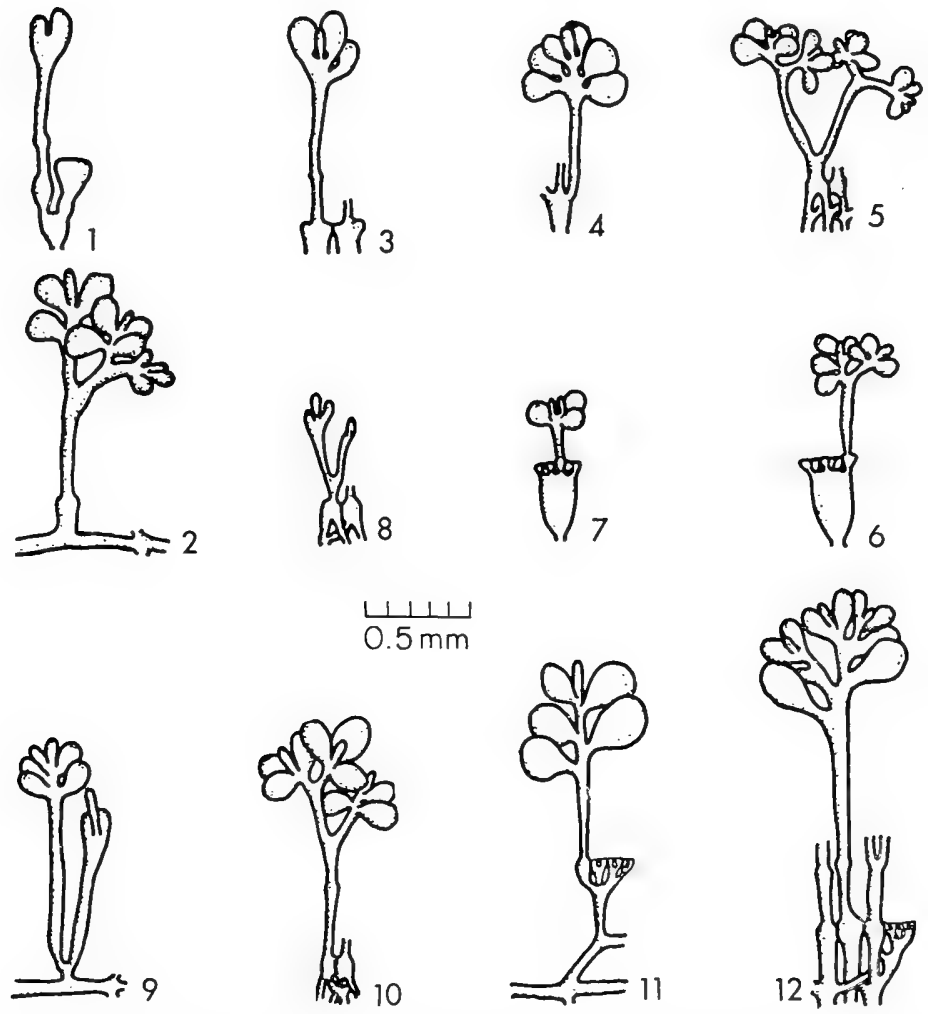

Fig. 64. Camera lucida drawings of gametangia on their gametophores (stalks), showing the three methods of origin of gametangia in Halimeda. Development from utricles is shown in Nos. 1, 6, 7 and 11; from medullary filaments of the segment in Nos. 2, 4 and 9 ; from medullary filaments at the node after fusion in Nos. 3, 5, 8, 10 and 12. Number 1, 3 and 4 are favulosa, Nos. 5-8 are discoidea, Nos. 2, 9 and 10 are scabra and Nos. 11 and 12 are monile. (From Hillis, 1959.)

The complete development of a zygote to a new thallus has not yet been observed and may possibly involve a different life-form.

\section{Development of gametangia}

Hillis (1959) described gametangia for favulosa, and listed the following species as those for which gametangia were known: ? cuneata (possibly misidentified), discoidea, gracilis, incrassata, macroloba, monile, scabra, simulans and tuna. Subsequently, gametangia have been described and drawn for opuntia (Kamura, 1966) and cryptica (Graham, 1975), and I have observed them on copiosa, cuneata, 
cylindracea, lacunalis f. lata, macroloba, macrophysa, micronesica and velasquezii. Gametangia are therefore known for $60 \%$ of the species.

The stalks supporting the gametangia (gametophores) arise from the segment in three ways (Hillis, 1959):

(i) as continuations of the main medullary filaments subsequent to the nodal fusion characteristic of the species (Fig. 64, Nos. 3, 5, 8, $10,12)$;

(ii) as lateral outgrowths without fusion from medullary filaments (Fig. 64, Nos. 2, 4, 9);

(iii) as extensions from peripheral or secondary utricles (Fig. 64, Nos. 1, 6, 7, 11).

Contents of the gametophore are continuous with those of the filaments of the supporting segment, and true plugs or septa such as noted by Howe for scabra (1905a) have not subsequently been reported for this or other species (Feldmann, 1951; Hillis, 1959; Colinvaux et al., 1965; Graham, 1975).

Significant taxonomic differences among species may occur in the dimensions of gametophores particularly the length, the extent of branching of gametophores, and in the size, shape and number of mature gametangia. In cryptica the gametangia are borne predominantly on the shaded under surface, rarely on the margins or at the nodes, and not on the upper surface (Graham, 1975). Non-reproductive characteristics, however, are more consistently available, and therefore are considerably more useful for species identification.

In laboratory aquaria I have found that when a Halimeda becomes fertile, the thallus changes, often dramatically, from green to white overnight or during the "dark" phase of growth, and clusters of gametangia develop on the surface of the segments or along their margins, from white filaments protruding beyond the surface of the segment. At first the developing gametangial structures are white, but they soon become pale green, then darken further as they mature (Fig. 61; Hillis-Colinvaux, 1973).

Electron micrographs of young, pale green gametangia show numerous plastids with sizeable starch grains (Fig. 65), at least in the vicinity of the wall which has the familiar matting of fine fibrils over its outer boundary. Electron-dense bodies (Section I) and granules are common, and spherical bodies are also present. Gametes have not yet formed.

The development of gametangia was once thought to be a rare event since few herbarium specimens have them. This paucity of fertile material in herbaria, however, is certainly a function of the brief 


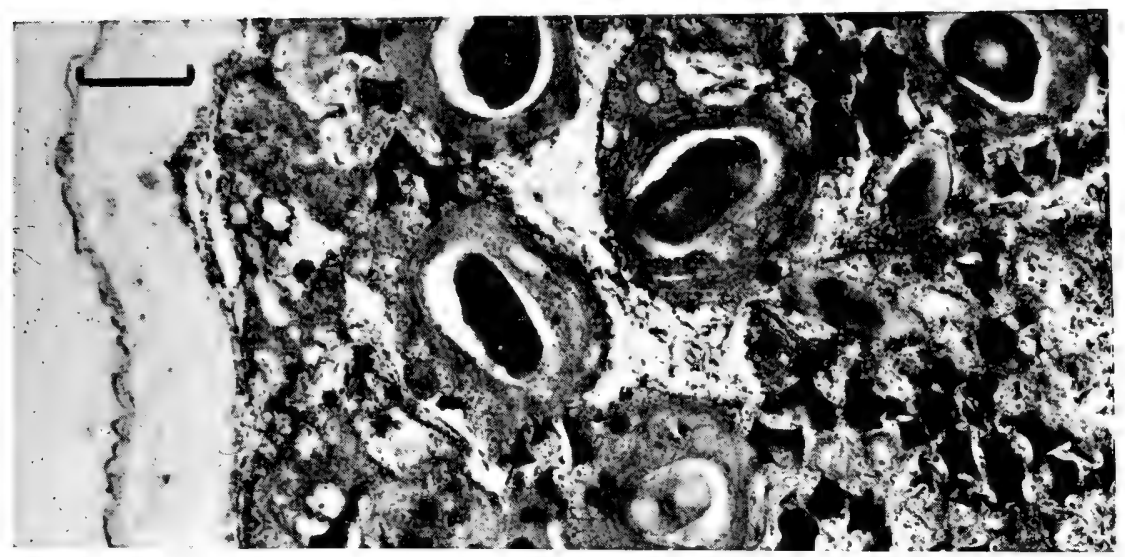

FIG. 65. $H$. incrassata. Section through immature, green gametangium in early organizational stages of microgametes, showing scattered chloroplasts often with starch and oil globules, electron-dense bodies and granules. Fine fibrils on exterior of gametangial wall can be seen in upper left-hand corner. Stained with lead tartrate. Scale bar is $1 \mu \mathrm{m}$.

existence of plants in the fertile condition. In my cultures gametes are usually released about 36 hours after the white gametangial stalks appear, leaving behind a white, disintegrating thallus which would be unlikely to be taken by collectors. Fertile plants can often be found in the field by diligent examination of large populations, but this procedure only became practicable with the advent of scuba. It remains true, however, that only a small proportion of a population may be found to carry gametangia at any one time (Beth, 1962), and that several asexual generations may pass before gametangia are produced.

\section{Development and fusion of gametes}

Gametangia in a late stage of development are either brownish or a very dark green and have the often-remarked "bunch of grapes" appearance. Electron micrographs of the dark green gametangia at an estimated 12-16 hours before the gametes would be released (Figs 66, 67 ) show that cleavage into microgametes is well advanced, although not yet complete. The microgametes contain a large, somewhat posteriorly oriented chloroplast, often with one or more starch grains. The single nucleus is generally above the plastid, and there are often three mitochondria. Two whiplash flagella are inserted into an anterior cytoplasmic papilla. The flagella have the standard $9+2$ arrangement of microtubules. Small vacuoles and occasionally a large lipid body are 


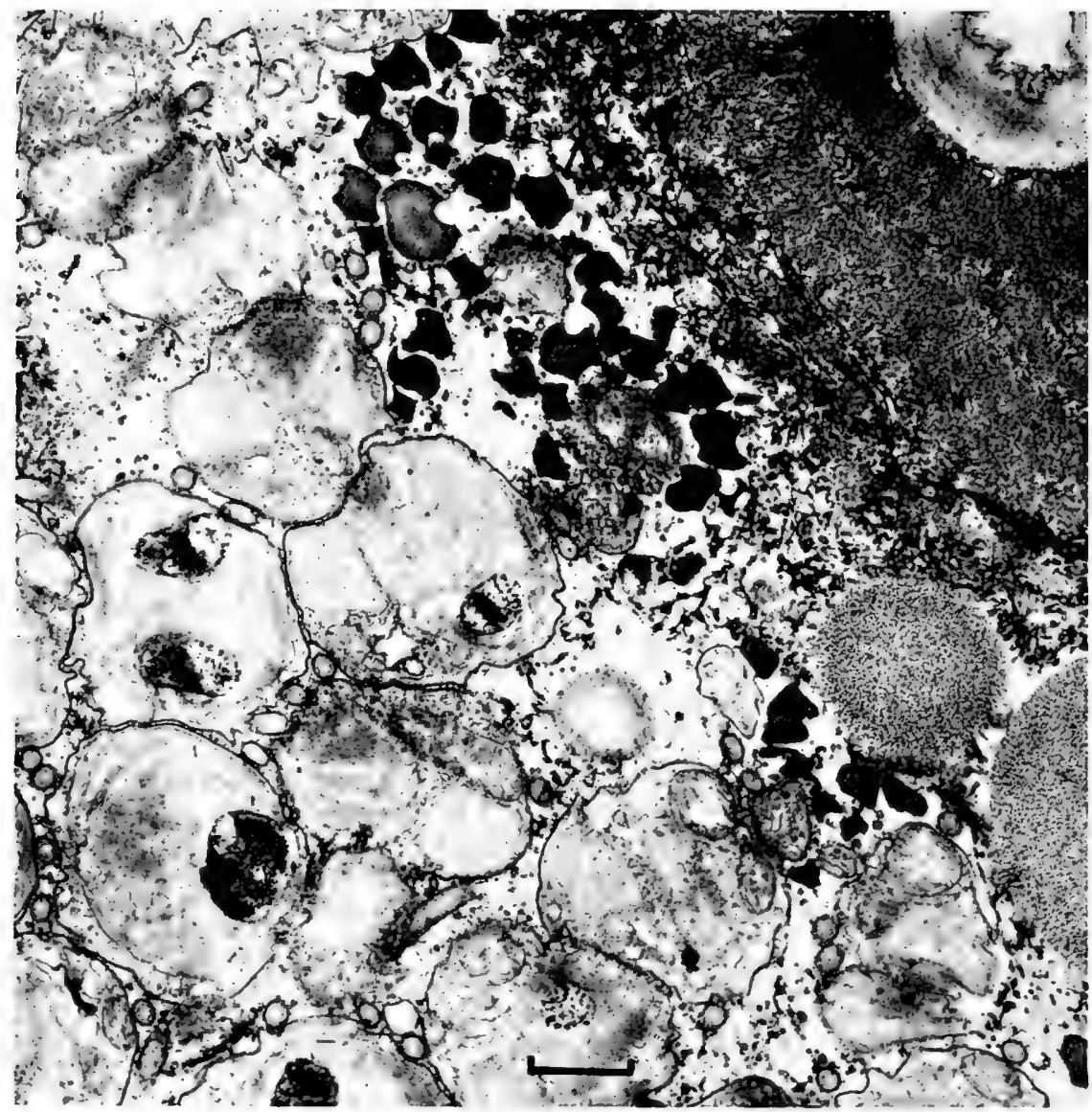

Fig. 66. H. incrassata. Section through very dark green gametangium fixed about 12-16 hours before the estimated release time of gametes. Gametes have been differentiated, but separation is not entirely complete (Fig. 67). Gametes containing chloroplast with starch, nucleus and mitochondria are separated from the gametangial wall shown in the upper right-hand corner by a thick layer of unidentified material, electron-dense bodies and spherical bodies. Several oblique sections of flagella are included. The wall has an outer coating of fine fibrils. Stained with Jead tartrate. Scale bar is $1 \mu \mathrm{m}$.

present in the gametes as well. Between the gametes and the wall there is commonly a layer of the electron-dense bodies, often two, three or more thick, and a layer as thick or thicker than the wall of an unknown material (Fig. 66). Some of these substances may provide the mucilage that is released with the gametes as described later. Spherical bodies and electron-dense granules also occur in the region between wall and developing gametes. The wall has the fine fibrillar coating found in the 


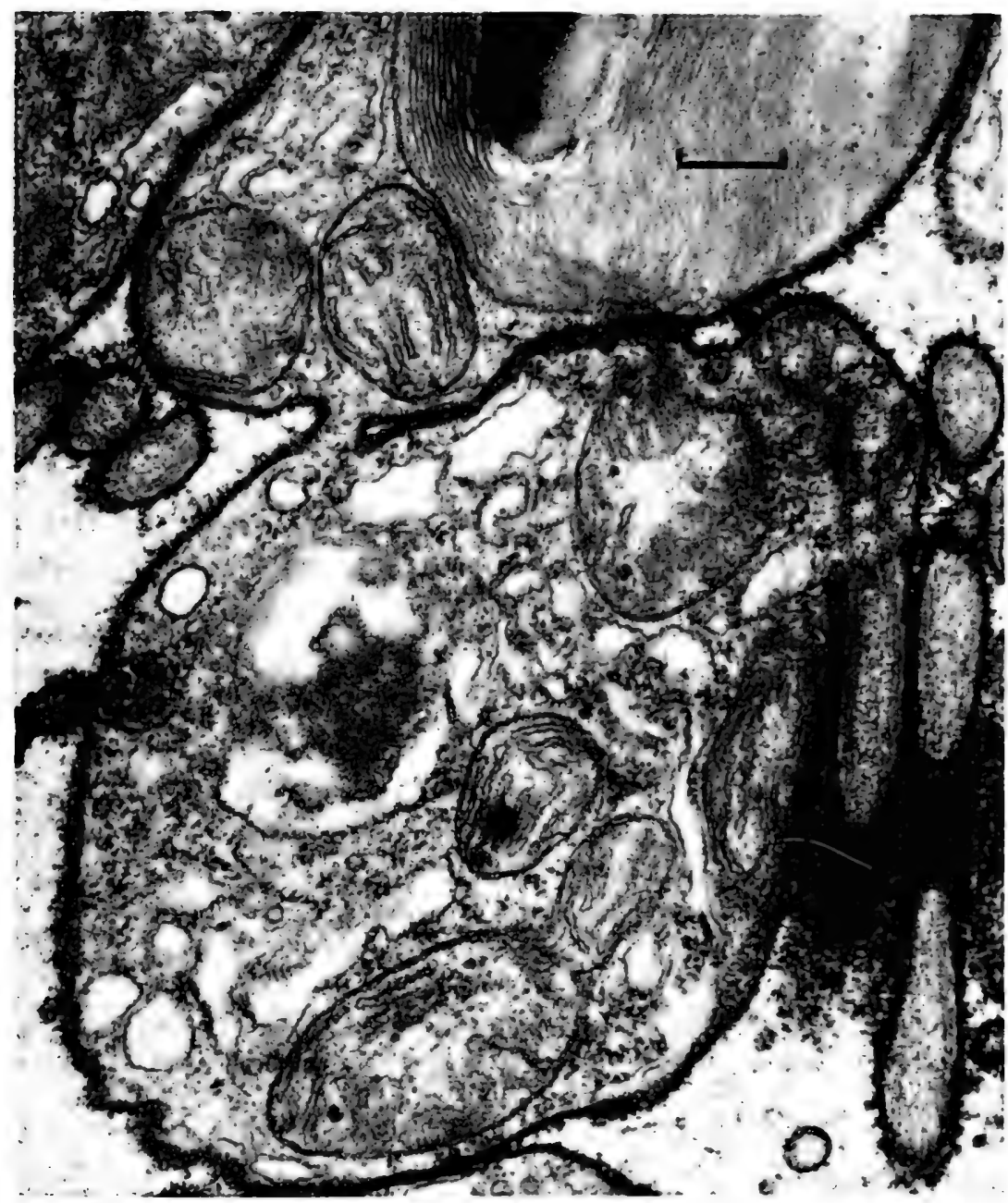

Fig. 67. $H$. incrassata. Section through very dark green gametangium fixed about 12-16 hours before the estimated time of discharge of gametes, showing gametes with mitochondria, chloroplast with starch (only partly shown), apical papilla with flagellum (second flagellum not in plane of sectioning). Also shown are long and oblique sections of flagella. Cleavage has not been completed, and the two micro. gametes are attached by a narrow bridge. Gametes were also observed joined in threes. Stained with lead tartrate. Scale bar is $1 \mu \mathrm{m}$.

younger gametangia and the filaments of the segment. Not all the cytoplasm is incorporated into the gametes.

I have followed the discharge of gametes, which in my laboratory cultures have been predominantly microgametes. Release orcurs about 
36 hours after the first sign of gametangial development, and usually within about an hour after lights go on in the controlled environment room. The number discharged by even a single thallus has frequently made the water of an $11.5 \mathrm{l}$ aquarium resemble thick pea soup, and observation becomes extremely difficult.

Gametes are released in a series of puffs, with the units of each puff often held together by mucilaginous material (Hillis-Colinvaux, 1973). Merten (1971) also reported a mucilaginous substance discharged from macroloba gametangia for 15 of the 25 releases she observed. For the remaining 10 a mucilaginous casing formed around the gametangia. Discharge is not from individual pores in gametangial walls, but from one, possibly two, central siphons within the gametangial cluster (Fig. 64) which represent the undifferentiated tip of the gametophore. It is through such a structure that the gametes rush in the related genus Chlorodesmis (Ducker, 1965). Discharged gametes are more distinctly pear-shaped than when enclosed in gametangia. Characteristics of macro- and microgametes of different species, as reported in the literature, are given in Table XVI.

Although I have observed fusion, I have not been able to induce the resulting zygote to develop after it settled, nor is it clear that any have done so when fertile plants have been left in my culture tanks. All fresh plants in my cultures may be best explained as being outgrowths from rhizoids in the sand, for which there is much direct evidence (see below). Meinesz (1972b, 1973), however, managed to follow the development of zygotes for about one year, though, even then, a recognizable thallus had not been produced.

Meinesz began his observations by bringing plants of both sexes of tuna, which he found fertile in the wild, into his laboratory. Thalli bearing the two kinds of gametangia were placed together in glass dishes containing Millepore-filtered seawater of field temperature and arranged in indirect sunlight. The bottoms of the dishes were covered with glass slides. Air and circulation were provided by bubbler and. pump. After the gametes had discharged and fused, the glass slides were placed in Petri dishes containing von Stosch's artificial seawater prepared with filtered water. The Petri dishes were exposed to different conditions of temperature and light, but the most successful were those maintained at $20-23{ }^{\circ} \mathrm{C}$ in indirect sunlight. The seawater was changed every 15 days, and the glass slides were moved to another container if other algae or bacteria developed. When, after one year the resultant growth was $0 \cdot 5-1 \mathrm{~cm}$ tall, the glass slides were placed in a closedsystem seawater aquarium equipped with bubbler and filter (Meinesz, 1973). 


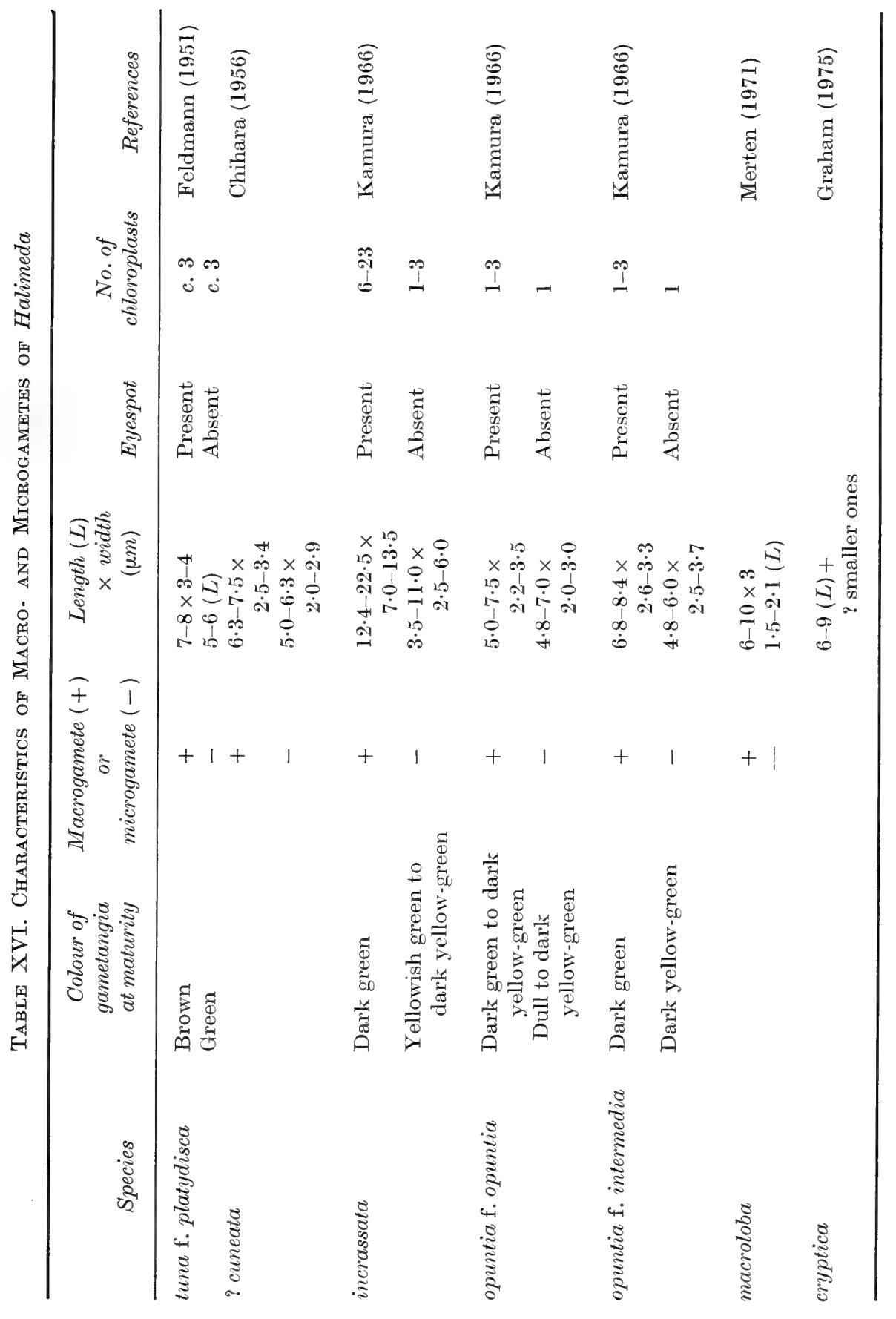


Meinesz $(1972 b, 1973)$ reported that after one week of growth under these conditions, the zygotes had a diameter of $5 \mu \mathrm{m}$, and contained a single nucleus and four to five chloroplasts. In seven months they developed into spheres of 100-150 $\mu \mathrm{m}$ diameter containing a single large nucleus of 7-10 $\mu \mathrm{m}$ diameter and over 500 lenticular chloroplasts with one or two large grains of starch. Amyloplasts were absent. This stage he called a "protosphere", the term protonema being inappropriate.

Then a number of changes occurred, spread over about two weeks. The coenocytic condition was established by division of the large nucleus to form nuclei of $2-3 \mu \mathrm{m}$ diameter. The chloroplasts lost their starch, and thereafter appeared like rice grains. Amyloplasts differentiated. A positively phototrophic filament of about $30 \mu \mathrm{m}$ diameter grew out of the sphere, and a few days later a negatively phototrophic filament developed from the opposite end.

After about five additional months of culture there were a number of erect and creeping filaments. The erect ones were about $90-130 \mu \mathrm{m}$ in diameter and $2 \mathrm{~cm}$ tall, and at the tips of some were slight dichotomous or trichotomous forkings. The creeping filaments proliferated in all directions, and sometimes produced additional erect filaments as well. The diameters of the creeping filaments, which were often constricted, were variable. A scheme of these changes is given in Fig. 68 . Subsequent development was not observed.

Meinesz' observations thus end with the production of a filamentous mat, and the stages that must be passed between this structure and an adult thallus are still unknown. We have a similar ignorance of the sexual development of many taxa in the whole order Caulerpales, not just in Halimeda. It may be that a mature thallus can grow directly from one or more of the filaments of the mat. On the other hand, new structures might develop which could be precursal to the Halimeda structures with which we are familiar. Various workers have suggested that some of the more filamentous Caulerpales, such as species of Chlorodesmis and Pseudochlorodesmis, may be part of the cycle of genera such as Halimeda (Taylor et al., 1953; Papenfuss, 1962; Ducker, 1965; Meinesz, 1972b).

In the laboratory, after the gametes have been released, the white thallus disintegrates, with segment after segment being shed until, within two or three weeks, little more than a heap of segments remains (Fig. 62). Merten (1971) observed that in the field the thallus collapsed in a day or two after the gametes were released. Occasionally only a few segments become fertile in laboratory cultures, and then only one or so branches are shed, but this pattern is uncommon. Usually most of the alga is involved. 


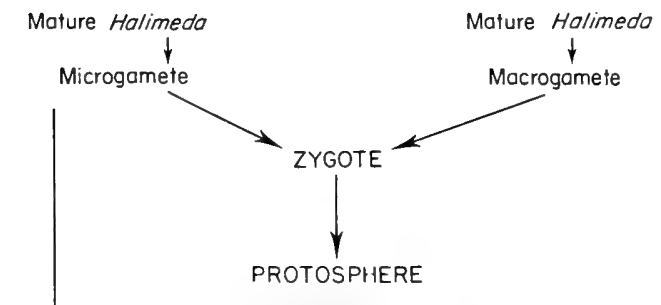

One large nucleus approximately $7-10 \mu \mathrm{m}$ in diameter; >500 lenticular chloroplasts with starch grains; no amyloplasts; 100-150 $\mu \mathrm{m}$ in diameter.

Erect, positively phototrophic filamentous extension approximately $30 \mu \mathrm{m}$ in diameter; nucleus divides forming regular-sized nuclei; chloroplasts lose starch and are the shape o a rice grain.

Negatively phototrophic filamentous extension developed at opposite end to other extension; first amyloplasts appear.

Filaments approximately $2 \mathrm{~cm}$ tall and 90 $130 \mu \mathrm{m}$ in diameter in five months; some erect filaments have dichotomous or trichotomous branching at their tips; creeping filaments proliferate with some branches becoming erect.

FIG. 68. Scheme of development, in culture, of zygote of Mediterranean tuna over one year, indicating morphological and cytological characteristics of protosphere and juvenile filament stages. The mature Halimeda thallus has not yet been obtained from zygotes in culture. (Adapted from Meinesz, 1972b, 1973.) 


\section{B. Vegetative reproduction of Halimeda}

Halimeda plants that grow in sand reproduce by "runners" of filaments (Fig. 69). These filaments, or bundles of filaments, are at least $20 \mathrm{~cm}$ long (the limits of my aquaria) and spread laterally through the substrate from the main holdfast (Colinvaux et al., 1965; Colinvaux, 1968a, b; Hillis-Colinvaux, 1972, 1973). They are non-photosynthetic,

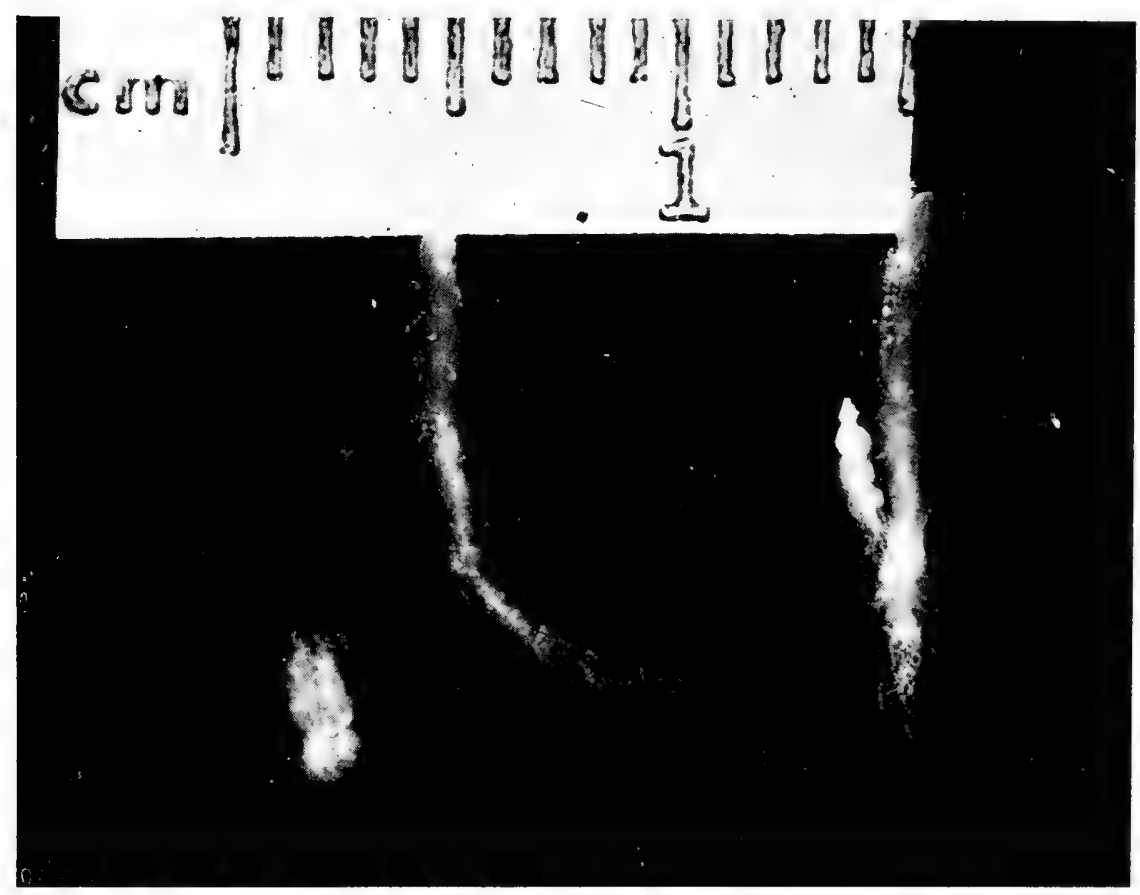

FIG. 69. Vegetative reproduction in Halimeda by "runners". A fine, filamentous thread or collection of such threads connects the rhizoidal portions of four young Halimedae which developed in an aquarium. See also Fig. 46. (Photograph by The Ohio State University Department of Photography.)

and are individually fine and threadlike. The walls of the filaments are relatively thick, and in places pigmented yellow and regularly constricted, so that the thread sometimes appears like a string of beads, particularly in the immediate vicinity of the plant. Eventually they produce a tight clump or cone-like mass of filamentous material (Fig. 70) which pushes up out of the substrate and from which the Halimeda segment is organized (Section VI). More segments are produced, sometimes at the rate of at least one a day per growing tip (Colinvaux et al., 1965). Eventually the physical connections between young and parent thallus are lost. 
This same mechanism, the development of new thalli by independent and usually horizontal growth of rhizoidal filaments away from the holdfast, may exist for rock growers as well. Certainly holdfasts and filaments of many other algae grow across rock or penetrate it, with the

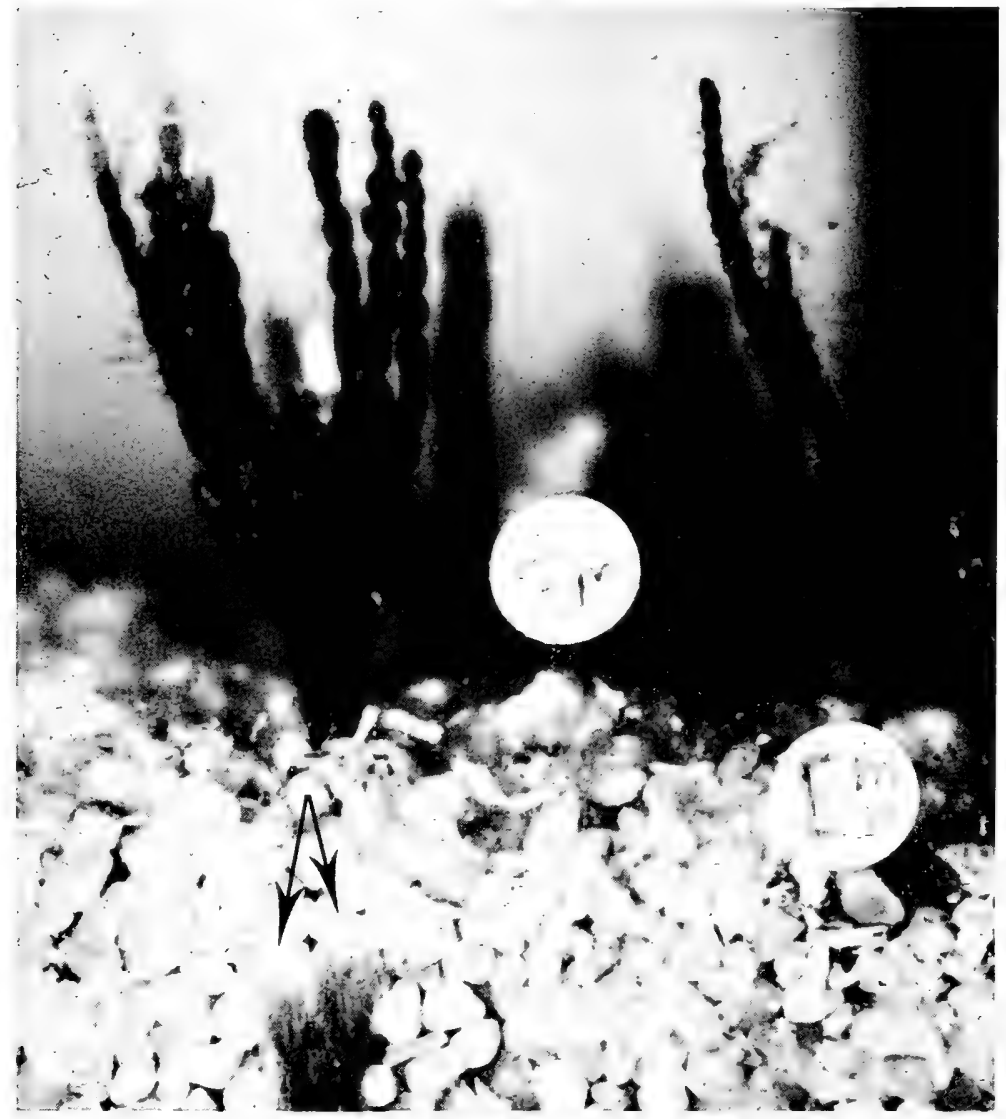

FIG. 70. Two young Halimeda plants (arrowed), not yet emergent from the substrate, developing from the larger thallus by rhizoidal runners. The white conelike masses at their tips are similar to ones that form the first segments in similar young plants. Development may be somewhat atypical because rhizoidal material, by being next to aquarium wall, has been exposed to light. The diameter of the white dises is $0.85 \mathrm{~cm}$.

siphonaceous alga Ostreobium, which appears to grow exclusively in rock, being a notable example of the ability of some filaments to penetrate this substrate.

There are also other methods of vegetative reproduction. Prostrategrowing Halimedae, such as micronesica, opuntia and to some extent 
renschii, sometimes produce medullary filaments which remain uncorticated. These filaments grow to a length of several segments and are frequently intertwined, forming coarse, orange-coloured ropes (Fig. 46) which I have sometimes referred to as "rope-like extensions" (Hillis, 1959; Section VI). Some thalli have a number of these extensions, produced on as many branches, which are frequently firmly fixed to rock at various points along their length. Sometimes noticeably younger thalli are attached to an older plant by these extensions, indicating that such filaments not only anchor a thallus, but initiate new ones (Fig. 46).

Another mechanism for vegetative reproduction lies in the production of rhizoidal filaments between segments. These filaments, at least initially, provide additional anchorage, but they also permit division of the alga into separate thalli as the older, more basal segments of the branch disintegrate. This method of growth and clone development (Fig. 71) appeared to be important in maintaining some of the large patches of macrophysa and opuntia at Enewetak.

On a few occasions I have observed how cloning might occur when a thallus is partially buried in shifting sand. Although half and sometimes more of the thalli observed were buried, and the buried portions had lost their green colour and started to disintegrate, extensive new growth occurred from the branch tips. The new segments had all the signs of vigour, possessed the muted green colour characteristic of many growing Halimedae and were unepiphytized. For these plants it seems likely that independent holdfasts would develop near the bases of the actively growing branches, perhaps as described above for macrophysa. A number of separate thalli would result.

In addition, vigorous branches of Halimeda which have been separated from the main thallus can develop holdfast systems, thereby functioning as reproductive structures (Hillis-Colinvaux, 1972, 1973). Such Halimeda "fragments" might be produced in the reef by waves, storms or animals, and they might be transported in currents. Under favourable conditions they could become established and develop into complete thalli.

Vegetative reproduction seems to be the way in which many individual Halimeda plants are produced. Many of the familiar aggregations of Halimedae, whether on rocks or in patches of sand, are probably clones (Figs 63, 72). And the commonest method of cloning is by the outgrowth of rhizoidal filaments, either from holdfasts or from the tips of segments. It is a matter of note, however, that the individual plants so produced have limited lives. The ageing thallus becomes coated with epiphytes whereas the segments of a young plant growing from the 


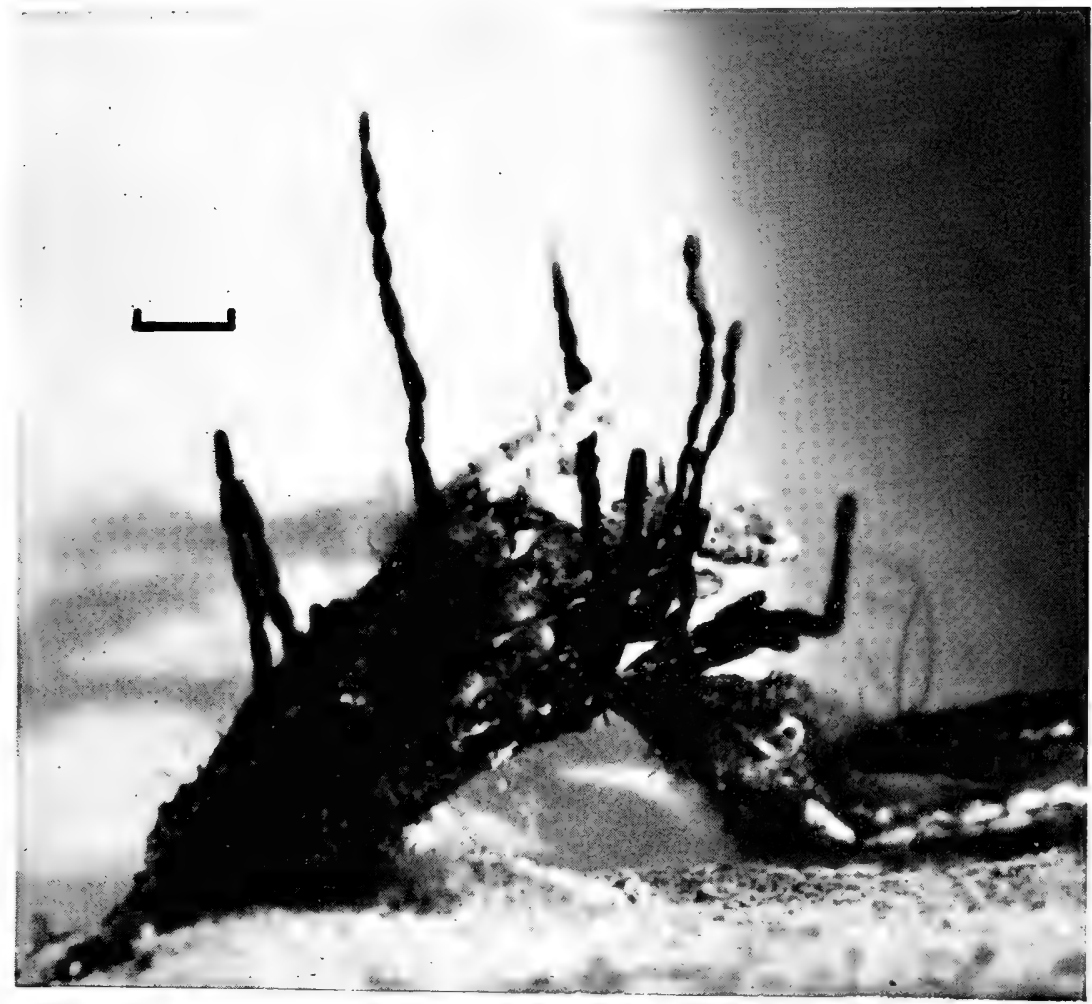

FIG. 71. Early stages in the clonal development in $H$. monile by disintegration of older thallus, and eventual development of new holdfasts near the bases of actively growing branches. In this way several vegetative thalli are produced. Two of the actively growing erect branches have whitish to pale green apical segments which are less than 48 hours old. Scale bar is $1 \mathrm{~cm}$.

parental filament is epiphyte-free. Cloning in Halimeda serves as a defence against epiphytes even as it increases the numbers of the plants.

\section{Reproduction in other Caulerpales}

The genera Penicillus, Rhipocephalus and Udotea also produce new thalli by filamentous runners from holdfast filaments (Colinvaux et al., 1965; Colinvaux, 1968b, c; Hillis-Colinvaux, 1973, includes earlier literature). In aquaria the filamentous connections have been of a single filament or several to many intertwined filaments. The connections observed have been considerably more delicate than the rhizome-like connections illustrated by Duchassaing (1850) for Penicillus ( =Nesea), and by Ernst (1904) for Udotea, and they do not appear to persist. New 

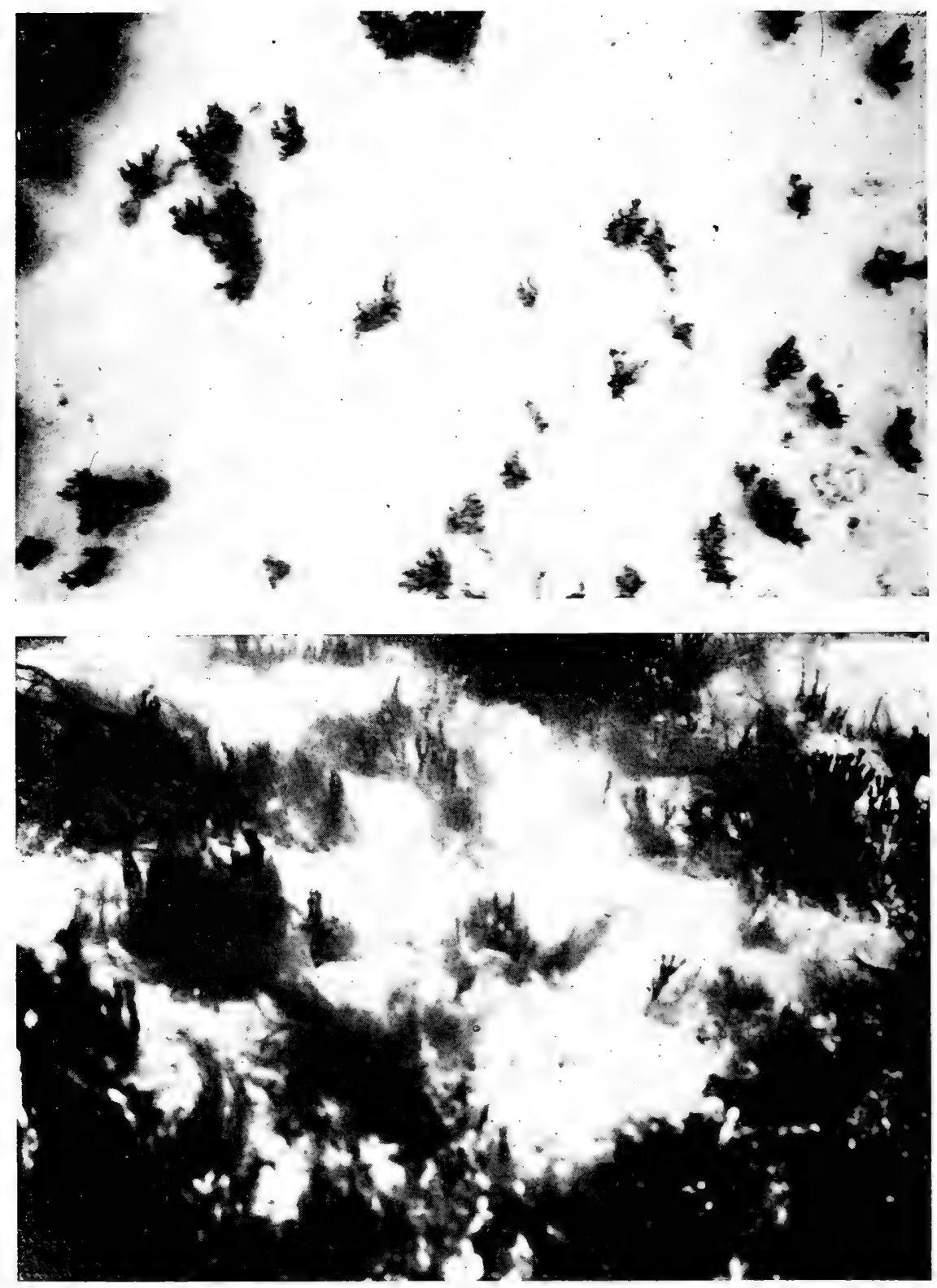

FiG. 72. (Top) A stand of $H$. cylindracea in the lagoon of Enewetak Atoll, photographed from above. Clumped and linear arrangements of thalli suggest clonal development. Long dimension of large clump in lower left-hand corner is approximately $9 \mathrm{~cm}$. (Bottom) Clonal development in stuposa, at the northern end of the lagoon of Enewetak Atoll. Excavation indicated that many of the stuposa clones were the result of lower portions of the thalli being buried in shifting sand. Note the different ages of thalli, the clumped or sometimes linear arrangement, and the overgrowth of some thalli by blue-green algae. Approximate width of the cylindrical segments is $2 \mathrm{~mm}$. 
generations of Penicillus, Rhipocephalus and Udotea have generally been produced in my culture systems more rapidly than those of Halimeda (Table XVII). For Penicillus the plants are also considerably shorter-lived, a Penicillus thallus living about two months.

Three types of thallus have developed from the Penicillus capitatus Lamarck plants in culture:

typical thallus with stalk and brush, which is the commonest; thallus of a very few filaments about $1-4 \mathrm{~cm}$ tall which sometimes branch dichotomously (Fig. 73);

cluster of filaments similar to those of the preceding type.

The second and third types of thallus resemble the espera condition of the forma mediterranea of the genus (Huvé and Huvé, 1961; Meinesz, 1972a; Roth and Friedman, 1976). The espera phase was first described as a distinct genus, Espera mediterranea Decaisne, then transferred to the genus Penicillus as P. mediterraneus (Decaisne) Thuret. Huvé and Huvé (1961) demonstrated that it was a stage in the life-cycle of Penicillus capitatus f. mediterranea (Decaisne) Huvé and Huvé. Vigorous Penicillus thalli can also regenerate a new capitulum if the old one is removed (Kupfer, 1907; Hillis-Colinvaux, 1973).

Sexual stages appear to be infrequent, again partly because the thallus is destroyed in the process. They are known for Udotea (Nizamuddin, 1963; Meinesz, 1969, 1972c) and Penicillus (Colinvaux, 1969b; Hillis-Colinvaux, 1973; Meinesz, 1975). In $U$ dotea the edge of the thallus becomes fringed with loose filaments (Nizamuddin, 1963; Meinesz, 1969) which appear to be short extensions of the filaments of the blade of the fan. Biflagellated gametes are released from the tips of the filaments (or gametangia) early in the morning, and thalli connected by stolons release their gametes at the same time (Meinesz, 1969).

The gametes are anisogamous and are borne on separate thalli for $U$. petiolata (Turra) Børgesen, with only the macrogametes possessing an eyespot (Meinesz, 1969) as in Halimeda.

The development of the zygote of $U$ dotea petiolata has been followed (Meinesz, 1972c), using the same techniques as for Halimeda. An irregularly shaped, somewhat flattened protosphere was first produced which reached its maximum development in culture in five months, with a diameter of between $60 \mu \mathrm{m}$ and $90 \mu \mathrm{m}$, a single nucleus of $6-9 \mu \mathrm{m}$ diameter, 200-300 chloroplasts and no amyloplasts. The protosphere subsequently produced two filamentous outgrowths from which a mass of filaments developed, which were heteroplastic and coenocytic, and were of the same general form as the filaments produced by the Halimeda zygote. Meinesz considered the filamentous stage he obtained 


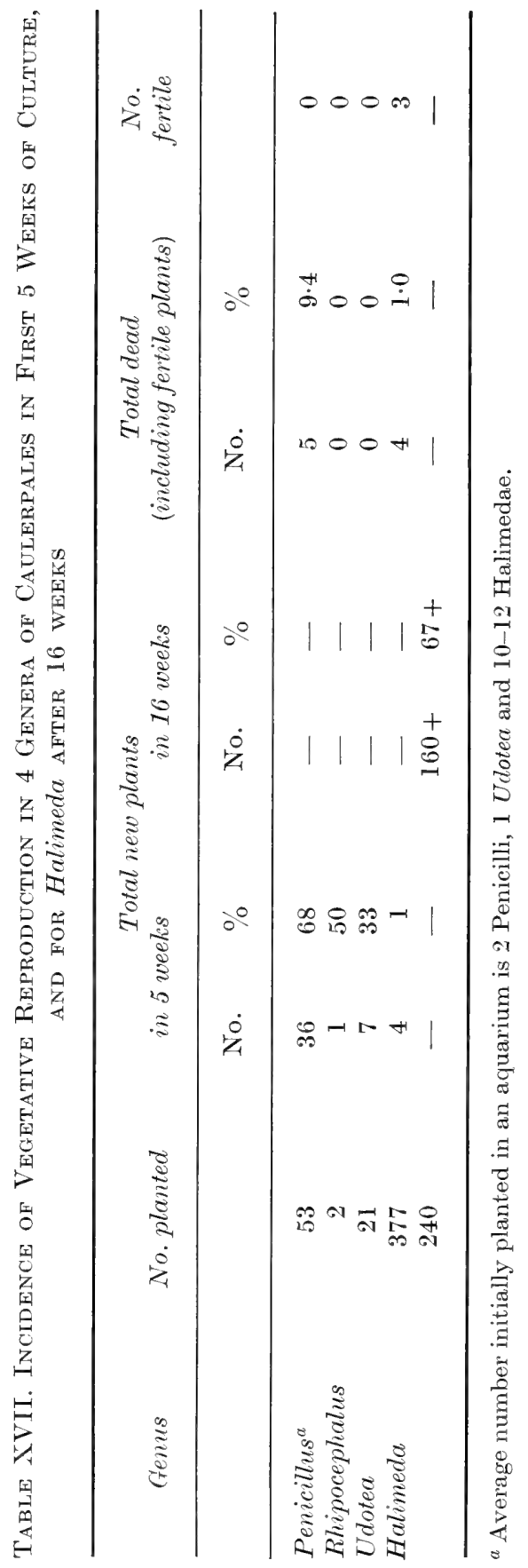



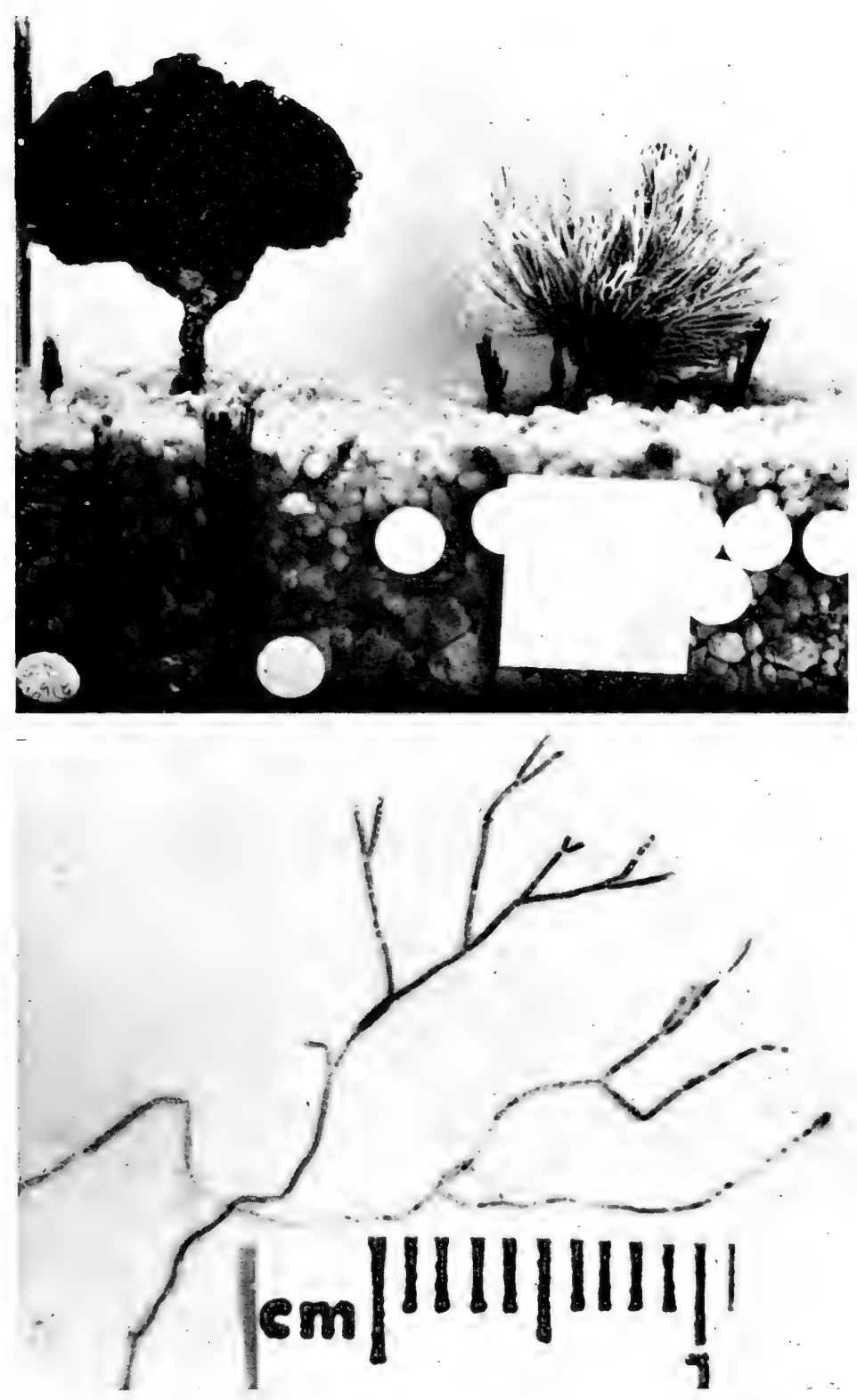

FIG. 73. Vegetative reproduction in Penicillus and Udoten. (Top) An aquarium showing a cluster of young Penicilli around an old Penicillus with white capitulum. Two other young Penicilli appear in the left foreground. A young Udotea is developing to the left of the large Udotea. All young plants are from rhizoidal runners, and the aquarium had been established five weeks when the photograph was taken. The diameter of the white dises is $0.85 \mathrm{~cm}$. (Bottom) Filaments of the espera stage of Penicillus capitatus from the Caribbean, developed in culture from rhizoidal runners. Scale shown is $11 \mathrm{~mm}$ long. (Lower photograph by The Ohio State University Department of Photography.) 
with $U$. petiolata to be identical with the vegetative thallus of $U$. minima Ernst.

The development of the zygote has not been observed for Penicillus but there are two reports of fertile plants with some variation in details. Hillis-Colinvaux (1973) observed the conspicuous white thalli of two individual Caribbean $P$. capitatus plants after gamete discharge in aquaria. The capituli of both thalli were surrounded by a halo of brown fuzz which microscopically appeared as soft, easily broken, noncalcareous extensions of the capitulum filaments (Fig. 74). They were

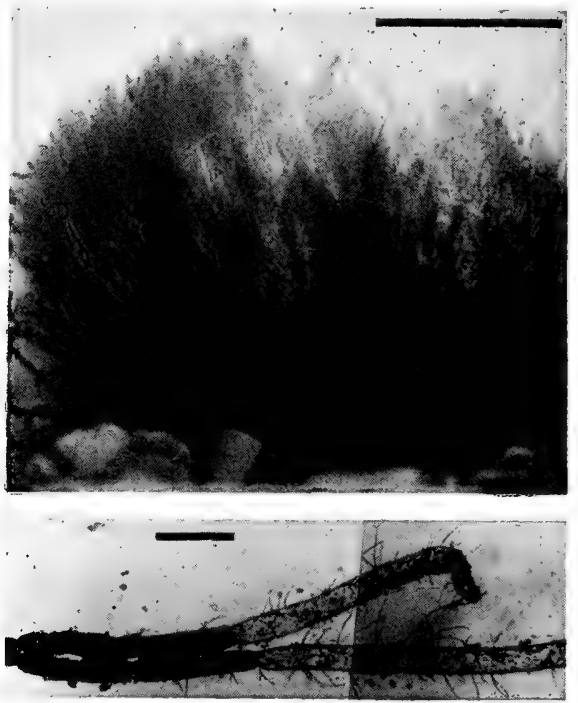

Fig. 74. Sexual reproduction in Penicillus. (Top) Mature Penicillus capitatus with brush (capitulum) covered with brownish, soft, uncalcified fuzz composed of extensions of the filaments of the capitulum. Scale bar is $1 \mathrm{~cm}$. (Bottom) Filaments from the capitulum showing calcified (left) and uncalcified (right) portions. The uncalcified portion is the presumed gametangium, although release of gametes was not observed. Scale bar is $500 \mu \mathrm{m}$.

about the same diameter as the regular filaments, without obvious cross walls between calcified and uncalcified portions, and were sometimes dichotomously branched. The tube extensions and main filaments of the capitulum were essentially empty of contents, indicating discharge, and the apical ends of the soft filaments were open (Fig. 74). Meinesz (1975) observed discharge from thalli of P. capitatus $\mathrm{f}$. mediterranea, and briefly described the gametangia, without figures, as spherical, and up to about $30 \mu \mathrm{m}$ in diameter. The gametangia were located among the filaments of the capitulum and discharge was by rupture of their walls. 
These few data from other Caulerpales suggest that similar breeding strategies prevail for much of the group. The principal method appears to be cloning by sending out "runners" of filaments. Sexual reproduction is infrequent and always leads to the death of the thallus. Development of zygotes seems to require many months, at least five, although the complete process of development has not been followed for any taxon of the group.

\section{Reproductive strategy and the strawberry-coral model}

Halimeda populations appear to be clones which maintain themselves by vegetative means for numbers of generations that seem to be unlimited. Yet occasionally individuals, or, more rarely, parts of individuals, devote their entire resources to a sexual episode. Although the full course of the development of the zygote is still not known, there is reason to suggest that sexual reproduction is followed by either a resting stage or dispersal. The value of both vegetative cloning and sex to plants and animals with life-cycles like this has been explained by Williams (1975) with his strawberry-coral model.

\section{The strawberry-coral model}

For an organism living in a habitat which remains unchanged for a time which is long in terms of the generation time, Williams (1975) argues that it is a better reproductive strategy to produce individuals identical to successful parents than it is to leave the next generation open to the risk of a great variety of competing genotypes. Individuals of a parental strawberry or coral clone will already have been selected during a series of competitive exclusions with neighbouring clones, and continued success requires that the winning formula be repeated. A sexual effort in such clones should only follow when the very high cost of producing many disastrously unsuitable experiments becomes less than the cost of making more copies of the parent. This cost of a sexual endeavour may well only be met when the cost of more vegetative reproduction is local extinction.

Sex, in Williams' view, should only be required when it is necessary to make individuals for competitive struggles in new and untried circumstances. Sex, therefore, should precede the making of resting stages that will survive a hostile environmental episode, since the circumstances in which the clones of the future will compete are likely to be different to those familiar to the parent clone. In a like manner, sex will also precede episodes of dispersion, since the propagules must 
colonize habitats which will certainly be unlike that familiar to the parent clone. Finally, sex may well be the reproductive resort of individuals in the middle of the parent clone, even when the habitat remains unperturbed. These individuals will gain no advantage in fitness by producing copies of themselves since their surroundings are already full of their own copies. For these crowded ones in the middle of the clone the best hope of fitness will be to send out colonizing propagules (made various by sex), or to flood the old clonal habitat with new experimental genotypes, one of which just might be better than the parental strain.

It is important to notice that Williams' model is based on the postulate that fitness will be won in competition with other individuals or clones. Diversity through sex is demanded, in the first instance, not by the physical needs of new habitats but because a slight competitive advantage in new or changed habitats may go to a fresh genotype. It is on grounds of competitive advantage that sex should precede resting and dispersal, or be the resort of individuals in the middle of clones.

\section{The Halimeda reproductive strategy summarized}

The commonest means of reproduction appears to be by vegetative cloning. Most of this takes place by sending out "runners" of rhizoidal filaments. Sand-dwelling forms thrust the filaments through the sand so that each plant looks to be de novo and independent. Rock forms spread more obviously from epicentres. Secondary forms of vegetative reproduction are the sprouting of vegetative parts and the establishment of pieces broken off from thalli.

Sexual reproduction is sporadic and almost always involves the death of the entire thallus. The usual pattern is that a sexual episode is separated from the next by one or more vegetative generations. Sex involves the production of an extremely large number of flagellated gametes to the manufacture of which the entire resources of the parental protoplasm have been devoted. This gamete swarm is to be expected to yield a large swarm of zygotes.

The data on what happens to the zygotes are extremely scanty, but nonetheless suggestive. The zygote appears to develop very slowly, taking months for the initial growth. And the result of this growth is a filamentous mat in no way like the parental thallus. After 12 months in a laboratory container no more development is observed. The development time of a zygote, therefore, appears to be of the order of one to two vegetative generations. It is also of a length to serve as a resting stage to pass the adverse seasons of an annual cycle. 


\section{Halimeda strategy as a variant of the strawberry-coral theme}

The correspondence of the Halimeda breeding strategy with the requirements of the strawberry-coral model is obvious and close. There are large populations established and maintained by cloning, and sex is an intermittent and unusual procedure. It becomes profitable to look at the life-history of Halimeda with the predictions of the model in mind.

(a) Fluctuations in the habitat are small compared with the generation time. Halimedae, in most environments, conform to this prediction in the same way that the corals discussed by Williams do. The habitat is unchanging on time-scales long enough to permit competitive exclusions between clones whose reproductive cycle is of the order of a calendar year. There is, however, the possibility of devastating grazing on clones. A number of browsing animals are known to eat Halimeda, raising the possibility that the almost pure stands produced by a clone could be systematically wiped out by a population or migration event among the herbivores. If Halimeda were to be regularly and drastically cropped, then it would be expected that competitive advantage would go to strains which are cropped least. The clonal habit would then be a disadvantage, the chances of fitness would be improved by variety, and the vegetative production of a clone should yield to sexual reproduction. There is at least reason to argue, therefore, that the unchanging environment demanded by the strawberry-coral model may not always exist for tropical Halimedae, even when the physical habitat remains constant.

Our data are not yet good enough to resolve this question. One way of looking at it is to note that it is a prediction of the strawberry-coral model that the environment be essentially constant, and to extrapolate from this the prediction that cropping of Halimeda must be slight. There are no data for a satisfactory test of this prediction, though there are lines of argument which suggest that the prediction may not be met. Opuntioid forms of Halimeda are grazed by urchins, and numerous taxa have been shown to eat the sand-dwelling forms (Randall, 1964, 1967; Mathieson et al., 1971; Earle, 1972). Also there is much patchiness in the distribution of Halimeda clones which might be easy to understand if the patches represented a pattern of grazing.

(b) Resting stages are produced by sexual reproduction. The scant data on zygote development are in keeping with this prediction, in that the zygotes develop very slowly. It is also true, however, that the adult thallus can persist for a very long time in an apparently moribund 
condition. Plants survive for at least 2 years in culture when covered with epiphytes. It may be that Halimeda has a dual system of providing resting stages, just as auxospores of diatoms may be sexually or asexually produced.

(c) Dispersal stages are expected to be produced by sexual reproduction. The evidence for how Halimeda disperses is extremely slender and, indeed, essentially no more than speculation. It is possible that the limited amount of transoceanic dispersal accomplished by members of the genus (Section VIII) may be accounted for entirely by the chance drifting of bits of broken thalli, and so do not require a sexual event. On the other hand, the zygotes are made after fusion of motile gametes and may result in producing something that would pass as part of the phytoplankton. It could also be that the filamentous mat which Meinesz (1972b) describes can float in the plankton and thus travel for months before settling. But there are no data. It would be worthwhile to test this prediction of the strawberry-coral model: that there may be in the tropical plankton zygotes or filamentous mats of Halimeda.

(d) Sexual episodes will be triggered by environmental cues for changing conditions or will occur in groups of individuals at the centres of clones. There are no convincing data that the production of gametangia is ever synchronous across a Halimeda clone or population. There have been some suggestions that chemical cues may be needed to bring on a sexual episode, a postulate which involves the prior postulate that sexual reproduction be synchronous. But observations of my cultures argue against this. Table XVIII describes the appearance of fertile individuals in my cultures over a six-month period following collection from Ocho

Table XVIII. Incidence, over a Six-month Pertod, of Fertile incrassata from Jamaica, Established in 44 Aquaria in Columbus, Ohio, on 2 July, 1969

\begin{tabular}{ccc}
\hline Aquarium identification & No. of thalli fertile & Approximate dates thalli fertile \\
\hline 45 & 4 & $8 . \mathrm{IX} .69,8 . \mathrm{X} .69(2),{ }^{a} 13 . \mathrm{X} .69$ \\
55 & 2 & 11. VIII.69, $10 . \mathrm{XI} .69$ \\
64 & 2 & $11 . \mathrm{XI} .69(2)$ \\
69 & 2 & $18 . \mathrm{IX} .69(2)$ \\
77 & 3 & $16 . \mathrm{IX} .69,30 . \mathrm{IX} .69,20 . \mathrm{X} .69$ \\
11 separate & 1 each & 12. VIII.69 to $6 . X I .69$
\end{tabular}

${ }^{a}$ Numbers in parentheses represent number in aquaria. 
Rios in Jamaica. The collections were planted in 44 aquaria, at densities of a dozen per tank on 2 July, 1969. In 11 tanks a single thallus became fertile and released gametes between 12 August and 6 November. In none of these 11 tanks did another plant become fertile, although all were bathed in an opaque green cloud of gametes for a number of hours. In five tanks more than one thallus developed gametangia and gametes, but individual plants waited up to a month after their neighbour's sexual episode before they too developed gametangia. These data suggest rather strongly that Halimeda thalli do not take sexual cues from one another. In addition, in 20 years of field work in three oceans, I have never seen any incidence of gametangia that would suggest that a synchronous reproductive effort was being made. This observation appears to be in keeping with the observations of other workers (Beth, 1962; Merten, 1971), and it is probably a safe, if tentative, conclusion that Halimeda populations do not produce gametangia synchronously.

It may be that Halimedae represent an extreme version of the strawberry-coral model which is an adaptation to some of the world's most constant physical environments. What changes there may be in the local physical circumstances of life in the tropical range of its growth are too small to be worth the expense of sexual reproduction, involving, as it does, the destruction of an entire thallus. Asexual cloning therefore, spans the seasons and persists from year to year. The only circumstance then left by the model, when sex will pay, is that of individuals in the centres of clones, for whom making carbon-copies of themselves is pointless. The sporadic sexuality of Halimeda may, in fact, represent the incidence with which individuals are surrounded by their own clonal descendants and thus forced into sex.

\section{Biogeggraphy and Phylogeny}

When identifying specimens of Halimeda, geographic distribution is often a helpful character with which to supplement morphological criteria. In spite of being an ancient pantropical genus, therefore, the evolutionary history of Halimeda is still recorded in its geography. There seem to be few species of very wide range but rather patterns of local parallel evolution. However constant is the distribution of warm equatorial waters the Halimedae of different parts of it are effectively isolated. They cross ocean gaps but poorly, as would be expected from our knowledge of their dispersal systems (Section VII). We may approach the study of biogeography and phylogeny of this genus, therefore, with the expectation that there is preserved the print of ancient episodes of 
dispersion, perhaps even those resulting from very slow processes like the movements of ocean plates.

\section{A. Present distribution}

Representatives of the genus Halimeda grow wherever there are warm seas, sufficient light and appropriate substrate. The band of sea known as tropical, and delimited by lines of latitude $23.5^{\circ}$ north and south of the equator, therefore provides a rough model of its worldwide distribution. Warm waters, however, are only approximately delimited by a fixed number of degrees of latitude, since their extent is determined by ocean currents, which in turn are affected by the rotation and orbiting of the earth and the topography of intervening land masses. The tropical band of sea is asymmetric. It is broad on the western side of the oceans, thin on the eastern side, a pattern which is most marked for the Atlantic and Pacific Oceans. The shores of island groups such as Bermuda and southern Japan, as a result, are bathed by warm waters, although geographically they are north of the Tropic of Cancer. Both afford habitats for Halimeda. But Peru, located within the tropics, has cold waters along its coast and is without Halimeda. The precise latitudinal extent of tropical water shifts seasonally, generally moving to the north in the middle months of the calendar year, to the south at the end and beginning of the year. Halimedae at the northern and southern limits of the generic range, therefore, are exposed to a seasonally fluctuating environment. The usual temperature of the tropical water is in the neighbourhood of $25^{\circ} \mathrm{C}$.

All the species of Halimeda are restricted to this asymmetric tropical band except tuna and cuneata (Fig. 75), and their distribution within this band is summarized in Table XIX. Halimeda tuna, both the typical and large-segmented forms, also grows in the Mediterranean where it is the only Halimeda species. Halimeda cuneata, alone among the species, occurs in a band of cooler water, to about $20^{\circ} \mathrm{C}$, which corresponds to the subtropical zone. This particular taxon appears to be absent from the tropical region where the other Halimeda species occur, although our knowledge of its precise distribution is confused because other species, particularly discoidea, have commonly been identified as cuneata (Hillis, 1959). Initially it appeared to be restricted to the southern subtropies, where it is known from the tip and western shores of South Africa, southern Madasgascar, south-west Australia and south-east Australia (Fig. 75; Hillis, 1959), but during the International Indian Ocean Expedition it was collected in the northern hemisphere near Okah, at the mouth of the Gulf of Cutch on the north-western 


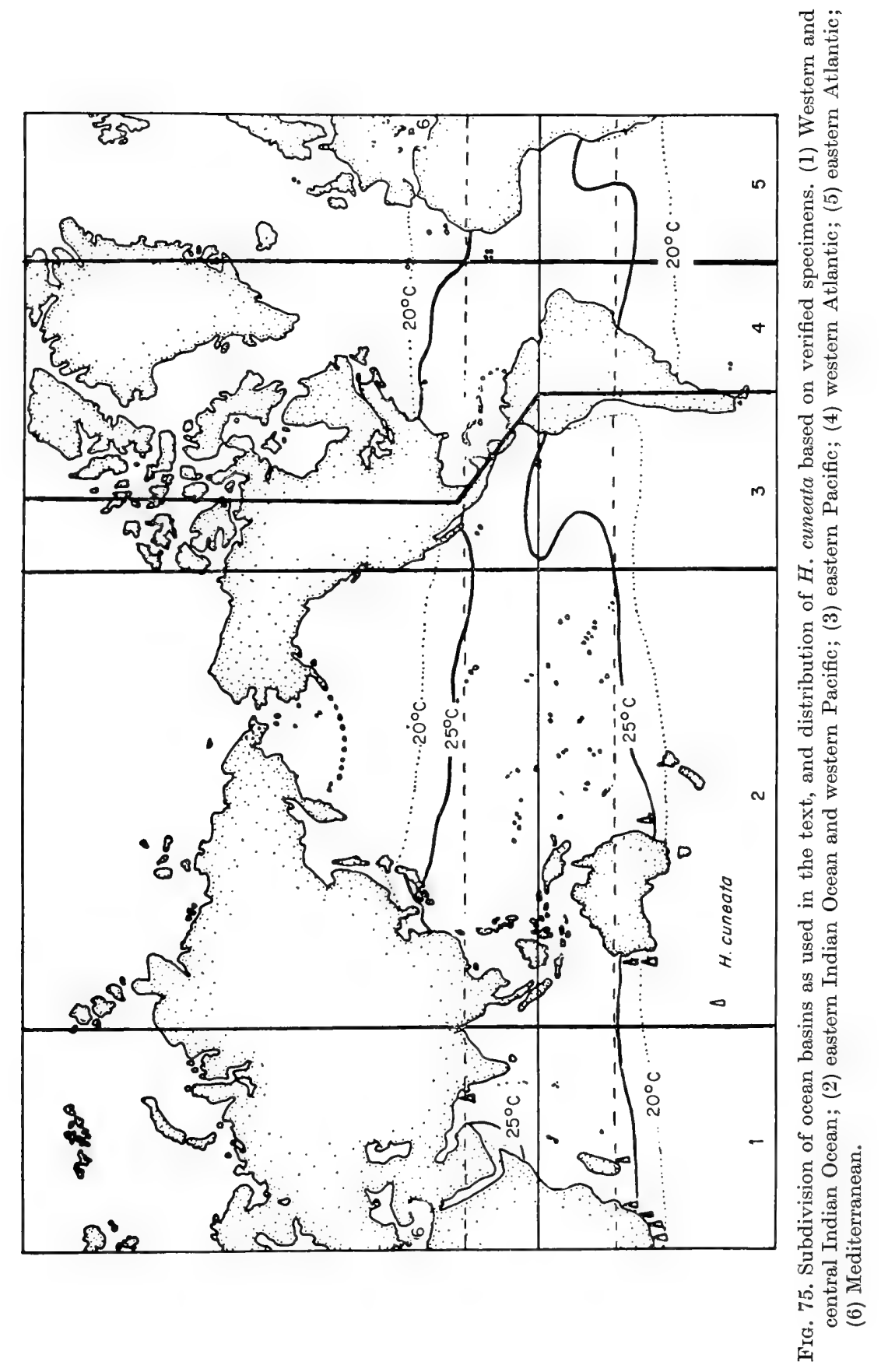


coast of India (Section IV). It is commonly reported from Japan, but the material I have seen has been discoidea.

Table XIX. Geographic Distribution of the Species of Halimeda

Map region (Fig. 75)

$\begin{array}{lllllll}1 & 2 & 3 & 4 & 5 & 6\end{array}$

Species w.central I.O. e.I.O. w.P.O. e.P.O. w.A. e.A. Med.

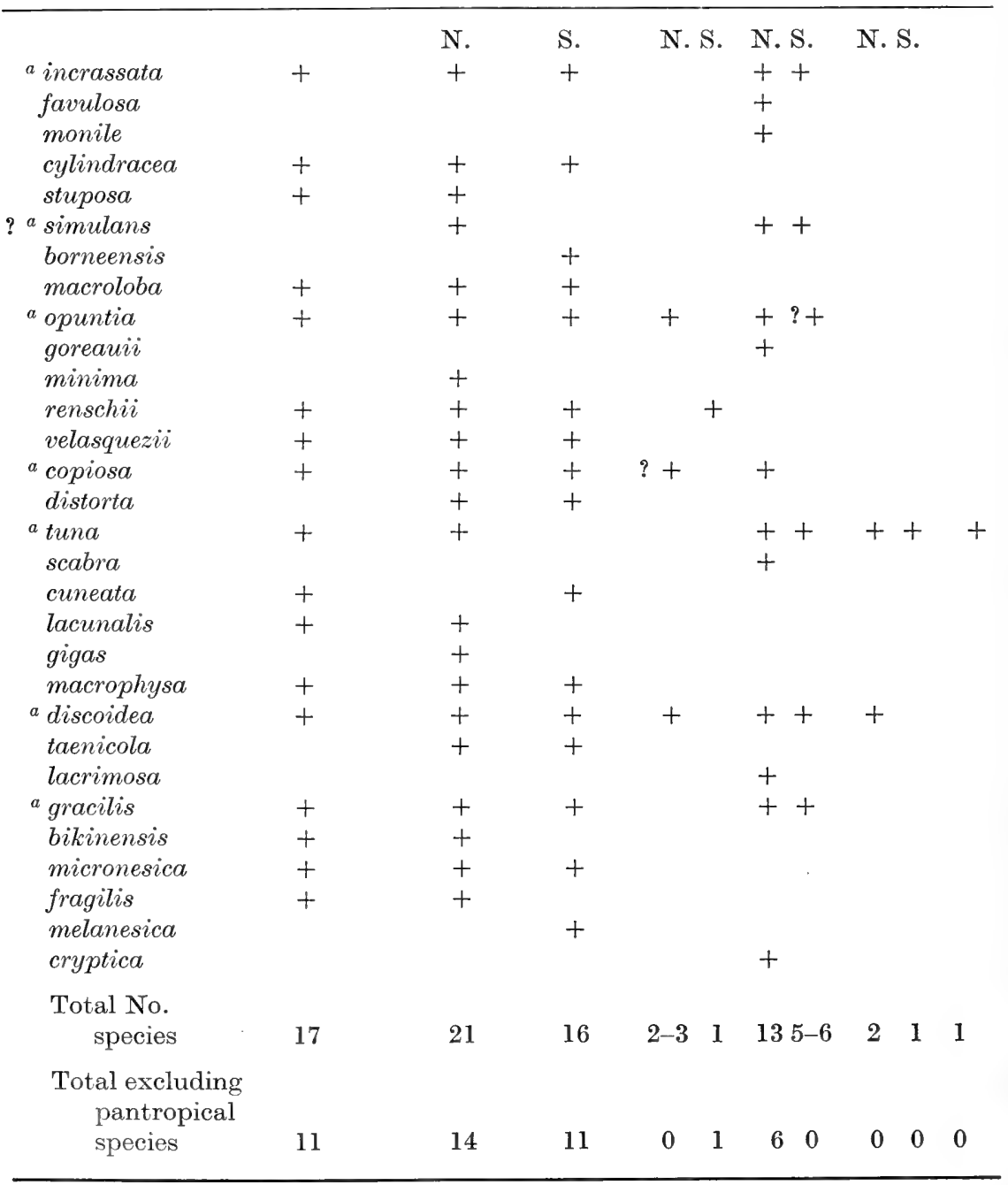

${ }^{a}$ Present in Regions 2 and 4; considered pantropical. 


\section{The ocean groups}

Table XIX groups the Halimeda species by region of the oceans in which they have been found. Only seven of the modern species are pantropical and are known at least for the western Atlantic, western Pacific and eastern Indian Oceans. Only one of the pantropical species has entered the Mediterranean Sea. Undoubtedly the lists for the Indian, Pacific and Atlantic Oceans will increase with more collecting, but definite patterns do emerge. Most striking of these is that characteristic species swarms of Halimedae have evolved for the Atlantic and Indo-Pacific regions, even though the environments of each are sufficiently alike for seven species to be established throughout. The youngest basin of warm water, the Mediterranean, has no endemic species and only one of those found worldwide. This pattern seems to speak of an ancient lineage in which local speciation proceeds but slowly.

Changes since the earlier revision of the genus (Hillis, 1959) include the addition of new species and the extension of known distributions, both of which are likely to occur in the future as well. It is particularly likely that some of the species now known only for the Pacific may be found in the Indian Ocean, where even less collecting has been done than in other oceans. It would also be interesting to know if species restricted to the Indian Ocean exist.

Further collecting will also be needed to determine the true extent of endemism within the genus, for it seems likely that the known ranges of some very "local" species like cryptica, favulosa, gigas, goreauii, lacrimosa, melanesica, scabra and velasquezii will be extended.

Table XIX also shows that of the four regions with more than ten Halimeda species, the greatest number is found in the Pacific, the least in the Atlantic. This pattern is exhibited by other tropical organisms, and may be a function both of area and of palaeohistory. This table also indicates that more species occur in the western portions of the Pacific and Atlantic Oceans. One might be tempted to conclude that the Marshall Islands, Jamaica and the Bahamas, with their peak numbers of Halimeda species for the Pacific and Atlantic Oceans respectively, represent centres of speciation or, alternatively, that larger areas or islands support more species of Halimeda. These conclusions, however, are premature, for these and other high numbers mostly represent regions of relatively intense collection and study. As many or possibly more species of Halimeda may eventually be known for other sites when their floras are adequately sampled and studied. The species list from Honduras, for example, has increased from six to nine as a result of 
relatively recent scuba collections. In reality, it may be longer, and some increase in numbers of species for neighbouring Central American countries is also likely, although the eventual total from these areas may never be as high. In the south-western Pacific, New Caledonia and other island groups probably have a more diverse Halimeda flora than is now recorded.

\section{Halimeda and coral distributions compared in outline}

Wells (1969) suggests that only two reef coral provinces are clearly recognizable, the Indo-Pacific and the Atlantic, and that subprovinces can be identified only "with misgivings". The preliminary data for Halimeda (Table XIX) suggest greater local differentiation than this, though the same major separation between Atlantic and Pacific is evident. It may be that when the Halimeda and other algal populations of reefs have been studied with the taxonomic intensity of the corals, their separation into provinces will be no more precise. Yet other explanations for the more local distributions are possible.

It seems likely that corals disperse much better than do Halimedae, since a dispersal phase is a normal part of the life-cycle of coral species whereas in most Halimeda reproduction is vegetative. Halimeda populations of a remote shoreline, therefore, are more insular than coral populations and likely to exhibit more local endemism. It may also be that plant habitats are less restricted than those of reef corals, because Halimeda grows not only on reefs, but also in sand, on dead reefs and at depths well below the lower limits for reef-building corals. There may thus be more opportunities for local speciation for Halimeda, perhaps particularly in sites which might not be reached so easily by propagules transported across oceans.

When the distribution of Halimeda species is better known it will be an interesting exercise to compare species distributions between corals and Halimeda species in some detail.

\section{Halimeda distributions in species-poor areas}

Since relatively few areas have been extensively worked for Halimeda, we cannot, at present, realistically ask some of the more interesting questions pertaining to the geographical distribution of the genus. Within this framework of caution some additional comments, nonetheless, are possible. A few areas with a low number of Halimeda species such as the Hawaiian Islands (four), Costa Rica (one), Easter Island (one), Galapagos Islands (none), Bermudan Islands (four), 
Mediterranean region (one) and the Red Sea (three to five) have been rather carefully worked, at least in the shallower parts of their reefs. It therefore seems to be established that these sites do indeed support very few Halimeda species. And there can be very little doubt that the Galapagos Islands are without Halimeda, even though the related siphonaceous genus Caulerpa is present. It is necessary to ask why the Halimeda flora of these places is so poor.

These sites combine two characteristics that might be expected to restrict the opportunities for Halimeda:

the sites are remote, insular or isolated;

the sites have either patchy or variable environments which may frequently be outside the physical tolerance of the genus.

The remoteness of the sites should be expected to restrict the rate of immigration or recruitment. This must work particularly strongly for an organism which seems to have very poor powers of dispersal. The variable environments might be expected not only to restrict the rate of establishment, but to increase the rate of local extinction. The paucity of Halimedae in these places, therefore, may be explained in the classic manner of MacArthur and Wilson (1967): we have equilibrium numbers of species set low by a high extinction rate and a low recruitment rate.

What we know of the reproductive strategy of Halimedae (Section VII) suggests that dispersal must indeed be slow. To reach a site as remote as Easter Island or the Galapagos with a piece of broken thallus drifting the seas seems an unlikely process, and we have no reason to believe that zygotes could survive such a voyage. And establishment of propagules of these kinds is probably very unlikely. The evidence of our cultures supports this. Other Halimeda relatives such as Batophora and Acetabularia frequently appear in culture tanks, even though pains have been taken to clean sand, water and cultivars. But no Halimeda has appeared which cannot be shown to be a vegetative outgrowth of another plant. The Halimeda reliance on vegetative cloning is an excellent tactic for spreading from a place of establishment, but it is not accompanied by an effective mechanism for making the first invasion.

It may be that the variable environments of these sites with few species operate more as further obstacles to immigration than as agents of extinction. All the sites have something unusual about their oceanic regimen: the periodic extremes of $\mathrm{El} \mathrm{Niño} \mathrm{at} \mathrm{the} \mathrm{Galapagos} \mathrm{(Wyrtki,}$ 1973); the winter in Bermuda and the Mediterranean. These events must narrow the window of opportunities for colonizations. In short, the 
low numbers of Halimedae in these places may not be so much the result of a MacArthur and Wilson equilibrium as an almost infinitely prolonged early colonization stage.

\section{B. Palaeobiogeography and prehistory}

Halimeda lived and contributed its segments to ancient reefs much as it does today. The known fossil Halimedae have been found in limestone facies of the Tethyan (Mediterranean and Persian Gulf) region (Elliott, 1960), Mexico and Texas (Johnson, 1969). The genus itself is first recorded from the Cretaceous (Elliott, 1960; Johnson, 1969), but would date from the Middle Jurassic if the two genera, Boueina and Arabicodium, which are similar to it, are included in the genus as recommended by Elliott (1965) and Johnson (1969). The epithet Halimeda has priority. These early Halimedae are smallsegmented, and are considered to have developed from hybridizations between the species groups Arabicodium and Bouenia (Elliott, 1965). The existence of such a long historical record, uncommon among macroalgae, has the potential of providing considerable information about the evolutionary history of the taxon as well as contributing to the understanding of present-day distribution. However, the data for Halimeda are few at present.

The known distribution of fossil material as indicated above is along part of the borders of the Tethys Sea and the western North Atlantic. It also seems likely that halimediform algae grew in shallowwater sites over a wider range of these particular shores as well as extending westward into the Indo-Pacific, along the eastern "Pacific" shores of the existing land masses, and by Miocene times possibly along the northern shores of Australia. Examination of new sites may prove that this is so. The faunas for the Caribbean and Mediterranean regions of the time appear to have much in common (Valentine, 1973; Berggren and Hollister, 1974a; Hallam, 1975), which is possibly the outcome of a current system common to much of the palaeoequatorial region, and to the low variability of climate. Perhaps the Halimeda flora also was fairly similar for much of the region.

Within the Tethyan area itself, five fossil species of Halimeda, $H$. nana Pia, $H$. praemonilis Morellet and Morellet, $H$. eocaenica Morellet and Morellet, $H$. praeopuntia Morellet and Morellet and an unnamed Halimeda species, have been reported for the Tertiary preceding the Messinian crisis (Morellet and Morellet, 1922, 1941; Elliott, 1960). One species of Boueina also occurred. There was, therefore, considerably more species diversity of Halimeda in this 
region than is shown by the taxon today for the Mediterranean, where only two forms of $H$. tuna are known.

Events in the history of the area during the intervening millions of years, as presently interpreted by plate tectonics and continental drift, may provide insights into the cause of this dramatic decrease in diversity. They include the closing of the eastern end, then the western end of the Tethys Sea during the first half of the Cenozoic. The effect was to isolate the Tethys from the marine biota of both east and west. These events were followed by extreme evaporation in the region, with a sea-level drop of several thousand feet in the western Tethys during the Miocene (Berggren and Hollister, 1974a, b; Hsü et al., 1977). This Messinian crisis was accompanied by massive extinction of marine life. It seems likely that the Halimeda flora did not survive, or at most existed in a relict flora to the immediate west.

Following this mass extinction of the Tethyan flora, the present Halimeda of the Mediterranean must have been the result of a recolonization event, probably from the Atlantic Ocean. This would be a plausible event following the Messinian crisis because there was then a more northerly extension of warm water in the Atlantic Ocean than now (Berggren and Hollister, 1974a, b). This warm water allowed penetration of the new Mediterranean basin by the panoceanic species, tuna.

This reconstruction of the history of the Mediterranean Halimeda flora is of special interest because it gives us a clue to the slow pace of evolutionary events within the genus. The events of the Pliocene and Pleistocene combined have left the Mediterranean with but a single species in circumstances which suggest that the initial colonization was at the beginning of this period. If this is true, then the panoceanic species $H$. tuna is ancient and conservative.

It is true, of course, that the above conclusions on longevity of species drawn from the Mediterranean reconstruction are vulnerable to arguments that tuna is a recent immigrant, but with the Suez Isthmus having been closed and the cool waters now prevailing in the adjacent Atlantic this seems unlikely. It may also be that a more complicated history of speciation in the Mediterranean is hidden from us by extinctions in the Pleistocene. It would be very useful indeed to recover a fossil history of the genus from the Mediterranean covering the last five million years.

This view of the paucity of species in the Mediterranean adds an extra dimension to the discussion of places with impoverished Halimeda floras that is given above. It is concluded there that the very low recruitment rate of Halimedae may be the principal factor in producing 
low diversity, so much so that it is not necessary to resort to processes of extinction required by an equilibrium model. If recruitment is not only difficult and slow, but is actually confined to brief geologic periods, when current patterns are favourable, then the slow-recruitment model is amplified. It is argued above that the Mediterranean may have collected its ancestral tuna population during a brief favourable period after the Messinian crisis. A similar argument can be applied to the flora of the Canary and Cape Verde Islands, which may been have acquired during the same limited opportunity.

Other historical events may explain the present low species diversity of Halimeda elsewhere. The eastern Pacific, for example, would have become isolated from any eastern centre of distribution after the uplift of the Isthmus of Panama during the Neogene. In addition, its biota then as now was separated from western Pacific centres of distribution by a distance which Halimeda propagules appear unable to bridge.

For the southern Atlantic, a change in the pattern of surface currents, possibly accompanied by increasing separation from the Tethyan centre of distribution and succeeded by a slow rate of speciation, could explain much of the present-day low Halimeda species diversity. Berggren and Hollister (1974a) postulated current systems which could have introduced Tethyan elements along the entire Brazilian coast as late as the early Palaeogene. Present-day current patterns isolate both northern and south-eastern coasts of Brazil from the modern centre of distribution of Halimeda in the Atlantic which is the Caribbean. Additional collecting in the southern Atlantic may increase the species list somewhat, but the Brazilian flora has been worked extensively by Joly and his students.

These available studies of the fossil record of Halimeda seem to hold the clear inference that the genus tends towards conservative species, that dispersal is indeed slow, and that present distributions may well reflect past geological events as well as contemporary ecological processes.

\section{Rates of speciation within the genus}

Once evolved, Halimeda relatively quickly seems to have replaced Arabicodium and Bouenia which are not known after the Cretaceous (Elliott, 1965). Elliott suggests, too, that the genus diversified rather rapidly during its early history into a number of species, some fossil, such as $H$. nana (Pia, 1932), H. praeopuntia (Morellet and Morellet, 1922), H. praemonilis and H. eocaenica (Morellet and Morellet, 1941), 
and some modern. There was also an increase in the size of segments and possibly in the size of the entire thallus. Three of the species, praeopuntia, eocaenica and praemonitis, are described by their authors as resembling the modern species opuntia, opuntia f. minor (=goreauii) and incrassata f. monilis (=monile) respectively (Morellet and Morellet, 1941), with similarities such that Morellet and Morellet questioned the assignment of separate names to them.

For the remaining taxa, $H$. nana and the undescribed species, the literature data are too sparse to associate them definitely with Recent species. Even so, two of the five types of nodal filament pattern delimited in Section III, those present in the Opuntia and Rhipsalis sections, and representing the sprawling and sand-binding habitats respectively, are represented in the species praeopuntia, eocaenica and praemonitis. It seems likely that one or more tunoid species (section Halimeda) also had differentiated before the Messinian crisis. If so, then three of the five types of nodal filament structure would have existed. These would correspond to the only patterns of nodal filaments present in modern species of pantropical distribution (Table XIX), plants which also represent the major habitat types of sprawling, sand-binding and rock-growing. And interestingly, only pantropical species are present in modern reef communities of the Hawaiian Islands, the American shores and nearby islands of the eastern Pacific (with the exception of Easter Island), the Mediterranean, the Canary and Cape Verde Islands and Brazil (Table XIX, bottom line), while three of the four species growing in the Bermudan Islands are pantropical also.

Halimeda has been an important sediment-producer throughout its history (Wray, 1977), which implies that overall conditions for its growth have been favourable, and that there have been substantial populations during much of this time regardless of alterations in oceans and currents. Some of these changes would have led to extinction, others to isolation sometimes followed by speciation. With the development of various barriers such as the Isthmus of Panama, or the land mass at the eastern end of Tethys, separate Indo-Pacific, western Pacific and Atlantic groups would have been created out of the pantropical stock. Subsequent speciation within them would lead to the development of taxa unique to these particular regions. Figure 76 illustrates possible lineages among Recent Halimeda species, and the directions in which development from pantropical stock may have occurred in different ocean regions as suggested by known distribution and similarities of habit and morphology. Some pantropical species, particularly tuna and incrassata, occur infrequently in many of the collections from the Pacific Ocean, and it is possible that satellite 


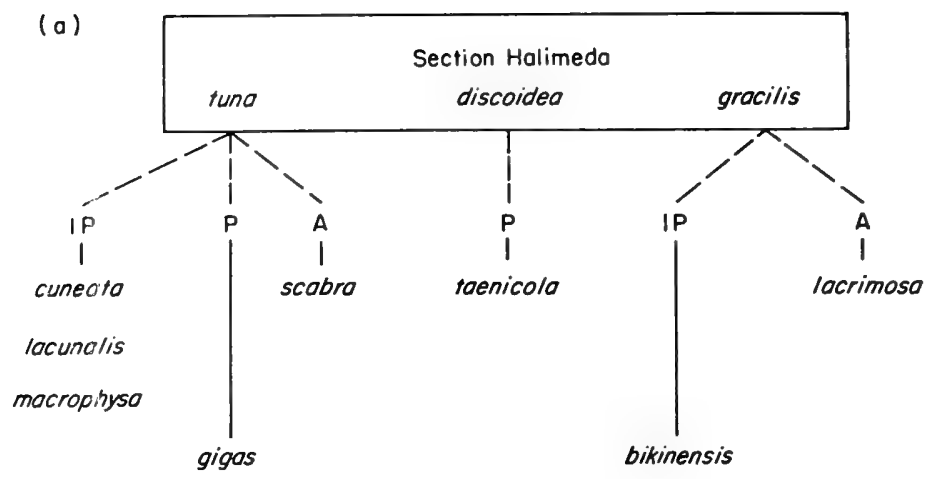

(b)

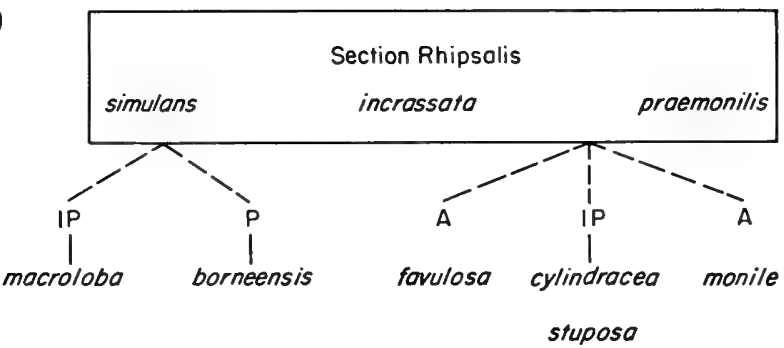

(c)

Section Micronesicae Section Crypticae

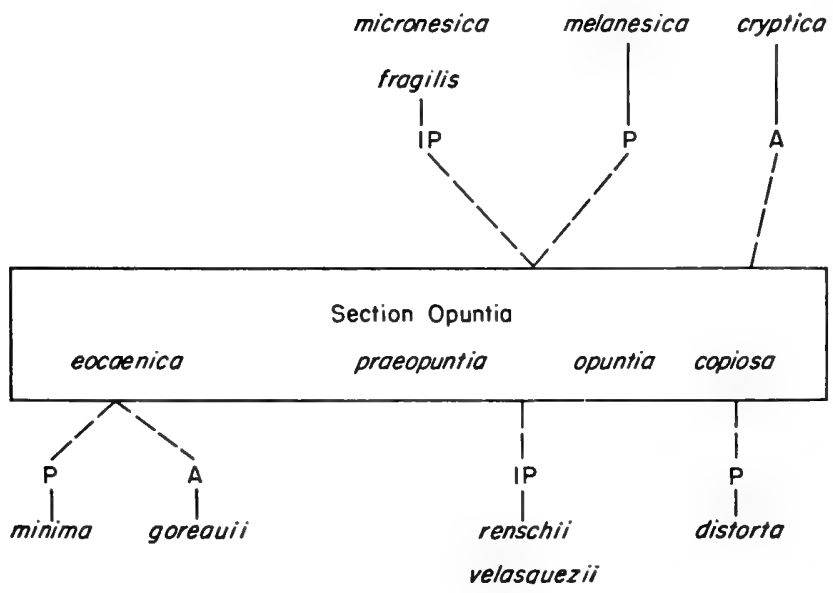

FIG. 76. Hypothetical lineages of Halimeda species from the pantropical modern and fossil species named in the boxes. (a) Species erect or pendant from rock except gracitis; holdfast usually $\leqslant 1 \mathrm{~cm}$ long. (b) Sand-"rooted" species; holdfast usually $>1 \mathrm{~cm}$ long. (c) Species that sprawl or creep; often more than one point of attachment on a thallus. IP $=$ Indo-Pacific $; P=$ Pacific $; A=$ Atlantic distributions as currentiy known, 
species such as lacunalis, macrophysa, macroloba or borneensis may be successfully replacing them. An alternative explanation is that their low numbers may be an artifact of the collections available.

The time-scale for the first events in the history of Halimeda has been ascertained by the location of fossils in the appropriate strata, and by inference from our understanding of subsequent historical events. Some modern species, however, may have existed earlier than hitherto implied. The reason for questioning the time-scale lies in the present disjunct distribution of $H$. cuneata. One explanation for its modern occurrence in the southern subtropical regions, delimited by the south-eastern tip of South Africa, southern tip of Madagascar, south-western and south-eastern coasts of Australia, and in the northern subtropical region of the Gulf of Cutch in north-west India (Fig. 75) is that this species had evolved at least by the time the regions represented were located in the same latitude, that is, before India had joined with continental Asia. The latest that they were in close proximity was in the Late Cretaceous (Smith and Briden, 1977). If cuneata existed then, it seems likely that other modern pantropical species had also evolved, and therefore would have coexisted with the fossil species which, as already indicated, have been described for a later epoch. An alternative explanation is that cuneata formerly occurred along much of the east coast of Africa and the western shores of India, that it eventually extended into subtropical waters and was displaced, or essentially so, from tropical regions. This line of reasoning does not require such an early differentiation of the taxon. Information from fossils may provide the decisive support for one of these hypotheses.

In conclusion it may be said that there is much direct evidence in the fossil record for Halimeda species being both conservative and ancient. The data allow the working hypothesis that many of the present panoceanic stocks can be identified as early as the beginning of the Tertiary. Local speciation has occurred only where isolation has been very prolonged. The possibility that diversity is a function of very poor and spasmodic opportunities for recruitment, rather than due to the establishment of species equilibria, is encouraged.

\section{A biogeographical approach to the phylogeny of the Caulerpales}

Morphological characteristics have provided most of the information for placing Halimeda in phylogenetic schemes (Gepp and Gepp, 1911; Gilmartin, 1966; Parker, 1970), but again biogeographical data can contribute useful support or indicate weaknesses. 
The Gepps (1911) suggested a common calcified ancestor for the calcareous genera, and devised a separate evolutionary scheme for the non-calcareous members of the group (Section III). This could be part of the scheme proposed below as well, with Udotea, Halimeda, Arabicodium, Boueina and the other calcareous genera developing from such an ancestor. However, even the limited data we have do not support the rigorous development of calcified and uncalcified taxa from calcified and uncalcified stock respectively. Calcified groups within the marine algae have arisen independently, Padina in the Phaeophyta for

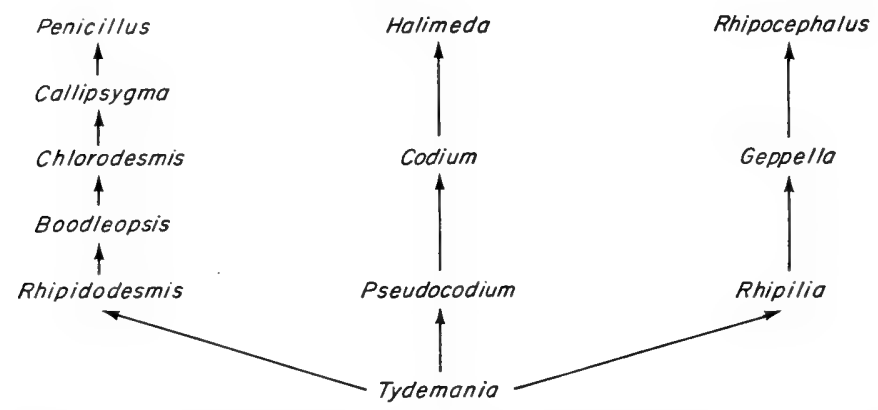

FIG. 77. Phylogenetic scheme for the Codiaceae proposed by Gilmartin (1966). The genera Udotea and Avrainvillea were considered to be in the Udoteaceae following Nizamuddin (1963), and hence were not included in the scheme.

example, and calcified and uncalcified phases alternate in the lifecycle of Pedobesia (MacRaild and Womersley, 1974; Section III), and possibly even in Halimeda. Whether or not the juvenile filaments of Halimeda (Section VII) are calcified is not indicated by Meinesz (1972b).

A more elaborate scheme is presented by Gilmartin (1966) (Fig. 77). He considered Tydemania, with its uniaxial construction, to be a primitive member of the Codiaceae and a connecting link between Rhipocephalus, Halimeda and Penicillus. Recent data have indicated some weaknesses in this scheme, however. It is not supported by wall chemistry, the wall of Codium containing mannan while that of Halimeda contains xylan (Parker, 1970). However, in spite of the helpful study of Parker, the data on wall chemistry within the group are scant, and the character may prove not to be a valid one for phylogenetic purposes. The scheme is also not supported by plastid structure, with both homoplasty and heteroplasty, and their associated differences, occurring in a single evolutionary line (Codium and Halimeda respectively); nor is it vindicated on ecological grounds. Gilmartin suggested that 
Tydemania, as a putative primitive Codiacean, may have survived in abundance only in deep-water habitats. Although it grows well in this environment, it also occurs in sizeable populations at some sites of $3-5 \mathrm{~m}$ depth in Enewetak Lagoon, the same lagoon in which Gilmartin worked (Hillis-Colinvaux, 1977), and I have observed well-developed stands of it in water of $-1 \mathrm{~m}$ to $-4 \mathrm{~m}$ in the Indian Ocean near the small islands of Banyak, Batu, Siburu and Stupai off the west coast of Sumatra.

The distributional data for the genera of the Caulerpales (Table XX) provide the basis for a new scheme (Fig. 78). It is suggested that the

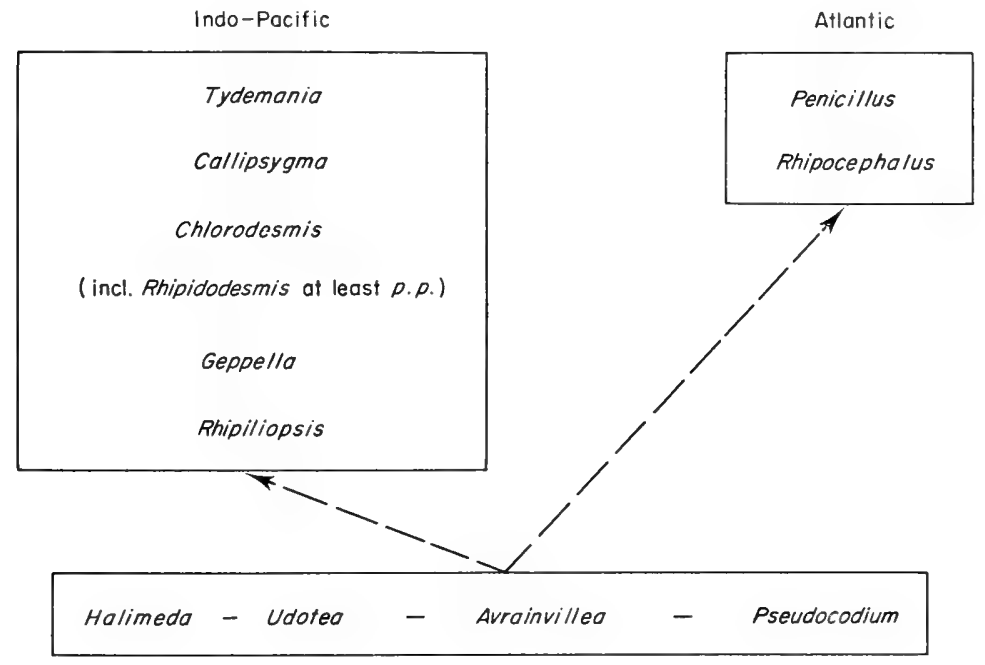

Pantropical

Fig. 78. New phylogenetic scheme of Caulerpales, excluding the monogeneric Caulerpaceae, based on biogeographic data.

five pantropical genera Halimeda, Udotea, Avrainvillea, Caulerpa and Pseudocodium are the oldest, and had differentiated before free eastwest exchange of tropical marine biota was brought to an end by the closing of the Tethys Sea. The other genera may have coexisted with them and subsequently have become extinct over part of the range, or they may have evolved later. Considering the present distribution of these genera, at least as known, the latter seems the more likely interpretation for the taxa of all but the last column which are not included in the scheme because the distributional patterns shown for them are interpreted as reflecting incomplete data. One or more of the genera in 


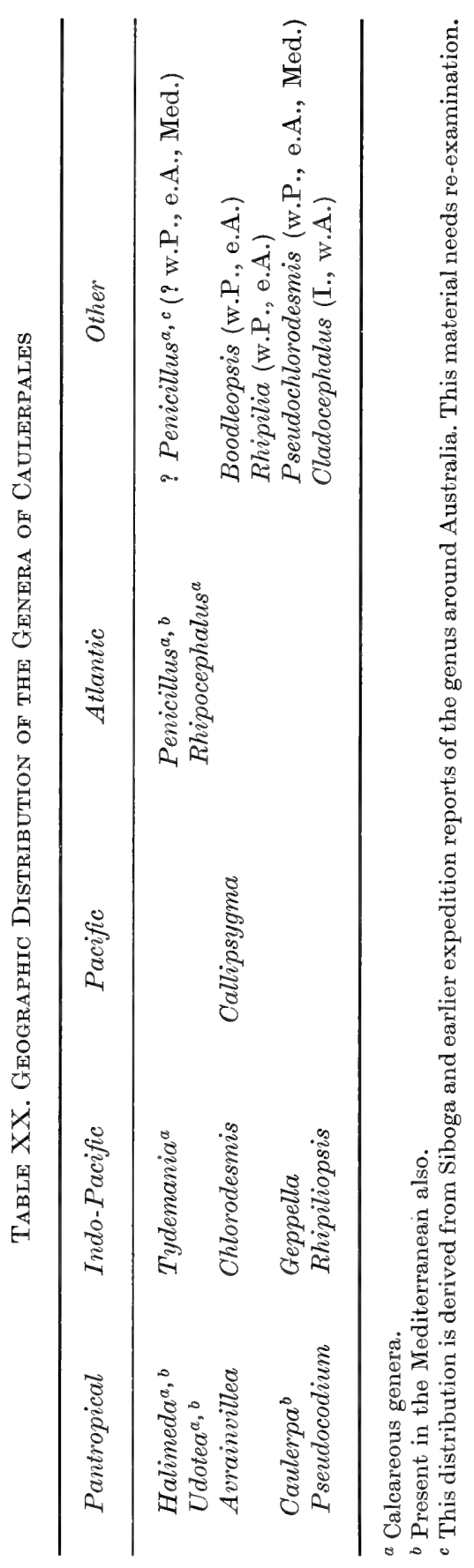


this column eventually may be shown to be pantropical. If the remaining taxa evolved later, then the calcareous genera Tydemania, Penicillus and Rhipocephalus, which are the ones of interest herein, would be more recent than Halimeda and Udotea. More detailed lineages have not been shown but Tydemania and Penicillus appear more closely related to Halimeda than to Udotea. Caulerpa, as the only genus of the Caulerpaceae, has not been included in the scheme which consequently is restricted to the Udoteaceae.

The uniaxial construction of Tydemania has an interesting parallel with that of $H$. cryptica, a species known only from $-25 \mathrm{~m}$ and deeper in the eastern Atlantic. It seems likely, however, that this morphological feature evolved independently in the two taxa, and is an adaptation of these two algae to a particular niche, rather than a primitive characteristic, as suggested by Gilmartin (1966). This niche may well involve successful growth under conditions of low light intensity and low energy reserves, leading to economy of form. In addition to the reduced numbers of medullary filaments that both taxa possess, the economy would extend, in H. cryptica, to the secondary utricles which are less fully developed on the shaded surface. So far a similar Halimeda species has not been found outside the Caribbean and the niche may be occupied by Tydemania or other taxa elsewhere, or perhaps, as with other Halimeda species, appropriate regions have not yet been explored adequately.

These phylogenetic schemes, both past and present, remain largely speculative. Some advances in understanding the relationships of the genera have been made, however, and there is an increased appreciation of avenues in which subsequent research would be particularly profitable. The long geological record of Halimeda and the widespread recent distribution of this genus indicate some of the impact the genus may have had, and is continuing to have, on tropical reefs. This contribution will be examined in more detail in the final sections.

\section{Productivity}

All Halimedae are plants of shallow coasts or of coral atolls and as such they are members of some of the very few highly productive communities of the oceans (Ryther, 1969; Koblentz-Mishke et al., 1970; Colinvaux, P. A., 1973, 1974, 1978; Bunt, 1975). The record of their own high productivity is preserved in many a coral reef, as in those at Funafuti where a significant part of the reef structure was found to be made of Halimeda segments (Section II). Understanding the productive 
capabilities of Halimedae, therefore, is necessary both for studies of energy flux through tropical reef communities, and for studies of the building of reefs themselves.

The productivity of atolls, on which so many Halimedae grow, is a particularly interesting subject since atolls are typically set in the unproductive blue waters of the main ocean deserts. Atolls are without the nutrients supplied by run-off from the land to coastal sites, nor are they typically supplied with the nutrients of upwellings. This has made their high productivity difficult to explain, and even now it is not understood in detail, though the outlines are becoming clear.

That the atoll marine system is not dependent on the nitrogen, phosphorus and zooplankton transported into it from the impoverished surrounding waters was demonstrated first by Sargent and Austin (1949, 1954) for Rongelap Atoll in the northern Marshall Islands. They established that this atoll was inwardly sustaining, using the technique of flow-respirometry, a method subsequently employed by Odum and Odum (1955) for their work on Enewetak Atoll which is also in the Marshall Islands. This atoll too they found to be selfsupporting, and their figure for the gross productivity of a coral reef community, together with a subsequent one obtained by Kohn and Helfrich (1957), is a useful base-line calculation of the productivity of tropical reefs since the technique measures community productivity for the transect of measurement. These studies do not tell us, however, how this high productivity is achieved, or the contribution of individual reef components, like the populations of large algae.

Answers to both these questions are essential to an understanding of productivity of the whole reef and energy flow in the reef system, as well as to reef modelling. Some appreciation of the first question, how the high productivity is achieved, is provided by the realization that nitrogen and possibly phosphorus are recycled within the system (Johannes et al., 1972), the presence of some such pattern being expressed earlier in the review of coral reefs by Yonge (1963). The 1972 report is part of the recent work of the SYMBIOS team that studied essentially the same part of the Enewetak reef as did the Odums, as well as a more northerly transect. Some details of the results of this team effort are still being published, but what is available adds strongly to the evidence that atolls may be nearly closed systems. They fix their own energy and cycle their own nutrients, are fertile islands in an infertile sea. In this respect coral atolls have to the ecologist something of the impact of lowland tropical rain forest, because this too supports itself on nutrient-poor substrate through very efficient nutrient retrieval systems. For the rain forests we have a fairly clear idea how nutrient 
retrieval and cycling work, but we know much less about the parallel systems in a coral atoll. It seems not unreasonable to expect that nutrient retrieval and cycling is sponsored by the primary producers, suggesting that the productivity of the various plant components of the reef ecosystem is a necessary subject for research.

Figures 79 and 80 are photographs of the section of the Enewetak reef studied by the Odums and the SYMBIOS group. This section was

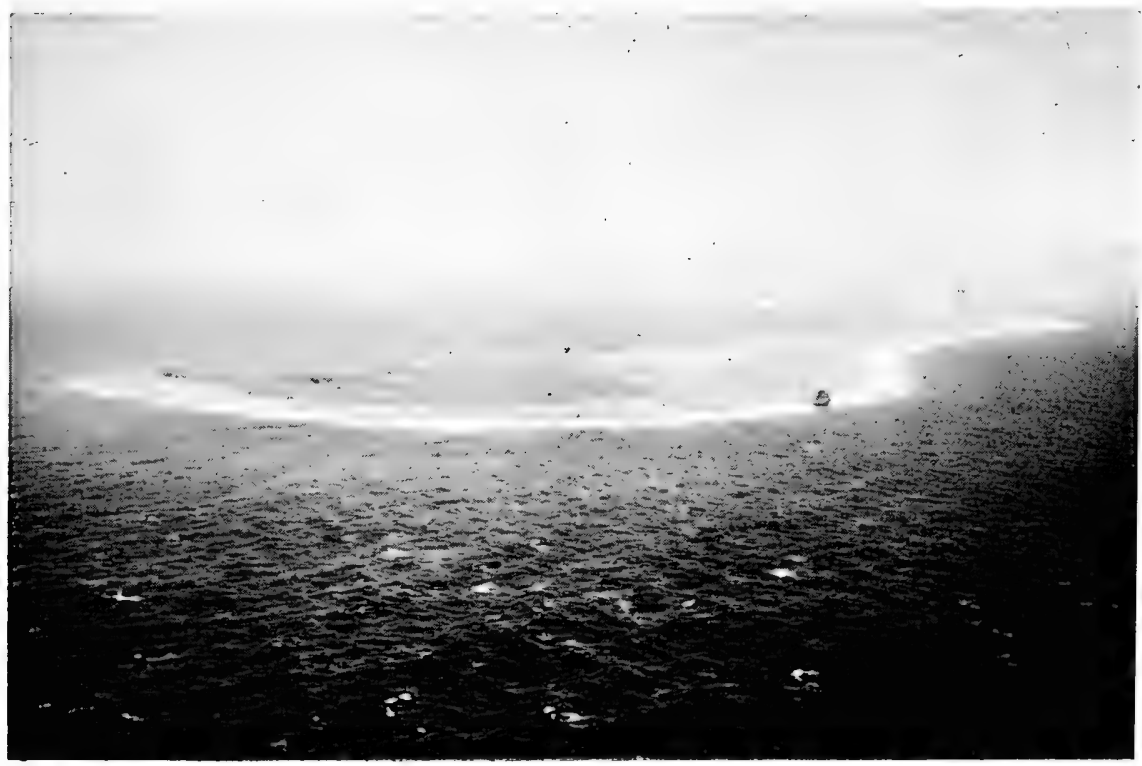

FIg. 79. The inter-island study site of Odum and Odum (1955) is $0.4 \mathrm{~km}$ north (right) of this islet, Japtan, on Enewetak Atoll, and north of the ship hulk, a relict of the Second World War. The Odum transect extended from the algal ridge, where the waves are breaking, towards the lagoon for approximately $300 \mathrm{~m}$. The reef in this region is approximately $455 \mathrm{~m}$ wide. (Data from Odum and Odum, 1955.)

chosen for its suitability to the flow-respiratory method of productivity measurement and does not include all parts of the atoll system. In particular, it does not include most of the macrophytes. Plants included in the transect were principally the algae of mats together with the symbiotic and boring algae associated with the corals, as well as some encrusting algae. In a careful search of much of this section of reef in 1975 I was unable to find a single Halimeda plant. This observation is perhaps brought into perspective by noting that borings from Enewetak show that Halimeda segments are a principal ingredient of the Enewetak reef matrix, just as they are at Funafuti (Couch et al., 1975). 

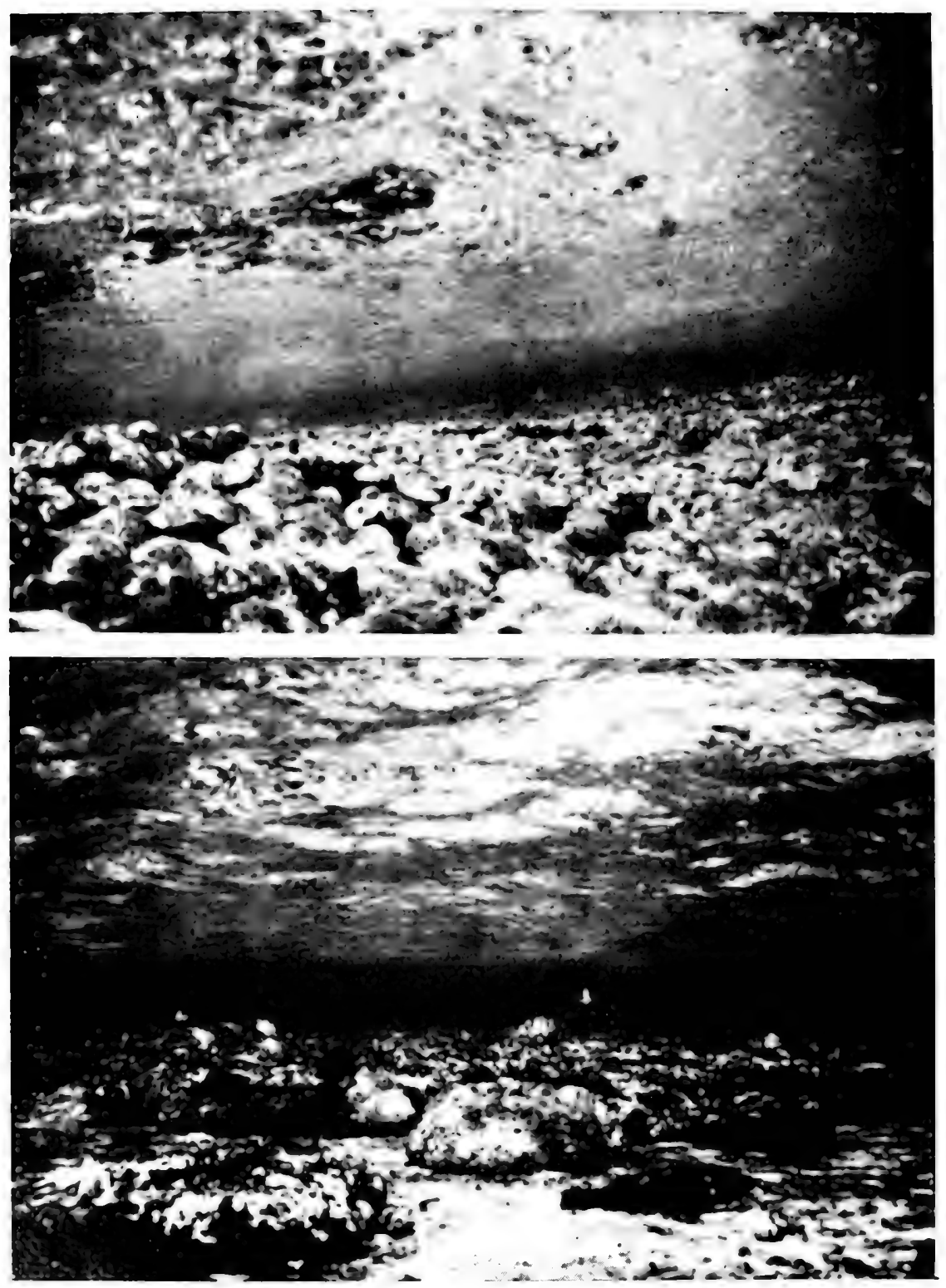

FIG. S0. Two of six zones of the Japtan transect described by Odum and Odum (1955) in their inter-island transect: the encrusting zone (top), and zone of smaller coral heads (bottom). Halimedae were not found in either zone during our December 1975 visit. Breaking waves show at the top of these underwater pictures. Depth is c. $1.5 \mathrm{~m}$. 
The Halimedae of an atoll live in the deep water of the outer slopes, in the shallows of the lagoonal coasts of the islets, in the reef passages, on pinnacles and on the lagoon floor. It is at these sites that much of the productivity of the reef system, both of carbon and of carbonate, must occur, and at these sites we have very few measurements indeed. Halimedae and other large algae occupy rather similar sites in fringing and barrier reefs, and there again the measurements are few.

Apart from work on coralline red algae like those of the reef front (Marsh, 1970; Littler, 1973; Smith and Marsh, 1973; Connor and Adey, 1977), our measurements of the productivity of macrophytes of reefs seem to be confined to a few on sea grasses (Odum, 1957; Westlake, 1963; Qasim and Bhattathiri, 1971; Patriquin, 1973, and a few on Halimeda and other Caulerpales (Gessner and Hammer, 1960; Drew, 1966; Drew and Larkum, 1968; Johnston and Cook, 1968; Johnston, 1969; Hillis-Colinvaux, 1974). Yet it obviously is necessary that we master the contribution of the calcareous green plants to both the energy and carbonate fluxes of reef systems.

\section{A. Production of organic carbon}

Primary productivity in aquatic communities is measured by a number of methods of which two of the principal ones are the light : dark bottle technique and the in situ ${ }^{14} \mathrm{C}$ uptake method (Steemann Nielsen, 1952; Strickland, 1960, 1966; Strickland and Parsons, 1968; National Research Council, 1969; Vollenweider, 1969). Their use has led to numerous papers on primary productivity, and the topic may appear at times to be well worked. For macrophytes, however, this is deceptive. These two techniques were developed for phytoplankton, and are hard to apply directly to macrophytes, although Drew and Larkum (1968) chose ${ }^{14} \mathrm{C}$ methodology for Udotea in the field, and Borowitzka and Larkum (1977) used it in a laboratory measure of photosynthesis with detached branches of Halimeda. The coenocytic nature of the algae involved could present special problems which are not discussed in these papers. The technique of flow-respirometry, which is also used, as mentioned earlier, generally provides a measure of community rather than population productivity, and is restricted to regions where there is significant water flow in one direction for a meaningful length of time. It is of limited use for most macrophytes except for calcareous Rhodophyta of the reef algal ridge.

A few attempts have been made to apply gas exchange techniques to individual plants, or to bits of reef or sand surface, by enclosing these in plastic bags, jars or acrylic hemispheres (Sargent and Austin, 
1954; Odum and Odum, 1955; Odum, 1957; Wells, 1977), the most elaborate being that of Wells. But none of these attempts have been directed to Halimeda or, indeed, to other large tropical macrophytes. They have measured gas exchange in encrusting or micro-communities of sand only. Johnston (1969) cut fresh discs from the non-calcareous siphonaceous alga Caulerpa in the field and measured the productivity of these discs by the standard light and dark bottle technique. Both

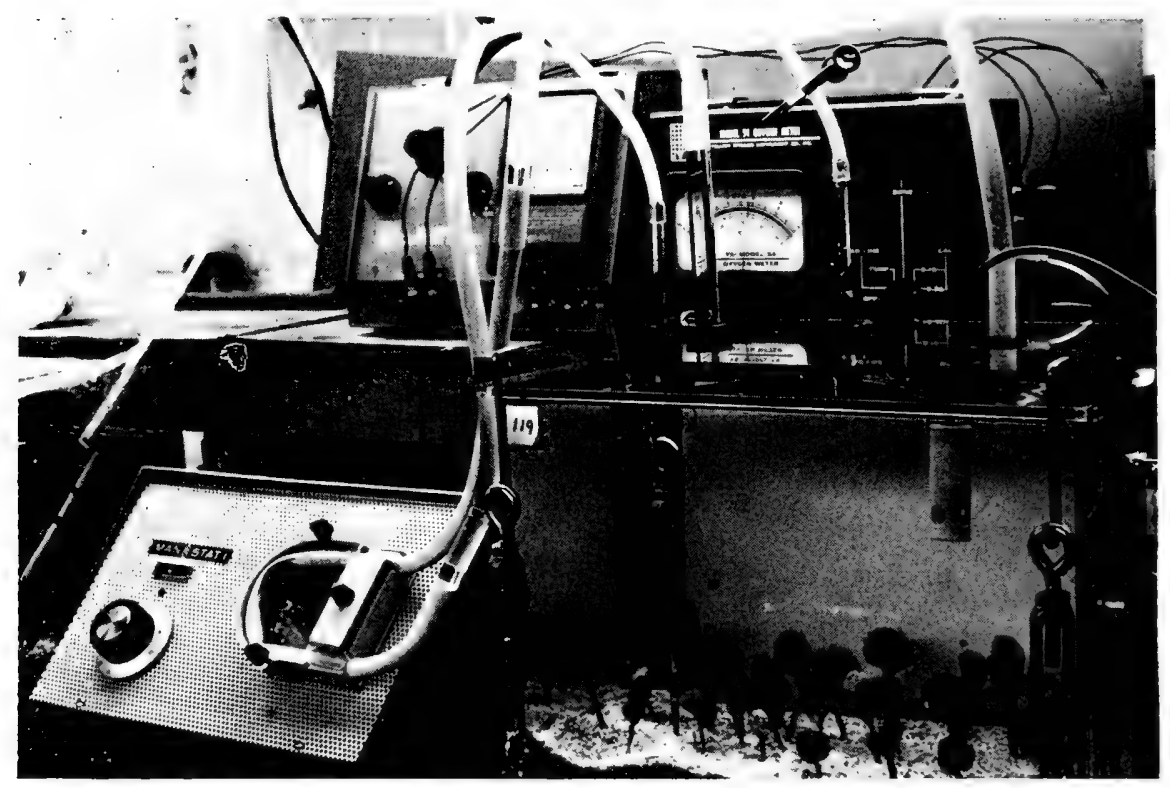

FIG. 81. Apparatus for measuring productivity of macrophytes growing in laboratory aquaria, by monitoring changes in oxygen production occurring within the aquarium over 36 hours or more. The aquarium with established, growing, clean plants is filled with water, and sealed with a thick plexiglass lid machined to fit, which in addition is held firmly in place by an O-ring seal and turnbuckles. The lid is designed with a number of entrance ports. A peristaltic pump, left front, maintains a water flow of approximately $0.3 \mathrm{~m} \mathrm{~s}^{-1}$ past the oxygen probe. Other equipment items of the system are an oxygen meter (top right) and recorder (top left). The aquarium in the photograph contains 40 Penicillus capitatus thalli, but production in Halimeda was measured in the same way.

Marsh (1970) and Hillis-Colinvaux (1974) established populations in aquaria which could then be converted into closed circulating-water systems (Fig. 81), with exchanges in oxygen production being monitored for a number of hours. Both authors manipulated environmental parameters to measure effects on photosynthesis, Marsh for calcareous red algae, and Hillis-Colinvaux for Halimeda and other calcareous 
green algae. The extent of the measurements for the productivity of Halimed $a$ and the other calcareous green macrophytes is therefore small.

\section{Productivity of Halimeda in laboratory culture}

Figure 81 illustrates the apparatus used for measuring the productivity of separate populations of Halimeda, Thalassia and Penicillus by gas exchange. Details of the method are given in Hillis-Colinvaux (1974), but essentially the procedure is to select tanks of healthylooking plants that have been maintained in the laboratory for a period of one or more months, to attach the fitted lid and apparatus to their aquarium tank, to record oxygen tensions for the cycle of 12 hours light and 12 hours dark to which they have been accustomed, and to calibrate the oxygen probe with Winkler titrations at the beginning and end of each run. Halimedae used were all the sand-dwelling incrassata in populations of about a dozen individuals, each approximately $7 \mathrm{~cm}$ tall (excluding the holdfast). This population density of about 220 plants $\mathrm{m}^{-2}$ is within the natural range for the species. Natural populations of $100 \mathrm{~m}^{-2}$ are common, and densities of nearly $500 \mathrm{~m}^{-2}$ are found in parts of the Glory Be reef (Section X). Energy provided was white light at intensities between 320 and $600 \mathrm{ft}$-c.

Under these conditions $H$. incrassata produced at the following rates:

net production

$2.5 \mathrm{mg} C$ per thallus per day, or $0.56 \mathrm{~g} \mathrm{C} \mathrm{m}^{-2} \mathrm{~d}^{-1}$

gross production $4.5 \mathrm{mg} C$ per thallus per day, or $1 \cdot 0 \mathrm{~g} \mathrm{C} \mathrm{m}^{-2} \mathrm{~d}^{-1}$.

Several of the conditions of the laboratory measurements, however, suggest these estimates are conservative. The thalli, at $7 \mathrm{~cm}$, were small, since many wild plants grow to $20 \mathrm{~cm}$ above the sand. This difference may, however, be somewhat offset by the fact that the lower portions of tall wild plants tend to be covered with epiphytes, or to have segments which are losing their green colour. Light intensities at noon in the shallow areas where this species attains high populations are much higher than those in our laboratory, and the plants are supplied with flowing tidal water instead of recirculating water.

Finally, it must be noted that laboratory measurements have not been applied to the Halimedae that attain the highest cover on reefs, the sprawling, rock-anchored forms like opuntia. On the Glory Be reef opuntia populations may attain a cover of $90 \%$, more than four times 
the cover of sand-dwelling forms like incrassata. The highest estimate for productivity of Halimeda populations given by Hillis-Colinvaux (1974) is arrived at by extrapolating the incrassata measurements to populations growing at the density of opuntia populations. By this procedure maximum productivities of $4 \cdot 1 \mathrm{~g} \mathrm{C} \mathrm{m}^{-2} \mathrm{~d}^{-1}$ (gross) and $2 \cdot 3 \mathrm{~g} \mathrm{C} \mathrm{m}^{-2} \mathrm{~d}^{-1}$ (net) are attained. These estimates for opuntia populations cannot as yet be confirmed in the laboratory because of the difficulty of maintaining the rock-attached forms of Halimeda in culture.

\section{Contribution of Halimeda to carbon production in reefs}

A rough estimate of the contribution of Halimeda to the carbon flux of an entire reef can be obtained by applying the above laboratory results on the productivity of individual Halimeda thalli to population data of the only reef for which we have a Halimeda census, the Glory Be reef on the north shore of Jamaica. Glory Be is the name given to a short section of the Jamaican fringing reef occupying a well-defined bay separated by headlands (Hillis-Colinvaux, 1972, 1974). The reef is described in Section X.A and illustrated in Figs 89-96. Percentage cover of Halimeda, by species, was estimated for each section of the reef from the shoreline to the region of the Acropora palmata corals and the buttresses. By using the cover data (Table XXI) and assuming that all species of Halimeda produce equally well regardless of depth or microhabitat, we can compute the contributions of the Halimeda populations to the total carbon flux of the reef.

Table XXI gives the results of applying the laboratory productivity data to the census of Glory Be reef. The total daily net production, from the region of the shallowest-growing Halimedae to the outer channel, an area of $9840 \mathrm{~m}^{2}$, which supports 1110300 Halimeda plants (calculated from Tables XXI and XXXIII) is

$$
2779 \mathrm{~g} \mathrm{C} \mathrm{d}^{-1} \text { or } 1014 \mathrm{~kg} \mathrm{C} \mathrm{yr}^{-1}
$$

yielding a range of net productivities for the reef, where estimated Halimeda cover was $10 \%$ or higher, of

$$
0 \cdot 31-2 \cdot 25 \mathrm{~g} \mathrm{C} \mathrm{m}^{-2} \mathrm{~d}^{-1} \text { or } \quad 113-821 \mathrm{~g} \mathrm{C} \mathrm{m}^{-2} \mathrm{yr}^{-1} \quad \text { (Table XXI). }
$$

The lower figures of this range were at sites where plants other than Halimeda predominated, or where there was grazing by urchins or fish, with one of the lowest figures in dense stands of Thalassia. Total macrophyte productivity in these stands is, of course, very large. The vertical sides of coral rocks are excluded from the range given, because 


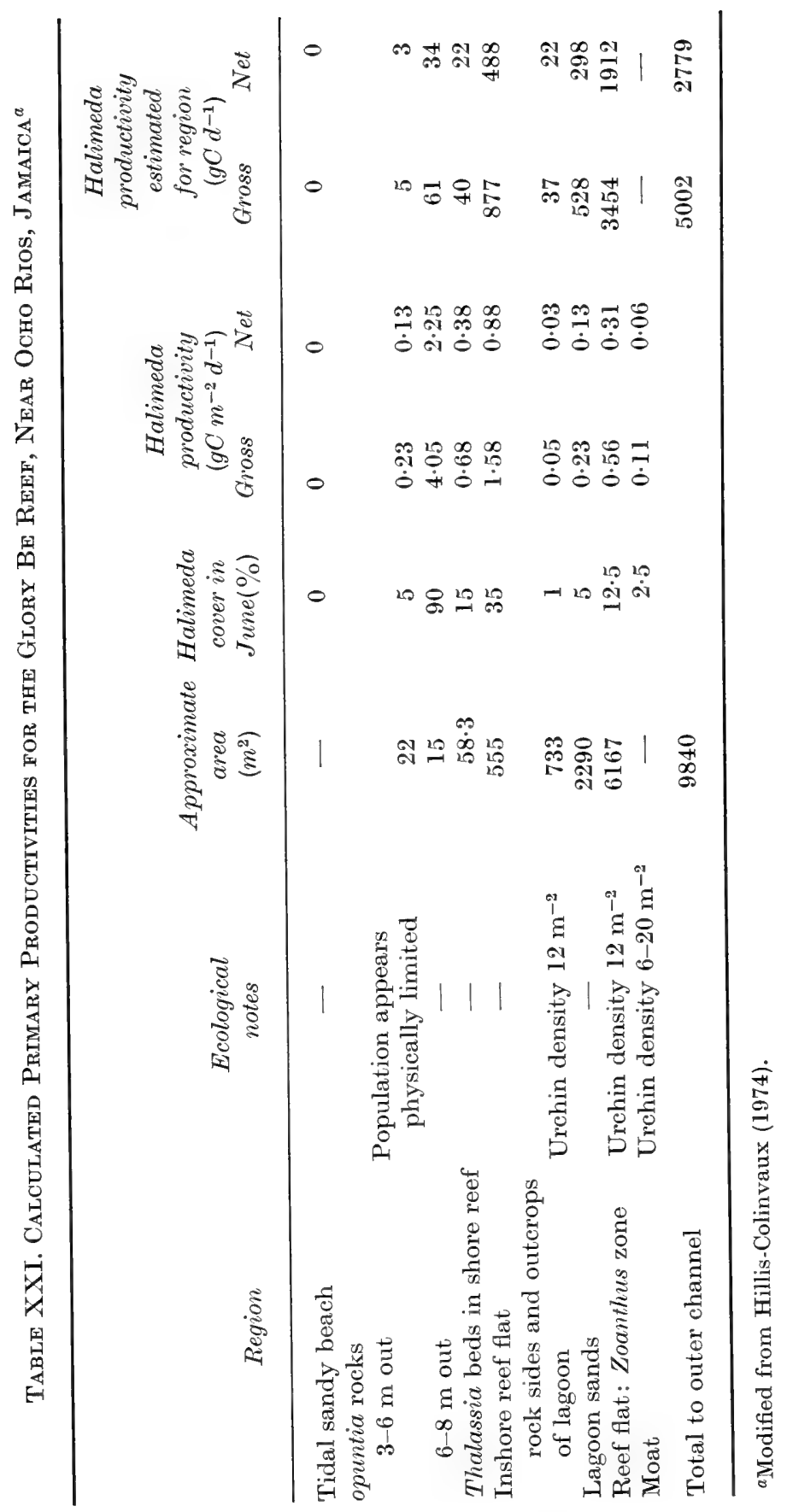


the Halimedae were essentially absent, probably because of grazing pressures. Outcrops of the back-reef and the moat of the reef crest (which contained much wave-stirred sand) are also excluded.

In Table XXII these results are compared with data for phytoplankton productivity supplied by Ryther (1969). The highest figure Ryther cites, that for upwellings, is about one-third of the performance of dense stands of Halimeda in a coral reef. Even where Halimeda plants are thinly spaced in Thalassia beds their contribution to productivity is still better than that of phytoplankton of typical coastal waters. Even the average productivity of the Halimedae of the Glory Be reef is equal

Table XXII. Comparison of Net Productivity

of Halimeda Populations with Phytoplankton

Production

\begin{tabular}{lc}
\hline \multicolumn{1}{c}{ Population } & $g C m^{-2} y^{-1}$ \\
\hline Phytoplankton $^{a}$ & \\
Coastal & 100 \\
Upwellings & 300 \\
Mean ocean & 50 \\
Halimeda populations ${ }^{b}$ & 139 \\
Low density in Thalassia beds & 321 \\
Low density in algal communities & 821 \\
High density & 190 \\
Mean of Glory Be reef & \\
\hline
\end{tabular}

a Data from Ryther (1969).

${ }^{b}$ Data from Table XXI.

to phytoplankton production in coastal waters, in spite of the fact that large areas of reef are denied to Halimeda by grazing animals, living corals and the surf.

The contribution of fixed carbon to a reef by Halimeda, therefore, may be very high, and the primary productivity of a tropical area or coral reef, taken as a mosaic of fleshy algae, calcareous algae, sea grasses and photosynthetic corals, may be of the same approximate order of magnitude as the most productive of Mann's (1972) Laminaria forests in Nova Scotia. Accounts of the productivity of tropical waters should include the high values encountered in these latitudes, as well as the proverbial low ones, a point well made in the comparative study of productivities of Antarctic and tropical-subtropical regions by El-Sayed and Turner (1977), and the significant contribution of benthic algae should not be ignored as is done so frequently. Coral reefs occupy about 
$0.2 \%$ of the unproductive world ocean (calculation based on reef area information in Smith (1978)), or about twice the space Ryther (1969) assigned to regions of upwelling. Since Ryther was able to show that upwelled areas produce about half the world's fish supply (he did not specifically include coral reefs in his calculations), the primary productivity of tropical reefs, to which Halimeda contributes significantly, is an important world resource.

\section{Halimeda productivity compared with other reef production}

In Table XXIII the Halimeda estimates are compared with other reef productivity data. Halimeda productivity appears to be of the same order of magnitude as that of Thalassia and species of intertidal Cyanophyta. The discrepancy with Caulerpa may be accounted for, at least partly, by differences in technique, particularly the cutting of discs from the siphonaceous Caulerpa thallus which would inevitably produce some loss and disruption of filament contents. More extensive comparisons must be made with caution since the data have been obtained by a variety of procedures, including different light intensities, and the impact of light intensity has not been fully evaluated. They have not been extrapolated to an annual basis because the pertinent standing crop data are sparse.

Except where there are extensive beds of Thalassia, Halimeda is usually one of the most obvious plants in a coral reef or atoll. In spite of the roughness of the data in Table XXIII, if seems apparent that Halimeda may well be as productive as other primary producers in the reef. Some of the estimates for whole-reef metabolism of parts of the reef where there are few to no Halimeda, like those of Odum and Odum (1955), appear larger than the estimate for Halimeda based on laboratory culture, but there seems good reason to believe that the Halimeda estimates are conservative. It must be of interest to obtain direct measures of the productivity of Halimedae as they grow on reefs.

It remains true that the Glory Be reef is the only reef for which we have a Halimeda census, and that on a solitary occasion. For no reef have we recurrent census descriptions of the standing crops of Halimeda at different times of the year. And there are apparently no measurements at all on the production of wild populations of Halimeda by gas exchange, cropping or incremental harvest. Until these measurements are made it will not be possible to state accurately the contribution of Halimeda to the remarkably high productivity of coral reefs. If the productivity of Halimeda in the wild is as high as these provisional data suggest, however, there must be interesting questions to be asked about 


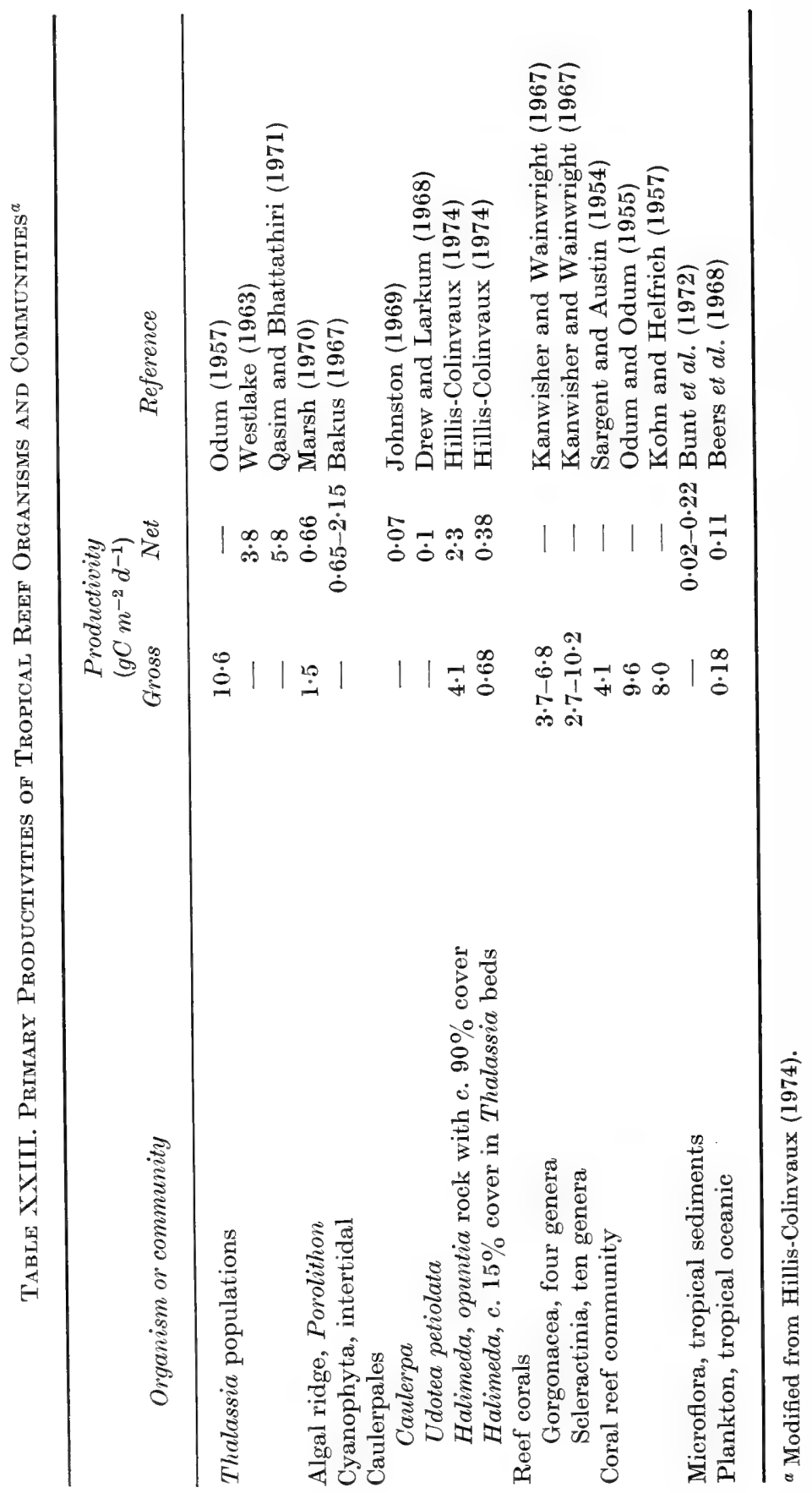


its nutrient supplies and its role in maintaining the nutrient cycles of a reef system.

\section{B. Carbonate production}

Halimeda is a producer, not only of reduced carbon, but also of loose carbonate sediment, and it has become clear that unconsolidated sediments are more important to the building of a reef than the carbonate incorporated into the reef framework (Milliman, 1974). Stoddart (1969) estimates that four to five times more loose sediment is produced than is incorporated as reef framework. This loose sediment is produced by Foraminifera, by the large benthic animals of the reef system like molluses and some echinoderms, as accretionary deposits on the blades of sea grasses, and by the green calcareous algae, the most abundant and widespread of which are Halimedae.

There seems some uncertainty in the minds of students of coral reefs over the relative importance of Halimeda segments to the total flux of loose sediments into a reef. The subject is naturally approached from the point of view that coral reefs are just what they are called, "reefs made of coral", which is to say that they are animal creations. Furthermore, a visit to a reef reveals corals in abundance but, unless you dive and hunt, no obvious green plants. As we noted earlier, the transect at Enewetak studied by the Odums and the SYMBIOS group (Johannes et al., 1972) contains few to no Halimedae or other large green algae. Apart from the borers and the symbionts, the main evidence of plant life is given by the encrusting red algae of the fore-reef where the waves break. But these red algae are properly regarded as part of that reef framework that contributes only a quarter of the reef mass (Stoddart, 1969).

\section{Halimeda as one of the principal contributors to atoll mass}

The classic borings at Funafuti (Hinde, 1904; Judd, 1904) provided the first evidence that the actual mass of a coral atoll (and hence perhaps of all coral reefs) might not be made of the visible corals and red algae of the reef ridge itself, and these borings implicated Halimeda. In the boring through the floor of the lagoon the first $20 \mathrm{~m}$ of sediment was between $80 \%$ and $95 \%$ recognizable Halimeda segments (Fig. 82). Similar conclusions were reached for the unconsolidated lagoon deposits at Bikini, Enewetak and other atolls of the Marshall Islands by Emery et al. (1954) (Fig. 83). Table XXIV shows similar results from a number of lagoons collected by Milliman (1974). It seems clear that Halimeda segments are a major constituent of many lagoon deposits. Table XXV 


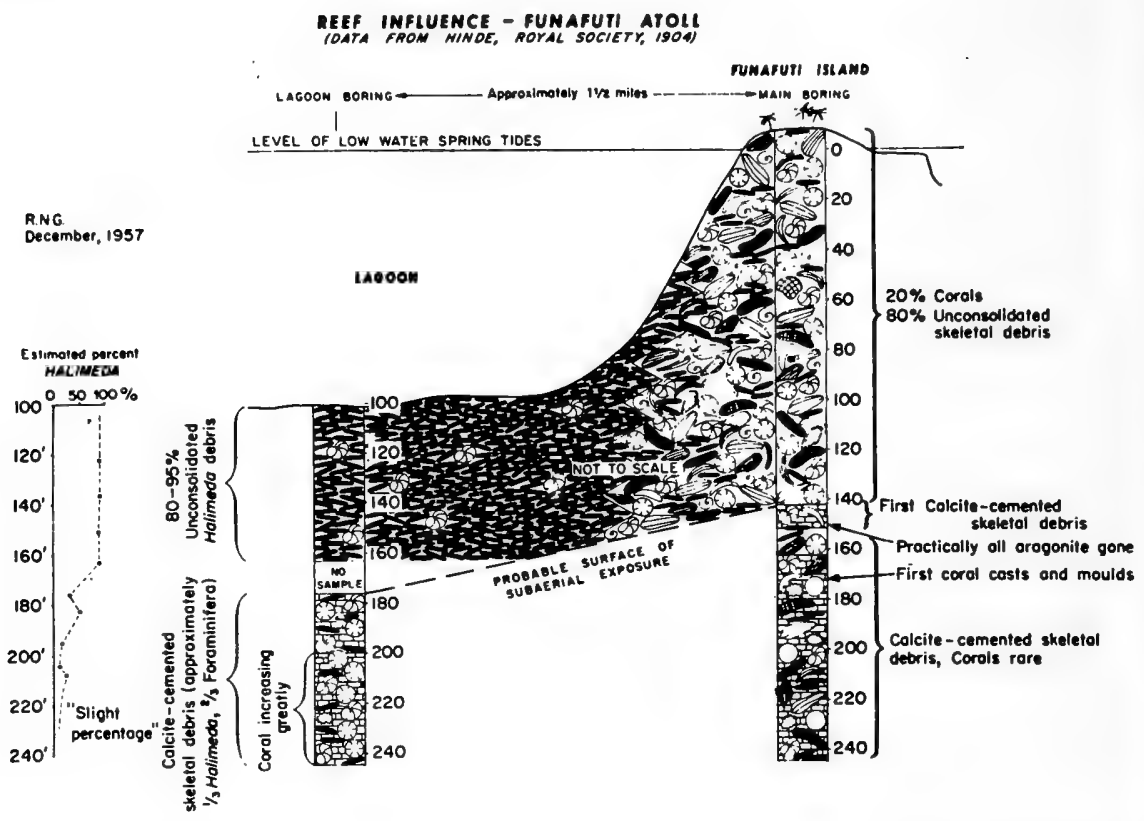

Frg. 82. Cross-section of Funafuti Atoll, Ellice Islands, showing some of the results of the cores raised by the Coral Reef Committee of the Royal Society (1904). Halimeda segments were the chief constituent for the first 60 feet below the lagoon floor. They also were the predominant component of the main boring between $652-660$ feet, but this depth is not included. (From Ginsburg et al. (1963), original data from Judd (1904) and Hinde (1904); reproduced with permission.)

extends the data to various forms of peripheral reef, where Halimeda segments can collect in channels, lagoons and behind sills.

At Funafuti the Halimeda-rich stratum of unconsolidated sediment ended with an unconformity which was almost certainly the subaerial exposure surface which had been weathered during the last eustatic lowering of sea-level. In the lower parts of this boring, under the unconformity, only one-third of the recognizable parts were Halimeda, the other two-thirds being foraminiferans (Fig. 82).

If we accept the Funafuti, Bikini and Enewetak results as correct in suggesting that lagoonal accretions of sediment are likely to be very largely Halimeda segments, then it is reasonable to postulate that the ultimate origin of the mass of an atoll depends on the relative rates of accretion on the lagoon floor and along the reef ridges. We may write:

$$
A_{\mathrm{m}}=\left(H_{\mathrm{s}} L+R_{\mathrm{v}} R_{\mathrm{h}}\right) t
$$

where $A_{\mathrm{m}}$ is the atoll mass, $H_{\mathrm{s}}$ is the deposition of Halimeda segments 

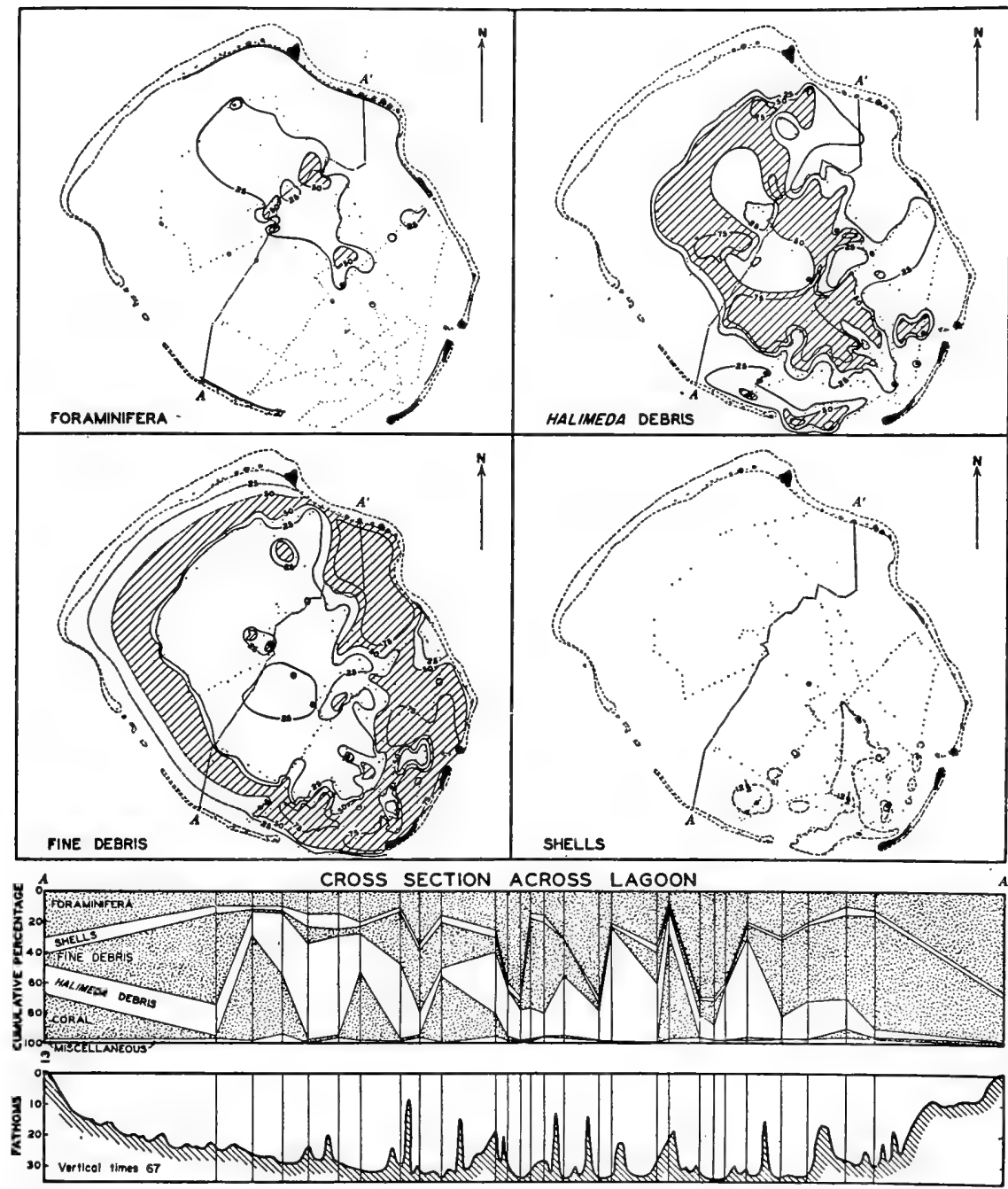

FIG. 83. The distribution of Halimeda sediments, compared to other major sediments, in the lagoon of Enewetak. Lines of equal abundance are drawn through the 25, 50 and $75 \%$ values. The lower two figures give the cumulative percentages of the six categories of sediments recognized along the transect $A A^{\prime}$, and a profile of the lagoon bottom from $A$ to $A^{\prime}$ showing some of pinnacles. (From Emery et al. (1954), reproduced with permission.)

per unit area, $L$ is the area of lagoon, $R_{\mathrm{v}}$ and $R_{\mathrm{h}}$ are the vertical and horizontal components of the growth of the reef ridge, $t$ is the time.

Both the lagoonal and reef-ridge contributions to the atoll mass must be functions of the history of sea-level and perhaps of other 
Table XXIV. Average Skeletal Composition of Sand-size Components of Some Lagoonal Sediments ${ }^{a}$

\begin{tabular}{|c|c|c|c|c|c|c|}
\hline $\begin{array}{c}\text { Source of } \\
\text { lagoonal sediment }\end{array}$ & $\begin{array}{l}\text { Hali- } \\
\text { meda }\end{array}$ & $\begin{array}{c}\text { Calcareous } \\
\text { red algae }\end{array}$ & Coral & Mollusca & $\begin{array}{l}\text { Forami- } \\
\text { nifera }\end{array}$ & Other \\
\hline \multicolumn{7}{|l|}{ Caribbean Reefs } \\
\hline Florida & 38 & 3 & 7 & 18 & 7 & 7 \\
\hline Alacran & 23 & 5 & 15 & 7 & 7 & 2 \\
\hline Hogsty & 1 & 1 & 4 & 10 & 4 & 1 \\
\hline Courtown Cays & 28 & 21 & 28 & 12 & 6 & 1 \\
\hline Albuquerque Cays & 31 & 14 & 20 & 12 & 6 & 3 \\
\hline Roncador Bank & 37 & 12 & 22 & 12 & 5 & - \\
\hline Serrana Bank, east & 61 & 4 & 9 & 7 & 5 & 1 \\
\hline Serrana Bank, west & 13 & 1 & 8 & 10 & 3 & 1 \\
\hline \multicolumn{7}{|l|}{ Pacific Reefs } \\
\hline Funafuti & 77 & $\operatorname{Tr}$ & $\operatorname{Tr}$ & $\operatorname{Tr}$. & 21 & Tr. \\
\hline Bikini & 57 & - & 17 & 9 & 15 & 1 \\
\hline Enewetak & 35 & - & 42 & 8 & 14 & - \\
\hline Johnson Island & 1 & 61 & 24 & 12 & 2 & - \\
\hline Cocos (Guam) & 17 & 18 & 45 & 18 & 2 & - \\
\hline Raroia & Tr. & Tr. & 43 & Tr. & 28 & - \\
\hline Ifaluk & 32 & 6 & 15 & - & 29 & 15 \\
\hline Midway & 7 & 31 & 18 & 15 & 19 & 10 \\
\hline Kure & 4 & 42 & 18 & 10 & 18 & 8 \\
\hline Pearl and Hermes & \multicolumn{2}{|c|}{$\longleftrightarrow-48 \longrightarrow$} & 17 & 18 & 6 & - \\
\hline
\end{tabular}

${ }^{a}$ Adapted from Milliman (1974). Figures are percentage skeletal components in total sediment.

Tr., trace.

processes in the growth of reefs of which we may not be fully aware. Each lowering of sea-level by eustacy would be expected to eliminate the lagoonal (largely Halimeda) contribution to the atoll mass in circumstances where at least the horizontal component of reef growth may continue, even if attenuated. Each eustatic lowering also affords an opportunity for the exposed reef ridge to be weathered and deposited on the Halimeda matrix of the old lagoon floors. Thus a history of eustacy will alternately favour the deposition of Halimeda and nonHalimeda sediments into the atoll mass. Added to this time-variant function must be the effects of different rates in the growth of the reef ridges themselves.

Coral matrix is formed by the vertical growth of the reef ridge which accompanies changes in relative sea-level associated with both eustacy and isostacy, by the horizontal growth of the reef ridge and by the 
Table XXV. Average Skeletal Composition of Sand-size Components of Some Peripheral Reef Sediments

\begin{tabular}{lcccccc}
\hline $\begin{array}{c}\text { Source of } \\
\text { peripheral sediment }\end{array}$ & $\begin{array}{c}\text { Hali- } \\
\text { meda }\end{array}$ & $\begin{array}{c}\text { Calcareous } \\
\text { red algae }\end{array}$ & Coral & Mollusca & $\begin{array}{c}\text { Forami- } \\
\text { nifera }\end{array}$ & Other \\
\hline Caribbean Reefs & & & & & & \\
$\quad$ Florida & 30 & 10 & 20 & 12 & 6 & 7 \\
Alacran & 40 & 11 & 26 & 7 & 8 & 1 \\
Andros & 17 & 33 & 24 & 6 & 12 & 6 \\
Hogsty & 2 & 19 & 27 & 22 & 5 & 1 \\
Courtown Cays & 28 & 21 & 35 & 10 & 3 & - \\
Albuquerque Cays & 32 & 21 & 30 & 9 & 2 & 1 \\
Pacific Reefs & & & & & & \\
$\quad$ Ifaluk & 10 & 23 & 36 & - & 23 & 9 \\
Midway & 6 & 35 & 25 & 12 & 14 & 8 \\
$\quad$ Kure & 2 & 52 & 15 & 12 & 10 & 9 \\
Great Barrier & $10-30$ & $17-40$ & $20-40$ & $4-15$ & $8-20$ & 5 \\
$\quad$ Inter-reef & $5-10$ & $0-15$ & $5-65$ & $15-40$ & $20-35$ & $5-30$ \\
\hline
\end{tabular}

${ }^{a}$ Adapted from Milliman (1974) and Orme (1977). Figures are percentage skeletal components in total sediments.

growth of coral pinnacles from the lagoon floor. A scheme describing the mutual influences of these accretion processes on the final composition of the atoll mass is given in Fig. 84.

The mutual dependency among these various processes is clear. Low sea-level will be a time of very low contribution of Halimeda to the atoll mass because of the extinction of the lagoon. It will also be a time of relatively low coral contribution because the pinnacles will be extinguished. In times when there is little eustatic fluctuation the contribution of Halimeda segments into the lagoon may be relatively large, perhaps being the dominant process. But the increase of atoll mass by the Halimeda segments must have an isostatic effect, thus increasing the possibilities for growth of the reef ridge and the pinnacles.

The history of the atoll fabric may be investigated by drilling, and the fabric revealed by drill cores from any part of the structure must reflect recurrent local changes, as the site may have fluctuated from pinnacle to lagoon and the sea-level may have been high or low. There is likely to be a bias, however, in the record since most borings are from on the reef ridges or near them. And there may be a difficulty in reconstructing the actual origin of the reef fabric being examined due to the changes which have taken place during diagenesis, cementation or 


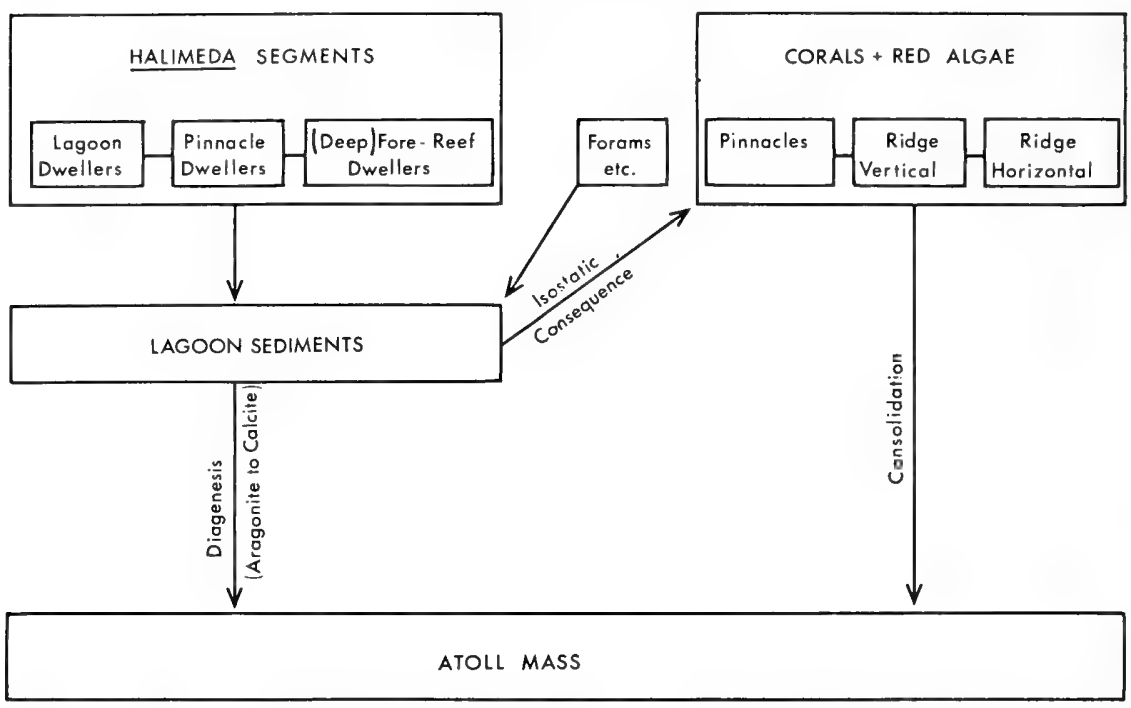

FIG. 84. Scheme showing influences of accretion processes on the final composition of atoll mass.

consolidation. In particular, it is worth noting that most of the Foraminifera contributing to reef structures have calcite skeletons which may well survive diagenetic processes better than the aragonite of Halimeda or corals.

Table XXVI describes some of the results from 3 of the 42 drill cores from the Enewetak Atoll recently raised by Couch et al. (1975). The core from Cactus Crater was chosen from this suite because it was near the outer edge of the reef, taken under $10 \mathrm{~m}$ of water in the crater left by an atom bomb exploded on the outer reef flat. The second core from the same island (Runit) was chosen as being the longest core from the middle of the island. The general sites of both these cores are shown in Figs 85 and 97. The core from Engebi was chosen merely on the basis of length. No examination of the matrices of the 42 cores was made in choosing these three data sets.

In Table XXVI the Enewetak core log data are abstracted at arbitrary intervals of $5 \mathrm{~m}$. The data are estimates by eye of the percentage composition of the various constituents of the core sections by volume. Names are given, therefore, only to what is well and clearly preserved. Both Halimeda and coral fragments are common, and fluctuate up and down the cores. Foraminifera occasionally predominate, but are usually of less importance than both Halimeda segments and coral fragments. As would be expected from the method of analysis, 
Table XXVI. Log Data from Three Boreholes at Enewetak ${ }^{a}$

\begin{tabular}{|c|c|c|c|c|c|c|c|}
\hline $\begin{array}{c}\text { Depth } \\
(m)\end{array}$ & Halimeda & Coral & $\begin{array}{l}\text { Forami- } \\
\text { nifera }\end{array}$ & $\begin{array}{c}\text { Red } \\
\text { algae }\end{array}$ & $\begin{array}{l}\text { Echino- } \\
\text { derms }\end{array}$ & Mollusca & $\begin{array}{l}\text { Unidenti- } \\
\text { fied }\end{array}$ \\
\hline
\end{tabular}

\begin{tabular}{|c|c|c|c|c|c|c|c|}
\hline \multicolumn{8}{|c|}{ HOLE XC-1. RUNIT IN CACTUS CRATER } \\
\hline 15 & 5 & 20 & 10 & Tr. & Tr. & - & 60 \\
\hline 20 & 10 & 20 & 5 & Tr. & Tr. & Tr. & 60 \\
\hline 25 & 10 & 20 & 5 & Tr. & Tr. & Tr. & 60 \\
\hline 30 & 5 & 20 & Tr. & Tr. & Tr. & Tr. & 60 \\
\hline 35 & 10 & 10 & Tr. & Tr. & Tr. & - & 85 \\
\hline 40 & 5 & 10 & Tr. & Tr. & - & - & 80 \\
\hline 45 & Tr. & 15 & Tr. & - & - & - & 60 \\
\hline \multicolumn{8}{|c|}{ HOLE XRU-2a. RUNIT ON LAND } \\
\hline 5 & Tr. & 15 & 5 & 10 & - & Tr. & 70 \\
\hline 10 & 5 & 50 & Tr. & Tr. & Tr. & Tr. & 30 \\
\hline 15 & 5 & 5 & 5 & 20 & Tr. & Tr. & 55 \\
\hline 20 & 15 & 10 & 5 & 10 & Tr. & Tr. & 55 \\
\hline 25 & 40 & 5 & Tr. & 5 & Tr. & Tr. & 40 \\
\hline 30 & Tr. & 5 & 10 & Tr. & - & Tr. & 80 \\
\hline 35 & Tr. & Tr. & Tr. & Tr. & - & Tr. & 90 \\
\hline 40 & 15 & 50 & 15 & Tr. & 一 & Tr. & 15 \\
\hline 45 & 15 & 50 & 15 & $\operatorname{Tr}$. & - & Tr. & 15 \\
\hline \multicolumn{8}{|c|}{ HOLE XEN-G. ENGEBI ON LAND } \\
\hline 10 & 5 & 20 & 55 & - & - & - & 15 \\
\hline 15 & 10 & 20 & 20 & - & - & Tr. & 30 \\
\hline 20 & 50 & 20 & 10 & 5 & Tr. & Tr. & 15 \\
\hline 25 & 40 & 30 & 10 & 10 & - & Tr. & 10 \\
\hline 30 & 30 & 30 & 10 & 5 & Tr. & 5 & 15 \\
\hline 35 & 30 & 30 & 10 & 5 & Tr. & 5 & 15 \\
\hline 40 & Tr. & 50 & - & - & - & 5 & 40 \\
\hline 45 & - & 95 & - & - & - & - & 5 \\
\hline 50 & 30 & 50 & - & 5 & - & - & 15 \\
\hline 55 & 5 & 40 & 5 & - & Tr. & Tr. & 40 \\
\hline 60 & 10 & 40 & 20 & - & - & Tr. & 30 \\
\hline 65 & 10 & 50 & - & - & Tr. & Tr. & 40 \\
\hline
\end{tabular}

${ }^{a}$ Data are culled from the drill logs given by Couch et al. (1975), and have been taken at arbitrary intervals of $5 \mathrm{~m}$. The original data are estimates by eye of the percentage of each constituent by volume (the percentages are approximate and have not been rounded to add up to 100). For location of Islets see Fig. 97.

Tr., trace.

the largest constituent consists of unidentified fragments. It may be that there is enough information in the complete data-set of the 42 cores to assign some part of the unidentified fraction to one of the other 

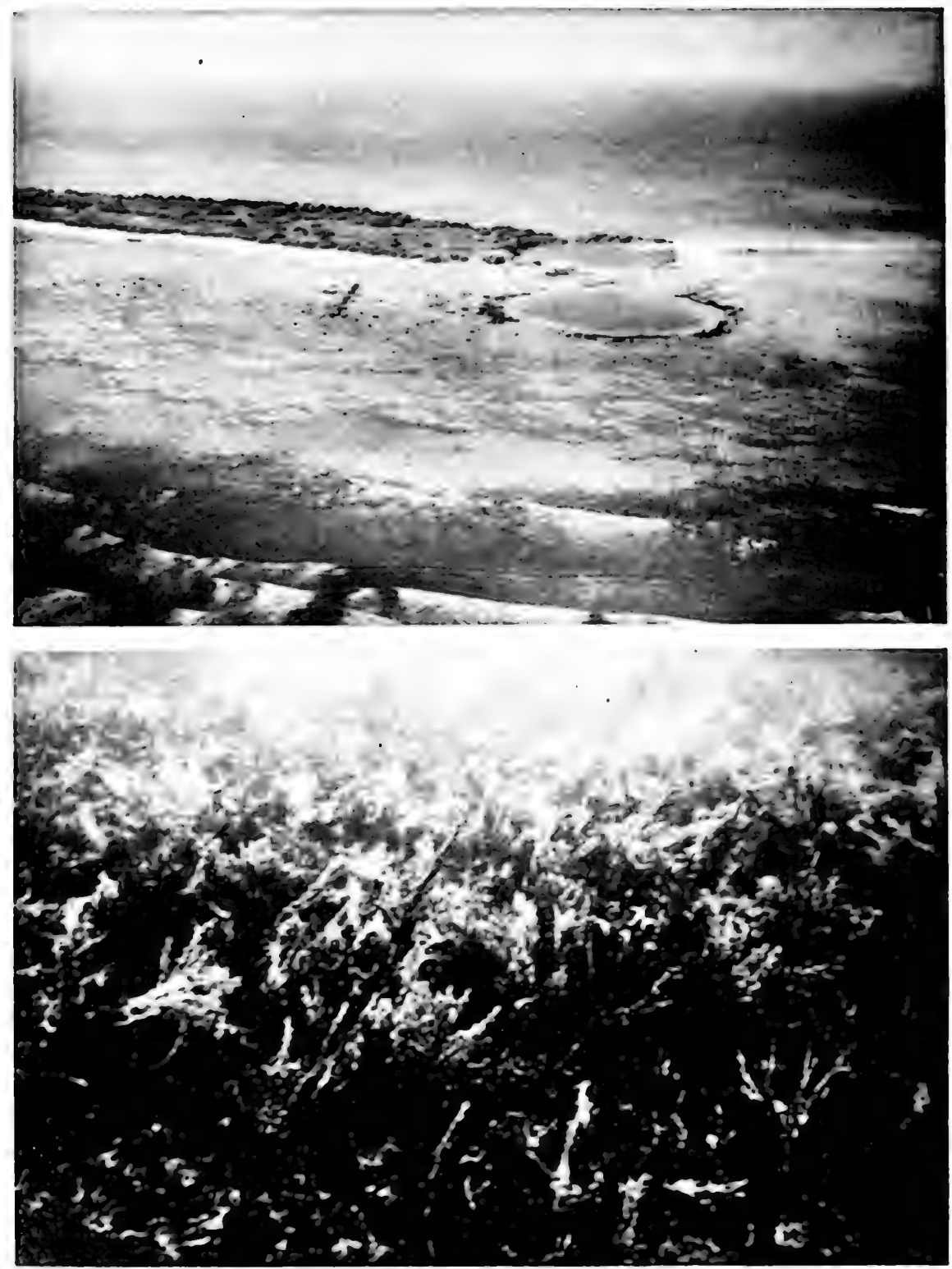

FIG. 85. (Top) Air photograph of Runit Islet showing two atom bomb craters in the reef, with LACROSSE in foreground (approximately $115 \mathrm{~m}$ horizontal diameter) and CACTUS behind it. The lagoon is in the background. (Bottom) A grove of $H$. incressata thalli in the centre of CACTUS crater, at - $11 \mathrm{~m}$. Diameter of broader segments is approximately $7 \mathrm{~mm}$. 
classes, lut the data in their present state are sufficient to suggest strongly that Halimeda contributes to the mass of a coral atoll to a significant extent compared with the coral contribution. And this observation comes from cores taken on islets or the reef ridge, not in the lagoon where the contribution of Halimeda would be largest.

The evidence of drill cores, therefore, is that a significant part of the mass of coral atolls is made of the segments of this one green alga, Halimeda. Much of the work of maintaining the atoll habitat is done by these plant populations, and the solar energy flux they transduce not only fuels food chains but also contributes to the structure of the ecosystem in a way that may be necessary to the system's homeostasis.

\section{The shedding of segments and the segment fates}

The aged, white, yellowish or greyish segments commonly are shed from the apical portions of a Halimeda thallus by a natural separation from the node, rather like a tree leaf being shed in the autumn. In sprawlers such as macrophysa and opuntia they also may be lost basally (Hillis-Colinvaux, 1977; Section VI).

Segments are also lost basally and deposited in situ when lower portions of a thallus are buried.

Initially much of the material contributed to the reef environment may be entire segments, but the segments of a few species such as macrophysa and favulosa are delicate, and sometimes may not be shed intact. It is noteworthy that these two species have the largest utricles (Hillis, 1959; Section III, IV), that in macrophysa the utricles do not adhere laterally, and in favulosa they are attached only lightly.

Segments of some of the rock growers-sprawlers, when shed, may shift deeper into the rock crevices in which the living thallus is clois-. tered. The species macrophysa is a good example, opuntia somewhat less so. Most commonly, however, the segments floor some surface in the immediate vicinity, from whence they may be transported by the currents to other sites, or they may be transported directly. The pattern of movement will depend both on their weight (branches may be involved initially as well as segments) and on the strength of the currents. Their transport out of the region may be slowed by the growth of blue-green algal mats over them (Figs 102, 103), or by various gelatinous materials within the sediments (Moore et al., 1976).

At Enewetak (Fig. 83) some of the lagoonal sediments may have originated on the fore-reef, and some lagoonally derived Halimeda material may be transported through the passes in the reef to outer areas. Such movements may be somewhat seasonally controlled, since 
both the amounts of Halimeda segments shed and the types of currents may have seasonal components. At the Enewetak sites I visited, the commonest species were macrophysa, opuntia, cylindracea, gigas, distorta, copiosa and lacunalis $\mathrm{f}$. lata. These, then, are the species, about half the total number found on the atoll reef, which would contribute most of the Halimeda sediments (Hillis-Colinvaux, 1977), but it is likely that two or three from this short list produce the bulk of the Enewetak sediments. Tydemania expeditionis, the only other calcareous green alga present at Enewetak in sizeable populations (Gilmartin, 1960, 1966;

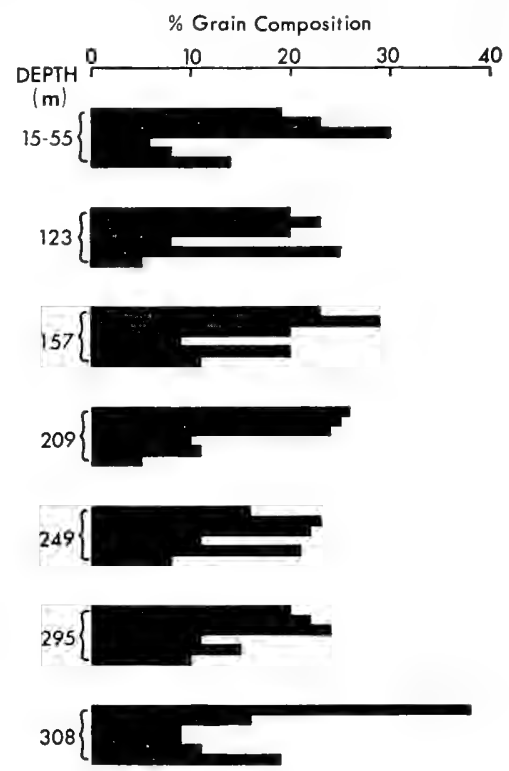

FIG. 86. Composition of sand-sized sediment from the fore-reef slope ( $-15 \mathrm{~m}$ to $-55 \mathrm{~m})$ and island slope $(-123 \mathrm{~m}$ to $-308 \mathrm{~m})$ of Discovery Bay, Jamaica. Graph bars from top to bottom represent Halimeda, calcareous red algae, corals, molluses, foraminifera and "other". (Data from Moore et al., 1976.)

Hillis-Colinvaux, 1977), also contributes to the sediments but not in an easily recognizable form.

In Jamaica most of the Halimeda sediments derived from the shallower parts of the reef, that is, from the back-reef, reef crest and fore-reef to about $-55 \mathrm{~m}$, are dammed by sill reefs at the base of the fore-reef slope (Goreau and Goreau, 1973; Goreau and Land, 1974; Noore et al., 1976). The contribution of the genus to identifiable sediments of the island slope (depth approximately $-122 \mathrm{~m}$ to $-305 \mathrm{~m}$ ) is at least as great (Fig. 86). In the suite of samples available for analysis 
from the island slope approximately $50 \%$ of the Halimeda material was identified as cryptica, $34 \%$ as goreauii, $7 \%$ as copiosa and $5 \%$ as gracilis. The deep fore-reef is a likely source for most of the cryptica (Moore et al., 1976) which is the most prominent species of this part of the reef (Fig. 86), but some may have been derived from the fore-reef, as goreauii and gracilis would appear to be, since cryptica grows in this region also (Colinvaux and Graham, 1964).

The fate of segments in the sediments varies. That many of them remain essentially entire or in sizeable pieces for some time is demonstrated in numerous samples of loose sediments, or in the whole segments that frequently floor the immediate vicinity of a grove of Halimedae. Eventually, by processes of disintegration, cementation and recrystallization, they may be bound, together with other reef organisms, into carbonate rock such as that described from the Marshall Islands (Emery et al., 1954) or the Halimeda-rich packstones and grainstones surrounding the Discovery Bay Canyon of Jamaica (Moore et al., 1976). They also may be weathered into carbonate muds early in their history, as on some of the Bahaman Banks where Neumann and Land (1975) report that calcareous green algae have produced 1.5-3 times the mass of aragonitic mud and Halimeda sand now in the $7 \mathrm{~m}$ deep Bight of Abaco.

A significant portion of the disintegration of Halimeda segments may result from the activities of sediment-feeders such as holothurians and echinoids, while living segments may be processed in situ by grazers. Grazing activity will decrease the quantity of recognizable sediments and affect the qualitative results of sediment determinations.

\section{Comparative calcium uptake by Halimeda and other reef organisms}

Goreau (1963) estimated rates of calcium uptake attained by many reef organisms over short periods. His methods were to place fresh and healthy terminal growing portions in light and dark bottles, to inoculate the bottles with ${ }^{45} \mathrm{Ca}$, and to leave them on the reef in $1-2 \mathrm{~m}$ of water for $1 \frac{1}{2}-2 \frac{1}{2}$ hours, ending in the full sunlight of noon. To be able to compare rates of calcium uptake between animals and plants of very different form he expressed all results in terms of nitrogen, determined on the same samples. When considering Goreau's results it must be remembered that the disturbance to the organism represented by the incubation procedure was very different from taxon to taxon, the light intensity being appropriate to the usual ambient conditions for some species but not for others, and so on. The data are of great interest, 


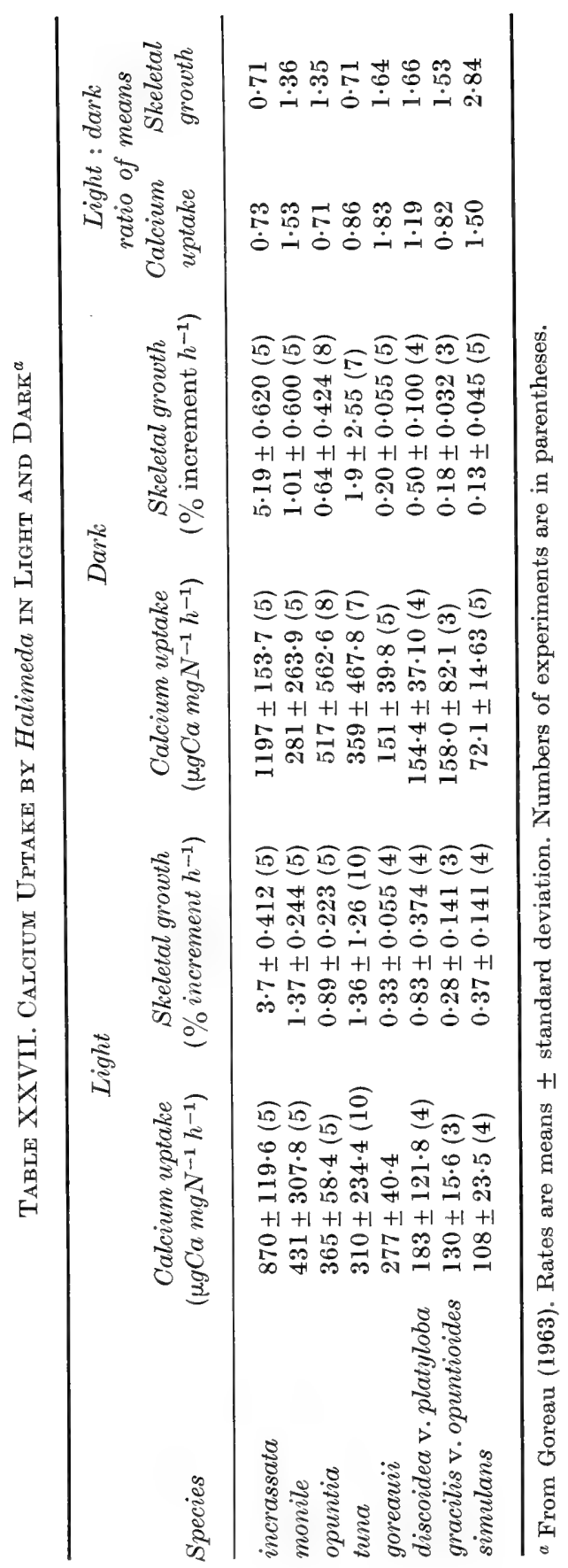


however, for the revelation that rates are remarkably similar throughout generic taxa, and for suggesting that rates of deposition in algae and in corals are greater in the light, and therefore may be associated with photosynthesis.

Table XXVII gives Goreau's results for the species of Halimedae he used and Table XXVIII for some hermatypic corals. The difference in the light : dark ratios of calcium uptake between the two groups is very

Table XXVIII. Rates of Calcium Uptake and Accretion in Hermatypic CORALS $^{a}$

\begin{tabular}{|c|c|c|c|c|c|c|}
\hline Coral sample & Uptake & $\begin{array}{l}\text { Accre- } \\
\text { tion }\end{array}$ & Uptake & $\begin{array}{l}\text { Accre- } \\
\text { tion }\end{array}$ & $\begin{array}{l}L: D \\
\text { Uptake }\end{array}$ & $\begin{array}{l}\text { Ratios } \\
\text { Accre. } \\
\text { tion }\end{array}$ \\
\hline Acropora cervicornis; & $118 \cdot 48$ & $0 \cdot 280$ & $47 \cdot 9$ & $0 \cdot 060$ & $2 \cdot 47$ & $4 \cdot 67$ \\
\hline apical corallites; & $134 \cdot 34$ & $0 \cdot 330$ & $19 \cdot 43$ & $0 \cdot 039$ & $6 \cdot 91$ & $8 \cdot 7$ \\
\hline (pooled samples) & $63 \cdot 6$ & $0 \cdot 140$ & $20 \cdot 6$ & $0 \cdot 029$ & $3 \cdot 10$ & $4 \cdot 8$ \\
\hline & $106 \cdot 2$ & $0 \cdot 272$ & $18 \cdot 4$ & $0 \cdot 04$ & $5 \cdot 8$ & $6 \cdot 8$ \\
\hline lateral corallites; & $77 \cdot 26$ & $0 \cdot 102$ & $13 \cdot 03$ & $0 \cdot 019$ & $4 \cdot 9$ & $5 \cdot 4$ \\
\hline (pooled samples) & $78 \cdot 42$ & 0.089 & $10 \cdot 16$ & $0 \cdot 011$ & $7 \cdot 7$ & $8 \cdot 1$ \\
\hline & $34 \cdot 01$ & $0 \cdot 059$ & $9 \cdot 48$ & $0 \cdot 010$ & $3 \cdot 6$ & $5 \cdot 9$ \\
\hline & $64 \cdot 3$ & $0 \cdot 102$ & $4 \cdot 90$ & 0.017 & $13 \cdot 1$ & $6 \cdot 0$ \\
\hline & $60 \cdot 7$ & 0.091 & - & - & - & - \\
\hline & $42 \cdot 2$ & $0 \cdot 066$ & 一 & - & 一 & - \\
\hline Millepora complanata; & $86 \cdot 6$ & $0 \cdot 026$ & $65 \cdot 2$ & 0.014 & $1 \cdot 3$ & $1 \cdot 9$ \\
\hline terminal $\mathrm{cm}$ only; & $77 \cdot 3$ & - & $34 \cdot 4$ & 一 & $2 \cdot 3$ & - \\
\hline (pooled samples) & $60 \cdot 3$ & 一 & $15 \cdot 2$ & 一 & $4 \cdot 0$ & - \\
\hline $\begin{array}{l}\text { Porites furcata; } \\
\text { terminal cm only; } \\
\text { (pooled samples) }\end{array}$ & $26 \cdot 7$ & 0.028 & $5 \cdot 6$ & 0.008 & $4 \cdot 8$ & $3 \cdot 5$ \\
\hline
\end{tabular}

${ }^{a}$ From Goreau (1963). Uptake in $\mu \mathrm{gCa} \mathrm{mgN}^{-1} \mathrm{~h}^{-1}$, accretion in percentage increment $\mathrm{h}^{-1}$.

apparent. Figure 87 illustrates Goreau's conclusion that there is a close affinity between the members of a plant taxon in the calcium uptake rate.

Calcium is present within the Halimeda segment not only as aragonite, but also in the cytoplasm, filament wall and spaces of the segment. Measurement of calcium uptake, therefore, is more than a measure of rate of calcification, and the variations obtained in calcium uptake rates with different labelling and washing times (Table XXIX) are partly a consequence of these different locations within the plant. Rate of calcium uptake also would be expected to vary with the environmental conditions of the experiment, and the physiological condition of the segment and plant. 


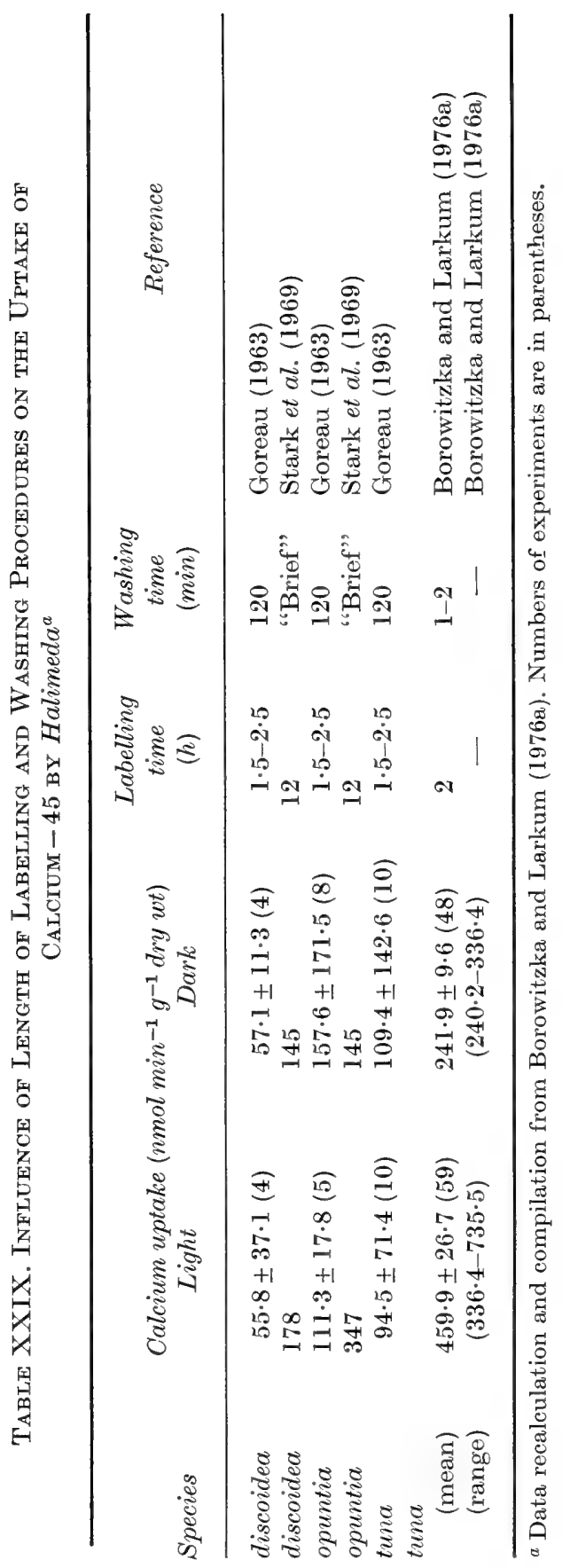




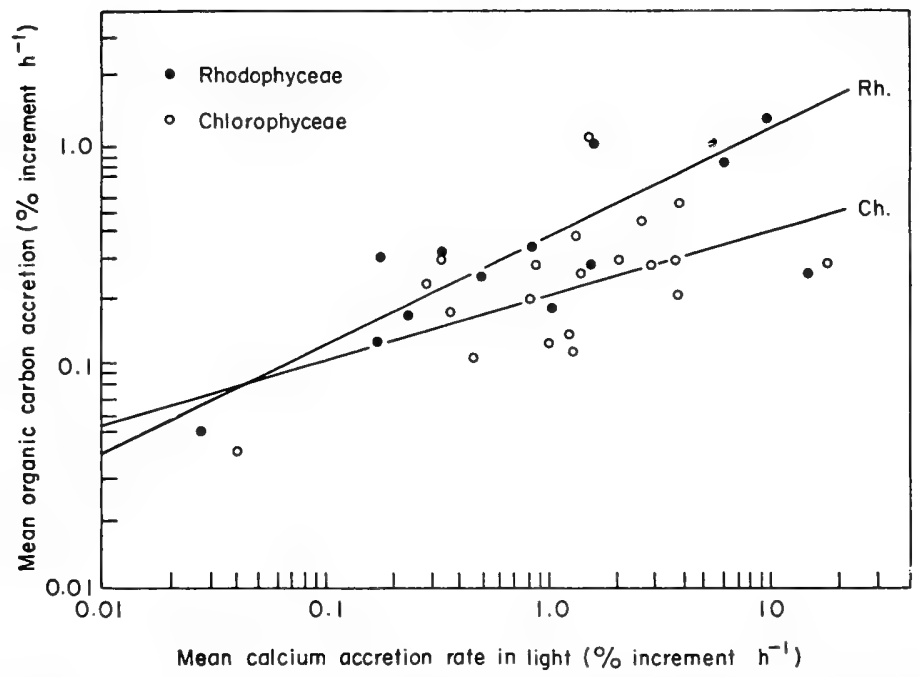

FIG. 87. Linear relationship of calcium uptake within members of a taxon. The Chlorophyta are represented by 18 taxa, the Rhodophyta by 16 . The overall linear relationship between the two functions is somewhat different in the two divisions of algae, as shown by the slopes of the regression lines. The curves were fitted by the least squares method. As the carbon accretion is related to tissue growth and the calcium accretion to skeletal growth, the slopes of the lines indicate that tissue growth rates in the Chlorophyta are proportional to the 0.3 power of the skeletal growth rate, whereas in the Rhodophyta the tissue growth rate is proportional to the 0.5 power of skeletogenesis. (From Goreau, 1963.)

It is probably unwise to attempt to convert Goreau's figures into carbonate productivities per segment, thallus or unit area. The nitrogen basis of the measurements is excellent for comparing rates of uptake at the apex in vigorously growing specimens over short time intervals, but it does not follow that estimates of nitrogen in whole plants will let these data yield carbonate fluxes from senile plants. It is noted in Table XXX that segments are at their heaviest at senescence. Calcium uptake may not be a linear function of segment age.

\section{Rate of segment production and the accumulation at Glory Be reef}

The contribution of Halimeda populations to the carbonate mass of a reef is a function of the rate at which segments are lost, the carbonate content of the segments at loss and the destruction of carbonate between loss from the Halimeda and incorporation into the sediment. Losses of carbonate from shed segments are by such processes as destruction by detritus-feeding animals (in which event the net carbonate accumulation may not be altered) and solution. These carbonate 


\begin{tabular}{|c|c|c|c|c|}
\hline Species & Description of material & $\begin{array}{l}\text { Sample } \\
\quad \text { size } \\
\text { (No. of } \\
\text { segments) }\end{array}$ & $\begin{array}{l}\mathrm{CaCO}_{3} \\
\text { per } \\
\text { segment } \\
(m g)\end{array}$ & $\begin{array}{l}\% \mathrm{CaCO}_{3} \\
\text { dry wt } \\
\quad \text { per } \\
\text { sample }\end{array}$ \\
\hline incrassata & $\begin{array}{l}\text { Eight small young thalli; pale olive } \\
\text { colour }\end{array}$ & 1051 & $2 \cdot 2$ & $57 \cdot 5$ \\
\hline \multirow[t]{5}{*}{ incrassata } & $\begin{array}{l}\text { (a) Apical }{ }^{b} \text { and subapical segments } \\
(=\text { segments } 1 \text { and } 2) \text {; dark } \\
\text { yellow-green }\end{array}$ & 110 & $1 \cdot 4$ & $66 \cdot 3$ \\
\hline & $\begin{array}{l}\text { (b) Segments 3-5 from apex; dark } \\
\text { yellow-green }\end{array}$ & 83 & $2 \cdot 3$ & $71 \cdot 0$ \\
\hline & $\begin{array}{l}\text { (c) Segments 6-10 from apex; } \\
\text { yellow-green }\end{array}$ & 43 & $3 \cdot 6$ & $70 \cdot 1$ \\
\hline & $\begin{array}{l}\text { (d) Basal segment; pale red-green, } \\
\text { average length } \times \text { width } \times \text { thickness } \\
=1 \times 0.5 \times 0.2 \mathrm{~cm}\end{array}$ & 5 & $13 \cdot 3$ & $59 \cdot 2$ \\
\hline & (e) Entire thallus & 241 & $2 \cdot 3$ & $67 \cdot 9$ \\
\hline incrassata & $\begin{array}{l}\text { Basal segment; light yellow-green, } \\
\quad 0.5 \times 0.7 \times 0.15 \mathrm{~cm}\end{array}$ & 1 & $3 \cdot 0$ & $69 \cdot 4$ \\
\hline \multirow[t]{4}{*}{ incrassata } & (a) Segments 1 and 2; light yellow-green & 96 & $1 \cdot 7$ & $60 \cdot 6$ \\
\hline & (b) Segments 3-5; light yellow green & 61 & $2 \cdot 3$ & $61 \cdot 6$ \\
\hline & (c) Segments 6-10; pale yellow & 19 & $2 \cdot 9$ & $56 \cdot 1$ \\
\hline & (d) Entire thallus & 176 & $2 \cdot 1$ & $59 \cdot 0$ \\
\hline incrassata & Light yellow-green plant & 98 & $1 \cdot 4$ & $56 \cdot 1$ \\
\hline incrassata & Dark yellow-green plant & 45 & $3 \cdot 1$ & $58 \cdot 5$ \\
\hline incrassata & Light yellow-green plant & 98 & $1 \cdot 8$ & $47 \cdot 3$ \\
\hline incrassata & Light yellow-green plant & 102 & $1 \cdot 7$ & $56 \cdot 2$ \\
\hline incrassata & Light yellow-green plant & 148 & $2 \cdot 4$ & $52 \cdot 2$ \\
\hline incrassata & $\begin{array}{l}\text { Plant recently fertile and segments } \\
\text { white }\end{array}$ & 210 & $2 \cdot 3$ & $55 \cdot 6$ \\
\hline incrassata & $\begin{array}{l}\text { Plant recently fertile and segments } \\
\text { white }\end{array}$ & 112 & $4 \cdot 2$ & $64 \cdot 3$ \\
\hline incrassata & $\begin{array}{l}\text { Plant recently fertile and segments } \\
\text { white }\end{array}$ & 98 & $2 \cdot 5$ & $67 \cdot 1$ \\
\hline incrassata & $\begin{array}{l}\text { Segments white and loose, would readily } \\
\text { be removed from plant by } \\
\text { currents; not basal }\end{array}$ & 763 & $2 \cdot 5$ & $77 \cdot 8$ \\
\hline incrassata & Segments white and fallen from plant & 299 & $4 \cdot 0$ & $83 \cdot 0$ \\
\hline \multirow[t]{5}{*}{ discoidea } & $\begin{array}{l}\text { (a) Segments } 1 \text { and } 2 \text {; light } \\
\text { yellow-green }\end{array}$ & 22 & $9 \cdot 2$ & $57 \cdot 6$ \\
\hline & $\begin{array}{l}\text { (b) Third segment from apex; light } \\
\text { yellow-green }\end{array}$ & 10 & $18 \cdot 2$ & $70 \cdot 7$ \\
\hline & $\begin{array}{l}\text { (c) Fourth segment from apex; light } \\
\text { yellow-green }\end{array}$ & 14 & $14 \cdot 0$ & $74 \cdot 1$ \\
\hline & $\begin{array}{l}\text { (d) Basal segments; pale olive, } \\
1.5 \times 1.0 \times 0.1 \mathrm{~cm}\end{array}$ & 2 & $7 \cdot 8$ & $65 \cdot 4$ \\
\hline & $\begin{array}{l}\text { (e) Entire thallus; collected at } 16 \mathrm{~m} \\
\text { depth }\end{array}$ & 48 & $15 \cdot 4$ & $66 \cdot 5$ \\
\hline \multirow[t]{2}{*}{ discoidea } & (a) Apical segments; light yellow-green & 57 & $2 \cdot 2$ & $57 \cdot 5$ \\
\hline & (b) Second segment; light yellow-green & 35 & $4 \cdot 2$ & $67 \cdot 0$ \\
\hline
\end{tabular}


TABLE XXX (cont.)

\begin{tabular}{|c|c|c|c|c|c|}
\hline \multirow[t]{5}{*}{ Species } & \multicolumn{2}{|r|}{ Description of material } & $\begin{array}{c}\text { Sample } \\
\text { size } \\
\text { (No. of } \\
\text { segments) }\end{array}$ & $\begin{array}{c}\mathrm{CaCO}_{3} \\
\text { per } \\
\text { segment } \\
(m g)\end{array}$ & $\begin{array}{c}\% \mathrm{CaCO}_{3} \\
\text { dry wt } \\
\text { per } \\
\text { sample }\end{array}$ \\
\hline & (c) & $\begin{array}{l}\text { Segments } 3 \text { and } 4 \text {, light yellow- } \\
\text { green }\end{array}$ & 27 & $6 \cdot 2$ & $64 \cdot 8$ \\
\hline & (d) & $\begin{array}{l}\text { Segments } 5,6 \text { and } 7 \text {; light yellow- } \\
\text { green }\end{array}$ & 15 & $10 \cdot 4$ & $68 \cdot 2$ \\
\hline & $(\Theta)$ & $\begin{array}{l}\text { Basal segments; light yellow-green, } \\
0.4 \times 0.5 \times 0.2 \mathrm{~cm}\end{array}$ & 9 & $17 \cdot 1$ & $57 \cdot 2$ \\
\hline & (f) & $\begin{array}{l}\text { Entire thallus; collected at } 16 \mathrm{~m} \\
\text { depth }\end{array}$ & 143 & $5 \cdot 2$ & $62 \cdot 8$ \\
\hline discoidea $^{c}$ & \multirow{2}{*}{\multicolumn{2}{|c|}{-}} & - & - & $47 \cdot 8 \pm 3 \cdot 6$ \\
\hline discoidea ${ }^{d}$ & & & - & - & $4 \overline{7 \cdot 4}$ \\
\hline goreauii & \multicolumn{2}{|c|}{ Pale yellow } & 175 & $1 \cdot 1$ & $65 \cdot 3$ \\
\hline goreauii & \multicolumn{2}{|c|}{ Pale yellow } & 102 & $1 \cdot 6$ & $65 \cdot 5$ \\
\hline goreauii & \multicolumn{2}{|c|}{ Pale yellow } & 168 & $1 \cdot 3$ & $72 \cdot 8$ \\
\hline goreauii & \multicolumn{2}{|c|}{ Pale yellow } & 151 & $1 \cdot 4$ & $68 \cdot 5$ \\
\hline goreauii & \multicolumn{2}{|c|}{ Pale yellow } & 96 & $1 \cdot 5$ & $69 \cdot 6$ \\
\hline opuntia & \multicolumn{2}{|r|}{ Reef top; outer green segments } & 152 & $9 \cdot 0$ & $72 \cdot 0$ \\
\hline opuntia & \multicolumn{2}{|r|}{ Reef top; lower whitish segments } & 474 & $6 \cdot 5$ & $61 \cdot 0$ \\
\hline opuntiac & \multirow{2}{*}{\multicolumn{2}{|c|}{ Basal }} & - & - & $84 \cdot 7 \pm 2 \cdot 05$ \\
\hline \multirow[t]{3}{*}{ opuntia ${ }^{d}$} & & & - & - & $80 \cdot 7-89 \cdot 6$ \\
\hline & \multicolumn{2}{|c|}{ Midway } & 一 & - & $55 \cdot 5-67 \cdot 4$ \\
\hline & \multicolumn{2}{|c|}{ Apical segment } & - & - & $27 \cdot 6-46 \cdot 4$ \\
\hline \multirow[t]{3}{*}{ cuneata $^{d}$} & \multicolumn{2}{|c|}{ Basale } & - & - & $22 \cdot 5$ \\
\hline & \multicolumn{2}{|c|}{ Midway ${ }^{e}$} & - & - & $31 \cdot 8$ \\
\hline & \multicolumn{2}{|c|}{ Apicale } & - & - & $32 \cdot 3$ \\
\hline \multirow[t]{3}{*}{ cuneata $^{d}$} & \multicolumn{2}{|c|}{ Basal $^{e}$} & - & - & $21 \cdot 8$ \\
\hline & \multicolumn{2}{|c|}{ Midway } & - & - & $34 \cdot 0$ \\
\hline & \multicolumn{2}{|c|}{ Apical } & $\ldots$ & - & $33 \cdot 0$ \\
\hline gracilis $^{d}$ & & - & - & - & $74 \cdot 3$ \\
\hline \multirow[t]{2}{*}{ macroloba ${ }^{f}$} & \multirow{2}{*}{\multicolumn{2}{|c|}{$\begin{array}{l}\text { Mature thalli } \\
\text { Juvenile thalli }\end{array}$}} & 44 thalli & - & $74 \cdot 3-80 \cdot 7$ \\
\hline & & enile thalli & 28 thalli & - & $70 \cdot 7-73 \cdot 3$ \\
\hline monile & & - & - & - & $71 \cdot 9$ \\
\hline $\operatorname{tuna}^{g}$ & & - & - & - & $59 \cdot 7$ \\
\hline
\end{tabular}

${ }^{a}$ All data Hillis-Colinvaux (unpublished), except as below.

${ }^{b}$ All apical segments are older than 48 hours and hence are calcified (Section VI).

c Stark et al. (1969).

${ }^{d}$ Böhm (1973a).

e Analysed by X-ray diffraction.

$f$ Merten (1971).

$g$ Prat and Hamackova (1946).

losses to shed segments are hard to estimate and may not be significant in the initial stages of forming loose sediment. The production of shed segments can be estimated if we know the carbonate content of typical segments, the rate at which a single thallus sheds segments, and standing cropdata. In this subsection the production of carbonate by the Halimeda 
populations of the Glory Be reef is estimated from these three components of carbonate production.

(a) Carbonate contents of Halimeda thalli. Figures for the amount of calcium carbonate in Halimeda thalli are given in Table XXX, and for comparison information is provided for other Caulerpales in Table XXXI. The data from our laboratory were obtained using the Hutchinson-MacLennan method (Barnes, 1959). Dried and cleaned young field specimens which I collected in Jamaica provided most of the material, but the fertile incrassata and the last two incrassata samples listed of "about to fall" and "fallen" segments were collected in a laboratory environment though much of the calcification occurred in the reefs of Jamaica. Although no uncalcified one- to two-day-old segments were included in the study, or any old white sub-basal and basal segments, the data show some of the range encountered within a species, as provided by segments of different ages and with different rates of metabolism. The variation among species, if the subtropical cuneata is excluded, is not as great, and might be even less if younger and older incrassata were better represented in the samples.

These data show, with the possible exception of cuneata, that the carbonate content of a segment is a function of segment age, which is a reasonable conclusion. Older segments generally have more carbonate than young segments, and this is particularly true of the final death and loss of segment stages, as is shown clearly in the data for incrassata, where the segments with most carbonate were those collected after death (the very heavy basal segments are specialized structures not typical of the segment flux). In interpreting the data for cuneata two factors must be considered: that apical segments older than about 48 hours generally are as physiologically mature as most other segments on the thallus (Section VI) and hence the separation into "apical" and "midway" segments is not necessarily meaningful, and that cuneata has, in addition to the regular segments, stalk and collar segments (Section IV). The stalk region is uncalcified; the extent of the aragonite deposits in collar segments has not been critically examined.

These conclusions are in agreement with results from an earlier calcification study by Wilbur et al. (1969). There must be further variations in carbonate content with local circumstance and with time of year. Thalli of some species, for example, appear to be more heavily calcified in deeper water (Fig. 88; Böhm, 1973a). But in spite of these caveats it seems reasonable to proceed to compute a carbonate flux using the estimate for a typical dead incrassata segment as given in Table XXX. 
Table XXXI. Aragonite Content of Calcareous Caulerpales Other than Halimeda ${ }^{a}$

\begin{tabular}{|c|c|c|c|}
\hline Species & Description of material & $\begin{array}{l}\mathrm{CaCO}_{3} \\
\text { in plant } \\
\quad(g)\end{array}$ & $\begin{array}{l}\% \mathrm{CaCO}_{3} \\
\text { dry wt per } \\
\text { sample }\end{array}$ \\
\hline $\begin{array}{l}\text { Penicillus } \\
\quad \text { capitatus }\end{array}$ & $\begin{array}{l}\text { Plant almost exposed at low tide; } \\
3 \mathrm{~cm} \text { tall, excl. holdfast, } 1.7 \mathrm{~cm} \\
\text { broad; young; pale olive }\end{array}$ & $0 \cdot 0565$ & $34 \cdot 4$ \\
\hline P. capitatus & $\begin{array}{l}\text { Small young plant, capitulum } 0.4 \mathrm{~cm} \\
\text { broad; dark greenish-grey }\end{array}$ & $0 \cdot 0028$ & $7 \cdot 5$ \\
\hline$P$. capitatus & $\begin{array}{l}\text { Small young plant, capitulum } 0.4 \mathrm{~cm} \\
\text { broad; dark greenish-grey }\end{array}$ & $0 \cdot 007$ & $10 \cdot 9$ \\
\hline$P$. capitatus & $\begin{array}{l}\text { Mature plant, capitulum } 3 \cdot 7 \mathrm{~cm} \\
\text { broad; light olive-grey }\end{array}$ & $0 \cdot 3778$ & $42 \cdot 0$ \\
\hline$P$. capitatus & $\begin{array}{l}\text { Mature; capitulum } 2 \cdot 4 \mathrm{~cm} \text { broad; } \\
\text { light olive-grey }\end{array}$ & $0 \cdot 1995$ & $29 \cdot 3$ \\
\hline P. capitatus & Mature; capitulum $1.7 \mathrm{~cm}$ broad & $0 \cdot 1715$ & $42 \cdot 9$ \\
\hline$P \cdot$ capitatus & $\begin{array}{l}\text { Mature; capitulum } 1.8 \mathrm{~cm} \text { broad; } \\
\text { light grey }\end{array}$ & $0 \cdot 2333$ & $46 \cdot 7$ \\
\hline P. capitatus & $\begin{array}{l}\text { Mature; capitulum } 2 \cdot 3 \mathrm{~cm} \text { broad; } \\
\text { light grey }\end{array}$ & $0 \cdot 2070$ & $41 \cdot 4$ \\
\hline P. capitatus ${ }^{b}$ & - & - & $55 \cdot 9$ \\
\hline P. ad lamourouxii & $\begin{array}{l}\text { Mature; capitulum } 3.5 \mathrm{~cm} \text { broad; } \\
\text { light grey }\end{array}$ & $0 \cdot 2604$ & $34 \cdot 6$ \\
\hline P. lamourouxii & - & - & $45 \cdot 9$ \\
\hline$P \cdot$ pyriformis $^{b}$ & $\longrightarrow$ & - & $58 \cdot 9$ \\
\hline $\begin{array}{l}\text { Rhipocephalus } \\
\text { phoenix }\end{array}$ & - & - & $46 \cdot 2$ \\
\hline$R . s p .^{b}$ & - & 一 & $54 \cdot 4$ \\
\hline Udotea flabellum & $\begin{array}{l}\text { Plant almost exposed at low tide; } \\
\text { light yellow-green }\end{array}$ & $0 \cdot 0553$ & $33 \cdot 3$ \\
\hline U. flabellum & Light yellow-green & $0 \cdot 0708$ & $42 \cdot 6$ \\
\hline U. flabellum & $\begin{array}{l}\text { Light yellow-green; holdfast shared } \\
\text { with preceding plant }\end{array}$ & $0 \cdot 1416$ & $47 \cdot 2$ \\
\hline$U \cdot$ flabellum $^{b}$ & -1 & - & $37 \cdot 9$ \\
\hline$U \cdot$ conglutinata $^{b}$ & - & - & $31 \cdot 5$ \\
\hline$U$. cyathiformis $^{b}$ & - & - & $35 \cdot 5$ \\
\hline U. ad spinulosa & Light yellow-green & $0 \cdot 0422$ & $38 \cdot 1$ \\
\hline$U \cdot$ wilsonii $^{b}$ & - & - & $37 \cdot 9$ \\
\hline
\end{tabular}

${ }^{a}$ All data Hillis-Colinvaux (unpublished), except as below.

${ }^{b}$ Böhm (1973a).

(b) Yield of carbonate as dead segments from $\mathrm{H}$. incrassata thalli. The mean carbonate content of 299 fallen incrassata segments is $4.0 \mathrm{mg}$ (Table XXX). We now need to know how many such segments an incrassata plant produces in a year, and for this the data are very 

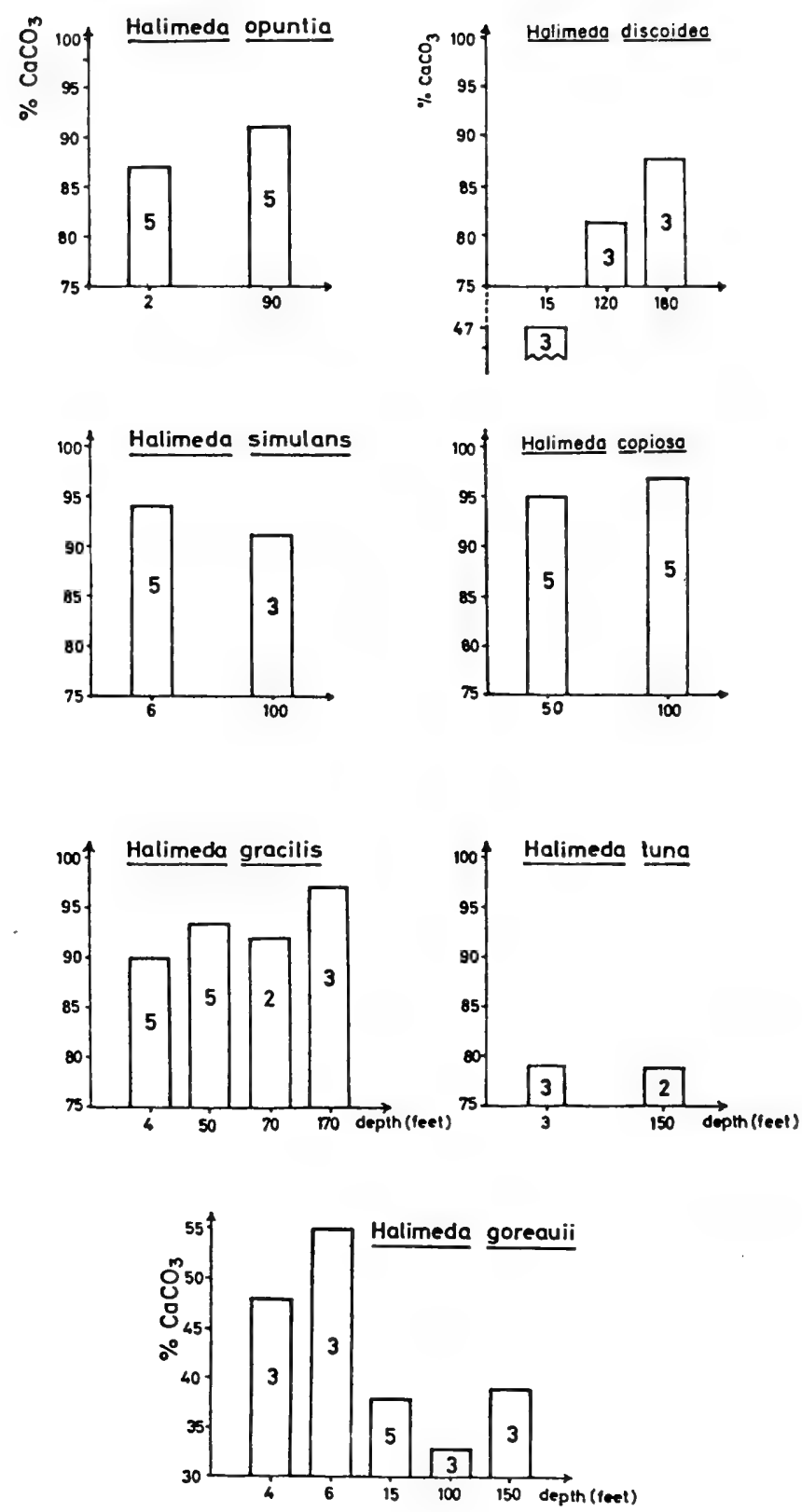

FIG. S8. Calcium carbonate content of some Jamaican Halimedae in relation to depth. The number of collections analysed is given in each box of the graph. (From Böhm, 1973a.) 
scanty. There are no field data beyond the general observation that white moribund segments are observed on wild plants, that plants do die as entire thalli and that death of the entire thallus always follows the release of gametes. None of these observations of wild plants allows estimates of either the frequency of death or the frequency at which single segments are shed. For the best approximations it is necessary to use data from our laboratory cultures.

In the aquaria cultures individual plants of incrassata have lived for as long as two years, though the latter part of such a life seems to be spent covered in epiphytes, or under attack from epiphytes which have to be removed at frequent intervals. Plants in that condition have been seen in the field, but they are not usual and it is hard to believe that they can persist. On the other hand, there is no evidence for rapid turnover of populations as occurs in culture with Penicillus of which there may be four or six laboratory generations per year. For want of better data it is, perhaps, conservative and best to assume that a typical wild incrassata would live out the more vigorous part of its laboratory term of months, which allows us to assume that it contributes its total stock of segments in the white senile condition in a year.

The mean number of segments on 15 incrassata thalli sacrificed for other purposes in the laboratory was 131. These were field-grown incrassata that had been in the laboratory only a few weeks, though some were in one sense "mature" since they became fertile. However, the field collections were always of smaller plants, because these were best suited to the aquaria, and the figure of 131 segments per plant is biased towards the small side. It seems reasonable to assume that the typical incrassata thallus in the wild has 200 segments when full grown.

The flux of carbonate to reef sediments from an incrassata population, therefore, is $200 \times 4 \mathrm{mg}=0.8 \mathrm{~g}$ per thallus per year. This and other conversion factors for computing productivities from Halimeda census data are given in Table XXXII.

(c) Carbonate flux from Halimedae at Glory Be reef. The Halimeda census data for Glory Be reef that were used when calculating the flux of reduced carbon can be used for calculating the carbonate flux also, if we accept some simplifying assumptions. All Halimedae of the reef are considered to be equivalent to incrassata thalli, and the rate of loss of senile segments is considered to be constant at all parts of the reef. The more dangerous assumption is that all of the Halimedae are equivalent to incrassata, though the errors introduced may not be great in the light of the other uncertainties. Table XXX shows that of the two common rock-growing Halimedae of cushion life-form in the 
Table xxyil. Conversion Factors Computing Productrvities from Halimeda Census Data

Carbonate production $=0.8 \mathrm{~g}$ carbonate thallus ${ }^{-1} \mathrm{yr}^{-1}$

Productivity (net) $\quad=2.5 \mathrm{mg} \mathrm{C}$ thallus ${ }^{-1} \mathrm{~d}^{-1}$

$1 \%$ cover (incrassata) $=10$ thalli $\mathrm{m}^{-2}$

Turnover time is $\frac{1}{2}-3$ generations $\mathrm{yr}^{-1}$

area, opuntia segments are heavier (mean weight of $\mathrm{CaCO}_{3} 7 \cdot 75 \mathrm{mg}$ ) than incrassata segments, and goreauii segments are lighter (mean $1.38 \mathrm{mg}$ ). A single specimen of goreauii in the laboratory collection had 175 segments and a single specimen of opuntia 626. An opuntia plant, however, covers more space than an incrassata plant. With these great uncertainties, it seems reasonable to base a rough estimate on converting cover data to incrassata thalli and proceeding on the assumption that each thallus contributes the computed $0 \cdot 8 \mathrm{~g} \mathrm{CaCO}_{3} \mathrm{yr}^{-1}$ to the reef.

The estimated reef population of 1110300 Halimeda plants then contributes $888 \mathrm{~kg}$ of carbonate per year, or approximately $90 \mathrm{~g} \mathrm{~m}^{-2}$ $\mathrm{yr}^{-1}$ (area $9840 \mathrm{~m}^{2}$, Table XXI). The equivalent rate of sedimentation, assuming $60 \%$ porosity as did Stockman et at. (1967), is $4066 \mathrm{~mm} \mathrm{yr}^{-1}$. This was on a reef where the average Halimeda cover was $10 \%$, although opuntia populations of shallow rocks reached local densities of $90 \%$ cover.

(d) Comparison with other calculations and possibilities of error. Neumann and Land (1975) made similar calculations for the whole Bight of Abaco in the Bahamas, a shallow basin of $2750 \mathrm{~km}^{2}$. With an average density of Halimeda plants of $25 \mathrm{~m}^{-2}$ they estimated the standing crop of the whole Bight of Abaco to produce $25.47 \times 10^{9} \mathrm{~g}$ carbonate. If we assume one crop a year, as was done above, this gives a carbonate flux of $9 \cdot 26 \mathrm{~g} \mathrm{~m}^{-2} \mathrm{yr}^{-1}$, or one-tenth of the estimate for the Glory Be reef. The discrepancy is undoubtedly due to the different Halimeda densities. A density of Halimeda of only 25 plants $\mathrm{m}^{-2}$ is low unless it is a species like macroloba. Sand-dwellers may grow at densities 20 times this, and higher densities still are represented by the sprawling thalli of opuntia plants growing on rocks at densities of $90 \%$ cover. The figures actually used for the Bight of Abaco work are in fact several times larger than the $9 \cdot 26 \mathrm{~g} \mathrm{~m}^{-2} \mathrm{yr}^{-1}$ calculated from the Abaco data here because it was assumed that there would be 6-12 crops of Halimeda per year. As is argued above, there is no evidence for such rapid turnover in Halimeda. 
Stockman et al. (1967) made a similar budget for the production of lime muds in Florida by Penicillus, concluding that Penicillus contributed between $3 \mathrm{~g}$ and $25 \mathrm{~g}$ carbonate $\mathrm{m}^{-2} \mathrm{yr}^{-1}$. These results depended on very low population densities of between two and eight plants per square metre, but the passage of six generations a year. This generation time is in accord with my experience of growing Penicillus in laboratory culture, it having a shorter life-cycle than Halimeda. But it is possible for Penicillus to exist at much higher densities than were found in the Florida study, when the total Penicillus carbonate production could equal that of the Halimedae of Glory Be reef.

It is evident that calculation of the carbonate flux produced by calcareous green algae is sensitive both to population density and turnover times. Population densities vary by two orders of magnitude, with commensurate effects on calculated carbon flux. Errors in estimating turnover time ought to be reduced by the realization that Halimeda is predominantly a long-lived alga. We need field data for the typical length of life of the various species, but it seems likely that more than one to three generations a year, depending somewhat on species, will be found to be unusual. Some additional data are provided by the observations of R. Spies, P. Lamberson and myself on an experimental plot of cylindraceae in Enewatak Lagoon, in which over $70 \%$ of the original thalli were present at the end of 4 months. Granted the errors that can be introduced by population densities and length of life, the agreement of the calculations of Chave et al. ( $100 \mathrm{~g}$ carbonate $\mathrm{m}^{-2} \mathrm{yr}^{-1}$ ) with the results from Glory $\mathrm{Be}$ is possibly fortuitous.

(e) Carbonate production in whole reefs: contribution of Halimeda. In the analysis of the mass of an atoll given above and in Fig. 84, it was suggested that the growth of a reef should be considered in two parts: the reef ridges and the lagoonal areas. In the former there is very active growth of the coral assemblage and encrusting algae, in the latter there is a large contribution of Halimeda and other green macrophytes. Smith and Kinsey (1976) likewise divided reef systems into two components, and further suggest that each has a characteristic modal rate of carbonate production.

Smith and Kinsey (1976) give calculations of carbonate production for the Enewetak reef ridge based on measures of the changing alkalinity of the waters flowing over the reef. Their measures are thus comparable to the measures of carbon fixation by flow-respirometry, and give a direct measure of carbonate accumulation on the section of the reef accessible to the technique. Accumulation on the reef ridge is given as $4 \mathrm{~kg} \mathrm{~m}^{-2} \mathrm{yr}^{-1}$. This is contrasted with estimates for lagoons 
and other still-water sites of $0.8 \mathrm{~kg} \mathrm{~m}^{-2} \mathrm{yr}^{-1}$. Where the lagoon is of considerable size, as in many atolls and barrier reefs, this bimodal division of production rates indicates that the lagoonal environments probably contribute most to the mass of the reef, since the area of the lagoon only has to be four to five times that of the reef ridges for its total contribution to be the larger.

Production of carbonate in lagoonal and still-water areas is principally divided between coral pinnacles, Foraminifera, chemical precipitation of calcite and the calcareous green algae. It is, therefore, of interest to see what densities of Halimeda are required to yield a significant part of the carbonate production of $0.8 \mathrm{~kg} \mathrm{~m}^{-2} \mathrm{yr}^{-1}$ found by Smith and Kinsey (1976) for the lagoon as a whole.

The incrassata production rate was calculated above to be $0.8 \mathrm{~g}$ per thallus per year. For the total production of a lagoon to be provided by sand-dwelling Halimedae growing on horizontal surfaces would require a population density of 1000 plants $\mathrm{m}^{-2}$. Apparently the highest densities so far recorded are 500 plants $\mathrm{m}^{-2}$ in a few "clearings" among the Thalassia beds of the Glory Be reef. Dense populations in shallow water at Glory Be, Enewetak and elsewhere of an incrassata-cylindracea type of thallus have about 100 plants $\mathrm{m}^{-2}$. A clearly visible growth of Halimeda over the floor of a whole lagoon, therefore, would produce about one-tenth of the total estimate of Smith and Kinsey. This is by no means impossible and there are reports in the literature of lagoon floors having what seem, from a ship-board collecting station, to be dense covers of Halimeda (Emery et al., 1954). On two dives to the floor of the Enewetak Lagoon in 1975, however, I found that much of the visible terrain was almost devoid of Halimedae. Shallower lagoons (Enewetak is from $40 \mathrm{~m}$ to $70 \mathrm{~m}$ deep), however, may have denser stands. But there are also other factors to be taken into account.

The above calculations neglect two sources of Halimeda segments that may well constitute the major part of the total Halimeda contribution: the rock-growing opuntia-type Halimedae of the pinnacles and of the deep fore-reef. Halimeda opuntia at Glory Be attained local cover densities of $90 \%$, which is roughly equivalent to an incrassata population of 900 plants $\mathrm{m}^{-2}$, and, since the sprawling life-form of these plants always tends to produce high cover, like the tillering patterns of grasses, local populations always tend to be dense. Some of the pinnacles at Enewetak support considerable populations of Opuntioid forms, and the total vertical faces of the pinnacles must be very large. With over 2000 pinnacles in the lagoon, if the lagoon were drained the aspect would be rather like the teeth of a rubber hair-brush. Without direct data on segment production by these rock-growing forms (not so far 
available because of the difficulty of maintaining them in culture) it is not possible to calculate their contribution, but there is clearly the possibility for a large component of total production to be included.

And to the pinnacle Halimedae must be added those of the deep fore-reef. In Jamaica, at depths of $-61.5 \mathrm{~m}$ to $-91 \mathrm{~m}$, there are very dense populations of cryptica and lesser populations of copiosa (an Opuntioid form) which locally attain 60\% cover (Moore et al., 1976). It seems likely that similar growths are prevalent outside the fore-reef of atolls, though no census data are available because of the difficulties of diving operations at these sites. Some considerable part of the production of the deep fore-reef, which contributes heavily to the sediments of the island slope of Jamaica (Fig. 86), may be swept up in the vigorous onshore currents of these atolls, to be deposited later in the still waters of lagoons.

In conclusion it may be said that the bimodal production suggested by Smith and Kinsey (1976) seems to accord with the drill-core data and the scanty Halimeda production figures. It is necessary to look at the older literature describing very high production figures for the whole reef, like those collected by Chave et al. (1971), with the realization that they do not imply actual growth of coral reef ridge itself, but the carbonate accumulations of the whole reef system. The largest part of this accumulation is probably in the large areas of the quiet lagoons. Halimeda is a very significant contributor to this accumulation both from the production of sand-dwelling plants in shallow water, and from the rock-hanging forms of the pinnacles and possibly of the deep fore-reef.

\section{Halimeda Distribution in two Reef Systems}

This chapter describes two reef systems from the point of view of Halimeda, or at least from the point of view of an investigator asking questions about reefs as the habitat of Halimeda. As with all reef studies there are constantly in the background questions of how the reefs were built, but these questions are again likely to be phrased from the point of view of Halimeda: "In what way have the Halimeda populations contributed to the structure and mass of the reef?" It is suggested that this might be a timely bias, since the great majority of studies on coral reef systems have been designed on the unspoken assumption that the essential process in reef-building is the construction of the coral framework. It has already been mentioned (Section IX) that the classic studies on reef productivity, like those of Sargent and Austin (1954) and Odum and Odum (1955), are of small sections 
of inter-island reefs in which Halimeda is entirely absent or a minor component. And yet Halimeda is one of the principal contributors to reef structure, sometimes perhaps the most important one (Section, IX).

Two reef systems have been examined with Halimeda principally in mind. They are a section of the fringing reef on the north shore of Jamaica where a Halimeda census was made (Hillis-Colinvaux, 1972), and Enewetak Atoll where two Halimeda investigators have dived.

\section{A. The Glory Be reef, Ocho Rios, Jamaica}

"Glory Be" is the name of a house near the village of Ocho Rios, sited roughly in the centre of the north shore of Jamaica. The patch of reef approached from the house was chosen for this study because two headlands marked off a convenient length of reef (Fig. 89), and because the high cliff of fossil limestone gave a vantage point which greatly aided mapping of the various regions of the reef. The approximate coordinates of the reef section are $77^{\circ} 0^{\prime} \mathrm{W}, 18^{\circ} 24^{\prime} \mathrm{N}$.

The reef at Ocho Rios is part of the Jamaican fringing reef which has been extensively studied and described by Goreau and members of his laboratory working from the nearby Discovery Bay (Goreau, 1959; Goreau and Goreau, 1973), and I first became interested in the northshore reef system when conducted overit by T.F. Goreau in 1962 . I made a preliminary survey of the Glory Be reef in September 1968 (when the water was somewhat disturbed from the passage of a hurricane), and carried out the main part of the census in three weeks in June 1969. The census extends out only to the beginning of the outer channel or moat zone ( 7 in Fig. 89), being extended beyond this down to a depth of $20 \mathrm{~m}$ (moat, buttress and fore-reef) only by qualitative observation, supplemented by observations at our other work site of Runaway Bay. Qualitative descriptions of Halimeda populations down to about $70 \mathrm{~m}$ are given in Goreau and Goreau (1973). Seasonal assays of Halimeda populations at these greater depths are urgently needed.

A profile through the Glory Be reef is given in Fig. 90, the numbered parts of which are included on Fig. 89 and in Table XXXIII. These reef zones need to be understood in the context of the reef nomenclature established by Goreau and his laboratory, the usages of which have changed slightly over the years. In Table XXXIII the Goreau equivalents are given as they appear in Goreau and Goreau (1973). The comparison of the Glory Be nomenclature with Goreau's reveals not only a finer classification of the near-shore zones at Glory Be, but also some added features of the Glory Be reef system not present in Goreau's generalized model. 


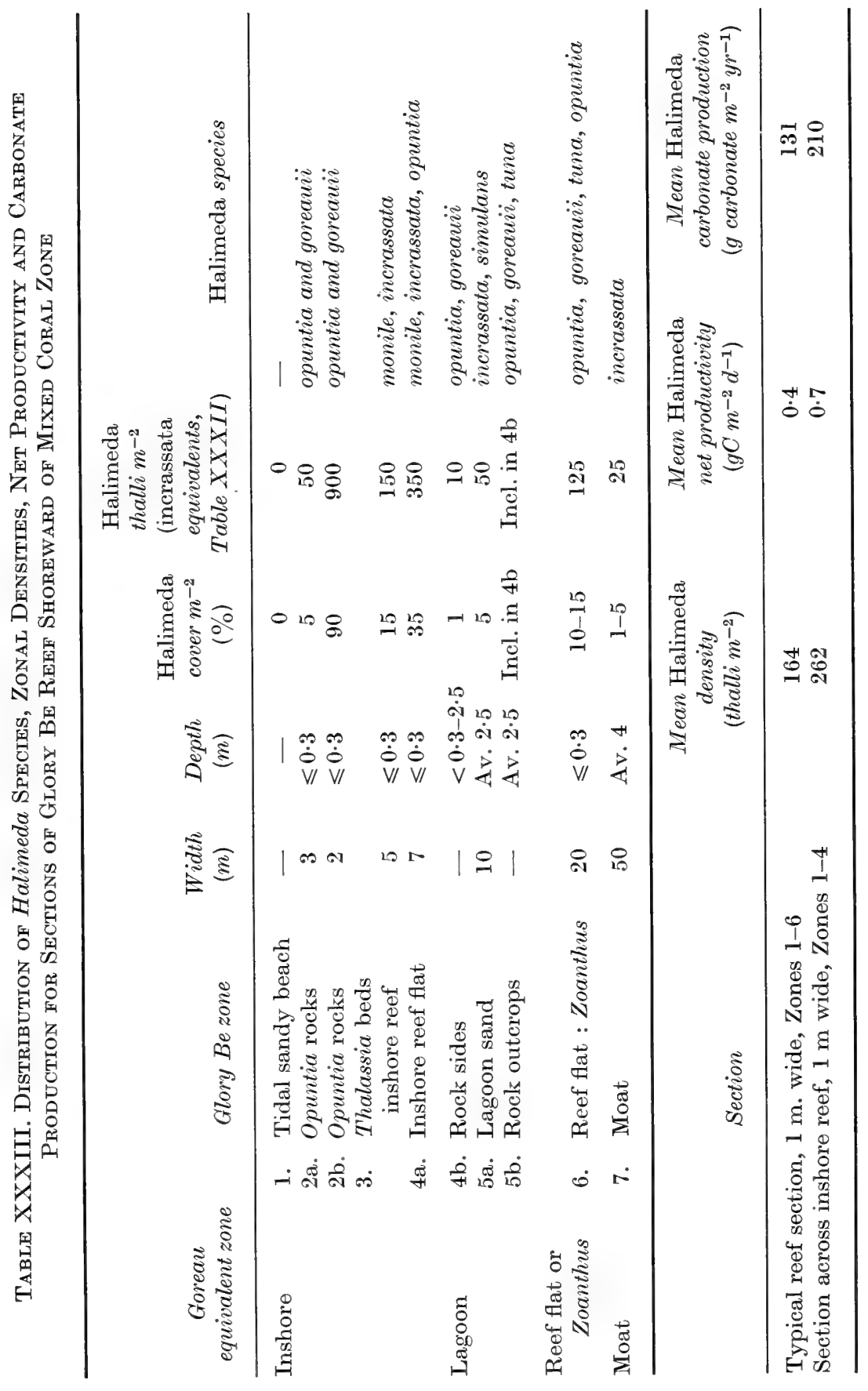




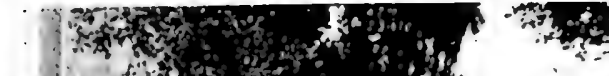

$\underline{2}$

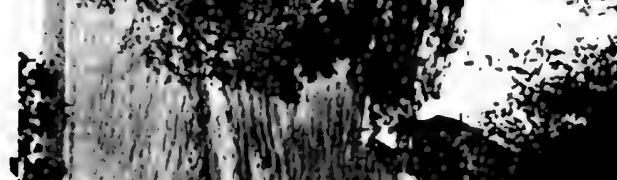

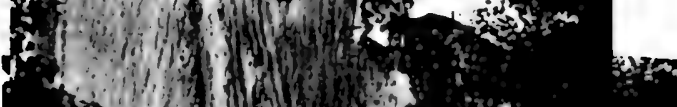

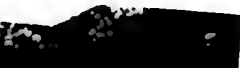

$\therefore$ - in

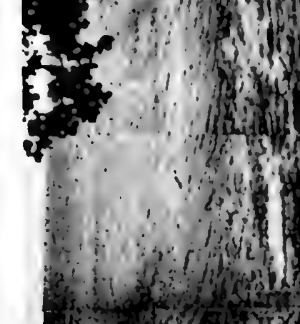

N

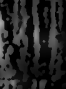

(1) 113

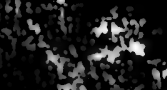

(1)

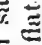

三

$\equiv \hat{\Xi}$

$\ddot{\Xi} \approx$

$\equiv$

百市

\%

宕宽

跣

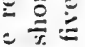

至金芒

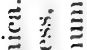

E

ఏうう

ชั

$\div \equiv$

范

$=\equiv$

官三

$=0$

$\cong$

흘

$\therefore=$

胥蓄

을

气

碂

药

苛范

$\div$

菃

흘

牙

药

ㄹ.

蓄莑

音

$\equiv$

$\sim$ - 5 (15 1 ind

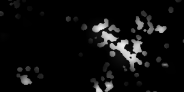

क人

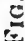




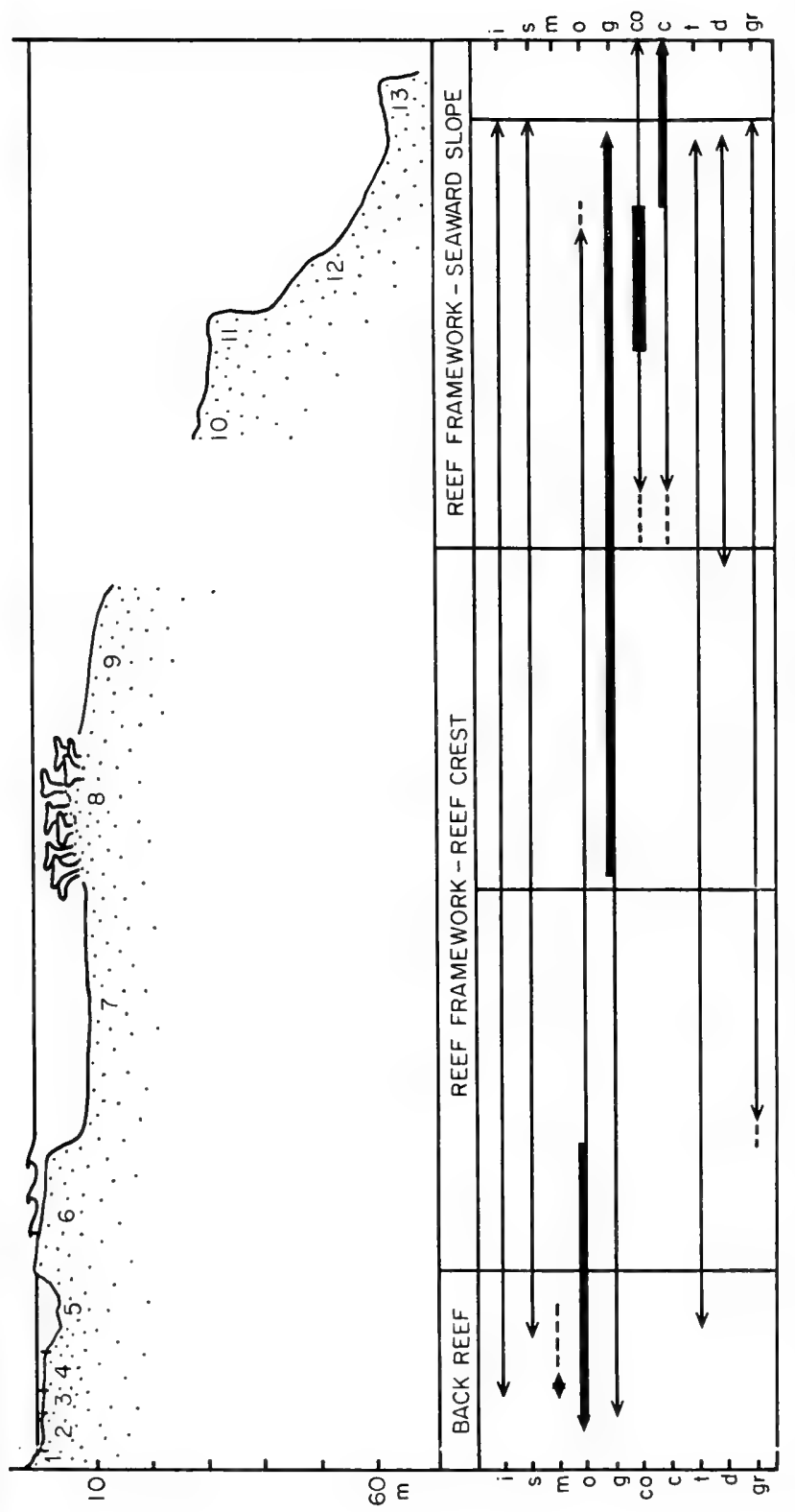

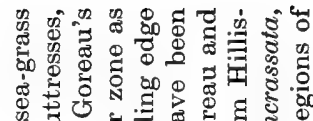

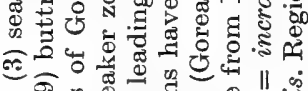

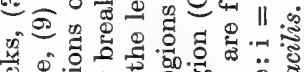

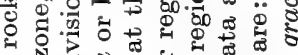
ᄂ

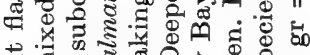
.ํㅕㄹ

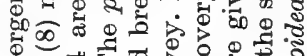

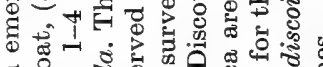

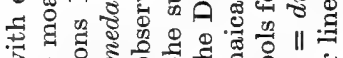
E比部워

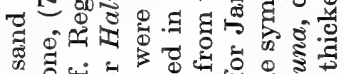
क्ष

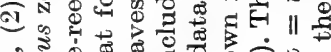

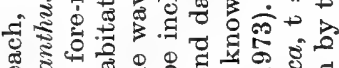

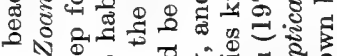

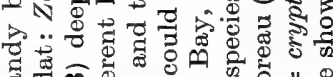

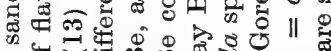
过

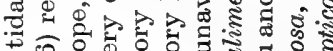

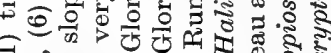
E.

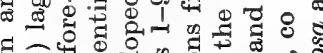

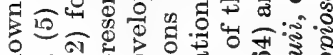
운

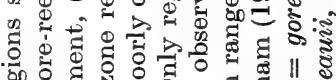

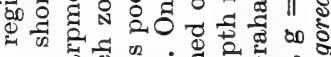

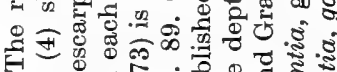

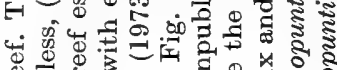
क्ष t. ต

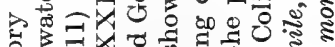

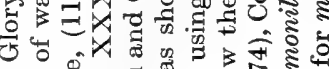

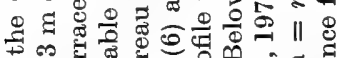

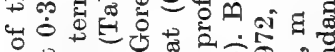

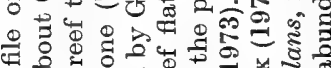

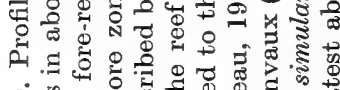

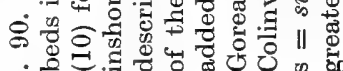
离 


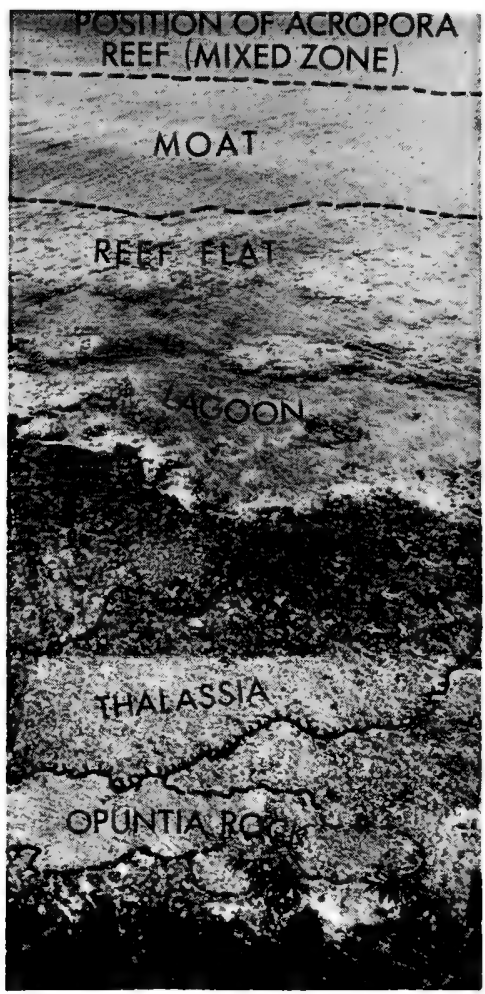

FIG. 91. Central section of panorama of Glory Be reef, with specimen areas of Thalassia and opuntia rocks outlined. Textural changes in panorama outside the reef flat: Zoanthus zone do not demarcate the bottom features accurately. The position of the Acropora, north of the moat, is sketched in.

Zones 1-4 of the Glory Be classification are all subdivisions of what Goreau calls the inshore zone. These subdivisions each represent a very different habitat, and it is suspected that the four zones together are important to the total carbonate, carbon and Halimeda-segment flux of the reef. The combined inshore zone at Glory Be is separated from the shore side of a reef flat: Zoanthus zone (6) by a lagoon (5) as in the Goreau typical reef. During the two periods of work at the reef, waves did not break at the palmata zone, even though in Goreau's general model they do, and he regards the palmata zone and the breaker zone as one and the same. At Glory Be the waves broke at the leading edge of the reef flat (Fig. 89), after crossing the inundated Acropora cervicornis and palmata corals or mixed zone (8) and the moat (7). For this reason we originally called the Glory Be zone (7) "the breaker zone", and it is so described 
in Hillis-Colinvaux (1974). Goreau's (1973) palmata zone has a more restricted interpretation than in the 1959 description of the reefs, where it is applied to the entire region between reef flat and buttresses, which in turn are followed by a cervicornis zone. The palmata zone, as delimited by Goreau and Goreau (1973) (their region 5), is poorly developed at Glory Be.

There is no need for concern that the obvious divisions of the Glory Be reef do not match precisely with Goreau's generalized model because every section of reef can be expected to be modified to local circumstances of tide, current and coastal morphology. And yet there is, perhaps, a question concerning the line at which the waves break; is the pattern at Glory Be an aberration because of the sheltered character of the bay?

\section{Methods of census}

The zonal boundaries in this system are distinct and can easily be identified both in the water and on the panorama (Fig. 89) made from the top of the cliff. The lengths and widths of the principal features of Fig. 89 were measured by identifying salient features such as individual rocks from the top of the cliff and on copies of the panorama, then taping the distances directly with a nylon line. Twenty-four lengths measured in this way were sufficient to compute the surface area occupied by each zone. Rough estimates for the mean width of each zone can also be made from a copy of the panorama on which the measured distances are superimposed, allowing the calculation of the relative areas of each zone along a metre-wide transect from the cliff to the outer channel. These estimates (Table XXXIII) are obviously crude, but the errors are probably not important for extrapolation purposes since reef-to-reef fluctuations in relative zone areas must be very large.

Estimates of densities of Halimeda and other algae were made by quadrat sampling, sets of nearest-neighbour samples and subjective estimates of percentage cover. A convenient quadrat for dense populations of Halimeda is a rectangle of plexiglass placed on top of the Halimeda population, when it is easy to count the plants underneath it. Nearest-neighbour samples were most convenient in sandy areas where Halimeda populations were sparse and where the swell made it hard for a diver to keep station. The diver chose one plant as it drifted into view, placed one edge of a steel rule against it, and pivoted to find the other plant of the pair. Estimates of percentage cover were found to be the only practicable way of assessing densities of the sprawling 
plants of opuntia and goreauii. The census occupied about 30 hours of bottom time.

In order to compute carbon and carbonate fluxes for the various portions of the reef it was necessary to convert our laboratory measurements on incrassata populations from fluxes per thallus to fluxes per unit of cover. To arrive at a conversion factor we estimated the percentage cover of incrassata populations of known density. A density of 500 incrassata $\mathrm{m}^{-2}$ covers $50 \%$, so $100 \%$ cover is taken as the equivalent of 1000 thalli $\mathrm{m}^{-2}$. The crudeness of this conversion for opuntia is selfevident, and it may be that the close-packed branches of a $90 \%$ cover stand of opuntia produce considerably more than would 900 incrassata plants. Without direct measures of the productivities of sprawling forms, however, there seems to be no way of making a more accurate estimate.

\section{Productivities at Glory Be}

The productivity of the parts of this reef has been discussed in Section IX, and the principal data are given in Tables XXI and XXXIII, with some of the results of the census being included in the latter. Conversion factors for computing productivities from Halimeda census data were derived from the Glory Be survey and the associated laboratory work and are given in Table XXXII.

\section{Narrative description of Glory Be reef}

At least ten species of Halimeda live in the reefs of the north shore of Jamaica, six of which (opuntia, goreauii, gracilis, tuna, incrassata and simulans) grow with varying success over much of the depth range of approximately $-0.3 \mathrm{~m}$ to $-60 \mathrm{~m}$ (Fig. 90 ; Section IV), or to the start of the deep fore-reef. None is regularly exposed at low tide. Of the remaining species, monile appears to be restricted to shallow water, and discoidea is limited essentially to the fore-reef and fore-reef slope (although it grows in shallow water elsewhere in the Caribbean). The thalli of discoidea sometimes appear to be growing in sand, but on closer examination they are invariably attached to some rock outcrop concealed by a thinnish veneer of sand. The species copiosa and cryptica are restricted mostly to the fore-reef slope and upper part of the deep fore-reef, that is, to depths of approximately $25-100 \mathrm{~m}$. Halimeda copiosa, however, does occur in shallower water in the Pacific (see below and Section IV). These two species are the only ones to establish sizeable populations on the deep fore-reef (Goreau and Goreau, 1973), with cryptica being the more abundant. 
(a) Hard substrates. Proceeding seaward onto the reef from the shore, the first Halimeda species to appear, whether it be a member of the Rhipsalis, Opuntia or Halimeda sections, is determined to a large extent by the substrate available. On the Glory Be reef it is rock, and sprawling over it are large, dense patches of opuntia, sometimes just covered by most low tides, with holdfast filaments developing frequently from between segments where the thallus makes contact with the substrate. When the mapping-transect study was carried out, this species occupied much of the surface of the very shallow inshore rock (regions 2, 4 and 6; Figs 89-91, and Fig. 92) as well as the rock sides of region 2 , and rock sides together with coral outcrops of region 5 . The total Halimeda cover of the very shallow inshore rocks (region 2), given in Table XXXIII, was the highest encountered in the parts of the reef

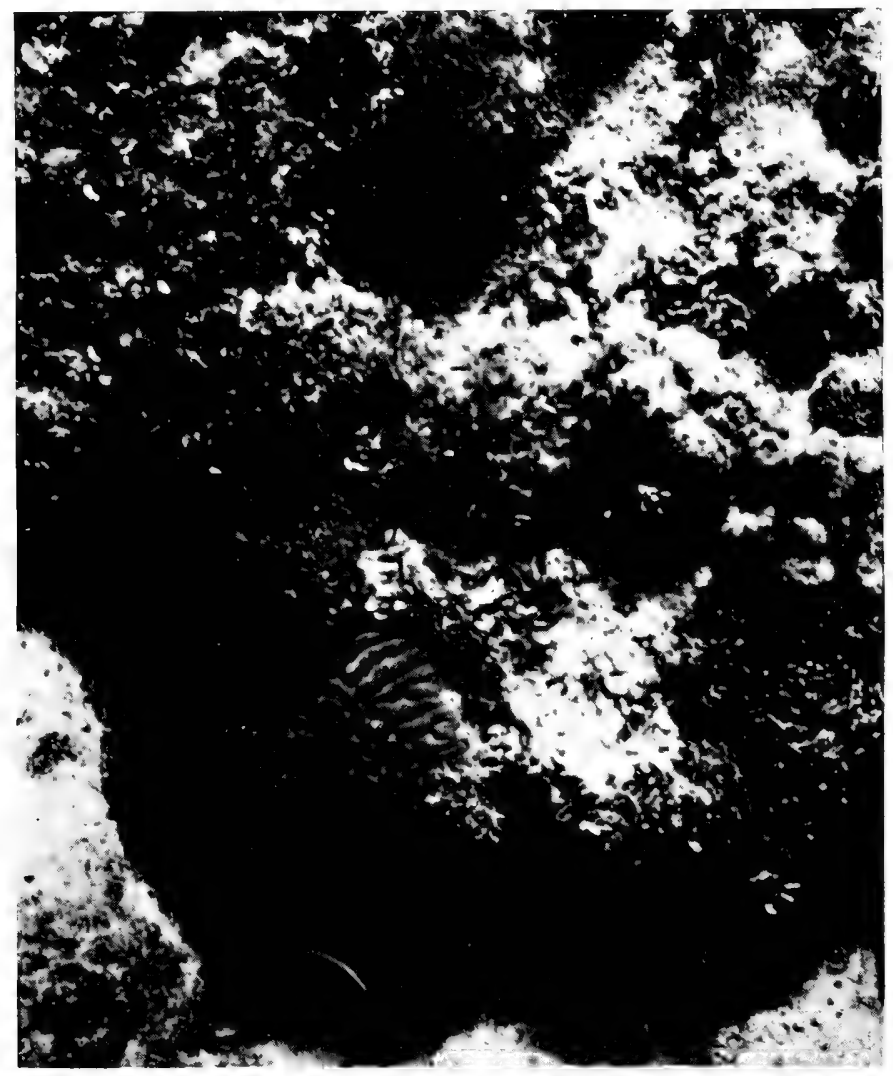

FIG. 92. Clumps of opuntia providing, at the site shown, about $50-60 \%$ three-dimensional cover on rocks of the inshore reef of Glory $\mathrm{Be}$, in about $1 \mathrm{~m}$ of water. The breadth of most of the segments shown is $5-8 \mathrm{~mm}$. 
surveyed. Beyond the very shallowest regions goreauii sometimes accompanied opuntia, but seemed to be restricted to certain exposures on the coral rocks in shallow water. Past the reef flat (6), goreauii was more conspicuous and tended to replace opuntia in the deeper regions of the reef (Fig. 90).

(i) Regions of low Halimeda density on hard substrate. The seaward edge of the inshore reef flat (region 4) was conspicuously barren of Halimeda, appearing as a whitish border which can be seen on the panorama (Figs 89, 91) running across Fig. 89 from the dock at the right. Instead of supporting the heavy opuntia cover of the adjacent regions, this band of about $0 \cdot 66 \mathrm{~m}$ width had a partial cover of grey-green algal fuzz, tiny opuntia and isolated opuntia cushions which showed signs of being grazed, with curved bites out of the segments, while the region was floored with similar segments. In addition, the few opuntia plants growing in the fringe had a conspicuously rounded cushion or cropped habit, and lacked the straggly projecting branches which result from active growth (Fig. 51). The coral rock itself was pitted, with numerous scattered hollows containing urchins at a daytime density of $12 \mathrm{~m}^{-2}$. The densest opuntia cover on this urchin border reached $5 \%$, with overall cover not greater than $1 \%$. The upper portion of the adjoining vertical wall also was relatively barren of macroalgae; lower on the wall Halimedae were present, although their distribution was patchy and sparse. A 1\% cover was estimated for the coral rock sides and rock outcrops of the lagoon. Halimeda tuna appeared on some of the latter, sometimes pendant and in shaded sites.

About two-thirds of the surface of the reef flat: Zoanthus zone (Fig. 91 ; region 6) also lacked Halimeda cover, and was urchin-barren like the one described for the seaward edge of the shore reef. The remaining third had an almost-closed cover similar to that of the inshore reef. Halimeda opuntia was the most prominent siphonaceous alga, and the thalli appeared to be grazed. Here also the seaward vertical face of the reef lacked conspicuous vegetation, including calcareous green algae. The Halimeda population was sparse throughout.

The buttress zone (Fig. 93 ; region 9), a region of hard substrate, might also seem a likely site for non-sand-growing Halimedae, including opuntia. Our census did not extend to this region at Glory Be, but at Runaway Bay (between Glory Be and Discovery Bay) Halimeda won little space on this wall of living coral, although scattered thalli of opuntia and goreauii occurred here and there. The absence of this genus from the north-shore buttresses was noted by Goreau and Goreau (1973). 


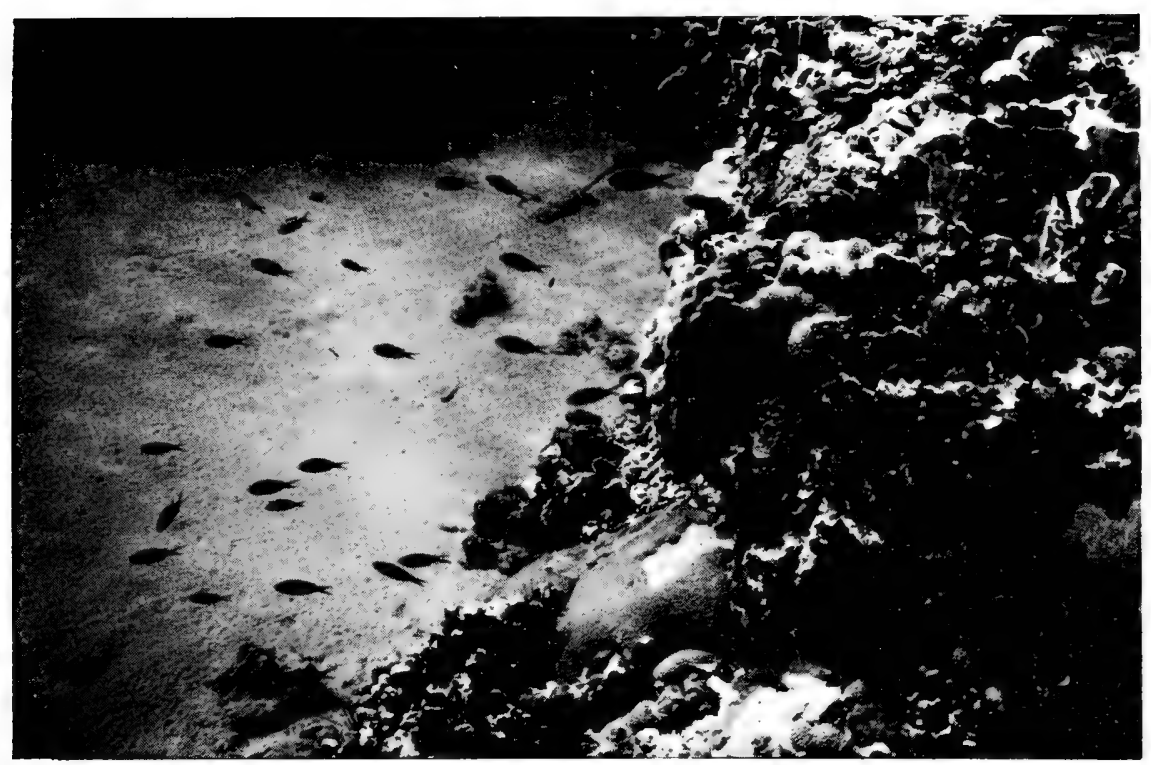

FIG. 93. Part of a buttress. Halimedae are rare in this region of Jamaican reefs. They are also absent from the sand at the bases of the buttresses.

On the hard surfaces provided by the fore-reef slope and deep forereef, the genus is more successful, and at depths of $-61.5 \mathrm{~m}$ to $-91 \mathrm{~m}$ on the deep fore-reef of Discovery Bay cover by Halimeda was estimated as $10 \%$, with cryptica occupying up to $60 \%$ of the available space on parts of promontories (Moore et al., 1976).

(b) Unconsolidated substrates. The Halimedae of sands and muds are principally members of the Rhipsalis section, although opuntia and gracilis, in their sprawling growth, are sometimes associated with such substrates. The greatest cover achieved by these Halimedae for the parts of the Glory Be reef surveyed was in the shallow sandy flats of regions 3 and 4 . These flats, although sometimes barren of macrovegetation, generally supported large populations of sea grasses, the Halimeda species monile and incrassata, and the related calcareous green algae Penicillus (often capitatus) and Udotea flabellum. The resultant cover was essentially closed, and although the sea grass Thalassia testudinum König was a clear areal dominant, about $40 \%$ cover was provided by the above three genera of calcareous green algae, with the two Halimeda species accounting for about 15\%. A fairly closed plant cover also existed in the sandy patches of the inshore reef flat (4), but much of it was provided by a spongy turf of about $16 \mathrm{~cm}$ 
thickness, composed of red and brown algae. Amidst this carpet grew compressed thalli of $H$. monile and $H$. incrassata, their buried basal portions white. In some places, about 300 of these Halimeda thalli occurred in a square metre of turf, compressed amidst the fleshy algae.

(i) Regions of low density of Rhipsalian Halimedae. Much of the lagoon (5) is sandy, and one might expect extensive stands of Halimeda, the other calcareous Caulerpales, which are predominantly sand growers, and sea grasses. Such stands did occur (Fig. 94). In these shallow sandy areas, I found Lilliputian forests of Thalassia testudinum, and the densest population of $H$. incrassata, 441 thallim $^{-2}$, encountered on this particular reef. But the vegetation was patchy, and there were extensive barren areas along the edges of the reef rock and in the main part of the channel. Where vegetation occurred the sea grasses were usually the commonest, although the Caulerpalean genera Halimeda, Penicillus, Udotea and to a lesser extent Rhipocephalus were prominent too. These algae usually grew in parts of the channel which were some distance from the bases of reef walls, although a conspicuous exception was Udotea ad spinulosa which pushed up in tight clumps of about 40 clonal thalli under reef overhangs. The commonest Rhipsalian species in the inner channel was incrassata, but simulans mingled with it, particularly near the periphery of dense stands. Halimeda cover of the lagoon sands was about $5 \%$.

Extensive patches of Rhipsalian Halimedae were anticipated in the wide moat (7) where the next unconsolidated substrate occurred proceeding seaward from the shore. There were, however, few obvious calcareous greens when the study was made. Seaward of the reef flat (6), with its few Acropora palmata and Millepora colonies, was first a channel of ripple-marked sand, some of it halimedoid, with dune-like waves being continually moved by the surge. Neither plants nor urchins were obvious, but worm cones occurred at intervals of a metre or so. The rippled area ended in a pebbled or cobbled region, also part of the moat (7). The rounded cobbles, typically $5 \mathrm{~cm}$ or so across but many larger, seemed to lie on Halimeda sand and occupied half the area. Patches of coral rock occurred throughout the cobble region. This part of the moat contained a Diadema population averaging about $6 \mathrm{~m}^{-2}$, in places reaching a density of $20 \mathrm{~m}^{-2}$. So large a population indicates heavy production, but sizeable algae such as Halimeda occupied only a tiny fraction of the grazed surface. Instead, over much of the pebblecobble floor a fuzz of filamentous green algae grew, and this population seemed to be maintained by urchin grazing (Fig. 95). About $20 \%$ of the moat also contained reasonably dense stands, about $300 \mathrm{~m}^{-2}$, of 


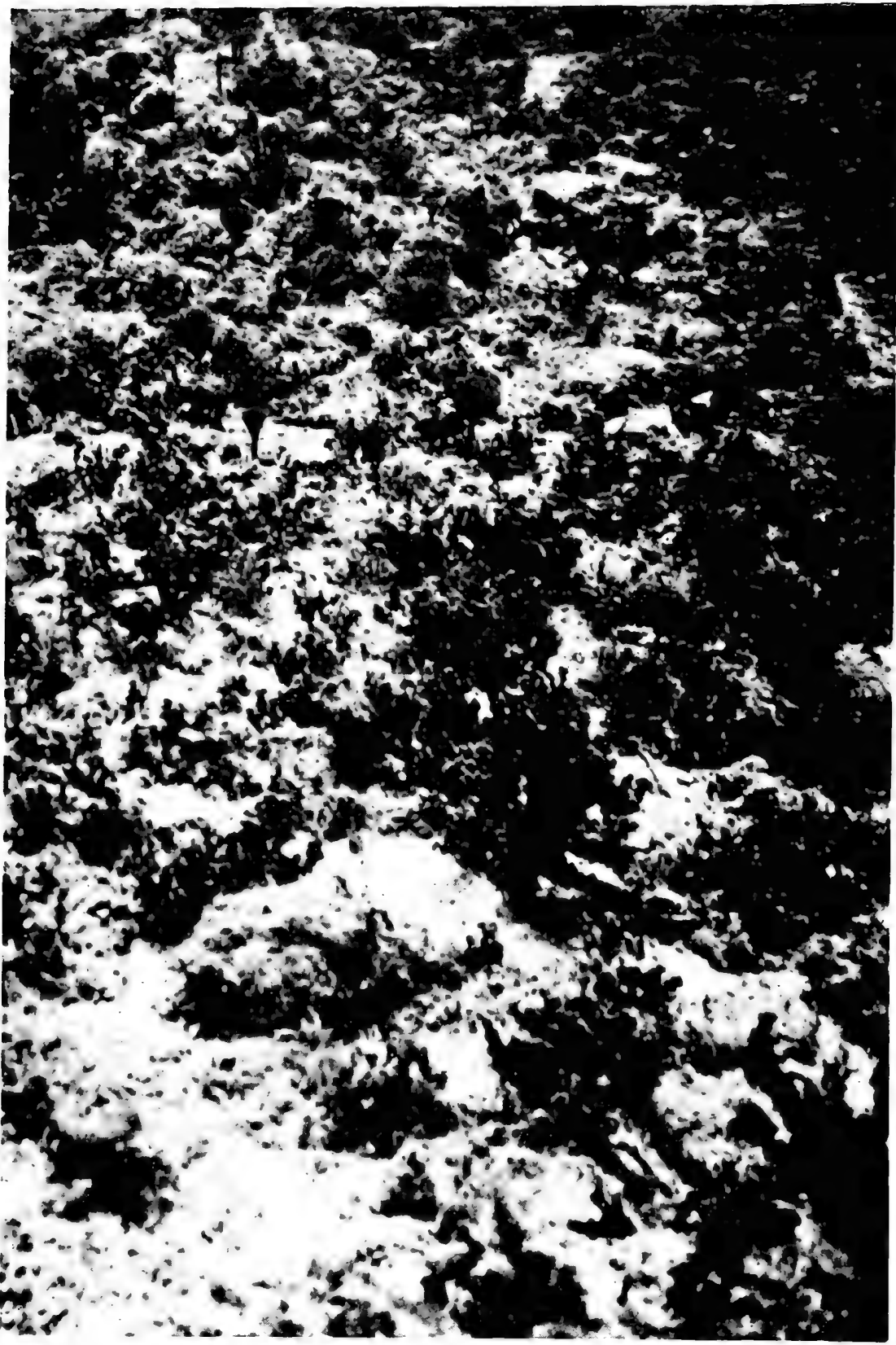

Fig. 94. A grove of $H$. incrassata with the occasional $H$. simulans in about $1.6 \mathrm{~m}$ of water in the lagoon of Glory Be. Cover by Halimeda is about $30 \%$, the proportion of young : mature : old Halimeda thalli in the region of which this photograph is a part was $1: 2: 1$ in September 1968. The commonest associated alga in this photograph is Penicillus capitatus. 


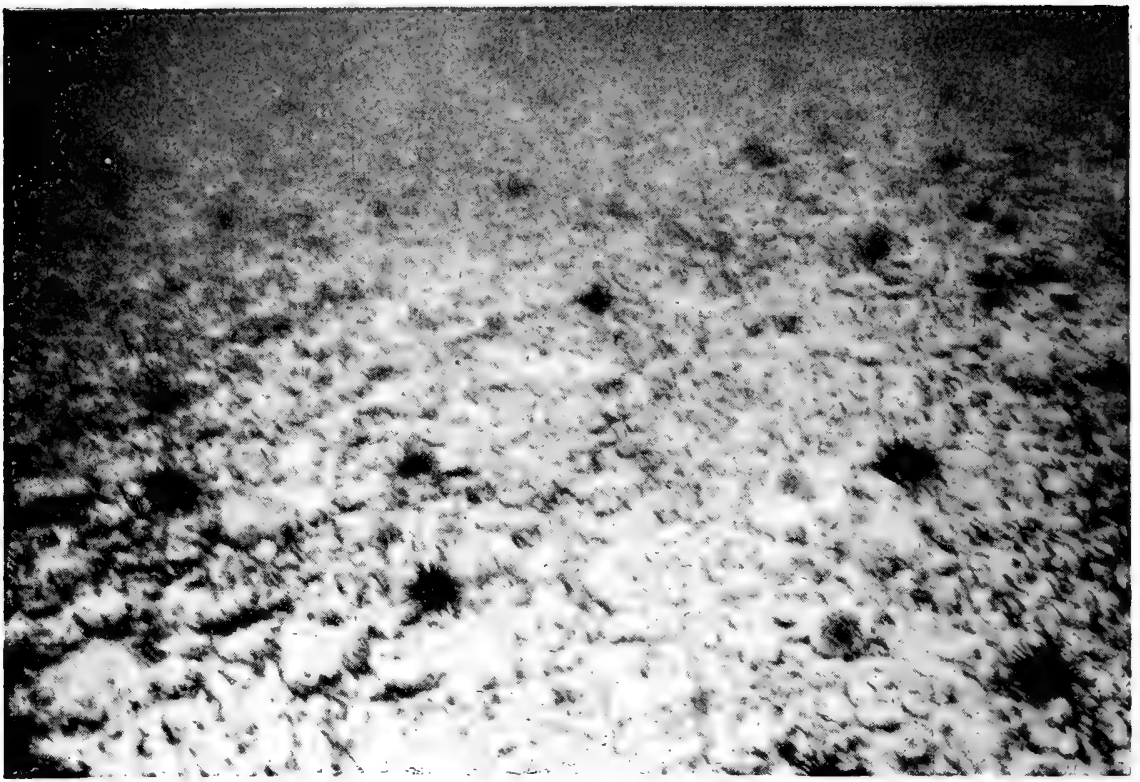

FrG. 95. The cobble-urchin-fuzz system of the moat. The density of Diadema for the region averaged $6 \mathrm{~m}^{-2}$, in places reaching $20 \mathrm{~m}^{-2}$.

Thalassia, together with white urchins Tripneustes esculentus Leske and heart urchins Clypeaster rosaceus Linnaeus. The density of each of the two urchin taxa was estimated as $1 \mathrm{~m}^{-2}$. Among the sea grasses were occasional small thalli of incrassata, of density about $4 \mathrm{~m}^{-2}$. The Thalassia stands, alternating with the grassless, ostensibly barren areas, gave the impression of advancing and retreating, while the heart urchins and fuzz remained.

Where there are appropriate substrates, Rhipsalian species also grow in the deeper portions of the reef (Section IV; Fig. 90) such as the upper fore-reef slope. However, these deep-water Rhipsalian populations are never dense, as they are in the shallows. This is, to some extent, remarkable, for rock-growing pendant species like copiosa and cryptica do achieve very dense populations in deep water. The disturbance of suitable substrates by silting, or by slumping of reef, perhaps accounts for these smaller Rhipsalian populations at depth.

\section{Summary: factors affecting Halimeda distributions at Glory Be}

(a) Association with sea grasses. One of the best places to find a dense $\left(c .450 \mathrm{~m}^{-2}\right)$ population of Rhipsalian Halimedae is in the region of dense patches of Thalassia. The Thalassia stands constitute welldefined communities, the sand consolidated by a network of Thalassia 
rhizomes (Fig. 96), and some of the less dense may contain very sizeable populations of Halimeda, or the dense Halimeda patches may be in adjacent areas. These especially thick Thalassia stands are restricted to shallow water between $-0.5 \mathrm{~m}$ and $-3 \mathrm{~m}$. Even in apparently optimum sites the distribution of the Thalassia stands is patchy, and there is evidence that the patches themselves are unstable. Most patches terminate in what could well be called a blow-out: there is an

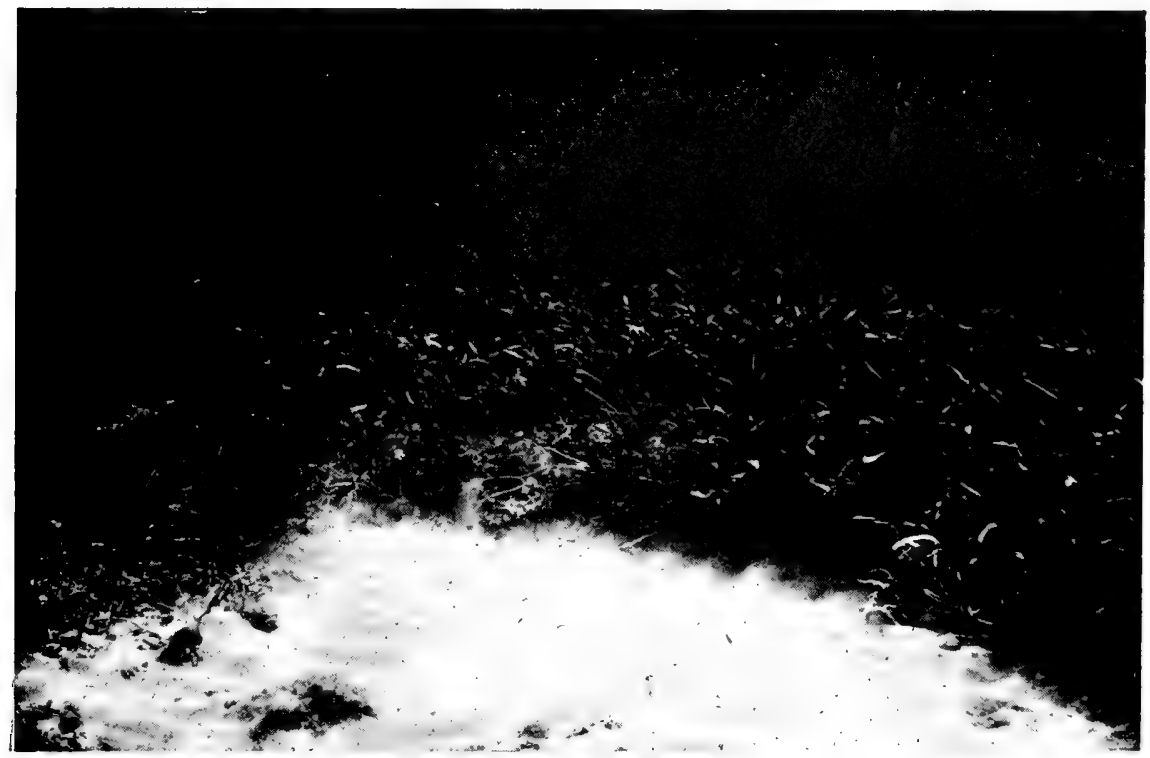

Fig. 96. Edge of a dense stand of Thalassia testudinum, partly fringed by other sea grasses such as Diplanthera wrightii. Here the calcareous alga Penicillus capitatus, with some Udotea, is prominent towards the edge of the bed, and extends into the sand of the lower left. There is a suggestion of a rotational process of colonizing sand, consolidation of the sand by sea-grass rhizomes, development of the dense Halimeda and other populations, and physical destruction of the community.

abrupt edge, with barren sand adjacent, and the discontinuity between the Thalassia community and the bare sand reveals a vertical section of the sand consolidated by the Thalassia rhizomes which in places is about $10 \mathrm{~cm}$ high. These observations suggest very strongly that there is a rotational process of colonizing sand, consolidation of the sand by sea grass rhizomes, development of the dense Halimeda and other alga or sea grass populations, and then physical destruction of the community. The dynamics of this process are of immense importance to the total Halimeda productivity of the reef. 
(b) Grazing and the Opuntioid forms. Straggling growth-forms of opuntia on rocks form the densest Halimeda stands, reaching covers of about $90 \%$, which is probably more than the equivalent of 900 Rhipsalian Halimedae per square metre. There seems to be good reason for thinking that the sites where densities like these can be attained are limited by grazers for many opuntia patches show direct signs of having been grazed, and apparently suitable sites are both barren of opuntia and are the habitat or territory of some urchins or fishes. It is possible that there are seasonal or periodic fluctuations in grazer populations, in which event total Halimeda densities may fluctuate very widely from time to time.

(c) Factors restricting Halimeda on bare bottoms. Halimeda populations are low on the sandy bottom of the moat and on the fore-reef terrace. For the sandy, duned parts of the moat that lacked vegetation, the explanation may be that the sands are kept too mobile by the wave surge, and that only exceptionally well-anchored plants survive. On the barrens of the moat floor urchin grazing is a possibility, because high densities of urchins were found, and the vegetation which was there, a short soft algal fuzz, is a life-form that might result from heavy grazing.

\section{B. Enewetak Atoll}

There are more data from Bikini and Enewetak (the spelling preferred by the Marshallese) than from any other atoll, a consequence of their use for bomb tests. Thirty-five atomic devices have been exploded at Enewetak, and the bomb craters themselves are sometimes interesting sites for marine botany. As always, research has been concentrated on processes leading to the construction, maintenance, productivity and geology of the reef framework, with processes in the lagoon and among the macrophyte populations examined to a lesser extent. Geology and the structure of the reefs are described in Emery et al. (1954) and Ladd (1973), with Ladd also providing a list of the chapters of U.S. Geological Survey Professional Paper 260 which reports on the Marshall Islands. Some of the results of core drilling of the reef are reviewed in Section IX. The classic studies of production on reef ridges by Odum and Odum (1955), as well as the more recent studies of the SYMBIOS group (Johannes et al., 1972; Pomeroy et al., 1974; Webb et al., 1975; Wiebe et al., 1975), also described Enewetak systems, with the earlier work of Sargent and Austin (1954) carried out in another atoll of the same group of islands. 
Marine botany began with Taylor's (1950) survey as part of the preparations for Operation Crossroads. Taylor's monograph is essentially the results of many dredge hauls made as the requirements of military logistics allowed. Dawson (1957) added to the algal collections by diving, but the main effort at ecological marine botany by diving was the work of Gilmartin $(1960,1966)$. In the first paper Gilmartin described the lagoon bottom, and collections of algae at 21 stations, comprising a complete east-west transect of the lagoon and reaching to the maximum depth at about $65 \mathrm{~m}$. It should be noted that the sand-dwelling Halimeda found most commonly by Gilmartin and described as monile is now properly known as cylindracea. The only report on algae at Enewetak since Gilmartin appears to be that of Hillis-Colinvaux (1977).

\section{Enewetak Atoll and the reef profile}

Enewetak Atoll consists of approximately 40 low islets on a broadly elliptical reef surrounding a large and deep lagoon (Fig. 97). Prevailing winds are important in shaping a reef (Yonge, 1951), and Ladd (1973) describes Enewetak as a typical "rough-water reef" since it lies in the belt of the north-east trade winds. Its windward side is consequently subjected to steady wave attack for about 9 months of the year. Its southern reefs are protected from the trade winds, but are periodically damaged by powerful long-period swells from the southern hemisphere, whereas the reefs of the west and north-west are exposed to relatively calm seas. These differences in the physical environment of the portions of reef bordering the small islets create an initial series of varied macrohabitats, to which are added the different conditions presented by the channels between the islets, and a lagoon of approximately $39 \mathrm{~km}$ in diameter, about $65 \mathrm{~m}$ at its deepest, with more than 2000 coral knolls or pinnacles (Fig. 83, bottom) and its own circulation system (von Arx, 1948).

Basic regions and features of the reef of this atoll are shown in profile in Fig. 98. Weather, accessibility of sites and work facilities severely limit the number of studies that can be made on the seaward portions of such reefs, so that we have few data of structure or communities to windward of the reef ridge.

The reef profile of Fig. 98 begins, therefore, just below the approximate depth (range $c$. $-14.5 \mathrm{~m}$ to $-25 \mathrm{~m}$ ) at which a pronounced change of slope is known to occur. The region preceding it has been frequently called the "ten-fathom terrace". But since the slope break occurs over a range of many metres (Stoddart, 1969; Orme, 1977; Smith 


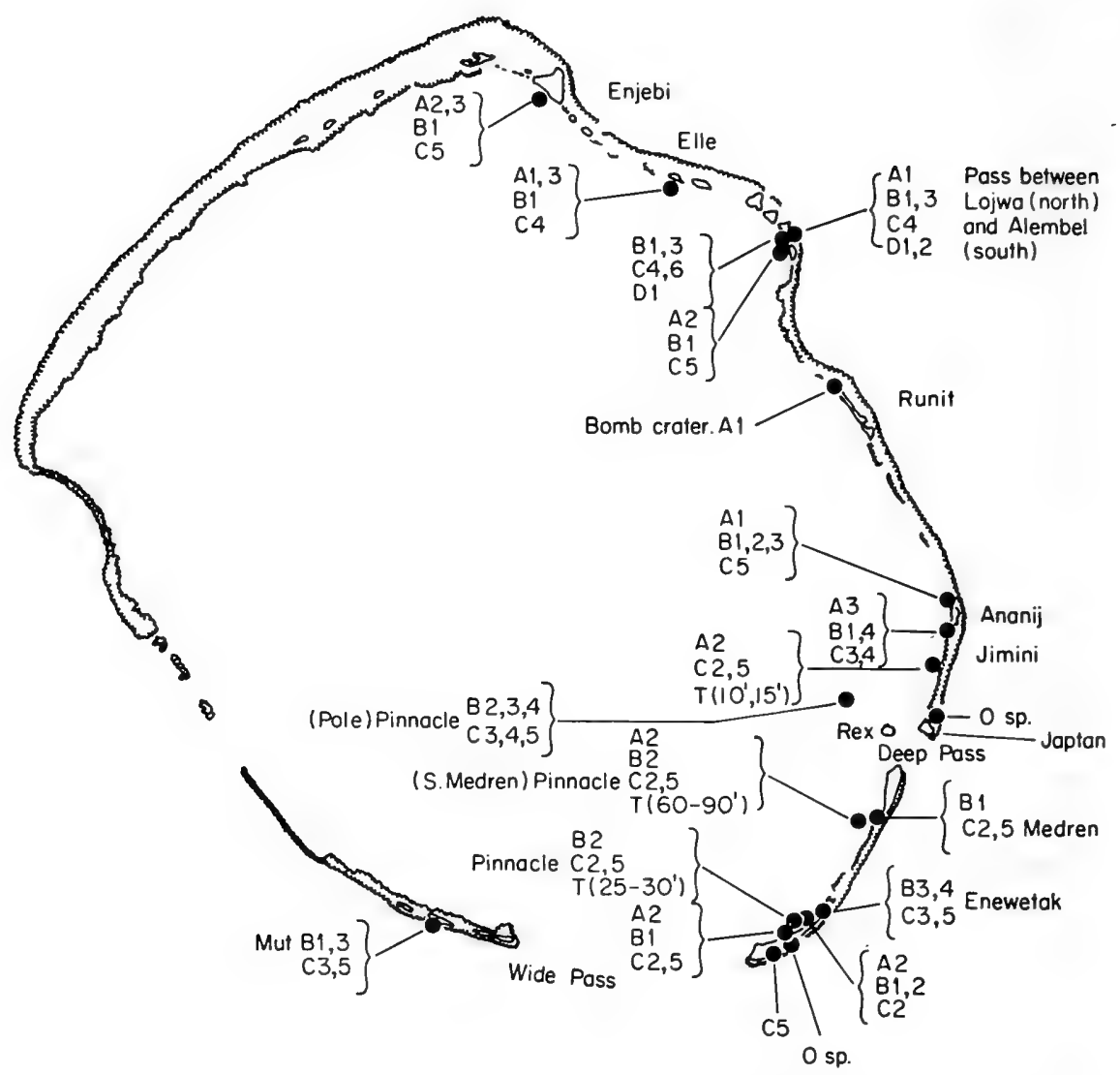

FIG. 97. Map of Enewetak Atoll showing stations visited for Halimeda project, 1975, and their Halimeda and Tydemania species. Halimeda species: $\mathrm{A} 1=$ incrassata, A2 $=$ cylindracea, $\mathrm{A} 3=$ stuposa $; \mathrm{B1}=$ opuntia, $\mathrm{B} 2=$ copiosa, $\mathrm{B} 3=$ distorta, $\mathrm{B} 4=$ minima $; \quad \mathrm{C} 2=$ gigas, $\quad \mathrm{C} 3=$ gracilis,$\quad \mathrm{C} 4=$ lacunalis f. lata,$\quad \mathrm{C} 5=$ macrophysa, $\mathrm{C} 6=$ taenicola $; \mathrm{D} 1=$ micronesica, $\mathrm{D} 2=$ fragilis. Tydemania species $: \mathrm{T}=$ expeditionis. (Modified from Hillis-Colinvaux, 1977.)

and Harrison, 1977), it is better called the fore-reef terrace. Proceeding shoreward a spur and groove region is encountered, and breaking the surface at low tide is the algal ridge. Development of spur-groove and algal ridges vary considerably, however, and they may be absent. The spur-groove system is best developed on the windward sides of atolls; on the lee side smooth margins are the pattern (Tracy et al., 1948).

The algal ridge has traditionally been called the "Lithothamnion ridge", and the component algae referred to as Lithothamneae or "nullipores". The name is a misleading one, however, brought about in 

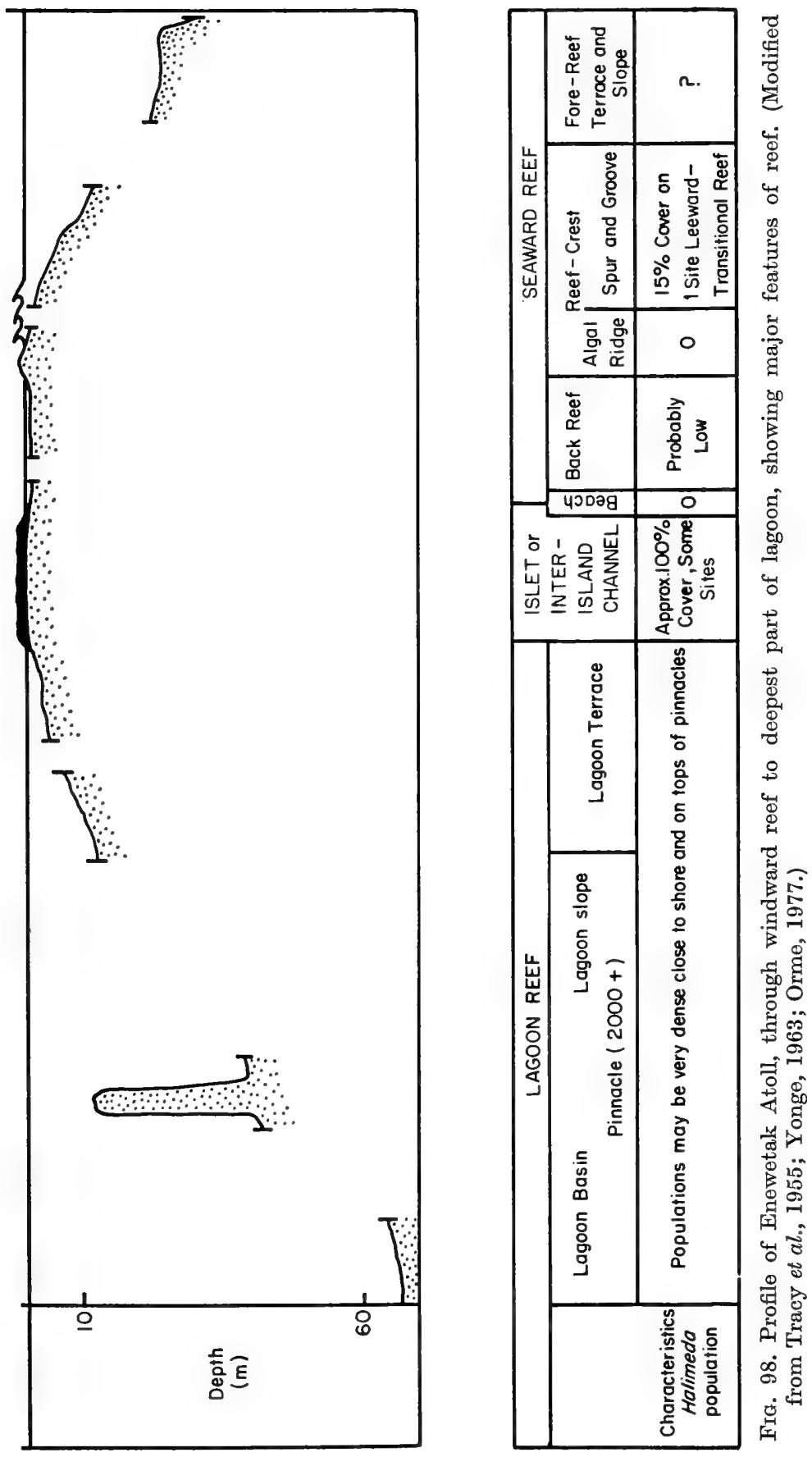
part by the tediousness, in the early stages of the taxonomy of the group, of identifying the calcareous algae involved, for Lithothamnion is a minor component, if present at all. The commonest members of the ridge are species of Neogoniolithon, Porolithon and Lithophyllum, and up to ten genera commonly may be present (Adey and MacIntyre, 1973). This ridge, showing various degrees of development, also occurs in the Caribbean (Adey, 1975; Adey and Burke, 1976; Adey et al., 1976), and it therefore does not represent a difference between the reefs of Atlantic and Pacific as formerly believed (Stoddart, 1969; Milliman, 1974). To the region of shallow waters shoreward of the ridge I have applied the general term back-reef (or reef flat). I have not subdivided it according to predominant coral type as is commonly done, since these divisions are not meaningful to our present understanding of Halimeda distribution at Enewetak.

Water flowing across this back-reef may continue directly into the lagoon, or its passage may be interrupted by low, carbonate islets built on the reef structure. Various vertical divisions of the lagoon reef have been described, again based on types of coral, but for Halimeda there is at present little reason for stressing them. Different environments among lagoon reefs are encountered in regions adjacent to interisland channels, on the lagoon side of the passage between islets and bordering the islets themselves. The many pinnacles of the lagoon are active, tall coral heads of immense significance to the productivity and carbonate budget of the atoll.

\section{The distribution and diversity of Halimeda at Enewetak}

Fourteen species of Halimeda are known for Enewetak (Table XXXIV), and although the number may be higher when some of the problems of nomenclature are resolved, it is, even so, the greatest number yet reported from any specific area in the world, and is about the same as the total number of species of Halimeda known for the Atlantic Ocean. The within-habitat diversity, sensu MacArthur (1965), at any place in the atoll, however, is low (Hillis-Colinvaux, 1977). Twenty-one sites were examined during a 3-week visit to Enewetak, and at no station were as many as half the species found (Fig. 97). At only $10 \%$ of the stations were there six species, and at $40 \%$ of the stations there were three or fewer. At two stations, including the site of the Odum transect, no Halimedae were found. A station represented about $1-2 \mathrm{~h}$ of diving time. A striking observation first made by Gilmartin (1960) is that both sand- and rock-adapted species are found at all depths of the lagoon, from the shallows to the bottom, 
though relative abundance and diversity appear to decrease with depth.

Rock habitats for the species with this habitat strategy are available on the reef crest, much of the back-reef, in the inter-island channels, at

Table XXXIV. Species and Abundances of Halimeda and Tydemania at ENEWETAK Atoll, DeCEMber $1975^{a}$

\begin{tabular}{|c|c|c|c|c|}
\hline $\begin{array}{c}\text { Map } \\
\text { code } \\
\text { (Fig.97) }\end{array}$ & Species & $\begin{array}{c}\text { Total No. } \\
\text { stations } \\
\text { where } \\
\text { present } \\
(\%)\end{array}$ & $\begin{array}{c}\text { Total No. } \\
\text { Halimeda } \\
\text { stations } \\
\text { where } \\
\text { present } \\
(\%)\end{array}$ & $\begin{array}{c}\text { Relative } \\
\text { in-site } \\
\text { abundance }\end{array}$ \\
\hline & Halimeda & & & \\
\hline Al & incrassata & 8 & 12 & 3 \\
\hline A2 & cylindracea & 37 & 54 & 3 \\
\hline A3 & stuposa & 11 & 16 & 3 \\
\hline B1 & opuntia & 58 & 85 & 3 \\
\hline B2 & copiosa & 24 & 35 & 2 \\
\hline B3 & distorta & 29 & 43 & 2 \\
\hline B4 & minima & 19 & 28 & 2 \\
\hline $\mathrm{C} 2$ & gigas & 32 & 47 & 3 \\
\hline C3 & gracilis & 16 & 24 & 1 \\
\hline $\mathrm{C} 4$ & lacunalis $\mathrm{f}$. lata & 24 & 35 & 3 \\
\hline C5 & macrophysa & 68 & 100 & 3 \\
\hline $\mathrm{C} 6$ & taenicola & 5 & 7 & 1 \\
\hline D1 & micronesica & 5 & 7 & 1 \\
\hline D2 & fragilis & 11 & 16 & 1 \\
\hline \multirow[t]{4}{*}{$\mathbf{T}$} & Tydemania & & & \\
\hline & expeditionis & 16 & 24 & 2 \\
\hline & Udotea & & & \\
\hline & Various species & - & - & 1 \\
\hline
\end{tabular}

${ }^{a}$ From Hillis-Colinvaux (1977).

${ }^{b} 1=a$ few species found by diligent searching; $2=$ common, but a minor part of Halimeda community; 3 = abundant, a major part of the Halimeda cover.

the lagoon borders, and on the pinnacles and mounds of the lagoon floor. Unconsolidated material floors most of the lagoon, but there is little sand habitat elsewhere except for patches in the reef and its channels. Significantly for the distribution of the Rhipsalis group of Halimeda, the windward back-reef lacks the extensive sand terrain so important for Halimeda production in the Caribbean. It may be that the absence of an extensive sand flat along the back-reef is a characteristic of atolls, which makes the basis of their carbonate budgets 
somewhat different from fringing reefs. An especially fine-grained unconsolidated substrate for Halimedae at Enewetak is provided by atom bomb craters.

(a) Halimedae on the fore-reef and the spur and groove zones. We have no data on Halimeda distributions on the fore-reef or at the greater depths below, but Jamaican experience suggests that there may well be dense populations or new species waiting to be found there. If these populations exist, they could be important to the carbonate budget of the lagoon because the strong onshore currents might be expected to carry shed segments over the reef. Species to be expected there include copiosa, opuntia, gracilis, macrophysa and gigas, with Tydemania expeditionis. This region is yet part of the "Mare Incognitum" (Ladd, 1961 ; Smith and Harrison, 1977) for plants as well as for corals.

There is no published account of Halimeda on the spur and groove region, but I was able to make one collection in a transitional spur and groove region in 1975. This was on the seaward side of the islet of Mut at the south-western corner of the atoll (Fig. 97) in about $-10 \mathrm{~m}$ to $-15 \mathrm{~m}$ of water. Four species of Halimeda were found on the spurs: opuntia, distorta, gracilis and macrophysa, with opuntia being much less common than the others. The species distorta and gracilis sprawled over, through and around the uneven reef surface, and together with macrophysa, which has a discrete rather than spreading habit (Fig. 99), filled many of the crevices between living coral heads. Halimeda macrophysa, in addition, hung somewhat more openly on the sides of the spur.

At the time of the visit, which was mid-December, some of the branches of distorta bore rows of several flabby, relatively uncalcified segments at their growing tips, which I interpreted as indicating very rapid growth. There were also many Halimeda segments in the sand in the immediate vicinity of the spur, which could indicate an equally rapid death and separation of older segments. Blue-green algae with unbranched trichomes were associated with the Halimedae. Cover of the spurs by Halimeda was estimated as approximately $15 \%$, and the relative conspicuousness of Halimeda on them presents a marked contrast to the buttresses of Jamaica where Halimedae were rare. No Rhipsalian species were noted in the vicinity of the spurs, but this observation is not necessarily significant because a search could not be made in the time available.

(b) Algal ridge and back-reef. At the seaward edge of this region, where much of the force of the breaking waves is spent, especially on 


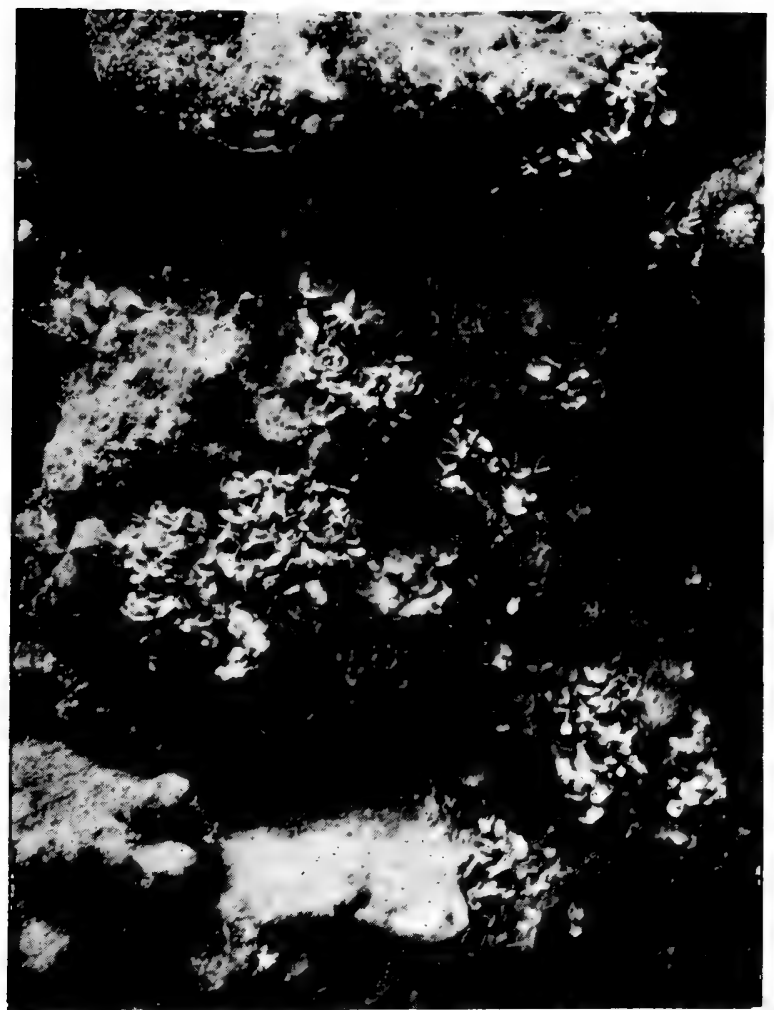

Fig. 99. Clumps of $H$. macrophysa on a transition buttress on the Islet of Mut, Enewetak Atoll, at depths of $10-15 \mathrm{~m}$.

the windward side, is the Porolithon ridge, almost a pure stand of encrusting red algae. The growth form of Halimeda is not adapted to the shock of waves as are those of calcareous reds, but the genus does grow, to some extent at least, in the passages and caverns of the surge channels. These are hung with lush green skeins which include the siphonaceous genus Bryopsis (Fig. 100). Taylor (1950) reports the Halimeda species opuntia, micronesica and taenicola from this approximate region on other Marshall Islands atolls, and they might well grow on some of the seaward reefs at Enewetak. Somewhat landward from the ridge Taylor also reports opuntia, taenicola, micronesica and tridens (=incrassata), and from the inner reef flat stuposa, opuntia, bikinensis and lacunalis, the last two in deep holes.

The part of the seaward reef I could explore most readily was that of the southern tip of Enewetak Islet (south-eastern part of the atoll). Stearns (1945) published on the decadent condition of this particular 


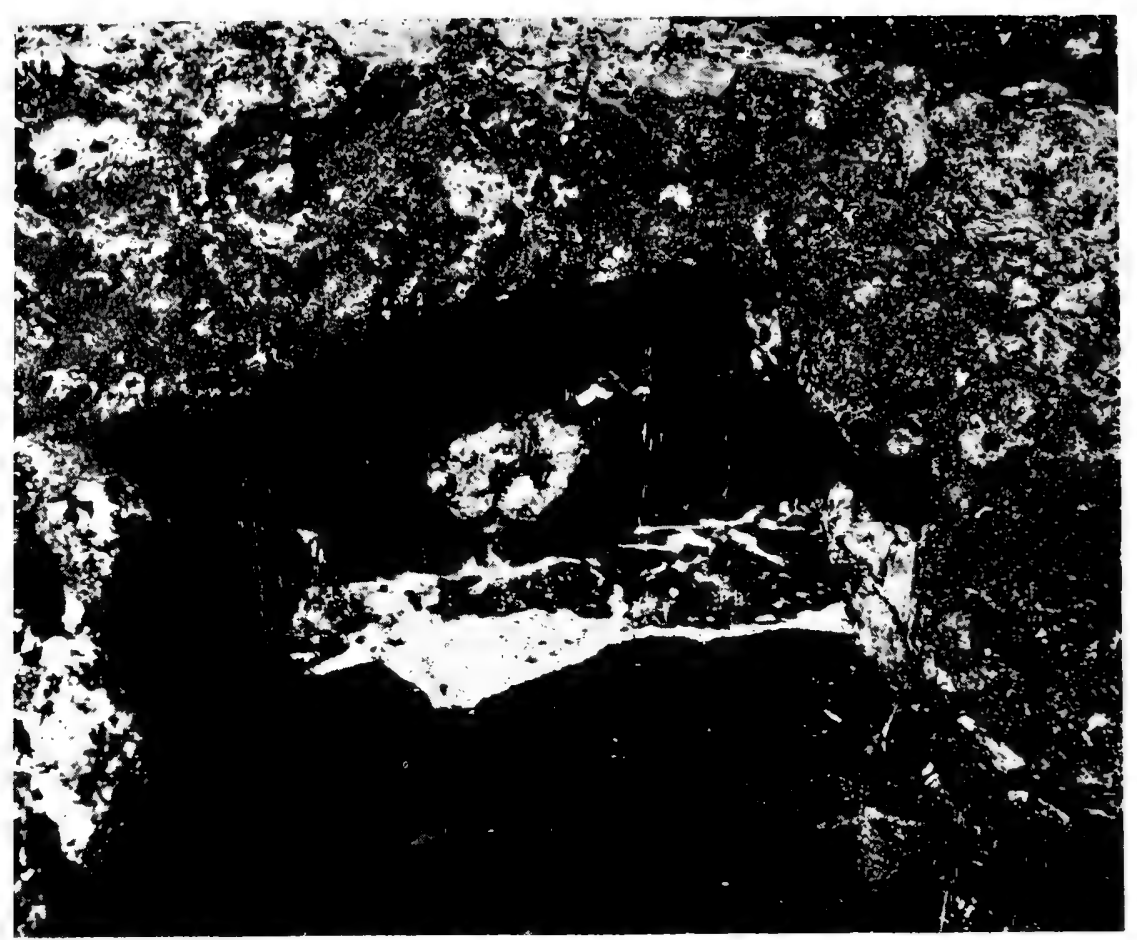

FIG. 100. Surge channel behind the algal ridge on the seaward reef of Enewetak Islet, Enewetak Atoll. Halimeda grows, to some extent at least, in the passages and caverns of these channels, although it is not shown here. The algal growth on the rock surface includes blue-greens, ulotrichean filaments and lush green skeins of Bryopsis.

reef, and Ladd in his visits of 1950 and 1952 found this and some of the other reefs of the windward shores drab (Emery et al., 1954), a condition which has been attributed both to rate of reef growth, and to the effects of bombardment and release of fuel oil during the Second World War. At the time of my visit to the area in 1975 the macroflora was sparse. There was, however, a good growth of smaller algae with much associated fauna. Many of the algae grew in short spongy turfs, and as green and blackish slimy rock coatings. The only Halimeda found was macrophysa, living in crevices behind the algal ridge, in water several centimetres deep at low tide.

In the abandoned limestone quarry of the inner back-reef of .nowetak Islet sizeable populations of the sprawlers distorta and graitis grew, as well as macrophysa, and a bushy form of minima. The water depth is $1-1.3 \mathrm{~m}$ at low tide. This setting is more protected than the open reef flat. 
(c) Inter-island channels. In the passes between the islets the flow of water across the algal ridge and back-reef continues into the lagoon uninterrupted by land. Most of the passes are shallow, and the current usually moves strongly in only one direction. Odum and Odum (1955), working in one of these channels on the windward side of Enewetak, obtained a maximum current of $1.44 \mathrm{~m} \mathrm{sec}^{-1}$ during high-water neap tide, and suggested that currents were probably twice this velocity during incoming springs.

The lushest growth of opuntia I encountered at Enewetak was towards the lagoon end of one of these channels, the pass between Lojwa and Alembel on the windward side of the atoll (Fig. 97). In its shallow $(-2 \mathrm{~m}$ to $-5 \mathrm{~m})$, well-lighted, fast-moving waters almost every crevice, especially those exposed to full sunlight, seemed filled with this species. Segment shape was particularly variable, and sometimes the segments were tiny, but the characteristics were unmistakably "opuntia". Such thalli, presented separately to the taxonomist, could well provoke at least a form epithet or two for the literature. Yet such names, under the circumstances, would have no ecological, and probably no real taxonomic significance. Flow-respirometry of one of these Halimeda channels might be expected to reveal productivities as high as any found for the Halimeda-free reef flat.

The Halimeda species lacunalis f. lata, taenicola, fragilis and micronesica also lived in these "streams", but in more sheltered locations than opuntia. The relatively abundant lacunalis $\mathrm{f}$. lata grew on the seaward and lee side of corals, often under overhangs provided by the undercut coral bases, or under promontories provided by the surface. Its segments, too, were sometimes dwarfed, and many of the apical segments grazed. In this inter-island channel it was the second most abundant Halimeda species; only opuntia was commoner. Other Udoteaceae were present too, but never prominent in any of the regions visited. This inter-island channel, lagoonward of midpoint, was one of the two sites with the greatest Halimeda species diversity encountered at Enewetak.

(d) Atom bomb craters. There are six nuclear craters underwater or in the reef flats of Enewetak which provide sites for Halimeda colonists, and I examined two of them, CACTUS and LACROSSE, in December 1975. Both are at the north end of Runit (Fig. 97). The larger, LACROSSE, formed in May 1956, is in the back-reef, whereas CACTUS, formed almost exactly two years later, is more an inpocketing of an inter-island channel (Fig. 85). Both craters are open to the sea, but CACTUS had most of the crater rim submerged, and so was 
flushed, in its shallows at least, with flowing reef water. Both craters were floored with very fine sediments, probably including clay-sized particles. I saw no sediments of comparable fineness elsewhere in the atoll. Both sediment bodies were contaminated with radionuclides. These craters are particularly interesting as sites for colonizers, and sites, moreover, with sediments of a size fraction not widespread in the neighbourhood. Unfortunately it is reported that CACTUS crater, the more interesting one, has been filled in as part of the recent clean-up operation on the atoll.

There were no Halimedae in LACROSSE, but a dense, pure stand of a lax form of incrassata was found in the centre of CACTUS (Fig. 85). No population count was made of this stand, but it had the appearance of a density of 200 or more thalli per square metre. This stand was in $11 \mathrm{~m}$ of water, in the very centre of the crater, where light was poor (visibility was about $1 \mathrm{~m}$ ), and the water murky with clay or a colloidlike suspension. The bottom was extremely soft and went into suspension at the flick of a flipper. It was also billowed, apparently by worm tubes.

Away from the centre of the crater where the slope of the floor was already apparent but at a depth of about $10 \mathrm{~m}$, the straggling thalli of incrassata thinned out and merged into a grove of Caulerpa ad serrulata. Tube worms with chitinous tubes were collected in this community. No Halimedae were found in shallower water, and a quick survey during descent suggested that the sides of the crater were barren of plants. The crater also contained a black-tipped shark.

The dense incrassata population in CACTUS is of special interest because we found this species to be rare at Enewetak, locating no dense populations other than this one. The species incrassata is the principal Rhipsalian Halimeda in the sandy and muddy shallows at Glory Be in Jamaica. Possibly this species is restricted at Enewetak by a paucity of fine substrates. But it certainly was able to disperse to this unusual site at Enewetak, and this is one of the few pieces of data on dispersal in Halimeda that we possess. It is possible that the dense population was found in the deepest water at the centre of the crater because a vegetative propagule settled there. Had the crater not been filled in, it would have been extremely interesting to see if the resulting clone spread up the sides.

(e) The lagoon: pinnacles. With over 2000 coral knolls in the lagoon (Emery et al., 1954) some considerable variation can be expected in their biota. Of the three on which I collected (Fig. 97), Pole pinnacle, north-west of Rex islet, was the most interesting for Halimeda, and 
possessed the same high Halimeda species richness that was encountered in the fast-flowing lagoonward end of the inter-island channel between Lojwa and Alembel. Species of section Opuntia other than opuntia, the taxa copiosa, distorta and to a lesser extent minima, achieved prominence on these knolls.

The flattish top of Pole pinnacle lies approximately $4 \mathrm{~m}$ below the surface of the water at low tide; its base is reached at about $-40 \mathrm{~m}$. Halimeda distorta and macrophysa filled crevices between colonies of

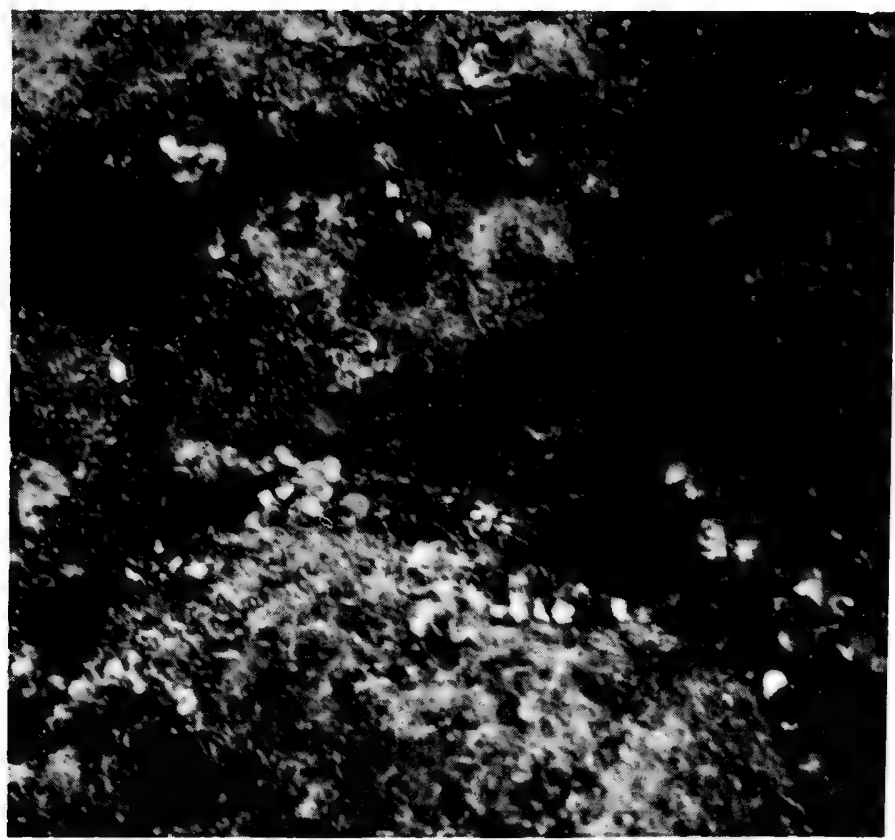

Fig. 101. Cluster of $H$. copiosa on Pole pinnacle near Rex Islet at a depth of $12-15 \mathrm{~m}$, in December. The thalli are relatively small, with the width of broadest segments shown being 10-14 $\mathrm{mm}$.

living coral on the brightly lighted, essentially horizontal upper surface of this pinnacle, with sizeable, dense clumps of macrophysa in places providing almost closed cover. The species copiosa, although present near the top with the other taxa mentioned, was more prominent under overhangs lower down (Fig. 101), often growing from under protuberances of the pinnacle. The thalli tended to be small, but this may be a seasonal phenomenon. Halimeda minima occurred under such overhangs too, but was not as abundant as copiosa, and other Halimeda 


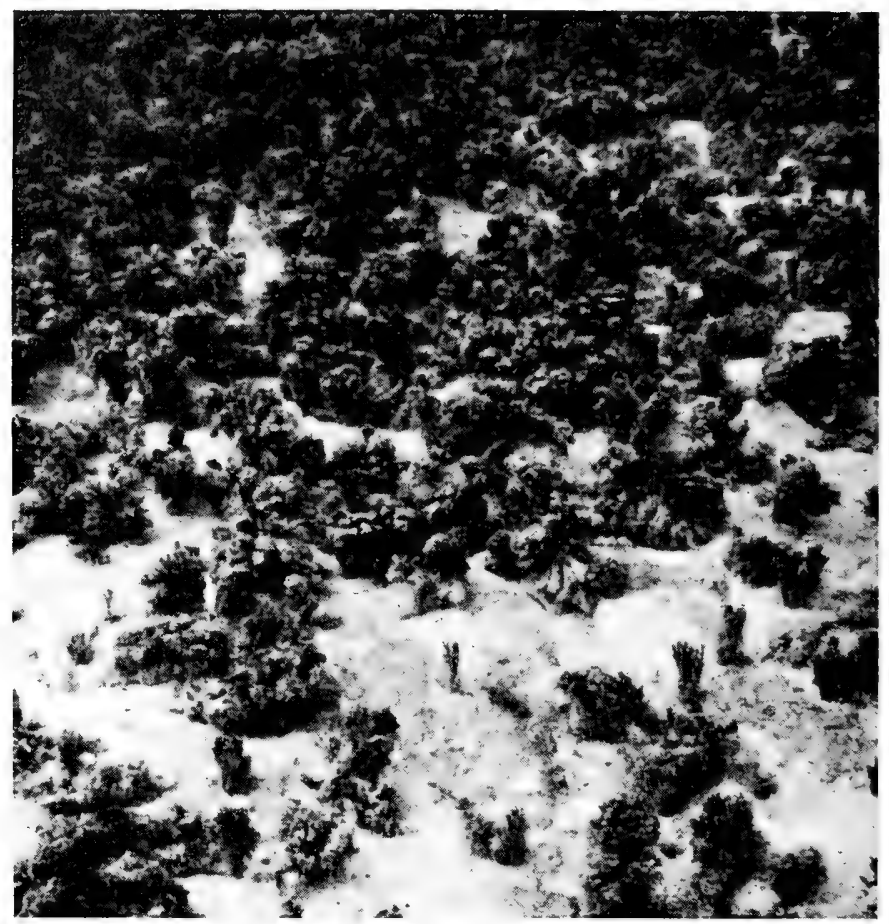

FIG. 102a. Grove of $H$. cylindracea in the lagoon near Enewetak Islet, Enewetak Atoll, at a depth of approximately $1.5-2.5 \mathrm{~m}$. Young, mature and old thalli are present, with many of the mature and older plants supporting relatively dense epifloral and epifaunal populations. The thalli are also silted. There is a spreading mat of bluegreen algae over portions of the sand, and shed segments of Halimeda are visible in the sand. Height range of thalli is $c .11 \cdot 5-14 \mathrm{~cm}$.

species were only occasional. On the South Medren pinnacle gigas was the most prominent Halimeda near the surface, that is at about $-10 \mathrm{~m}$. The commonest Halimeda species on the three pinnacles in December, both on their more or less horizontal tops and their gently sloping or more often steep sides, was macrophysa. Halimeda macrophysa also grew in widely scattered clumps on rock patches away from the pinnacle base. These deep-water thalli had few segments, however, in this way differing from the more familiar shrubbier plants of the sun-flooded shallows.

On two of the pinnacles Tydemania expeditionis was draped over considerable areas, in water only $8 \mathrm{~m}$ deep. Gilmartin (1966) reported it as prominent at the sites of some of his deepest dives in the lagoon, to about $-63 \mathrm{~m}$. Lush patches of this alga, which generally has been considered a deep-water plant, were also observed at depths of $-3 \mathrm{~m}$ 


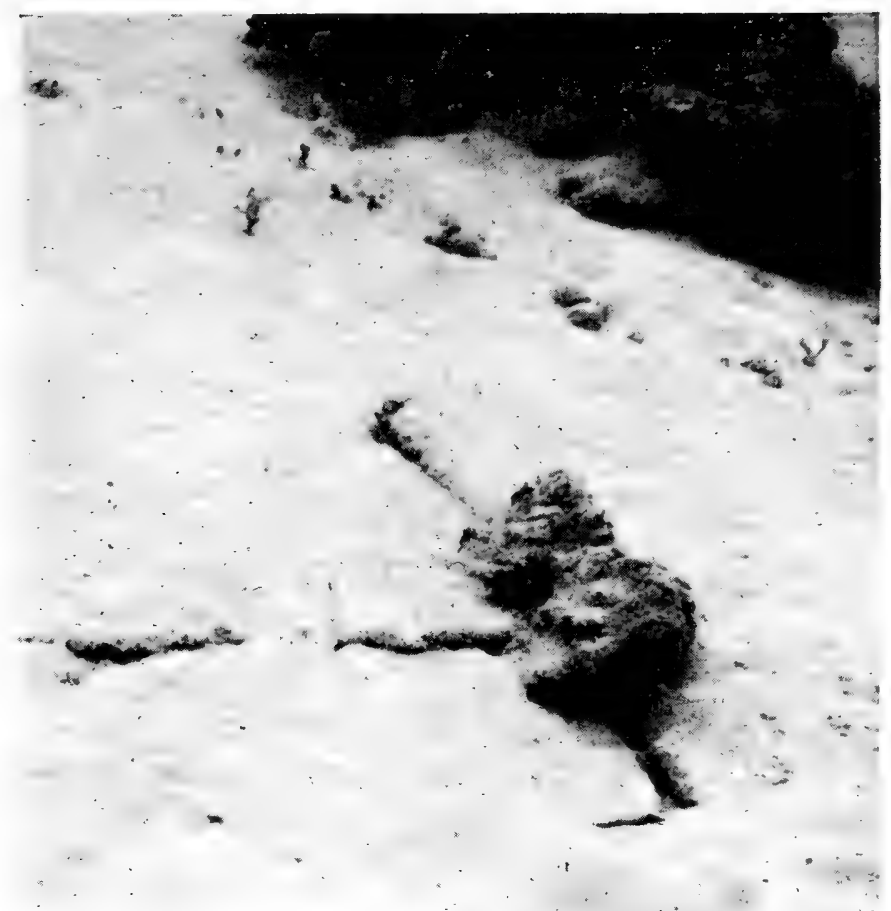

Fig. 102b. The lagoon floor, here near the base of south Medren pinnacle at approximately $-40 \mathrm{~m}$, appears to be essentially barren of Halimedae, although the occasional plants were observed. Some of the erect structures in this photograph in the sand near the rock outcrop, height approximately $8 \mathrm{~cm}$, are cylindracea.

to $-5 \mathrm{~m}$ on the lagoon reefs of Jimini. Among green algae Tydemania is second only to Halimeda as a carbonate producer at Enewetak.

Other noteworthy algal associates of Halimeda on vertical or near vertical faces of pinnacles, particularly below $20 \mathrm{~m}$, were species of Cyanophyta, their reddish or purply filaments at times streaming from under overlapping plates of coral colonies. Masses of some of these filaments also grew out of the sand-rock substrate some distance from pinnacles.

These Halimeda populations of the sides of pinnacles require more study because they may well be principal suppliers of carbonate to the reef floor. Gilmartin (1960) showed, and our own dives confirm, that the lagoon floors have very low densities of Halimedae growing on them, and yet there are the various bits of drill-core evidence that Halimeda segments are important constituents of the lagoonal sediments (Section IX). Halimeda macrophysa and some of the Opuntioids growing 


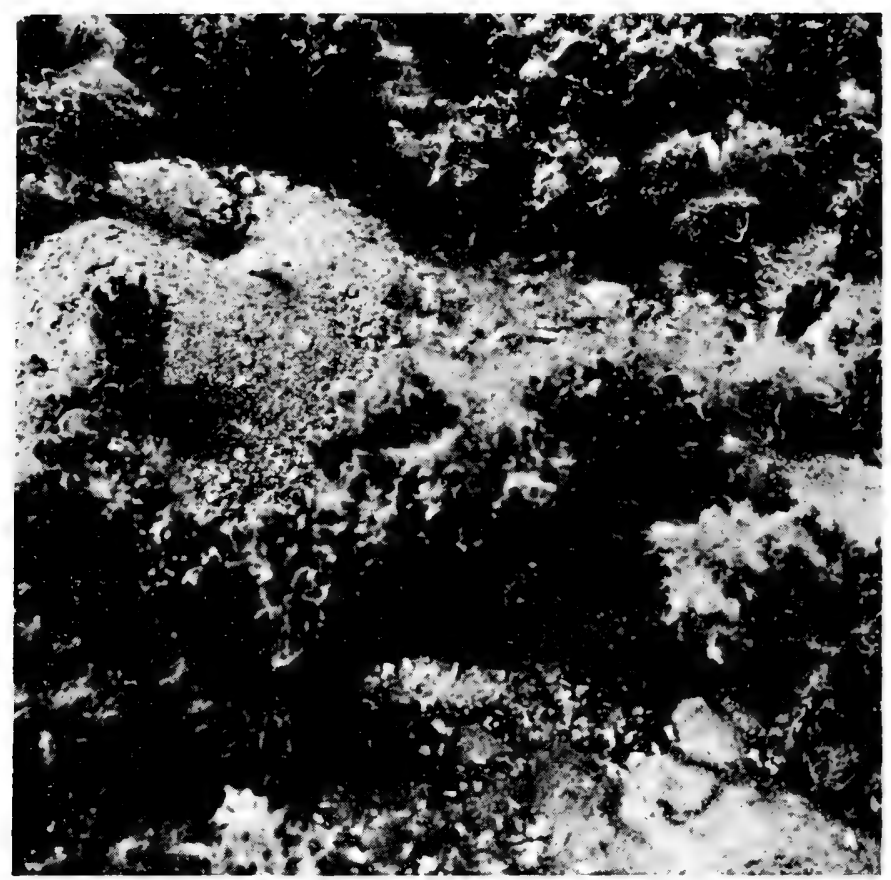

FIG. 103a. A part of the grove shown in Fig. 102a, showing the spreading algal mat over loose substrate in the foreground, and overgrowth of the older thalli. The animal mound in the upper left indicates some of the disturbances of the substrate in these communities which might effect the extent of cloning of Rhipsalian Halimedae by "runners" through the sand. Height range of the thalli in this and Fig. 103b is approximately $9 \mathrm{~cm}$.

on the flanks of 2000 pinnacles may be the solution to this problem of the Halimeda sediments at Enewetak. We need Halimeda production data from pinnacles.

(f) The lagoon shallows. Coming to an atoll with the experience of a fringing reef, it would be logical to expect the unconsolidated sediments of shallows, with associated coral rock, to be a prime site of Halimeda and carbonate production. There is certainly some, but not what might be expected if the measure is the inshore reef of the Jamaican north shore at Glory Be. At Enewetak the densities of Rhipsalian Halimedae growing on sand are much less striking than on the Jamaican fringing reef. There are more hard-substrate species, but even these do not seem abundant by the standards of a fringing reef.

The shallows on the lagoon sides of the islets have much living or dead coral and rock debris, among which sandy surfaces are not 


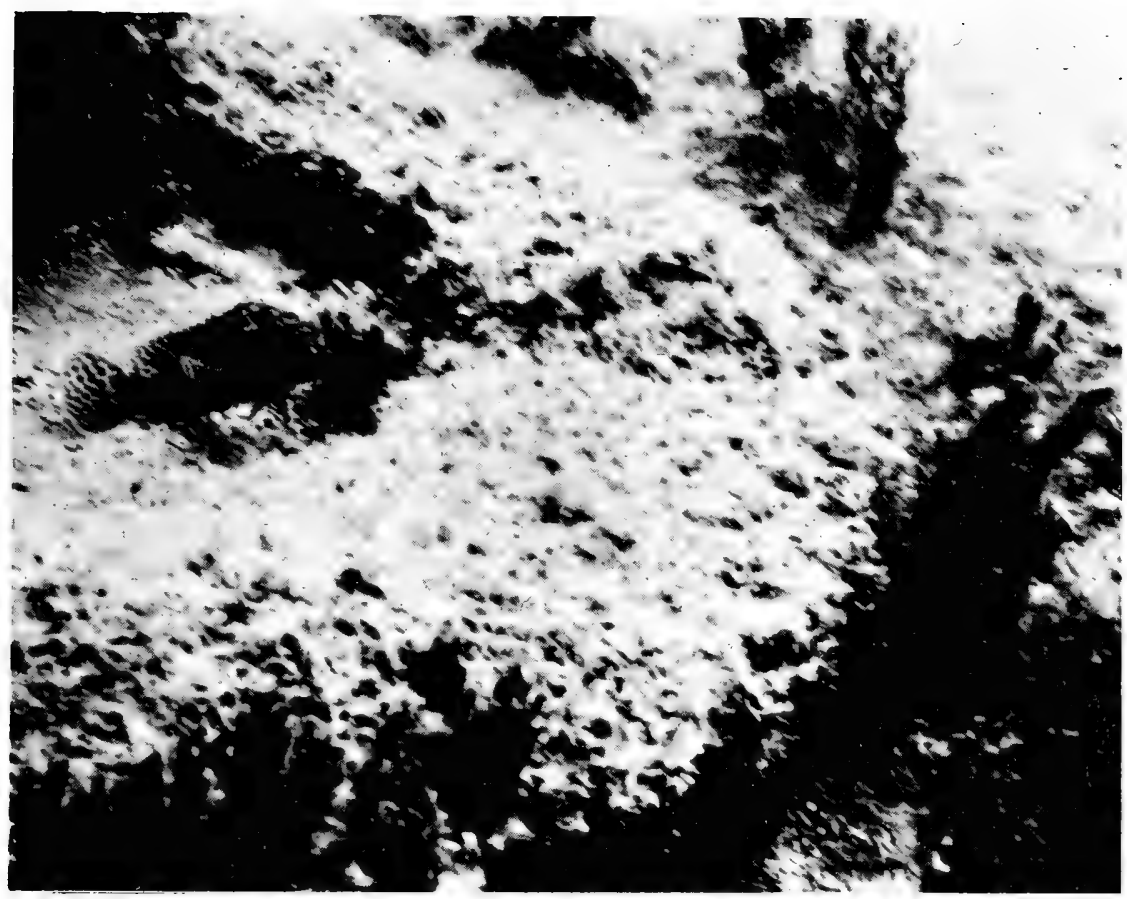

FIG. 103b. Many of the $H$. cylindracea populations at Enewetak develop in the vicinity of rock although it sometimes is buried, rather than in the more open patches of loose substrate. In the photograph, thalli of cylindracea have developed at the edge of rock substrate.

extensive. Halimeda macrophysa populations were prominent on rock surfaces or in crevices, sometimes accompanied with lesser amounts of gigas. Halimeda opuntia was much less extensive than in the island channels, though it sometimes festooned branching Acropora. All these populations were greatest in shallow water (as shallow as $-1 \mathrm{~m}$ ), but nowhere were there dense populations like those of opuntia in the rapidly moving waters of channels between islets. There also appears to be some geographic separation of populations of rock-attached forms within the atoll because in the northern parts the commonest species was none of the above three, but lacunalis $\mathrm{f}$. lata. At depths of 1-2 $\mathrm{m}$ at low tide it was common near the undercut bases of coral heads and hidden in Acropora thickets. It is possible that it is left in these protected places by grazing pressure, for the segments showed clear signs of being nibbled, perhaps by the common parrot fish.

Two Rhipsalian species, cylindracea (Figs 102, 103) and stuposa (Fig. 72, bottom), were abundant on unconsolidated substrates of the 
shallows. As with the rock forms, there seems to be a geographical separation of their ranges, at least to the extent that stuposa is mostly restricted to the northern parts of the lagoon (Fig. 98). In shallow parts in the north the two species together formed extensive meadows, though these are not really comparable to the incrassata meadows of Jamaica. Perhaps more significantly, these meadows in no way compare to the Thalassia meadows of Jamaica, not even in the apparent density of the Halimeda contribution to the Jamaican Thalassia meadows. It was remarked in the study of Glory Be that a Thalassiadominated community seemed to be involved in stabilizing patches of sand, and that Rhipsalian Halimedae were more abundant near or in these communities than in the open. Part of the low density of Rhipsalian Halimedae at Enewetak, therefore, may be a reflection of the absence of sea grasses. And this absence of sea grasses may be significant to the economy of the atoll.

(g) The lagoon floor. If the flats of the lagoon floor were covered with dense stands of Rhipsalian Halimedae, the source of the bulk of the reef carbonate would be explainable in one observation. But the floor is not so covered. This was first demonstrated by Gilmartin (1960) and our observations confirm this (Fig. 102b). There are very low densities of cylindracea (called monile in Gilmartin's paper), particularly near the bases of coral pinnacles. But for the most part the lagoon floor has few populations of Halimeda, and the ones that are there are rock-attached forms on coral blocks, particularly macrophysa. Gilmartin (1960) noted changes in the form of cylindracea with depth (Fig. 104), and postulated that the paucity of the species on the lagoon floor was a function of two processes: low light intensity and disturbance by burrowing animals. The relative prominence of animal mounds and castings on the lagoon floor near the base of pinnacles in $40 \mathrm{~m}$ of water certainly encourages acceptance of Gilmartin's hypothesis. Mounds and diggings show that the bottom is constantly overturned (Fig. 103). Plants growing at light intensities of $5 \%$ or $10 \%$ of that at the surface may well not achieve sufficiently vigorous growth to survive such constant digging.

\section{Halimeda at Enewetak: summary}

There are no obvious rivals to Halimedae as carbonate producers among the green algal macrophytes at Enewetak. Tydemania expeditionis is second, but a much lesser producer. 


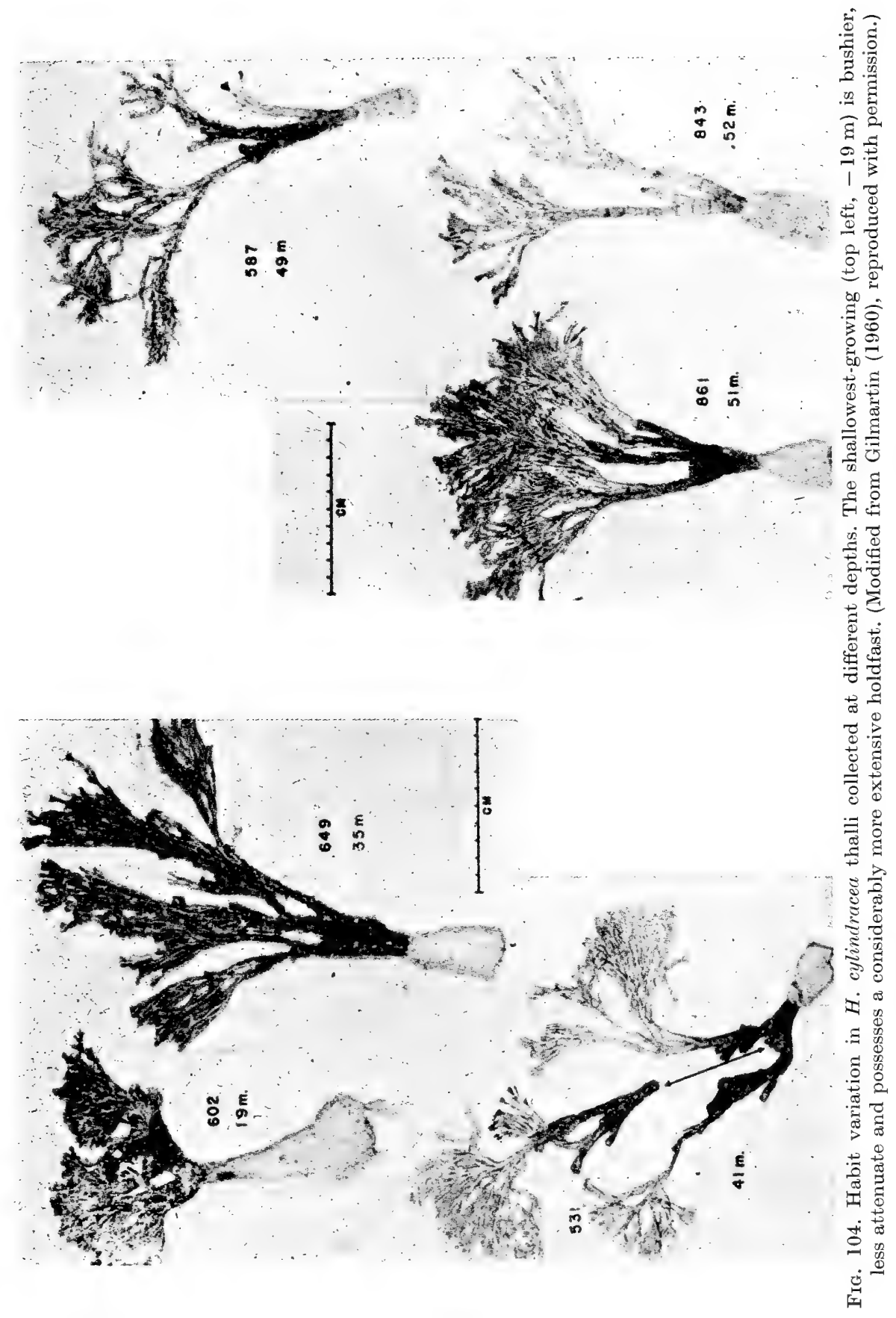


At least 14 species are present, of which macrophysa, opuntia, cylindracea, gigas, distorta, copiosa and lacunalis $\mathrm{f}$. lata appear to be the commonest (Hillis-Colinvaux, 1977). These, then, are the species which would contribute most to the atoll's primary productivity and calcium carbonate budgets.

Except for one collection, we have no information of the species, their species richness or biomass, seaward of the algal ridge. The high cover they provided at this one site, approximately $15 \%$ of a spur, presents a marked contrast to the spurs of Jamaica where Halimedae are rare.

It is likely that the Halimeda populations of the sides of the pinnacles are the prime producers of the Halimeda segments incorporated into the reef mass and thus are prime builders of the atoll. There are few Halimedae on the lagoon floor, and the lagoon floor, therefore, is not a prime source of Halimeda sediment.

There are no sea grasses at Enewetak, and this appears to have important consequences for Halimeda populations in unconsolidated sediments. Some of the densest sand-growing populations of Halimeda elsewhere are in association with sea-grass stands, and these dense stands are therefore not found at Enewetak. Communities of Halimeda and other algae do not seem to be able to replace sea grasses on sand substrates of the shallows. Whatever cause keeps sea grasses from Enewetak probably lowers the contribution of the lagoon shallows to the carbonate flux of the atoll.

\section{Acknowledgements}

My work on this paper has taken more than a decade. Very many people helped, not all of whom can be listed below. I am grateful to them all. Research in the field has needed the large financial support inseparable from work in remote places, and I list all grant support below. I particularly want to give my thanks to the United States Office of Naval Research, without whose enlightened support of a female planning to dive on coral reefs more than a dozen years ago, much of the framework of this research would not have been possible.

I began writing the paper at the British Museum (Natural History) where I held the Founder's Fellowship of the American Association of University Women. I am particularly grateful for this vital and timely support, and to Mr R. Ross, then Keeper of Botany of the British Museum (Natural History), and my colleagues there, for the privileges and pleasure associated with the Fellowship year, and for courtesies and assistance extended to me on other visits as well.

For the opportunity to examine Halimeda with the Ellis Aquatic Microscope (c. 1752) and other contemporary microscopes, I thank Mr F. W. 
Palmer, Keeper of Physics, the Science Museum, London. I also thank the curators and staff of the following herbaria and museums for arrangements to study Halimeda collections, and for their hospitality and assistance: the Botanical Museum (Lund), the Botanical Museum (Copenhagen), the Rijksherbarium (Leiden), the State Botanic Garden (Brussels), the National Museum of Natural History (Paris), the Royal Botanic Garden (Kew), the Linnean Society (London), the Belfast Museum (Northern Ireland), the State Herbarium of Western Australia (Perth), the Institute of Jamaica (Kingston), the New York Botanic Garden (New York City), the United States National Museum (Washington), the University of Michigan (Ann Arbor), the University of California (Berkeley), Yale University (New Haven) and Harvard University (Cambridge). In addition, Professor A. Pitot of the Botany Laboratory of the University of Caen and Professor S. Ruffo, Director of the Civic Museum of Natural History, Verona, provided helpful information about Halimeda collections.

My first opportunity for extensive field study of Halimedae among reefs came when I was aboard the Te Vega in the International Indian Ocean Expedition, funded by National Science Foundation Grant 17465, with field activities assisted by Drs K. Rützler, A. J. Kohn, J. Rosewater, students and crew. Additional research opportunities at ports of call were provided by the ship's agents, and by Mr H. M. Burkill, Director of the Singapore Botanic Gardens, and Mrs Burkill, Mr K. R. Romimohtarto of the Institute of Marine Research, Pasar Ikan (Djakarta), Mrs D. J. Everett in Singapore and Mrs J. Harris, Phuket (Thailand). Doctors G. F. Papenfuss, R. F. Scagel, S. A. Earle, H. E. Hackett and M. J. Wynne contributed their International Indian Ocean Expedition Halimedae for examination.

Doctor Thomas F. Goreau invited me to look at the Halimedae of Jamaican reefs before the Discovery Bay laboratory became a reality, and this visit was the basis for three subsequent expeditions, and my research on the Glory Be reef east of Ocho Rios, to which Miss Marion Simmons so graciously gave access, work which was funded by the Office of Naval Research N00014-67-C-0262, and 313-3018 under NR 104-873.

Doctor Stephen V. Smith encouraged me to examine Halimedae on Enewetak Atoll, work which was funded by the United States Energy Research and Development Administration. Doctor K. M. Wilbur of Duke University provided the opportunity to investigate calcification and ultrastructure, with the help of Dr N. Watabe and with the support of the National Institute of Dental Research, National Institutes of Health, grants DE-01382-04 and 5 TI DE 92-03, and by the Office of Naval Research, Biology Branch, grant Nonr 1181 (06).

My first culture work was undertaken at the Queen's University, Belfast, Northern Ireland, where I had the privilege of serving as a visiting faculty member for a year at the invitation of Professor D. J. Carr.

Further support for the research has been provided by National Science Foundation grant GB 3296, Sigma Xi, and the Ohio State University. In addition the work has been aided by: O. Almborne, L. R. Almodovar, 
A. Austin, A. and C. Barens, J. R. Beers, A. J. Bernatowicz, H. Blackler, R. Bolin, P. Bourrelly, G. C. and B. Carl, E. Chin, J. W. Collinson, D. J. Cooke, R. Cooper, J. D. Costlow, F. C. Croley, M. Dautartas, E. Y. Dawson, V. Deisner, M. Denizot, M. Diaz-Piferrer, R. Doeringer, M. S. Doty, R. Douce, S. C. Ducker, G. F. Elliott, R. Ellis, W. F. Farnham, J. Feldmann, F. M. Fenner, F. R. Fosberg, A. Gittings, E. A. Graham, L. Greene, F. Gross, J. A. Hagler, J. B. Hansen, J. Hayworth, B. Herrimann, C. van den Hoek, P. K. Holmgren, H. J. Humm, P. W. Hummelinck, L. Irvine, W. E. Isaac, E. Jaasund, D. M. John, H. H. Johnson, C. D. Kendall, D. Kinsman, J. Th. Koster, C. Krupke, J. and P. Lamberson, Y. Lipkin, L. Lisiecki, J. Marsh, D. Maxwell, D. McConnell, E. G. Meñez, S. P. Meyers, P. J. Miller, J. D. Milliman, D. Mills, J. Moore, E. Moul, A. Muster, R. P. Norris, J. S. Pate, M. Peery, P. Petrovic, C. Pierce, J. H. Price, L. Provasoli, J. Ramirez, A. Y. Reyes, C. F. Rhyne, D. P. Rogers, C. T. Rogerson, R. D. Royce, J. C. Rupert, G. Sartoni, E. K. Schofield, P. C. Silva, R. Spies, W. W. M. Steiner, W. H. Sutcliffe Jr, S. E. Talbot, Sir George Taylor, W. R. Taylor, K. V. Thimann, I. Titley, G. Trono, R. Tsuda, G. Valet, R. T. Wilce, H. B. S. Womersley, J. L. Wray and Y. Yamada.

\section{REFERENCES}

Adey, W. H. (1975). The algal ridges and coral reefs of St. Croix: their structure and Holocene development. Atoll Research Bulletin, 187, 1-67.

Adey, W. H. and Burke, R. (1976). Holocene bioherms (algal ridges and bankbarrier reefs) of the eastern Caribbean. Geological Society of America Bulletin, 87, 95-109.

Adey, W. H. and Macintyre, I. G. (1973). Crustose coralline algae: a reevaluation in the geological sciences. Geological Society of America Bulletin, 84, 883-904.

Adey, W. H., Adey, P. J., Burke, R. and Kaufman, L. (1976). The Holocene reef systems of eastern Martinique, French West Indies. Atoll Research Bulletin, $218,1-40$.

Agardh, J. G. (1887). Till algernes systematik. VIII. Siphoneae. Acta Universitets Lund, 23, Afd. 3(2), 1-174.

Agardh, J. G. (1894). Analecta algologica, observationes de speciebus algarum minus cognitus earumque dispositione. Continuatio I. Acta Universitets Lund, 29, Afd. 2(9), 1-144.

Askenasy, E. (1888). Algen. In "Die Forschungsreise S.M.S. Gazelle 1874 bis 1876 unter Kommando ... Freiherrn von Schleinits", Th. 4, Bot., 58 pp. Berlin.

Aspinall, G. O. and Kessler, G. (1957). The structure of callose from the grape vine. Chemistry and Industry, London, 1296.

Bakus, G. J. (1967). The feeding habits of fishes and primary production at Eniwetok, Marshall Islands, Micronesica, 3, 135-149.

Barnes, H. (1959). "Apparatus and Methods of Oceanography. Part I: Chemical", $341 \mathrm{pp}$. Allen and Unwin, London.

Barton, E. S. (1900). On the forms, with a new species of Halimeda, from Funafuti. Biological Journal of the Linnean Society of London, 34, 479-482.

Barton, E. S. (1901). The Genus Halimeda. Monographs of the Siboga Expedition. 60, $32 \mathrm{pp}$. Leiden. 
Bauhin, J. H. and Cherler, J. H. (1651). "Historia Plantarum Universalis" (D. Chabré and F. L. von Graffenried, eds), Vol. 3, Part 39, pp. 802-803. Yverdo. Baxter, J. (1761). Dissertationemhanc de Zoophytis. Philosophical Transactions, 52, 108-118.

Beers, J. R., Steven, D. M. and Lewis, J. B. (1968). Primary productivity in the Caribbean Sea off Jamaica and the tropical north Atlantic off Barbados. Bulletin of Marine Science, 18, 86-104.

Berggren, W. A. and Hollister, C. D. (1974a). Paleography, paleobiogeography, and the history of circulation in the Atlantic Ocean. In "Studies in PaleoOceanography" (W. W. Hay, ed.), pp. 126-186. Society of Economic Paleontologists and Mineralogists Special Publication No. 20. Tulsa, Oklahoma.

Berggren, W. A. and Hollister, C. D. (1974b). Currents of time. Oceanus, 17, 28-32.

Bertolini, A. (1819). "Amoenitates Italicae", 472 pp. Bologna.

Beth, K. (1962). Reproductive phases in populations of Halimeda tuna in the Bay of Naples. Publicazioni della Stazione Zoologica di Napoli, Italy, 32 (suppl.), 515-534.

Blackman, F. F. and Tansley, A. G. (1902). A revision of the classification of the green algae. New Phytologist, 1, 17-24, 47-48, 67-72, 89-96, 114-120, 133-144, 163-168, 189-192, 213-220, 238-244.

Böhm, E. L. (1972). Cation-anion balance in some calcium carbonate depositing algae and the detection of organic calcium fractions in the calcareous alga, Halimeda opuntia L. (Chlorophyta, Udoteaceae). Internationale Revue der Gesamten Hydrobiologie, 57(5), 685-693.

Böhm, E. L. (1973a). Studies on the mineral content of calcareous algae. Bulletin of Marine Science, 23(2), 177-190.

Böhm, E. L. (1973b). Composition and calcium binding properties of the water soluble polysaccharides in the calcareous alga, Halimeda opuntia $\mathbf{L}$. (Chlorophyta, Udoteaceae). Internationale Revue der Gesamten Hydrobiologie, 58(1), 117-126.

Böhm, E. L. and Goreau, T. F. (1973). Rates of turnover and net accretion of calcium and the role of calcium binding polysaccharides during calcification in the calcareous alga, Halimeda opuntia L. Internationale Revue der Gesamten Hydrobiologie, 58(5), 723-740.

Bold, H. C. and Wynne, M. J. (1978). "Introduction to the Algae. Structure and Reproduction", 706 pp. Prentice-Hall, Englewood Cliffs, New Jersey.

Børgesen, F. (1911). Some Chlorophyceae from the Danish West Indies. Botanisk Tidsskrift, 31, 127-152.

Børgesen, F. (1913). The marine algae of the Danish West Indies. I. Chlorophyceae and Phaeophyceae. Part 1 Chlorophyceae. Dansk Botanisk Arkiv, 1 (4), 1-160.

Borowitzka, M. A. (1977). Algal calcification. Oceanography and Marine Biology, Annual Review, 15, 189-223.

Borowitzka, M. A. and Larkum, A. W. D. (1974a). The caulerpalean thylakoid organizing body. Eighth International Congress on Electron Microscopy, Canberra, Vol. 2, 588-589.

Borowitzka, M. A. and Larkum, A. W. D. (1974b). Chloroplast development in the caulerpalean alga Halimeda. Protoplasma, 81, 131-144.

Borowitzka, M. A. and Larkum, A. W. D. (1976a). Calcification in the green alga Halimeda. II. The exchange of $\mathrm{Ca}^{2+}$ and the occurrence of age gradients in calcification and photosynthesis. Journal of Experimental Botany, $27(100)$, 864-878. 
Borowitzka, M. A. and Larkum, A. W. D. (1976b). Calcification in the green alga Halimeda. III. The sources of inorganic carbon for photosynthesis and calcification and a model of the mechanism of calcification. Journal of Experimental Botany, 27(100), 879-893.

Borowitzka, M. A. and Larkum, A. W. D. (1976c). Calcification in the green alga Halimeda. IV. The action of metabolic inhibitors on photosynthesis and calcification. Journal of Experimental Botany, 27 (100), 894-907.

Borowitzka, M. A. and Larkum, A. W. D. (1977). Calcification in the green alga Halimeda. I. An ultrastructure study of the thallus development. Journal of Phycology, 13(1), 6-16.

Borowitzka, M. A., Larkum, A. W. D. and Nockolds, C. E. (1974). A scanning electron microscope study of the structure and organization of the calcium carbonate deposits of algae. Phycologia, 13(3), 195-203.

Brand, F. (1901). Über einige Verhältnisse des Baues und Wachsthums von Cladophora. Beihefte zum Botanischen Zentralblatt, 10, 481-521.

Bunt, J. S. (1975). Primary productivity of marine ecosystems. In "Primary Productivity of the Biosphere" (H. Lieth and R. H. Whittaker, eds), pp. 169-183. Springer-Verlag, New York.

Bunt, J. S., Lee, C. C. and Lee, E. (1972). Primary productivity and related data from tropical and subtropical marine sediments. Marine Biology, 16, 28-36.

Burr, F. A. and West, J. A. (1970). Light and electron microscope observations on the vegetative and reproductive structures of Bryopsis hypnoides. Phycologia, 9(1), 17-37.

Burr, F. A. and West, J. A. (1971a). Comparative ultrastructure of the primary nucleus in Bryopsis and Acetabularia. Journal of Phycology, 7(2), 108-113.

Burr, F. A. and West, J. A. (1971b). Protein bodies in Bryopsis hypnoides: their relationship to wound-healing and branch septum development. Journal of Ultrastructure Research, 35(5-6), 476-498.

Calvert, H. E., Dawes, C. J. and Borowitzka, M. A. (1976). Phylogenetic relationships of Caulerpa (Chlorophyta) based on comparative chloroplast ultrastructure. Journal of Phycology, 12(2), 149-162.

Chadefaud, M. (1941). Les pyrénoides des algues. Annales des Sciences Naturelles (Botanique Séries) 11, 1-44.

Chadefaud, M. (1960). Les végétaux non vasculaires. In "Traité de Botanique Systématique" (M. Chadefaud and L. Emberger, eds), Vol. 1, pp. 334-383. Masson, Paris.

Chapman, V. J. (1964). The Chlorophyta. In "Oceanography and Marine Biology, Annual Review" (H. Barnes, ed.), pp. 193-228. Allen and Unwin, London.

Chauvin, J. F. (1842). Recherches sur l'organisation, la fructification et la classification de plusieurs genres d'algues, avec la description de quelques espèces inédites ou peu connues. Caen, $132 \mathrm{pp}$.

Chave, K. E., Smith, S. V. and Roy, K. J. (1972). Carbonate production by coral reefs. Marine Geology, 12, 123-140.

Chen, J. C. W. and Jacobs, W. P. (1966). Quantitative study of development of the giant coenocyte, Caulerpa prolifera. American Journal of Botany, 53(5), 413-423.

Chihara, M. (1956). Studies on the life-history of the green algae in the warm seas around Japan. IV. On the life-history of Halimeda cuneata Hering (1). Journal of Japanese Botany, 31(4), 102-110.

Christensen, T. (1966). Alger. In "Systematisk Botanik" (T. W. Böcher, M. Lange and 'T. Sørenson, eds), 2nd Edn, Vol. 2, No. 2, pp. 1-180. Munksgaard, Copenhagen. 
Clusius, C. (1601). In "Rariorum Plantarum Historia, ex Officiana Plantiniana apud Ioannem Moretum" (C. de l'Ecluse, ed.), 304 pp. Antwerp.

Colinvaux, L. Hillis (1968a). New species of Halimeda: a taxonomic reappraisal. Journal of Phycology, 4, 30-35.

Colinvaux, L. Hillis (1968b). Vegetative reproduction of Halimeda and related Siphonales in laboratory culture. Journal of Phycology, 4 (Suppl.), 4.

Colinvaux, L. Hillis (1968c). "Research on and Culture of Calcareous Green Algae," 10 pp. Report to Department of the Navy, Office of Naval Research, Washington, DC.

Colinvaux, L. Hillis (1969a). Halimeda copiosa and Halimeda hederacea. Journal of Phycology, $\mathbf{5}(1), 88$.

Colinvaux, L. Hillis (1969b). Research on and culture of calcareous green algae. In "Oceanic Biology", pp. 53-54, Office of Naval Research Report, Dr-151. Office of Naval Research, Washington, DC.

Colinvaux, L. Hillis and Graham, E. A. (1964). A new species of Halimeda. Nova Hedwigia, 7(1-2), 5-10.

Colinvaux, L. Hillis, Wilbur, K. M. and Watabe, N. (1965). Tropical marine algae: growth in laboratory culture. Journal of Phycology, 1(2), 69-78.

Colinvaux, P. A. (1973). "Introduction to Ecology", $621 \mathrm{pp}$. John Wiley and Sons, New York.

Colinvaux, P. A. (1974). Why the sea is blue. The Yale Review, 64(1), 135-142.

Colinvaux, P. A. (1978). "Why Big Eierce Animals are Rare: An Ecologist's Perspective", 256 pp. Princeton University Press, Princeton.

Collins, F. S. (1901). The algae of Jamaica. Proceedings of the American Academy of Arts and Sciences, 37(9), 229-270.

Collins, F. S. (1909-1918). The green algae of North America. Tufts College Studies, 2(3), 79-480; 3(2), 69-109; 4(7), 1-106.

Colombo, P. M. and Orsenigo, M. (1977). Sea depth effects on the algal photosynthetic apparatus. II. An electron microscopic study of the photosynthetic apparatus of Halimeda tuna (Chlorophyta, Siphonales) at $-0.5 \mathrm{~m}$ and $-6.0 \mathrm{~m}$ sea depths. Phycologia, 16(1), 9-17.

Connor, J. L. and Adey, W. H. (1977). The benthic algal composition, standing crop and productivity of a Caribbean algal ridge. Atoll Research Bulletin, 211, $1-15$.

Couch, Jr, R. F., Fetzer, J. A., Goter, R. R., Ristvet, B. L., Tremba, E. L., Walter, D. R. and Wendland, V. P. (1975). "Drilling Operations on Eniwetok Atoll During Project EXPOE", Final Report (AFWL-TR-75-216), 270 pp. Air Force Weapons Laboratory, Kirtland Air Force Base, New Mexico.

Czurda, V. (1928). Morphologie und Physiologie der Algen-Stärkekörnes. Beihefte zum Botanischen Zentralblatt, 45, 97-270.

Dawes, C. J. and Rhamstine, E. L. (1967). An ultrastructural study of the giant green algal coenocyte, Caulerpa prolifera. Journal of Phycology, 3(3), $117-126$.

Dawson, E. Y. (1957). An annotated list of marine algae from Eniwetok Atoll, Marshall Islands. Pacific Science, 11, 92-132.

Dawson, E. Y. (1966). "Marine Botany," 371 pp. Holt, Rinehart and Winston, New York.

Decaisne, M. J. (1841). Plantes de l'Arabic heureuse, recueillies par M. P. E. Botta. Archives du Museum National d'Histoire Naturelle (Paris), 2, 89-199.

Decaisne, M. J. (1842). Mémoire sur les corallines ou polypiers calcifères. Annals of Botany, 18, 96-128. 
Delle Chiaie, S. (1829). "Hydrophytologia Regni Neapolitani Icones", 27 pp. Naples.

Derbès, A. A. and Solier, J. J. (1856). Mémoire sur quelques points de la physiologie des algues. Comptes Rendus Hebdomadaires des Séances de l'Académie des Sciences, Paris, 1 (suppl.), 1-120.

Descomps, S. (1965). Observations sur l'infrastructure des plastes de Caulerpales (Chlorophycées). Comptes Rendus Hebdomadaires des Séances de l'Académie des Sciences, Paris, 261(4), 1061-1063.

De Toni, G. B. (1889). "Sylloge Algarum. I. Sylloge Chlorophycearum", 1315 pp. Padua.

Drew, E. A. (1966). A technique for determination of photosynthetic ability of attached marine algae at various depths in situ. Symposium of the Underwater Association for Malta 1965, pp. 65-67.

Drew, E. A. and Larkum, A. W. D. (1968). Photosynthesis and growth of Udotea, a green alga from deep water. Underwater Association Report, 1966-1967, $65-71$.

Duchassaing, P. (1850). "Animaux Radiaires des Antilles", pp. 27-28. Paris.

Ducker, S. C. (1965). The structure and reproduction of the green alga Chlorodesmis bulbosa. Phycologia, 4(3), 149-162.

Ducker, S. C. (1967). The genus Chlorodesmis (Chlorophyta) in the Indo-Pacific region. Nova Hedwigia, $13(1 / 2), 145-182$.

Earle, S. A. (1972). The influence of herbivores on the marine plants of Great Lameshur Bay, with an annotated list of plants. In "Results of the Tektite Program: Ecology of Coral Reef Fishes" (B. B. Collette and S. A. Earle, eds), pp. 17-44. Bulletin of the Natural History Museum of Los Angeles County, No. 14.

Egerod, L. E. (1952). An analysis of the siphonous Chlorophycophyta with special reference to the Siphonocladales, Siphonales and Dasycladales of Hawaii. University of California Publications in Botany, 25, 325-454.

Elliott, G. F. (1960). Fossil calcareous algal floras of the Middle East with a note on a Cretaceous problematicum, Hensonella cylindrica gen. et sp. nov. Quarterly Journal of the Geological Society of London, CXV, 217-232.

Elliott, G. F. (1965). The interrelationships of some Cretaceous Codiaceae (calcareous algae). Palaeontology, 8(2), 199-203.

Ellis, J. (1755). "An Essay Towards a Natural History of the Corallines", 103 pp. London.

Ellis, J. (1767). Extract of a letter from John Ellis, Esq. F.R.S. to Dr. Linnaeus, of Upsal F.R.S., on the animal nature of the genus of zoophytes called Corallina. Philosophical Transactions, 57, 404-427.

Ellis, J. and Solander, D. (1786). "The Natural History of many Curious and Uncommon Zoophytes Collected from Various Parts of the Globe by ... John Ellis... Systematically Arranged and Described by ... Daniel Solander, etc.", 208 pp. London.

El-Sayed, S. A. and Turner, J. T. (1977). Productivity of the Antarctic and tropical/subtropical regions : a comparative study. In "Polar Oceans" (M. J. Dunbar, ed.), pp. 463-503. The Arctic Institute of North America.

Emery, K. O., Tracey, Jr, J. I. and Ladd, H. S. (1954). "Geology of Bikini and Nearby Atolls, I. Geology," 265 pp. United States Survey Professional Paper No. 260-A.

Ernst, A. (1904). Siphoneen-Studien. II. Beiträge zur Kenntnis der Codiaceen. Beihefte zum Botanischen Zentralblatt, 16(104), 199-236. 
Esper, E. J. C., ed. (1788-1830). "Pflanzenthiere", Vols 1-3, Fortsetz. 2, 1798-1806. Nürnberg.

Fabbri, F. and Palandri, M. (1969). First observations on the ultrastructure of young and old segments of Halimeda tuna (Ell. et Sol.) Lamour. Giornale Botanico Italiano, 103, 610.

Feldmann, J. (1946). Sur l'hétéroplastie de certaines Siphonales et leur classification. Comptes Rendus Hebdomadaires des Séances de l'Académie des Sciences, Paris, 222(13), 752-753.

Feldmann, J. (1950). Sur l'existence d'une alternance de générations entre l'Halicystis parvula Schmitz et le Derbesia tenuissima (De Not.) Crn. Comptes Rendus Hebdomadaires des Séances de l'Académie des Sciences, Paris, 230, 322.

Feldmann, J. (1951). Sur la reproduction sexuée de l'Halimeda tuna (Ell. et Sol.) Lamour. f. platydisca (Decaisne) Barton. Comptes Rendus Hebdomadaires des Séances de l'Académie des Sciences, Paris, 233(14), 1309-1310.

Feldmann, J. (1954). Sur la classification des Chlorophycées Siphonées. VIII. Congrès International de Botanique, Rapports et Communications, Section 17, pp. 96-98.

Feldmann, J. (1955). Les plastes des Caulerpa et leur valeur systématique. Revue Général de Botanique, 62, 422-431.

Feldmann, J. (1968). Les types biologiques des cryptogames non-vasculaires. Les types biologiques d'algues marine benthiques. Bulletin de la Société Botanique de France, Mémoires, 1966, 45-60.

Finckh, A. E. (1904). Biology of the reef-forming organisms at Funafuti Atoll. In "The Atoll of Funafuti. Borings into a Coral Reef and the Results", pp. 125-150. The Royal Society of London.

Frei, E. and Preston, R. D. (1964). Non-cellulosic structural polysaccharides in algal cell walls. I. Xylan in siphoneous green algae. Proceedings of the Royal Society of London, 1960B, 293-313.

Friedmann, E. I., Roth, W. C., Turner, J. B. and McEwen, R. S. (1972). Calcium oxalate crystals in the aragonite-producing green alga Penicillis and related genera. Science, 177, 891-893.

Fritsch, F. E. (1935). "The Structure and Reproduction of the Algae", Vol. I, $91 \mathrm{pp}$. Cambridge University Press, Cambridge.

Fritsch, F. E. (1948). "The Structure and Reproduction of the Algae", Vol. I, 791 pp. Cambridge University Press, Cambridge.

Gepp, A. and Gepp, E. S. (1911). "The Codiaceae of the Siboga Expedition Including a Monograph of Flabellarieae and Udoteae," 150 pp. E. J. Brill, Leiden.

Gepp, E. S. (1904). The sporangia of Halimeda. Journal of Botany, London, 42, 193-197.

Gessner, F. and Hammer, L. (1960). Die Primärproduktion in mediterranen Caulerpa-Cymodocea-Wiesen. Botanica Marina, 2, 160-165.

Gilbert, W. J. (1947). Studies on Philippine Chlorophyceae. III. The Codiaceae. Bulletin of the Torrey Botanical Club, 74(2), 121-132.

Giles, K. L. and Sarafis, V. (1974). Implications of rigescent integuments as a new structural feature of some algal chloroplasts. Nature, London, 248, $512-513$.

Gilmartin, M. (1960). The ecological distribution of the deep water algae of Eniwetok Atoll. Ecology, 41(1), 210-221. 
Gilmartin, M. (1966). Ecology and morphology of Tydemania expeditionis, a tropical deep-water siphonous green alga. Journal of Phycology, 2(3), 100-105.

Ginsburg, R. N., Lloyd, R. M., Stockman, K. W. and McCallum, J. S. (1963). Shallow-water carbonate sediments. In "The Sea" (M. N. Hill ed.), Vol. 3, pp. 554-582. Interscience Publishers, New York.

Goreau, T. F. (1959). The ecology of Jamaican reefs. I. Species composition and zonation. Ecology, 40, 67-90.

Goreau, T. F. (1963). Calcium carbonate deposition by coralline algae and corals in relation to their roles as reef-builders. Annals of the New York Academy of Sciences, 109, 127-167.

Goreau, T. F. and Goreau, N. I. (1973). The ecology of Jamaican coral reefs. II. Geomorphology, zonation and sedimentary phases. Bulletin of Marine Science, 23(2), 399-464.

Goreau, T. F. and Graham, E. A. (1967). A new species of Halimeda from Jamaica. Bulletin of Marine Science, 17(2), 432-441.

Goreau, T. F. and Land, L. S. (1974). Fore-reef morphology and depositional processes, North Jamaica. In "Reefs in Time and Space" (L. E. Laporte, ed.), pp. 77-89. Society of Economic Paleontologists and Mineralogists Special Publication No. 18.

Graham, E. A. (1975). Fruiting in Halimeda (order Siphonales). I. Halimeda cryptica Colinvaux and Graham. Bulletin of Marine Science, 25(1), 130-133.

Greville, R. K. (1830). "Algae Britannicae", 218 pp. Edinburgh.

Hallam, A. (1975). "Jurassic Environments", 270 pp. Cambridge University Press, Cambridge.

Hammer, F. L. (1829-1930). In "Pflanzenthiere" (E. J. C. Esper, ed.), Vol. 3, Parts 16 and 17, Nürnberg.

Hanic, L. A. and Craigie, J. S. (1969). Studies on the algal cuticle. Journal of Phycology, 5(2), 89-102.

Harvey, W. H. (1858). Nereis Boreali-Americana. Part III, Chlorospermae. Smithsonian Contributions to Knowledge, 10, 1-140.

Harvey, W. H. (1860-1863). "Phycologia Australica", Vols 1-5. London.

Hauck, F. (1886). Uber einige von J. M. Hildebrandt im Rothen Meere und Indischen Ocean gesammelte Algen, I. Hedwigia, 25(5), 165-168.

Hill, J. (1751). "A General Natural History", Vol. 2, "A History of Plants", 649 pp. London.

Hillis, L. (1959). A revision of the genus Halimeda (order Siphonales). Publications of the Institute of Marine Science, University of Texas, 6, 321-403.

Hillis-Colinvaux, L. (1972). "Research on and Culture and Calcareous Green Algae", Ohio State University Research Foundation, Report to Department of the Navy, Office of Naval Research, Washington, DC.

Hillis-Colinvaux, L. (1973). Reproduction in the calcareous green algae of coral reefs. Journal of the Marine Biological Association of India, 14(1), 328-334.

Hillis-Colinvaux, L. (1974). Productivity of the coral reef alga Halimeda (Siphonales). Proceedings of the Second International Coral Reef Symposium, Vol. 1, pp. 35-42.

Hillis-Colinvaux, L. (1975). Halimeda renschii revived and Halimeda batanensis (Chlorophyta, Siphonales). Phycologia, 14(2), 93-97.

Hillis-Colinvaux, L. (1977). Halimeda and Tydemania: distribution, diversity and productivity at Enewetak. Proceedings of the Third International Coral Reef Symposium, Vol. 1, pp. 365-370, 
Hinde, G. J. (1904). Report on the materials from the borings at the Funafuti Atoll. In "The Atoll of Funafuti. Borings into a Coral Reef and the Results", Section XI, pp. 186-361. The Royal Society of London.

Hoek, C. van den, Cortel-Breeman, A. M., Rietema, H. and Wanders, J. B. W. (1972). L'interprétation des données obtenues, par des cultures unialgales, sur les cycles évolutifs des algues. Quelques exemples tirés des recherches conduites au laboratoire de Groningue. Société Botanique de France, Mémoires, 1972, $45-66$.

Hori, T. (1974). Electron microscope observations on the fine structure of the chloroplasts of algae. II. The chloroplasts of Caulerpa (Chlorophyceae). Internationale Revue der Gesamten Hydrobiologie, 59(2), 239-245.

Hori, T. and Ueda, R. (1967). Electron microscope studies on the fine structure of plastids in siphonous green algae with special reference to their phylogenetic relationships. Science Report Tokyo Kyoiku Daigaku, Sect. B, 12(187), $225-244$.

Hori, T. and Ueda, R. (1975). The fine structure of algal chloroplasts and algal phylogeny. In "Advance of Phycology in Japan" (J. Tokida and H. Hirose, eds), pp. 11-42. Veb Gustav Fischer Verlag, Jena.

Howe, M. A. (1905a). Phycological studies. 1. New Chlorophyceae from Florida and the Bahamas. Bulletin of the Torrey Botanical Club, 32, 241-252.

Howe, M. A. (1905b). Phycological studies. II. New Chlorophyceae, new Rhodophyceae and miscellaneous notes. Bulletin of the Torrey Botanical Club, 32, $563-586$.

Howe, M. A. (1907). Phycological studies. III. Further notes on Halimeda and Avrainvillea. Bulletin of the Torrey Botanical Club, 34, 491-516.

Howe, M. A. (1909). Phycological studies. IV. The genus Neomeris and notes on other Siphonales. Bulletin of the Torrey Botanical Club, 36, 75-104.

Howe, M. A. (1911). Phycological studies. V. Some marine algae of lower California, Mexico. Bulletin of the Torrey Botanical Club, 38, 489-514.

Hsü, J. K. et al. (1977). History of the Mediterranean salinity crisis. Nature, London, 267, 399-403.

Huizing, H. J. and Rietema, H. (1975). Xylan and mannan as cell wall constituents of different stages in the life-histories of some siphoneous green algae. British Phycological Journal, 10, 13-16.

Huizing, H. J., Rietema, H. and Sietsma, J. H. (1979). Cell wall constituents of several siphoneous green algae in relation to morphology and taxonomy. British Phycological Journal, 14(1), 25-32.

Hustede, H. (1964). Entwicklungsphysiologische Untersuchungen über den Generationswechsel zwischen Derbesia neglecta Berth. und Bryopsis Halymeniae Berth. Botanica Marina, 6, 134-142.

Huvé, P. and Huvé, H. (1961). A propos de Penicillus capitatus Lamarck, forma Mediterranea (Decaisne) comb. nov. (Caulerpale, Udotéacée). Fourth International Congress on Seaweeds, pp. 99-111.

Imperato, F. (1599). 'Dell'Historia Naturale, nella quale Ordinatamente si Tratta della Diversa Conditione di Miniere, e Pietre. Con Alcune Historie de Piante e Animali; sin'hora non data in Luce", Vol. 28, 791 pp. Naples.

Isaac, W. E. (1971). Marine botany of the Kenya coast. 5. A third list of Kenya marine algae. Journal of the East Africa Natural History Society and National Museum, 28(122), 1-23. 
Jacobs, W. P. (1958). Experiments on the growth and differentiation of the giant siphonaceous alga, Caulerpa prolifera. Third International Seaweed Sym. posium, Abstracts, p. 12.

Jeffrey, S. E. (1968). Pigment composition of siphonales algae in the brain coral Favia. Biological Bulletin, 135(1), 141-148.

Johannes, R. E. et al. (1972). The metabolism of some coral reef communities: a team study of nutrient and energy flux at Eniwetok. BioScience, 22, 541-543.

Johnson, J. H. (1969). A review of the Lower Cretaceous algae. Professional Contributions of the Colorado School of Mines, No. 6, 180 pp. Golden, Colorado.

Johnston, C. S. (1969). The ecological distribution and primary production of macrophytic marine algae in the eastern Canaries. Internationale Revue der Gesamten Hydrobiologie, 54(4), 473-490.

Johnston, C. S. and Cook, J. P. (1968). A preliminary assessment of the techniques for measuring primary production in macrophytic marine algae. Experientia, 24, 1176-1177.

Judd, J. W. (1904). General report on the materials sent from Funafuti, and the methods of dealing with them. In "The Atoll of Funafuti. Borings into a Coral Reef and the Results", Section X, pp. 176-180. The Royal Society of London.

Kamura, S. (1966). On the sexual reproduction of two species of Halimeda (Chlorophyta). Bulletin of Arts and Science, University of the Ryukyus, Mathematics and Natural Sciences, 9, 302-313.

Kanwisher, J. W. and Wainwright, S. A. (1967). Oxygen balance in some reef corals. Biological Bulletin, 133(2), 378-390.

Kinsman, D. J. J. (1964). Reef coral tolerance of high temperatures and salinities. Nature, London, 202(4939), 1280-1282.

Kleinig, H. (1969). Carotenoids of siphonous green algae: a chemotaxonomical study. Journal of Phycology, 5(4), 281-285.

Koblentz-Mishke, O. J., Volkovinsky, V. V. and Kabanova, J. G. (1970). Plankton primary production of the world ocean. In "Scientific Exploration of the South Pacific" (W. S. Wooster, ed.), pp. 183-193. National Academy of Science, Washington, DC.

Kohn, A. J. and Helfrich, P. (1957). Primary organic productivity of a Hawaiian coral reef. Limnology and Oceanography, 2, 241-251.

Kornmann, P. (1938). Zur Entwicklungsgeschichte von Derbesia und Halicystis. Planta, 28, 464-470.

Krauss, F. (1846). Pflanzen des Cap- und Natal-Landes. Flora, Treviso, 1846(14), 209-219.

Kupfer, E. (1907). Studies in plant regeneration. Memoirs of the Torrey Botanical Club, 12(3), 195-241.

Kützing, F. T. (1857-1858). "Tabulae Phycologicae", Vol. 7, 1857, 40 pp.; Vol. 8, 1857-1858, 48 pp. Nordhausen.

Ladd, H. S. (1961). Reef building. Science, 134, 703-715.

Ladd, H. S. (1973). Bikini and Eniwetok Atolls, Marshall Islands. In "Biology and Geology of Coral Reefs" (O. A. Jones and R. Endean, eds), Vol. 1, Geology 1, pp. 93-112. Academic Press, New York and London.

Lamarck, J. P. B. (1813). Sur les polypiers empates. Annales Musée d'Histoire Naturelle de Marseille, 20(7), 294-312.

Lamouroux, J. V. F. (1812). Extrait d'une mémoire sur la classification des polypiers coralligènes non entièrement pierreux. Nouveau Bulletin Scientifiques Société Philomatique, 3, 181-188. 
Lamouroux, J. V. F. (1816). Histoire des polypiers coralligènes flexibles, vulgairenommes zoophytes. Caen, $460 \mathrm{pp}$.

Lanjouw, J. and Stafleu, F. A. (1964). "Index Herbariorum", Part I, "The Herbaria of the World", 50th edn. International Bureau of Plant Taxonomy and Nomenclature, Utrecht.

Lanjouw, J. et al. (eds) (1956). "International Code of Botanical Nomenclature", $338 \mathrm{pp}$. International Bureau of Plant Taxonomy and Nomenclature, Utrecht.

Lanjouw, J. et al. (eds) (1966). "International Code of Botanical Nomenclature", $704 \mathrm{pp}$. International Bureau of Plant Taxonomy and Nomenclature, Utrecht.

L'Écluse, C. de (1601). "Rariorum Plantarum Historia, ex Officiana Plantiniana apud Ioannem Moretum", $364 \mathrm{pp}$. Antwerp.

Lewin, J. C. (1962). Calcification. In "Physiology and Biochemistry of Algae" (R. A. Lewin, ed.), pp. 457-465. Academic Press, New York and London.

Lewin, R. A. (1976). "The Genetics of Algae", Botanical Monographs No. 12, $360 \mathrm{pp}$. University of California Press, Berkeley.

Link, H. F. (1834). Sur les zoophytes en général et en particulier sur certaines plantes qu'on a confondues avec eux. Annales des Sciences Naturelles (Botanique Séries), 2, 321-331.

Linnaeus, C. A. (1758). "Systema Naturae" Vol. 1, 10th edn., 828 pp. Stockholm.

Linnaeus, C. A. (1766-1767). "Systema Naturae", Vol. 1, 12th edn., 1327 pp. Stockholm.

Littler, M. M. (1973). The productivity of Hawaiian fringing reef crustose Corallinaceae and an experimental evaluation of production methodology. Limnology and Oceanography, 18(6), 946-952.

Ludwig, C. G. (1760). "Definitiones Generum Plantarium" (D. G. R. Boehmer, ed.), 516 pp. Leipzig.

MacArthur, R. H. (1965). Patterns of species diversity. Biological Reviews, 40, $510-533$.

MacArthur, R. H. and Wilson, E. O. (1967). "The Theory of Island Biogeography", 203 pp. Princeton University Press, Princeton, New Jersey.

MacRaild, G. N. and Womersley, H. B. S. (1974). The morphology and reproduction of Derbesia clavaeformis (J. Agardh) de Toni (Chlorophyta). Phycologia, 13(2), 83-95.

Maeda, M. and Nisizawa, K. (1972). Cell wall constituents of siphonous green algae with reference to their phylogenetic position. In "Contributions to the Systematics of Benthic Algae of the North Pacific" (I. A. Abbott and M. Kurogi, eds), pp. 33-44. Japanese Society of Phycology, Kobe.

Maeda, M., Kuroda, K., Iriki, Y., Chihara, M., Nisizawa, K. and Miwa, T. (1966). Chemical nature of major cell constituents of Vaucheria and Dichotomosiphon with special reference to their phylogenetic positions. Botanical Magazine, Tokyo, 79, 634-643.

Mann, K. H. (1972). Ecological energetics of the sea-weed zone in a marine bay on the Atlantic coast of Canada. II. Productivity of the seaweeds. Marine Biology, 14, 199-209.

Marsh, J. A. (1970). Primary productivity of reef-building calcareous red algae. Ecology, 51, 225-263.

Marzelek, D. S. (1971). Skeletal ultrastructure of sediment producing green algae. Proceedings of the Fourth Annual Scanning Electron Microscope Symposium, pp. 273-280. 
Mathieson, A. C., Fralick, R. A., Burns, R. and Flahive, W. (1971). Comparative studies of subtidal vegetation in the Virgin Islands and the New England coastlines. In "Scientists-in-the-Sea" (J. W. Miller, J. G. Van Derwalker and R. A. Waller, eds), pp. 106-131. United States Government Printing Office, Department of the Interior, Washington, DC.

McConnell, D. and Colinvaux, L. Hillis (1967). Aragonite in Halimeda and Tydemania (order Siphonales). Journal of Phycology, 3(4), 198-200.

Meinesz, A. (1969). Sur la reproduc'ion sexué de l'Udotea petiolata (Turra) Boergesen. Comptes Rendus Hebdomadaires des Séances de l'Académie des Sciences, Série D, 299, 1063-1065.

Meinesz, A. (1972a). Sur la croissance et le développement du Penicillus capitatus Lamarck forma mediterranea (Dec.) P. and H. Huvé (Caulerpale, Udotéacée). Comptes Rendus Hebdomadaires des Séances de l'Académie des Sciences, Série D, 275(5), 667-669.

Meinesz, A. (1972b). Sur le cycle de l'Halimeda tuna (Ellis et Solander) Lamouroux (Udotéacée, Caulerpale). Comptes Rendus Hebdomadaires des Séances de l'Académie des Sciences, Série D, 275(13), 1363-1365.

Meinesz, A. (1972c). Sur le cycle de l'Udotea petiolata (Turra) Boergesen (Caulerpale, Udotéacée). Comptes Rendus Hebdomadaires des Séances de l'Académie des Sciences, Série D, 275(18), 1975-1977.

Meinesz, A. (1973). Les caulerpales des cotes françaises de la Méditerranée. Biologie et écologie, $95 \mathrm{pp}$. Thesis, University of Paris.

Meinesz, A. (1975). Premières observations sur la reproduction du Penicillus capitatus Lamarck forma mediterranea (Decaisne) P. and H. Huvé (Caulerpale, Udotéacée). Annales du Musée d'Histoire Naturelle de Nice, 3, 19-20.

Merten, M. J. (1971). Ecological observations of Halimeda macroloba Decaisne (Chlorophyta) on Guam. Micronesica, 7(1-2), 27-44.

Milliman, J. D. (1974). "Recent Sedimentary Carbonates", Part I "Marine Carbonates", 378 pp. Springer-Verlag, New York.

Mirande, R. (1913). Recherches sur la composition chimique de la membrane et le morcellement du thalle chez les Siphonales. Annales des Sciences Naturelles, (Botanique Séries) 18, 147-264.

Miwa, T., Iriki, Y. and Suzuki, T. (1961). Mannan and xylan as essential cell wall constituents of some siphonous green algae. Collègues Internationaux du Centre de la Recherche Scientifique, 103, 135-144.

Moore, Jr, C. H., Graham, E. A. and Land, L. S. (1976). Sediment transport and dispersal across the deep fore-reef and island slope $(-55 \mathrm{~m}$ to - $305 \mathrm{~m})$, Discovery Bay, Jamaica. Journal of Sedimentary Petrology, 46(1), 174-187.

Morellet, L. and Morellet, J. (1922). Contribution à l'étude paléontologique du genre Halimeda Lamx. Compte Rendu Sommaire et Bulletin de la Société Géologique de France, iv, 22, 291-296.

Morellet, L. and Morellet, J. (1941). Études sur les algues calcaires de l'Éocène du Cotentin. Compte Rendu Sommaire et Bulletin de la Société Géologique de France, v, 10, 201-206.

Naccari, F. L. (1828). "Algologia Adriatica", 77 pp. Bologna.

Nardo, G. D. (1834). De corallinis ac nulliporis. Oken's Isis, 1834(6), 673-675.

Nasr, A. H. (1947). Synopsis of the marine algae of the Egyptian Red Sea coast. Bulletin of the Faculty of Science, Egyptian University, 26, 1-155. 
National Research Council, Biological Methods Panel, Committee on Oceanography, Division of Earth Sciences (1969). "Recommended Procedures for Measuring the Productivity of Plankton Standing Stock and Related Oceanic Properties", 59 pp. National Academy of Science, Washington, DC.

Neumann, A. C. and Land, L. S. (1975). Lime mud deposition and calcareous algae in the bight of Abaco, Bahamas: a budget. Journal of Sedimentary Petrology, 45(4), 763-786.

Neumann, K. (1974). Zur Entwicklungsgeschichte und Systematik der siphonalen Grünalgen Derbesia und Bryopsis. Botanica Marina, 17(3), 176-185.

Nizamuddin, M. (1963). Studies on the green alga, Udotea indica, A. \& E. S. Gepp, 1911. Pacific Science, 17(2), 243-245.

Odum, H. T. (1957). Primary production measurements in eleven Florida springs and marine turtle-grass community. Limnology and Oceanography, 2, 85-87.

Odum, H. T. and Odum, E. P. (1955). Trophic structure and productivity of a windward coral reef community on Eniwetok Atoll. Ecological Monographs, 25, 291-320.

Oltmanns, F. (1905). "Morphologie und Biologie der Algen", Vol. 2, 443 pp. Verlag von Gustav Fischer, Jena.

Orme, G. R. (1977). Aspects of sedimentation in the coral reef environment. In "Biology and Geology of Coral Reefs" (O. A. Jones and R. Endean, eds), Vol. IV, Geology 2, pp. 129-182. Academic Press, New York and London.

Palandri, M. (1972a). Unusual mitochondria in coenocytic alga Halimeda tuna. Caryologia, 25(1), 95-101.

Palandri, M. (1972b). Aspetti ultrastrutturali dell'invecchiamento dei filamenti genocitici in Halimeda tuna (Ell. et Sol.) Lamour. Caryologia, 25(2), 211-235.

Pallas, P. S. (1766). "Elenchus Zoophytorum", 451 pp. The Hague.

Papenfuss, G. F. (1946). Proposed names for the phyla of algae. Bulletin of the Torrey Botanical Club, 73, 217-218.

Papenfuss, G. F. (1962). Clearing old trails in systematic phycology. Proceedings of the Ninth Pacific Science Congress, 1957, Vol. 4, pp. 229-233.

Papenfuss, G. F. and Egerod, L. E. (1957). Notes on South African marine algae. Phytomorphology, 7(1), 82-93.

Parker, B. C. (1970). Significance of cell wall chemistry to phylogeny in the algae. In "Phylogenesis and Morphogenesis in the Algae" (J. F. Fredrick and R. M. Klein, eds), pp. 417-428. Annals of the New York Academy of Sciences, 175, 413-781.

Parkinson, J. (1640). "Theatrum Botanicum", 1755 pp. London.

Patriquin, D. (1973). Estimation of growth rate, production and age of the marine angiosperm Thalassia testudinum König. Caribbean Journal of Science, 13(1-2), 111-123.

Petiver, J. (1767). "Pteri-graphia Americana." London.

Pia, J. (1932). Remarques sur les algues calcaires. In "Études Géologiques sur les Calcaires de Bekrit et de Timhadit (Moyen Atlas)" (J. Pia, J. Pfendu and H. Termier, eds), pp. 13-24. Service des Mines et de la Carte Géologique du Maroc, Notes et Mémoires No. 20.

Piccone, A. (1879). Catalogo delle alghe raccolte durante le crociere del cutter "Violante" e specialmente in alcune piccole isole Mediterranee. Mémoires de l'Académie Lincei, iii, 4, 19-35.

Pollinius, C. (1824). "Flora Veronensis", Vol. 3, 898 pp. Verona. 
Pomeroy, L. R., Pilson, M. E. Q. and Wiebe, W. J. (1974). Tracer studies of the exchange of phosphorus between reef water and organisms on the windward reef of Eniwetok Atoll. Proceedings of the Second International Coral Reef Symposium 1. Great Barrier Reef Committee, Brisbane, pp. 87-96.

Prat, S. and Hamackova, J. (1946). The analysis of calcareous marine algae. Studia Botanica Czechoslovaca, 7(2-4), 112-126.

Preston, R. D. (1968). Plants without cellulose. Scientific American, 218, 102-108.

Preston, R. D. (1974). "The Physical Biology of Plant Cell Walls", 491 pp. Chapman and Hall, London.

Puiseux-Dao, S. (1966). Siphonales and Siphonocladales. In "The Chromosomes of the Algae" (M. B. E. Godward, ed.), pp. 52-77. Edward Arnold, London.

Puiseux-Dao, S. (1970). "Acetabularia and Cell Biology", 162 pp. Springer-Verlag, New York.

Qasim, S. E. and Bhattathiri, P. M. A. (1971). Primary production of a seagrass bed on Kavaratti Atoll (Laccadives). Hydrobiologia, 38, 29-38.

Randall, J. E. (1964). Notes on the biology of the echinoid Diadema antillarum. Caribbean Journal of Science, 4(2-3), 421-433.

Randall, J. E. (1967). Food habits of reef fishes of the West Indies. Studies in Tropical Oceanography Miami, 5, 665-847.

Raunkiaer, C. (1934). "The Life Forms of Plants and Statistical Plant Geography; Being the Collected Papers of C. Raunkiaer", 632 pp. Oxford University Press, Oxford.

Rietema, H. (1969). A new type of life history in Bryopsis (Chlorophyceae, Caulerpales). Acta Botanica Neerlandica, 18, 615-619.

Rietema, H. (1970). Life-histories of Bryopsis plumosa (Chlorophyceae, Caulerpales) from European coasts. Acta Botanica Needlandica, 19, 859-866.

Rietema, H. (1975). Comparative investigations on the life-histories and reproduction of some species in the siphoneous green algal genera Bryopsis and Derbesia, 130 pp. Doctoral Dissertation, Rijksuniversity of Groningen.

Rogers, D. J. and Fleming, H. (1964). A computer program for classifying plants. II. A numerical handling of non-numerical data. BioScience, 14(9), 15-28.

Roth, W. C. and Friedmann, E. I. (1976). Occurrence of the espera stage of Penicillus in North America. Journal of Phycology, 12 (suppl.), 27.

Round, F. E. (1963). The taxonomy of the Chlorophyta. British Phycological Bulletin, 2(4), 224-235.

Round, F. E. (1971). The taxonomy of the Chlorophyta. II. British Phycological Journal, 6(2), 235-264.

Round, F. E. (1973). "The Biology of Algae," 2nd ed., 277 pp. Edward Arnold, London.

Ryther, J. H. (1969). Photosynthesis and fish production in the sea. Science, 166, $72-76$.

Sabnis, D. D. (1969). Observations on the ultrastructure of the coenocytic marine alga Caulerpa prolifera, with particular reference to some unusual cytoplasmic components. Phycologia, 7(1), 24-42.

Sargent, M. C. and Austin, T. S. (1949). Organic productivity of an atoll. Transactions of the American Geophysical Union, 30(2), 245-249.

Sargent, M. C. and Austin, T. S. (1954). Biologic economy of coral reefs. Geological Survey Professional Paper No. 260-E, pp. 293-300.

Savage, S. (1948). "Catalogue of the Manuscripts in the Library of the Linnean Society of London", Part IV, "Calendar of the Ellis Manuscripts", $104 \mathrm{pp}$. Linnean Society, London. 
Schmitz, F. (1880). Über die Bildung der Sporangien bei der Algengattung Halimeda. S. B. niederrhein. Ges. Nat.-u. Heilk., 1879, 140-146.

Setchell, W. A. (1929). The genus Microdictyon. University of California Publications in Botany, 14, 453-588.

Sloane, H. (1907). "A Voyage to the Islands, Madera, Barbados, Nieves, St. Christophers and Jamaica", Vol. I, 264 pp. London.

Smith, A. G. and Briden, J. C. (1977). "Mesozoic and Cenozoic Paleocontinental Maps", 66 pp. Cambridge University Press, Cambridge.

Smith, G. M. (1938). "Cryptogamic Botany", Vol. I, "Algae and Fungi”, 545 pp. MeGraw-Hill, New York.

Smith, G. M. (1955). "Cryptogamic Botany", Vol. I, "Algae and Fungi", 546 pp. McGraw-Hill, New York.

Smith, J. E. (1819). John Ellis. In Rees, A., Cyclopaedia, 12, Section 2.

Smith, S. V. (1978). Coral-reef area and the contributions of reefs to processes and resources of the world's oceans. Nature, London, 273, 225-226.

Smith, S. V. and Harrison, J. T. (1977). Calcium carbonate production of the Mare Incognitum, the upper windward reef slope at Enewetak Atoll. Science, 197, 556-559.

Smith, S. V. and Kinsey, D. W. (1976). Calcium carbonate production, coral reef growth and sea level change. Science, 194, 937-939.

Smith, S. V. and Marsh, J. A. (1973). Organic production on the windward reef flat of Eniwetok Atoll. Limnology and Oceanography, 18, 953-961.

Sprengel, A. (1827). "Caroli Linnaei Systema Vegetabilium", 16th edn, Vol. 4, $410 \mathrm{pp}$. Göttingen.

Stark, L. M., Almodovar, L. and Krauss, R. W. (1969). Factors affecting the rate of calcification in Halimeda opuntia (L.) Lamouroux and Halimeda discoidea Decaisne. Journal of Phycology, 5(4), 305-312.

Stearns, H. T. (1945). Decadent coral reef on Eniwetok Island, Marshall group. Bulletin of the Geological Society of America, 56, 783-788.

Steeman Nielsen, E. (1952). The use of radioactive carbon $\left(\mathrm{C}^{14}\right)$ for measuring organic production in the sea. Journal du Conseil, 18, 117-140.

Stockman, K. W., Ginsburg, R. N. and Shinn, E. A. (1967). The production of lime mud by algae in South Florida. Journal of Sedimentary Petrology, 37(2), $633-648$.

Stoddart, D. R. (1969). Ecology and morphology of Recent coral reefs. Biological Revieus, 44, 433-498.

Strand, J. A., Cummins, J. T. and Vaughan, B. E. (1966). Artificial culture of marine seaweeds in recirculation aquarium systems. Biological Bulletin, 131(3), 487-500.

Strickland, J. D. H. (1960). Measuring the production of marine phytoplankton. Fisheries Research Board of Canada, Bulletin, 122, 172 pp.

Strickland, J. D. H. and Parsons, T. R. (1968). A practical handbook of seawater analysis. Fisheries Research Board of Canada, Bulletin, No. 167, 311 pp.

Taylor, W. R. (1928). The marine algae of Florida with special reference to the Dry Tortugas. Papers of Tortugas Laboratory, 25, 1-219.

Taylor, W. R. (1950). "Plants of Bikini and other Northern Marshall Islands", 227 pp. University of Michigan Press, Ann Arbor, Michigan.

Taylor, W. R. (1962). Two undescribed species of Halimeda. Bulletin of the Torrey Botanical Club, 89(3), 172-177.

Taylor, W. R. (1973). A new Halimeda (Chlorophyceae, Codiaceae) from the Phillippines. Pacific Science, 27(1), 34-36. 
Taylor, W. R. (1975). A new species of Halimeda from Malaysia. Contributions from the University of Michigan Herbarium, 11(2), 81-83.

Taylor, W. R., Joly, A. B. and Bernatowicz, A. J. (1953). The relation of Dichotomosiphon pusillus to the algal genus Boodleopsis. Papers of the Michigan Academy of Science, Arts, Letters, 38, 97-108.

Techet, K. (1908). Su talune forme aberranti di alghe marine allevate in colture artificiali. Nuova Notarisia, 19, 171-184.

Tracey, Jr, J. I., Ladd, H. S. and Hoffmeister, J. E. (1948). Reefs of Bikini, Marshall Islands. Bulletin of the Geological Society of America, 59, 861-878.

Turner, J. B. and Friedmann, E. I. (1974). Fine structure of capitular filaments in the coenocytic green alga Penicillus. Journal of Phycology, 10(2), $125-134$.

Valentine, J. W. (1973). "Evolutionary Paleoecology of the Marine Biosphere", 511 pp. Prentice-Hall, Englewood Cliffs, New Jersey.

Valet, G. (1966). Sur une espèce rare et une nouvelle espèce d'Halimeda de Mélanésie. Revue Générale de Botanique, 73, 680-685.

Vickers, A. (1905). Liste des algues marines de la Barbade. Annales des Sciences Naturelles (Botanique Séries), ix, 1, 45-66.

Vickers, A. and Shaw, M. H. (1908). "Phycologia Barbadensis. Iconographie des Algues Marines Récoltées à l'Ile Barbade (Antilles)". Part I, "Chlorophyceae", 30 pp. Paris.

Vollenweider, R. A. (1969). "A Manual on Methods for Measuring Primary Production in Aquatic Environments", I. B. P. Handbook No. 12. Blackwell, Oxford.

Von Arx, W. S. (1948). The circulation systems of Bikini and Rongelap Lagoons. Transactions of the American Geophysical Union, 29, 861-870.

Webb, K. L., Du Paul, W. D., Wiebe, W., Sottile, W. and Johannes, R. E. (1975). Eniwetok Atoll: Aspects of the nitrogen cycle on a coral reef. Limnology and Oceanography, 20(2), 198-210.

Wells, J. M. (1977). A comparative study of the metabolism of tropical benthic communities. Proceedings of the Third International Coral Reef Symposium, Vol. 1, 545-549.

Wells, J. W. (1969). Aspects of Pacific coral reefs. Micronesica, 5(2), 317-322.

Westlake, D. F. (1963). Comparison of plant productivity. Biological Reviews, 38, $385-425$.

Whittaker, R. H. (1975). "Communities and Ecosystems", 2nd edn, 385 pp. Macmillan, New York.

Wiebe, W. J., Johannes, R. E. and Webb, K. L. (1975). Nitrogen-fixation in a coral-reef community. Science, 188, 257-259.

Wilbur, K. M., Colinvaux, L., Hillis and Watabe, N. (1969). Electron microscope study of calcification in the alga Halimeda (order Siphonales). Phycologia, 8(1), 27-35.

Williams, G. C. (1975). "Sex and Evolution", 200 pp. Princeton University Press, Princeton, New Jersey.

Wray, J. L. (1977). "Calcareous Algae", 186 pp. Elsevier, New York.

Wyrtki, K. (1973). Teleconnections in the equatorial Pacific Ocean. Science, 180, 66-68.

Yamada, Y. (1934). The marine Chlorophyceae from Ryukyu, especially from the vicinity of Nawa. Faculty of Science Hokkaido University, 3(2), 33-88.

Yamada, Y. (1941). [Species of Halimeda in the South Sea.] Kagaku Nanyo, 4(2), 108-121. 
Yamada, Y. (1944). New Caulerpas and Halimedas from Micronesica. Scientific Papers of the Institute of Algological Research of Hokkaido University, 3(1), 27-29.

Yonge, C. M. (1951). The form of coral reefs. Endeavour, 10(39), 136-144.

Yonge, C. M. (1963). The biology of coral reefs. In "Advances in Marine Biology" (F. S. Russell, ed.), Vol. 1, pp. 209-260. Academic Press, London and New York.

Zanardini, J. (1851). Algae novae vel minus cognitae in Mari Rubro a Portiero Collectae. Flora, Treviso, 1851, 33-38.

Zanardini, J. (1858). Plantarum in Mari Rubro hucusque collectarum enumeratio. Memorie del R. Instituto Veneto di Scienze, Lettere ed Arti, 7, 209-309. 



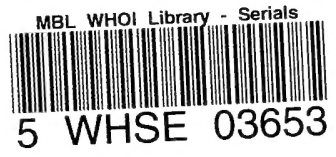


